$4 x$

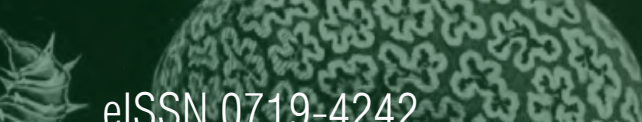

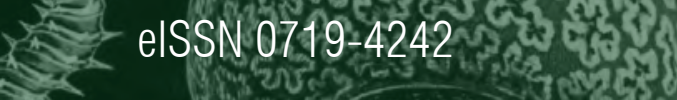

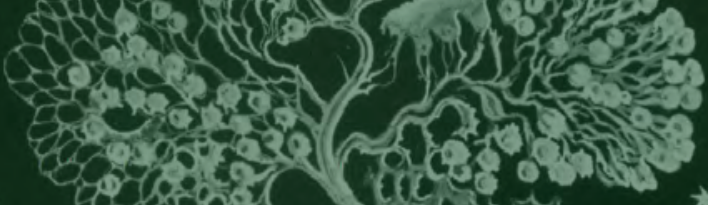

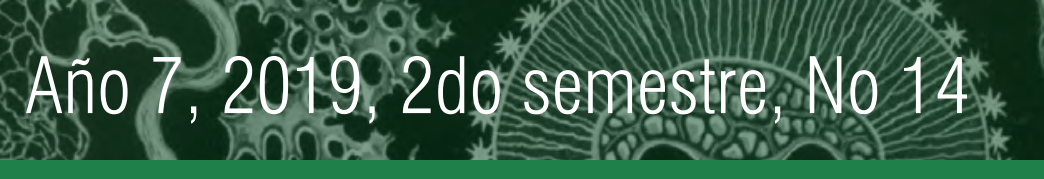

\section{Revista de Humanidades de Valparaíso}

Revista internacional de filosofía
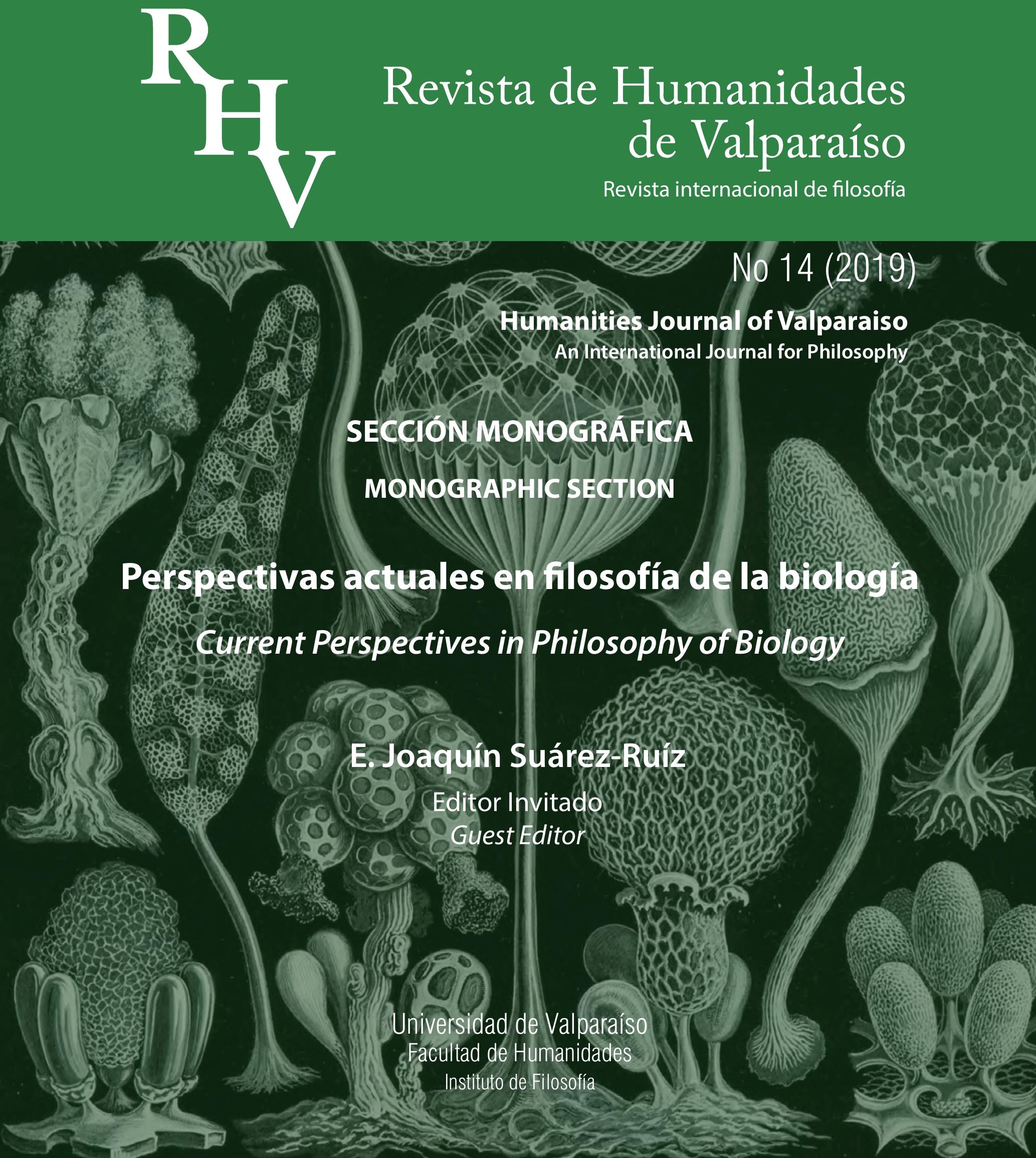



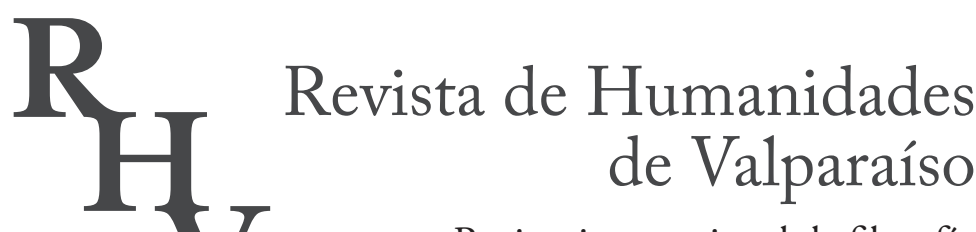 Revista internacional de filosofía}

\section{Humanities Journal of Valparaiso}

An International Journal of Philosophy

No 14 (2019)

\section{SECCIÓN MONOGRÁFICA}

MONOGRAPHIC SECTION

Perspectivas actuales en Filosofia de la Biología

Current Perspectives in Philosophy of Biology

E. Joaquín Suárez-Ruíz

Editor Invitado

Guest Editor

Universidad de Valparaíso

Facultad de Humanidades

Instituto de Filosofía 


\section{Revista de Humanidades de Valparaíso (RHV) Humanities Journal of Valparaiso}

eISSN 0719-4242 - https://revistas.uv.cl/index.php/RHV/

CDD: 090

Sección Monográfica de / Monographic Section of: RHV No 14 (2019)

Páginas: $7-426$

DOI: https://doi.org/10.22370/rhv2019iss14pp7-426

Contacto / Contact: rhv.editores@gmail.com

Comité Editorial / Editorial Board:

Directores / Directors:

Juan Redmond (Universidad de Valparaíso, Chile)

Shahid Rahman (Université Lille 3, France)

Editor / Editor in Chief:

Rodrigo Lopez-Orellana (Universidad de Salamanca, España)

Editor Asociado / Associate Editor:

Jorge Budrovich Sáez (Universidad de Valparaíso, Chile)

Asistente Técnico / Technical Assistant:

Rodrigo Castro Reyes (Universidad de Valparaíso, Chile)

Comité Científico / Scientific Board:

Ángel Nepomuceno, Universidad de Sevilla, España

David Miller, University of Warwick, United Kingdom

Francisco Salguero, Universidad de Sevilla, España

Franck Lihoreau, Universidade Nova de Lisboa, Portugal

José Tomás Alvarado Marambio, Pontificia Universidad Católica de Chile, Chile

Laurent Keiff, Université Lille 3, France

María Cecilia Sánchez, Universidad Academia de Humanismo Cristiano, Chile

María Manzano Arjona, Universidad de Salamanca, España

Norah Dei Cas, Université Lille 3, France

Olga Pombo, Universidade de Lisboa, Portugal

Rafael Marin, Université Lille 3, France

Sergio Fiedler, Universidad Diego Portales, Chile

Víctor Duplancic, Universidad de Congreso, Argentina

Imagenes de portada y contraportada: ilustraciones de Ernst Haeckel, de su libro Kunstformen der Natur (1899-1904). 


\section{Nota del editor}

Este ejemplar corresponde a la Sección Monográfica "Perspectivas actuales en Filosofía de la Biología" del No 14 (2019) de la Revista de Humanidades de Valparaiso (RHV).

La RHV es editada por el Instituto de Filosofía de la Facultad de Humanidades de la Universidad de Valparaíso desde el año 2013. Su periodicidad de publicación es bianual de artículos inéditos y reseñas bibliográficas del área de la filosofía. La RHV publica en cuatro idiomas (castellano, portugués, inglés y francés), no se suscribe a ninguna doctrina particular y está abierta a artículos de diferentes perspectivas filosóficas y con un alcance internacional.

\section{Editor's Note}

This issue is from the Monographic Section "Current Perspectives in Philosophy of Biology" of No 14 (2019) of the Humanities Journal of Valparaiso (RHV, for its acronym in Spanish)

The RHV is edited by the Institute of Philosophy of the Faculty of Humanities of the University of Valparaiso since 2013. Its periodicity is biannual for unpublished works in the field of philosophy. The RHV published in four languages, Spanish, Portuguese, English and French; and does not subscribe to any particular doctrine and is open to articles from different philosophical perspectives and with an international scope. 



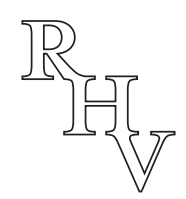

Revista de Humanidades de Valparaíso

Humanities Journal of Valparaiso

eISSN 0719-4242 - ( 2019 Instituto de Filosofía, Universidad de Valparaíso

Distributed under the terms of the Creative Commons Attribution-NonCommercial-NoDerivatives 4.0 Internacional License

(). (1) O O CC BY-NC-ND

\section{No 14 (2019) - SECCIÓN MONOGRÁFICA}

Perspectivas actuales en Filosofía de la Biología

Current Perspectives in Philosophy of Biology

Tabla de Contenidos / Table of Contents

Introducción del Editor / Guest Editor's Introduction

I. Michael Ruse

Why did the stegosaurus have plates, or is biology second-rate because it thinks in terms of ends?

¿Por qué el estegosaurio tiene placas, o es la biología una ciencia de segunda clase porque piensa en términos de fines?

2. Gustavo Caponi

Lo natural, lo seglar y lo sobrenatural

The natural, the secular and the supernatural

3. Ariel Jonathan Roffé; Santiago Ginnobili

El estatus metateórico de ZFEL

The meta-theoretical status of ZFEL

4. Julio Torres MelÉndez

Códigos de barras y esencias históricas: una crítica a la versión moderada

del esencialismo biológico intrínseco

Barcodes and historical essences: a critique of the moderate version

of intrinsic biological essentialism

5. Anna Estany

Biología y guerra: una perspectiva pragmática

Biology and war: a pragmatic perspective

6. Maurizio Esposito

En el principio era la mano: Ernst Kapp y la relación entre máquina y organismo

In the beginning was the hand: Ernst Kapp and the relation between machine and organism ..

7. Ana Cuevas Badallo

The question of animal technical capacities

La cuestión de las capacidades técnicas de los animales 
8. Mauricio de Carvalho Ramos

Centros celulares nutritivos e espumas microscópicas como formas

elementares dos seres viventes

Nutritious cell centers and microscopic foams as elementary forms of living beings

9. Leonardo González Galli

Perspectivas darwinistas sobre la mente y la conducta humanas:

alcances, limitaciones e implicancias educativas

Darwinian perspectives on the human mind and behavior:

scope, limitations and educational implications

IO. LORENZO BARAVALLE

París, California y la búsqueda por una teoría del cambio cultural

Paris, California and the quest for a theory of cultural change

I I. Mariano Martín Villuendas

Una discusión en torno a los límites del concepto especie

$A$ discussion about the limits of the species concept

I 2. Susana Gisela Lamas

El ideal de unificación en biología: el caso de la Síntesis Evolutiva Extendida

The ideal of unification in biology: the case of extended evolutionary synthesis

I3. Federico Bernabé

Androcentrismo, ciencia y filosofía de la ciencia

Androcentrism, science and philosophy of science

i 4. Rodrigo Lopez-Orellana; Juan Redmond; David Cortés-García

Un enfoque inferencial y dinámico de la modelización y de la comprensión en biología

An inferential and dynamic approach to modeling and understanding in biology

i 5. IsaAc Hernández; Davide Vecchi

Individuación colectiva y emergencia de la organismalidad

Collective individuation and emergence of organismality

i6. Luis Marone; Javier Lopez de Casenave; Rafael González del Solar

The synthetic thesis of truth helps mitigate the "reproducibility crisis"

and is an inspiration for predictive ecology

La tesis sintética de la verdad ayuda a mitigar la "crisis de reproducibilidad" $e$

inspira a la ecología predictiva....

I7. E. JOAQUín SuÁREZ-Ruíz

Sobre la legitimidad de la interrogación meta-filosófica en filosofía de la biología

On the legitimacy of the meta-philosophical interrogation in philosophy of biology....

i 8. Daniel Labrador Montero

La evolución de la biología y la biología evolucionista. Especie y

finalidad desde Aristóteles hasta Darwin

The evolution of biology and the evolutionist biology: species and finality

$395-426$

Revista de Humanidades de Valparaíso, 2019, No 14

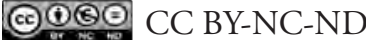




\section{Sección Monográfica: Perspectivas actuales en Filosofía de la Biología}

Monographic Section: Current Perspectives in Philosophy of Biology

\section{Introducción del Editor}

\section{Guest Editor's Introduction}

Actualmente, la filosofía de la biología es una de las disciplinas filosóficas más prósperas, no sólo porque posee un origen relativamente reciente, sino por el hecho de que la ciencia que examina suma nuevos e insoslayables conocimientos cada día, los cuales no sólo son pasibles de ser objeto del análisis filosófico, sino que, y este es quizás el rasgo más polémico del vínculo contemporáneo entre filosofía y biología, parecen implicar revisiones profundas de la filosofía misma.

Por un lado, la filosofía de la biología se ha establecido como un campo de investigación fundamental para esclarecer, discutir o construir conceptos ligados a las particularidades de la ciencia en cuestión. Con los desarrollos de subáreas como la epigenética o la evo-devo, se están presentando nuevos retos en relación a los temas más clásicos de la filosofía general de la ciencia, especialmente respecto de la caracterización de las teorías, la modelización y la experimentación científicas. De hecho, no por casualidad este es el tipo de análisis más extendido al interior de esta disciplina, ya que, justamente, dada la vertiginosidad actual con que se producen conocimientos al interior de las diferentes ciencias biológicas, del mismo modo aumenta el riesgo de que se vayan anquilosando supuestos dogmáticos en la práctica científica y, en consecuencia, se vuelve imprescindible la inclusión de la mirada crítica propia de la filosofía.

Ahora bien, por otro lado, y volviendo a la vía más polémica, la filosofía de la biología también está extendiendo sus análisis hacia tópicos que exceden la epistemología tradicional. En primer lugar, es posible afirmar que existe una línea contemporánea centrada en las implicancias políticas de la biología, desde la cual se analiza, por ejemplo, el impacto social de la instrumentalización de los desarrollos biológicos, la existencia de supuestos de género tras la actividad científica o, incluso, la plausibilidad o no de las afirmaciones "transhumanistas". En segundo lugar, en los últimos años han emergido investigaciones biológicas que renuevan interrogantes pertenecientes a otras subdisciplinas filosóficas y que, aún más, parecen exigir una revisión en profundidad del

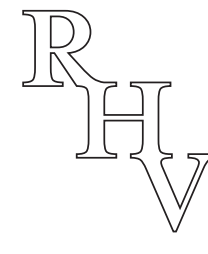

elSSN 0719-4242 - (C) 2019 Instituto de Filosofía, Universidad de Valparaíso

This article is distributed under the terms of the

Creative Commons Attribution-NonCommercial-NoDerivatives 4.0 Internacional License

(ㄷ)(응 $C C$ BY-NC-ND 
supuesto de una discontinuidad radical de lo humano que, no pocas veces, suele hallarse todavía presente en la producción filosófica actual. Este tipo de interrogantes serían, por ejemplo, ¿hasta qué punto es posible hablar de una 'naturaleza humana'?, ¿cómo debería comprenderse la "diferencia antropológica", es decir, lo "propiamente humano", a la luz de una perspectiva post-darwiniana de nuestra especie?, o ¿en qué medida características como la moral podrían considerarse un rasgo compartido con otros animales?

Como puede verse, estas dos últimas vías de investigación explicitan hasta qué punto la filosofía de la biología se ha alejado de las características de la filosofía de la física, dado que la tradición que suponía que el vínculo entre filosofía y ciencias biológicas debía ser exclusivamente mediante una aproximación puramente epistemológica de la primera sobre las segundas, parece ya no ser viable.

Justamente, uno de los filósofos que abordarán aquí este tema, a saber, la distancia entre filosofía de la biología y filosofía de la física, es el eminente filósofo Michael Ruse, a quien se le suma un gran número de investigadores latinoamericanos e ibéricos dedicados a los diversos tópicos y vías de investigación recién aludidos. En este punto, y hablando ya en primera persona, preciso explicitar que mi campo de estudio específico no es la filosofía de la biología sino la ética, pero ante la necesidad de abarcar las implicancias y la complejidad de, por decirlo rápidamente, una visión continuista de la moral humana y los problemas éticos, me vi en la necesidad de profundizar en las diversas aristas de esta disciplina.

De modo que, teniendo en cuenta su heterogeneidad actual, la filosofía de la biología muestra estar ampliando sus fronteras y, en consecuencia, necesitando nuevos espacios que faciliten su desarrollo y fomenten la investigación de sus problemáticas más recientes. Dado que el ámbito filosófico iberoamericano es uno de los contextos donde más están prosperando estas nuevas perspectivas, nos propusimos contribuir a dicha apertura a través de una convocatoria internacional abierta para lograr reunir artículos originales de investigadores comprometidos en arrojar luz sobre los caminos contemporáneos del ámbito del saber que nos ocupa. Consideramos que este número monográfico de la Revista de Humanidades de Valparaíso, dedicado exclusivamente a la filosofía de la biología, no sólo permitirá reconocer en ella un espacio de discusión inter-disciplinario que incluye perspectivas diversas, sino que le otorgará nuevas fuerzas a la producción filosófica hispanohablante ligada a esta especialidad.

\section{E. Joaquín Suárez Ruíz}

Universidad Nacional de la Plata 


\title{
Why did the stegosaurus have plates, or is biology second-rate because it thinks in terms of ends?
}

\author{
¿Por qué el estegosaurio tiene placas, o es la biología una ciencia de segunda \\ clase porque piensa en términos de fines?
}

\author{
Michael Ruse \\ Department of Philosophy, Florida State University, United States \\ mruse@ffsu.edu
}

\begin{abstract}
There is something distinctively different about explanation in the biological sciences, as opposed to explanation in the physical sciences. In the former one has functional arguments, arguments making reference to what Aristotle called "final causes." As in: "The function of the plates on the back of the Stegosaurus was to keep the body at a constant temperature." Since the Scientific Revolution, such explanations have been forbidden in the physical sciences. Does this then mean that biology is second rate, as is suggested by many including Immanuel Kant? It is argued that the Darwinian mechanism of natural selection explains why there is need of functional explanation in biology and that once this point is grasped, there is no reason to judge biology second rate.
\end{abstract}

Keywords: Stegosaurus, final cause, adaptation, Charles Darwin, natural selection.

\section{Resumen}

Hay algo distintivamente diferente en la explicación propia de las ciencias biológicas, en tanto opuesta a la explicación en las ciencias físicas. En las primeras tenemos argumentos funcionales, argumentos que hacen referencia a lo que Aristóteles llamó "causas finales"; por ejemplo, "La función de las placas de la parte posterior del estegosaurio era mantener el cuerpo a una temperatura constante". Desde la Revolución Científica, explicaciones de este tipo han sido prohibidas en la física. ¿Significa esto que la biología es de segunda clase, como sugieren algunos, entre ellos Immanuel Kant? Se defenderá en este artículo

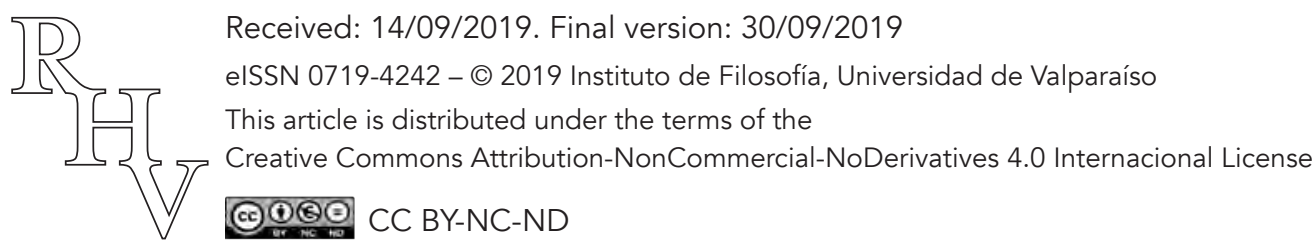


Why did the Stegosaurus have Plates, or is Biology Second-Rate because it thinks in Terms of Ends?

Michael Ruse

que el mecanismo darwiniano de selección natural explica por qué hay necesidad de una explicación funcional en biología y, que una vez que se comprende este punto, no hay razón para juzgar a la biología como ciencia de segunda clase.

Palabras clave: Estegosaurio, causa final, adaptación, Charles Darwin, selección natural.

Stegosaurus plates have been viewed as "armor" or as anatomical structures that enhanced species-specific agonistic and sexual displays. Whatever the merits of these suggestions, the plate morphology and experimental and computational evidence assembled and discussed below suggest an important thermoregulatory function. We hope to demonstrate that their arrangement, size, shape, and probable vascularity ensured their value as convective heat loss fins, not unlike those currently used to enhance forced convective heat transfer in compact engineering devices. (Farlow, Thompson, and Rosner 1976, 1123)

\section{Function talk and its discontents}

This is an opening paragraph of a ground-breaking article on the plates that run along the back of the dinosaur, Stegosaurus, a herbivorous, Jurassic (about 150 mya) dinosaur (Figure 1). They long puzzled paleontologists as to the reason why they were there, why they had the shape they had, and why they were spaced in the way that they are. As you can see, several suggestions had been made, none entirely satisfactory. Perhaps they are armor for use when the animal is fighting or being attacked? The trouble is that the bone structure suggests that they would snap off almost immediately. Perhaps they are used for attracting mates? But then why do both males and females have them? Perhaps they are easy recognition appendages? Now comes the suggestion that they are for heat regulation. Dinosaurs are reptiles, meaning that they are cold-blooded, they don't (unlike mammals and birds) have internal heat regulators. So they rely on external factors for heat control, and the fins are perfect for cooling the brutes down in the heat of the day. Instead of having to hide in the shade, they can go about their everyday business, thanks to their cooling blades. (This would have been important for the Stegosaurus. It was a herbivore, with a five ton body, so, like sheep and cows and other herbivores today, would have needed to spend a great deal of time foraging for the low-grade fuel on which it existed. Sleeping the day away under a bush was not an option. That is for carnivores, who need only few intakes of their high-grade fuel. Think how much time dogs spend sleeping.) 


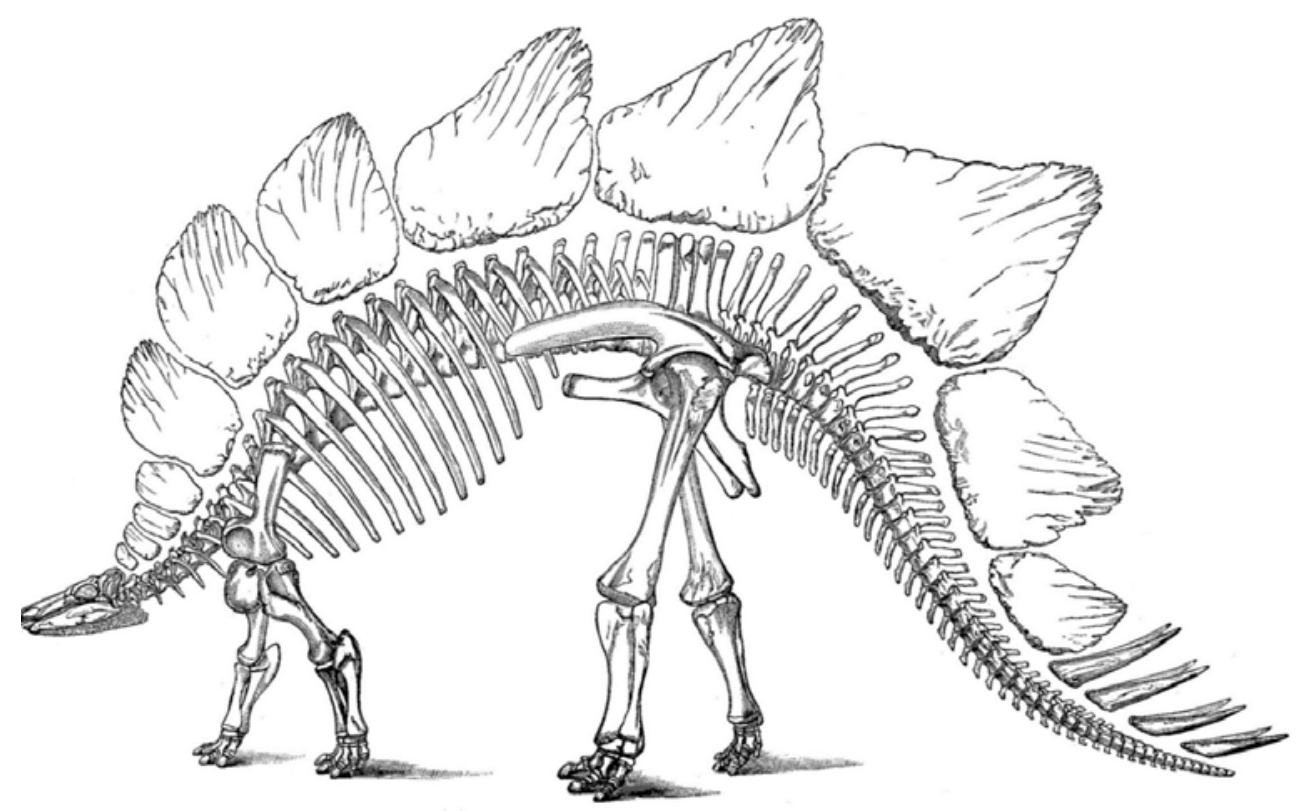

Figure 1.

Note some interesting features about this explanation. The authors use the word "function." They ask about the function of the plates. The authors use the word "value," in trying to determine why the beasts have the plates. The authors use an analogy, drawing attention to the similarity between the Stegosaurus plates and those found in "compact engineering devices." In these respects, the explanation differs from the kind of explanation one finds in the physico-chemical sciences. No one is going to ask about the function of the moon. You might reply humorously that it is to light the way home for drunken philosophers, but although apparently in the eighteenth century it was so used by members of the Lunar Society (a monthly meeting of a group of British businessmen and inventors), that is not an explanation from physics. The moon does its thing according to unbroken law. It doesn't have any function. Things in the physico-chemical sciences don't have values. Those are for human things, and as Karl Popper (1972) reminded us, "science is knowledge without a knower." Human interests and desires don't come into it. I might regret global warming, but all that science can do is tell us if it is happening and how fast. Finally, it is certainly the case that you can get analogies in physics and chemistry. Trying to show how it is that gravity keeps the spinning moon from flying off into space, John F. W. Herschel (1830) drew the analogy of a stone tied to a piece of string, that is then made to go whizzing in circles around your finger. He tells us that we feel a tug from the stone trying to fly off, that we prevent by pulling on the string. Our pulling is the same as gravity. Gravity prevents the moon from leaving. Notice, however, that the stone on the string going around the finger has no point to it. It is not designed for 
Why did the Stegosaurus have Plates, or is Biology Second-Rate because it thinks in Terms of Ends?

Michael Ruse

anything. It has no end. This is the difference with compact engineering devices. They do have an end, a purpose, a function - cooling things down in a hydroelectric generating towers, for instance.

One final point. The language and the way of thinking of these authors is not one-off or a moment's aberration or laziness or whatever. Thinking in terms of function is central to the argument. I quote the conclusion of a follow-up article.

If we now compare the various hypotheses put forward to account for the function of Stegosaurus plates, our histological data suggest the following: First, the classic reconstruction of the plates in a subvertical position is substantiated beyond any reasonable doubt. Second, it is highly unlikely that the plates could change their orientation from a recumbent to an erect one or vice versa through contraction of epaxial musculature. Third, the plates could not function as a plating or armor in the usual sense. Fourth, the display function of the plates, either for in transpecific or interspecific interactions, remains a distinct possibility which is not, moreover, mutually exclusive with other possible functions. Whatever their possible primary adaptive significance, the plates did enhance or otherwise modify the dinosaur's apparent size and shape. Fifth, the physiological function of the plates as parts of a thermoregulatory system seems a plausible interpretation. We believe that a thermo regulatory interpretation of plate function remains, with some modifications (emphasizing the role of the skin and perhaps minimizing the role of the bony plate itself in the heat exchange device), the most robust hypothesis presently available, as it better accounts for anatomical, histological, and paleoecological data than any competing functional hypothesis. (de Buffrénil, Farlow, and Ricqulès 1986, 473)

These articles appeared in top-level journals - first the weekly Science, the major, weekly, scientific publication, and then Paleobiology, the definitive home for paleontological articles with a biological interest. You don't get more professionally respectable than this. These are the kinds of homes you virtually put in neon signs on your cv when you are hoping for tenure or promotion.

So here is my question. Function-talk is what philosophers call "teleological" talk (Ruse 2017). In historical terms, it is what Aristotle would have called "final cause" talk, as opposed to the normal kind, physico-chemical-acceptable, "efficient" cause talk. What does this mean and why would it be worrisome? The answer is this. Causes produce effects. Let's suppose we have a Heinrich Himmler sort of case, where I have been captured by the Allies and, in order to escape trial and execution, I commit suicide. I swallow prussic acid and moments later I drop dead. Analyze this. Cause: I swallow the prussic acid. Effect: I drop dead. When we use efficient-cause thinking, the cause always precedes or is simultaneous with the effect. Swallow the acid. Five minutes later, heart stops beating. When you talk about the effect, you know the cause occurred or is occurring. However, with final-cause talk - function talk - you are referring to the future. I swallowed the acid in order to kill myself. The cause of what is going on is in the future. Cause: I want to die (future). Effect: I swallow the acid (past or present).

Revista de Humanidades de Valparaíso, 2019, No 14, 9-25

(ㄷ)(1)(8) CC BY-NC-ND 
Why did the Stegosaurus have Plates, or is Biology Second-Rate because it thinks in Terms of Ends?

Michael Ruse

Now, here's the rub. With efficient causes, if you have the effect - dropping dead - you know the cause occurred - swallowing acid. With final cause, if you have the effect swallowing acid - the cause might or might not occur. You hope for and explain in terms of an end, and then the end never comes. Someone might immediately inject you with an antidote and your heart never misses a beat. That means you might be explaining things in terms of the non-existent! The problem of the "missing goal object." I swallowed the acid to drop dead, but I didn't drop dead, so how can swallowing the acid be explained in terms of dropping dead? Likewise with the Stegosaurus plates. The Stegosaurus grew plates to be nice and cool on sunny days. Unfortunately, just as baby Stego was about to set out on life, a nasty carnivore came along and spoilt everything. Plates for cooling. No cooling. How then can the plates be for cooling?

In the human case, we have an obvious and pretty good answer. It's the thought that counts! What motivated my acid-swallowing was not the actual dropping dead but my thought that, if I drink the acid, I will drop dead. The thought is an efficient cause which has already occurred when I drop dead. The thought is unchanged whether or not I drop dead. I still thought I would drop dead by swallowing the acid. Unfortunately you cannot play that sort of trick in the non-human world. The Stegosaurus plates didn't have the thought of cooling down their owner, whether or not it did do any cooling. No thoughts. No way out of the dilemma. What's the conclusion? That biologists are simple, sloppy folk, who anthropomorphize their subject matter no less that a shaman among the savages who thinks that trees have life and feelings and carry on conversations when no one is around in the forest. No wonder that biology is a second-rate science.

Such at least was the opinion of the great German philosopher Immanuel Kant. You want to make the life sciences equal to the physical sciences? Faint hope! "We can boldly say that it would be absurd for humans even to make such an attempt or to hope that there may yet arise a Newton who could make comprehensible even the generation of a blade of grass according to natural laws that no intention has ordered; rather, we must absolutely deny this insight to human beings" (Kant 1790, 271). Can we help biology at this point? I believe we can. I am an evolutionist and I believe that the answer to today's problems and questions are almost always to be found in the past. Let us therefore then follow my intuition.

\section{The legacy of Greece}

If we go back to the Ancient Greeks, the main foundation for Western thought, there were those who simply dismissed the whole question as bogus. Ends are irrelevant, because everything happens by chance. What eventually happens has no relevance to what has gone before. The atomists, Leucippus and his student Democritus, argued that all of reality is particles buzzing around in space. Sometimes they cohere and work, but not 
Why did the Stegosaurus have Plates, or is Biology Second-Rate because it thinks in Terms of Ends?

Michael Ruse

for any good reason. They stick together just because they do. The Roman poet Lucretius, several centuries later, following another atomist Epicurus, a follower of Democritus, gave the fullest exposition.

At that time the earth tried to create many monsters

with weird appearance and anatomy-

androgynous, of neither one sex nor the other but

somewhere in between; some footless, or handless;

many even without mouths, or without eyes and blind;

some with their limbs stuck together all along their body,

and thus disabled from doing harm or obtaining anything

they needed.

These and other monsters the earth created.

But to no avail, since nature prohibited their development.

They were unable to reach the goal of their maturity,

to find sustenance or to copulate.

Thus far, nothing works. It is just a mess, of no value whatsoever. But then, given infinite time, things joined up in functioning ways.

First, the fierce and savage lion species

has been protected by its courage, foxes by cunning, deer by

speed of flight. But as for the light-sleeping

minds of dogs, with their faithful heart,

and every kind born of the seed of beasts of burden,

and along with them the wool-bearing flocks and the horned tribes,

they have all been entrusted to the care of the human race,

(Lucretius 1969, 5.862-67)

All very well, but truly in the opinion of most sensible Greeks, completely implausible. Something like the plates on the back of the Stegosaurus just doesn't seem to be random particles sticking together. At least, such was the opinion of two of the greatest of the Greek philosophers, Plato and Aristotle, both of whom had things to say. Although, their different answers reflected the difficulties of getting to grips with the issue.

In the Phaedo, Plato recognized that there is more to understanding, especially about the organic world, that simple efficient-cause thinking. If I want to understand why my body builds, of course I am going to talk about food and the effect it has on body growth. But there is still the question of why we would want to grow - the question of why we would think it (and note here another of our flag words coming up) of value to grow. And here Plato extends what we have just being saying about human purpose or end thinking, to say that if not us then apparently some bigger, designing mind or Mind. "One day I heard someone reading, as he said, from a book of Anaxagoras, and saying that it is Mind 
Why did the Stegosaurus have Plates, or is Biology Second-Rate because it thinks in Terms of Ends?

Michael Ruse

that directs and is the cause of everything. I was delighted with this cause and it seemed to me to be good, in a way, that Mind should be the cause of all. I thought that if this were so, the directing Mind would direct everything and arrange each thing in the way that was best" (Plato 1997, $97 \mathrm{c}-\mathrm{d}$ ). So, now one has a guide to understanding and as a bonus a guide to discovery." Then if one wished to know the cause of each thing, why it comes to be or perishes or exists, one had to find what the best way was for it to be, or to be acted upon, or to act."

The function of the Stegosaurus plates is to cool the animal in the heat of the mid-day sun, and the reason for all of this is that an external Mind planned things that way. No problem with the missing goal object. If the Stegosaurus gets eaten before it can put its plates to use, it is still the case that the Mind did the planning. The Mind had the end in view before it started to make the plates. For Plato, as is well known, this Mind was not the Christian God - he was four centuries before Jesus, and he was not a Jew (so Yahweh was not on) - but rather the Form of the Good. In the Timaeus he identifies this with the Demiurge who is, not creator (everything is eternal), but Designer.

Plato is what is known as an external teleologist. His student Aristotle, who had been a practicing biologist, was an internal teleologist. Like Plato he thought that everything, organic and non-organic, can be given a final-cause explanation, but it was in the world of organisms where he thought this all-important. We need to know how things come about - efficient causes - but we need also to know the reasons why things come about - final causes.

To say, then, that shape and colour constitute the animal is an inadequate statement, and is much the same as if a woodcarver were to insist that the hand he had cut out was really a hand. Yet the physiologists, when they give an account of the development and causes of the animal form, speak very much like such a craftsman. What, however, I would ask, are the forces by which the hand or the body was fashioned into its shape? The woodcarver will perhaps say, by the axe or the auger; the physiologist, by air and by earth. Of these two answers the artificer's is the better, but it is nevertheless insufficient. For it is not enough for him to say that by the stroke of his tool this part was formed into a concavity, that into a flat surface; but he must state the reasons why he struck his blow in such a way as to effect this, and what his final object was; namely, that the piece of wood should develop eventually into this or that shape. (Aristotle 1984)

Notice that, as always, value is the underlying theme. "In dealing with respiration we must show that it takes place for such or such a final object; and we must also show that this and that part of the process is necessitated by this and that other stage of it" (Barnes 1984, 642a32-34). The very essence of showing the final object of respiration is that of demonstrating that the process is of value to the organism that is respiring.

Where Aristotle differed crucially from Plato was in that he didn't want to appeal to an external designer, or Designer, but wanted it all to come from within, a kind of motive

Revista de Humanidades de Valparaíso, 2019, No 14, 9-25

(ㄷ)(1)(8) CC BY-NC-ND 
Why did the Stegosaurus have Plates, or is Biology Second-Rate because it thinks in Terms of Ends?

Michael Ruse

or vital force. We should be careful however of thinking of this as a form of substance. In respects, it is more a principle of organization. Something demanding final-cause explanation is organized in a way that something not demanding such explanation is not. Aristotle had a supreme being, the Unmoved Mover. This is perfection and everything strives towards it, in the sense of trying to emulate it. It is no creator like the Christian God, nor is it a Designer like the Christian God or Plato's Demiurge. Indeed it does not even know of our existence for it does the only thing a perfect being can do, namely contemplate its own perfection!

The pattern was set now for nigh two thousand years. Both the external position of Plato and the internal position of Aristotle were Christianized, the former by Augustine and the latter by Aquinas. Because everyone now did believe in a good, creator-designer, the teleological aspect of the world, of organisms particularly, was taken as one of the definitive proofs of God's existence.

We see that things which lack knowledge, such as natural bodies, act for an end, and this is evident from their acting always, or nearly always, in the same way, so as to obtain the best result. Hence it is plain that they achieve their end, not fortuitously, but designedly. Now whatever lacks knowledge cannot move knowledge and intelligence; as the arrow is directed by the archer. Therefore, some intelligent being exists by whom all natural things are directed to their end; and this being we call God. (Aquinas 1963, [1a. 75-83], 2, 3).

\section{Kant's dilemma}

It was the Scientific Revolution, from Copernicus at the beginning of the sixteenth century to Newton at the end of the seventeenth century, that spelt the end of this happy world picture. For the Greeks and their successors, the world was seen as a kind of superorganism - justified if only by its seasons. Spring's birth and growth, Summer's fullness of life, Autumn moving towards old age, and finally death with the return of Winter. Then the switch was made to the world as a machine, simply a contraption governed by unbreakable, eternal laws, endlessly going through the motions, with (unlike humanmade machines) no ultimate purpose.

The physicist-philosopher Robert Boyle was good on this, arguing that the world is "like a rare clock, such as may be that at Strasbourg, where all things are so skillfully contrived that the engine being once set a-moving, all things proceed according to the artificer's first design, and the motions of the little statues that as such hours perform these or those motions do not require (like those of puppets) the peculiar interposing of the artificer or any intelligent agent employed by him, but perform their functions on particular occasions by virtue of the general and primitive contrivance of the whole engine" (Boyle 1996, 12-13). 
Why did the Stegosaurus have Plates, or is Biology Second-Rate because it thinks in Terms of Ends?

Michael Ruse

Yet Boyle had to admit that organisms still seemed to demand final-cause thinking. As he wrote in his "Disquisition about the Final Causes of Natural Things," happily taking the opportunity to make a philosophical point while putting the boot into the French: "For there are somethings in nature so curiously contrived, and so exquisitely fitted for certain operations and uses, that it seems little less than blindness in him, that acknowledges, with the Cartesians [followers of the French philosopher René Descartes], a most wise Author of things, not to conclude, that, though they may have been designed for other (and perhaps higher) uses, yet they were designed for this use" (Boyle 1996, 5:397-98.). Boyle continued that supposing that" a man's eyes were made by chance, argues, that they need have no relation to a designing agent; and the use, that a man makes of them, may be either casual too, or at least may be an effect of his knowledge, not of nature's." Apart from anything else, not only does this take us from the chance to do science - the urge to dissect and to understand how the eye "is as exquisitely fitted to be an organ of sight, as the best artificer in the world could have framed a little engine, purposely and mainly designed for the use of seeing" - it takes us away from the designing intelligence behind it.

Boyle was being forced into playing a double game here. His stance supposedly is not something threatening to the mechanical position. It complements it! How can this be so? Boyle is distinguishing between acknowledging the use of final causes qua science and the inference qua theology from final causes to a designing god. First: "the bodies of animals it is oftentimes allowable for a naturalist, from the manifest and apposite uses of the parts, to collect some of the particular ends, to which nature destinated them. And in some cases we may, from the known natures, as well as from the structure, of the parts, ground probable conjectures (both affirmative and negative) about the particular offices of the parts" (Boyle 1966, 5:424). Then, the science finished, one can switch to theology: "It is rational, from the manifest fitness of some things to cosmical or animal ends or uses, to infer, that they were framed or ordained in reference thereunto by an intelligent and designing agent." From a study in the realm of science, of what Boyle would call "contrivance," to an inference about design - or rather Design - in the realm of theology.

A solution, but not a happy one. It is true that the way is now opened for much good biological science, and one can justify it by saying one is doing God's work, but why should the organic world demand this dual approach when the inorganic world - surely as much the creation and design of the very same good God - does not? It is here, that a hundred years later at the end of the eighteenth-century, Immanuel Kant stepped in and gave his take on the problem. The world is not to be understood teleologically in any fundamental or ontological sense. However, because the future tends to be like the past, and because in the case of organisms we have an ongoing chain of causation, as a rule of thumb we can explain in terms of the expected future. Feature, consequence, leading again to feature, consequence, and so forth. Teeth, eating, leading to next generation with teeth, eating, leading to.... Although there is no guarantee that teeth will lead to eating 
Why did the Stegosaurus have Plates, or is Biology Second-Rate because it thinks in Terms of Ends?

Michael Ruse

- like the baby Stego, a predator might spoil everything - so there can be no genuine scientific understanding, normally we expect teeth to lead to eating - they have in the past, so we expect them to do so in the future. It is a good bet. Hence, heuristically, we can rely on thinking - indeed, it proves invaluable - in the organic world.

The concept of a thing as in itself a natural end is therefore not a constitutive concept of the understanding or of reason, but it can still be a regulative concept for the reflecting power of judgment, for guiding research into objects of this kind and thinking over their highest ground in accordance with a remote analogy with our own causality in accordance with ends; not, of course, for the sake of knowledge of nature or of its original ground, but rather for the sake of the very same practical faculty of reason in us in analogy with which we consider the cause of that purposiveness. (Kant 2000, 247)

This led to the harsh judgment that biology will never be as good as physics.

\section{Charles Darwin and natural selection}

Enter Darwin who was determined to be the Newton of biology. In his Origin of Species, published in 1859, he proposed his theory of evolution through natural selection. All organisms, living and dead, are or were part of the unifying tree of life. "As buds give rise by growth to fresh buds, and these, if vigorous, branch out and overtop on all sides many a feebler branch, so by generation I believe it has been with the great Tree of Life, which fills with its dead and broken branches the crust of the earth, and covers the surface with its ever branching and beautiful ramifications" (Darwin 1859, 130). The mechanism of change is natural selection. First Darwin argued to a struggle for existence.

A struggle for existence inevitably follows from the high rate at which all organic beings tend to increase. Every being, which during its natural lifetime produces several eggs or seeds, must suffer destruction during some period of its life, and during some season or occasional year, otherwise, on the principle of geometrical increase, its numbers would quickly become so inordinately great that no country could support the product. Hence, as more individuals are produced than can possibly survive, there must in every case be a struggle for existence, either one individual with another of the same species, or with the individuals of distinct species, or with the physical conditions of life. (Darwin 1859, 63)

Then, from this, taking note that new variations seem always to arise in each generation of organisms, Darwin argued to natural selection.

Let it be borne in mind how infinitely complex and close-fitting are the mutual relations of all organic beings to each other and to their physical conditions of life. Can it, then, be thought improbable, seeing that variations useful to man have undoubtedly occurred, that other variations useful in some way to each being in the great and complex battle of life, should sometimes occur in the course of thousands of generations? If such do occur, can

Revista de Humanidades de Valparaíso, 2019, No 14, 9-25

(). (18) CC BY-NC-ND 
Why did the Stegosaurus have Plates, or is Biology Second-Rate because it thinks in Terms of Ends?

Michael Ruse

we doubt (remembering that many more individuals are born than can possibly survive) that individuals having any advantage, however slight, over others, would have the best chance of surviving and of procreating their kind? On the other hand, we may feel sure that any variation in the least degree injurious would be rigidly destroyed. This preservation of favourable variations and the rejection of injurious variations, I call Natural Selection. (Darwin 1859, 80-81)

What is important here is that Darwin didn't think that natural selection merely leads to change, but rather change of a particular kind, namely that which is going to help its possessors. The eye is created as it is in order to see. The flower to attract pollinators. The fangs of the snake to kill. The instincts of the nest-building bird to promote and continue life:

Under nature, the slightest difference of structure or constitution may well turn the nicelybalanced scale in the struggle for life, and so be preserved. How fleeting are the wishes and efforts of man! how short his time! and consequently how poor will his products be, compared with those accumulated by nature during whole geological periods. Can we wonder, then, that nature's productions should be far "truer" in character than man's productions; that they should be infinitely better adapted to the most complex conditions of life, and should plainly bear the stamp of far higher workmanship? (Darwin 1859, 83-84)

Note, Darwin is not denying the existence of God. Although later he became an agnostic, at this time he was a deist, thinking God works through unbroken law (Ruse 2015). However, like Boyle, Darwin felt that these sorts of thoughts belong to religion not to science. Science begins and ends with unbroken law. Where Darwin went beyond Boyle was in bringing organisms in from the cold. No longer must they be studied as part of theology or religion. They can now be studied as part of science. The Newton of the blade of grass, indeed!

\section{Making sense of things}

The story of course continues for another hundred and fifty years, down to the present. But the solution we accept today - the solution presupposed by our Stegosaurus investigators - is that of Darwin. Let us end our story by putting everything into historical context.

Darwin's theory of evolution through natural selection explains adaptation - the eye, the hand, the plates along the back of the Stegosaurus. Or, at least, let us say more accurately, Darwin's theory gives scientists the framework within which to explain adaptation (Ruse 2006). Darwin, as such, does not explain the hand or the eye or the plates. He gives investigators tools to tackle the problem. How is the feature under investigation going to help its possessor in the struggle to exist and to reproduce? Organisms with sight are better off than organisms without sight. (Always there are exceptions, in this case

Revista de Humanidades de Valparaíso, 2019, No 14, 9-25

()ㅇㅇㅇㅛ CC BY-NC-ND 
Why did the Stegosaurus have Plates, or is Biology Second-Rate because it thinks in Terms of Ends?

Michael Ruse

cave-dwelling organisms that have no use for eyes and who would find them dangerous in the sense of being prone to infection and the like.) Organisms with hands are better off than organisms without hands. (Again exceptions. Whales have given up limbs, let alone hands, as have snakes.) Stegosauruses with plates are better off than stegosauruses without plates. Note the work that goes into this finding. First you have got to show that other options - defense - seem implausible. Second, you have got to show why your option is not just a fairly story. What critics of Darwinism call a "just-so" story (Gould and Lewontin 1979). In the paper referred to at the beginning of this essay, there is a lot of heavy-duty discussion about wind flow and the like. Of the three co-authors, only one was a paleontologist. His home was in the Division of Vertebrate Paleontology, Peabody Museum of Natural History, and Department of Geology and Geophysics, Yale University. The second was in the Department of Engineering and Applied Science, Yale University. The third was located in the Chemical Engineering Section, Department of Engineering and Applied Science, Yale University. A lot of hard work using nuts-andbolts, non-biological science went into the arguments of this paper.

Notice what Darwin is doing, or rather what he is not doing. He is not denying teleology or explaining it away. He is offering final-cause explanations. The final cause of the plates on the back of the Stegosaurus is heat control. Behind this assumption or inference is the argumentation of Kant. The future tends to be like the past. Hence, because in the past the plates led to heat control, we assume that in the future they will lead to heat control. Sometimes this doesn't happen. That is the problem with rule of thumb explanations. But generally it does happen, or happen enough that organisms of this kind do get on to survive and reproduce, and that is enough. The future is not controlling the past. But we can expect that what has happened before will happen again, so we can use the expected future to explain what we have right now, today. Often, in the Origin, quite unselfconsciously, relying on this kind of reasoning, Darwin uses the language of final cause. Talking about embryological development.

In certain cases the successive steps of variation might supervene, from causes of which we are wholly ignorant, at a very early period of life, or each step might be inherited at an earlier period than that at which it first appeared. In either case (as with the short-faced tumbler) the young or embryo would closely resemble the mature parent-form. We have seen that this is the rule of development in certain whole groups of animals, as with cuttle-fish and spiders, and with a few members of the great class of insects, as with Aphis. With respect to the final cause of the young in these cases not undergoing any metamorphosis, or closely resembling their parents from their earliest age, we can see that this would result from the two following contingencies; firstly, from the young, during a course of modification carried on for many generations, having to provide for their own wants at a very early stage of development, and secondly, from their following exactly the same habits of life with their parents; for in this case, it would be indispensable for the existence of the species, that the child should be modified at a very early age in the same manner with its parents, in accordance with their similar habits. (Darwin 1859, 448)

Revista de Humanidades de Valparaíso, 2019, No 14, 9-25

(c) (1) 8 (을 CC BY-NC-ND 
Why did the Stegosaurus have Plates, or is Biology Second-Rate because it thinks in Terms of Ends?

Michael Ruse

Aristotle would be proud of him!

So Darwin is offering final-cause explanations. He really is! Admittedly final cause explanations that conform to efficient-cause explanations, but real final-cause explanations for all that. What about the problems with these? Most obvious is one we have highlighted, the "missing goal object." I take the poison to kill myself but then you intervene and save me. No problem when you have consciousness involved. The efficient cause was my thought, my intention, to kill myself. I have that whether I follow through or not. But what about cases where no consciousness is involved? What about the plates along the back of the Stegosaurus? One thing you can be sure about is that it was not the mind of the Stegosaurus in play here. It had a brain about the size of a walnut, miniscule even by dinosaur standards. It had three ounces of grey matter to drive that five ton body. In the running for a Nobel Prize it was not. Plato says that God or the Form of the Good, the Demiurge, was doing it, so He (or It) had the thought in mind. The Demiurge was planning nice cool summers for the Stegosaurus, so even if the Stegosaurus doesn't get through Spring, the thought was there. Notice that here we have the notion of design. Plato thinks there was a Designer. Darwin as a scientist isn't going to commit himself on this one, but he does agree that organisms, inasmuch as they are adapted, are designlike. That is the whole point and why natural selection is needed. To a fellow scientist, in 1865 (six years after the publication of the Origin) Darwin wrote: "I believe we entirely agree that purpose or design is one of the surest \& simplest roads to discovery in Natural History" (Darwin 1865). Some evolutionists of his day - famously his "bulldog" Thomas Henry Huxley - always preferred "saltationism," evolution by jumps - fox into dog in one generation. Darwin had no time for this. Jumps are random, and random means no design or appearance of design. In this sense, Darwin is $100 \%$ with Plato. And this is the reason why Darwin and his successors, including our Stegosaurus explainers, feel happy to draw analogies with machinery. Machinery is designed to have some end, some function, unlike random things put together like stones circling a finger at the end of a piece of string. Looking at the functions of machinery helps with the functions of organisms.

Aristotle says that it was some kind of force that is responsible for the plates. In some way, the Stegosaurus is directed towards a happy fulfilled life. One suggestion Aristotle makes (in De Anima) is that, in reproduction, although organisms do not become eternal, they get as close to the eternal as possible, and that in itself is a good. "The acts in which [the soul] manifests itself are reproduction and the use of food, because for any living thing that has reached its normal development ... the most natural act is the production of another like itself, an animal producing an animal, a plant a plant, in order that, as far as nature allows, it may partake in the eternal and divine. That is the goal to which all things strive, that for the sake of which they do whatsoever their nature renders possible" (Barnes 1984, 661). I am not sure how keen Darwin would be on the "eternal and the divine." He certainly wouldn't want to bring it into his science. But he would be happy with the general idea, especially if the force is thought of less as a material thing and more as a

Revista de Humanidades de Valparaíso, 2019, No 14, 9-25

(). (18) CC BY-NC-ND 
Why did the Stegosaurus have Plates, or is Biology Second-Rate because it thinks in Terms of Ends?

Michael Ruse

principle of organization. The whole point about adaptations is that they are organized, as if designed. They are not random, non-functioning, as you get from saltations. Darwin is not an Aristotelian but there is a family resemblance.

And so to Kant. Darwin agrees entirely with Kant that science cannot go outside law, unaided by God. Kant, was quite sure that there is a God involved - at the time of writing the Origin, Darwin probably thought so too - but Kant, and following him Darwin, was adamant that God had to stay outside science. In today's language, Kant and Darwin were "methodological naturalists," even though they might not have been "metaphysical naturalists." (It is plausible that Kant's thinking fed right through to Darwin. An important mentor of Darwin was the historian and philosopher of science, William Whewell. Although a strong Anglican - and hater of evolution - Whewell, who was a major Kantian, always kept religion out of science. His solution to the problem of organic origins was that of Boyle - whatever the origin, its understanding is outside science.) Darwin would agree also with Kant that final-cause thinking is invaluable from a heuristic standpoint. It is not just a prop for the inadequate. It is vital. You would never understand the plates on the back of the Stegosaurus unless you asked why they are there. Without asking that question, you wouldn't know about their existence, their nature (why, for instance, they are not made of the strongest possible materials - they don't need to be), their spacing, and much more. Where Darwin disagrees with Kant is in concluding that biology is second-rate. Darwin has given a fully adequate efficient cause for the plates and for other adaptations - or rather he has shown the way to giving explanations based on, and only on, efficient causes. It is just that, in the case of biology unlike the physical sciences, the subject matter is end-directed and that needs an explanation over and above the efficient-cause explanation.

What about value? The physical sciences don't generally talk about value. Saturn is not better than Jupiter. A cool planet is not better than a warm planet. It may be that we would prefer a cooler planet over a warmer planet, but that is our problem not that of science. It has no place for emotions. Knowledge without a knower. And yet here are our Stegosaurus researchers calmly telling us that the plates are of "value as convective heat loss fins." What is going on here? At this point it is important to distinguish between comparative value and absolute value (Nagel 1961). It is perfectly legitimate to talk in science about comparative value. One part or component of an existing machine does better than a proposed replacement. There is no real value in replacing what we have already. What is wrong in science is to talk about absolute value. As a scientist, you cannot say that global warming is a bad thing. You can say that if you continue to use fossil fuels at the rate we do, the planet will keep heating up and we will find it unpleasant. But that is us, not science. David Hume knew the score. Reason, which is what science is all about, is not the same as emotion, which is what our feeling of like and dislike, good 
Why did the Stegosaurus have Plates, or is Biology Second-Rate because it thinks in Terms of Ends?

Michael Ruse

and evil, are all about. "It is not contrary to reason to prefer the destruction of the world to the scratching of my finger" (Hume 1739-1740, 415). You may be very sorry if you let it happen, but don't blame reason. Blame that itchy finger!

Darwin is not saying or implying that the Stegosaurus is better in some absolute sense than dinosaurs that don't have plates. He is simply saying that Stegos with plates do better than Stegos without plates. It is comparative value here not absolute value. I suspect that a lot of people might say that, in some absolute way, they prefer tigers over rats. But from an evolutionary point of view, rats do better than tigers. Apparently, their adaptations - like coming to fertility quickly, being able to adapt to circumstances quickly - are of more value to them, than the tigers' - being fierce and fast and fearless - are to them. Comparative value not absolute value.

Finally, let us take home an important philosophical message. As with students competing for prizes - for philosophers rising higher on various rankings devised by the web blog, The Philosophical Gourmet - areas of science compete for status. The sciences over the humanities, the humanities over the social sciences, everybody over education. Any reader of this article who does not agree that philosophers are the brightest people on campus is either abnormal or a liar. Among the sciences, we all know that physicists consider themselves the top dogs, with chemistry just behind, followed by molecular biology, and organismic biology - to which category the Stegosaurus study belongs - in last place. Even biologists can feel a bit that way, although then at once they turn round and console themselves that they are not sociologists.

All of this is harmless enough so long as it is confined to Friday night discussions in the faculty club. Where it goes wrong is when people start taking it seriously. There is a feeling that, unless in some way you can bring biology up to the standards of the physicists, it is forever doomed - and should get no more grants wasted on it. Perhaps best would be if biology could be reduced to physics, in the sense of being shown to be a deductive consequence of physics. Know your molecules. Know your Stegosauruses. Molecular biology is a good start. It is interesting that in their follow-up paper, Farlow and his fellow workers get right into "histology," defined by Meriam-Webster as "a branch of anatomy that deals with the minute structure of animal and plant tissues as discernible with the microscope." They cut up the plates and examined them under the microscope using all kinds of physical techniques involving lighting and the like, and they boiled their discussions down to issues amenable to physico-chemical understanding, like heat flow and transfer and the rates of liquid transmission through pipes (ferrying fluids of various temperature around the body) and so forth. They may not have been physicists, but they did their best!

Our discussions show that these dreams of reduction, specifically of biology to physics, the dream of the dominant philosophy of science known as "logical empiricism" and flourishing fifty years ago, are doomed to failure. Biology has, and demands, different

Revista de Humanidades de Valparaíso, 2019, No 14, 9-25

(). (18) CC BY-NC-ND 
Why did the Stegosaurus have Plates, or is Biology Second-Rate because it thinks in Terms of Ends?

Michael Ruse

forms of explanation than physics and chemistry. This is not because it is second-rate but because it is different - it is explaining organized, end-directed entities, adaptations, of a kind unknown to the physical sciences. I doubt most people today would think they could reduce psychology to physics. Whatever is the nature of consciousness, only the crudest kind of materialist could think it is nothing but molecules in motion. The same is true of biology. So long as you have adaptations, you are going to need final causes. Physics doesn't need them. Biology does. That doesn't make biology second rate. Just different.

Let us give our Stegosaurus authors the last word. Teleology is not about to vanish.

While more complete energy balance studies on Stegosaurus and its unfinned contemporaries might shed valuable additional light on questions of their climatic tolerances and extinction, we now believe that Stegosaurus's plates, because of their evidently efficient deployment as forced convective heat loss fins, constituted a physiologically effective thermoregulatory adaptation. (de Buffrénil, Farlow, and Ricqulès 1986, 473)

\section{References}

Aristotle (1984). De Partibus Animalium. In Jonathan Barnes (ed.), The Complete Works of Aristotle, pp. 1087-110. Princeton: Princeton University Press.

Barnes, J. (ed.) (1984). The Complete Works of Aristotle. Princeton: Princeton University Press.

Boyle, R. (1688/1966). A Disquisition about the Final Causes of Natural Things. In The Works of Robert Boyle. Edited by T. Birch, 5, pp. 392-444. Hildesheim: Georg Olms.

Boyle, R. (1996). A Free Enquiry into the Vulgarly Received Notion of Nature. Edited by E. B. Davis, and M. Hunter. Cambridge: Cambridge University Press.

Darwin, C. (1859). On the Origin of Species by Means of Natural Selection, or the Preservation of Favoured Races in the Struggle for Life. London: John Murray.

Darwin, C. (1865). Letter to Henry Wentworth Acland, Darwin Correspondence Project, Letter no. 4948. Accessed on 7 October 2019, https://www.darwinproject.ac.uk/letter/DCPLETT-4948.xml

de Buffrénil, V., Farlow, J. O., Ricqlès A. (1986). Growth and function of Stegosaurus plates: evidence from bone histology. Paleobiology, 12: 459-73.

Farlow, J. O., Thompson, C. V., Rosner, D. E. (1976). Plates of the dinosaur Stegosaurus: forced convection heat loss fins? Science, 192: 1123-25.

Gould, S. J., Lewontin, R. C. (1979). The spandrels of San Marco and the Panglossian paradigm: a critique of the adaptationist programme. Proceedings of the Royal Society of London, Series B: Biological Sciences, 205: 581-98.

Herschel, J. F. W. (1830). Preliminary Discourse on the Study of Natural Philosophy. London: Longman, Rees, Orme, Brown, Green, and Longman. 
Why did the Stegosaurus have Plates, or is Biology Second-Rate because it thinks in Terms of Ends?

Michael Ruse

Hume, D. (1739-1740/1978). A Treatise of Human Nature. Oxford: Oxford University Press.

Kant, I. (1790/2000). Critique of the Power of Judgment. Edited by P. Guyer. Cambridge: Cambridge University Press.

Lucretius (1969). The Way Things Are: The De Rerum Natura of Titus Lucretius Carus. Bloomington, Ind.: Indiana University Press.

Nagel, E. (1961). The Structure of Science, Problems in the Logic of Scientific Explanation. New York, NY: Harcourt, Brace and World.

Popper, K. R. (1972). Objective Knowledge. Oxford: Oxford University Press.

Ruse, M. (2006). Darwinism and its Discontents. Cambridge: Cambridge University Press.

Ruse, M. (2015). Atheism: What Everyone Needs to Know. Oxford: Oxford University Press.

Ruse, M. (2017). On Purpose. Princeton, N. J.: Princeton University Press. 



\title{
Lo natural, lo seglar y lo sobrenatural
}

\section{The natural, the secular and the supernatural}

\author{
Gustavo Caponi \\ Departamento de Filosofia, Universidade Federal de Santa Catarina, \\ Florianópolis SC, Brasil \\ gustavoandrescaponi@gmail.com
}

\begin{abstract}
Resumen
En Filosofía de la Biología, pero también en la Filosofía de la Mente, en la Ética, en la Epistemología, y hasta en la Estética, el término naturalización se suele usar de dos maneras diferentes. Se lo suele usar en sentido meta-filosófico para indicar un modo de desarrollar la reflexión filosófica que, de algún modo, la aproximaría de la investigación científica. Pero también se lo suele usar en sentido meta-teórico. En ese caso, se lo usa para caracterizar una operación explicativa propia de la ciencia. En ocasiones, esa operación científica consiste en explicar, en términos de ciencias natural, lo que antes era explicado por un recurso a lo sobrenatural. Otras veces, esa operación explicativa resultaría en una explicación biológica de lo antes explicado en términos propios de las Ciencias Sociales. En la primera situación, lo natural se entiende como lo opuesto a lo sobrenatural; y la ciencia procura avanzar sobre ese espacio, produciendo progreso cognitivo. En la segunda situación, lo natural se entiende como lo opuesto a lo seglar; y la Biología avanza sobre esa esfera, pero no sin correr el riesgo de operar como una ideología capaz de legitimar desigualdades injustas y evitables. Esto no tiene por qué ser necesariamente así, pero el pensamiento debe precaverse de ese riesgo.
\end{abstract}

Palabras clave: Richard Lewontin, Stephen Jay Gould, desigualdad, inequidad, legitimación, naturalización de lo social, reduccionismo.

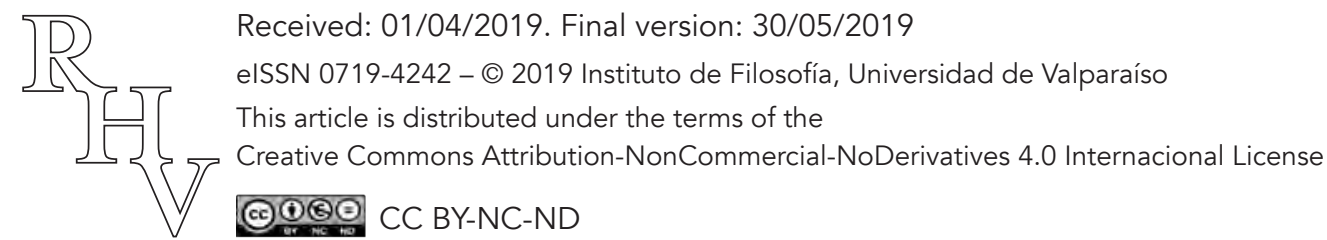


Lo natural, lo seglar y lo sobrenatural

Gustavo Caponi

\begin{abstract}
In Philosophy of Biology, but also in Philosophy of Mind, in Ethics, in Epistemology, and even in Aesthetics, the term naturalization is usually used in two different ways. It is often used in a meta-philosophical sense to indicate a way for doing philosophy that, in some way, would approximate this reflection to scientific research. But it is also often used in a meta-theoretical sense. In that case, it is used to characterize an explanatory operation proper to science. Sometimes, this scientific operation consists of explaining, in natural science terms, what was previously explained by recourse to the supernatural. Other times, this explanatory operation would result in a biological explanation of what, up to that moment, was explained above in terms of the Social Sciences. In the first situation, the natural is understood as the opposite of the supernatural; and science seeks to advance on that domain, producing cognitive progress. In the second situation, the natural is understood as the opposite of the secular; and Biology advances on that sphere, but not without running the risk of operating as an ideology capable of legitimating unjust and avoidable inequalities. This does not necessarily have to be so, but thought must guard against that risk.
\end{abstract}

Keywords: Richard Lewontin, Stephen Jay Gould, inequality, legitimation, naturalization of the social, reductionism, unfairness.

\title{
1. Introducción
}

En algunas áreas de los estudios filosóficos, como la Filosofía de la Mente, o como la propia Filosofía de la Biología, pero también en la Ética, el término 'naturalización' es usado de un modo que puede conllevar una anfibología que sería conveniente evitar. En ciertos contextos, dicha expresión es utilizada de modo meta-filosófico: ora metaepistemológico, ora meta-ético, ora meta-estético. En otros contextos, mientras tanto, ella es usada de modo meta-teórico. En el primer caso, se pretende caracterizar un modo de plantear y tratar los problemas filosóficos; y, en el segundo caso, lo que se pretende es caracterizar ciertas operaciones teóricas tendientes a explicar distintos aspectos del mundo. Por eso digo que este último es un modo meta-teórico de usar la expresión. Pero, y he ahí el tema que más me interesa discutir aquí, en ese modo meta-teórico de hablar de naturalización, tampoco deja de haber cierta ambigüedad de la que también valdría precaverse.

En el modo meta-teórico de hablar, lo natural suele oponerse a lo sobrenatural, pero también a lo cultural y a lo social; que serían las esferas de lo seglar: aquello cuyos cambios están sujetos a las vicisitudes de nuestras acciones y conflictos, sin que ahí precise mediar el cambio evolutivo ${ }^{1}$. En el primer caso, la naturalización consiste en que algo que

${ }^{1}$ En el Diccionario del Español Moderno, de Martín Alonso (1979, 926), se da el siguiente significado para

Revista de Humanidades de Valparaíso, 2019, No 14, 27-55

(). (18) CC BY-NC-ND 
Lo natural, lo seglar y lo sobrenatural

Gustavo Caponi

antes era explicado sobrenaturalmente (teológicamente, espiritualmente, mágicamente, etc.) pasa a ser explicado en virtud de variables y mecanismos accesibles a las ciencias naturales. Ya en el segundo caso, la naturalización consiste, concretamente, en un supuesto avance de la Biología sobre el campo de disciplinas como la Sociología, la Economía, y la Antropología; o incluso sobre el campo de esos saberes caracterizados como 'vulgares', con los cuales solemos abordar los más diferentes aspectos y problemas de nuestra existencia. Y son las operaciones explicativas denotadas por ese segundo modo meta-teórico de entender el término 'naturalización' que yo quiero discutir en estas páginas.

Mi interesa hacerlo porque este último tipo de naturalización puede conllevar riesgos políticos e ideológicos que están ausentes en el primer caso. Riegos de los cuales hay que precaverse, teórica y empíricamente. Así, para darle una forma más precisa a esa precaución epistemológica, enunciaré un principio metodológico al que denominaré 'Regla de Lewontin-Gould'. Debe quedar siempre claro, sin embargo, que dicha precaución no supone ninguna objeción en contra de esos emprendimientos explicativos que apuntan a la naturalización de lo antes explicado sobrenaturalmente. Pueden suscitarse sospechas sobre la naturalización de lo seglar, sospechas que habrá que discutir y que ulteriormente podrán ser despejadas, sin que eso redunde en nada que pueda considerarse como remotamente próximo de una duda sobre la naturalización de lo otrora sobrenaturalmente considerado.

Entretanto, para que el asunto que me interesa quede debidamente delimitado, también habrá que dedicar algunas primeras páginas al uso meta-filosófico del término 'naturalización'. Es necesario que quede claro lo siguiente: el desarrollo, el éxito, y la aceptación de emprendimientos explicativos, que meta-teóricamente puedan caracterizarse como naturalizaciones, no depende, bajo ningún punto de vista, del hecho de que se acepte, o no se acepte, una meta-filosofía naturalista; y tampoco es cierto que la aceptación de esos emprendimientos explicativos pasibles de ser caracterizados como naturalizaciones, resulte en una legitimación de las meta-filosofías naturalistas. Se trata de cuestiones totalmente diferentes; $y$, en lo que atañe a eso, yo parto de una posición que creo pertinente explicitar desde el vamos: las operaciones explicativas naturalizadoras pueden ser más o menos satisfactorias, mejor o peor logradas, y en algunos casos pueden conllevar riesgos a ser evitados; pero las pretensiones de las diferentes variantes de naturalismo meta-filosófico son siempre improcedentes y perniciosas.

'seglar': "relativo a la vida del mundo o siglo". A continuación, el mismo diccionario admite las expresiones 'seglaridad' y 'seglarmente'. Yo me permitiré también usar las expresiones 'seglarización' y 'seglarizada'. He preferido 'seglar' a 'secular', porque, conforme Martin Alonso $(1979,925)$ también lo consigna, 'secular' significa: "que se repite casa siglo"; o bien que "dura un siglo" o "desde hace siglos".

Revista de Humanidades de Valparaíso, 2019, No 14, 27-55

(). (18) CC BY-NC-ND 
Lo natural, lo seglar y lo sobrenatural

Gustavo Caponi

\section{Naturalización en sentido meta-teórico y en sentido meta-filosófico}

Conforme lo que acabo de decir, cuando hablamos de naturalización en sentido meta-teórico, o meta-científico, la expresión de marras es usada para caracterizar el resultado, o el objetivo, de ciertos logros o emprendimientos explicativos de las ciencias naturales; y muy especialmente de las ciencias biológicas. Desde una perspectiva epistemológica, meta-teórica, analizamos un desarrollo, un resultado, o un argumento científico, y lo caracterizamos usando una noción que también es meta-teórica: que se predica, precisamente, de desarrollos, de constructos discursivos, de resultados, o de argumentos, científicos o pretendidamente científicos. Como ocurre cuando se dice, o se discute, si tal o cual teoría es o no determinista, si tal o cual explicación es causal o no, o si tal o cual noción es o no teleológica. Así, usando la expresión 'naturalización' en esa acepción meta-teórica o epistemológica, se puede decir que la explicación del diseño biológico operada por la Teoría de la Selección Natural sería una naturalización de la teleología (Sober 1993, 82). A partir de Darwin, esa adecuación de estructura y función que es tan notoria en los seres vivos, y que las ciencias de la vida no podían dejar de reconocer pero que hasta ahí no habían conseguido explicar, pudo ser considerada como el resultado no accidental de un proceso natural (Caponi 2014, 190). Así, la tentación de aprovechar esa dificultad para buscar una salida por el lado de lo sobrenatural, quedaba definitivamente desechada. Por eso decimos que la explicación darwiniana del diseño biológico es una naturalización.

Pero, ya este modo meta-teórico de usar el término 'naturalización', en sí mismo inobjetable, puede depararnos algunas dificultades. Con toda justicia, si puede decirse que la explicación darwinista del diseño biológico es una naturalización de la teleología orgánica; también puede decirse que una explicación neurofisiológica de algún proceso cognitivo constituye una 'naturalización' del pensamiento (Andler 2004, 24; Hernández Chávez 2007, 254), y que una explicación de la evolución de nuestras categorías cognitivas constituye una naturalización del conocimiento ${ }^{2}$. Siendo posible decir otro tanto respecto de una explicación evolutiva de esas pautas comportamentales y emotivas que serían los inevitables cimientos de nuestra sociabilidad y de nuestra moralidad. Ahí podría hablarse de una naturalización de nuestra sociabilidad y de nuestra moralidad; y con ello querría decirse que las pautas que rigen nuestro comportamiento social, y definen lo que aceptamos como correcto o bueno, son (en mayor o menor grado) un producto de la evolución

\footnotetext{
${ }^{2}$ Con esto me refiero a la Teoría Evolucionaria del Conocimiento esbozada por biólogos como como Konrad Lorenz (1974), Rupert Riedl (1983), y Franz Wuketits (1984). No estoy pensando en las analogías entre evolución de la ciencia y evolución biológica como las propuestas por Stephen Toulmin (1977) y David Hull (2001). Ni tampoco estoy considerando la analogía que, muy limitadamente (Bradie 1997, 262), puede establecerse entre el funcionamiento de la mente individual y la selección natural (Campbell 1983). Popper (1974) se asomó a las tres cosas: a la genuina Teoría Evolucionaria del Conocimiento pensada a la Lorenz; a la inconducente analogía entre el desarrollo de la ciencia y la evolución biológica; y a la comparación de esta última con los procesos de aprendizaje. Paul Thagart (1997) desarrolló una excelente crítica de las analogías entre evolución de la ciencia y evolución biológica.
}

Revista de Humanidades de Valparaíso, 2019, No 14, 27-55

(c) (1) 8 (을 CC BY-NC-ND 
Lo natural, lo seglar y lo sobrenatural

Gustavo Caponi

de nuestro linaje (Stamos 2008, 262) . Valiendo lo mismo en el caso de las pautas que rigen nuestro sentido de lo bello y de lo agradable ${ }^{4}$. Lo que no está tan claro, por supuesto, es hasta dónde puede llegar esa explicación de nuestra sociabilidad, de nuestra moralidad, y de nuestro gusto. Ese tópico, entretanto, será discutido en la próxima sección. Aquí sólo quiero señalar la deriva meta-filosófica que, erróneamente, parece tener un punto de inicio en esas posibles naturalizaciones en sentido meta-teórico.

El tema no es fácil de abordar porque nunca queda del todo claro hasta dónde, y de qué modo, el conocimiento del funcionamiento de nuestro cerebro y de la evolución de nuestras facultades cognitivas, pautas comportamentales, y emotividad, puede realmente incidir en nuestra reflexiones epistemológicas, éticas, estéticas y políticas ${ }^{5}$. De hecho, esas pretendidas naturalizaciones de la reflexión filosófica no van más allá de las enunciaciones programáticas y de indecisas reflexiones respecto de cómo ellas deberían ser, hasta donde podrían llegar y qué ventajas podrían traerle a la reflexión filosófica (Bradie 2007). Todas, además, se empantanan en una misma dificultad: no hay un camino directo para justificar normas y decisiones, a partir de hechos. Es decir: ese paso nunca se puede hacer sin suponer otras normas o decisiones, valores, y preferencias de alguna índole; y sin presuponer, sobre todo, reglas respecto de cómo es que ese plexo normativo y axiológico debe articularse con los hechos para, a partir de ahí, derivar otras normas y así dirimir los diferentes conflictos normativos y axiológicos que puedan suscitarse.

Lo interesante del caso es que, cuando iniciamos esas reflexiones respecto de la relación entre normas y hechos, ya nos introducimos de lleno en el campo de reflexiones filosóficas que se tramitan de un modo que en nada se compadece con las pretensiones, o ilusiones, que las propuestas naturalistas parecen abrigar. Esas reflexiones (éticas, epistemológicas o estéticas) procuran elucidar y reconstruir los principios y conceptos más fundamentales que, de modo implícito, pautan y orientan nuestras discusiones y opciones prácticas o teóricas. Cabiendo también el desafío de hacer que esos principios sean más precisos y más coherentes entre sí; modificando incluso nuestro modo inicial de entenderlos para así ampliar su universalidad y hasta su área de aplicación ${ }^{6}$. Además, aunque la correcta caracterización de esas elucidaciones sea motivo de arduas e interminables polémicas meta-filosóficas, de lo que sí podemos estar seguro que ellas no pretenden fundarse ni en dogmas religiosos ni en decisiones anteriores, o exteriores, a las prácticas argumentativas cuyas gramáticas se pretende delimitar y clarificar. No es necesario, por

\footnotetext{
${ }^{3}$ Sobre la evolución de la moral y de la sociabilidad, léase: Tort (2008); Axelrod y Hamilton (2010); Montiel Castro y Martínez Contreras (2012); Rosas (2014); Strassmann y Queller (2016); Clavien y Fitzgerald (2018).

${ }^{4} \mathrm{Al}$ respecto se puede consultar: Rusch y Voland (2013); Cela Conde \& Ayala (2014); y Davies (2018).

${ }^{5}$ El tópico ya ha sido planteado por Ruse (1987), Bradie (1994) y Woolcock (1999), entre muchos otros.

${ }^{6}$ En "La amplia agenda de la Filosofía de la Ciencia" (Caponi 2007) me permití algunas disquisiciones meta-filosóficas que podrían servir para dejar más clara mi posición sobre la naturaleza y los objetivos de la reflexión epistemológica.
}

Revista de Humanidades de Valparaíso, 2019, No 14, 27-55

(c) (1) 8 (을 CC BY-NC-ND 
Lo natural, lo seglar y lo sobrenatural

Gustavo Caponi

otro lado, que esas polémicas meta-filosóficas se cierren para saber que las constataciones empíricas nunca son suficientes para justificar normas o valoraciones; y siendo ese plus lo que nos llama a la reflexión ética, epistemológica o estética.

Que sepamos que nuestro cerebro está organizado de forma tal que ciertas geometrías le resultan más accesibles que otras, en nada va cambiar el modo de construir las demostraciones geométricas. Aunque saber eso sí pueda relevante en el momento de organizar la didáctica de la Geometría. Como tampoco se dirime una discusión epistemológica sobre la naturaleza de las explicaciones causales en virtud de consideraciones sobre la ontogenia o la filogenia de la noción de causalidad; aunque dichas consideraciones también puedan resultar útiles en la didáctica de la ciencia. Y lo que ocurre en el caso de las cuestiones epistemológicas, no es muy diferente de lo que ocurre en áreas como la Ética o la Filosofía Política7. Que sepamos que, en general, preferimos ayudar más a nuestros hijos y parientes, que a los hijos y parientes de los otros, y por sólidas que puedan ser las explicaciones evolutivas de nuestra sujeción a ese patrón comportamental (Pinker 2012, 429), nada de eso va a servirnos como una legitimación del nepotismo. Dar una explicación evolutiva de nuestras normas y modos de actuar no es lo mismo que justificarlos (Ruse 1989, 292; Rosenberg 2010,369). Aunque, el conocimiento de esas preferencias, sí pueda llevarnos a reforzar las tecnologías institucionales tendientes a neutralizar prácticas y emociones que sabemos frecuentes pero, no obstante eso, consideramos condenables (Singer 1999, 61; Gould 2004, 242).

En lo que atañe a la Ética, lo mismo que en lo atinente a la Epistemología y a la Estética, sigue valiendo lo ya dicho por Wittgenstein (1973[1922], §4.1122): "la teoría darwinista no tiene que ver con la filosofía más que cualquier otra hipótesis de la ciencia natural"8. Y eso, por lo general, no es desmentido por lo que de hecho se llega a hacer cuando se habla de 'Epistemologías Evolucionistas' (Campbell 1997), de 'Epistemología Naturalizada' (Quine 1974), de 'Ética Naturalizada' (Rottschaefer 2000) o de 'Ética Evolucionista' (Wilson 2007). De hecho, en todos esos casos se incurre, o bien en un error categorial o bien en un equívoco. El error categorial sería el de confundir cuestiones filosóficas con temas de Biología, como sería el caso del estudio de la evolución de nuestras categorías cognitivas y de nuestras pautas morales más básicas. Y el equívoco, aparentemente menos pernicioso que el error, sería el de aludir a un área de investigación empírica, usando el nombre con el que se designa una reflexión que tiende a la justificación, a la evaluación y a la fundamentación de normas y decisiones. Lo cierto, de todos modos, es

\footnotetext{
${ }^{7}$ Así lo han señalado: Ruse (1989, 289); Kitcher (1994, 440); y Rosenberg \& MacShea (2008, 222).

${ }^{8}$ Creo, además, que las críticas de Stephen Jay Gould $(2004,287)$ a las propuestas de naturalización de la Estética esbozadas por Edward Wilson (1998, 229), muestran que eso es inmediatamente extensible a dicha disciplina Filosófica.
}

Revista de Humanidades de Valparaíso, 2019, No 14, 27-55

(ㄷ)(1)(2) CC BY-NC-ND 
Lo natural, lo seglar y lo sobrenatural

Gustavo Caponi

que el equívoco terminológico acaba siendo solidario del error categorial; induciéndonos a creer que estamos ante una revolución meta-filosófica, cuando en realidad sólo estamos ante un simple abuso de lenguaje.

Por fin, antes de dejar de lado estas disquisiciones sobre el uso meta-filosófico de la noción de naturalización, quisiera hacer referencia a otro modo de pensar la Filosofía de la Ciencia que, aunque es distinto del propuesto por Quine, y nada tiene que ver con la Epistemología Evolucionista pensada a la Campbell, puede llegar a ser calificado de 'naturalista'. Aludo a la superposición, o aproximación, entre ciencia y Filosofía de la Ciencia que suele insinuarse, no siempre claramente, entre aquellos que se ocupan de la Filosofía de la Biología. La idea sería que entre ciencia y filosofía de la ciencia no hay identidad, pero sí continuidad temática. La Filosofía de la Ciencia no sería una reflexión puramente meta-teórica sino que su finalidad también residiría en conocer el mundo y a nosotros como parte de él. Las reflexiones meta-teóricas, en todo caso, serían sólo un momento de ese emprendimiento cognitivo; pero la Filosofía de la Ciencia no tendría por qué limitarse a tales reflexiones. Ella no tendría por qué renunciar a cualquier derecho de decir algo sobre el propio mundo que la ciencia procura conocer.

Entre los filósofos de la Biología, Peter Godfrey-Smith $(2014,4)$ se ha transformado en el abanderado de esa posición. Según él, la Filosofía de la Ciencia entendida sólo como meta-teoría sería una Filosofía de la Ciencia restringida: Filosofía de la Ciencia en el sentido habitual, y estrecho, de la palabra. Pero, cuando la Filosofía de la Ciencia asume la tarea de "entender el universo y nuestro lugar en él", ella llega a ser Filosofía de la Naturaleza. Así, Godfrey Smith no sólo echa mano de un término que ya ha sido objeto de muchos usos; sino que además, aunque quizá sin saberlo, lo hace utilizándolo en un sentido que recuerda al modo en el que, esa misma expresión, era usada en la tradición neotomista del Siglo XX. Allí, el término 'Filosofía de la Naturaleza' designaba una disciplina que, teniendo como objeto los entes también estudiados por la ciencia natural, los consideraba, no en virtud de sus propiedades observables, sino en virtud de sus propiedades puramente inteligibles (Jolivet 1960, 25; Maritain 1978[1963], 280) ${ }^{9}$. Godfrey-Smith nunca daría esa caracterización escolástica de su Filosofía de la Naturaleza; pero su modo de entenderla

\footnotetext{
${ }^{9}$ Godfrey-Smith usa la expresión 'Philosopy of Nature'. Él no usa el término 'Natural Philosophy'; que es la traducción de 'Philosophia Naturalis”. Expresión, esta última, con la que Newton (1687; 1846[1726]), y sus contemporáneos ingleses, designaban una ciencia de la naturaleza que, por su generalidad y sus pretensiones explicativas, se distinguía de la Historia Natural: un conocimiento de procesos y objetos particulares de carácter predominantemente descriptivo y taxonómico. Pero 'Philosopy of Nature' es una de las posibles traducciones del término 'Natürphilosophie', usado por Schelling (2004[1799]). Es obvio, entretanto, que Godfrey-Smith no estaba pensando en nada que pudiese tener que ver con el tipo de especulaciones a las que Schelling designaba con esa expresión. Ni tampoco sería posible aproximar el uso que Godfrey-Smith le da a ese término con aquel que le da Miguel Espinoza (2000, 5). Para este autor, la expresión designa una reflexión orientada a establecer las condiciones que hacen que la naturaleza sea accesible, o inteligible, a la ciencia.
}

Revista de Humanidades de Valparaíso, 2019, No 14, 27-55 
Lo natural, lo seglar y lo sobrenatural

Gustavo Caponi

parece suponer que se trata de un discurso referido al mundo que, quizá coyunturalmente, no puede ser objeto de la evaluación observacional y experimental de la que sí puede ser objeto la ciencia propiamente dicha. Así, esa Filosofía de la Naturaleza puede desarrollarse sin precisar someterse, inmediatamente al control experiencial, promoviendo la apertura de nuevos campos de indagación y ampliando nuestras agendas de indagación.

La Filosofía de la Naturaleza, pensada a la Godfrey-Smith sería un modo deliberado y razonado de desarrollar, y de discutir, esa metafísica heurísticamente fértil que Popper (1985a, 232; 1985b, 177) gustaba de reivindicar. Pero, siendo así, en la medida en ella asume una finalidad teórica, pretendiendo producir conocimiento sobre el mundo, la Filosofía de la Naturaleza puede ser objeto de crítica teórica y también de reflexión meta-teórica. Por eso, si ella abrigase intenciones naturalizantes, las mismas deberían ser juzgadas con parámetros semejantes a los que hemos de usar para juzgar los desarrollos científicos que, desde una perspectiva meta-teórica, merezcan ser considerados como naturalizaciones o como proyectos de naturalización. Que dichas intenciones se formulen y desarrollen en el marco de una pretendida Filosofía Natural no las pone al resguardo de las críticas de las que las mismas podrían ser objeto si enunciadas sin establecer una diferencia, entre simple ciencia natural y Filosofia de la Naturaleza, como la que Godfrey-Smith propone.

Es decir, si se acepta la tesis (o la propuesta) meta-filosófica de Godfrey-Smith sobre la Filosofía de la Naturaleza, esta debe ser objeto de reflexiones y de críticas epistemológicas semejantes a esas reflexiones y críticas, epistemológicas de las que debe ser objeto la ciencia tout court. Así, aunque desde un punto de vista meta-filosófico aceptemos decir que la forma de entender la Filosofía de la Ciencia promovida Godfrey-Smith constituye una naturalización de la Filosofía de la Ciencia, eso no pone sus tesis fuera del alcance de la reflexión meta-teórica; sino todo lo contrario. En este sentido, lo que a continuación se diga sobre las naturalizaciones (en sentido meta-teórico) que podrían buscarse en ciertos dominios de la Biología, también habrá de valer, mutatis mutandis, para propuestas análogas que pudiesen surgir en el campo de esa putativa Filosofía de la Naturaleza.

Entiendo, de todos modos, que, en realidad, la expresión 'Filosofía de la Naturaleza', por lo menos de la forma en que la usa Godfrey-Smith, es totalmente dispensable y que los problemas que este autor se plantea no dejan de ser, por lo menos en su mayor parte, cuestiones meta-teóricas. Sus reflexiones, por lo general, tienden a elucidaciones conceptuales que caben perfectamente en una Filosofía de la Ciencia entendida, por ejemplo, a la manera de Díez y Moulines (1999, 23-5). Su modo de plantear y de tratar dichas elucidaciones descuida, sin embargo, la distinción entre los niveles discursivos teórico y meta-teórico; que de por sí están siempre muy entrelazados. Pero ese descuido en el modo de exponer es muy frecuente en toda la Filosofía de la Biología; y no creo que sea demasiado pernicioso, ni que invalide las reflexiones epistemológicas que así se desarrollan. Lo que si habría que evitar es la tentación de tratar a ese descuido, a esa desprolijidad, en el modo de exponer, como si ella fuese la expresión de una innovación meta-filosófica. De miseria no se hace virtud.

Revista de Humanidades de Valparaíso, 2019, No 14, 27-55

(c) (1) 8 (을 CC BY-NC-ND 
Lo natural, lo seglar y lo sobrenatural

Gustavo Caponi

\section{La naturalización de lo social}

Dije que asumo una posición definitivamente contraria a los proyectos de naturalización de las disciplinas filosóficas. Pero espero que también haya quedado claro que eso no se transfiere a lo que caractericé como proyectos de naturalización en sentido meta-teórico. Ya aludí a la explicación darwinista del diseño biológico como siendo una naturalización ejemplar; y, en línea con Dennett (1996, 521), me atrevo a decir que ella es sólo la ur-naturalisierung. Partiendo de esa madre de todas las naturalizaciones, pudieron ser entrevistos los caminos para acometer otros desafíos explicativos que durante mucho tiempo, y semejantemente a lo que solía ocurrir con el propio diseño biológico, parecían ser la sempiterna oportunidad para la postulación de los más diversos 'guinchos celestiales' (Dennett 1996, 83). Aludo a los ya mencionados esfuerzos por dar con explicaciones evolutivas relativas al origen de los cimientos biológicos de nuestras capacidades cognitivas, de nuestra emotividad, de nuestra sociabilidad, e incluso de nuestra moralidad. Esfuerzos que, por ir en contra de cualquier escape hacia una explicación sobrenatural de nuestras capacidades de pensar, de conocer, de convivir y de juzgar, merecen ser meta-teóricamente caracterizados como naturalizaciones del pensamiento, de la cognición, de la emotividad, de la sociabilidad, de la moralidad y del gusto.

Dichos emprendimientos explicativos, lo subrayo, no son sólo posibles y legítimos: son obligatorios. En cierto sentido, la explicación de los orígenes y cimientos biológicos de la moralidad, de la sociabilidad, de la emotividad, del gusto, y de las capacidades cognitivas en general, es un imperativo del cual la Biología no puede hurtarse. La capacidad de individualizar relaciones causales, los sentimientos de agrado o desagrado que puede generar una forma o un sonido, y el rechazo o aceptación que puede suscitar la conducta de otro miembro de nuestro grupo, son cosas que no pueden dejar de estar ancladas en un sustrato neurofisiológico que de alguna forma las posibilitan y las pautan. Y esas capacidades cognitivas y emotivas no pueden ser otra cosa que el resultado de una larga historia evolutiva que puede y debe ser reconstruida; no menos de lo que puede ser identificado y comprendido su anclaje neurofisiológico. Negarse a eso es abandonar el materialismo para así coquetear con lo sobrenatural: es invocar viejos fantasmas; que es lo que Thomas Nagel (2012) nos quiere invitar a hacer. En ese sentido, rechazar dichas 'naturalizaciones' implicaría querer defender una explicación sobrenatural de lo que ocurre en la naturaleza; y eso está excluido del dominio de la ciencia.

Es decir: en el dominio de la ciencia no se puede apelar a ninguna explicación que suponga la postulación de variables cuyo conocimiento sea ajeno a la propia ciencia natural. La ciencia sólo puede explicar en virtud de lo que también pueda considerarse científicamente explicable; y ese dominio de lo científicamente explicable coincide con el espacio de aquello que, por lo menos en cierta escala y bajo ciertas condiciones quizá muy restrictas, puede ser experimentalmente producido o intervenido. Las presiones selectivas, por ejemplo, son un buen ejemplo de esas variables experimentalmente producibles e intervenibles: en ciertas condiciones, dentro de ciertos límites, podemos producir presio-

Revista de Humanidades de Valparaíso, 2019, No 14, 27-55

()ㅇㅇㅇ CC BY-NC-ND 
Lo natural, lo seglar y lo sobrenatural

Gustavo Caponi

nes selectivas y controlarlas experimentalmente (Futuyma y Bennett 2009); como ocurre con las fuerzas gravitacionales y con los empujes arquimedianos. Con el 'diseñador inteligente' de Michael Behe (1996), en cambio, no se da nada de eso. Dada la explicación por selección natural de la frecuencia de un carácter en una población, cabe preguntarse qué factores cabría modificar para que esa frecuencia se viese alterada. Nada de eso es posible con el diseñador inteligente; que es una variable inescrutable y ajena a cualquier intervención o interferencia experimental.

El problema, entretanto, reside en el hecho de que esas naturalizaciones (en sentido epistemológico o meta-científico) a las que los desarrollos de la Biología parecen dar fundamento y aliento, no sólo acaban con el espacio que algún trasnochado podría reclamar para lo sobrenatural. En realidad, en la mayor parte de los casos, las banderas de la naturalización son enarboladas cuando están en estudio la cognición, la emotividad, y la sociabilidad humanas: eso es lo que se ve en el caso de esos capítulos de la Sociobiología (Wilson 1980a; Ruse 1989) que aluden a nuestra especie, y también en toda la Psicología Evolucionista (Barkow et al. 1992; Cosmides et al. 1992). En esos desarrollos teóricos, temas que normalmente son explicados en virtud de los recursos teóricos producidos y usados por disciplinas como la Sociología, la Etnografía, la Etnolingüística, la Economía y la Historia, ésas que llamamos 'ciencias sociales', 'ciencias humanas' o 'ciencias de la cultura', pasan a ser explicados, por lo menos parcialmente, en términos de Biología Evolucionaria.

Allí la naturalización aparece como 'reduccionismo' (Gould 2004, 226); o como 'determinismo biológico' (Lewontin et al. 2003, 13). Por su vía, lo seglar pasa a ser explicado por lo natural; y eso no puede ser considerado como un simple extensión, o como una exigencia, del avance sobre la esfera de lo antes pensado en términos sobrenaturales. Al aludir a variables y procesos que están al alcance de nuestras intervenciones, que pueden ser interferidos por nuestras acciones e interacciones simbólicas, las ciencias sociales escapan de cualquier contubernio con lo sobrenatural. El lenguaje que dichas ciencias desarrollan para enunciar y comunicar el saber que ellas mismas producen, es diferente de los también heterogéneos, y variados, lenguajes desarrollados por las ciencias naturales; pero, limitándose a aludir al ámbito de lo por nosotros intervenible, ese conocimiento cabe perfectamente en lo que podría caracterizarse por una ontología materialista (Athusser 2014, 85). Y lo mismo vale para los saberes informales sobre el entorno que desarrollamos en nuestras interacciones cotidianas (Caponi 2016a, 162). Lo seglar se inscribe en la esfera de lo material; que es lo que realmente debe oponerse a lo sobrenatural.

Por eso, el logro paradigmático de esas reducciones de lo seglar a lo biológico ya no consiste en mostrar y ratificar que nuestros modos de actuar, de pensar y de sentir no dependen de algo sobrenatural. Eso, felizmente, ya se daría por obvio. Lo que sí importaría mostrar es que dichos modos de actuar, de pensar y de sentir son el resultado, en mayor o menor grado, de nuestra evolución biológica (Stamos 2008). Por eso, según se supone, ellos dependen, en algún grado, de ciertos factores innatos; y no tanto de la

Revista de Humanidades de Valparaíso, 2019, No 14, 27-55

(c) (1) 8 (을 CC BY-NC-ND 
Lo natural, lo seglar y lo sobrenatural

Gustavo Caponi

simple diversidad cultural o social, o de las diferentes experiencias de vida a las que podemos estar expuestos ${ }^{10}$. Los defensores de ese punto de vista 'naturalista' condenan un supuesto Modelo Estándar de las Ciencias Sociales (Cosmides y Tooby 1992, 25; Stamos 2008, 73), según el cual todas, o la mayoría, de las pautas que rigen nuestra cognición, nuestra emotividad y nuestra sociabilidad, serían producto de la propia historia social y cultural, sin que exista ningún anclaje o soporte biológico que limite o predetermine significativamente dicha evolución cultural y social. Para ellos, en cambio, esos límites y esa predeterminación biológica de nuestra cognición, de nuestra emotividad y de nuestra sociabilidad, son claves para entender lo que ocurre, lo que ha ocurrido, y lo que puede ocurrir, en nuestra vida social y cultural. Y es ahí que pueden esconderse algunos riesgos, ideológicos pero también teóricos, de los que nos debemos precaver. No pocas veces, la naturalización de lo social y cultural ha operado como legitimación de injusticias, crueldades y hasta aberraciones.

El avance de la Biología sobre las ciencias sociales puede tener dos formas. En ocasiones, las explicaciones biológicas sólo parecen establecer un límite, o un constreñimiento, a lo social y culturalmente posible (Sterelny y Griffiths 1999, 17). Instituciones, usos, costumbres, preferencias, lo mismo que el surgimiento y el devenir de los procesos y conflictos sociales, deberán recibir explicaciones sociológicas y culturales. Pero dichos fenómenos sociales y culturales serán considerados como teniendo su condición de posibilidad en ciertas infraestructuras que también delimitan el margen de lo que puede ocurrir y dejar de ocurrir en una sociedad. En otros casos, mientras tanto, ese avance de las ciencias biológicas sobre el campo de las ciencias humanas, parece querer ir más lejos. En ocasiones, lo que parece estar en juego es un relevamiento de las explicaciones sociológicas y culturales (Sterelny y Griffiths 1999, 17). De hecho, los teóricos de la Sociobiología y de la Psicología Evolucionista gustan de tratar a las ciencias sociales como disciplinas subdesarrolladas (Wilson 1998, 189) o fracasadas (Cosmides y Tooby 1992, 22): el enfoque biológico vendría a remediar las supuestas incapacidades de las Ciencias Sociales, tomando su lugar en el esfuerzo explicativo. Lo que restaría para las Ciencias Sociales, en todo caso, sería simplemente dar cuenta de la diversidad de formas en que pueden manifestarse esos patrones cognitivos, emotivos y etológicos, supuestamente previos a cualquier determinación cultural o social, y ya explicados biológicamente.

Lo cierto, entretanto, es que, en ambas formas de entender el avance de la Biología sobre el campo de las Ciencias Sociales, aparece un mismo problema. Tanto cuando sólo se supone que lo cultural y socialmente posible está sólo biológicamente delimitado, como cuando se llega a aceptar que lo cultural y lo social están positivamente determinados por lo biológico, lo que se asume es lo mismo: hay algo que pauta lo social y lo cultural, pero que no puede ser inmediatamente afectado por cambios culturales y sociales. A no ser,

\footnotetext{
${ }^{10}$ Esa posición ha sido paradigmáticamente enunciada por Edward Wilson (1998); y después retomada por la Psicología Evolucionista (Barkow et al. 1992; Cosmides y Tooby 1992; Pinker 2012).
} 
Lo natural, lo seglar y lo sobrenatural

Gustavo Caponi

claro, que se suponga la intervención de ciertos tipos de procesos como los que suelen aludirse con las expresiones 'Efecto Baldwin' (Diogo 2017), 'Co-evolución Gen-Cultura' (Bortolini et al. 2014), y 'Construcción de Nichos' (Odling-Smee et al. 2003). En esos casos, es verdad, los cambios culturales y sociales podrían redundar en presiones selectivas capaz de producir transformaciones evolutivas. Pero, incluso en tales circunstancias, esos cambios culturales y sociales, para poder ocurrir, tendrían que ser compatibles con estructuras biológicas pre-existentes; y, en algunos casos, ellos hasta resultarán de la operación de dichas estructuras. Aun cuando estas últimas acaben siendo ulteriormente, evolutivamente, modificadas. Y es ahí que se abre el espacio para cierto tipo de hipótesis con las que es mejor tener mucho cuidado.

En muchos casos, dichas hipótesis aparecen asociadas a la idea de una 'naturaleza humana universal' ${ }^{11}$. Es decir: a la idea de un conjunto de patrones cognitivos, emotivos, y comportamentales que, siendo el resultado de la evolución, está sujeto a ella y a toda la variabilidad que presenta cualquier estado de carácter. Pero que, aun así, y de forma puramente coyuntural, se da en todos los linajes de nuestra especie dentro de ciertos valores medios bastante constantes (Gould 1983a, 267). En otros, sin embargo, hoy minoritarios pero otrora muy frecuentes, esa referencia a una roca madre biológica, recalcitrante a un influjo demasiado significativo de lo social y cultural, aparece asociada a la idea de que dichos patrones cognitivos, emotivos, y comportamentales presentan una variación relevante cuando se comparan los diferentes linajes, las supuestas razas, de nuestra especie (Gould 1983a, 267). Pero, aunque esta última variante sea la más obviamente peligrosa, la primera, el recurso a una naturaleza humana universal menos sujeta a variaciones inter-poblacionales, también puede tener efectos políticos e ideológicos bastante perversos.

El primero de ellos es la aceptación de la supuesta inevitabilidad, o casi inevitabilidad, de ciertas emociones y modos de comportarnos. Para Pinker $(2018,428)$ ese sería el caso, por ejemplo, del etnocentrismo y de otra formas de hostilidad entre grupos. El racismo, en este sentido, y según Michael Ghiglieri $(2000,209)$ parece sostener, sería algo 'natural'. Algo que, aunque condenemos, no podemos evitar y con lo cual tenemos que, de algún modo, convivir. Cosa que, por supuesto, le resulta más fácil al grupo que está en posición de marginar y no de ser marginado. Pero otro de los grandes tesoros de los teóricos de la naturaleza humana, está en las supuestas diferencias emotivas y cognitivas que existirían entre los sexos. El tópico tiene una larga historia; pero sus precedentes más inmediatos los encontramos en el Siglo XIX, cuando Paul Broca $(1861,15)$ pretendía demostrar la supuesta inferioridad mental de la mujer con base en mediciones craneométricas (Gould 1983b, 167; 1988, 95). La Craneometría, entretanto, no era el único espacio en que esas

\footnotetext{
${ }^{11}$ Ese recurso a la 'naturaleza humana' se encuentra paradigmáticamente enunciado en: Wilson (1980b); Barkow et al. (1992); y Pinker (2012).
} 
Lo natural, lo seglar y lo sobrenatural

Gustavo Caponi

ideas se ventilaban. La inferioridad mental de la mujer fue un tema recurrente en la Psiquiatría de la segunda mitad del Siglo XIX (v.g. Bombarda 1896, 130) y de las primeras décadas del Siglo XIX (v.g. Moebius 1982[1906], 6).

Pero, en las últimas décadas las diferencias entre los sexos (en lo que atañe a sus habilidades cognitivas y a sus disposiciones emotivas) han vuelto a ser muy tematizadas bajo los auspicios de la Psicología Evolucionista. Ahí, es cierto, ya no se habla de una inferioridad mental de la mujer; pero sí de un dimorfismo sexual, de carácter emotivo y cognitivo, cuyo reconocimiento echaría luz sobre diferentes problemas sociales y culturales que suscitan las relaciones entre géneros (Nelkin 2002, 311). Las mujeres no tendrían capacidades cognitivas o disposiciones emotivas pasibles de ser calificadas como superiores o inferiores a los de los hombres; pero sí como diferentes: ellas tendrían habilidades cognitivas que los hombres no tienen, y viceversa. Sobre todo viceversa. Lo que no implicaría menospreciar a nadie, pero si reconocer que los roles sociales posibles de hombres y mujeres no pueden ser idénticos. Así, y como bien lo apuntan Richard Lewontin, Steven Rose, y Leon Kamin (2003, 160), esos discursos acaban legitimando el orden patriarcal. No porque se lo considere deseable; sino por el hecho de que, pretender cambiarlo, podría traer más problemas y sufrimientos que ventajas. Al fin y al cabo, nada es peor que querer ir en contra de nuestra naturaleza.

Es interesante ver, incluso, la manera en que las conclusiones de las investigaciones hechas por los psicólogos evolucionistas, encajan perfectamente con los más conocidos prejuicios y lugares comunes de la 'sabiduría popular masculina'. Sobre todo en lo que respecta al tópico 'lo que a las mujeres les gusta'. En lo que atañe a eso, los experimentos y observaciones de los Psicólogos Evolucionistas no dicen nada diferente de lo que puede escucharse en las mesas de galanes de bares de Buenos Aires, de São Paulo, de Paris, o de Chicago. El capítulo que David Stamos $(2008,139)$ le dedica a "la evolución y el sexo" en su libro Evolución es un buen ejemplo de eso. Pero, el gran pionero de ese discurso fue David Buss (1994). Steven Pinker, por su parte, tampoco se privó de esa línea de argumentación; $\mathrm{y}$, aludiendo a la división sexual del trabajo doméstico, también la consagró como natural. Llegando a decir, entre otras cosas, que, por naturaleza, "las mujeres prestan más atención a los lloros habituales de sus bebés", y que "son más solícitas con sus hijos en general" (Pinker 2012, 503). Además de eso, Pinker $(2012,537)$ subscribe la tesis de que los hombres son naturalmente propensos a la violación; y que por eso, en ciertos contextos, las mujeres no deberían usar ropa sexy. Por supuesto, cualquier desvío individual de esos patrones, sobre todo si muy arraigado, será considerado una variación hereditaria. Como podría ser el caso de la homosexualidad (Horvath 2007, 303; Stamos 2008, 166).

Por otra parte, si las capacidades y pautas cognitivas, emotivas y comportamentales, que hacen a la naturaleza humana están genéticamente predeterminadas; entonces, en la misma medida en que eso sea así, dichas capacidades y pautas también estarán sometidas a la variabilidad y transmisibilidad de cualquier característica heredable. Lo que ratifica

Revista de Humanidades de Valparaíso, 2019, No 14, 27-55

(c) (1) 8 (을 CC BY-NC-ND 
Lo natural, lo seglar y lo sobrenatural

Gustavo Caponi

la idea de que, en alguna medida, las capacidades y pautas cognitivas, emotivas y comportamentales de los individuos, dependerán de la dotación genética de sus ancestros mediatos e inmediatos (Nelkin 2002, 308; Lewontin et al. 2003, 118). Así, cosas como la propensión a los comportamientos violentos, o la capacidad de aprovechar mejor o peor la educación recibida, dependerán de factores hereditarios; restando, en lo que atañe a dichas cuestiones, menos margen de influencia para acción de la educación, de la cultura, y de las condiciones de vida (Nelkin 2002, p.311). Y ese modo de pensar, cuya historia y retórica Gould (1988) analizó en La falsa medida del hombre, pervive en los teóricos de la Psicología Evolucionista. Según Pinker, la evidencia acumulada no deja dudas de la marcada incidencia de la herencia en cosas como la propensión a los comportamientos agresivos (Pinker 2012, 451), o en el mayor o menor rendimiento escolar (Pinker 2012, 428). Galton y sus seguidores eugenistas pensaban lo mismo.

En sus Principles of Genetics and Eugenics de 1935, Nathan Fasten $(1935,4)$ sostenía que el acceso a las diferentes modalidades y niveles de educación, debía ajustarse a la capacidad intelectual heredada de cada alumno; y ésta, como ocurría con la propensión a la criminalidad (Fasten 1935, 330), debía estimarse en virtud de lo que supiésemos de la genealogía de cada individuo. Por lo tanto, las oportunidades educativas de todos los individuos, lo mismo que las oportunidades de rehabilitación en caso de criminales y de menores infractores, o simplemente 'problemáticos', deberían darse en virtud del conocimiento de esa filiación. Así, niños con antecedentes familiares de bajo rendimiento escolar merecerían cierto tipo de educación; y los que proviniesen de familias con mejor rendimiento escolar merecerían otro tipo de educación. Cómo podemos imaginarlo, si en un barrio pobre abundaban las familias en las que se perpetuaba el fracaso escolar, eso no se explicaba por las condiciones de vida; sino por las disposiciones intelectuales heredadas. El determinismo biológico, como también lo apuntan Richard Lewontin, Steven Rose, y Leon Kamin $(2003,82)$ siempre es un estupendo legitimador de la desigualdad.

Por supuesto, de ahí a pensar que esa genealogía viene dada, básicamente, por la pertenencia a un linaje racial específico, hay un paso casi inevitable (Gould 1984a). De hecho, la idea de que las capacidades intelectuales estén férreamente determinadas por factores hereditarios, siempre acabó sirviendo para estigmatizar y excluir grupos étnicos particulares (Gould 1984b, 313). En el Siglo XIX, eso fue hecho invocando frágiles consideraciones craneométricas (Gould 1983c, 273; 1983d, 159; 1988, 61); como las de Broca $(1861,40)$. Luego fue el momento de los test de coeficiente intelectual; que pretendían medir una inteligencia innata, independiente de factores educacionales, y delimitable con prescindencia de cualquier consideración cultural (Gould 1983c, 273). Y esas son ideas que, como lo muestran Nelkin $(2002,309)$ y Sussman $(2014,249)$, están muy lejos de haber muerto: ellas siempre amenazan con retornar, aunque travestidas con ropajes más à la page. Stanley Stamos $(2008,226)$, por ejemplo, que se cuenta entre los que bregan por una supuesta rehabilitación racism free del concepto de raza, considera factible que distintos grupos étnicos presenten capacidades cognitivas diferenciadas en virtud de sus

Revista de Humanidades de Valparaíso, 2019, No 14, 27-55

(c) (1) 8 (을 CC BY-NC-ND 
Lo natural, lo seglar y lo sobrenatural

Gustavo Caponi

diferentes historias evolutivas (Stamos 2008, 225). Nicholas Wade (2015, 264), por su parte, llega a afirmar que: "Las sociedades difieren mucho debido a diferencias evolutivas en el comportamiento social". Algunos grupos étnicos, deberíamos entonces pensar, estarían naturalmente inhabilitados para participar de ciertos ordenamientos institucionales y para ejercer ciertas actividades.

\section{Naturalización y resignación}

En la medida en que nuestros esquemas cognitivos, comportamentales y emotivos sean explicados en virtud de la evolución de nuestro linaje, dichos esquemas pasaran a ser considerados como teniendo una raíz que, en alguna medida, deberá ser entendida como anterior a las formas en las que están actualmente organizadas nuestra sociedades, a los recursos materiales y simbólicos con los que ellas hoy cuentan, y a la forma en la que en ellas se distribuyen dichos recursos. Así, cuanto más profundo y decisivo sea considerado el anclaje biológico de esas pautas cognitivas, comportamentales y emotivas, más independientes se las considerará del contexto social y cultural en el que ellas se desarrollan; y eso puede tener consecuencias que merecen atención. La naturalización, entendida como biologización de los fenómenos sociales, puede conducirnos a una aceptación o resignación ante esos fenómenos, que no sería muy diferente, en la práctica, a esa aceptación y resignación ante esos fenómenos a las que puede llevarnos su sobrenaturalización. En ambos casos, los fenómenos en estudio pasan a ser considerados como estando fuera del alcance de nuestras acciones, de nuestros acuerdos y negociaciones, de nuestra imposiciones y de nuestras críticas o preferencias. Piénsese, nuevamente, en lo que puede resultar de la naturalización de una diferencia en rendimiento escolar que pueda verificarse entre alumnos de diferentes etnias, o de géneros diferentes; y piénsese también en lo que puede resultar de una naturalización de la violencia sexual.

Si se concluyese que los escolares de una etnia cualquiera tienen un desempeño en geometría que es menor que el de otros estudiantes de la misma región y condición social, y terminamos explicando esa diferencia en virtud de una diferencia en las capacidades cognitivas de esa etnia que obedecería a su historia evolutiva; entonces, en ese caso, es muy posible que se desista de ofrecerles, a esos escolares, una formación en matemáticas que les permita alcanzar las habilidades de sus compañeros. Cosa que es mucho más simple y barata que intentar determinar, por la vía de la Etnomatemática, qué aspectos de nuestras formas de enseñar Geometría pueden colidir con la forma en que las nociones espaciales son entendidas en esa cultura. Por su parte, la naturalización de la violencia sexual puede promover castigos extremos como la castración química; pero, dependiendo de la condición socio-étnica del agresor y la víctima, también podrá invocarse como atenuante. Ya lo sabemos: castración química para el violador pobre, y mal defendido, 
Lo natural, lo seglar y lo sobrenatural

Gustavo Caponi

de una mujer rica; y alivio de pena para el violador rico, con abogados bien pagos, que actuó incitado por la ropa sexy de una mujer pobre. Esa mismo tipo de ropa que Pinker recomienda no usar en ciertas circunstancias.

La naturalización, tanto como la sobrenaturalización, pueden promover actitudes conservadores y pueden contribuir a legitimar un status quo que además de ser indeseable e injusto también sería modificable. Las dos van a contramano de una visión seglarizada del orden social. El recurso a lo sobrenatural consagra ese orden (Althusser 2014, 60); y su naturalización lo reputa inamovible. Lo que, en la práctica, termina resultando más o menos en lo mismo. Por eso, dando ya por sentado que la sobrenaturalización es una alternativamente definitivamente excluida, indigna de ser mínimamente considerada, en lo que atañe a la naturalización (entendida como biologización) nunca debemos abandonar una actitud de sospecha y de estricta vigilancia político-epistemológica. Más aún: en la medida en que la naturalización puede resultar en alguna forma de legitimación, el pensamiento crítico siempre debe procurar la desnaturalización de lo que quiere imponerse como ineluctable. Y desnaturalizar no tiene nada que ver con sobrenaturalizar; porque esto último, como acabo de decir, también implica una aceptación de lo que podría ser recusado (Caponi 2016a, 162). Desnaturalizar es mostrar que lo que está ahí no se impuso porque sí, 'por su propio peso'; sino que es el resultado de conflictos, negociaciones y contingencias cuyos resultados pueden ser revistos y alterados. Desnaturalizar es seglarizar: es mostrar que algo está al alcance de nuestra acción y de nuestras deliberaciones.

En Una izquierda darwiniana, Peter Singer $(1999,61)$ decía que un darwinista de izquierda no debe "asumir que todas las desigualdades se deben a discriminación, prejuicio, opresión o condicionamiento social". Muchas de ellas, nos dice él, lo son; "pero eso no puede ser presupuesto en todos los casos". Por mi parte, sin rechazar el rótulo que Singer también propone para sí mismo, debo reconocer que los hechos y las referencias teóricas refuerzan su posición. A priori, por lo menos, no hay como negar que existan ciertas características heredadas que, dada la disponibilidad o indisponibilidad de ciertos recursos ontogenéticos ofrecidos por las condiciones de vida, faciliten u obstaculizan, en mayor o menor grado, el desarrollo de ciertas habilidades cognitivas y de algunas disposiciones emotivas. Por lo mismo, también es muy posible que esa dotación hereditaria disímil explique algunas diferencias en la suerte corrida por diferentes individuos y en el tipo de vida que acabaron teniendo. Eso es posible aunque también sea verdad que esas diferencias hereditarias son muy difíciles de medir y de prever. Dudo, de todos modos, que esa variación hereditaria esté significativamente relacionada con el dimorfismo sexual; $y$, por muchos motivos, teóricos y no éticos, la idea de que esa variación esté asociada a algo así como la raza, me parece insostenible.

Pero, para justificar esas presunciones hay que argumentar a partir de evidencia empírica y de apoyo conceptual. Que es algo que no haré aquí; ni siquiera en la medida en que puede incumbir hacerlo desde la Filosofía de la Biología. En lugar de eso, y para posicionarme debidamente ante un enfoque como el de Peter Singer, asumiendo incluso

Revista de Humanidades de Valparaíso, 2019, No 14, 27-55

(c) (1) 8 (을 CC BY-NC-ND 
Lo natural, lo seglar y lo sobrenatural

Gustavo Caponi

la tarea de caracterizar la actitud a ser tomada por un 'darwinista de izquierda', quiero referirme a la perspectiva que habría que adoptar previamente al surgimiento de cualquier evidencia tal que explique una diferencia social a partir de una diferencia biológica. Y para hacerlo se puede partir de una distinción entre dos modos fundamentales de explicar una desigualdad: uno al cual llamaré 'conservador', pero que podría llamar 'de derecha'; y otro que llamaré 'contestatario', pero que podría llamar 'de izquierda'. Según el modo conservador de pensar, la primera hipótesis para explicar una desigualdad es que, en última instancia, dicha desigualdad se explica por lo que podría caracterizarse como una 'desigualdad primitiva'; y por eso habría que entender una desigualdad cuya reversión, o atenuación, escapa, totalmente, o en gran medida, a nuestras posibilidades. Por eso, las desigualdades hereditarias, o innatas, serían los ejemplos más claros de dichas desigualdades primitivas; y por eso ellas son el gran tesoro del pensamiento conservador. Mientras tanto, según el modo contestatario de pensar, la primera hipótesis para explicar una desigualdad es que, en última instancia, dicha desigualdad resulta de una falta de equidad parcial o totalmente subsanable. Una falta de equidad cuyas causas están en el orden de lo seglar: que es orden que brota de nuestras interacciones sociales y que, consecuentemente, también puede ser afectado por esas interacciones.

El desempeño escolar comparativamente deficiente de los escolares del barrio pobre al que aludí en la sección anterior, puede explicarse por el bajo nivel educativo y cultural en el cual se forman; y, para lo que caractericé como posición conservadora, esa no es una explicación del todo mala. Al fin y al cabo, ese medio socio-cultural no es tan fácil de cambiar y se puede pensar que, pretender revertir o paliar esa desventaja, es algo que escapa a las posibilidades del sistema educativo; comprometiendo su debido funcionamiento si se insiste inútilmente en hacerlo, sin antes ir modificando, muy lenta y paulatinamente, las condiciones generales del grupo o sector social del cual esos escolares provienen. No aceptar eso sería, como suele decirse, una 'ingenuidad', o pura 'demagogia'. Mejor es que cada grupo social tenga el tipo y el nivel de educación que realmente puede aprovechar. Por ejemplo: formación técnica y profesionalizante, más que formación científica y humanística. Pero eso sería mucho más fácil de 'aceptar' si se estableciese que esos escolares del barrio pobre, además de carecer de buenas estímulos familiares para aprovechar ciertos tipos de instrucción formal, también están menos dotados genéticamente para hacerlo; sea por su origen racial, o por el hecho de que heredaron sus capacidades de progenitores que ya son poco dotados y, por eso, laboralmente fracasados y pobres. Los genes del fracaso, para decirlo de otro modo, se transmitirían junto con la misma pobreza que ellos generarían. A cada uno le tocaría lo que sus genes le permiten conquistar.

Por el contrario, cuando se asume una posición contestaría, como la que paradigmáticamente asumieron Pierre Bourdieu y Jean-Claude Passeron (1974) en La reproducción, se tenderá a pensar de otro modo. Se tenderá a pensar, no sólo que la desventaja de los estudiantes pobres es por lo menos parcialmente reversible por el propio sistema educativo; sino que hasta se podrá aventar la sospecha de que la forma en que ese sistema opera

Revista de Humanidades de Valparaíso, 2019, No 14, 27-55

(). (18) CC BY-NC-ND 
Lo natural, lo seglar y lo sobrenatural

Gustavo Caponi

tiende, de por sí, a la producción de las diferencias y desniveles que él, según se supone, debería tender a revertir. La idea es que, por lo menos en una proporción significativa, los desempeños escolares entre estudiantes pobres y ricos son diferentes porque el sistema educativo, por sus propias reglas de funcionamiento, produce esa desigualdad y da muy poco espacio para que ella sea revierta. Los estudiantes pobres entran en inferioridad de condiciones y el propio sistema agudiza dicha desigualdad. Y lo que tenemos ahí es un déficit de equidad. En cualquier situación que pueda describirse como la competición o pugna entre dos partes, o grupos, la equidad estará ausente en la misma medida en que una de esas partes está forzada a entrar en dicha puja aceptando que la otra imponga, o aproveche, reglas y condiciones que la favorezcan con relativa independencia de sus capacidades y desempeños; y también con relativa independencia de los objetivos que ambas partes, de común acuerdo, podrían asumir como propios de la pugna en la que están participando.

La nación imperial que, gracias a su ejército, le impone a su colonia condiciones de intercambio que son muy desiguales, y que la colonia no aceptaría de no mediar la ocupación militar, está generando una situación de inequidad. Así, aunque pueda decirse que la extinción de la manufactura de la colonia, se debió a que la misma era más primitiva e ineficiente que la industria de la potencia imperial, eso no quitará el hecho de que la competencia de dio en condiciones que se impusieron, no por la propia eficiencia de la industria imperial, sino por la fuerza militar. Como también hay una situación de inequidad cuando, en día muy caluroso y húmedo, una multitud de aspirantes pasan por un mismo examen, compitiendo por un número limitado de plazas en una carrera universitaria; pero cada uno lo hace en la escuela de su propio barrio. Así, los estudiantes de barrios más ricos hacen la prueba en escuelas cuyas aulas cuentan con aire acondicionado; y lo más pobres lo hacen en las escuelas menos equipadas de sus propios barrios, sufriendo el calor y la humedad de aulas que ni siquiera tiene ventiladores. De ese modo, el resultado de la prueba no sólo reflejará diferencias de formación, sea cual su causa; sino que también reflejará un desequilibrio, una obvia falta de equidad, en las condiciones en que la evaluación tuvo lugar.

Pero las inequidades suelen presentarse de maneras menos obvias; más difíciles de ser detectadas y debidamente sopesadas. Como la relación entre una inequidad y la desigualdad que de ella resulta, suele estar mediada por otras desigualdades, más o menos injustas, puede tenderse a explicar la desigualdad inicialmente constatada por otras cuyo análisis, si unilateral o parcial, puede conducirnos a perder de vista las inequidades que pueden estar ahí involucradas. Por eso, partir inmediatamente para la naturalización de la desigualdad puede relevarnos del esfuerzo investigativo que exigiría desentrañar la trama de desigualdades e inequidades, parcial o totalmente reparables, que están en la base de esa desigualdad que inicialmente hemos verificado y que quizá nos interesaría remediar. (Nelkin 2002, 316). Así, aunque Peter Singer esté en lo cierto cuando dice que no todas las desigualdades resultan de la discriminación, del prejuicio, de la opresión o del condi-

Revista de Humanidades de Valparaíso, 2019, No 14, 27-55

(). (18) CC BY-NC-ND 
Lo natural, lo seglar y lo sobrenatural

Gustavo Caponi

cionamiento social; también hay que decir que esa posición a la que él llama 'darwinismo de izquierda' no puede definirse por la simple admisión de ese hecho. Porque, en todo caso, eso sería lo propio de todo darwinismo: incluso de aquel que Singer podría llamar 'darwinismo de derecha'. En realidad, lo que sería propio de un genuino darwinista de izquierda sería su sujeción a ese modo contestatario de pensar que es pasible de ser enunciado como una regla metodológica: Para explicar una desigualdad social, la primera hipótesis a ser considerada es que, en última instancia, ella resulta, por lo menos en alguna medida, de una inequidad parcial o totalmente remediable.

No creo, entretanto, que esa regla pueda tener una justificación científica: no hay fundamento, ni teórico, ni empírico, para suponer que las explicaciones de la desigualdad que apelen a una desigualdad primitiva sean, a priori, menos plausibles que aquellas que lo hacen apelando a inequidades, o incluso desigualdades, evitables. Ni creo que tampoco se pueda dar una fundamentación meta-teórica de dicha regla. Su justificación es, definitivamente, de carácter político, o ético. Se trata de un principio de prudencia, o de precaución, que apunta a evitar que la investigación científica pueda convalidar, o de algún modo disculpar, inequidades que deberían ser denunciadas y remediadas. Situaciones, incluso, cuya reversión o reparación podría verse facilitada si las mismas fuesen correcta y cabalmente analizadas. Sobre todo cuando hay razones para suponer que, en muchos casos, habrá en juego intereses, o privilegios, que pueden verse contrariados si dicha inequidad es puesta en evidencia. Intereses y privilegios que, además, siempre pueden estar en condiciones de influir en el curso de las investigaciones, y en la legitimación de los resultados que de ahí deriven. Sobre todo si esos supuestos resultados nos ponen ante una putativa desigualdad primitiva: difícil o imposible de revertir.

El pensamiento científico, es verdad, siempre debe rendirse a las evidencias empíricas y a las constricciones conceptuales: esa es la ley primera; ésa es la regla metodológica fundamental. Pero también es cierto que, cuando las cuestiones científicas aluden al orden social, es muy fácil que el fiel de la balanza que sopesa el apoyo empírico y teórico de una hipótesis, se posicione en un punto que favorezca y refuerce posiciones que puedan venir a respaldar, de alguna forma, los intereses y privilegios de los grupos beneficiados por ese status quo en cuyo marco una ciencia se desarrolla y del cual ella depende para sostenerse. Grupos que deberían resignar privilegios si ese orden se altera; y que no verían con simpatía que la legitimidad de ese orden fuese cuestionada. Por eso, para neutralizar ese efecto distorsivo de los intereses extra-teóricos, en esos casos, ante cualquier esfuerzo por naturalizar lo social, el pensamiento crítico debe extremar su rigor y multiplicar sus dudas. Sobre todo cuando, conforme Nelkin $(2002,313)$ lo señala, los grupos favorecidos por el status quo son lo suficientemente poderosos como para definir, alentar o desalentar diferentes líneas y protocolos de investigación, contando también con los medios necesarios para controlar los espacios institucionales en los que esas investigaciones se realizan y se validan.

Revista de Humanidades de Valparaíso, 2019, No 14, 27-55

(c) (1) 8 (을 CC BY-NC-ND 
Lo natural, lo seglar y lo sobrenatural

Gustavo Caponi

Se me objetará, seguramente, que, si se trata de revertir o paliar desigualdades, nada mejor que reconocer su verdadera causa. Más allá de que esta sea una 'desigualdad primitiva' o una desigualdad decurrente de una situación de inequidad. Lo primero es determinar esa causa para luego ver cómo se pueden anular, revertir o paliar sus efectos. Cosa que podría verse comprometida si se parte de una preferencia a priori por cierto tipo de explicaciones. Entiendo, sin embargo, que, en lo que se refiere a esas explicaciones de la desigualdad que están apoyadas en naturalizaciones de los procesos y fenómenos sociales, la historia nos lleva a ser muy cautos y no demasiado cándidos con los intentos de biologizar lo social. Porque, si es cierto que la Filosofía de la Biología nos muestra que la naturalización de ciertos aspectos básicos de nuestra sociabilidad, de nuestra emotividad, y de nuestros modos de pensar es un imperativo teórico irrecusable; tampoco deja de ser cierto que la Historia Epistemológica de las Ciencias de la Vida nos habla de innúmeras situaciones en los que las que dichas ciencias incurrieron en groseras pseudo-naturalizaciones, siquiera bien fundadas en los marcos teóricos y metodológicos del saber científico de su época, que sólo operaban como justificaciones ideológicas de inequidades e incluso de atrocidades ${ }^{12}$. Y la actitud contestaría que se expresa en la regla metodológica enunciada más arriba sería la forma de precaverse ante esos riesgos.

\section{Conclusión: un programa para el darwinismo de izquierda}

Es claro, sin embargo, que no estoy proponiendo nada inédito, ni original. La regla metodológica que enuncié más arriba, y que caractericé como propia del modo contestatario de pensar, no hace más que proponer una actitud de crítica y de vigilancia, científica y epistemológica, sobre las propuestas de biologizar lo social, que ya ha sido adoptada por muchos cientistas sociales, por algunos filósofos de la ciencia, y por no pocos biólogos. Entre estos últimos, los más notorios y brillantes han sido Stephen Jay Gould y Richard Lewontin. Si Singer quería dos buenos darwinistas de izquierda, era ahí que podía encontrarlos. Sus muchos trabajos sobre los usos sociales de la Biología son los casos paradigmáticos de la regla que propuse; y esta no aspira ser otra cosa que una elucidación de un principio guía que estos autores han sabido seguir con mucho rigor. De hecho, la regla podría llamarse Regla de Lewontin-Gould. Porque, además de haber sido críticos severos de la naturalización de lo social, estos autores han sabido hacer eso sin contradecir un darwinismo mínimo e innegociable. Ellos nunca negaron que la cognición, la emotividad y la sociabilidad humana tuviesen cimientos y pautas fundamentales que resultaban de la evolución biológica de nuestro linaje. Gould y Lewontin sólo se limitaron a poner en evidencia y a criticar cualquier especificación, o extensión, injustificada y abusiva de ese presupuesto irrecusable; sobre todo cuando esa especificación o extensión podía conducir a la legitimación de una desigualdad.

\footnotetext{
${ }^{12}$ Obras como La falsa medida del hombre, de Gould (1988) y El mito de la raza de Sussman (2014), entre muchas otras, se pueden encontrar innúmeros ejemplos de ese uso conservador de la Biología.
}

Revista de Humanidades de Valparaíso, 2019, No 14, 27-55

()ㅇㅇㅇㅇ CC BY-NC-ND 
Lo natural, lo seglar y lo sobrenatural

Gustavo Caponi

Por eso, ni Lewontin, ni Gould, pretendieron apelar, nunca, a una deslegitimación $a$ priori, y en bloque, de cualquier intento posible de explicar biológicamente algún aspecto de la cognición, de la emotividad o de los patrones conductuales humanos. No se ampararon en una supuesta singularidad de los fenómenos humanos que haría que su estudio fuese refractario a cualquier abordaje biológico. Ni tampoco incurrieron en una descalificación global, relativista, de todo enfoque evolucionista. Su propia formación como Biólogos Evolucionarios darwinista les impedía adoptar esas actitudes retrogradas; y sabían que no existía un criterio general para determinar cuándo, y hasta donde, el enfoque biológico tendría algo para decirnos sobre el comportamiento humano. Eso había que verlo caso a caso y en base al propio conocimiento biológico. La crítica de los (malos) usos sociales de la Biología tenía que ser casuística y basada en modos de argumentar científicamente legítimos. Philip Kitcher $(2004,3$; 2009, 210) caracterizó eso como una crítica local: como una crítica que renunciaba a la pretensión de poder matar con un único disparo a la persistente medusa del reduccionismo abusivo. Conforme Gould y Lewontin lo hicieron, lo único que queda es ir cortando sus cabezas una a una, conforme ellas se van regenerando (Kitcher 2004, 4). Y esa crítica es la que surge de lo que me he permitido llamar 'Regla de Lewontin-Gould'.

De una forma bastante torpe, casi policialesca, David Stamos (2008, 225-6) explica la actitud crítica de Gould y Lewontin en relación a la explicación biológica de los fenómenos sociales, diciendo que la misma obedecía a las convicciones marxistas de ambos autores. El calificativo, sin embargo, es totalmente impertinente cuando aplicado a una posición metodológica como la que Gould y Lewontin adoptan frente a los asuntos que estamos discutiendo. Más allá de que Lewontin ciertamente se definiría como marxista, el compromiso con en el marxismo en lo que atañe a la historia y a la estructura de las sociedades humanas, o en lo que respecta a las formas que debe adoptar la política revolucionaria, no es condición suficiente, ni necesaria, para adoptar una posición metodológica sobre la biologización de lo social como la que él y Gould adoptaron. Por eso no cabe caracterizarla como 'marxista'. Posiblemente, lo que Stamos quería decir es que Gould y Lewontin adoptaban una posición de izquierda; algo que en los Estados Unidos quizá podría ser dicho usando la expresión 'liberal'. Término que en ese país significa exactamente lo opuesto que en América Latina; donde la expresión se transformó en la auto-denominación preferida por el conservadorismo oligárquico. Pero, en los Estados Unidos, el rotulo 'marxista' es más fácil de ser usado cómo epíteto descalificador que 'liberal'.

No creo, sin embargo, que sea preciso rechazar la alegación de Stamos $(2008,226)$ según la cual tanto Gould como Lewontin eran presos de los imperativos de la corrección política. Stamos también recurre a eso como si fuese una descalificación. Pero, si estar alerta en relación a cualquier discurso que pueda legitimar desigualdades y discriminaciones injustas, es ajustarse a los imperativos de la corrección política; entonces, la actitud metodológica que aquí se está recomendando puede considerarse como una regla metodológica que recomienda cierta corrección política en el desarrollo de algunas te-

Revista de Humanidades de Valparaíso, 2019, No 14, 27-55

(). (18) CC BY-NC-ND 
Lo natural, lo seglar y lo sobrenatural

Gustavo Caponi

máticas biológicas. El posible impacto político de los discursos biológicos es tan grande, y ya ha dado muestras de poder ser tan pernicioso, que toda precaución, o corrección, a ese respecto debería ser siempre bienvenida. Por lo demás, las ironías sobre la corrección política, y la insistencia sobre sus abusos, siempre han sido patrimonio de sectores conservadores que quieren preservar un status quo injusto e indefendible. Lo mismo que la reivindicación de la 'incorrección política'. Forma retórica, esta última, en donde la insistencia en los estereotipos más vulgares y tontos pretende pasar por fina ironía.

Hay que decir, por otra parte, que una perspectiva como la adoptada por Lewontin y Gould no conduce a adoptar una posición puramente negativa, de crítica o censura, frente a ciertos posibles desarrollos de las ciencias biológicas. Por el contrario: dicha perspectiva puede ser la base para la articulación de un programa de investigación sobre la hominización, y sus resultados, que ponga el énfasis en la evolución de la plasticidad cognitiva, emotiva y comportamental de nuestro linaje. Esa misma plasticidad que explica la variedad cultural y social desplegada por Homo sapiens; y que también debe ser considerada para entender la flexibilidad emotiva, cognitiva y comportamental que los individuos de nuestro linaje normalmente exhiben. Una flexibilidad que los habilita a desempeñar diferentes roles sociales dentro de esa variedad cultural e institucional que los diferentes sociedades humanas han producido (Rose 2002, 297; Caponi 2016b, 84). Como ha dicho Gould $(1988,351)$, "la flexibilidad es la marca de la evolución humana"; y en la Biología Evolutiva actual no faltan desarrollos teóricos tendientes a comprender la evolución de la plasticidad fenotípica, no sólo en Homo, sino en los seres vivos en general (West-Eberhard 2003). El propio Gould $(1988,351)$ llegó a proponer una hipótesis a ese respecto que tiene el interés de enfocar esa plasticidad desde la perspectiva de la Biología Evolucionaria del Desarrollo, apelando a la neotenia que se verifica en nuestro linaje.

Según Gould $(1977,401)$ propone, los individuos del género Homo, y sobre todo los de la especie Homo sapiens, nasceríamos con un repertorio de disposiciones y pautas comportamentales aún no plenamente diferenciado y cristalizado; pasible de tomar diferentes sendas ontogenéticas según el contexto en los que esa ontogenia se da. Algo que confluye con la Teoría de los Sistemas de Desarrollo ${ }^{13}$, y que apunta en una dirección muy distinta de la explorada por la Psicología Evolucionista. Tanto nuestro repertorio conductual, como nuestras capacidades y disposiciones cognitivas y emotivas, no estarían predeterminadas por un colección predefinida de módulos mentales, que es lo que la Psicología Evolucionista propone (Cosmides y Tooby 1997, 76; 2006, 181); sino que todo eso estaría construido sobre una base más abierta, más flexible y más indiferenciada, pasible de desarrollarse por distintas sendas del paisaje ontogenético. Stamos (2008, 73) tiene razón cuando dice que el Modelo Estándar de las Ciencias Sociales precisa de

\footnotetext{
${ }^{13}$ Sobre la Teoría de los Sistemas de Desarrollo, y su forma de entender la relación entre herencia y desarrollo, ver: Oyama (1985); Griffiths \& Gray (1994; 2001; 2005); Oyama et al. (2001); y Botelho (2011a; 2011b).
} 
Lo natural, lo seglar y lo sobrenatural

Gustavo Caponi

una explicación evolutiva de la plasticidad. Pero él parece pasar por alto que la Biología Evolucionaría actual ya está dando claves para explicar esa plasticidad desde un punto de vista evolutivo y para entender su impacto en la propia evolución ${ }^{14}$.

Si se piensa la evolución de la cognición, de la emotividad y de la sociabilidad humana a partir de dichos desarrollos, se podría ir construyendo una articulación entre Biología y Ciencias Sociales que no supondría la descualificación de estas últimas que la Sociobiología y la Psicología Evolucionista parecen promover. Eso hasta permitiría pensar en naturalizaciones que pudiesen apartarse de los riesgos políticos e ideológicos que siempre se han corrido cuando se abordó lo social desde una perspectiva biológica que reduce lo seglar al orden de lo natural. Porque, si se admite esa plasticidad cognitiva, emotiva y comportamental que la neotenia haría posible, se puede pensar, sin dificultad, que lo cultural y social, en lugar de meramente propiciar u obstaculizar la ocurrencia de una ontogenia predeterminada, también definen la dirección que esa ontogenia habrá de tomar (Oyama 2000; Griffiths 2011). Que es lo que propone la Psicología Evolucionaria Cultural delineada por Cecilia Heyes (2018). Y si se acepta pensar de esa forma, tendremos que entender los circuitos causales por los que ese orden social o cultural puede producir efectos significativos en el orden biológico. Hasta ahora, sin embargo, lo dominante, en Biología, es considerar los efectos que el orden biológico produce sobre el orden social. Por lo general, ante estos asuntos, se piensa unidireccionalmente. Por eso, Lewontin y Levins (2015) nos dirían que tendríamos que ser más dialecticos; y así Stamos vería ratificada su sospecha de que en todo esto hay marxismo encerrado.

\section{Referencias bibliográficas}

Alonso, M. (1979). Diccionario del Español Moderno. Madrid: Aguilar.

Althusser, L. (2014). Initiation à la Philosophie pour les non-philosophes. Paris: Presses Universitaires de France.

Andler, D. (2004). Calcul et representation: les sources. Introduction à D. Andler (ed.), Introduction aux sciences cognitives, pp. 13-52. Paris: Gallimard.

Axelrod, R., Hamilton, W. (2010). The evolution of cooperation. En A. Rosenberg, R. Arp (eds.), Philosophy of Biology, pp. 347-357. Oxford: Wiley-Blackwell.

Barkow, J., Cosmides, L., Tooby, J. (1992). Evolutionary Psychology and Conceptual Integration. Introduction to J. Barkow, L. Cosmides, J. Tooby (eds.), The adapted mind, pp. 3-17. Oxford: Oxford University Press.

Behe, M. (1996). Darwin’s black box. New York: Free Press.

\footnotetext{
${ }^{14}$ Sobre la temática de la plasticidad fenotípica, y su vinculación con los procesos evolutivos, ver: West-Eberhard (2003); Fuller (2003); Kaplan (2008); Sterelny (2009); Pigliucci (2010); Moczek et al. (2011); Sultan (2011); y Laland et al. (2015).
}

Revista de Humanidades de Valparaíso, 2019, No 14, 27-55

(c) (1) 8 (을 CC BY-NC-ND 
Lo natural, lo seglar y lo sobrenatural

Gustavo Caponi

Bombarda, M. (1896). Lições sobre a Epilepsia. Lisboa: António Pereira.

Bordieu, P., Passeron, J.-C. (1970). La reproduction. Paris: Minuit.

Bortolini, M., Hünemeier, T., Bisso-Machado, R. (2014). Coevolução gene-cultura. Ciência \& Ambiente, 48: 165-174.

Botelho, J. F. (2011a). Teoria dos Sistemas de Desenvolvimento e autopoiese. En J. Cofre, K. Saalfeld (eds.), Discussão de novos paradigmas: vida, embriologia, evolução, pp. 39-67. Florianópolis: EDUFSC.

Botelho, J. F. (2011b). Epigênese. En N. Vaz, G. Ramos (eds.), Onde está o organismo, pp. 61-86. Florianópolis: EDUFSC.

Bradie, M. (1994). Epistemology from an evolutionary point of view. En E. Sober (ed.), Conceptual issues in Evolutionary Biology, pp. 453-47. Cambridge: MIT Press.

Bradie, M. (1997). Una evaluación de la Epistemología Evolucionista. En S. Martínez, L. Olivé (eds.), Epistemología Evolucionista, pp. 243-284. México: Paidos.

Bradie, M. (2007). Evolution and normativity. En M. Mauthen, C. Stephens (eds.), Philosophy of Biology, pp. 201-218. Amsterdam: Elsevier.

Broca, P. (1861). Sur le volumen et la forme du cerveau. Paris: Henneuyer.

Buss, D. (1994). The strategies of human mating. American Scientist, 82: 238-249.

Campbell, D. (1983). Variación injustificada y retención selectiva en los descubrimientos científicos. En F. Ayala, T. Dobszhansky (eds.), Estudios sobre la Filosofía de la Biología, pp. 188-217. Barcelona: Ariel.

Campbell, D. (1997). Epistemología Evolucionista. En S. Martínez, L. Olivé (eds.), Epistemología Evolucionista, pp. 43-104. México: Paidos.

Caponi, G. (2007). La amplia agenda de la Filosofía de la Ciencia. Filosofía, 8(2): 75-82.

Caponi, G. (2014). Leyes sin causa y causas sin ley en la explicación biológica. Bogotá: Universidad Nacional de Colombia.

Caponi, G. (2016a). No es la ciencia: es el materialismo. Ludus Vitalis, 24(46): 159-162.

Caponi, G. (2016b). El mono flexible. En A. Makinistian (ed.), Cincuenta años de Homo habilis (1964-2014), pp. 77-89. Rosario: Universidad Nacional de Rosario.

Cela Conde, C., Ayala, F. (2014). Claves del cerebro en la apreciación de la belleza: una historia de dos mundos. En R. Gutiérrez Lombardo, J. Sanmartin Esplugues (eds.), La Filosofía desde la Ciencia, pp. 97-114. México: Centro Lombardo Toledano.

Clavien, C., Fitzgerald, C. (2018). The evolution of moral intuitions and their feeling of rightness. En R. Joyce (ed.), The Routledge Handbook of Evolution \& Philosophy, pp. 309-321. London: Routledge.

Cosmides, L., Tooby, J. (1992). The psychological foundations of culture. En J. Barkow, L. Cosmides, J. Tooby (eds.), The adapted mind, pp. 19-137. Oxford: Oxford University Press.

Revista de Humanidades de Valparaíso, 2019, No 14, 27-55

(c) (1) 8 (음 $\mathrm{CC}$ BY-NC-ND 
Lo natural, lo seglar y lo sobrenatural

Gustavo Caponi

Cosmides, L., Tooby, J. (1997). The modular nature of human intelligence. A. Scheibel, W. Schopf (eds.), The origin and evolution of intelligence, pp. 71-101. Sudbury: Jones \& Bartlett.

Cosmides, L., Tooby, J. (2006). Toward mapping the evolved functional organization of mind and brain. En E. Sober (ed.), Conceptual issues in Evolutionary Biology, pp. 175-196. Cambridge: MIT Press.

Davies, S. (2018). Evolution, aesthetics and art: an overview. En R. Joyce (ed.), The Routledge Handbook of Evolution \& Philosophy, pp. 359-371. London: Routledge London.

Dennett, D. (1996). Darwin's dangerous idea. London: Penguin.

Díez, J., Moulines, C. U. (1999). Fundamentos de Filosofia de la Ciencia. Barcelona: Ariel.

Diogo, R. (2017). Evolution driven by organismal behavior. Cham: Springer.

Espinoza, M. (2000). Philosophie de la Nature. Paris: Ellipses.

Fasten, N. (1935). Principles of Genetics and Eugenics. Boston: Ginn.

Fuller, T. (2003). The integrative Biology of phenotypic plasticity. Biology \& Philosophy, 18: 381-389.

Futuyma, D., Bennett, A. (2009). The importance of experimental studies en Evolutionary Biology. En T. Garland, M. R. Rose (eds.), Experimental evolution, pp. 15-30. Berkeley: University of California Press.

Ghiglieri, M. (2000). The dark side of man: tracing the origins of male violence. Cambridge: Perseus books.

Godfrey-Smith, P. (2014). Philosophy of Biology. Princeton: Princeton University Press.

Gould, S. (1977). Ontogeny and Phylogeny. Cambridge: Harvard University Press.

Gould, S. (1983a). La no-ciencia de la naturaleza humana. En S. Gould, Desde Darwin, pp. 265272. Madrid: Blume.

Gould, S. (1983b). El cerebro de las mujeres. En S. Gould, El pulgar del panda, pp. 161-168. Madrid: Blume.

Gould, S. (1983c). Los argumentos racistas y el CI. En S. Gould, Desde Darwin, pp. 273-280. Madrid: Blume.

Gould, S. (1983d). Sombreros anchos y mentes estrechas. En S. Gould, El pulgar del panda, pp. 153-160. Madrid: Blume.

Gould, S. (1984a). La política de los censos. En S. Gould, Dientes de gallina y dedos de caballo, pp. 323-331. Madrid: Blume.

Gould, S. (1984b). La ciencia y la inmigración judía. En Stephen Gould, Dientes de gallina y dedos de caballo, pp. 311-322. Madrid: Blume.

Gould, S. (1988). La falsa medida del hombre. Buenos Aires: Orbis.

Gould, S. (2004). Érase una vez el zorro y el erizo. Barcelona: Crítica.

Revista de Humanidades de Valparaíso, 2019, No 14, 27-55

() (1) $\mathrm{C}$ C BY-NC-ND 
Lo natural, lo seglar y lo sobrenatural

Gustavo Caponi

Griffiths, P. (2011). Our plastic nature. En E. Jablonka, S. Gissis (eds.), Transformations of Lamarckism, pp. 319-330. Cambridge: MIT Press.

Griffiths, P., Gray, R. (1994). Developmental and evolutionary explanations. Journal of Philosophy, 91: 277-304.

Griffiths, P., Gray, R. (2001). Darwinism and developmental systems. En S. Oyama, P. Griffiths, R. Gray (eds.), Cycles of contingency: developmental systems and evolution, pp. 195-218. Cambridge: MIT Press.

Griffiths, P., Gray, R. (2005). Discussion: three ways to misunderstand developmental systems theory. Biology \& Philosophy, 20: 417-425.

Heyes, C. (2018). Cogitive gadgets: the cultural evolution of thinking. Cambridge: Harvard University Press.

Hull, D. (2001). A mechanism and its metaphysics. En D. Hull, Science and selection, pp. 97-124. Cambridge: Cambridge University Press.

Hernández Chávez, P. (2007). Cómo naturalizar la Epistemología sin olvidar la razón. En J. Martínez Contreras, V. Aréchiga (eds.), En busca de lo humano, ciencia y filosofia, pp. 237-262. México: Centro Lombardo Toledano.

Horvath, C. (2007). Biological explanations of human sexuality. En D. Hull, M. Ruse (eds.), The Cambridge Companion to Philosophy of Biology, pp. 291-303. Cambridge: Cambridge University Press.

Jolivet, R. (1960). Tratado de Lógica y Filosofía 1: Lógica y Cosmología. Buenos Aires: Carlos Lohlé.

Kaplan, J. (2008). Phenotypic plasticity and reaction norms. En S. Sarkar, A. Plutynski (eds.), A companion to Philosophy of Biology, pp. 205-222. Malden: Blackwell.

Kitcher, P. (1994). Four ways of biologicizing Ethics. En E. Sober (ed.), Conceptual issues in Evolutionary Biology, pp. 439-450. Cambridge: MIT Press.

Kitcher, P. (2004). Evolutionary theory and the social uses of Biology. Biology \& Philosophy, 19: $1-15$.

Kitcher, P. (2009). Evolutionary theory and the social uses of Biology. En W. Allmon, P. Kelley, R. Ross (eds.), Stephen Jay Gould, pp. 207-226. Oxford: Oxford University Press.

Laland, K., Uller, T., Feldman, M., Sterelny, K., Müller, G., Moczek, S., Jablonka, E., OdlingSmee, J. (2015). The extended evolutionary synthesis: its structure, assumptions and predictions. Proceedings of the Royal Society B, 282: 1-14.

Lewontin, R., Rose, S., Kamin, L. (2003). No está en los genes. Barcelona: Crítica.

Lewontin, R., Levins, R. (2015). El biólogo dialéctico. Buenos Aires: Ediciones R\&R.

Lorenz, K. (1974). La otra cara del espejo. Barcelona: Plaza \& Janes.

Maritain, J. (1978[1963]). Los grados del saber. Buenos Aires: Club de Lectores.

Revista de Humanidades de Valparaíso, 2019, No 14, 27-55

(9) $Q 0$ CC BY-NC-ND 
Lo natural, lo seglar y lo sobrenatural

Gustavo Caponi

Moebius, P. (1982[1906]). La inferioridad mental de la mujer. Barcelona: Bruguera.

Montiel Castro, A., Martínez Contreras, J. (2012). En busca del origen evolutivo de la moralidad: el cerebro social y la empatía. Signos Filosóficos, 14(28): 31-56.

Moczek, A., Sultan, S., Foster, S., Ledón-Rettig, C., Dworkin, I., Nijhout, F., Abouheif, E., Pfnning, D. (2011). The role of developmental plasticity in evolutionary innovation. Proceedings of the Royal Society B, 278: 2705-2713. https://doi.org/10.1098/rspb.2011.0971

Nagel, T. (2012). Mind and cosmos. Oxford: Oxford Unversity Press.

Nelkin, D. (2002). Reductionism and social policy. En M. Regenmortel, D. Hull (eds.), Promises and limits of reductionism in the biomedical sciences, pp. 305-321. London: Wiley.

Newton, I. (1687). Philosophiae Naturalis Principia Mathematica. Londini: Samuel Pepys, Reg. Soc. Praeses.

Newton, I. (1846[1726]). Mathematical Principles of Natural Philosophy. New York: Daniel Adee.

Odling-Smee, J., Laland, K., Feldman, M. (2003). Niche construction. Princeton: Princeton University Press.

Oyama, S. (1985). The ontogeny of information: developmental systems and evolution. Cambridge: Cambridge University Press.

Oyama, S. (2000). Evolution's eye. London: Duke University Press.

Oyama, S., Griffiths, P., Gray, R. (2001). What is Developmental Systems Theory? Introduction to S. Oyama, P. Griffiths, R. Gray (eds.), Cycles of contingency: developmental systems and evolution, pp. 1-11. Cambridge: MIT Press.

Pigliucci, M. (2010). Phenotypic plasticity. En M. Pigliucci, G. Müller (eds.), Evolution: the extended synthesis, pp. 307-330. Cambridge: MIT Press.

Pinker, S. (2012). La tabla rasa. Barcelona: Paidos.

Popper, K. (1974). Conocimiento Objetivo. Tecnos: Madrid.

Popper, K. (1985a). Realismo y el objetivo de la ciencia - Post Scriptum a la Lógica de la Investigación Cientifica, Vol.1. Madrid: Tecnos.

Popper, K. (1985b). Teoría cuántica y el cisma en Física - Post Scriptum a la Lógica de la Investigación Científica, Vol.3. Madrid: Tecnos.

Quine, W. (1974). Naturalización de la epistemología. En W. Quine, La relatividad ontológica, pp. 93-120. Madrid: Tecnos.

Riedl, R. (1983). Biología del conocimiento. Barcelona: Labor.

Rosas, A. (2014). El proyecto de explicación darwinista del comportamiento moral. En G. Gutiérrez, M. Papini (eds.), Darwin y las ciencias sociales, pp. 475-490. Bogotá: Universidad Nacional de Colombia.

Revista de Humanidades de Valparaíso, 2019, No 14, 27-55

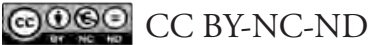


Lo natural, lo seglar y lo sobrenatural

Gustavo Caponi

Rose, S. (2002). Levels of explanation in human behaviour: the poverty of Evolutionary Psychology. En M. Regenmortel, D. Hull (eds.), Promises and limits of reductionism in the biomedical sciences, pp. 279-298. London: Wiley.

Rosenberg, A. (2010). Darwinism in contemporary Moral Philosophy and Social Theory. En A. Rosenberg, R. Arp (eds.), Philosophy of Biology, pp. 358-370. Oxford: Wiley-Blackwell.

Rosenberg, A., McShea, D. (2008). Philosophy of Biology. New York: Routledge.

Rottschaefer, W. (2000). Naturalizing Ethics: The Biology and Psychology of moral agency. Zygon, 35(2): 253-286.

Rusch, H., Voland, E. (2013). Evolutionary Aesthetics. Aisthesis, 6(2): 113-133.

Ruse, M. (1987). Tomándose a Darwin en serio. Barcelona: Salvat.

Ruse, M. (1989). Sociobiología. Madrid: Cátedra.

Schelling, F. (2004[1799]). First outline of o System of the Philosophie of Nature. Albany: State University of New York.

Singer, P. (1999). A Darwinian left. New Haven: Yale University Press.

Sober, E. (1993). Philosophy of Biology. Oxford: Oxford University Press.

Stamos, D. (2008). Evolución. Barcelona: Buridán.

Sterelny, K. (2009). Novelty, plasticity and niche construction: the influence of phenotypic variation on evolution. En A. Barberousse, M. Morange, T. Pradeu (eds.), Mapping the future of Biology, pp. 93-110. London: Springer.

Sterelny, K., Griffiths, P. (1999). Sex and death. Chicago: Chicago University Press.

Strassmann, J., Queller, D. (2016). Cooperación humana y conflicto. En J. Losos, R. Lenski (eds.), Cómo la evolución configura nuestras vidas, pp. 73-91. Barcelona: Buridán.

Sultan, S. (2011). Evolutionary implications of individual plasticity. En E. Jablonka, S. Gissis (eds.), Transformations of Lamarckism, pp. 193-204. Cambridge: MIT press.

Sussman, R. (2014). The myth of the race. Cambridge: Harvard University Press.

Thagart, P. (1997). En contra de la epistemología evolucionista. En S. Martínez, L. Olivé (eds.), Epistemología Evolucionista, pp. 285-292. México: Paidós.

Tort, P. (2008). L'effect Darwin. Paris: Seuil.

Toulmin, S. (1977). La compresión Humana I - El uso colectivo y la evolución de los conceptos. Madrid: Alianza.

Wade, N. (2015). Una herencia incomoda. Barcelona: Ariel.

West-Eberhard, M. (2003). Developmental plasticity and evolution. Oxford University Press: Oxford.

Wilson, C. (2007). Evolutionary Ethics. In M. Mauthen, C. Stephens (eds.), Philosophy of Biology, pp. 219-247. Amsterdam: Elsevier. 
Lo natural, lo seglar y lo sobrenatural

Gustavo Caponi

Wilson, E. (1980a). Sociobiología. Barcelona: Omega.

Wilson, E. (1980b). Sobre la naturaleza humana. México: Fondo de Cultura Económica.

Wilson, E. (1998). Consilience. New York: Knoff.

Wittgenstein, L. (1973[1922]). Tractatus Logico-Philosophicus. Madrid: Alianza.

Woolcock, P. (1999). The case against Evolutionary Ethics today. En J. Maienschein, M. Ruse (eds.), Biology and the foundations of ethics, pp. 276-306. Cambridge: Cambridge University Press.

Wuketits, F. (1984). Teoría Evolutiva del conocimiento: principios, conceptos, síntesis. En K. Lorenz, F. Wuketits (eds.), La evolución del pensamiento, pp. 11-27. Barcelona: Argos Vergara. 



\title{
El estatus metateórico de ZFEL
}

\section{The meta-theoretical status of ZFEL}

\author{
Ariel Jonathan Roffé; Santiago Ginnobili** \\ *CEFHIC-UNQ-CONICET, Universidad de Buenos Aires, \\ Universidad Nacional de Tres de Febrero, Argentina \\ ariroffe@hotmail.com \\ ${ }^{* *}$ CEFHIC-UNQ-CONICET, Universidad de Buenos Aires, \\ Universidad Nacional de Tres de Febrero, Argentina \\ santi75@gmail.com
}

\begin{abstract}
Resumen
En un libro reciente McShea y Brandon defienden que la diversidad y la complejidad de la vida se explican, principalmente, por la acción de un principio que llaman "la ley evolutiva de fuerzas cero" o "ZFEL". Tal principio actuaría de un modo implícito por detrás de muchas explicaciones de la biología, pero nunca habría sido explicitado. Asumiendo que esta idea es interesante, y que los autores en cuestión tienen razón, discutiremos el modo metateórico en que presentan dicho principio, como siendo parte de la teoría de la probabilidad. Esto permite a los autores afirmar que la teoría de la probabilidad brindaría la base reductiva para toda la biología evolutiva (dado que consideran que otros principios, como el de selección natural, también serían parte de la teoría de la probabilidad). Defenderemos que, efectivamente, ZFEL no es propio de la biología únicamente, pero no por formar parte de la teoría de la probabilidad, sino por tratarse de una versión específica del principio de causa común.
\end{abstract}

Palabras clave: ley evolutiva de fuerzas cero, complejidad, diversidad, teoría de la probabilidad, principio de causa común.

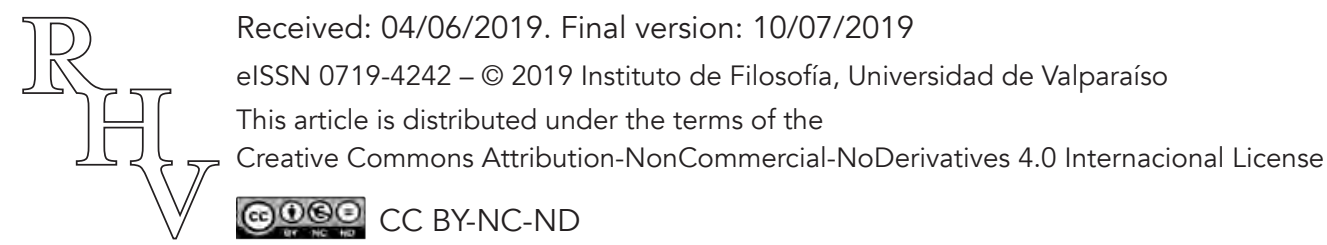




\begin{abstract}
In a recent book, McShea and Brandon argue that the observed diversity and complexity of life are explainable by a principle they call the "zero-force evolutionary law" or "ZFEL". Although this principle would be implicit in many explanations given by biologists, it would have never been made explicit. Assuming that this idea is interesting, and that the authors are right, we will discuss the metatheoretical way in which they present said principle, as being a part of probability theory. This allows the authors to claim that probability theory provides the reductive basis for all evolutionary biology (given that they consider other principles, such as the principle of natural selection, as part of probability theory as well). We will defend, in accordance with them, that ZFEL is not a solely biological principle, but not because it is a part of probability theory, but rather because it is a specific version of the principle of common cause.
\end{abstract}

Keywords: zero-force evolutionary law, complexity, diversity, probability theory, principle of common cause.

\title{
1. Introducción
}

Entre los enigmas fundamentales que Darwin intentó desentrañar en su obra monumental, se encuentra el dar cuenta de la diversidad de la vida. La respuesta explicita que Darwin da a esta cuestión apela al principio de divergencia, que (dejando de lado discusiones acerca de su naturaleza, alcance o adecuación, p.e. Richards 2012) parece vincularse intrínsecamente con la teoría de la selección natural.

Según tal principio,

Los descendientes modificados de cualquier especie prosperarán tanto mejor cuanto más diferentes lleguen a ser en su conformación y sean de este modo capaces de usurpar los puestos ocupados por otros seres. (Darwin 1859, 116)

Darwin considera que la selección natural produce diversidad, porque resulta una estrategia exitosa apartarse de la media de la especie y (dicho en lenguaje posterior) ocupar nuevos nichos en los que la competencia no sea tan feroz. Tal principio, según el mismo Darwin afirma, permitiría explicar la tendencia de los organismos a divergir de sus ancestros. El problema es caracterizado como de gran importancia, y el principio es presentado como la solución única y suficiente (Darwin 1958, 120-21).

Por supuesto, los científicos innovadores no suelen tener una comprensión total ni de la naturaleza y ni del alcance de su propia obra, y no debiera sorprendernos que Darwin, por carecer de las herramientas metateóricas y la comprensión de la ciencia que se ganaría en el siglo siguiente, no pudiera realizar exitosamente el salto semántico que involucra la presentación metateóricamente adecuada de las propias teorías y los vínculos interteó- 
ricos involucrados ( $\sin$ dejar de señalar que Darwin es un autor con extrema claridad de pensamiento y en parte en eso debe haber radicado su éxito). Sin embargo, resulta algo sorprendente que en su ejemplar paradigmático de cómo nuevas especies divergen tanto de sus ancestros al punto de convertirse en nuevas especies, el caso de los pinzones en Galápagos, el principio de divergencia no juegue ningún rol.

La explicación darwiniana de la divergencia entre los diferentes pinzones apela al aislamiento geográfico de las islas con el continente y entre sí. Los pinzones habrían colonizado las islas gracias a medios ocasionales de transporte, y se habrían adaptado a sus diferentes ambientes (Darwin 1859, 400-401). Por supuesto, el mecanismo principal por el cual habría ocurrido la adaptación, según Darwin, habría sido la selección natural (Darwin 1859, 401), pero no a través del principio de divergencia, sino, sencillamente, por los diferentes caminos evolutivos que se producirían gracias a los diferentes nichos existentes en las diferentes islas.

Este desfasaje existente entre las explicaciones brindadas por Darwin, y su propia presentación y comprensión metateórica de sus propias ideas, permite realizar una introducción adecuada al trabajo de McShea y Brandon en el que intentan explicitar y elucidar el principio que en la biología actual, según afirman, explica en mayor grado la diversidad y la complejidad de los organismos vivos, aunque funcionando de manera implícita (McShea y Brandon 2010). Como ocurría con Darwin, el modo en que los biólogos contemporáneos explican la diversidad (y también la complejidad) de los organismos vivos, y el modo en que creen que lo hacen, no coincide. Podemos, de hecho, encontrar la misma tensión que existe en Darwin, a la hora de explicar la diversidad, en manuales de biología evolutiva. Por ejemplo Ridley (2004, 487-89), explica el patrón jerárquico de la filogenia y la forma arbórea de la evolución, apelando al principio de divergencia darwiniano. Pero al igual que veíamos en el caso de Darwin, el principio de divergencia no cumple ningún rol a la hora de explicar la especiación en el caso de los pinzones de Galápagos (Ridley 2004, 595-96). Otra vez, la selección natural operando de manera independiente en cada isla, parece ser suficiente.

La principal meta del trabajo de McShea y Brandon consiste en la correcta enunciación del principio que explica la complejidad y diversidad de los organismos vivos en mayor medida, que funciona implícitamente unificando muchas áreas y explicaciones de la biología evolutiva: la ley evolutiva de fuerzas cero (en adelante ZFEL, por sus siglas en inglés). Presentaremos ZFEL en la sección 2 del trabajo.

McShea y Brandon defienden tres tesis de diferente tenor:

1. ZFEL es un principio que opera implícitamente en la biología actual y por lo tanto merece ser explicitado y reconstruido.

2. ZFEL logra explicar la diversidad y la complejidad de manera más adecuada o en mayor grado que otros mecanismos que pretenden explicarlas. 
3. Finalmente, los autores hacen una serie de afirmaciones acerca de la naturaleza metateórica de ZFEL, que se trata de una ley universal, que funciona como hipótesis nula, que puede ser pensando, en analogía con la mecánica clásica, como una ley de fuerzas cero. Sin embargo, la afirmación más sustantiva de las que realizan los autores tiene que ver con que ZFEL es un principio que forma parte de la teoría de la probabilidad.

En este trabajo no discutiremos los primeros dos puntos, que nos parecen bien defendidos por los autores ${ }^{1}$, sino que nos concentraremos en la discusión acerca de la naturaleza metateórica del principio. En particular con su idea de que ZFEL no es más que una parte de la teoría de la probabilidad aplicada a la biología, que sumada a su idea de que el principio de selección natural también es una parte de la teoría de la probabilidad aplicada, los lleva a sostener que la teoría de la probabilidad es la base reductiva de la biología evolutiva (McShea y Brandon 2010, 108-9). Presentaremos esta idea en la sección 3.

En este trabajo defenderemos que, si bien es cierto que puede utilizarse la teoría de la probabilidad para presentar ZFEL, no es adecuado considerar que tal principio se identifica con una parte de la teoría de la probabilidad. Pues, como intentaremos mostrar en la sección 4, la naturaleza transdisciplinar de ZFEL (o de una versión más generalizada de ZFEL), señalada por los mismos autores, queda mejor reflejada si se considera a ZFEL como una aplicación del principio de causa común (PCC en adelante) a la biología, y, como sostendremos, no puede considerarse a tal principio como reducible a la teoría de la probabilidad. Si bien no es tema de este trabajo discutir la naturaleza del principio de causa común, presentaremos en la sección 5 una breve reseña de la discusión respecto a la naturaleza del tal principio. En la sección 6 estarán nuestras conclusiones.

\section{La ZFEL}

En su libro Biology's First Law, McShea y Brandon introducen un principio que, según ellos, los biólogos evolutivos utilizan implícitamente para explicar la gran diversidad y complejidad de la vida. Llaman a este principio ZFEL (por Zero-Force Evolutionary Law) y lo enuncian del siguiente modo: "En cualquier sistema evolutivo en el que hay variación azarosa y herencia, en ausencia de fuerzas y constricciones, la diversidad y la complejidad tenderán a aumentar" (McShea y Brandon 2010, 4).

Es necesario hacer una serie de clarificaciones para ver cómo estos autores comprenden este principio y sus alcances. En primer lugar, según ellos, la ZFEL se aplica de manera transversal a muchos niveles simultáneamente (McShea y Brandon 2010, 9-10). Por ejemplo, si cada población dentro de un ensamble de poblaciones evoluciona inde-

\footnotetext{
${ }^{1}$ Para discusiones respecto a la enunciación de ZFEL y su importancia y alcance puede apelarse a (Barrett et al. 2012), así como a la respuesta que los autores dan en (Brandon y McShea 2012).
} 
pendientemente, la expectativa sería la dispersión / el aumento de la varianza (medida genotípica o fenotípicamente) en el nivel del ensamble. Lo mismo ocurrirá con un conjunto de especies dentro de un género, un conjunto de géneros dentro de una familia o incluso un conjunto de órganos dentro de un organismo (a través de las generaciones). Una analogía ilustrativa propuesta por los mismos autores para entender la idea general es la de un conjunto de personas que caminan en diferentes direcciones, independientemente unas de otras. En ausencia de constricciones que los hagan caminar hacia el mismo lugar, la expectativa es que las personas se alejen más y más unas de otras.

En segundo lugar, los mecanismos mediante los cuales los individuos del ensamble (en el nivel que sea) evolucionan pueden ser de distinto tipo - i.e. el requisito de evolución independiente puede instanciarse de diversos modos. En particular, en los casos biológicos de interés, los individuos del ensamble (que recuérdese, pueden ser poblaciones / especies / etc.) pueden estar evolucionando o bien por deriva o bien por selección natural. En el primer caso, la dispersión se dará porque la deriva es evolución azarosa, lo cual significa que los individuos no tenderán a ir hacia un punto común. En el segundo caso, sólo se cumplirá el requisito de ausencia de constricciones cuando los óptimos hacia los cuales la selección hace tender a los individuos del ensamble sean independientes unos de otros (lo cual, a su vez, puede entenderse como presiones selectivas no compartidas). Un ejemplo del segundo tipo de caso sería el ya mencionado de los pinzones de Galápagos. Dado que las presiones selectivas a las que están sometidas las poblaciones de pinzones de cada una de las islas son independientes entre sí (porque cada isla plantea problemas ambientales diferentes), la ZFEL indica que las poblaciones de pinzones tenderán a alejarse entre sí, como de hecho ocurrió. Volviendo al ejemplo de los caminantes, la dispersión entre ellos puede ser resultado de que caminan en direcciones azarosas (deriva) o de que cada una camina en una dirección determinada, no azarosa, - por ejemplo, una camina hacia su casa, otra hacia su trabajo, etc. - pero que no haya ninguna constricción que los haga caminar hacia el mismo lado (selección).

A su vez, nótese que un mecanismo evolutivo puede reducir la diversidad (fenotípica o genotípica) en un nivel y aumentarla en otro. Por ejemplo, tanto la selección direccional como la deriva tienden a reducir la diversidad a nivel intrapoblacional, pero pueden aumentarla interpoblacionalmente, si diferentes poblaciones fijan distintos rasgos o genes. Esto ilustra nuevamente el hecho de que la ZFEL se aplica en distintos niveles independientemente unos de otros. Adicionalmente, el hecho de que los mecanismos que originan la diversidad en el nivel superior puedan ser de diversos tipos otorga a ZFEL un gran poder unificador, mostrando que fenómenos en apariencia muy distintos (p.e. la especiación alopátrica y la acumulación de variaciones azarosas en regiones no codificantes del genoma) explican el surgimiento de la diversidad de modos similares.

En tercer lugar, es necesario aclarar cómo se relacionan la diversidad y la complejidad para McShea y Brandon, ya que la ZFEL predice un aumento de ambas. Al hablar de complejidad los autores no pretenden hablar del uso coloquial de dicho concepto, 
que suele involucrar cosas como funcionalidad, sofisticación, etc. En cambio, utilizan un concepto que llaman "complejidad pura", definido únicamente a partir de la cantidad de tipos de partes que tiene una entidad, o el grado de diferenciación entre ellas (McShea y Brandon 2010, 7, 46), sean funcionales o no. De este modo, la complejidad en un nivel no es más que la diversidad vista desde un nivel superior. Por ejemplo, la complejidad de un género es la diversidad de las especies que lo componen; la complejidad de la columna vertebral es la diversidad -como cantidad de tipos- de vertebras que contiene (McShea y Brandon 2010, 10).

Un último punto aclaratorio refiere a lo que los autores entienden por constricciones y fuerzas. En este punto, McShea y Brandon siguen a Sober (1984), quien presentó a la teoría evolutiva como una teoría de fuerzas (análoga a la mecánica clásica newtoniana). ${ }^{2}$ En dicho libro, Sober presenta a la teoría evolutiva como estando caracterizada por una ley de fuerzas cero, que especifica el estado en el que se encontrará una entidad en ausencia de fuerzas, y un conjunto de fuerzas que pueden alejar a las entidades de ese estado, y que pueden componerse entre sí para actuar conjuntamente. Partiendo del modo como la genética de poblaciones caracteriza a los procesos microevolutivos, Sober había identificado a la ley de fuerzas cero con la ley Hardy-Weinberg, y por consiguiente a la mutación, migración, deriva y selección como las fuerzas relevantes. En consecuencia, para este autor, la expectativa en ausencia de fuerzas es la estasis, siendo el cambio el que debe ser explicado postulando fuerzas.

La posición de McShea y Brandon puede verse como una aceptación del marco general de la analogía, pero discutiendo cuáles son las fuerzas, y por consiguiente el estado libre de fuerzas. Uno de los objetivos centrales de estos autores es provocar un cambio gestáltico, redibujando el panorama conceptual sobre qué es lo esperable y qué es lo que requiere una explicación especial. Contrariamente a Sober, sostienen que lo esperable es el cambio, y que la estasis / la estabilidad es lo sorprendente, y es algo que requiere una explicación que apele a algún tipo de factor adicional, fuerza o constricción. La clave para operar este cambio consiste en no considerar como fuerzas / constricciones ni a la mutación ni a la deriva. Por consiguiente, una población evolucionando en ausencia de fuerzas estará sometida a la mutación y a la deriva, y por consiguiente tenderá a variar.

McShea y Brandon ofrecen diferentes motivos para no considerar a la mutación y la deriva como fuerzas. Por ejemplo, respecto de la deriva, afirman que no es analogable a una fuerza porque no tiene una dirección predecible a priori (vease también Brandon 2006; Roffé 2017). A su vez, tanto de la mutación como de la deriva, afirman que no son fuerzas porque son "constitutivas" de los sistemas evolutivos. Con esto quieren decir que deben ser relegadas al background explicativo, o bien porque son necesarias o bien por

\footnotetext{
${ }^{2}$ Sober no fue el primero ni el último en trazar esta analogía. Sin embargo, Sober sí fue quien articuló la analogía en detalle por primera vez, dando origen a una amplia literatura en filosofía de la biología al respecto.
} 
motivos heurísticos (ambos puntos les fueron discutidos, véase Luque 2016; Pence 2017). No nos ocuparemos aquí de examinar la adecuación de los motivos que ofrecen para defender estos puntos. En la sección siguiente nos centraremos una característica adicional que le atribuyen a ZFEL, y que será el foco central de nuestro análisis: el hecho de no ser más que teoría de la probabilidad aplicada.

\section{ZFEL y la teoría de la probabilidad}

En esta sección nos enfocamos en el modo en que ZFEL es presentado por McShea y Brandon. Concediendo que efectivamente, ZFEL parece funcionar implícitamente en diferentes partes de la biología, discutiremos el modo en que es explicitado por los autores, especialmente, la idea que proponen de que ZFEL se derivaría de la teoría de la probabilidad:

ZFEL surge de propiedades contingentes de la variación en la naturaleza, propiedades que son del dominio formal de la teoría de la probabilidad. (McShea y Brandon 2010, 7)

Más bien, para ZFEL, como para PNS [el principio de selección natural], la teoría de la probabilidad provee la fundación reductiva para la teoría evolutiva universal [...] la ZFEL se sigue deductivamente de la teoría de la probabilidad. (McShea y Brandon 2010, 109)

La razón que brindan para sostener esto se encuentra fundamentalmente en el capítulo 2 del libro, y se relaciona con su "modelo de la partícula", de modo que es necesario presentar este modelo abstracto, así como elucidar por qué los autores creen que el modelo tiene algún tipo de relevancia para la biología.

El modelo consta de una partícula que se mueve azarosamente (con probabilidad 0,5 ) o bien un paso a la izquierda, o bien un paso a la derecha (no puede permanecer en el mismo lugar) en cada momento. Si representamos cada momento en un eje vertical, la distribución de probabilidades para el movimiento de la partícula tras cuatro momentos se ve como sigue: 
El estatus metateórico de ZFEL

Ariel Jonathan Roffé; Santiago Ginnobili

\begin{tabular}{|c|c|c|c|c|c|c|c|c|}
\hline 0,0625 & & 0,25 & & 0,375 & & 0,25 & & 0,0625 \\
\hline & 0,125 & & 0,375 & & 0,375 & & 0,125 & \\
\hline & & 0,25 & & 0,5 & & 0,25 & & \\
\hline & & & 0,5 & & 0,5 & & & \\
\hline 0 & & 0,25 & & $\mathbf{0 , 5}$ & & 0,75 & & 1 \\
\hline
\end{tabular}

Fig. 1. Distribución de probabilidad para el modelo de la partícula de McShea y Brandon.

Lo que el modelo de la partícula representa gráficamente es un proceso de muestreo de Bernoulli. Este tipo de proceso es uno en el cual una muestra de tamaño $n$ es extraída, con reemplazo, de una población compuesta de dos tipos de objetos.

Por ejemplo, puede pensarse a la población como una urna que contiene un conjunto de bolillas, las cuales son de dos colores (p.e. rojo y azul). Supóngase que hay un número infinito de bolillas en la urna, que la frecuencia $p$ de bolillas rojas es 0,5 (i.e. la mitad son rojas y la otra mitad azules), que el tamaño $n$ de muestra es 4 . La probabilidad de que la muestra contenga $k=4$ bolillas rojas puede calcularse del siguiente modo. La probabilidad de que la primera bolilla muestreada sea roja es 0,5 . Del $50 \%$ de los casos en los que la primera bolilla es roja, habrá otro $50 \%$ de casos en donde la segunda también será roja. Esto es, la probabilidad de que las primeras dos bolillas muestreadas sean rojas es $0,5 \times$ $0,5=0,25$ (nótese que este es el número de la derecha en el momento $s_{2}$, en la Fig. 1). Utilizando un razonamiento análogo, puede notarse que la probabilidad de que la muestra contenga a las 4 bolillas rojas es $0,5^{4}=0,0625$ (nuevamente, véase el valor de la derecha en la fila $s_{4}$, Fig. 1). El cálculo para $k$ distintos de 0 y 4 es un tanto más complejo. Por ejemplo, existen cuatro modos posibles de obtener una muestra con $k=1$ bolillas rojas, que corresponden con las cuatro secuencias $\langle\mathrm{R}, \mathrm{B}, \mathrm{B}, \mathrm{B}\rangle,\langle\mathrm{B}, \mathrm{R}, \mathrm{B}, \mathrm{B}\rangle,\langle\mathrm{B}, \mathrm{B}, \mathrm{R}, \mathrm{B}\rangle, \mathrm{y}\langle\mathrm{B}, \mathrm{B},-$ $\mathrm{B}, \mathrm{R}\rangle$, cada una de las cuales tiene una probabilidad de $0,5^{1} \times 0,5^{3}$. El resultado es, por tanto, 0,25 (véase la segunda columna de la fila $s_{4}$ ). De manera más general, la probabilidad de que la muestra contenga exactamente $k$ bolillas rojas y $n-k$ azules está dado por:

$$
\left(\begin{array}{l}
n \\
k
\end{array}\right) p^{k} q^{n-k}
$$

lo cual es conocido como una distribución binomial. 
En el gráfico de la partícula, muestrear un individuo rojo estaría representado por un movimiento de la partícula hacia la derecha, mientras que uno azul lo estaría con un movimiento hacia la izquierda (la probabilidad de ir a la derecha y a la izquierda representarían la frecuencia de las bolillas rojas y azules en la población). Así, el tamaño de la muestra está representado por la cantidad de filas. Los diferentes modos de obtener una muestra con la misma composición (es decir, con una distribución dada de frecuencias) están representados en el gráfico de la partícula como distintos caminos llevando al mismo punto. Así, en la fila superior, el gráfico de la partícula contiene los mismos valores que una distribución binomial.

Un motivo para pensar que este modelo matemático abstracto ilustra algo acerca de poblaciones biológicas es que la genética de poblaciones suele representar a las transiciones generacionales en términos de procesos de muestreo (Beatty 1984, 188-189, los llama "muestreo parental" y "muestreo de gametas"). De ese modo, el modelo de la partícula puede verse como una representación de los procesos probabilísticos usados en genética de poblaciones para inferir la composición genética de las generaciones filiales. Cada partícula que evoluciona independientemente representaría entonces una población biológica. Dada la distribución de probabilidades ilustrada en la Fig. 1, el modelo ilustraría así que un conjunto de poblaciones que parten de un mismo punto, si son dejadas a evolucionar independientemente, tenderán a alejarse entre sí (i.e. la varianza para el parámetro $p$ aumenta entre ellas de $s_{1}$ a $s_{4}$ ). Los autores parecen ver a esto como una demostración matemática de ZFEL.

Nuevamente, una serie de autores han objetado a los alcances de esta demostración. Por ejemplo, Barret et al. (2012) y Roffé (2017) notan que si las poblaciones fuesen iniciadas en puntos distintos del espacio (p.e. todas muy cerca de $p=1$ ) entonces, dado que la deriva tiende a fijar el alelo más frecuente, la varianza entre ellas tendería a reducirse, no a aumentar (es decir, el resultado dependería de unas condiciones iniciales particulares, no valiendo en otras). Del mismo modo, el modelo de la partícula presentado en la Fig. 1 representa solamente una transición generacional. Pero la genética de poblaciones estándar muestra que, en el largo plazo, si las poblaciones evolucionan independientemente por deriva, entonces todas tenderán a fijar o bien uno o bien el otro alelo (i.e. las poblaciones se acumularían todas en los dos extremos de la distribución, tras lo cual la diversidad se estancaría).

En su respuesta, McShea y Brandon afirman que ambos casos de estancamiento o reducción de la varianza se deben a que hay una constricción operando: el hecho de que haya "barreras absorbentes" en los extremos de la distribución -i.e. el hecho de que una frecuencia no pueda ir más allá de 0 o 1 . Es decir, dado que la posición que ocupa la partícula representa una frecuencia, el "espacio" en el que esta puede moverse es finito. Pero si esta constricción no estuviese presente, las partículas seguirían alejándose entre sí incluso en el largo plazo (McShea y Brandon 2010, 104; Brandon y McShea 2012, 741). 
Más recientemente, los autores presentaron una generalización del aparato matemático mediante el cual supuestamente "demostraron" ZFEL (McShea, Wang, y Brandon 2019). En este trabajo, las partículas pueden no solo moverse hacia la izquierda o la derecha, sino también mantenerse en el lugar (i.e. ir hacia arriba en el espacio). Adicionalmente, no suponen en este trabajo que las partículas comienzan todas en el mismo lugar, sino que asumen que ellas comienzan a cualquier distancia arbitraria. El modo de demostrar el resultado consiste en obtener las probabilidades de que la distancia entre ellas se mantenga idéntica tras $n$ generaciones (estasis y cambio paralelo), de que se reduzca (llaman a esto cambio convergente) y de que aumente (cambio divergente). McShea, Wang y Brandon muestran que, en el largo plazo, la probabilidad de cambio divergente es mayor a la probabilidad de cambio convergente y de que no haya cambio, y que la distancia esperada entre dos partículas tiende a ir en aumento. En el caso extremo en que dos partículas se encuentran inicialmente a cierta distancia, y que la de la izquierda tiene mayor probabilidad de ir hacia la derecha y viceversa, si bien la distancia entre ellas se reducirá inicialmente, con el paso de las generaciones volverá a aumentar dado que las trayectorias se cruzarán. Nuevamente, sin embargo, la demostración asume que el espacio no tiene barreras absorbentes, y que las probabilidades para el movimiento de las partículas no cambian según la región del espacio en la que se encuentran. Por ese motivo, es lícito preguntarse si responden completamente a las objeciones planteadas anteriormente.

Nuevamente, no nos ocuparemos de examinar la adecuación de estas objeciones, ni de las respuestas. En la sección siguiente, plantearemos un tipo de objeción distinta, no tanto al contenido fáctico de ZFEL sino al estatus metateórico (de ser un resultado puramente probabilístico) que McShea y Brandon le atribuyen.

\section{ZFEL y el principio de causa común}

La presentación de McShea y Brandon de ZFEL adecuada a los fines de explicar con claridad en qué consiste el principio y cuál es su importancia. Sin embargo, puede preguntarse, por un lado, si esta presentación en términos de probabilidad pura es suficiente para caracterizar el fenómeno biológico de interés, o si la aplicación a la biología presupone otros principios fácticos. Por otro lado, cabe cuestionarse si la presentación en términos probabilísticos es necesaria, o si el principio puede ser presentado de otros modos. Si bien creemos que la respuesta a ambas preguntas es negativa, en lo que sigue, nos centraremos en la segunda. En esta sección, asumiendo que ZFEL puede presentarse adecuadamente apelando a conceptos probabilísticos, defenderemos que ello no es necesario. Argumentaremos que ZFEL es una instancia o especificación de un principio mucho más general, que puede aplicarse transversalmente a una gran cantidad de disciplinas científicas: el PCC. Tal principio, que puede y ha sido elucidado a través de nociones probabilísticas, trasciende la teoría de la probabilidad.

Revista de Humanidades de Valparaíso, 2019, No 14, 57-73

(c) (1) 8 (을 CC BY-NC-ND 
Un primer argumento de plausibilidad para sostener la tesis de que la teoría de la probabilidad no es necesaria para la utilización de ZFEL es que, según los propios autores, esta ley está presupuesta en eventos de especiación alopátrica. Como dijimos en la sección I, el propio Darwin apela a este tipo de especiación en sus textos (p.e. en casos como el de los pinzones). Darwin, sin embargo, apela a este tipo de especiación sin utilizar conceptos probabilísticos. En cambio, puede afirmarse que está utilizando una versión más potente de ZFEL, no probabilística, que queda mejor presentada en términos causales como una versión del PCC. Como veremos a continuación, la presentación de ZFEL en términos del PCC permite ver que, tanto las explicaciones cuantitativas de la genética de poblaciones (ya que el PCC puede elucidarse probabilísticamente) como las más cualitativas (tanto darwinianas como de especiación alopátrica en exposiciones actuales), instancian un mismo patrón explicativo.

Detrás de la idea de que la evolución independiente en las diferentes islas lleva a la diversificación, lo que se encuentra presupuesto (por fuera de todo el lenguaje estadístico / probabilístico de la genética de poblaciones) es un principio condicional como el siguiente:

No hay causas comunes operando sobre la diversidad en dos $\longrightarrow \quad \begin{aligned} & \text { La diversidad entre ambas poblaciones } \\ & \text { se incrementará }\end{aligned}$
poblaciones diferentes poblaciones diferentes

A su vez, el condicional de arriba es equivalente a:

No hay causas comunes operando

sobre la diversidad en dos

poblaciones diferentes

No es cierto que el curso evolutivo de ambas poblaciones coincidirá

Como se vio, el motivo por el que el consecuente vale dado el antecedente es que si las poblaciones realmente evolucionan independientemente (i.e. si no hay causas comunes), entonces que su curso evolutivo coincida sería una coincidencia altamente improbable. ZFEL puede pensarse entonces como una versión más específica y en el dominio de la evolución de un principio más general que afirma que:

No hay causas comunes

$\longrightarrow \quad$ No ocurre una coincidencia improbable

La contrapositiva de este condicional afirma que:

Ocurre una coincidencia impobrable $\longrightarrow$ Hay una causa común operando 
Lo cual no es otra cosa que el PCC. En su formulación estándar, el PCC afirma justamente "Si una coincidencia improbable ha ocurrido, entonces debe existir una causa común" (Reichenbach 1956, 157). Para que la coincidencia sea improbable, por supuesto, debe existir una correlación sin una relación causal directa entre los eventos para los que se da la coincidencia. En la versión de Sober, también informal y apenas más sofisticada, se incluye esta cuestión "Si el evento X e Y correlacionan, entonces o X causó Y, o Y causó X, o X e Y son efectos conjuntos de una causa común” (Sober 2001, 331).

Puede objetársenos que la formulación del antecedente del primer condicional presentado presupone parte de lo que queremos mostrar (ya que está formulada en términos de causas comunes y no de fuerzas o constricciones). Esta objeción, a su vez, puede dividirse en dos. En primer lugar, puede formularse la objeción al uso del vocabulario causal. Existe un largo debate acerca de si los análogos a las fuerzas newtonianas en la teoría evolutiva pueden o no ser pensados como causas (p.e. Baravalle y Vecchi, por aparecer; Matthen y Ariew 2002; Stephens 2004; Lewens 2010; Reisman y Forber 2005; Walsh, Lewins, y Ariew 2002). Sin embargo, esta discusión va más allá de nuestro punto. Podrían aceptarse ZFEL y el uso del PCC en la biología sin comprometerse con la causalidad en un sentido sustantivo (p.e. los propios empiristas lógicos tenían reservas con el uso del vocabulario causal, y sin embargo se dedicaron a elucidar el PCC). En todo caso, la discusión pasaría por ver cómo entender al concepto de causa del PCC.

Por otro lado, incluso concediendo que las fuerzas evolutivas son causas, podría objetarse la formulación en términos de causas comunes. Es decir, en su formulación original, ZFEL vale en ausencia de fuerzas y constricciones. Si se acepta hablar de causas en lugar de fuerzas y constricciones, esto equivale a hablar de ausencia de causas, no de causas comunes. Sin embargo, la formulación original de ZFEL sí asume que las fuerzas y constricciones son compartidas. Por ejemplo, como se vio arriba, la selección natural sólo va en contra de ZFEL (i.e. solo se incumple la condición de ausencia de fuerzas) cuando las presiones selectivas son compartidas. Caso contrario (presiones selectivas independientes) el antecedente de ZFEL vale. Por ese motivo, no creemos que sea distorsionador hablar en términos de causas comunes.

Otras aplicaciones (no biológicas) del PCC pueden ilustrar su similaridad con ZFEL. Por ejemplo, el siglo XVI, cuando se descubrió una nova que no cambiaba su posición relativa con las estrellas fijas, obligaba a los que defendían el modelo aristotélico a ubicarla sobre el mismo soporte que al resto de las estrellas fijas. Esta es la razón por la cual la nova tenía un carácter anómalo para la astronomía antigua en la que no podían ocurrir cambios en el mundo supralunar. En este caso, la aplicación del principio en juego sería: Si la posición de un objeto celeste con respecto a las estrellas fijas no cambia (lo cual constituiría una coincidencia improbable) entonces el objeto está engarzado en la misma esfera que ellas (la causa común de su movimiento en el cielo). Al igual que con ZFEL, podría presentarse este principio aplicado por la contrapositiva: si la trayectoria de un 
objeto celeste no mantiene su posición relativa con las estrellas fijas (i.e. si no ocurre una coincidencia improbable), entonces no está engarzado en la esfera correspondiente (no hay una causa común).

Qué cuenta como causa común depende del tipo de causas que gobiernan los fenómenos en cuestión (o del marco conceptual con el que uno investigue el tipo de fenómenos en cuestión). Lo que vuelve específico al PCC en su aplicación a la biología (i.e. ZFEL) tiene que ver con el tipo de factores que pueden operar como causas comunes: migración, selección natural estabilizadora, mismas presiones selectivas, etc., y a lo que constituiría una coincidencia improbable: la coincidencia en el camino evolutivo específico.

Antes de proseguir, es necesario hacer una aclaración importante. En el caso biológico, si dos poblaciones coinciden en su trayectoria evolutiva, esto puede deberse o bien a una causa común o bien a un tipo de causa común. Por ejemplo, si dos poblaciones distintas de polillas en un mismo bosque evolucionan un patrón de coloración oscuro porque la polución industrial contamina los árboles del bosque, entonces estaríamos ante un caso de una única causa común. Sin embargo, si dos poblaciones en dos bosques distintos evolucionan la coloración oscura porque ambos bosques fueron contaminados por distintas industrias, entonces estamos ante un caso de un mismo tipo de causa (y la explicación apela a algo así como un PCC para tipos). Esto, que puede implicar algunos detalles en la discusión acerca del modo más adecuado de pensar la naturaleza del PCC (ver por ejemplo, Sober 2001), para el punto de nuestro trabajo no es difícil de conceder. Piénsese el ejemplo brindado por el mismo Reichenbach de aplicación del PCC en la vida cotidiana: el caso en que dos lámparas se apagan a la vez (Reichenbach 1956, 157). Sería una causa común que la misma causa específica actúe, p.e. un corte de luz, pero también lo sería que ambas lámparas tuvieran la misma fecha de expiración. Este segundo caso sería una causa común en el mismo sentido en que la convergencia como adaptación a mismos ambientes lo es. Esto nos basta para continuar. En adelante, haremos omisión de este importante detalle, no diferenciando entre un PCC para casos y otro para tipos.

\section{El principio de causa común y la teoría de la probabilidad}

Entender que ZFEL es una instancia del PCC es aclarador respecto de varios puntos. Por ejemplo, McShea y Brandon defienden la naturaleza transdisciplinar de una versión generalizada de ZFEL, que denominan G-ZFEL: "en un sistema en el cual hay persistencia, variación y memoria, en la ausencia de fuerzas y constricciones actuando sobre la diversidad y la complejidad, la diversidad y la complejidad aumentarán en promedio" (McShea y Brandon 2010, 111-12) Según los autores, esto aplicaría tanto a poblaciones biológicas de individuos (en donde persistencia y memoria son entendidos como reproducción y herencia) como a las estacas individuales de una cerca (en donde persistencia y memoria son continuidad a través del tiempo y perpetuación de los accidentes que ocurran a cada estaca — p.e. no hay nadie pintando la cerca continuamente). Es decir, dada

Revista de Humanidades de Valparaíso, 2019, No 14, 57-73

(ㄷ)(1)(2) CC BY-NC-ND 
una cerca inicialmente igual, si cada estaca es víctima de accidentes diferentes, la cerca se volverá más compleja (las estacas más diversas). Que ZFEL (o en este caso G-ZFEL) sean instancias del PCC explica su naturaleza transdisciplinar.

Respecto del punto que es objetivo de este artículo, que es entender la relación entre ZFEL y la teoría de la probabilidad, la subsunción de ZFEL bajo el PCC también resulta esclarecedora. Las relaciones entre las diversas teorías de la causalidad y la teoría de la probabilidad son complejas. Pero en principio puede afirmarse, de manera no muy controvertida, que:

- Las nociones probabilísticas pueden permitir caracterizar el fenómeno de la causalidad, e incluso la inferencia a la causa común.

- Las inferencias probabilísticas nos pueden permitir detectar relaciones causales.

En ambos casos la apelación a la probabilidad tiene que ver con que las correlaciones causales no son perfectas. Por ejemplo, tratando a la causalidad de modo humeano, como la mayoría de las veces la conjunción constante sobre la que la causalidad se sustenta es aproximada, es necesario caracterizarla apelando a nociones probabilísticas. Así, por ejemplo, Suppes define "causa" del siguiente modo (Suppes 1970, 12):

$B_{t}$, es prima facie causa del evento $A_{t}$ si y sólo si

(i) $t^{\prime}<t$,

(ii) $P\left(B_{\mathrm{t}}\right)>0$,

(iii) $P\left(A_{\mathrm{t}} / B_{\mathrm{t}}\right)>P\left(A_{\mathrm{t}}\right)$.

En el mismo sentido, en el caso del PCC, la coincidencia improbable puede ocurrir. Sólo que es improbable que ocurra. La inferencia a la causa común no es, en consecuencia, absolutamente certera, sino que aumenta de acuerdo a la improbabilidad de la coincidencia, o la repetición de las coincidencias (Reichenbach 1956, 158). Y esa es la razón por la que tal principio suele ponerse en términos probabilísticos. Por ejemplo, Van Fraassen $(1980,28)$ presenta el principio de Reichenbach del siguiente modo:

Si las coincidencias de dos eventos A y B ocurre más frecuentemente que lo que correspondería para su ocurrencia independiente, esto es, si los eventos satisfacen la relación

(1) $P(A \& B)>P(A) . P(B)$,

entonces debe existir una causa común $\mathrm{C}$ para esos eventos tal que la tríada $\mathrm{ACB}$ es conjuntiva, esto es, satisface las relaciones (2)-(5) siguientes:

(2) $P(A \& B / C)=P(A / C) \cdot P(B / C)$ 
(3) $P(A \& B / \bar{C})=P(A / \bar{C}) \cdot P(B / \bar{C})$

(4) $P(A / C)>P(A / \bar{C})$

(5) $P(B / C)>P(B / \bar{C})$

Independientemente de que este sea un modo de adecuado de dar cuenta del principio, lo que se puede afirmar con claridad es que el hecho de que se utilice teoría de la probabilidad para caracterizar la causalidad y el PCC o para detectar relaciones causales o causas comunes subyacentes, no implica que ni la causalidad ni el PCC (y por lo tanto ZFEL) sean parte de la teoría de la probabilidad. En el segundo caso (la utilización de la teoría de la probabilidad para detectar relaciones causales particulares) el punto es obvio. En el primer caso, porque la utilización de ciertos recursos matemáticos para formular una teoría fáctica no vuelve a la segunda parte de los primeros. De otro modo habría que decir que la mecánica clásica no es más que cálculo infinitesimal, que la astronomía antigua no es más que geometría, etc. La característica distintiva de las teorías fácticas (como lo sería una teoría de la causalidad a la Suppes, o una formulación del PCC a la Reichenbach) es que, si bien se formulan usando tales herramientas matemáticas, postulan axiomas nuevos e independientes por sobre los de la teoría formal que tienen a la base. Esto es, $F=m a$ no es un teorema del cálculo infinitesimal, así como tampoco lo son los axiomas con los que Suppes y Reichenbach caracterizan a la causalidad y el PCC de ningún cáclulo de probabilidad.

\section{Conclusiones}

En el presente trabajo, hemos presentado la ZFEL de McShea y Brandon - la ley que proponen como caracterizando el estado de fuerzas cero en la teoría evolutiva-, y discutido su estatus metateórico respecto a su relación con la teoría de la probabilidad.

Las primeras dos secciones mostraron que el modo en el que diversos autores y manuales dicen que explican la diversidad y la complejidad, y el modo como efectivamente lo hacen, no siempre coincide. En ese sentido, la ZFEL fue introducida como un principio que está presupuesto en las explicaciones que efectivamente se dan, y que es unificador respecto de un conjunto muy amplio de casos. Se presentaron además algunos detalles acerca del alcance y el significado de los términos de esta ley (sin entrar en la discusión acerca de ellos).

La tercera sección elucida el motivo por el cual los autores sostienen que la ZFEL no es más que teoría de la probabilidad aplicada. Se mostró por qué el modelo matemático abstracto, de una partícula que se mueve hacia los costados, sería relevante para comprender fenómenos biológicos. Ilustramos además por qué McShea y Brandon creen que la 
difusión que se observa en el modelo cuenta como una demostración de que la diversidad debe incrementarse en las poblaciones biológicas, y notamos algunas objeciones que se le han hecho a esta afirmación.

Por último, en las últimas dos secciones, examinamos la tesis metateórica según la cual ZFEL no es más que teoría de la probabilidad aplicada. Mostramos que el motivo por el cual esta ley es aplicable de un modo transdisciplinar tan amplio se debe a que no es otra cosa que la contrapositiva del PCC. Esta identificación nos permitió, además, en la sección $\mathrm{V}$, criticar a la tesis metateórica mencionada. Las relaciones entre la teoría de la probabilidad y la causalidad son complejas, pero en ningún caso nos permiten afirmar que las caracterizaciones de la causalidad en términos probabilísticos "reduzcan" a esta a pura probabilidad aplicada.

\section{Referencias bibliográficas}

Baravalle, L., Vecchi, D. (por aparecer). Drift as a Force of Evolution: A Manipulationist Account. Life and Evolution.

Barrett, M., Clatterbuck, H, Goldsby, N., Helgeson, C., McLoone, B., Pearce, T., Sober, E., Stern, R., Weinberger, N. (2012). Puzzles for ZFEL, McShea and Brandon's Zero Force Evolutionary Law. Biology and Philosophy, 27(5): 723-35.

Beatty, J. (1984). Chance and Natural Selection. Philosophy of Science, 51(2): 183-211. Retrieved from: http://links.jstor.org/sici?sici=0031-8248\%28198406\%2951\%3A2\%3C183\%3ACA $\mathrm{NS} \% 3 \mathrm{E} 2.0 . \mathrm{CO} \% 3 \mathrm{~B} 2-\mathrm{C}$

Brandon, R. N. (2006). The Principle of Drift: Biology's First Law. The Journal of Philosophy, 103(7): 319-35.

Brandon, R. N., McShea, D. W. (2012). Four Solutions for Four Puzzles. Biology and Philosophy, 27(5): 737-44.

Darwin, C. R. (1859). On the Origin of Species by Means of Natural Selection. London: John Murray.

Darwin, C. R. (1958). The Autobiography of Charles Darwin 1809-1882. With the Original Omissions Restored. Edited and with Appendix and Notes by His Grand-Daughter Nora Barlow. Edited by Nora Barlow. New York: W.W. Norton.

Fraassen, B. C. V. (1980). The Scientific Image. Oxford: Clarendon Press.

Lewens, T. (2010). The Natures of Selection. The British Journal for the Philosophy of Science, 61(2): 313-33. doi: https://doi.org/10.1093/bjps/axp041.

Luque, V. J. (2016). The Principle of Stasis: Why Drift Is Not a Zero-Cause Law. Studies in History and Philosophy of Science Part C: Studies in History and Philosophy of Biological and Biomedical Sciences, 57: 71-79. doi: https://doi.org/10.1016/J.SHPSC.2016.04.001 
Matthen, M., Ariew, A. (2002). Two Ways of Thinking about Fitness and Natural Selection. Journal of Philosophy, 99(2): 55-83.

McShea, D. W., Brandon, R. N. (2010). Biology's First Law. Chicago: The University of Chicago Press.

McShea, D. W., Wang, S. C., Brandon, R. N. (2019). A Quantitative Formulation of Biology's First Law. Evolution. doi: https://doi.org/10.1111/evo.13735

Pence, C. H. (2017). Is Genetic Drift a Force? Synthese, 194(6): 1967-88. doi: https://doi.org/10.1007/s11229-016-1031-2

Reichenbach, H. (1956). The Direction of Time. Berkeley: University of California Press.

Reisman, K., Forber, P. (2005). Manipulation and the Causes of Evolution. Philosophy of Science, 72(5): 1113-23. doi: https://doi.org/10.1086/508120

Richards, R. J. (2012). Darwin's Principles of Divergence and Natural Selection: Why Fodor Was Almost Right. Studies in History and Philosophy of Science Part C: Studies in History and Philosophy of Biological and Biomedical Sciences, 43(1): 256-68. doi: https://doi.org/10.1016/J.SHPSC.2011.10.014

Ridley, M. (2004). Evolution - Third Edition. Malden: Blackwell.

Roffé, A. J. (2017). Genetic Drift as a Directional Factor: Biasing Effects and a Priori Predictions. Biology \& Philosophy, 32(4): 535-58. doi: https://doi.org/10.1007/s10539-017-9575-1

Sober, E. (1984). The Nature of Selection. Chicago: The University of Chicago Press.

Sober, E. (2001). Venetian Sea Levels, British Bread Prices, and the Principle of the Common Cause. British Journal for the Philosophy of Science, 52(2): 331-46. doi: https://doi.org/10.1093/bjps/52.2.331

Stephens, C. (2004). Selection, Drift, and the 'Forces' of Evolution. Philosophy of Science, 71: $550-570$.

Suppes, P. (1970). A Probabilistic Theory of Causality. Amsterdam: North-Holland Publishing Company.

Walsh, D., Lewins, T., Ariew, A. (2002). The Trials of Life: Natural Selection and Random Drift. Philosophy of Science, 69(3): 429-46. doi: https://doi.org/10.1086/342454 



\title{
Códigos de barras y esencias históricas: una crítica a la versión moderada del esencialismo biológico intrínseco
}

\author{
Barcodes and historical essences: a critique of the moderate version \\ of intrinsic biological essentialism
}

\author{
Julio Torres Meléndez \\ Universidad de Concepción, Chile \\ jutorres@udec.cl
}

\begin{abstract}
Resumen
La actual tendencia a moderar las expectativas de que el código de barras de ADN pueda ser un método de descubrimiento de nuevas especies se debería a que la interpretación esencialista de esta analogía científica es conceptualmente insostenible. Algo semejante ha ocurrido en el campo filosófico con el debilitamiento de las versiones iniciales del esencialismo biológico intrínseco (EBI). Para examinar la naturaleza de esta transición propongo dos principios que definen al EBI moderado: uno que asume que la historia de un taxón es dependiente metafísicamente de la evolución de sus propiedades intrínsecas y, otro, que asume la coextensividad necesaria entre las propiedades intrínsecas que explican el fenotipo de una especie y las propiedades portadoras de las condiciones de identidad de una especie. Argumento que ambos principios son conceptual y empíricamente insatisfactorios.
\end{abstract}

Palabras clave: especies, códigos de barras de ADN, identidad trayecto-dependiente, pleiotropía ecológica/sexual, especiación ecológica.

\begin{abstract}
The current tendency to moderate expectations that DNA barcode can be a method of discovering new species is due to the essentialist interpretation of this scientific analogy that is conceptually unsustainable. Something similar has happened in the philosophical field with the weakening of the initial versions of intrinsic biological essentialism (EBI). To examine the nature of this transition, I propose two principles that define a moderate EBI: one that assumes that the history of the taxon is metaphysically dependent on the evolution
\end{abstract}

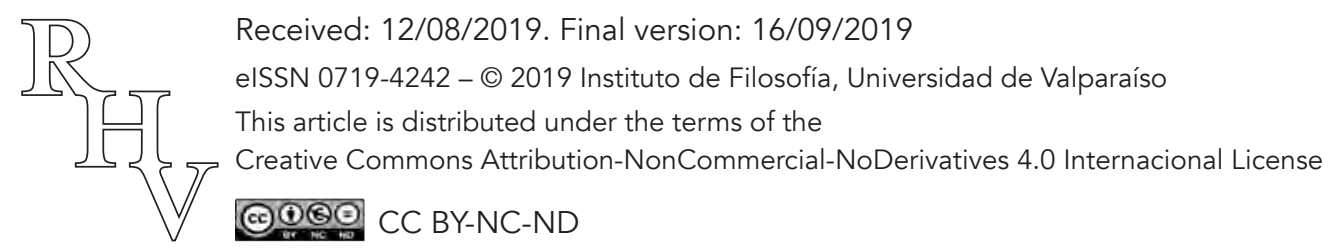


Códigos de barras y esencias históricas: una crítica a la versión moderada del esencialismo biológico intrínseco

Julio Torres Meléndez

of its intrinsic properties and another that assumes the necessary coextensivity between the intrinsic properties that explain the phenotype of the species and the bearers of identity conditions of a species. I argue that both principles are conceptually and empirically unsatisfactory.

Keywords: species, DNA barcodes, path dependence, mating/ecology pleiotropy, ecological speciation.

\section{Introducción}

De acuerdo con el esencialismo biológico intrínseco (EBI), la identidad biológica de las especies reside básicamente en su microestructura genética. La tesis es a la vez metafísica y epistémica. Esas propiedades microestructurales hacen a una individualidad biológica, en un determinado medio, ser lo que es y conocemos su naturaleza esencial conociendo esas propiedades. El EBI es una tesis de metafísicos que es ampliamente rechazada por los filósofos de la biología. Estos han argumentado que la variación genética intrapoblacional y el carácter poblacional de la explicación darwiniana hacen inviable la defensa de esta forma de esencialismo. No habría, según este punto de vista, propiedades genéticas suficientemente estables e invariables para ser candidatas a propiedades esenciales de una especie. Y, de acuerdo con un argumento desarrollado por Elliott Sober, sobre la base de las ideas de Ernst Mayr acerca del carácter no tipológico del pensamiento evolucionista, la explicación de la naturaleza de las especies no requeriría de un compromiso con propiedades esenciales intrínsecas de ningún tipo que compartan los organismos que componen una especie (Sober 1980). La explicación darwiniana es poblacional y antiindividualista: "La población es una entidad sujeta a sus propias fuerzas y que obedece a sus propias leyes" (Sober 1980, 370). El EBI es en cambio fuertemente individualista (Walsh 2006, 440). En defensa del EBI puede argumentarse que el desarrollo de la biología molecular y de los métodos para medir la distancia genética entre poblaciones, sobre la base de secciones mínimas, y suficientemente apropiadas del genoma, conocidas como códigos de barras de $A D N$, han permitido identificar especies a pesar de ese trasfondo de variabilidad genética $y$, también, han facilitado el descubrimiento de especies crípticas y especies polimórficas. Estos logros objetivos de la biología molecular junto con las representaciones que algunos taxónomos moleculares se han hecho de sus propios métodos parecen, a primera vista, apoyar las convicciones de los esencialistas microestructurales. Es así como en un primer momento los proponentes del método del código de barras de ADN han estado comprometidos también con el EBI. Esto ha ocurrido cuando se ha hecho una interpretación desmesurada de esta analogía entre, por un lado, una determinada sección del genoma mitocondrial de especies animales (el gen citocromo oxidasa subunidad 1) $\mathrm{y}$, por otro, la codificación digital de la identidad universal de un producto comercial o código de barras (Hebert, Stoeckle, Zemlak y Francis 2004). Bajo esta interpretación el

Revista de Humanidades de Valparaíso, 2019, No 14, 75-89

()ㅇㅇㅇㅛ CC BY-NC-ND 
Códigos de barras y esencias históricas: una crítica a la versión moderada del esencialismo biológico intrínseco

Julio Torres Meléndez

código de barras de ADN contiene en sí mismo la identidad esencial de la especie y esta identidad podría, en principio, ser rápidamente descubierta usando un dispositivo lector portátil como el imaginado en algunas historietas de ciencia ficción. El tricodificador de Star Trek es un buen ejemplo aquí (Holmes 2004).

Pero en la misma comunidad científica comenzó una discusión acerca de los fundamentos conceptuales de este proyecto. Se acusó a los proponentes del código de barras de ADN de confundir los métodos que facilitan la identificación de especies previamente conocidas con los procesos de descubrimiento de nuevas especies (la misión de la taxonomía alfa) (Rubinoff, Cameron y Will 2006). De acuerdo con los taxónomos integrativos, el método del código de barras de ADN no puede ser un método de descubrimiento taxonómico, aunque pueda ser de gran utilidad para identificar muestras fragmentarias, especímenes juveniles y, también, para generar hipótesis, acerca de la existencia de especies no descubiertas, sobre la base de la evidencia de que los códigos de barras de ejemplares desconocidos no concuerdan «con ninguna especie presente en la base de datos de referencia» (Paz, González y Andrew 2011, 163). Es decir, estos métodos moleculares pueden ser utilizados para apoyar hipótesis sobre la base de lo que los filósofos llaman 'inferencias a la mejor explicación' en el contexto de los procesos de descubrimiento. Sin embargo, de acuerdo con el enfoque integrativo, la identidad de las especies se establece por medio de propiedades relacionales tales como el grado de aislamiento reproductivo o las relaciones de ancestro-descendiente (Will, Mishler y Wheeler 2005). Por esta razón es que las hipótesis taxonómicas que puedan generarse a partir del método del código de barras de ADN deben ser testeadas o justificadas usando una pluralidad de propiedades biológicas que estén correlacionadas, por ejemplo, con el grado de aislamiento reproductivo, como ocurre con la diferenciación morfológica, ecológica, etológica y también genética (utilizando una información molecular más amplia que la usada por el código de barras de ADN). Estas propiedades biológicas permiten contrastar hipótesis acerca de la existencia de una comunidad aislada reproductivamente o acerca de la existencia de determinadas relaciones filogenéticas, pero ellas no constituyen un criterio de especie. Cuando, por ejemplo, no hay evidencia directa acerca del grado de aislamiento reproductivo, el taxónomo usa esas propiedades, que en su teoría proporcionan una información conceptualmente independiente de su criterio de especie (es decir, de la manera en que se define la categoría de especie), como indicadores inductivamente correlacionados con el aislamiento reproductivo para contrastar sus hipótesis o propone una determinada hipótesis acerca del grado de aislamiento reproductivo como la mejor explicación de la evidencia disponible. Pero en la interpretación desmesurada de la analogía del código de barras de $\mathrm{ADN}$, se trata a la evidencia molecular como un criterio de especie y, por esto, no pueden existir, en principio, propiedades independientes de la evidencia molecular que pueda confirmar o refutar una hipótesis taxonómica de este tipo. El problema se muestra en poblaciones estrechamente relacionadas. No es aquí posible determinar, en principio, solo con la evidencia molecular, qué valor de distancia genética

Revista de Humanidades de Valparaíso, 2019, No 14, 75-89

(). (18) CC BY-NC-ND 
Códigos de barras y esencias históricas: una crítica a la versión moderada del esencialismo biológico intrínseco

Julio Torres Meléndez

se corresponde con una distinción real, no meramente convencional, entre poblaciones (Lee 2004, 2). El método del código de barras de ADN como método de descubrimiento aparece ilusoriamente plausible cuando se comparan especies distantes filogenéticamente, pero en estos casos la evidencia morfológica y etológica ha proporcionado desde siempre la información requerida como lo muestra el alto grado de coincidencia entre las identificaciones vernáculas y científicas de los taxa a nivel de especie (Mayr 1968, 33). No ocurre así entre poblaciones recientemente escindidas de un ancestro común.

Pero todo indica que las interpretaciones esencialistas de este método han quedado superadas a pesar del entusiasmo inicial y, también, del intento de equiparar sus problemas en el descubrimiento de especies a las dificultades empíricas que son comunes a la aplicación de los diversos conceptos de especie que se apoyan en propiedades biológicas relacionales (véase al respecto las afirmaciones que hace Paul Hebert en Holmes 2004, 34). Es probable que se haya advertido que las dificultades del código de barras de ADN, como he mostrado, son más bien conceptuales y esto explicaría que se aluda ahora a su importancia de una manera claramente instrumental para los fines de la taxonomía integrativa. Su utilidad en el descubrimiento radicaría "especialmente en grupos poco estudiados, ya que puede filtrar rápidamente las colecciones de especies presuntas, para que entonces puedan ser objeto de estudio taxonómico" (Hebert, Hollingsworth y Hajibabaei 2016, 5). El código de barras de ADN es visto apropiadamente como un recurso para iniciar aceleradamente el trabajo taxonómico, pero no como un método que por sí mismo resuelva los problemas del descubrimiento de nuevas especies (Kekkonen y Hebert 2014).

Paralelamente, en el campo filosófico, las versiones moderadas del EBI parecen también corregir sus posiciones anteriores a la luz de las críticas recibidas. Un síntoma de esto es que sus proponentes han integrado propiedades históricas y relacionales a sus definiciones intrínsecas de la categoría de especie y de jerarquías taxonómicas superiores. Como veremos la manera en que se produce esta integración de la historia y de otras propiedades relacionales reviste cierta complejidad en el contexto del EBI y no estará libre de problemas conceptuales y de inconsistencias con los logros de la investigación empírica. Las interpretaciones moderadas del código de barras de ADN que integran criterios históricos o relacionales a su definición de la categoría de especie deben ser entendidas también como versiones moderadas del EBI y los problemas conceptuales y empíricos de estas versiones moderadas deberían reproducirse también en las interpretaciones moderadas del código de barras de ADN, aunque no abordaré esta cuestión aquí. Me propongo entonces identificar la naturaleza conceptual de la transición desde las concepciones iniciales o tradicionales del EBI hacia la versión moderada, para argumentar en contra de lo que considero una concepción insatisfactoria, desde el punto de vista evolutivo, del componente histórico que se incorpora al EBI como parte de la esencia

Revista de Humanidades de Valparaíso, 2019, No 14, 75-89

(ㄷ)(1)(2) CC BY-NC-ND 
Códigos de barras y esencias históricas: una crítica a la versión moderada del esencialismo biológico intrínseco

Julio Torres Meléndez

de un taxón. Finalmente, muestro que hay también razones empíricas, provenientes de un caso de especiación ecológica en murciélagos, para dudar acerca de lo que propondré son algunos de los principios centrales del EBI.

\section{Historia y roles constitutivos}

De acuerdo con EBI, ¿qué relevancia tiene la historia en el descubrimiento de la esencia de un taxón? Considérese, en primer lugar, la distinción entre propiedades constitutivas y propiedades que originan o causan esas propiedades constitutivas, que introduce Travis Dumsday en el contexto de esta discusión. De acuerdo con Dumsday, propiedades relacionales, tales como ocupar un determinado nicho ecológico, pueden causar que una determinada población tenga una determinada identidad intrínseca, pero esa propiedad relacional no es constitutiva de tal identidad (Dumsday 2012, 499). Dumsday separa aquí las propiedades constituyentes de la identidad de una especie de las propiedades que los diversos modelos de especiación identifican para explicar el origen de las especies. Y algo similar había sostenido previamente Michael Devitt. De acuerdo con Devitt, la cuestión central del EBI es qué mecanismo, independientemente de cuál sea su origen, explica ahora la verdad de las generalizaciones acerca de los taxa (Devitt 2008, 352). Devitt hace esta distinción usando los conceptos de explicación estructural y explicación histórica de Philip Kitcher (2003 [1984], 121). Una explicación estructural nos permite hacer generalizaciones acerca de las propiedades fenotípicas de un organismo que se apoyan en la existencia de determinados mecanismos microestructurales (propiedades genéticas y procesos de desarrollo celular). La explicación histórica, en cambio, "nos dice cómo los miembros de un taxón llegan a tener estos mecanismos" (Devitt 2018a, 8; Devitt 2008, 353). El concepto de explicación estructural tiene aquí la ventaja de mostrar con mayor claridad que las esencias que postula el proponente del EBI cumplen un doble rol: dan cuenta de la identidad de un organismo y, también, explican causalmente sus propiedades fenotípicas por medio de propiedades intrínsecas o microestructurales. De acuerdo con Devitt, "la esencia intrínseca" es un mecanismo causal que hace de un determinado organismo lo que organismo es y explica la manera en que lo es (Devitt 2018a, 10). Llamaré 'propiedades constitutivas' a las propiedades intrínsecas que cumplen este rol tanto individualizador como causal y cuyo origen es, en este contexto, irrelevante. Las clases naturales de la teoría química son, por cierto, el paradigma de esa separación entre propiedades constitutivas y propiedades históricas. El proceso, natural o no, que causó que una determinada molécula sea la que es, por ejemplo, una molécula de agua, no es parte de las propiedades constitutivas del agua. Dondequiera que se ejemplifiquen esas propiedades constitutivas habrá agua y, por tanto, el origen o la historia que explica la instanciación de esas propiedades es irrelevante para la determinación de su naturaleza. Las clases naturales de la química son también el paradigma de la concatenación del doble rol que cumplen esas propiedades constitutivas: proporcionan la identidad de cada clase y explican causalmente sus propiedades físico-químicas. Las especies biológicas

Revista de Humanidades de Valparaíso, 2019, No 14, 75-89

(). (18) CC BY-NC-ND 
Códigos de barras y esencias históricas: una crítica a la versión moderada del esencialismo biológico intrínseco

Julio Torres Meléndez

reproducen, de acuerdo con el EBI, por un lado, este mismo patrón de división entre origen y constitución; y, por otro, reproducen también la coincidencia extensional entre propiedades responsables de la individuación y propiedades que proporcionan explicación estructural. Expresaré estas tesis, respectivamente, como formas de compromiso con dos principios:

Principio de irrelevancia del origen: la historia evolutiva de un taxón no cumple ningún rol constitutivo.

Principio de coextensividad de los roles constitutivos: las propiedades intrínsecas que causan en un determinado medio el fenotipo de un taxón son también sus propiedades individualizadoras.

Sin embargo, a pesar de su insistencia inicial respecto de que los procesos causales que originan una especie no son constitutivos de su identidad, Dumsday afirmó recientemente que las propiedades intrínsecas del genoma de una especie no permiten, por sí mismas, la determinación de su identidad. Según este punto de vista es una condición necesaria pero no suficiente de la identidad de una especie el que ella tenga tal propiedad microestructural. Para determinar su identidad debemos obtener también información acerca de su ubicación en un determinado linaje o línea de descendencia (Dumsday 2017, 606; Dumsday 2012, 499). Dumsday hace una distinción aquí entre una versión tradicional del EBI y una versión moderada. La versión moderada, a primera vista, parece abandonar por completo el Principio de irrelevancia del origen y conservar el Principio de coextensividad de los roles constitutivos. Dumsday rechaza de esta manera el esencialismo tipológico: las especies no son tipos o géneros naturales que conserven su identidad donde quiera que se instancie una determinada microestructura genética. La propiedad relacional de pertenecer a determinado linaje tiene ahora, parcialmente, un rol constitutivo respecto de la identidad. Esta tesis es asumida también por Devitt quien sostiene "que hay, al menos, un componente histórico" en la esencia de cada taxón (Devitt 2018a, 5), aunque, como veremos, no abandona su anterior idea según la cual las propiedades intrínsecas tienen prioridad causal respecto de las propiedades relacionales tal como el aislamiento reproductivo (la propiedad relacional que utiliza en Concepto Biológico de Especie como el criterio de especie). Esta prioridad causal del componente intrínseco la encontramos también respecto de las propiedades históricas o filogenéticas. De acuerdo con Devitt, el error del esencialismo estrictamente histórico fue olvidar "la dependencia del componente histórico" respecto del componente intrínseco (Devitt 2018b, 1). La tesis esencialista de Samir Okasha es representativa de este punto de vista que ataca Devitt. Okasha afirma que las especies tienen propiedades relacionales esenciales (como el aislamiento reproductivo o la relación ancestro-descendiente), pero al mismo tiempo rechaza la idea de que ellas tengan propiedades intrínsecas esenciales. Por ejemplo, desde el punto de vista de un concepto filogenético de especie, la propiedad que cumple el rol individualizador de una especie la constituye la propiedad esencial de "pertenecer a un particular segmento del

Revista de Humanidades de Valparaíso, 2019, No 14, 75-89

(c) (1) 8 (을 CC BY-NC-ND 
Códigos de barras y esencias históricas: una crítica a la versión moderada del esencialismo biológico intrínseco

Julio Torres Meléndez

nexo genealógico" (Okasha 2002, 202). No hay razones a priori, afirma Okasha, para que una propiedad esencial relacional tenga tanto una función causal como una función semántica o individualizadora (Okasha 2002, 203). En la sistemática filogenética esas propiedades relacionales cumplen, según Okasha, la función semántica pero no la causal y lo mismo debería afirmarse respecto de otras propiedades que utilizan los distintos conceptos relacionales especie para determinar la identidad de un taxón.

Devitt rechaza esa forma débil de esencialismo porque, entre otras razones, una esencia estrictamente histórica, esto es, sin componente intrínseco, carece de poder causal y por ello no sería capaz de producir explicaciones estructurales (una tesis que Devitt comparte con Okasha). Devitt asume que una propuesta genuinamente esencialista debe proporcionar no solo un criterio de identidad sino también una explicación causal de las propiedades estructurales de un género natural (Tahko 2015 y Ereshefsky 2010b). Un esencialismo histórico sin componente microestructural no cumpliría ninguno de estos roles constitutivos. Sería, por sí mismo, incapaz de proporcionar criterios de identidad para dos especies que se han escindido de una especie ancestral. Si las especies B y $\mathrm{C}$ se han escindido de la especie ancestral $\mathrm{A}$, ¿cómo podríamos distinguir entre $\mathrm{B}$ y $\mathrm{C}$ sin criterios intrínsecos? La individuación en términos históricos no podría, de acuerdo con Devitt, hacer esta distinción. Entonces no cualquier historia cuenta como parte del componente histórico de la esencia de las especies. La clase de historia que es esencial a un organismo, dice Devitt, es aquella en donde un determinado tipo intrínseco evoluciona hacia otro determinado tipo intrínseco (Devitt 2018a, 14). En Devitt 2018b se sostiene asimismo: "la historia relevante de un taxón $\mathrm{T}$ es aquella en donde los organismos de un tipo evolucionan a organismos de otro tipo [...]" (p. 6). La versión moderada del EBI abandonada solo parcialmente la idea según la cual la historia es irrelevante para la determinación de la identidad, es decir, el EBI moderado abandona el Principio de irrelevancia de origen propiamente tal, para reemplazarlo por una versión restringida que puede expresarse de la siguiente manera:

Principio restringido de irrelevancia del origen: la historia de un taxón que tiene un rol constitutivo para su identidad es la historia dependiente metafísicamente de la evolución de las propiedades intrínsecas de los organismos de ese taxón.

Devitt expresa este principio también bajo la idea de que la esencia intrínseca de un organismo implica su componente histórico. De esto se sigue también la tesis de que los organismos pertenecen esencialmente a su taxón. Un organismo $\mathrm{O}$ es esencialmente un miembro de un taxón $\mathrm{T}$, si y solo si, la esencia de $\mathrm{O}$ entraña la esencia de su taxón $\mathrm{T}$ (Devitt 2018a, 2) ${ }^{1}$. Pero, como veremos, este principio deja parte importante de la historia de un taxón fuera del alcance individualizador y también causal que tienen, para el EBI, las propiedades intrínsecas.

${ }^{1}$ La formulación original es " $\mathrm{O}$ is essentially a member of $\mathrm{T}$ iff its having Eo entails its having Et".

Revista de Humanidades de Valparaíso, 2019, No 14, 75-89

(c) (1) 8 (음 $\mathrm{CC}$ BY-NC-ND 
Códigos de barras y esencias históricas: una crítica a la versión moderada del esencialismo biológico intrínseco

Julio Torres Meléndez

\section{La historia à la Devitt no es historia evolutiva}

Podemos ahora enunciar el problema central de la tesis según la cual los taxa tienen un componente histórico dependiente de su componente intrínseco esencial: de acuerdo con esta tesis la historia de un taxón sobreviene a la evolución de las propiedades intrínsecas de sus organismos ${ }^{2}$. Pero esta idea es extraña al pensamiento evolucionista y parece más bien un retroceso hacia una explicación estructuralista pre-darwiniana de la forma biológica, al otorgar prioridad causal exclusiva a las propiedades intrínsecas de los taxa y no a las contingencias históricas que explican gran parte del patrón de sus adaptaciones. En favor de este principio está el hecho de que las propiedades intrínsecas condicionan tanto negativamente como positivamente la evolución. Este es el sentido que S. J. Gould le da a la constricción interna o estructural como "impedimento o límite al poder de la selección natural", pero también "como promotor, suministrador o causa de la dirección del cambio evolutivo" (Gould 2004 [2002], 1057). Hay evidencia experimental al respecto. El microbiólogo Richard Lenski lideró en 1988 un experimento evolucionista de larga duración con doce poblaciones bacterianas genéticamente idénticas y sometidas también a idénticas presiones ambientales (experimento conocido como Long-term Experimental Evolution o LTEE). Los doce linajes han evolucionado divergentemente durante más de 65.000 generaciones (al año 2016) y se han diferenciado en relación a su volumen celular y a su aptitud relativa a pesar de que les ocurrieran, con excepciones, una acumulación de las mismas mutaciones favorables en los mismos genes (aunque raramente idénticas a nivel de nucleótidos) (Blount, Lensky y Losos 2018). Aunque estas mutaciones les permitieron, en general, la adaptación a los mismos desafíos ecológicos, ellas surgieron, presumiblemente, en un orden temporal distinto, lo que explica la divergencia de la historia evolutiva. La secuencia en que surgen las mutaciones es relevante también para que la selección acumulativa produzca tales o cuales fenotipos. Esta es una forma de historicidad que, de acuerdo con Eric Desjardins, se expresa tanto en la dependencia del proceso evolutivo respecto de las condiciones iniciales intrínsecas como también en la dependencia de la trayectoria [path dependence], es decir, en el hecho de que la probabilidad de que un determinado resultado pueda cambiar si se toma, entre distintas alternativas posibles, una determinada trayectoria y no otra (Desjardins 2011, 353). Esto es justamente lo que ocurre cuando el orden de las mutaciones es determinante para que solo en una de las poblaciones bacterianas del LTEE evolucionara la capacidad de crecer aeróbicamente en citrato (Cit+) (Blount, Lensky y Losos 2018, 4). El LTEE confirma la tesis moderada del EBI: las doce poblaciones bacterianas tienen una historia evolutiva que es el resultado de la interacción entre la naturaleza intrínseca de los organismos y el medio, pero no hay cambios en esa historia evolutiva que no estén acompañados por cambios intrínsecos y cada diferencia entre las distintas poblaciones es dependiente exclusivamente de la evolución de las propiedades intrínsecas de cada una de ella a

${ }^{2}$ Acerca del concepto de superveniencia invocado aquí, cf. Kim (2003[1993]) y García-Carpìntero (1996).

Revista de Humanidades de Valparaíso, 2019, No 14, 75-89

(ㄷ)(1)(8) CC BY-NC-ND 
Códigos de barras y esencias históricas: una crítica a la versión moderada del esencialismo biológico intrínseco

Julio Torres Meléndez

partir de un estado inicial común. Sometidas a las mismas presiones ambientales, y a partir de las mismas condiciones iniciales, la diferencia en la historia evolutiva solo puede ser explicada por la existencia de una diversidad de alternativas posibles y por la dinámica contingente de la acumulación de mutaciones favorables que toman una u otra de esas alternativas. No ocurre lo mismo, sin embargo, en los eucariotas pluricelulares de reproducción sexual. El LTEE ha servido tanto para contrastar hipótesis científicas acerca del carácter contingente, impredecible e irreversible de la evolución como también para el examen filosófico de la naturaleza y la relevancia de la historia en la explicación evolucionista, pero sus resultados no son completamente simétricos respecto de cómo la dependencia de la trayectoria afecta la identidad de los taxa pluricelulares altamente integrados y en donde también hay un alto grado de división entre células somáticas y células germinales (Godfrey-Smith 2009). Esto no es sorprendente dado que el surgimiento de una individualidad darwiniana pluricelular representa, como se ha sostenido, una de las mayores transiciones evolutivas (Maynard Smith y Szathmary 1995; Veit 2019). Si en estos taxa la contingencia histórica puede comenzar antes de que exista una evolución de las propiedades intrínsecas de sus individuos y, por esta misma razón, puede, posteriormente, de manera retrospectiva, condicionar su identidad, entonces el Principio restringido de irrelevancia del origen no representa correctamente la historicidad de la evolución. Al menos, no de las poblaciones cuyos individuos se reproducen sexualmente y en donde consecuentemente los procesos de especiación suponen el surgimiento de barreras que impiden el intercambio génico entre estas poblaciones. La idea de que podemos prescindir de la historia biológica que no dependa de la evolución de las propiedades intrínsecas, tal como se expresa en el Principio restringido de irrelevancia de origen, es inconsistente con la identidad trayecto-dependiente que suponen los distintos modelos de especiación. De la dependencia metafísica que establece el Principio restringido de irrelevancia del origen entre la historia y la evolución de las propiedades intrínsecas, se sigue que debe haber diferencia intrínseca para que dos organismos que pertenezcan a taxones distintos entrañen un componente histórico distinto. Si no hay diferencia intrínseca entre dos taxones recientemente escindidos de una especie ancestral, entonces este entrañamiento no podría ser sino mágico. ¿Por qué estaría entrañando un determinado taxón y no el otro? Pero debe advertirse que el punto de origen de una especie radica en el punto de división o ramificación de una especie ancestral. Considérese que en el modelo alopátrico de especiación no es posible determinar que el aislamiento geográfico de una población escindida de una especie ancestral constituya el origen de una nueva especie si no conocemos el resto de la historia de la especie. No se trata aquí solo de una contingencia epistémica, una cuestión relativa a la imposibilidad de conocer esa historia o al menos de conocerla con precisión, sino de una indeterminación ontológica que solo se resuelve retrospectivamente. Solo retrospectivamente podemos determinar que ese proceso de división dio origen a una nueva especie. Las especies son entidades cuya naturaleza es dependiente de la historia de una manera singular: su entidad no solo está condicionada por el estado inicial, sino que también por lo que sucederá en el futuro

Revista de Humanidades de Valparaíso, 2019, No 14, 75-89

(ㄷ)(1)(8) CC BY-NC-ND 
Códigos de barras y esencias históricas: una crítica a la versión moderada del esencialismo biológico intrínseco

Julio Torres Meléndez

como lo ha argumentado Marc Ereshefsky (Ereshefsky 2014, 720). Aunque la evolución bacteriana parece confirmar el Principio restringido de irrelevancia de origen, los taxa pluricelulares altamente integrados no lo hacen.

\section{Pleiotropía ecológica/sexual y el Principio de coextensividad de los roles constitutivos}

En lo que sigue consideraré un ejemplo de especiación ecológica en murciélagos que refuta el Principio de coextensividad de los roles constitutivos. Como veremos, si no hay coextensividad en el sentido requerido por EBI, pierde justificación tanto la tesis según la cual los organismos entrañan el componente histórico del taxón al que pertenecen como la tesis de que su pertenencia es necesaria. Consideremos el caso del murciélago herradura (Rhinolophus philippinensis). Los biólogos Tigga Kingston y Stephen Rossiter han identificado tres morfos caracterizados por tres tamaños, cuyo rango de largo de brazo va, aproximadamente, de 47 a $56 \mathrm{~mm}$ (grandes, intermedios y pequeños) (Kingston y Rossiter 2004). Estos morfos están aislados reproductivamente presumiblemente debido a su diferencia en la frecuencia de llamada de ecolocalización. Los grandes emiten llamados de baja frecuencia, cuya gran amplitud de onda permite la captura de insectos grandes, aunque son funcionalmente sordos a los pequeños. Los medianos emiten llamados de frecuencia intermedia que permite la captura de insectos de talla media. Los de tamaño pequeño emiten llamadas de alta frecuencia que les permite solo atrapar presas de menor tamaño, y son, por ello, sordos a los insectos grandes. Dado que las llamadas de ecolocalización permiten también la comunicación y el reconocimiento sexual, las presiones ecológicas pueden resultar disruptivas y eliminar los morfos intermedios produciendo, al mismo tiempo, aislamiento reproductivo entre estas poblaciones. De ahí que la llamada de ecolocalización constituya un ejemplo de 'rasgo mágico' (Gavrilets 2004, 368) o de 'pleiotropía ecológica/sexual' [mating/ecology pleiotropy] (Bolnick y Fitzpatrick 2007, 470). Un rasgo de este tipo tiene la peculiaridad de realizar una doble función (una relativa a sus interacciones ecológicas y otra de reconocimiento sexual). Estas dos funciones generalmente residen en rasgos distintos, pero en este caso ellas coinciden extensionalmente en un solo rasgo controlado por un solo conjunto de genes (Nosil 2012, 34; Servedio et al. 2011, 389).

Kingston y Rossiter sostienen que el origen de los saltos armónicos es un problema no resuelto en sus aspectos fisiológicos, aunque se presume que se debe a cambios en la estructura del sistema auditivo (la dimensión de la cóclea), un sistema que está estrechamente relacionado con la afinación de la frecuencia de ecolocalización (Kingston y Rossiter 2004). Para los presentes propósitos asumiré simplemente que los saltos armónicos constituyen un acervo de variabilidad fenotípica, generada por mutación y recombinación, que tiene una distribución normal en la población cuando no hay presiones

Revista de Humanidades de Valparaíso, 2019, No 14, 75-89

(c) (1) 8 (을 CC BY-NC-ND 
Códigos de barras y esencias históricas: una crítica a la versión moderada del esencialismo biológico intrínseco

Julio Torres Meléndez

ecológicas que provoquen adaptación disruptiva o divergente. Así fue interpretado hipotéticamente por Gareth Jones y Sofie Van Parijs para el caso de la distribución bimodal de las frecuencias de llamado que detectaron en los murciélagos Pipistrellus pipistrellus:

Una distribución normal de las frecuencias de llamada puede ser dividida en una distribución bimodal por la selección disruptiva. Si esto ocurrió así y los murciélagos con similares frecuencias tendieron a agregarse en colonias, nuevas especies pudieron formarse en la misma área geográfica. [...] La competición entre los extremos podría ser menor que la que hay entre los intermedios y la frecuencia puede divergir. (Jones y Van Parijs 1993, 124)

Aunque, al parecer, no es este el punto de vista de Kingston y Rossiter. Ellos sostienen que:

[...] si asumimos que la comunicación acústica es importante para el reconocimiento de pareja, como típicamente ocurre en los murciélagos, los saltos armónicos pueden proveer de un mecanismo intrínseco de aislamiento precopulatorio instantáneo [instantaneous premating isolation]. (Kingston y Rossiter 2004, 655)

Pero esta afirmación no es consistente con el modelo ecológico de especiación que ellos mismos asumen cuando afirman que la "selección ecológica divergente" podría producir aislamiento reproductivo, si el rasgo bajo selección puede influir en el reconocimiento de pareja y tiene como resultado la segregación de cruzamiento (Kingston y Rossiter 2004, 655). No hay tal mecanismo intrínseco de aislamiento instantáneo, dado que los saltos armónicos podrían mantenerse y propagarse en la población sin producir aislamiento si no hay presiones ecológicas disruptivas sobre ella. Aquí, como en las especies anillo, el flujo génico interespecífico podría ser posible a través de los morfos intermedios (Ereshefsky 2010b, 681). De hecho, Kingston y Rossiter detectaron alguna evidencia al respecto:

Los grandes y pequeños morfos son [...] funcionalmente sordos a otras llamadas de frecuencia-constante. Aunque los morfos intermedios podrían ser capaces de oír las frecuencias usadas por los grandes morfos, y pueden ser oídos por los morfos pequeños, en ningún caso esta receptividad es recíproca (Kingston y Rossiter 2004, 655).

También admiten que es muy posible que la población ancestral haya contenido más diversidad genética que la que actualmente conocemos (Kingston y Rossiter 2004, 655). Esto puede ser un indicio de que la selección disruptiva eliminó una parte importante de los morfos intermedios que hacían posible la percepción recíproca de las señales de ecolocalización y que en el pasado pudo haber permitido el flujo génico en toda la población. Esta interpretación haría consistentes los resultados empíricos con el modelo ecológico de especiación, aunque subsiste un problema. Las diferencias de frecuencia encontradas corresponden a saltos armónicos sobre la base de una frecuencia fundamental. Las frecuencias de llamado de los distintos morfos son efectivamente múltiplos de esa frecuencia fundamental. Las frecuencias intermedias respecto de los armónicos son

Revista de Humanidades de Valparaíso, 2019, No 14, 75-89

(c) (1) 8 (을 CC BY-NC-ND 
Códigos de barras y esencias históricas: una crítica a la versión moderada del esencialismo biológico intrínseco

Julio Torres Meléndez

físicamente posibles, pero probablemente tendrían muy poco valor para la sobrevivencia. Quizás esta sea la razón por la cual para Kingston y Rossiter los saltos armónicos constituyen un mecanismo intrínseco de aislamiento reproductivo instantáneo.

La coincidencia extensional en los rasgos mágicos entre, por un lado, determinada propiedad que cumple una función adaptativa y, por otro, una propiedad de reconocimiento sexual, parece, a primera vista, respaldar el Principio de coextensividad de los roles constitutivos. Efectivamente, los genes que causan la llamada ecolocalización son también los genes que causan las señales de reconocimiento sexual que dan origen al aislamiento reproductivo y que determinan la identidad biológica de la población. Pero debe advertirse que es parte del concepto de rasgo mágico el que se trate de un rasgo sometido a selección divergente tal como se muestra en la incipiente especiación ecológica de $R$. philippinensis. Antes de que hubiera selección divergente, la pleiotropía ecológico/sexual estaba presente pero no generó aislamiento reproductivo. La magia (como siempre) es una ilusión: la pleiotropía ecológico/sexual propia de los rasgos mágicos no produce, como hemos visto, especiación instantánea o automática. Se requiere también selección divergente que elimine los fenotipos intermedios por su menor eficacia biológica respecto de los fenotipos extremos en la distribución normal de la población original (Soler 2003, 139). La coextensividad de los roles constitutivos que requiere, en cambio, el EBI, es incondicionada e individualista. Sus principio de identidad no depende de ninguna propiedad relacional y poblacional tal como el grado de aislamiento reproductivo, sino simplemente de las propiedades intrínsecas del genoma del individuo. Este y otros casos de especiación ecológica muestran que el Principio de coextensividad de los roles constitutivos es falso y con ello también lo es la tesis según la cual los organismos entrañan el componente histórico del taxón al que pertenecen. No puede haber tal entrañamiento, pues antes y después del proceso de especiación ecológica, las propiedades intrínsecas son exactamente las mismas para los individuos de la población ancestral y para los individuos que pasan a integrar poblaciones aisladas reproductivamente luego de la acción de la selección divergente que elimina los morfos intermedios. La historia del taxón se ha escindido, pero esta historia no es dependiente de la evolución de las propiedades intrínsecas de los individuos. Aquí la historia no superviene en las propiedades genómicas de los individuos, dado que estas propiedades no han cambiado a pesar de la divergencia histórica de estas dos poblaciones. Y los organismos tampoco pertenecen de manera necesaria al taxón al que pertenecen: su pertenencia es obviamente contingente, está condicionada a la contingencia de la selección divergente.

\section{Conclusiones}

He mostrado que tanto las interpretaciones esencialistas del código de barras de ADN, como las versiones tradiciones del EBI, han moderado sus posiciones integrando propiedades relacionales e históricas a sus criterios inicialmente puramente intrínsecos

Revista de Humanidades de Valparaíso, 2019, No 14, 75-89

(). (18) CC BY-NC-ND 
Códigos de barras y esencias históricas: una crítica a la versión moderada del esencialismo biológico intrínseco

Julio Torres Meléndez

para delimitar especies. Las interpretaciones desmesuradas del código de barras de ADN son inviables por razones conceptuales y no, como lo han supuesto algunos taxónomos integrativos, por razones meramente empíricas. Respecto de la versión moderada del EBI, he propuesto dos principios que pretenden definirla: el Principio restringido de irrelevancia del origen y el Principio de coextensividad de los roles constitutivos. El primero es refutado por la identidad trayecto-dependiente que es propia de la naturaleza histórica de los procesos evolutivos de los organismos multicelulares altamente integrados. La identidad dependiente de la trayectoria no requiere que la historia sobrevenga a las propiedades genéticas de los individuos como se muestra en el proceso de especiación ecológica que divide a $R$. philippinensis en dos poblaciones aisladas reproductivamente. Las propiedades genéticas de los organismos individuales deberían aquí, por sí mismas, entrañar su componente histórico como requiere el EBI moderado. Pero esta noción de entrañamiento carece de sentido en el contexto de los modelos ecológicos de especiación. Estos modelos suponen que la diferencia genética que va a caracterizar a ambas poblaciones debe estar previamente distribuida en los extremos de la curva normal de la frecuencia de la variación genética de la población y, por esta razón, esta variación existe en los organismos individuales antes del proceso de especiación por selección divergente. La historia evolutiva de ambas poblaciones cuyo ancestro común es $R$. philippinensis no es entonces dependiente metafísicamente de la evolución de las propiedades intrínsecas de sus organismos componentes. Este ejemplo de especiación refuta también el Principio de coextensividad de los roles constitutivos. No hay tal coextensividad a pesar de que los rasgos mágicos suponen la coincidencia extensional entre una función adaptativa y otra de reconocimiento sexual. El concepto de rasgo mágico es un concepto poblacional que implica simultáneamente pleiotropía ecológico/sexual y selección divergente. La entidad de un rasgo mágico no es individual como debería presuponer el EBI. Si lo fuera entonces la pleiotropía ecológico/sexual determinaría por sí misma la identidad de los individuos y tendría justificación la tesis esencialista según la cual los individuos pertenecen necesariamente a su taxón.

\section{Referencias bibliográficas}

Bolnick, D., Fitzpatrick, B. (2007). Sympatric speciation: models and empirical evidence. Annual Review of Ecology, Evolution, and Systematics, 38(1): 459-487. doi: https://doi. org/10.1146/annurev.ecolsys.38.091206.095804

Blount, Z. D., Lenski, R. E., Losos, J. B. (2018). Contingency and determinism in evolution: Replaying life's tape. Science, 362(6415): eaam5979. doi: 10.1126/science.aam5979

Desjardins, E. (2011). Historicity and experimental evolution. Biology \& Philosophy, 26(3): 339364. doi: https://doi.org/10.1007/s10539-011-9256-4

Devitt, M. (2008). Resurrecting biological essentialism. Philosophy of Science, 75: 344-382. doi: https://doi.org/10.1086/593566

Revista de Humanidades de Valparaíso, 2019, No 14, 75-89

(). (18) CC BY-NC-ND 
Códigos de barras y esencias históricas: una crítica a la versión moderada del esencialismo biológico intrínseco Julio Torres Meléndez

Devitt, M. (2018a). Individual essentialism in biology. Biology \& Philosophy, 33(5-6): 39. doi: https://doi.org/10.1007/s10539-018-9651-1

Devitt, M. (2018b). Historical biological essentialism. Studies in History and Philosophy of Biological and Biomedical Sciences, 71:1-7. doi: https://doi.org/10.1016/j. shpsc.2018.05.004

Dumsday, T. (2017). Transhumanism, theological anthropology, and modern biological taxonomy. Zygon ${ }^{\circledR}, 52:$ 601-622. doi:10.1111/zygo.12346

Dumsday, T. (2012). A new argument for intrinsic biological essentialism. Philosophical Quarterly, 62: 486-504. doi: https://doi.org/10.1111/j.1467-9213.2012.00048.x

Ereshefsky, M. (2014). Species, historicity, and path dependency. Philosophy of Science, 81(5): 714-726. doi: $10.1086 / 677202$

Ereshefsky, M. (2010b). What's wrong with the new biological essentialism. Philosophy of Science, 77: 674-685. doi: 10.1086/656545

García-Carpintero, M. (1996). Superveniencia y determinación del contenido amplio. Revista de Filosofia, IX(16): 57-92.

Gavrilets, S. (2004). Fitness landscapes and the origin of species. Princeton: Princeton University Press.

Godfrey-Smith, P. (2009). Darwinian Populations and Natural Selection. Oxford: University Press.

Gould, S.J. (2004 [2002]). La estructura de la teoría de la evolución. Traducción de Ambrosio García Leal. Barcelona: Tusquets.

Hebert, P.D.N., Stoeckle, M., Zemlak, T., Francis, C. (2004). Identification of birds through DNA barcodes. PLoS Biol, 2(10): e312. doi: doi.org/10.1371/journal.pbio.0020312

Hebert, P.D.N., Hollingsworth, P.M, Hajibabaei, M. (2016). From writing to reading the encyclopedia of life. Phil. Trans. R. Soc. B, 371(1702): 20150321. doi: 10.1098/ rstb.2015.0321

Holmes, B. (2004). Barcode me. NewScientist, 182: 32-35.

Jones, G., Van Parijs, S. (1993). Bimodal echolocation in pipistrelle bats: are cryptic species present? Proc. R. Soc. Lond. Ser. B, 251: 119-125. doi: https://doi.org/10.1098/rspb.1993.0017

Kekkonen, M., Hebert, P. D. (2014). DNA barcode-based delineation of putative species: efficient start for taxonomic workflows. Mol Ecol Resour, 14: 706-715. doi:10.1111/17550998.12233

Kim, J. (1993). Supervenience as a philosophical concept. En Supervenience and Mind, pp. 131160. Cambridge: Cambridge University Press.

Kingston, T., Rossiter, S. (2004). Harmonic hopping in Wallacea's bats. Nature, 429(6992): 654657. doi: $10.1038 /$ nature 02487

Revista de Humanidades de Valparaíso, 2019, No 14, 75-89

(c) (1) 8 (을 BY-NC-ND 
Códigos de barras y esencias históricas: una crítica a la versión moderada del esencialismo biológico intrínseco Julio Torres Meléndez

Kitcher P. (2003 [1984]). Species. En P. Kitcher, Mendel's mirror: philosophical reflections on biology, pp. 113-134. New York: Oxford University Press.

Lee, M. (2004). The molecularisation of taxonomy. Invertebrate Systematics, 18(1): 1-6. doi: doi. org/10.1071/IS03021

Lenski, R., Travisano M. (1994). Dynamics of adaptation and diversification: a 10,000-generation experiment with bacterial populations. Proc Natl Acad Sci U S A, 91(15): 6808-14. doi: 10.1073/pnas.91.15.6808

Maynard Smith, J., Szathmary, E. (1995). The major transitions in evolution. Oxford: University Press.

Mayr, E. (1968 [1966]). Especies animales y evolución. Santiago de Chile-Barcelona: Universidad de Chile y Ariel.

Nosil, P. (2012). Ecological Speciation. Oxford University Press, Oxford.

Okasha, S. (2002). Darwinian Metaphysics: Species and The Question of Essentialism. Synthese, 131: 191-213. doi: 10.1023/A:1015731831011

Paz, A., González, M., Andrew, J. (2011). Códigos de barras de la vida: introducción y perspectivas. Acta biol. Colom., 16(3): 161-176.

Rubinoff, D., Cameron, S., Will, K. (2006). Are plant DNA barcodes a search for the Holy Grail? Trends in Ecology and Evolution, 21(1): P1-2. doi: 10.1016/j.tree.2005.10.019

Servedio, M.R, Van Doorn, G. S., Kopp, M., Frame, A. M., Nosil, P. (2011). Magic traits in speciation: 'magic' but not rare? Trends. Ecol. Evol., 26(8): 389-397. doi: 10.1016/j. tree.2011.04.005

Sober, E. (1980). Evolution, Population Thinking, and Essentialism. Philosophy of Science, 47: 350-383. doi: https://doi.org/10.1086/288942

Soler, M. (2003). Selección natural y adaptación. En M. Soler (ed.), Evolución. La base de la biología, pp. 127-157. Granada: Proyecto Sur de Ediciones.

Tahko, T. (2015). Natural Kind Essentialism Revisited. Mind, 124(495): 475-822. doi: 10.1093/ $\operatorname{mind} /$ fzv027

Veit, W. (2019). Evolution of multicellularity: cheating done right. Biology \& Philosophy, 34(3): 34. doi: https://doi.org/10.1007/s10539-019-9688-9

Walsh, D. (2006). Evolutionary Essentialism. The British Journal for the Philosophy of Science, 57(2): 425-448. doi: https://doi.org/10.1093/bjps/ax1001

Will, K.W., Mishler, B.D., Wheeler, Q.D. (2005). The perils of DNA barcoding and the need for integrative taxonomy. Syst Biol., 54(5): 844-51. doi: 10.1080/10635150500354878

Revista de Humanidades de Valparaíso, 2019, No 14, 75-89

(c) (1) $\mathrm{O}$ (을 BY-NC-ND 



\title{
Biología y guerra: una perspectiva pragmática*
}

\author{
Biology and war: a pragmatic perspective
}

\author{
Anna Estany \\ Departamento de Filosofía, Univesidad Autónoma Barcelona, España \\ anna.estany@uab.cat
}

\begin{abstract}
Resumen
Una aproximación a la filosofía de la biología en el siglo XXI requiere ir más allá de su vertiente epistemológica, apostando por los aspectos pragmáticos, en el sentido del impacto social de la instrumentalización de los desarrollos biológicos. Dichos avances tienen tanto consecuencias beneficiosas como perjudiciales para la humanidad. Entre las últimas, está su utilización para conflictos bélicos, como resultado de los avances en biotecnología. El objetivo de este trabajo es abordar el papel de los conocimientos biológicos en las guerras, analizando algunos casos especialmente relevantes como el bioterrorismo, pero también otro tipo de conflictos en los que la biología, entendida en sentido amplio con sus distintas ramas, juega un papel importante. En primer lugar, introduciré los conceptos más importantes en la relación entre biología y guerra, teniendo en cuenta los precedentes históricos en esta materia. En segundo lugar, a partir de que la biología entra con fuerza en los conflictos bélicos, abordaré el caso del bioterrorismo como uno de los problemas más acuciantes en tanto en cuanto es una de las formas que toma la guerra en la actualidad, así como una de sus derivadas, el "agroterrorismo", que consiste en provocar la destrucción de cosechas o la muerte de ganado que alimenta a la población. En este sentido, examinaré otras formas de dirimir los conflictos en los que factores biológicos juegan un papel importante a la hora de establecer el dominio entre dos o más naciones o poblaciones enfrentadas, prestando
\end{abstract}

\footnotetext{
*Este trabajo ha sido financiado por el Ministerio de Ciencia, Innovación y Universidades dentro del Subprograma Estatal de Generación del Conocimiento a través del proyecto de investigación FFI2017-85711-P Innovación epistémica: el caso de las ciencias biomédicas.

Este trabajo forma parte de la red de investigación consolidada Grupo de Estudios Humanísticos de Ciencia I Tecnología (GEHUCT), reconocida y financiada por la Generalitat de Catalunya, referencia 2017 SGR 568.
}

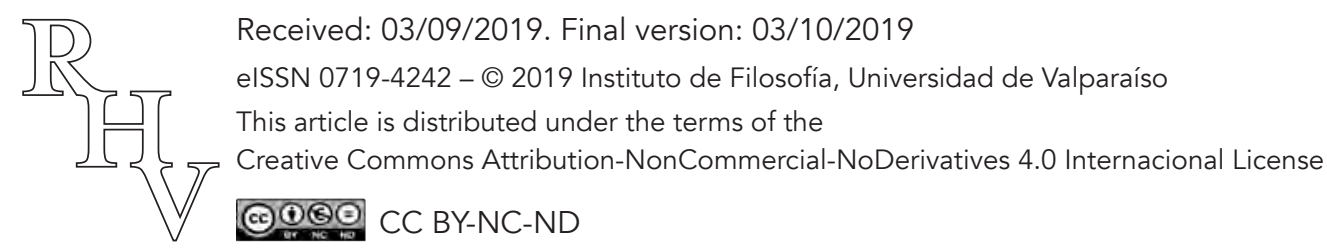


Biología y guerra: una perspectiva pragmática

Anna Estany

especial atención a la agricultura y a la ganadería. Respecto a los posibles modelos teóricos para analizar estos conflictos me centraré en la relación entre ciencia pura, aplicada y tecnología, los modelos metodológicos de las ciencias de diseño y la reflexión ética y moral.

Palabras clave: guerra biológica, bioterrorismo, agroterrorismo, ciencias de diseño, dilemas éticos.

\begin{abstract}
An approach to the philosophy of biology in the 21 st century requires going beyond its epistemological side, betting on pragmatic aspects, in the sense of the social impact of the instrumentalization of biological developments. These advances have both beneficial and harmful consequences for humanity. Among the latter, it is its use for military conflicts, as a result of advances in biotechnology. The objective of this work is to address the role of biological knowledge in wars, analyzing some especially relevant cases such as bioterrorism, but also other types of conflicts in which biology, broadly understood with its different branches, plays an important role. First, I will introduce the most important concepts in the relationship between biology and war, taking into account historical precedents in this area. Secondly, since biology enters in military conflicts, I will address the case of bioterrorism as one of the most pressing problems in that it is one of the forms that war is currently taking, as well as one of its derivatives, "agroterrorism", which consists in causing the destruction of crops or the death of livestock that feeds the population. In this regard, I will examine other ways of resolving conflicts in which biological factors play an important role in establishing dominance between two or more nations or populations facing each other, paying special attention to agriculture and livestock. Regarding the possible theoretical models to analyze these conflicts, I will focus on the relationship between pure, applied science and technology, the methodological models of design sciences and ethical and moral reflection.
\end{abstract}

Keywords: biological warfare, bioterrorism, agroterrorism, design sciences, ethical dilemmas.

\title{
1. Introducción
}

Una aproximación a la filosofía de la biología en el siglo XXI requiere ir más allá de su vertiente epistemológica, apostando por los aspectos pragmáticos, en el sentido del impacto social de la instrumentalización de los desarrollos biológicos, desde los insecticidas a los productos para engordar el ganado, entre otros muchos. Dichos avances tienen tanto consecuencias beneficiosas como perjudiciales para la humanidad. Entre las últimas, está su utilización para conflictos bélicos, que ha aumentado considerablemente en las últimas décadas como resultado de los avances en biotecnología. Sin embargo, la implicación en conflictos bélicos tiene más historia la física (bomba atómica) y la química (utilización de productos químicos tóxicos), siendo estudiadas y discutidas con más asiduidad que la 
intervención de la biología. En consecuencia, las discusiones sobre ciencia y tecnología suelen centrarse en estas disciplinas. Y lo mismo ocurre en los estudios sobre geopolítica y geoestrategia, como muestra el libro de Pedro Baños (2017) Así se domina el mundo. Desvelando las claves del poder mundial. Sin embargo, la biología ha entrado también a formar parte de los conflictos bélicos y militares y, en consecuencia, de los debates y contradicciones entre los propios científicos.

El objetivo de este trabajo es abordar el papel de los conocimientos biológicos en las guerras, analizando algunos casos especialmente relevantes como el bioterrorismo, pero también otro tipo de conflictos en los que la biología, entendida en sentido amplio con sus distintas ramas, juega un papel importante. En primer lugar, introduciré los conceptos más importantes en la relación entre biología y guerra, teniendo en cuenta los precedentes históricos en esta materia. En segundo lugar, a partir de que la biología entra con fuerza en los conflictos bélicos, abordaré el caso del bioterrorismo como uno de los problemas más acuciantes en tanto en cuanto es una de las formas que toma la guerra en la actualidad, así como una de sus derivadas, el "agroterrorismo", que consiste en provocar la destrucción de cosechas o la muerte de ganado que alimenta a la población. En este sentido, examinaré otras formas de dirimir los conflictos en los que factores biológicos juegan un papel importante a la hora de establecer el dominio entre dos o más naciones o poblaciones enfrentadas, prestando especial atención a la agricultura y a la ganadería.

Respecto a los posibles modelos teóricos para analizar este tipo de conflictos me centraré en la relación entre ciencia pura, aplicada y tecnología, en los modelos metodológicos de las ciencias de diseño y en la reflexión ética y moral. En el caso de la ética, hay que decir que el campo de la bioética ha sido muy desarrollado actualmente, aunque - fundamentalmente - se ha limitado a las cuestiones de salud a través de los comités de bioética en los hospitales. Aunque también tiene un papel importante en los centros de investigación en los que se utilizan animales a fin de que se cumpla la normativa que atiende a su bienestar. La propuesta que presento frente a la cuestión de biología y guerra es la necesidad de introducir la reflexión moral y ética en el análisis de los conflictos internacionales, para lo cual es imprescindible que los comités que vayan a intervenir en dichos conflictos sean inter-trans-multidisciplinares a fin de abordar el conflicto desde los diversos elementos que intervienen en la guerra biológica, especialmente acuciante en el caso del bioterrorismo, pero no menos importante para las situaciones de hambruna provocadas por la destrucción de la producción agrícola y ganadera.

\section{Ciencia y guerra: una perspectiva histórica}

Seguramente para ser más precisos habría que hablar de "conocimiento y guerra", en el sentido de que determinados conocimientos que no corresponden a nuestro concepto de ciencia actual fueron utilizados como armas para ganar la guerra. Por ejemplo, en el mundo antiguo pudieron usar cadáveres y restos de animales para contaminar las aguas. 
Los persas, griegos y romanos de la antigüedad envenenaban los pozos de sus enemigos arrojando dentro cadáveres. También en la conquista de América la llegada de los conquistadores tuvo como consecuencia la introducción de enfermedades euroasiáticas que eran nuevas en los territorios de América. Lo que no está probado es que Hernán Cortés y Pizarro llevaran deliberadamente las enfermedades para diezmar a los indígenas (García de los Ríos y Jiménez Gómez 2007, 10). También Julio Sotelo (2012) se refiere a los antecedentes históricos de las armas biológicas, remontándose al siglo XIV durante las invasiones tártaras a Crimea, en la ciudad de Kaffa, donde fragmentos de cadáveres de sujetos fallecidos por peste bubónica fueron arrojados por catapulta al interior de la ciudad en un intento por debilitar los efectivos de sus defensores. Los ingleses en el siglo XVII dieron intencionalmente cobijas impregnadas con secreciones de viruela a indios norteamericanos, cundiendo una incontenible epidemia de viruela que los diezmó con más efectividad que otra estrategia militar. Hay que decir que en esas épocas poco se sabía de las enfermedades infecciosas y se desconocían sus microscópicos agentes causales, ya que los microorganismos no fueron descubiertos hasta finales del siglo XVII y no se supo que causaban enfermedades infecciosas hasta finales del XIX. Por tanto, es difícil que anterior a estas fechas pudieran utilizarse conscientemente como armas biológicas. Eran conocimientos adquiridos por ensayo y error que se habían adquirido a través de la experiencia y que se utilizaban tanto para lo bueno (curar enfermedades) como para lo malo (la guerra).

Podemos decir que es en el siglo XX cuando estos conocimientos tienen una base científica en el sentido de conocer la causa y no solo la correlación. Este fenómeno plantea el debate de la relación entre ciencia y guerra, aunque no en todos los campos dicho debate ha aflorado de igual forma ni con la misma intensidad. En este sentido, hay que señalar que los agentes radiológicos (física) y químicos han sido los más estudiados, así como los debates correspondientes sobre la participación o neutralidad de los científicos en los conflictos bélicos. Esto no significa que la biología haya estado ausente de dichos conflictos que tuvieron lugar a lo largo del siglo XX, pero no cabe duda de que no han acaparado la misma atención que la química y, sobre todo, de la física. Wendy Barnaby (2002) señala que tras muchos decenios en los que apenas se les prestó atención, las Armas Biológicas (AB) han pasado a ser una prioridad en los planes internacionales de seguridad ${ }^{1}$.

Las dos guerras mundiales del siglo XX pusieron a prueba la difícil relación de los científicos con las empresas militares de sus países, en torno a la colaboración o neutralidad y las repercusiones para la investigación científica en sus respectivos campos. La literatura sobre armas radiológicas y químicas es abundante y los casos que se han analizado también, por lo que solamente con ofrecer un panorama de lo que han sido nos llevaría no solo a un artículo sino a un libro, como mínimo. Por tanto, los casos aportados son solo

${ }^{1}$ La participación de la biología en los conflictos bélicos la abordaremos ampliamente en el apartado 3. 
Biología y guerra: una perspectiva pragmática

Anna Estany

una pequeña muestra como ejemplos del debate en torno al papel y contradicciones de los científicos en la elaboración de dichas armas y en la colaboración con los estamentos militares de sus respectivos estados.

\subsection{El gas mostaza en la Primera Guerra Mundial}

Las primeras armas químicas se usaron en 1915 en los combates que tuvieron lugar en el frente occidental de la guerra. En 1860 el químico inglés Frederic Guthrie (18331886) sintetizó el gas mostaza, un arma de guerra química usada durante la Primera Guerra Mundial en julio de 1917 por los alemanes para impedir el ataque británico cerca de Ypern (Bélgica). El gas mostaza también se le conoce con el nombre de "Lost", por los descubridores alemanes (Lommel und Steinkopf) o "yperita", por el lugar donde se utilizó por vez primera. En 1919 se observaron - además de los efectos tóxicos sobre la piel y mucosas - una profunda leucopenia y aplasia del tejido linfoide en las personas expuestas al gas. Como consecuencia de esta barbarie, tras la gran guerra se procede a redactar el "Protocolo sobre la prohibición del uso en la guerra, de gases asfixiantes, tóxicos o similares y de medios bacteriológicos". Lo cual no significa que, por desgracia, no se volvieran a utilizar en otras guerras.

Como contrapunto y que ahonda en las paradojas con las que se enfrentan los científicos, el gas mostaza tiene un derivado en oftalmología. Con un medicamento derivado del gas mostaza desarrollado en la década de los años 20 y 30 del siglo XX, la mostaza nitrogenada, enfermos afectados de linfomas se trataron por primera vez con éxito en la Universidad de Yale (USA) en 1943. Su uso terapéutico en oftalmología lo introdujo un internista español, el Dr. Emilio Roda Pérez (1907-1983) en 1950, un hecho apenas conocido de la historia de la medicina y oftalmología española, que cuenta Antonio Bergua (2006).

\subsection{Armamento nuclear y Proyecto Manhattan}

El Proyecto Manhattan fue el nombre en clave de un proyecto científico llevado a cabo durante la Segunda Guerra Mundial por los Estados Unidos con ayuda parcial del Reino Unido y Canadá (Guerrero G. y Vega H. 2011). El objetivo final del proyecto era el desarrollo de la primera bomba atómica antes de que la Alemania nazi la consiguiera. La investigación científica fue dirigida por el físico Julius Robert Oppenheimer mientras que la seguridad y las operaciones militares corrían a cargo del general Leslie Richard Groves. El 9 de octubre de 1941, Roosevelt autoriza el desarrollo del arma atómica, dando comienzo al Proyecto Manhattan, que posteriormente se aceleraría de forma sustancial con la entrada de EE. UU. en la Segunda Guerra Mundial, hecho que ocurrió el 7 de diciembre de 1941, con el ataque de los japoneses a la costa hawaiana de Pearl Harbor. 
Biología y guerra: una perspectiva pragmática

Anna Estany

Como conclusión general, cabe destacar el Proyecto Manhattan como uno de los grandes hitos de la historia científica y armamentística ya que puso punto final a la Segunda Guerra Mundial con el bombardeo de Hiroshima y Nagasaki.

También es significativa la repercusión social que generó, ya que ocasionó miles de muertes. Además, la mayoría de las personas que participaron no conocían la finalidad del proyecto y, junto con muchos de los que sí la conocían, al ver la magnitud de dichos artefactos quedaron arrepentidos de haber participado y promovieron la no utilización de esas armas en el futuro. En cuanto a los afectados, las ciudades de Hiroshima y Nagasaki quedaron totalmente destruidas, no solo a nivel infraestructural sino a nivel poblacional, siendo significativa también la cantidad de radiación que afectaría en esas zonas durante años. A modo de reflexión personal, señalan Manuel Guerrero Giampaglia y Victoria Vega Hernández, "podemos destacar la falta de necesidad de los bombardeos ya que Japón estaba prácticamente rendida antes de que sucedieran. Además, opinamos que el hecho de que se crearan bombas atómicas "para crear la paz" supone un atraso del cual seguimos sufriendo las consecuencias actualmente" (Guerrero Giampaglia y Vega Hernández 2011, 26).

Ambos casos provocaron un debate muy interesante en torno al papel de los científicos en la guerra durante el siglo XX. Sánchez Ron (1995) examina distintas teorías sobre la guerra desde el punto de vista ético como la "concepción realista", según la cual la guerra está justificada cuando sirve al interés nacional y la "teoría de la guerra justa", según la cual la violencia nacional puede ser legítima siempre que pretenda servir fines justos y bien especificados y se rija por una serie de normas establecidas. Sánchez Ron también da cuenta de distintas manifestaciones de intelectuales, científicos, artistas, etc., por ejemplo, el manifiesto de 93 intelectuales alemanes "Llamamiento al mundo civilizado", a raíz de las repercusiones negativas que había tenido la invasión de Bélgica el 4 de octubre de 1914.

En el debate sobre ciencia y guerra son relevantes las reflexiones de Javier Ordóñez, catedrático emérito de lógica y filosofía de la ciencia, que expone en una entrevista el 12 de abril de 2019. A la pregunta de Empar Vengut Climent sobre si la relación entre los científicos y la guerra ha podido propiciar una imagen negativa de la ciencia, Javier Ordóñez responde:

Puede ser, pues es un hecho que la ciencia ha ayudado a la guerra [...] Me estoy refiriendo a las situaciones en las que el estado, como máxima autoridad social, es capaz de pedir a los científicos que dediquen sus esfuerzos a la fabricación de armas, como sucedió por ejemplo en el proyecto Manhattan. (Vengut Climent 2019)

Comenta también que esta inversión continuó durante la Guerra Fría y ejemplo de ello son las distintas generaciones de armas nucleares, en cuya construcción participaron 
Biología y guerra: una perspectiva pragmática

Anna Estany

algunos científicos relevantes reclutados por el estado para llevar a cabo el desarrollo armamentístico. Especialmente importante fue el apoyo a la física fundamental en Estados Unidos de América durante casi treinta años.

Un ejemplo de debate entre el papel de los científicos en la fabricación de armas lo expone el historiador de la física Finn Aaserud en el análisis de la actuación de la comunidad de físicos de Estados Unidos de América y el Ministerio de defensa. Aaserud en una conferencia pronunciada en la Universidad de California San Diego en 1993, titulada "In power or on tap? The making of JASON", analizaba la relación entre la comunidad de físicos y los organismos políticos y militares implicados en la Defensa de los EUA, después de la Segunda Guerra Mundial. Durante la misma, la comunidad de físicos adquirió considerables cotas de poder, dada la decisiva importancia de sus progresos científicos para el desarrollo de la guerra y la seguridad nacional de los EUA.

En la posguerra, en plena guerra fría, el lanzamiento del Sputnik el 4 de octubre de 1957 por los soviéticos creó la impresión de que la Unión Soviética iba muy por delante de los EUA en cuanto a ciencia y tecnología. La respuesta por parte de los EUA no se hizo esperar, y entre las iniciativas para recuperar la delantera científico-tecnológica está la de implicar a la comunidad de físicos, a fin de que se estableciera una estrecha colaboración entre ellos y el Ministerio de Defensa. Esto se plasmó en diversas propuestas surgidas de ambas partes para llegar a acuerdos concretos de colaboración. Uno de estos acuerdos fue el surgimiento de JASON, un proyecto que agrupaba a científicos alrededor del físico Charles Townes y que tenía como objetivo la estrecha cooperación de la comunidad científica con el Departamento de Defensa. Aaserud señala que la colaboración llegó hasta tal punto de que las líneas de investigación estaban determinadas por las necesidades de defensa, perdiendo así los físicos una buena parte de su autonomía y del predominio que habían tenido en épocas anteriores.

\section{La biología entra en guerra}

Como ya hemos indicado, la biología no quedó atrás en su papel relevante en los conflictos bélicos del siglo XX. Así empezó lo que se denomina "Guerra Biológica" (GB), como uso de organismos vivos o de sus productos para causar daños al enemigo (personas), a sus animales y a sus cosechas ${ }^{2}$. A pesar de que no tuvo la misma repercusión, como en el caso de la física y la química, en los debates ético-políticos sobre la participación de las comunidades científicas, hubo movimientos y manifiestos que cuestionaron este tipo de actividades por parte de los científicos biólogos. María Eneida de Albeida señala que "A lo largo del siglo XX hasta hoy se ha desarrollado un amplio campo de investigación tecnológica de la biología de guerra o biología militar, que trabaja en la invención y desa-

\footnotetext{
${ }^{2}$ Para las cuestiones más técnicas sobre bioterrorismo me he basado en García de los Ríos y Jiménez Gómez (2007).
}

Revista de Humanidades de Valparaíso, 2019, No 14, 91-116

(c) (1) 8 (을 BY-NC-ND 
rrollo de armas biológicas" (Almeida 2015, 2256). Por tanto, la biología es cada vez más importante en la biodefensa. Almeida considera que hay dos proyectos originales de "Big science", a saber: en el campo de la física el Proyecto Manhattan, con la construcción de la bomba atómica (1941); y en el campo de la biología el Proyecto del Genoma Humano para desentrañar el código genético de todos los seres vivos (1985).

Nieva Machin Osés (2010) observa cierta similitud bélica entre las armas biológicas recombinadas genéticamente y las nucleares. Ambas poseen un alto poder destructivo, sin embargo, las armas biológicas recombinadas genéticamente superarían en efectividad a las nucleares ya que éstas no atentarían contra las infraestructuras del país, sino que afectarían a la población humana, favoreciendo que el país agresor pudiera ocupar sin mayor obstáculo el área atacada siempre y cuando la población ocupante estuviera vacunada. Además, señala W. Barnaby (2002) que, empleadas en las mismas cantidades, las armas biológicas son mucho más mortíferas que las armas nucleares o las químicas y, además, son más baratas. Por tanto, podemos decir que en el siglo XX y, en concreto, en las dos guerras hubo utilización de armas biológicas pero quedaron eclipsadas por las químicas y radiológicas, al menos a nivel de repercusión social e informativa.

Así durante la Segunda Guerra Mundial se propusieron programas para la utilización de armas químicas y biológicas, tanto desde Japón como desde Alemania, aunque también los aliados llegaron a desarrollar un programa como posible respuesta a ataques biológicos por parte de Alemania, que nunca se produjo. Las investigaciones sobre AB llevadas a cabo por Gran Bretaña, Estados Unidos y Canadá estuvieron estrechamente conectadas hasta mucho después de la segunda guerra mundial. Y lo mismo podemos decir de los países como Alemania, la Unión Soviética, Japón y Sudáfrica de los que hay información de las investigaciones y experimentos en AB (Barnaby 2002, caps. 5 y 6).

El principio de la guerra fría y la guerra de Corea supuso la proliferación de armas biológicas, tanto por parte de la URSS como de la administración norteamericana. Entre las revelaciones de los tránsfugas y el posterior reconocimiento oficial, la Unión Soviética debió poseer la mayor producción y acumulación de armas biológicas que ningún país haya tenido jamás, incluyendo carbunco, viruela, peste, muermo, encefalitis equina venezolana, virus de Marburg, toxinas de varios tipos, etc., así como los medios para su dispersión (García de los Ríos y Jiménez Gómez 2007, 22). Un caso especial de análisis de guerra biológica es el bioterrorismo por ser uno de los de mayor impacto social y político a nivel mundial. El bioterrorismo es la liberación de bacterias, virus o toxinas con el propósito de causar daños a la población civil.

\subsection{Bioterrorismo y agroterrorismo}

La relación de los microorganismos con las enfermedades infecciosas fue estudiada de forma exhaustiva por la escuela francesa de Louis Pasteur y la alemana de Robert Koch. 
Biología y guerra: una perspectiva pragmática

Anna Estany

A los microorganismos causantes de las enfermedades infecciosas se los define como microorganismos patógenos y su relación con la enfermedad es la virulencia, que es el grado de patogenicidad. Entre los factores de virulencia que poseen los microorganismos destacan las toxinas producidas por las bacterias. De todas las vías de transmisión, la que siempre se ha buscado, por parte de los que están enfrentados en una guerra, ha sido la inhalación, ya que todos necesitamos respirar varias veces por minuto (García de los Ríos y Jiménez Gómez 2007, 48). Y esto tanto para las armas biológicas como para las químicas. Entre las características de un arma biológica ideal, entendida como eficiente para destruir al enemigo, pueden señalarse las siguientes: ser altamente incapacitante, ser fácil de obtener en grandes cantidades, ser fácil de introducir en armas, ser difícil de detectar al menos en los primeros momentos y con gran impacto en la salud pública, causando pánico y alarma social.

García de los Ríos y Jiménez Gómez clasifican los agentes biológicos de uso en el bioterrorismo en A, B y C con las características siguientes:

Categoría A: fácilmente diseminados o transmitidos de persona a persona, con altas tasas de mortalidad, con gran impacto en la salud pública, causantes de pánico y alarma social, y que requieren preparación especial de la Salud Pública. Entre estos agentes están la viruela, el carbunco, la peste, la tularemia y la toxina botulínica.

Categoría B: moderadamente fáciles de diseminar, con moderada morbilidad y bajas tasas de mortandad, que requieren el aumento de la capacidad de los centros de diagnóstico e incremento de vigilancia. En esta categoría están la salmonella, el cólera, las fiebres de Malta y el muermo.

Categoría $\mathrm{C}$ : se trata de patógenos emergentes que pueden ser manipulados para diseminación en masa en el futuro, debido a su disponibilidad, facilidad de producción y diseminación, así como potenciales tasas elevadas de morbilidad y mortandad. Por ejemplo, el virus Nipah causa de una encefalitis transmitida a partir de cerdos; y los hantavirus causantes de un síndrome pulmonar relacionado con roedores.

García de los Ríos y Jiménez Gómez $(2007,191)$ califican a los agentes víricos bioterroristas como el enemigo invisible por sus especiales características. A diferencia de las bacterias, los virus suelen ser organismos más difícilmente cultivables pero también más peligrosos. Este hecho es la razón por la que los gobiernos deben invertir en laboratorios de vigilancia donde equipos de profesionales mantienen sus puestos de vigías. Estos autores señalan que no conviene bajar la guardia, ya que relajar nuestro nivel de control puede facilitar un ataque bioterrorista y traernos consecuencias fatales.

Entre los virus que producen enfermedades y que, en algún grado, pueden ser objeto de bioterrorismo están los siguientes. Por un lado, las enfermedades agrupadas en torno a las fiebres hemorrágicas virales, como el ébola y la fiebre amarilla. Y, por otro, las incluidas 
en algún tipo de encefalitis: afección de los hemisferios cerebrales, tronco del encéfalo o cerebelo por un proceso infeccioso. Su causa es una patología de etiología viral: encefalitis equina venezolana (EEV) y encefalitis equina del este (EEE)/Occidental (EED) ${ }^{3}$.

Una derivada del bioterrorismo es el "agroterrorismo". Alberto Cique Moya $(2017,3)$ señala que "a lo largo de todos los tiempos la mayoría de los conflictos han sido, y serán en última instancia, por dominar los recursos hídricos y alimentarios". Por lo que "la mayoría de los programas biológicos iniciados en el siglo XX incluyen líneas de investigación específicas para conseguir agentes biológicos que afectaran a las cosechas y a los animales". Moya considera que:

[...] en este punto es importante resaltar desde un punto de vista conceptual que si a los que utilizan agentes biológicos contra las personas se les denomina bioterroristas, a los que usan, o están dispuestos a utilizar o a amenazar con su empleo, agentes biológicos contra la ganadería y la agricultura tendríamos que denominarlos agroterroristas (el objetivo último son las personas pero a través de un daño indirecto porque los primeros afectados serían las plantas o los animales). (Moya 2017, 8)

Según Moya,

[...] el agroterrorismo plantea menores retos para alcanzar la capacidad operacional de diseminación, pudiendo pasar desapercibido su uso hasta que los efectos sean devastadores. De igual forma, el agroterrorismo plantea menores dilemas éticos que el bioterrorismo al ser las consecuencias fundamentalmente económicas, considerándose que la sola amenaza de empleo tendrá efectos directos sobre la sociedad en su conjunto. (Moya 2017, 1)

Hay otra cuestión importante y distintiva de la GB que tiene que ver con la dificultad para detectar si un estado está desarrollando y desplegando armas biológicas. En el caso de las armas nucleares es relativamente sencillo, pero las $\mathrm{AB}$ son distintas y por ello no es fácil detectar si un estado las está desarrollando, o simplemente es para defenderse de posibles ataques.

Las bacterias y los virus que emplean se producen exactamente igual que los utilizados en la medicina legítima para vacunas y antibióticos. Los microorganismos con los que se fabrican las $\mathrm{AB}$ se producen con el mismo equipamiento que se encuentra en las empresas farmacéuticas, los laboratorios universitarios de biología, las fábricas de cerveza, las destilerías, las fábricas de leche, los laboratorios de diagnóstico y las instalaciones para producir vacunas. Es por ello que el equipamiento que puede emplearse tanto para fines militares como civiles se le denomina "de doble uso" y su existencia constituye uno de los mayores obstáculos para el control eficaz del desarrollo de AB (Barnaby 2002, 63).

\footnotetext{
${ }^{3}$ Para una explicación técnica de estas enfermedades, ver García de los Ríos y Jiménez Gómez (2007, cap. VII).
} 
Nos podemos preguntar qué nos depara el futuro respecto al bioterrorismo. Hacer predicciones siempre es arriesgado y más en esta cuestión. Las armas biológicas estarán siempre a punto para ser utilizadas, como cualquier otro tipo de arma. No cabe duda que, como señalan García de los Ríos y Jiménez Gómez, las llamadas para terminar definitivamente con las armas biológicas, su desarrollo y su almacenamiento están partiendo de todos los organismos internacionales, como ocurre con otros tipos de armas o como rezan los acuerdos para el caso de guerras con el trato de prisioneros, etc. Otra cosa es hasta qué punto se cumple, aunque no hay otras formas de proceder para paliar el lado malo de la investigación científica. De hecho, los descubrimientos científicos, originalmente no han sido pensados para producir el mal, aunque pueden luego ser reconducidos a este fin. La responsabilidad no sería del que descubre algo que después puede ser mal empleado, sino de los que desarrollaron un proceso para hacer daño. Y aquí volvemos al papel de los científicos en las guerras y en las contradicciones y responsabilidades morales y éticas con las que pueden encontrarse.

\section{Los nuevos derroteros de las guerras biológicas}

Los conflictos actuales en el marco de la geopolítica y geoestrategia se dirimen no solo militarmente, aunque también, sino que las formas de ejercer el poder y el dominio sobre otros países van más allá de las armas convencionales. La literatura sobre estas cuestiones es amplia por lo que vamos a centrarnos en algunos de los textos que son especialmente representativos, como es el caso del estudio sobre geopolítica y geoestrategia de Pedro Baños (2017). El acento, una vez más, está en el papel de tecnología con base en la física en primer lugar y en la química, sin apenas referencias explícitas a la biología, al menos en este estudio de Baños. No hay que olvidar que la biotecnología se ha puesto al servicio de la agricultura, para bien pero también para mal, ya que puede convertirse en una forma de agroterrorismo. Siguiendo con la relación de la tecnología y la economía Baños señala:

Respecto a los aspectos tecnológicos, la clave actual de la pugna económica es el dominio de la innovación en ciencia y tecnología. Quien no invierta en estos aspectos fundamentales debe tener claro que se convertirá en el futuro esclavo tecnológico de los países más desarrollados. (Baños 2007, 45)

Respecto al papel de la economía Pascal Lorot y François Thual afirman que la actualidad geopolítica está caracterizada por la marginación relativa del factor militar-estratégico en beneficio del económico y por la búsqueda de la potencia económica como objetivo estratégico central de los gobiernos occidentales desarrollados (Baños 2007, 63). Además del factor económico están lo que Baños denomina "armas de comunicación masiva", el ciberespacio como campo de batalla, la guerra jurídica y la religión como arma de guerra. Todos estos factores actualmente han adquirido un papel clave en la capacidad de dominio geoestratégico y geopolítico. 
En el marco de la guerra económica está el control de la producción agrícola planetaria. Baños señala que el mercado mundial del grano, cereales y leguminosas está prácticamente dominado en su totalidad por cuatro grandes corporaciones: ADM (estadounidense), Bunge (de origen brasileño con sede en Estados Unidos), Cargill (estadounidense) y Dreyfus (de origen francés y asentada en Holanda), conocidas como las ABCD. Directamente o a través de empresas subsidiarias, tienen la capacidad de establecer a escala mundial los precios de alimentos tan básicos como el arroz, el maíz, el trigo o la soja. (Baños 2007, 69). Teniendo en cuenta la importancia de los cereales como base de la alimentación, es comprensible la lucha por el dominio en este campo. Baños aporta una cita de Henry Kissinger muy significativa de la importancia de la agricultura en el dominio geopolítico. Dice así: "Controla los alimentos y controlarás a la gente; controla el petróleo y controlarás a las naciones; controla el dinero y controlarás el mundo".

Vemos pues que el papel de la economía tiene derivadas en la agricultura por lo que bien puede relacionarse con los seres vivos y su papel en la riqueza y pobreza de los territorios y, en consecuencia, con el dominio y el poder ejercido por una nación sobre otra. A partir de esta premisa entran en juego algunas ramas de la biología, como la botánica y la zoología, a través de las cuales la relación entre biología y guerra queda patente. Según la RAE, la biología es la ciencia que trata de los seres vivos considerando su estructura, funcionamiento, evolución, distribución y relaciones. A veces se habla de ciencias biológicas como un concepto más amplio pero ligado a "lo bio" en el sentido de vida. Y aquí entrarían campos como la biología marina, la botánica, la zoología, etc. De todos estos campos vamos a centrarnos en la botánica y en la zoología por su papel relevante en los ejemplos que constituyen armas para dirimir conflictos.

La botánica es la rama de la biología que estudia los vegetales a todos los niveles: descripción, clasificación, distribución, funcionamiento, reproducción (Portela 2016). Para el objetivo de este trabajo es relevante la distinción entre botánica pura y aplicada, como indica Portela (2016):

La botánica pura se encarga del estudio de los vegetales como ciencia básica y la botánica aplicada estudia los vegetales para su explotación comercial, ya sea forestal, farmacéutica, alimentaria, etc. [...] Los vegetales, especialmente los cereales y las legumbres, son la base de la alimentación humana, de ahí la gran importancia que se dio a su investigación ya desde la antigüedad.

Portela señala que la botánica tiene importantes usos en el día a día, estudiando compuestos presentes en los vegetales y que se utilizan para desarrollar medicamentos, desde el ácido salicílico (que se emplea en las aspirinas y ya era conocido por civilizaciones antiguas, que consumían corteza de abedul para beneficiarse de esta substancia) a la morfina o la cafeína. De hecho, la selección de semillas y la hibridación entre variedades botánicas se han utilizado desde los albores de la agricultura para mejorar los cultivos, con espectaculares resultados. Por ejemplo, algunas especies silvestres como el maíz o 
Biología y guerra: una perspectiva pragmática

Anna Estany

el trigo resultan difícilmente comestibles, por lo que hizo falta un proceso de selección para que las plantas produjeran granos cada vez mayores. Para Portela (2016), "la botánica es una ciencia fascinante con numerosas aplicaciones para nuestra sociedad y está relacionada con otras ramas de la biología como la ecología, la taxonomía, la genética o la bioquímica".

La zoología, como rama de la biología, se dedica al estudio de los animales. La palabra

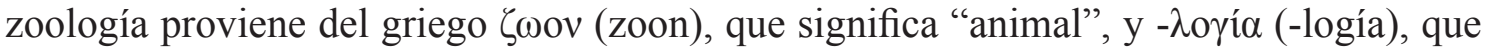
traduce "estudio" o "ciencia". El principal objetivo de la zoología es el examen de la descripción morfológica y anatómica de las diversas especies animales: su reproducción, desarrollo, comportamiento y distribución. Para el tema de este trabajo es especialmente relevante la zoología aplicada que se encarga del estudio de los animales con resultados económicos o prácticos. En este sentido, la zootecnia trata de la cría y multiplicación de los animales, así como de la producción de sus derivados, como la leche, teniendo en cuenta el bienestar del animal.

Como en la mayoría de los casos las aplicaciones de los conocimientos científicos comportan beneficios en muchos ámbitos de la sociedad pero también pueden utilizarse para perjudicar tanto al medio ambiente como a colectivos y naciones que se quiere destruir o dominar. En una palabra, puede constituir un arma de guerra. Vamos a examinar algunos de estos casos en que ramas de la biología como la botánica y la zoología, en ambos casos aplicadas, han sido utilizadas como arma de guerra, directa o indirectamente. Los casos que señalamos a continuación son fruto de conflictos, algunos enmarcados en lo bélico y militar, pero las consecuencias agropecuarias no son consecuencias de las armas biológicas sino de políticas y ataques militares, que ocasionan perjuicios muy serios para cosechas y ganado y, en último término, para los habitantes de determinadas regiones.

\subsection{Las "guerras" del campo: COAG"}

La Coordinadora de Organizaciones de Agricultores y Ganaderos (COAG) tiene su referente histórico más remoto en las movilizaciones campesinas que se produjeron a finales de la década de los 60 y principios de los 70. En aquellos años las reivindicaciones se relacionaban fundamentalmente con los precios agrarios. Era el tiempo de las "guerras" del pimiento, del maíz, de la leche, de la patata, etc.

La experiencia asociativa que supusieron estos movimientos espontáneos sirvió para que en los últimos años del régimen franquista se crease un embrión de lo que sería durante la transición la configuración de lo que más tarde sería la COAG. Los agricultores

\footnotetext{
${ }^{4}$ https://www.centroestudioscervantinos.es/ramas-de-la-biologia/

${ }^{5}$ http://www.coag.org/
} 
Biología y guerra: una perspectiva pragmática

Anna Estany

que participaron en aquellas protestas y reivindicaciones por los precios descubrieron su propia capacidad organizativa y la escasa o nula representatividad de las llamadas entonces "Hermandades Sindicales de Labradores y Ganaderos".

Las Uniones recién creadas no defendían ya una mera cuestión coyuntural como fueron las "guerras" por los precios, que pasan a un segundo plano, sino que ahora se plantean y reivindican un modelo productivo para el campo basado en la Explotación Familiar Agraria (EFA), así como la defensa del Agricultor a Título Principal (ATP).

El entrecomillado de guerra es de la propia organización COAG, ya que son conscientes de su utilización como analogía o metáfora de los conflictos bélicos. Pero, tal como hemos indicado, los conflictos no se dirimen solo militarmente, aunque las consecuencias pueden ser también muy perjudiciales, cuando no destructivas, de las poblaciones implicadas en dichos conflictos. En el caso de las denominadas "guerras del campo" se juega la supervivencia y bienestar de las poblaciones afectadas, pero también el abastecimiento alimenticio del conjunto de la sociedad.

\subsection{El papel de la agricultura y la ganadería en el conflicto entre Palestina e Israel}

El conflicto entre Palestina e Israel se juega, aunque no sólo, en el dominio de los productos agrícolas y ganaderos. Digo que "no sólo" porque tiene una baza muy importante en lo militar, pero incluso las acciones militares tienen consecuencias inevitables en la agricultura y en la ganadería. Esta circunstancia en la que convergen lo bélico y lo agroganadero hace que este caso sea muy ilustrativo del carácter multifactorial de los conflictos de nuestra época. El texto "Cultivando injusticia: El comercio internacional con las compañías agrícolas israelíes y la destrucción de la agricultura palestina", publicado por organizaciones agrícolas y de la sociedad civil palestina en febrero del 2013, da cuenta de ello.

Para los palestinos, la agricultura es mucho más que la producción de olivos, cítricos y otros productos frescos o la cría de ganado. La agricultura está ligada a la identidad del pueblo palestino, a su historia y a la resistencia a la ocupación ilegal israelí. La soberanía alimentaria ha sido definida por los campesinos internacionales del movimiento Via Campesina como sigue:

La soberanía alimentaria es el derecho de los pueblos a definir su propia alimentación y su propia agricultura; a proteger y regular su producción agrícola doméstica y a negociarla para lograr objetivos de desarrollo sostenible; a determinar la extensión de lo que ellos quieren para ser autosuficientes; a restringir el "dumping" de productos en sus mercados;

\footnotetext{
${ }^{6}$ https://www.stopthewall.org/sites/default/files/Injusticia\%20Agricola.pdf_
} 
Biología y guerra: una perspectiva pragmática

Anna Estany

y a dar a las comunidades de base de los pescadores locales la prioridad del control del uso y los derechos de sus recursos acuáticos. (Organizaciones agrícolas y de la sociedad civil palestina 2013,5)

Esta soberanía se ve cuestionada por las acciones de Israel sobre Palestina. Entre los datos que nos ofrecen las organizaciones agrícolas podemos destacar las que afectan a las cosechas, a la pesca, al agua y al comercio internacional.

\subsubsection{Cosechas}

- En mayo del 2009 las tropas israelíes incendiaron las cosechas palestinas a lo largo de la frontera de Gaza con Israel. Fueron destruidas más de 200.000 metros cuadrados de cosechas, incluyendo trigo y cebada que ya estaban listas para recolectar, así como frutas y verduras, olivos y granados.

- Las repetidas ofensivas militares israelíes contra Gaza y sus años de asedio han llevado a una caída dramática en el número de palestinos empleados allí en el sector agrícola, reduciendo la producción y los ingresos de los granjeros palestinos, dejando al 80\% de los palestinos en Gaza dependientes de la ayuda alimentaria ${ }^{7}$.

- La destrucción de los medios de vida palestinos y la negación de suministros y bienes esenciales a los granjeros de Gaza son herramientas usadas conscientemente por los que diseñan las políticas israelíes. Un alto funcionario israelí describía la política israelí en Gaza diciendo que "la idea" es "poner a los palestinos a dieta, pero no hacerlos morir de hambre". El gobierno israelí calculó el número mínimo de calorías que necesitan los 1.500.000 habitantes de Gaza para evitar la malnutrición y esos números fueron usados para determinar la cantidad de comida que se permitirá entrar cada día ${ }^{8}$. A pesar de ello muchos granjeros palestinos continúan cuidando sus tierras agrícolas en partes de las zonas de defensa a pesar del gran riesgo de muerte o de heridas graves.

\footnotetext{
${ }^{7}$ La referencia que ofrecen para esta información es: Israel reduce el suministro de trigo a la Franja de Gaza: La seguridad alimentaria en Gaza en gran riesgo mientras continua el asedio israelí (2010). Centro Al Mezan para los Derechos Humanos. Obtenido de http://www.mezan.org/en/details.php?id=11120\&ddname $=\&$ id_dept $=9 \& p=$ center

${ }^{8}$ La referencia que ofrecen para esta información es: Cook, J. (2012). Israel's starvation diet for Gaza. 8. The Electronic Intifada. Obtenido de http://electronicintifada.net/content/israels-starvation-diet-gaza/11810.
} 


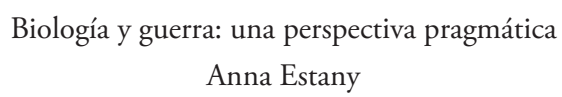

- Los olivos juegan un papel importante muy especial en la economía palestina y en la identidad palestina en general. Israel por otra parte es muy consciente de eso; el ejército israelí y los colonos fanáticos conjuntamente han desarraigado, quemado y destruido cerca de 1.500 .000 olivos desde el $2001^{9}$.

Una consecuencia del decaimiento de la agricultura es que, como la zona de tierra disponible para las granjas se encoge, los palestinos que quieren trabajar en la agricultura están obligados a moverse a las zonas urbanas para trabajar, lo que al mismo tiempo reduce el tamaño de las comunidades agrícolas y el número de palestinos con conocimientos y experiencia en las faenas agrícolas.

\subsubsection{Pesca}

Israel también ha aplicado un área de defensa naval. A pesar de los Acuerdos de Oslo que declaran que los palestinos tienen el derecho de pescar hasta las 20 millas náuticas de la costa de Gaza, Israel impuso un límite de tres millas en junio del $2007^{10}$. Dado que están obligados a pescar en esas aguas tan poco profundas, los pescadores palestinos solo pueden pescar principalmente peces pequeños que han sido contaminados por la salida inadecuada de las instalaciones de tratamiento de aguas residuales.

\subsubsection{Agua}

Cisjordania es muy rica en recursos acuíferos, pero Israel ilegalmente controla todas las fuentes de agua en Cisjordania, incluyendo el Río Jordán, y saca casi el 90 por ciento anualmente del agua necesaria de sus ricos acuíferos, dejando a los granjeros palestinos con un chorrito ${ }^{11}$. Amnistía Internacional ha acusado a Israel de privar a los palestinos de su acceso al agua "como un medio de expulsión"12.

La zona del Valle del Jordán tiene unos 2,400 km2, y está ubicada el Este de Cisjordania, ocupando el $28.5 \%$ de su área. Con su clima favorable, tierra fértil y un buen suministro de agua, el Valle del Jordán es la principal zona agrícola de Cisjordania y en total forma los territorios palestinos ocupados.

\footnotetext{
${ }^{9}$ La referencia que ofrecen para esta información es: One Million Trees Campaign (MTC) II, http://29. apnature.org/en/content/one-million-trees-campaign-mtc-ii.

${ }^{10}$ La referencia que ofrecen para esta información es: PCHR 19. 2011 Annual Report. (2011). Palestinian Centre for Human Rights, p. 29.

${ }^{11}$ La referencia que ofrecen para esta información es: Assessment of Restrictions on Palestinian Water Sector. Development. (2009). World Bank.

${ }^{12}$ La referencia que ofrecen para esta información es: Troubled waters: Palestinians denied fair access to water 34 (2009). Amnesty International.
} 
Biología y guerra: una perspectiva pragmática

Anna Estany

\subsubsection{Comercio internacional}

Las compañías agrícolas israelíes como Mehadrin y Hadiklaim participan en la colonización de la tierra palestina y de sus recursos y se aprovechan del continuado asedio a Gaza. Están entre los primeros beneficiados de la destrucción de la agricultura palestina. A los productores palestinos a veces no les queda más opción que exportar a través de las compañías exportadoras israelíes, que a veces etiquetan los productos palestinos como "Hecho en Israel".

El conflicto continúa y las denuncias a acciones de Israel que afectan a la agricultura también. Así lo explica Juan Carlos Sanz en un reportaje sobre "La 'guerra herbicida' de Israel arrasa cultivos en Gaza" el 21 de julio de 2019 en El País. Una investigación constata que las fumigaciones ordenadas por el Ejército israelí afectan al enclave palestino. El perímetro interior de la frontera de la franja de Gaza con Israel se ha convertido en un terreno yermo donde los francotiradores militares pueden hacer blanco con facilidad. El Ejército ha ordenado 30 fumigaciones aéreas con agentes herbicidas en los últimos cinco años. En el reportaje se alude a Arquitectura Forense - una agencia multidisciplinar asentada en Londres que recurre a técnicas arquitectónicas, legales y de los peritos forensesque reconstruye en el informe "La guerra de herbicidas en Gaza" la destrucción sufrida en tierras cultivables y cosechas, así como los daños potenciales que se derivan para la salud humana, en la franja costera. Las concentraciones de productos químicos tóxicos superan los niveles permitidos por la Unión Europea, y uno de los pesticidas utilizados contiene glifosato, sospechoso de ser cancerígeno según la Organización Mundial de la Salud. Tenemos un caso de convergencia de armas químicas y consecuencias en al campo de la botánica y de la salud. Podríamos decir que intervienen las ciencias biomédicas como consecuencia de los conocimientos químicos.

Como apuntamos al principio en el conflicto entre Palestina e Israel confluyen desde el militar hasta el comercial. El dominio de Israel sobre Palestina se ejerce atacando la soberanía alimenticia que afecta a la agricultura, la ganadería y la pesca, con consecuencias comerciales y, en último término, económicas.

\subsection{Corea y Japón}

Baños aporta un caso muy relevante para comprender un nuevo episodio de la guerra económico-agrícola. Durante el siglo XIX, Corea era un "reino ermitaño", contrario a establecer relaciones diplomáticas y comerciales con los países occidentales. Corea prefería mantener una alianza con una China que también pugnaba por librarse de la injerencia occidental. La primera guerra chino-japonesa (1894-1895) fue motivada principalmente por el dominio de Corea, alzándose Tokio con la victoria. En 1897, el emperador Gojong proclamó el Gran Imperio de Corea, que significaba dejar de ser el apéndice de China que llevaba siendo desde 1636. 
Biología y guerra: una perspectiva pragmática

Anna Estany

Japón, convertida en potencia industrial, se anexionó el Imperio de Corea en 1910 para explotarlo económicamente. El gobierno nipón promovió la llegada a la península coreana de agricultores y pescadores japoneses, a los que hacía entrega gratuita de tierras o se las vendía a un precio simbólico. Mientras los coreanos pasaban hambre, los japoneses se llevaban la mayor parte de las cosechas de arroz para alimentar a su propia población. Los japoneses consideraban a los coreanos como étnicamente inferiores y no se reprimieron a la hora de aplicar sobre ellos las mayores crueldades (Baños 2007, 81).

Durante la Segunda Guerra Mundial, aunque los datos varían según las fuentes, las cifras son escalofriantes. En los tres años de guerra se pudieron lanzar unas 650.000 toneladas de bombas sobre Corea del Norte. (....) Cuando se acabaron los objetivos urbanos, comenzaron a bombardear pantanos y presas, lo que provocó la inundación de granjas y destruyó las cosechas. En comparación, Estados Unidos arrojó más toneladas de bombas en Corea del Norte que en todo el Pacífico durante la Segunda Guerra Mundial, y se destruyeron más ciudades que en Alemania o Japón. Una guerra que empezó militarmente con conocimientos, fundamentalmente, de la física, la química y la tecnología, terminó con consecuencias muy graves para la agricultura y la ganadería.

\section{5. ¿Podemos hablar de una filosofía de la guerra?}

La filosofía se genera como consecuencia de la capacidad recursiva del Homo Sapiens. Así podemos pintar un cuadro, escribir una novela o construir una teoría y al mismo tiempo reflexionar sobre ello y así hasta el infinito. Al menos teóricamente la capacidad recursiva del ser humano no tiene límites, aunque luego los filósofos delimiten sus niveles de reflexión (Estany 2006). Desde este punto de vista la filosofía sería un saber adjetivo, no sustantivo, es decir, "filosofía de". Así tenemos la ética, la estética, la filosofía política y la filosofía de la ciencia como reflexiones sobre sistemas morales, estéticos, políticos y científicos, respectivamente.

Hay que aclarar que la filosofía no es la única actividad que se sitúa en este segundo nivel de conceptualización, la musicología, las distintas críticas (literaria, de arte etc.) o los comentaristas (deportivos, de modas etc.) son otras actividades de segundo orden. Ninguna de estas funciones supone la habilidad en la actividad que se está analizando: así pues un musicólogo no necesariamente toca algún instrumento, ni un crítico literario escribe novelas. Pero sí necesita tener conocimiento del objeto que está analizando, por ejemplo, un musicólogo tiene que saber leer una partitura y un crítico literario saber cuál es la estructura de una novela. El filósofo de la ciencia no tiene por qué ejercer de científico: toma los productos científicos para analizarlos. Conclusión, no solamente podemos hablar de filosofía de la guerra, sino que es uno de los retos de la filosofía en el mundo actual. 
Biología y guerra: una perspectiva pragmática

Anna Estany

La filosofía de la ciencia a lo largo del siglo XX ha estado centrada en el análisis de las ciencias puras, cuyo objetivo es la descripción y explicación del mundo natural y social. Sin embargo, en la actualidad y, muy especialmente, después de la II Guerra Mundial, la imbricación entre ciencia y tecnología y la importancia de la ciencia aplicada ha hecho emerger una serie de campos disciplinares como las ingenierías, la medicina, las ciencias de la información y de la educación, etc., dando lugar a las denominadas "ciencias de diseño", entre las que estaría la ciencia de la guerra. No cabe duda de que estas reflexiones suponen una distinción entre ciencia pura y ciencia aplicada y entre ciencia y tecnología, que algunos filósofos, sociólogos y científicos cuestionan. Por ejemplo, Javier Echeverría (2003) introduce en sus propuestas la idea de "tecnociencia", como campo de interrelación entre ciencia y tecnología (Estany 2005). Sobre esta cuestión podemos decir que, a pesar de que en la práctica la ciencia y su aplicación interaccionan, conceptualmente no solo pueden distinguirse, sino que no hacerlo lleva a la confusión a la hora de tomar decisiones en las que la ciencia tiene un papel relevante.

La conclusión de estas primeras consideraciones sobre el papel de la filosofía en el análisis de las cuestiones sobre la biología aplicada en todas sus ramas va tomando cuerpo. A veces, en la comunidad filosófica, pero no solo, se plantea la muerte de la filosofía que podría ser sustituida por la ciencia y la tecnología, pero si entendemos el hacer filosófico como una reflexión sobre cualquier actividad intelectual, la muerte de la filosofía solo se produciría por la extinción de la humanidad. Lo que hay son nuevos retos, nuevas formas de abordarlos, pero así como la ausencia de planes para una persona individual significa el fin de la vida también aquí el fin de la filosofía sería el fin de la capacidad recursiva como humanos.

Una vez constatada la relevancia de la filosofía vamos a centrarnos en aquellas cuestiones que mejor nos pueden iluminar en el tema central de este trabajo, a saber: la relación entre ciencia y guerra desde la vertiente pragmática de la biología. Como modelos teóricos para abordar dichas cuestiones vamos a analizar la relación entre ciencia pura y aplicada, en el marco de las ciencias de diseño y sus correspondientes metodologías. Finalmente, veremos lo que la ética puede aportar a un fenómeno tan complejo como importante para la humanidad.

\subsection{Ciencia pura y aplicada}

La distinción entre ciencia pura y aplicada, así como entre ciencia y tecnología ha sido motivo de debate en filosofía de la ciencia. De forma especial el papel relevante de lo que se ha denominado "big science", en el sentido de la ciencia que requiere de grandes infraestructuras para poder llevarse a cabo, desde tecnológicas hasta las organizativas y financieras. En este sentido, son interesantes las reflexiones de Nils Roll-Hansen (2009, 8) quien señala que "Esta ambigüedad genera debates confusos, por ejemplo en relación con los niveles adecuados de financiación o de utilidad social de la inversión en la in- 
Biología y guerra: una perspectiva pragmática

Anna Estany

vestigación científica $\mathrm{y}$, finalmente, se toman decisiones poco adecuadas". Y añade lo siguiente: "Parece difícil negar que había una diferencia "moralmente significativa" entre la investigación de Hahn-Meitner sobre la reacción en cadena del uranio 236 y el proyecto Manhattan de la construcción de una bomba atómica" (Roll-Hansen 2009, 26). Por el contrario, marcar las diferencias puede reportar clarificación para la política de la ciencia, ya que "estas diferencias podrían mejorar las posibilidades de desarrollar una política de la ciencia para servir a la sociedad en su conjunto y no solo a los intereses particulares de determinados grupos, ya sean empresas privadas, movimientos políticos, religiones particulares, la comunidad científica, u otros" (Roll-Hansen 2009, 2; Estany y Herrera 2016, cap. 1). Aplicado a la investigación en el campo de la biología esta distinción es sumamente relevante por el doble uso que puede hacerse de los agentes biológicos y la frágil línea que separa el desarme versus el desarrollo o la defensa versus la ofensa.

Una de las posibles razones de porqué se cuestiona la distinción entre ciencia pura y aplicada es por la imbricación que en la actualidad existe entre la investigación básica, la utilización de ésta por las ciencias de diseño y la construcción de artefactos (tecnología) para cambiar la realidad. Esta interrelación no es un fenómeno estrictamente nuevo pero sí lo es la celeridad con la que se produce. M. Kranzberg, historiador de la tecnología, señala en "The unity of science-technology" (1967) que pasaron 1700 años desde que la máquina de vapor fuera diseñada en Alejandría hasta que Watt la hizo funcionar, el principio de fotografía tardó en llevarse a la práctica 200 años desde que fue esquematizado por Leonardo, el motor eléctrico tardó 40 años, la energía nuclear 5 años, el transistor 5 años, los plásticos transparentes 2 años y los rayos láser 18 meses. Esto, dice Kranzberg, apoya la tesis de que la asociación de la ciencia (que quiere saber el "porqué") y la tecnología (que quiere saber el "cómo") produce una reacción en cadena de descubrimiento científico e invención tecnológica. Podemos concluir que entre ciencia pura y aplicada y tecnología hay convergencia en la práctica, pero diferencias conceptuales importantes.

\subsection{Las ciencias de diseño}

Las "ciencias de diseño", denominadas así por H. Simon (1996) y analizadas desde la filosofía por I. Niiniluoto (1993), son el resultado de la cientificación y mecanización de las artes en el sentido de habilidades para resolver problemas prácticos. Las ingenierías, la medicina y las ciencias de la educación y las de la información son ejemplos de este tipo de disciplinas. Consideramos que las propuestas de Simon y Niiniluoto constituyen marcos teóricos idóneos para una aproximación racionalista a la perspectiva pragmática de la ciencia y, en concreto, a lo que podemos denominar "filosofía de la guerra".

Simon (1996) señala que el modelo tradicional de ciencia ofrece una imagen engañosa de campos como la ingeniería, medicina, arquitectura, economía, educación, etc., que están interesadas en el "diseño", en el sentido de propósito o meta a conseguir, es decir, no tienen como objetivo saber cómo son las cosas sino cómo tienen que ser para

Revista de Humanidades de Valparaíso, 2019, No 14, 91-116

(c) (1) 8 (을 CC BY-NC-ND 
conseguir determinados fines. A esta lista de ciencias de diseño podemos añadir la ciencia de la guerra. Niiniluoto, a partir de las ideas centrales de Simon, distingue entre ciencias descriptivas, ciencias de diseño y tecnología. Las primeras nos dicen cómo es el mundo, las segundas qué debemos hacer para transformarlo y la tecnología es el instrumento para esta transformación.

Desde el campo de las ciencias aplicadas se ha cuestionado la metodología clásica de la ciencia porque no encaja con su forma de proceder. Así, el método científico estándar, consiste en poner a prueba una hipótesis y si ésta se confirma a través de una prueba experimental se añade al conocimiento existente hasta que haya contraejemplos que la cuestionen. Sin embargo, el diseño de cualquier artefacto, proyecto, etc. es más complejo, siendo el resultado de dos entradas, la científica y la no técnica o de reconocimiento de las necesidades. La entrada científica incluye el conocimiento existente relevante para el diseño de lo que queramos producir. En el reconocimiento de la necesidad están implícitos los factores socioeconómicos para los que los valores contextuales son relevantes para los objetivos propuestos. Sin embargo, las necesidades no son inocuas, sino que tienen consecuencias y favorecen a colectivos distintos. Cualquier decisión supondrá progreso en algún aspecto, pero será percibido de forma distinta por los diversos sectores de la sociedad.

En el caso de la guerra biológica, por un lado, tendríamos los factores científicos que serían los conocimientos aportados por la biología, desde la biología molecular hasta la botánica y la zoología; por el otro, los factores contextuales, desde los geopolíticos a los económicos, serían los objetivos que se pretende alcanzar. Y en el caso de las armas biológicas habría de considerar desde los terapéuticos hasta los defensivos y ofensivos. El diseño final sería el resultado de la conjunción de todos estos factores. Cuáles priorizar o hacer prevalecer tendrá que ver con valores no solo científicos sino ético-morales, que es la siguiente cuestión que nos podemos plantear desde la reflexión filosófica.

\subsection{Dilemas éticos de la investigación biológica}

Los dilemas éticos no son exclusivos de la investigación en biología, pero sí que es especialmente relevante por el hecho de que la mayoría son de doble uso. También tienen usos distintos la investigación en física y en química, pero en biología la línea está más difuminada. El caso de la comunidad de físicos y el ministerio de defensa de los EUA, al que nos hemos referido en el apartado 2, analizado por Finn Assaraud es una muestra de estas contradicciones. Para la biología, vamos a referirnos a un caso descrito por Wendy Barnaby ${ }^{13}$ que muestra dichas contradicciones y nos da elementos para la reflexión ética.

\footnotetext{
${ }^{13}$ Este caso está ampliamente explicado en Barnaby (2002, cap. 10).
} 
Biología y guerra: una perspectiva pragmática

Anna Estany

En 1996 un doctorando de la Facultad de Medicina de Illinois acudió al catedrático de Política y Ética Sanitarias Marc Lappe para consultarle un dilema que se le había planteado. El joven se había especializado en biología marina. Era una autoridad en las propiedades de la saxitoxina, una de las sustancias más tóxicas que se conocen. Producida por las algas, la saxitoxina puede ser letal para quienes ingieren marisco contaminado. En su forma purificada, puede matar a una persona en quince minutos si se le introduce en el cuerpo mediante un proyectil.

El establecimiento de Fort Detrick, Maryland, donde en aquel momento se llevaba a cabo una investigación ofensiva y defensiva sobre la GB, había ofrecido una beca posdoctoral al joven científico. Éste consultó al profesor Lappe si debía aceptar. Sabía que en los laboratorios de Fost Detrick encontraría la mejor infraestructura posible para realizar sus investigaciones, consistente en estudiar las consecuencias de la ingestión de saxitoxina. Pero le preocupaba la posibilidad de que parte de su trabajo se incorporase al programa ofensivo. ¿Debía aceptar la beca?

El profesor Lappe argumenta (Smith 1996, 2) que el joven no debería haber aceptado la beca. Aunque su propósito fuera mejorar un problema que afectaba a la salud pública, sabía que quienes le financiaban los estudios se dedicaban a la investigación bélica y que, por tanto, sus resultados podrían emplearse para fines bélicos. Imaginar que no se es responsable de los fines a los que otros aplican tu trabajo, dice Lappe, es "basarse en la premisa de que el conocimiento científico es moralmente neutro y de que los eventuales usos que se le den no pueden ser averiguados ni por el más avisado de los investigadores" (Smith 1996, 49).

Robert L. Sinsheimer, catedrático de biología de la Universidad de California, Santa Bárbara, también ha explicado elocuentemente porqué las responsabilidades de los científicos son mayores. Las armas biológicas, afirma Sinsheimer, "representan una perversión de los mayores logros acumulados a lo largo de las generaciones en el campo del esfuerzo y el conocimiento científicos. Su utilización despojaría de sentido a las vidas de los científicos de todos los tiempos" (citado por Barnaby 2002, 197). A pesar de estas consideraciones de algunos científicos, según Barnaby, son pocos los científicos en activo a quienes les interesan estos asuntos. Muchos piensan que la GB es un asunto periférico, sobre todo ahora que se debe consagrar tanto tiempo a conseguir fondos para las investigaciones y que, por el hecho de ser científico no se sienten responsables de advertir de los peligros de los nuevos avances de educar al público.

Barnaby también hace referencia a la bióloga celular Sue Mayer que en 1988 daba clases en la Escuela de Ciencias Veterinarias de la Universidad de Bristol. Uno de sus colegas estaba a punto de aceptar fondos del Ministerio de Defensa para llevar a cabo una investigación. Sue Meyer explicó los motivos porqué ella y varios de sus compañeros se oponían a aceptar dichos fondos. Meyer trabajaba con un equipo denominado "Grupo Aerobiología", cuyo objeto de estudio eran los caballos ya que es un buen modelo para

Revista de Humanidades de Valparaíso, 2019, No 14, 91-116

(c) (1) 8 (을 CC BY-NC-ND 
extrapolarlo a los humanos. Algunos compañeros estaban estudiando lo que sucede cuando se inhalan microorganismos y cómo provocan las enfermedades, así como la manera de determinar qué dosis resulta infecciosa. Y ésta era la investigación que interesaba al Ministerio de Defensa, a fin de conocer el funcionamiento de los pulmones y la manera en que se operaba ese proceso de reparación, y así saber cuántos microorganismos son necesarios para provocar una enfermedad. Evidentemente, comprender cómo los pulmones reparan los daños subletales también sería útil para propósitos civiles. Por ejemplo, en lo relacionado con la higiene del aire, ya que se puede creer que no hay bacterias infecciosas en el aire cuando en realidad sí las hay. Averiguarlo sería de gran ayuda, pongamos por caso, en la sala de infecciosos de un hospital o en un establo.

Por el hecho de que esta investigación la financiara el Ministerio de Defensa, generaba a Sue Meyer y a su equipo una cierta desconfianza. De hecho, el Ministerio de Defensa solo estaba autorizado a investigar en cuestiones de defensa, pero se tenía miedo de que esta investigación no fuera a utilizarse para una GB. Al final la investigación se llevó a cabo, pero Meyer se opuso y dejó la Universidad ya que las autoridades académicas aceptaron llevar a cabo esta investigación financiada por el Ministerio de Defensa. Barnaby cuenta que Meyer se convirtió en directora científica de Greepeace.

\subsection{1 ¿Qué hacer?}

Los dilemas éticos respecto a la ciencia interpelan, de manera especial, a los científicos pero no podemos descargar sobre ellos toda la responsabilidad. Actualmente, la difusión de los conocimientos científicos ha crecido considerablemente y también los colectivos que desean que se tenga en cuenta su opinión, por tanto, es la sociedad en su conjunto que tiene que intervenir en las políticas científicas diseñadas por los gobiernos. Los nuevos retos de la ciencia nos atañen a todos.

Una de las cuestiones es bajo qué criterios podemos tomar una decisión como la que se enfrentaron el doctorando de la Facultad de Medicina de Illinois y Sue Mayer como responsable del proyecto de investigación del Grupo Aerobiología. Como en cualquier dilema ético, soluciones salomónicas no existen y entrar a juzgar moralmente decisiones personales nos adentramos en un terreno resbaladizo que plantea nuevos dilemas de hasta qué punto podemos intervenir en las decisiones personales de otros. Hay otro elemento que forma parte esencial de la investigación en biología y es el doble uso de dichas investigaciones, lo cual complica la decisión y su moralidad. El caso de Sue Mayer es una muestra de ello.

Como proyección de futuro para abordar la responsabilidad como sociedad podemos apuntar algunas propuestas, posiblemente todas necesarias pero ninguna suficiente. Una mayor concienciación de la sociedad de las posibilidades positivas y negativas de una misma investigación científica y, en consecuencia, mayor responsabilidad de cada uno de 
Biología y guerra: una perspectiva pragmática

Anna Estany

nosotros. Es necesario que esta participación se institucionalice, como se ha hecho en el caso de los comités de bioética en los hospitales y en los laboratorios que investigan con animales. Esto significa que debería haber comités de ética en todas las etapas del proceso de investigación, desde el laboratorio hasta sus aplicaciones. Todo ello tanto a nivel nacional como internacional. La educación y la difusión de la ciencia no debe ser ajena a los dilemas éticos que hemos planteado. Todo este entramado daría más confianza a los jóvenes doctorandos a la hora de decidir si aceptan determinado tipo de investigación. La fuente de financiación es importante pero no puede centrarse solo en el Ministerio de Defensa, al menos mientras no haya una desmilitarización universal. El fomento de la cultura de la paz tiene que ser el telón de fondo de la perspectiva ética de la ciencia.

\section{Conclusiones}

El papel de la biología en la guerra y en los conflictos, sean o no militares, ha sido cada vez más importante a lo largo del siglo XX y continua en la actualidad.

Es cada vez más relevante la intervención de distintas ramas de la biología como la botánica y la zoología, ambas aplicadas, por su implicación en la soberanía alimenticia que puede provocar hambruna, con lo cual constituye un arma de guerra, aunque no militar. Es lo que se ha denominado "agroterrorismo".

Las especiales características de las armas biológicas hacen que puedan ser accesibles por grupos terroristas fuera de cualquier tipo de control político y de acuerdo que pueda ser un freno en la utilización de estas armas.

Aunque con un cierto retraso respecto a la física y a la química, la biología también ha entrado en el debate sobre el papel de los científicos y su colaboración con los estamentos militares en los conflictos bélicos. Uno de los factores, aunque no el único, que hace especialmente difícil la reflexión sobre la responsabilidad de los biólogos en la investigación en este campo es el doble uso de la mayor parte de los proyectos que se llevan a cabo. La línea que separa lo que puede ser defensa de lo que es ofensiva no siempre está meridianamente clara.

A pesar de ello, la reflexión filosófica sobre estos temas puede ayudar a esclarecer algunas de las cuestiones más espinosas. En este sentido, la distinción conceptual entre ciencia pura y aplicada a la vez que su convergencia en la práctica ayuda a dirimir cuestiones complejas respecto a la responsabilidad en el campo político de la ciencia. Como modelos teóricos para la ciencia aplicada, la idea de ciencias de diseño y sus correspondientes metodologías constituyen formas de filosofía aplicada.

En cuanto a la responsabilidad de los científicos en la guerra, la ética puede abrir caminos a fin de paliar las posibles consecuencias más destructivas de la investigación científica. Como dijimos al principio, la reflexión ética se ha institucionalizado en el ámbito de la salud a través de comités de bioética en muchos centros hospitalarios y en

Revista de Humanidades de Valparaiso, 2019, No 14, 91-116

(c) (1) 8 을 BY-NC-ND 


$$
\begin{gathered}
\text { Biología y guerra: una perspectiva pragmática } \\
\text { Anna Estany }
\end{gathered}
$$

los laboratorios que trabajan con animales a fin de que se respeten las normas que velan por su bienestar. Es hora de que estos comités se instalen en todas las instancias políticas nacionales e internacionales que establecen las reglas de juego en los conflictos y toman decisiones que afectan a personas inmersas en dichos conflictos.

\section{Referencias bibliográficas}

Almeida, M. E. de (2015). A permanente relação entre biologia, poder e guerra: o uso dual do desenvolvimento biotecnológico. Ciência saúde coletiva, 20(7): 2255-2266.

Aznar Fernández-Montesinos, F. (2014). Filosofía de la guerra. Arbor, 190(765): a096. doi: http:// dx.doi.org/10.3989/arbor.2014.765n1003

Baños, P. (2017.) Así se domina el mundo. Desvelando las claves del poder mundial. Barcelona: Planeta.

Barnaby, W. (2002). Fabricantes de epidemias. El mundo secreto de la guerra biológica. Madrid: Siglo XXI.

Bergua, A. (2006). El uso pionero de la mostaza nitrogenada por Emilio Roda Pérez en el tratamiento de las uveítis idiopáticas. Archivos de la Sociedad Española de Oftalmología, 81: 557-562.

Coordinadora de Organizaciones de Agricultores y Ganaderos (COAG). http://www.coag.org

Echeverría, J. (2003). La revolución tecnocientífica. Madrid: FCE.

Estany, A. (2005). Progress and social impact in design sciences. En W. González (ed.), Science, Technology and Society: A Philosophical Perspective. A Coruña: Netbiblo.

Estany, A. (2006). Introducción a la filosofía de la ciencia. Cerdanyola del Vallés: Edicions Universitat Autónoma Barcelona.

Estany, A., Herrera, R. M. (2016). Innovación en el saber teórico y práctico. Londres: College Publications.

García de los Ríos, J. E., Jiménez Gómez, P. A. (2007). Hablemos de bioterrorismo. Madrid: Pearson Alhambra.

Guerrero Giampaglia, M., Vega Hernández, V. (2011). El proyecto Manhattan. Tecnología nuclear. Retrieved from: http://laplace.us.es/wiki/images/1/10/Trabajo26m.pdf

Kranzberg, M. (1967). The unity of science-technology. American Scientist, 55(1): 48-66.

Kranzberg, M. (1968). The disunity of science-technology. American Scientist, 56(1): 21-34.

Machín Osés, N. (2010). Las armas biológicas: Perspectivas de futuro. Comentario UNISCI, No 86. Retrieved from: https://www.ucm.es/data/cont/media/www/pag-72542/86MACHIN. pdf 


$$
\begin{gathered}
\text { Biología y guerra: una perspectiva pragmática } \\
\text { Anna Estany }
\end{gathered}
$$

Moya, A. C. (2017). Preparación y respuesta frente al agroterrorismo. Instituto Español de Estudios Estratégicos, No 50. Retrieved from: http://www.ieee.es/Galerias/fichero/docs opinion/2017/DIEEEO50-2017_Agroterrorismo_CiqueMoya.pdf

Niiniluoto, I. (1993). The aim and structure of applied research. Erkenntnis, 38: 1-21.

Organizaciones agrícolas y de la sociedad civil palestina (2013). Cultivando Injusticia. El comercio internacional con las compañías agrícolas israelíes y la destrucción de la agricultura palestina. Retrieved from: https://www.stopthewall.org/sites/default/files/Injusticia\%20 Agricola.pdf

Portela, R. (2016). ¿Qué es la botánica? Retrieved from: https://cienciaybiologia.com/ramas-dela-biologia-botanica/

Roll-Hansen, N. (2009). Why the distinction between basic (theoretical) and applied (practical) research is important in the politics of science. Technical Report (London School of Economics and Political Science. Centre for the Philosophy of the Natural and Social Sciences), No 4/9. London: London School of Economics and Political Science, Contingency and Dissent in Science Project.

Sánchez Ron, J. M. (1995). Ciencia, científicos y guerra en el siglo XX: algunas cuestiones éticomorales. Isegoría, 12: 119-136.

Simon, H. (1996). The science of the artificial. Cambridge, Massachusetts: The MIT Press.

Smith, J. E. (1996). Biotechnology. Cambridge: Cambridge University Press.

Sotelo, J. (2012). Las armas biológicas en tiempos de guerra. Revista Anexos, 415: 94-97.

Vengut Climent, E. (2019). Entrevista a Javier Ordóñez: Las guerras siempre empiezan con palabras. Revista online Mètode. Retrieved from: https://metode.es/noticias/entrevistas/ entrevista-a-javier-ordonez.html 


\title{
En el principio era la mano: Ernst Kapp y la relación entre máquina y organismo
}

\author{
In the beginning was the hand: Ernst Kapp and the relation between \\ machine and organism
}

\author{
Maurizio Esposito \\ Universidade Federal do ABC, Brasil / Universidad de Santiago de Chile, Chile \\ maurizio.esposito@ufabc.edu.br
}

\begin{abstract}
Resumen
La relación entre organismos y máquinas es muy antigua. Hace más de un siglo, el filósofo e historiador francés Alfred Victor Espinas señalaba que ya para los griegos la inteligibilidad de lo orgánico suponía una comparación con el mundo de la técnica. Aristóteles, por ejemplo, equiparaba los órganos con los artefactos mecánicos para entender el movimiento de los animales. En el período moderno, Descartes, Borelli y otros mecanicistas defendieron la idea que los organismos eran máquinas. Hoy en día, no faltan filósofos y científicos que consideran al genoma como un programa informático y al cerebro como un computador. En este artículo, pretendo reconsiderar la relación entre organismos y máquinas a partir de propuesta de un autor todavía poco conocido: el filósofo y geógrafo alemán Ernst Kapp (1808-1896), unos de los padres fundadores de la Filosofía de la Técnica y la Tecnología. Rompiendo con una larga tradición filosófica, Kapp defiende la idea que las máquinas son, en realidad, "proyecciones orgánicas". Los organismos no son máquinas, sino que, por el contrario, las máquinas son una imitación o reflejo del mundo orgánico. En primer lugar, aclararé la hipótesis de la proyección orgánica (así como sus alcances y límites), y, en segundo lugar, exploraré algunas de las consecuencias filosóficas de dicha hipótesis respecto al debate actual entre mecanicistas y anti-mecanicistas. Finalmente, defenderé la importancia de un acercamiento entre la Filosofía de la Tecnología y la Bio-filosofía para mejor entender el desarrollo de la Biología contemporánea.
\end{abstract}

Palabras clave: mecanismo, organismo, máquina, filosofía de la biología, filosofía de la tecnología.

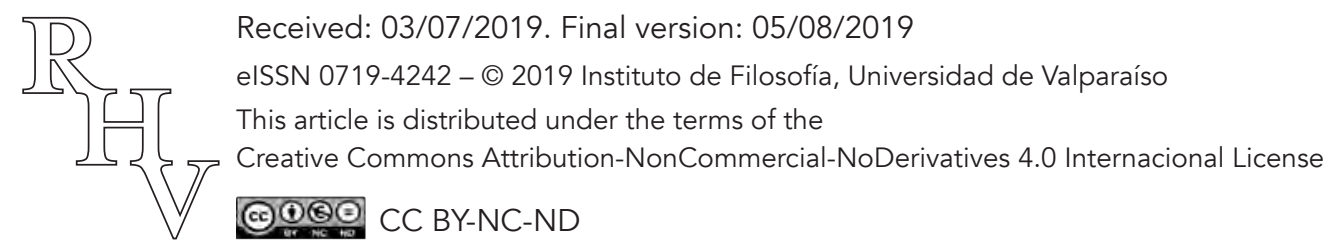


En el principio era la mano: Ernst Kapp y la relación entre máquina y organismo Maurizio Esposito

\begin{abstract}
The relation between organisms and machines is very old. Over a century ago, the French historian and philosopher Alfred Victor Espinas observed that from the Greeks onwards the intelligibility of the organic world presupposed a comparison with technical objects. Aristotle, for instance, associated living organs with mechanical artefacts in order to understand animals 'movements. In the modern period, Descartes, Borelli and other mechanists defended the idea that organisms are, in reality, machines. Today, philosophers and scientists still argue that the genome is like a software and the brain is like a computer. In this article I reconsider the relation between organisms and machines from the perspective of the German geographer and philosopher Ernst Kapp (1808-1896), one of the founding fathers of the Philosophy of Technology. Breaking with a long and venerable philosophical tradition, Kapp argued that machines are, in reality, "organic projections". Organisms are not machines; they are an imitation or reflection of the organic world. First of all, I clarify the hypothesis of "organic projection" (including its virtues and limits). Secondly, I consider some of the philosophical consequences that such a hypothesis entails over the debate between machinists and anti-mechanists. Finally, and following the previous considerations, I defend the importance of reconnecting the philosophy of technology with philosophy of biology in order to better understand the development of contemporary biology.
\end{abstract}

Keywords: mechanism, organism, machine, philosophy of biology, philosophy of technology.

\title{
1. Introducción
}

¿Qué es un organismo? ¿Qué es una máquina? Parece que no podemos responder a la primera pregunta sin considerar a la segunda. El filósofo e historiador francés Alfred Victor Espinas señalo que ya para los griegos la inteligibilidad de lo orgánico suponía la comparación con el mundo de la técnica. La ambigüedad de la palabra ópyavov - la cual denotaba ambos instrumentos artificiales o partes de un organismo - atestigua esta antigua afinidad. Aristóteles, por ejemplo, equiparaba los órganos a las máquinas estableciendo una conexión productiva entre la comprensión de los movimientos de los animales y los artefactos mecánicos (Espinas 1897; 1903). Además, en su tratado sobre el alma (Пعрì $\Psi v \chi \tilde{\eta} \varsigma$ ), Aristóteles consideraba los cuerpos vivos (soma organikon) como un conjunto de instrumentos (órganos) para el alma. ${ }^{1}$ Si bien los griegos establecieron un lazo significativo entre entidades biológicas y objetos técnicos, es solo en el periodo moderno que la relación entre máquinas y organismos se vuelve un problema filosóficamente urgente. Con René Descartes, Giovanni Borelli o Julien Offray de la Mettrie, así como también con los varios artesanos e ingenieros como Jacques de Vaucanson o Pierre Jaquet-Droz,

\footnotetext{
1 "Todos los cuerpos naturales, en efecto, son órganos del alma tanto los de los animales como los de las plantas [...]", 2.4.415b18 (Aristóteles 2003).
}

Revista de Humanidades de Valparaíso, 2019, No 14, 117-138

(ㄷ)(1)(8) CC BY-NC-ND 
En el principio era la mano: Ernst Kapp y la relación entre máquina y organismo Maurizio Esposito

la idea que pueda subsistir una continuidad profunda entre mundo vivo y artefactos se hizo muy persuasiva, aunque cuando la naturaleza especifica de dicha continuidad estaba lejos de ser clara (Duchesneau 1998; Wood 2002; Riskin 2007; Heudin 2008). Después de todo, ¿En qué sentido una máquina puede ser considerada una representación de una entidad orgánica? ¿Podemos decir que la máquina (autómata, reloj o herramienta) captura algunos elementos esenciales que caracterizan un organismo (ej. movimiento, fines, organización, etc.)? $\mathrm{O}$, ¿Que la máquina es una herramienta epistémico/instrumental que nos puede ayudar a comprender lo que es un ser orgánico en general $?^{2}$ Ahora, si consideramos la correlación entre artefactos mecánicos y organismos en su desenvolvimiento histórico, podemos rastrear por lo menos dos maneras fundamentales de compararlos $\mathrm{y}$, en la eventualidad, contrastarlos. La primera manera es la que llamo "mecanocéntrica" y la segunda es la que denomino tentativamente "organocéntrica".

Sin duda, la relación "mecanocéntrica" ha sido históricamente la más importante. Desde los griegos hasta la filosofía moderna y contemporánea, la idea que los organismos se "parecen" a las máquinas es la postura que ha recibido gran parte de la atención. Con relación "mecanocéntrica" me refiero a la idea que la representación que tenemos de un organismo posee una relación isomorfamente aproximada a la representación que tenemos de una máquina. Desde una perspectiva estructural y funcional, podemos decir que un organismo es una máquina muy compleja y la diferencia entre el primero y la segunda es solo de grado y no de calidad. Por tanto, en el ámbito de la relación "mecanocéntrica", tenemos posturas mecanicistas o anti-mecanicistas dependiendo si se enfatizan o restan los parecidos entre máquinas y seres vivos. A diferencia de la primera, la relación "organocéntrica" ha raramente suscitado un interés parecido, con la excepción de algunos notables autores que mencionaré en el presente artículo. Este tipo de relación parte de un presupuesto muy distinto respecto a la manera "mecanocéntrica", es decir, los organismos son máquinas solo en la medida que estas últimas imitan a los primeros. En otras palabras, la máquina, o los varios tipos de mecanismos artificiales son, en realidad, una proyección o extensión del mundo biológico. Los organismos, por tanto, no pueden ser considerados como máquinas porque estas últimas son un derivado mimético del mundo orgánico. En términos un poco más esquemáticos, podemos decir que de acuerdo a la relación "mecanocéntrica", el dominio de lo mecánico incluye el subconjunto de lo orgánico. Por el contrario, en la relación "organocéntrica" el dominio de las máquinas es un subconjunto del dominio del mundo orgánico en cuanto el organismo es el prototipo o modelo de cualquier máquina. En el primer caso, entonces, los organismos son, en verdad, máquinas o algo parecido. En el segundo caso las máquinas son, en principio, reducibles al mundo orgánico.

Quizás sorprenda que no haya muchos autores que exploraron seriamente esta segunda opción. Entre los más importantes, el más reciente es el filósofo francés Canguilhem y el

\footnotetext{
${ }^{2}$ Para un análisis filosófico más profundo relacionado a estas preguntas, ver Nicholson 2012.
} 
En el principio era la mano: Ernst Kapp y la relación entre máquina y organismo Maurizio Esposito

más antiguo es el geógrafo alemán Ernst Kapp. Canguilhem, dedica un breve y muy profundo ensayo al asunto: Machines et Organisme. En este ensayo, Canguilhem observaba que, en realidad, era la noción de organismo a definir la de mecanismo y no lo contrario: En enfatizando la ambigüedad esencial, y al mismo tiempo reveladora, del concepto griego de ópyavov, Canguilhem concluía aristotélicamente que las: "Herramientas y máquinas son órganos y los órganos son herramientas y máquinas" (1952). Por supuesto, Canguilhem retomó esta idea de interconexión entre tecnología y organismo desde Espinas y Espinas, a su vez, la había tomada de Ernst Kapp. ${ }^{3}$ Este último anticipó la hipótesis del origen orgánico de las máquinas en su magnus opus, Grundlinien einer Philosophie der Technik (Elementos de Filosofía de la Técnica), publicada en $1877^{4}$, unos de los primeros libros filosóficos dedicados al fenómeno de la técnica y tecnología.

En el presente artículo pretendo hacer tres cosas: en primer lugar, aclarar en la mejor manera posible la relación "organocéntrica" entre máquinas y organismos reconsiderando y analizando el trabajo de Kapp de 1877. En segundo lugar, explorar algunas de las consecuencias filosóficas que dicha relación implica examinando las siguientes preguntas: si las máquinas son una proyección e imitación de lo orgánico, como Kapp sostenía, ¿Qué pasa con la dicotomía tradicional mecanicismo/ anti-mecanicismo? Además, ¿cómo y en qué sentido un artefacto puede entregar conocimientos sobre entidades orgánicas? En tercer lugar, pretendo señalar algunos puntos de conexiones estratégicos entre la Filosofía de la biología y Filosofía de la tecnología y sugerir que, si aceptamos la hipótesis "organocéntrica", podemos llegar a la siguiente conclusión: los organismos son ontológicamente distintos de las máquinas y, sin embargo, éstas nos proporcionan conocimientos validos sobre diferentes aspectos del mundo orgánico. Esto significa que podemos ser ontológicamente escépticos respecto a la identidad entre organismo y máquina $\mathrm{y}$, al mismo tiempo, ser confiados sobre al valor epistémico de las máquinas para conocer los fenómenos biológicos. En suma, la hipótesis de la proyección orgánica (relación organocéntrica) —la cual es el resultado de una conjunción eficaz entre bio-filosofía y tecno-filosofía - nos permite defender una postura anti-mecanicista a un nivel ontológico y mecanicista a un nivel epistémico.

\footnotetext{
${ }^{3}$ En los años que siguieron la publicación de Machines et Organisme, un estudiante de Canguilhem que desarrolló en forma extensa la relación entre técnica y organismo, Gilbert Simondon, solo considera a los trabajos de Espinas por medio de Canguilhem mientras que la fuente original se había en buena parte olvidado (Simondon 2012). De hecho, hay que considerar que, hasta donde alcanzo a conocer, la primera traducción en francés del opus magnus de Kapp, Grundlinien einer Philosophie der Technik, remonta a 2017 y la traducción en inglés es de 2018.

${ }^{4}$ Es cierto que a finales del siglo XIX y a lo largo del siglo XX las ideas "organocéntrica" se desarrollan en diferentes maneras de acuerdo a varios autores. Podemos recordar, entre otros y aparte Espinas y Canguilhem, el antropólogo Arnold Gehlen (1989), el filósofo José Ortega y Gasset (1965) e incluso el controversial historiador Oswald Spengler (2015). Un autor más reciente que reconsidera la tradición "órganocéntrica" es Hacking (1998).
}

Revista de Humanidades de Valparaíso, 2019, No 14, 117-138

(ㄷ)(1)임 CC BY-NC-ND 


$$
\begin{gathered}
\text { En el principio era la mano: Ernst Kapp y la relación entre máquina y organismo } \\
\text { Maurizio Esposito }
\end{gathered}
$$

\section{Desde los órganos a las máquinas}

Ernst Kapp nace en Ludwigstadt, Bavaria, en 1808. Tal como el filósofo de Trier, Karl Marx, Kapp es un asiduo lector de Hegel y se orienta hacia la corriente de la izquierda hegeliana. En principio Kapp estudia filología clásica en la Universidad de Bonn. Luego se dedica a desarrollar un materialismo filosófico dirigido a integrar la nueva disciplina de la geografía (que Carl Ritter había fundado en la Universidad de Berlín) con la historia humana. En particular, Kapp es interesado a como el medio ambiente pueda plasmar y fomentar distintas formaciones socio-culturales (Mitcham 1994). En 1849, como consecuencia de un proceso por sedición relacionado a la publicación de un ensayo ${ }^{5}$ en contras del despotismo político, Kapp escapa en los Estados Unidos. Llega en Sisterdale, una pequeña colonia alemana en Texas. El ambiente de la frontera estadunidense, junto a su actividad de agricultor, fomenta su interés sobre la relación entre máquinas, herramientas y anatomía humana. En 1865 vuelve a Alemania y se dedica nuevamente al trabajo académico. Su Grundlinien del 1877 es una síntesis de sus estudios de geografía comparada y sus reflexiones sobre la experiencia americana (Mitcham 1994). El texto presenta una teoría muy ambiciosa sobre la relación entre biología y tecnología, y, por tanto, una hipótesis ingeniosa sobre las conexiones entre órganos y máquinas, considerando estas últimas como una "derivación" de los primeros.

De hecho, en contras de la tradición Cartesiana, Kapp era muy enfático en sostener que no había que confundir las máquinas con los organismos. Si bien podemos identificar varios elementos de similitud - entre otros, organización, movimiento, estructura y función-, las dos entidades, así como los conceptos de mecanismo y orgánico, refieren a dominios distintos. Confundir el concepto de máquina con el concepto de organismo significaba, por Kapp, no entender la verdadera relación entre los dos. Como primera aproximación, podemos decir que, desde la perspectiva de Kapp - y de varias posturas "organocéntricas" posteriores - asimilar el organismo a la máquina sería equivalente en asimilar un retrato de Luis XVI con el rey Luis XVI. Hay seguramente un parecido entre el rey y su retrato, sin embargo, no podemos concluir que el retrato es, en realidad, el rey. $\mathrm{Si}$ aplicamos el mismo razonamiento criticando la postura mecanicista, podemos argumentar que el parecido de una máquina a un organismo no sugiere una verdad sobre el estatus ontológico de los organismos (ej. Una identidad entre la primera con el segundo), sino señala algo sobre las producciones y representaciones humanas respecto a ciertas entidades naturales. Es decir, los artefactos mecánicos no son ontológicamente asimilables a algunos principios básicos de la organización biológica, sino que son una derivación de estos últimos, así como un retrato es una derivación o "proyección" del individuo Luis XVI. La relación entre entidad y su derivado es lo que Kapp llama “proyección orgánica”.

\footnotetext{
${ }^{5}$ El articulo incriminado era: "Der konstituierte Despotismus und die konstitutionelle Freiheit" ("Constituted despotism and constitutional liberty").
}

Revista de Humanidades de Valparaíso, 2019, No 14, 117-138

()ㅇㅇㅇㅛ CC BY-NC-ND 
Para entender la naturaleza de la "proyección orgánica" y apreciar la novedad la postura de Kapp respecto a la relación máquina/organismo, tenemos que adentrarnos en algunos asuntos históricos, culturales y epistemológicos que caracterizan su propuesta. Empezando con los asuntos históricos, Kapp sostiene que la fabricación y uso de artefactos representa el verdadero inicio de la historia humana. En el primer capítulo de su Grundlinien, Kapp explica que la alienación inicial entre el ser humano (como ser orgánico entre otros) y el mundo externo queda superada a partir de la mediación de las actividades manuales. Mientras que los animales perciben el mundo externo sin tener la posibilidad de comprenderlo, los seres humanos lo comprenden en la medida que lo manipulan. Y en virtud de esta interacción práctica, el ser humano es el único organismo que logra ir más allá del puro dado empírico. En otras palabras, para los organismos no humanos, el mundo externo es un mundo de fenómenos caóticos, un conjunto de acontecimientos sin un sentido particular; un revoltijo de eventos que el organismo debe simplemente sufrir y tolerar para sobrevivir. En este caso, la relación con el mundo es puramente instintiva. Por lo contrario, en el caso del animal humano, la asimilación es posible en la medida que el organismo no solo percibe los fenómenos, sino que los controla, los domina y los predice. Este control y dominio de los fenómenos no puede ser algo abstracto o teórico (contemplativo), sino algo esencialmente concreto y práctico: los seres humanos asimilan (comprenden) el mundo externo por medio de sus intervenciones y manipulaciones. Inicialmente este proceso practico se orienta hacia los objetos naturales presentes en el entorno (piedras, huesos, troncos de madera etc.), después y progresivamente, la atención se mueve hacia la fabricación de artefactos. La verdadera integración con el medio ambiente, y lo que diferencia la prehistoria de la historia, es la articulación intencional de objetos funcionales.

Ahora, Kapp no sostiene que los seres humanos son meros primates que fabrican herramientas. Si así fuese, deberíamos extender esta capacidad a muchos otros organismos. La diferencia esencial entre los humanos y no humanos no se reduce a la mera fabricación de utensilios sino en la consciencia que los seres humanos adquieren por medio de esta actividad. De hecho, Kapp sostiene que la producción de artefactos es un factor evolutivo donde el ser humano aprende sobre su entorno y sí mismo. La autoconsciencia es un producto de una reflexión sobre el trabajo de las manos. Hacer y manejar utensilio es una condición esencial para la emergencia del pensamiento reflexivo. Esto implica que la autoconsciencia no es un fenómeno puramente mental, sino un fenómeno que emerge a partir de la reiteración productiva de actividades prácticas. La autoconsciencia es un producto de la mente en un cuerpo y no un derivado etéreo del cuerpo. En este sentido, mientras que los animales plasman y utilizan herramientas por medio de instintos específicos, los seres humanos producen a partir de una reflexión o actividad concreta que es genuinamente creativa. Kapp explicita la relación entre consciencia y actividad práctica reconstruyendo la etimología de la palabra alemana selbst, el cual sería un término compuesto de si y liba, es decir, "vida" y "miembros". La palabra misma nos indica que la 
En el principio era la mano: Ernst Kapp y la relación entre máquina y organismo Maurizio Esposito

consciencia de sí mismo, lo que los anglosajones llaman self, es el efecto de la interacción entre acción y reflexión, concreción y abstracción, estructura y función, cognición y cuerpo. Más allá de la veracidad etimológica de selbst, Kapp nos quiere convencer de dos premisas fundamentales que están a la base de su argumento de la "proyección orgánica": 1) Los artefactos son al mismo tiempo, herramientas de adaptación y herramientas de comprensión. 2) La historia humana comienza con la práctica, con la fabricación y uso de utensilios en la medida que la praxis y manejo de instrumentos es la condición esencial para le emergencia de la autoconsciencia. Como Kapp argumenta:

Los animales también tienen una percepción sensible inmediata de las cosas. Empero, el animal no entiende lo que observa y escucha, come o huele; estas cosas permanecen distantes o alienas a su ser, como una antítesis en la cual el animal persiste. El ser humano, por el contrario, supera esta antítesis en virtud de su disposición original que le confiere la competencia en expandir ad infinitum, en forma productiva y receptiva, sus habilidades sensoriales que comparte con los otros animales por el medio de suportes mecánicos - en otras palabras, por el medio del trabajo de sus manos. (Kapp 2018, 23)

No entendemos el sentido de la proyección orgánica si no entendemos que el ser humano es, en su esencia, un ser productivo y al mismo tiempo reflexivo. Y es precisamente la dialéctica entre producción y reflexión que define el proceso "proyectivo" de algunos elementos internos, subjetivo, hacia el exterior. El inicio de la historia (por medio de la acción) y el comienzo de la consciencia (por medio de la reflexión concreta sobre la producción) son coextendidos con la proyección orgánica.

Pero ¿en qué consiste, en lo específico, dicha "proyección”? Como primera aproximación, Kapp entiende con "proyección" la acción de ejecutar o explicitar algunos atributos subjetivos interiores hacia el exterior. Representaciones como un cuadro o una estatua pueden ser consideradas como "proyecciones" en la medida que estas se proyecten, en un soporte material, algunas imágenes subjetivas. Una obra de arte es entonces una "proyección" de un estado interior. Ahora, si bien haya una relación entre representación y proyección, Kapp sostiene que la proyección sea una actividad más fundamental, desde un punto de vista evolutivo y cultural, de la misma representación. El ser humano "proyecta" o "extrínseca" sus facultades cognitivas en objetos concretos y materiales cada vez que interactúa productivamente con la realidad. El acto fundacional epistémico que caracteriza la relación entre organismos humanos y medio ambiente reside, para Kapp, en la interacción práctica y concreta entre sujetos y mundo externo por medio de órganos/herramientas. La ambigüedad entre el concepto de órgano y el concepto de herramienta no es casual. Si el órgano/herramienta primitivo es la mano, el primero órgano/herramienta artificial es el martillo. La mano es el órgano/herramienta innato universal y es el prototipo de todos los otros órganos/herramientas artificiales (a partir del martillo). La mano (como recordaba Aristóteles en su Acerca del Alma), es el órgano de los órganos y el martillo es una "proyección orgánica" de la mano (y del brazo, como veremos). A su vez,

Revista de Humanidades de Valparaíso, 2019, No 14, 117-138

(c) $(18$ 을 CC BY-NC-ND 
En el principio era la mano: Ernst Kapp y la relación entre máquina y organismo Maurizio Esposito

el martillo es el órgano/herramienta prototípico de muchos otros órganos/herramientas artificiales. No hay límites a la cantidad de proyecciones orgánicas posibles que pueden surgir (y que de hecho surgieron) a parir de la articulación entre mano y martillo:

De esta manera, una abundancia de creaciones emerge a partir de la fuerza productiva humana por medio de la mano, brazo y diente. Un dedo torcido se vuelve un gancho, el hueco de la mano se trasforma en un recipiente. En una espada, una lanza, un remo, una pala, un rastrillo, arado, horquilla, podemos fácilmente rastrear la tendencia dinámica del brazo, de la mano y de los dedos, así como sus adaptaciones a las actividades de caza, pesca, siembre y cosecha. (Kapp 2018, 38)

En suma, todos los primeros artefactos (órganos/herramientas artificiales) son proyecciones de órganos/herramientas innatos (órganos del cuerpo). La misma historia humana nace con el martillo, el cual consiste en la "proyección orgánica" más importante en términos históricos y fisiológicos. El martillo, en conjunción con la mano, es el prototipo de todas las otras proyecciones orgánicas más complejas; desde una espada hasta la máquina a vapor. ${ }^{6}$

La producción de artefactos tiene entonces un valor filogenético. De hecho, Kapp sostiene que las manos, los brazos, así como todo el cuerpo co-evoluciona con los mismos artefactos y herramientas. Es decir, una herramienta se vuelve progresivamente un órgano/herramienta en la medida que un órgano innato se adapta a la herramienta artificial. Si bien con el proceso de co-evolución se realiza una articulación siempre más profunda entre órgano y herramienta, la evolución de los artefactos y de las máquinas adquieren, con el tiempo, una cierta autonomía. En la evolución de los martillos, espadas, rastrillos etc., la proximidad con los órganos humanos se mantiene. Con la evolución de los molinos, máquinas a vapor, telégrafos o locomotoras la proximidad se pierde, aunque el lazo con el organismo creador nunca se rompa. Kapp enfatiza que por cuanto una tecnología pueda ser sofisticada y por cuanto una máquina pueda perder cualquier semblanza con la fisiología humana o animal, todos los artefactos tienen su último origen en una proyección. Un descendiente de una proyección orgánica es a su vez una proyección orgánica.

\footnotetext{
${ }^{6}$ Hoy en día un buen ejemplo es el computador.
}

Revista de Humanidades de Valparaíso, 2019, No 14, 117-138

(9) 80 CC BY-NC-ND 
En el principio era la mano: Ernst Kapp y la relación entre máquina y organismo Maurizio Esposito

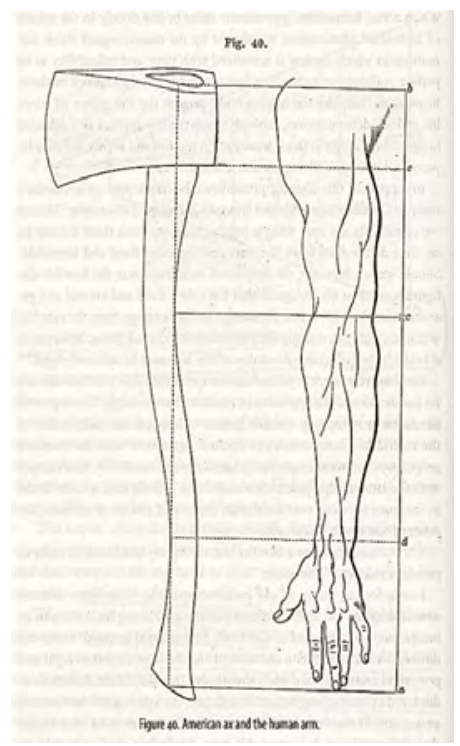

Fig. 1. Relación "proyectiva” entre un brazo y un hacha (Kapp 1877, 174).

Unos de los aspectos más interesantes de la teoría "organocéntrica" de Kapp es que la relación entre máquina y organismo no se basa sobre un isomorfismo explicito, sino sobre un lazo diacrónico y, al mismo, tiempo, practico. Me refiero al lazo diacrónico en la medida que existe una filogenia de proyecciones que tienen su antepasado común en el brazo y la mano y me refiero a un lazo práctico en la medida que los artefactos, las herramientas y después las máquinas, extienden o intensifican el trabajo humano remplazándolo. La necesidad fomenta la producción de una herramienta. La práctica y el trabajo estimulan el perfeccionamiento de la herramienta. El conjunto entre necesitad y practica incentiva el desarrollo de un artefacto tecnológico. Sin embargo, la relación virtuosa entre organismo y máquina no se reduce a una estrategia pragmática de integración con el medio ambiente. La máquina misma, como "proyección orgánica", es también y sobre todo lo que llamo un "dispositivo epistémico", es decir, una herramienta que produce comprensión. Para entender como un artefacto se vuelve un dispositivo que produce conocimiento del entorno, hay que mencionar algunos elementos importantes que rodean la hipótesis de la "proyección orgánica" de Kapp.

La teoría "organocéntrica" de Kapp presupone un momento inconsciente y un momento consciente respecto a la proyección. Mientras que inicialmente un artefacto es una proyección "inconsciente" de lo orgánico, en un segundo momento este mismo artefacto se vuelve un dispositivo que conscientemente nos entrega explicaciones y comprensión del mundo orgánico. Un aparato óptico no solamente amplia la visión, sino que también nos permite de entender la visión misma. Un aparato acústico no solamente amplifica nuestro oído, sino que también nos permite entender o representar la fisiología del oído. Una má- 
En el principio era la mano: Ernst Kapp y la relación entre máquina y organismo Maurizio Esposito

quina a vapor no solamente incrementa nuestra fuerza, sino que nos permite representar la misma naturaleza de la fuerza y del trabajo. Un cable del telégrafo no solamente extiende nuestras posibilidades de comunicar, sino que también nos entrega comprensión respecto a un cordón nervioso (ver Fig. 2 en la siguiente sección). En breve, el fenómeno de la proyección orgánica se puede dividir en tres momentos fundamentales: en primer lugar, hay la producción inconsciente de un artefacto que amplifica una función orgánica. En segundo lugar, hay el manejo del artefacto que lleva el sujeto a realizar, en forma consciente, que este último es una proyección de un órgano. Y, en tercer lugar, sobreviene la intuición que el artefacto es un dispositivo que genera comprensión respecto al mismo órgano y organismo. En la próxima sección veremos más en detalles como las proyecciones orgánicas, los artefactos y mecanismos, se vuelven dispositivos epistémicos confiables a partir de la dialéctica entre lo inconsciente y consciente.

\section{Repensar las máquinas a partir de los organismos}

En 1872, el historiador alemán, Alfred Wilhelm Dove, señaló que: “...entendemos el mecanismo de la naturaleza (fisiología del cuerpo) solo después que nosotros lo hemos libremente inventado - entendemos el ojo después de la invención de la cámara, así como entendemos los nervios después de la invención del telégrafo" (Dove, citado en Kapp 2018, 109). Kapp sigue detenidamente la intuición de Dove con una diferencia esencial; la producción de un artefacto no es algo puramente creativo (en un sentido de creación ex nihilo), sino una proyección inconsciente que, luego, se vuelve una herramienta de comprensión. Kapp explora una serie de ejemplos específicos para mostrar como un artefacto pueda funcionar como dispositivo epistémico. El considera aparatos ópticos (telescopio, microscopio, camera obscura etc.), infraestructuras (puentes), máquina a vapor (trenes), y el telégrafo (en particular la tecnología de los cables). Mi intención no es aquí comentar en detalle el texto de Kapp, sino subrayar algunos elementos que nos puedan ayudar a entender la lógica de la proyección orgánica y su relevancia actual.

Empezamos con la invención y desarrollo de los aparatos ópticos. ¿Cuál es la diferencia entre un ojo y una camera obscura? ¿Podemos sostener, de acuerdo a la hipótesis "mecanocéntrica", que el primero se puede reducir a la segunda? Kapp argumenta que la relación entre el órgano y el artefacto no es de "reducción" (ej. el ojo no es nada más que una especie de camera obscura), sino de "proyección" (ej. La camera obscura es una externalización inconsciente de un ojo, así como una lente del aparato es una proyección del cristalino del ojo). El hecho de que haya una relación de proyección inconsciente no implica que exista una identidad (mecanocéntrica) entre el aparato y el ojo. Lo que la relación realmente indica es que el inventor se ha inspirado, en forma inconsciente, a una entidad orgánica para construir un artefacto. Esto significa que no es el ojo que se parece a una camera obscura, sino que es esta última que se constituye a partir del primero. La relación "mecanocéntrica" se fundamenta sobre una relación "organocéntrica". En este

Revista de Humanidades de Valparaíso, 2019, No 14, 117-138

(ㄷ)(1)(2) CC BY-NC-ND 
En el principio era la mano: Ernst Kapp y la relación entre máquina y organismo Maurizio Esposito

sentido, podemos sostener que el fenómeno de la proyección orgánica no es nada más que un proceso de bio-mimetismo involuntario. Y es precisamente en virtud de esta relación "biomimética" involuntaria que el aparato óptico se trasforma en un dispositivo epistémico. Una camera obscura, un telescopio o un microscopio no solamente nos permiten de fijar imágenes, engrandar los objetos lejanos o pequeños; ellos nos revelan los principios ópticos de la visión:

El misterio de la fisiología de este órgano (ojo) puede ser resuelto solo después que haya sido "proyectado" en diferentes números de aparatos mecánicos; así estableciendo una referencia externa para su propia construcción anatómica. El ser humano ha aprendido desde el instrumento que el mismo ha constituido a partir del órgano/herramienta óptico y los llevó a la comprensión del mecanismo de foco en relación a la luz refracta en el ojo hasta las lentes. (Kapp 2018, 62)

El mismo razonamiento se puede aplicar a otros artefactos y tecnologías, aunque la relación de "proyección” pueda manifestarse en diferentes formas. Por ejemplo, ¿Cuál puede ser la relación entre una máquina a vapor y un organismo? ¿En qué sentido una máquina a vapor manifiesta una similitud estructural o funcional con un cuerpo orgánico? Para los fisiólogos alemanes Hermann von Helmholtz y Robert von Mayer, la relación entre una máquina a vapor y un organismo se establece a nivel de movimiento y trabajo. Si nos preguntamos cual es el verdadero origen del movimiento y trabajo de una entidad cualquiera, la máquina a vapor podía servir como un dispositivo epistémico muy eficaz. Kapp justamente nos dirige hacia aquellos textos donde los dos fisiólogos reconocen una continuidad "organocéntrica" entre máquina y organismo. Helmholtz, en su ponencia "Uber die Wechselwirkung der Naturkrafte und die darauf bezuglichen neuesten Ermittelungen der Physik" (Sobre la interacción de las fuerzas naturales...), observaba que por medio de la máquina a vapor los fisiólogos habían esclarecido las orígenes del movimiento y del trabajo de un órgano/herramienta: "El cuerpo del animal no se diferencia, por tanto, de la máquina a vapor a partir de la manera de como produce calor y trabajo, sino de los propósitos y las maneras en que este calor y trabajo es aplicado" (Helmolthz, citado por Kapp 2018, 97). En otras palabras, tenemos fines, materias y estructuras distintas, sin embargo lo que une un organismo a una máquina a vapor comparten es su manera de producir calor y movimiento. Antes que Helmolthz formulara el principio de conservación de la energía en 1847, von Meyer había observado que los nutrientes son combustibles que generan calor, y por tanto movimiento y trabajo. Que sea carbón para la máquina o nutrientes para el organismo, todos se reducen por último a la energía solar acumulada y conservada en los vegetales. Por tanto, la construcción y funcionamiento de una máquina a vapor nos revela algunos de los principios básicos y simples que animan el movimiento orgánico. La máquina a vapor puede ser considerada dispositivo epistémico en virtud de una proyección orgánica que antecedió y fomentó el mismo desenvolvimiento de esta tecnología. Por tanto, no son los organismos que se reducen a una máquina, sino son las

Revista de Humanidades de Valparaíso, 2019, No 14, 117-138

(ㄷ)(1)임 CC BY-NC-ND 
En el principio era la mano: Ernst Kapp y la relación entre máquina y organismo Maurizio Esposito

máquinas que deben vincularse con el mundo orgánico. Se puede considerar la máquina a vapor un "organismo" solo en la medida en que la primera imita algunos elementos básicos que caracterizan los seres vivos.

Otro ejemplo que Kapp menciona es la tecnología del telégrafo. Poco más de 30 años antes que Kapp publicara su Grundlinien, Samuel Morse pone en función la primera línea telegráfica entre Washington y Baltimore. El 1 de mayo 1844, el mensaje "¡Miren lo que Dios ha hecho!" llega exitosamente a la estación de Mount Clare. La posibilidad técnica de la comunicación a distancia se hace posible y, entre el 1866 y 1878, el barco a vapor SS Great Eastern instala alrededor de 48.000 kilómetros de cables transoceánicos conectando Inglaterra con Canadá e India (Hartmann 2014) Ahora, lo que llama la atención de Kapp respecto a estos acontecimientos no es simplemente la posibilidad de intercambiar información entre lugares distantes, sino la misma estructura interna de los cables (ver Fig. 2). Kapp recuerda el patólogo alemán Rudolf Virchow, el cual en una ponencia dedicada a la anatomía y fisiología de la medula espinal, había observado que la estructura interna de un nervio se parece a la estructura interior de un cable telegráfico submarino: "De hecho - declaraba Virchow - los nervios son los cables del cuerpo animal así como los cables telegráficos son los nervios de la humanidad" (Virchow, citado en Kapp 2018, 104). Uno de los aspectos más interesantes de las metáforas virchowianas es la sugerencia que con la construcción de los cables transcontinentales nos proporciona conocimientos respecto a la relación entre escultura y función de los nervios. El parecido entre los nervios y los cables telegráficos no llamó solo la atención a Virchow.

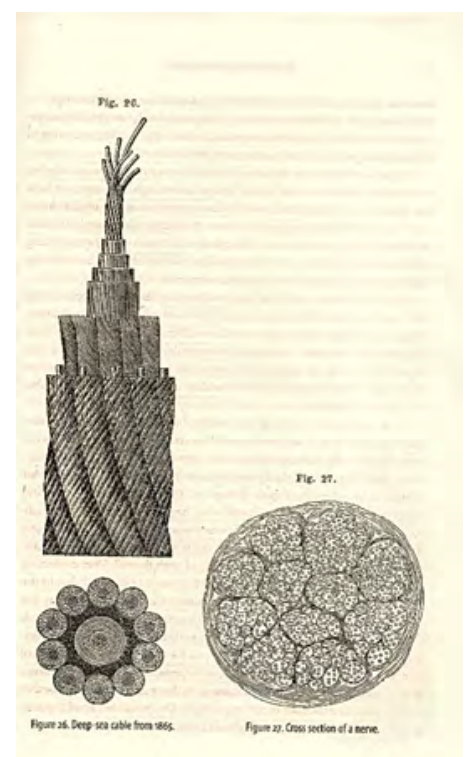

Fig. 2. Comparación entre un cable submarino y una sección de un nervio (Kapp 2018, 105). 


\section{En el principio era la mano: Ernst Kapp y la relación entre máquina y organismo Maurizio Esposito}

Kapp también recuerda el filósofo natural Carl Gustav Carus, que encontró una coincidencia entre las fibras nerviosas y los cables conductores de un telégrafo "galvánico" (Telégrafo electromagnético). En este sentido, un telégrafo galvánico adquiere el estatus de dispositivo epistémico en la medida que nos puede ayudar a entender el funcionamiento del sistema nervioso. Lo sorprendente es que Kapp olvida de mencionar el trabajo de William Thomson (Lord Kelvin) "On the Theory of Electric Telegraph" del 1855, donde el matemático ingles desarrolla la teoría matemática útil para las instalaciones de los cables transoceánicos. Esta teoría está a la base de la así llamada ecuación del cable que describe y calcula el flujo de la corriente en las dendritas y axones (Holmes 2014). Una vez más, no es el sistema nervioso que se puede reducir o describir en términos mecánicos, sino que es la tecnología telegráfica que revela puntos de contactos significativos con el sistema nervioso. La relación entre las fibras nerviosas y los cables del telégrafo es "organocéntrica" y no "mecanocéntrica".

El último ejemplo que quiero mencionar para esclarecer la teoría de la proyección orgánica se refiere a algunas infraestructuras arquitectónicas. De hecho, para Kapp, hay muchas similitudes interesantes entre la arquitectura de los puentes de armadura (truss bridges) y la estructura ósea. La función que ambas estructuras tienen que satisfacer son similares: sustentar pesos y resistir a distintas solicitudes externas. Kapp menciona el anatomista y cirujano alemán Julius Wolff (1836-1902) el cual había identificado una clara correlación entre la conformación ósea y las tenciones y compresiones que esta misma conformación debía tolerar. La ley de Wolff, de hecho, supone que la misma forma y desarrollo de la estructura ósea responde a las solicitudes físicas y mecánicas externas. En otras palabras, la morfología de un fémur humano, que es el objeto de estudio de Wolff, depende de factores externos que lo moldean de acuerdo a las tenciones y compresiones externas. Esto significa que la distribución de las líneas de tención y de compresión — que el mismo Wolff podía observar cortando el hueso en láminas delgadas - seguía en las solicitudes físicas que el mismo hueso había sufrido durante su desarrollo. La estructura, por tanto, depende y se origina a partir de la función de una manera parecida a la morfología de un puente. Para Wolff era evidente que la naturaleza construyó los huesos como un ingeniero construye un puente (Kapp 2018, 87). De acuerdo a la teoría de la proyección orgánica, existe una relación entre las soluciones que la naturaleza encuentra para resolver problemas específicos y las soluciones que los seres humanos encuentran para resolver problemas similares. Kapp explica la interrelación entre estructura mecánica y orgánica (huesos) postulando dos movimientos esenciales: por un lado tenemos,

[...] un desplazamiento hacia el exterior del cuerpo en su "imagen residual" material (after image) y por el otro lado tenemos la aplicación inversa del mecanismo para entender el organismo, incrementando la consciencia respecto a la conjugación inconsciente de un interior y exterior...la estructura esponjosa de la substancia ósea, hueso esponjoso, ha siempre sido a la vista. Los hombres primitivos lo conocían como los anatomistas modernos; en cortando el hueso en forma longitudinal con un hacha para sacar la medula. $(2018,89)$

Revista de Humanidades de Valparaíso, 2019, No 14, 117-138

(c) (1) 8 (을 CC BY-NC-ND 


\section{En el principio era la mano: Ernst Kapp y la relación entre máquina y organismo Maurizio Esposito}

Paradójicamente, entendemos la estructura interna de un hueso construyendo un puente en la medida que este último, como "imagen residual" material, puede funcionar como dispositivo epistémico para comprender algunos principios básicos que caracterizan la estructura ósea. También en este ejemplo, que probablemente es el más especulativo y débil de Kapp, se desprende una línea argumentativa bastante sofisticada: la relación entre máquina y organismo no es simplemente metafórica, sino que es al mismo tiempo práctica y epistémica. La relación es practica porque la proyección orgánica - y por tanto el lazo que se establece entre artefacto, máquinas - requiere una interacción constante, inconsciente o consciente, con el medio. No hay proyección sin una manipulación reiterada con el mundo externo y, por tanto, no hay relación entre máquina y organismo sin praxis (que sea un aparato óptico respecto a los ojos, la máquina a vapor respecto a la cinemática orgánica, que sean los cables telegráficos respectos al sistema nervioso o un puente en correspondencia con la estructura ósea). La relación es epistémica en virtud del hecho que un mecanismo surge a partir de una práctica que es, antes inconsciente y luego, a partir de sus productos, consciente. El conocimiento del mundo orgánico depende literalmente del conjunto de artefactos y máquinas que los seres humanos han ido construyendo desde el inicio de la historia, es decir, a partir de la construcción de los primeros utensilios?.

Antes de pasar a la siguiente sección, nos queda una tarea importante. Hemos visto que un aspecto fundamental de la teoría de loa proyección orgánica es la producción inconsciente de lo que Kapp llama "imagen residual" material, es decir, la construcción del órgano/herramienta que mantiene sus lazos miméticos con el organismo. Sin embargo, ¿Qué se entiende con "inconsciente”? ¿En qué sentido la producción de un artefacto es "inconsciente”? Y, ¿Por qué Kapp entiende el fenómeno de la proyección orgánica como una dialéctica entre inconsciente y consciente? Antes que todo, hay que recordar que Kapp escribe antes de Freud, por tanto su concepción de "inconsciente" no tiene ninguna relación con la concepción Freudiana. El referente principal de Kapp es el referente de caso todos los que escribieron sobre el inconsciente en el siglo XIX y XX (incluso el mismo Freud), es decir, el filósofo alemán Eduard von Hartmann y su texto Philosophie des Unbewußten (Filosofía del inconsciente) publicado al 1869 y traducido en ingles en 1884. El punto inicial de la reflexión de Hartmann es una breve sección de la Antropología de Kant: "Sobre las ideas que tenemos sin ser conscientes de ella" (von Hastmann 1884, Cap. I). En la sección Kant expresa muy claramente el dominio de reflexión que debe interesar el filósofo del inconsciente. Aunque la palabra Unbewusste todavía no existía, Kant sostuvo que: "...lo cierto es que podemos ser mediatamente conscientes de tener una representación, aun cuando no seamos inmediatamente conscientes de ella. Este

\footnotetext{
${ }^{7}$ Es una lástima que Kapp no haya podido asistir al desarrollo de la industria aeronáutica. Pocos años después de la muerte de Kapp en 1896, los hermanos Wright y el inventor brasileño Alberto Santos Dumont construían los primeros prototipos de aeroplanos. Muy probablemente, Kapp hubiera considerado el avión como una proyección orgánica de un ave, y, luego, un dispositivo epistémico que nos entrega conocimientos de primera mano sobre los principios del vuelo.
}

Revista de Humanidades de Valparaíso, 2019, No 14, 117-138

(c) (1) 8 (을 CC BY-NC-ND 
En el principio era la mano: Ernst Kapp y la relación entre máquina y organismo Maurizio Esposito

género de representaciones se llama, entonces, obscuras; las restantes son claras" (Kant 2014, 19). Lo que Kant entiende con obscuro o claro, mediato o inmediato tiene una relación con lo que los psicólogos de la Gestalt llamaban cosificación, es decir, la facultad de completar, añadir elementos o formas a percepciones fragmentarias con la diferencia esencial que para Kant lo que no percibimos inmediatamente los percibimos en forma no consciente:

Cuando se es consciente de estar viendo a lo lejos, en una pradera, un hombre, si bien no se es consciente de ver sus ojos, nariz, boca, etc., propiamente se concluye solo que aquella cosa es un hombre; pues sí, porque no se es consciente de percibir estas partes de la cabeza (e igualmente las restantes partes de ese hombre), se quisiera sostener que no se tiene en absoluto en la intuición la representación de ellas, tampoco se podría decir que se ve un hombre; pues de estas representaciones parciales está compuesta la total (de la cabeza o del hombre). $(2014,19)$

Lo "inconsciente" kantiano, entonces, se refiere a todas aquellas sensaciones que no alcanzan a formar una representación clara (consciente). Y, como después notaran todos los más importantes pensadores de los inconscientes, Kant también enfatiza el hecho que el dominio de las sensaciones inconscientes es mucho mayor que el dominio de lo consciente:

El hecho que sea inmenso el campo de aquellas nuestras intuiciones de los sentidos y las sensaciones de las que no somos conscientes; si bien podemos concluir indubitablemente que las tenemos; esto es, de las representaciones obscuras en el hombre (y también en los animales); de que las claras, por el contrario, encierren solo unos, infinitamente pocos, puntos de aquellos que están abierto a la consciencia $[\ldots](2014,20)$

Por supuesto, Hartmann desarrolla la intuición básica de Kant dividiendo su análisis entre la manifestación del inconsciente en el cuerpo y en la mente humana hasta proponer - como sugiere el mismo Kapp - una "modesta" teoría del universo (Kapp 1870). Sin embargo, con la excepción de la reseña que dedicó a Hartmann en 1870, Kapp no profundiza mucho el asunto en relación a su teoría de la proyección orgánica. Mencioné Hartmann, y especialmente me detuve sobre Kant, para aclarar lo que probablemente asumía Kapp cuando escribe de "inconsciente" en relación a la proyección orgánica. De hecho, con "inconsciente" no debemos imaginar algo místico o vago sino algo bastante simple: las primeras interacciones de los seres humanos con su ambiente son interacciones prácticas que generan un conjunto de saberes, creencias, actitudes y enfoques que son inicialmente "obscuras", es decir, no existe una representación o teoría "clara" respecto a lo que se hace y como se hace. La distinción Ryleiana entre "saber cómo" y "saber que" es una buena aproximación a la diferencia Kappiana entre conocimiento inconsciente y consciente (Ryle 1945). La práctica que establece una primera vinculación con el medio construyendo artefactos es algo inconsciente (un tipo de saber cómo). Esta misma prác-

Revista de Humanidades de Valparaíso, 2019, No 14, 117-138

()ㅇㅇㅇㅛ CC BY-NC-ND 
En el principio era la mano: Ernst Kapp y la relación entre máquina y organismo Maurizio Esposito

tica se vuelve consciente cuando el sujeto reconoce "claramente" que el artefacto es una proyección orgánica de un órgano/herramienta. El artefacto es el medio que conduce al sujeto a producir un "saber qué", o una teoría o representación, respecto al mundo orgánico. En síntesis, la práctica, por un lado, es intuitiva, eficiente respecto a sus objetivos $\mathrm{y}$, por la mayor parte, obscura respecto a sus representaciones (inconsciente). El conocimiento teórico, adquirido por medio de esta práctica, es reflexivo, consciente y, por la mayor parte claro, en referencia a sus representaciones. De acuerdo a este esquema, la proyección orgánica es el resultado de un movimiento dialectico entre practica (elemento inconsciente - obscuro) y teoría (elemento consciente - claro) así que podemos tener representaciones claras sobre los orgánico cuando ya hemos interiorizado, en forma inconsciente, las prácticas que nos han llevado a producir un artefacto o mecanismo que es, en realidad, una proyección de lo orgánico.

\section{Desde la Bio-filosofía a la Tecno-filosofía}

Unas de las implicancias de la filosofía de Kapp — así como todas las filosofías que ven la tecnología como una proyección, directa o indirecta, de lo orgánico- es que hay una relación constitutiva e imprescindible entre máquina y organismo. Esto no significa defender, como hemos visto, que un organismo es nada más que una máquina o que puede ser reducido, es sus elementos principales, a un artefacto mecánico. El argumento es más sofisticado: la relación mecanocéntrica que podemos reconocer es solo el producto de un proceso dialectico que involucra la historia, la ontología y la práctica. Una máquina se parece a un organismo no porque subsiste una identidad evidente y/o obvia entre los dos, sino porque un mecanismo es una proyección orgánica del organismo mismo. Es en virtud de esta inversión del argumento que podemos identificar las afinidades y diferencias entre máquinas y organismos. En distintas ocasiones, Kapp sostiene que no podemos confundir una máquina con un órgano u organismo porque: "El organismo, como todo el mundo natural, es un devenir mientras que el mecanismo es algo terminado. En el primero hay desarrollo y vida, en el segundo hay solo composición e inercia. Los que no comparten esta diferencia no entienden la distinción entre un sacacorchos que llevan en el bolsillo y su muñeca como un participante integral de una actividad orgánica auto motivada" (Kapp 2018, 49-50). Lo que nos sugiere Kapp es que, por un lado y desde una perspectiva ontológica, el organismo no es un mecanismo y tampoco puede ser reducido a este. Por el otro lado, el mecanismo si puede entregarnos conocimientos sobre el mundo orgánico, en virtud de su estatus de proyección o mimesis orgánica. En suma, la máquina y organismo son dos entidades ontológicamente distintas, pero tienen una relación epistémica heurísticamente productiva.

Si excluimos la idea que haya una continuidad ontológica entre mecanismos y mundo orgánico (así como no hay una continuidad ontológica entre el sujeto de un retrato y el retrato mismo), es evidente que la pregunta filosófica interesante no es si un organis-

Revista de Humanidades de Valparaiso, 2019, No 14, 117-138

(ㄷ)(1)임 CC BY-NC-ND 
En el principio era la mano: Ernst Kapp y la relación entre máquina y organismo Maurizio Esposito

mo sea realmente un mecanismo (no puede serlo de acuerdo a lo anterior). De acuerdo a la perspectiva "órganocéntrica", la pregunta filosóficamente pertinente es: ¿Qué tipo de relaciones subsisten entre prácticas, artefactos, máquinas y nuestra comprensión del mundo orgánico? El problema que debemos enfrentar es entonces epistémico y se refiere al paralelismo histórico y cognitivo entre determinadas tecnologías y representaciones (objetos e ideas). Dada lo anterior, podemos reinterpretar de una manera "organocéntrica" la visión de los cartesianos que identificaban los animales con los autómatas complejos. Y podemos hacer lo mismo con Helmholtz o Meyer, que veían el cuerpo humano como un tipo de máquina a vapor. Con Virchow y Carus, que veían el sistema nervioso como un conjunto de cables telegráficos. Con Wolff, que veía un fémur como un ejemplo de puente de armadura. La lista podría bien continuar hasta nuestros días. Podemos incluir, entre otros, a Norbert Wiener, que veía un organismo como un mecanismo cibernético. A James Watson and Francis Crick, que veían la secuencia de las bases de ADN y sus productos (cadena de aminoácidos) como un código basado en cuatro "letras". Hoy en día no faltan científicos que comparan el genoma a un programa informático y el cerebro a un computador. La interpretación que normalmente se ofrece para explicar esta relación entre entidad orgánica y artefacto tecnológico es "mecanocéntrica". Simplemente se asume que el genoma o el cerebro tienen una conexión privilegiada con las tecnologías de la información porque los principios de funcionamiento del genoma y cerebro son mecánicos. ${ }^{9}$ Sin embargo, se reinterpretamos dicha conexión en términos "organocéntricos", un nuevo espacio de investigación muy interesante se abre para los bio-filósofos y tecno-filósofos en conjunto. Y este espacio consistiría en explorar y averiguar cómo nuevas tecnologías crean las condiciones para comprensión del mundo orgánico sin que este último se reduzca a las primeras.

En las últimas décadas, la proliferación de entidades híbridas no ha hecho que consolidar la intuición de Kapp que haya una proyección contante de lo orgánico a lo mecánico, con la diferencia que la distinción entre máquina y organismo se puede esfumar con la creación de un organismo sintético. Con los avances tecnológicos, la proyección se puede trasformar en identidad ontológica en el momento que organismos sintéticos pueden producir otros organismos sintéticos (es decir, máquinas/organismos). Por supuesto, dicha identidad ontológica todavía no se ha cumplido y es material de especulación respecto a cuándo será posible realizarla. Empero, la tecnología actual hace esta posibilidad muy probable en las próximas décadas. La proyección orgánica, es decir la imagen residual,

\footnotetext{
${ }^{8}$ Es evidente que la metáfora del "código" presupone la existencia de alguna tecnología de la información.

${ }^{9}$ Incluso los que cuestionan la relevancia o la pertinencia de las metáforas mecanicistas, no pueden negar su fuerza y utilidad, ahora como antes. Después de todo, identificar las diferencias entre máquina y organismo no necesariamente implica descalificar el mecanismo, sino usarlo como marco heurístico que nos permite reconocer algunos elementos únicos e irreducibles de los organismos mismos. Los elementos de continuidad y discontinuidad entre máquinas y organismos nos proporcionan igualmente conocimientos positivos sobre ambos.
}

Revista de Humanidades de Valparaíso, 2019, No 14, 117-138

(ㄷ)(1)임 CC BY-NC-ND 
En el principio era la mano: Ernst Kapp y la relación entre máquina y organismo Maurizio Esposito

puede aproximarse a tal punto a un organismo que la proyección misma coincidiera con una verdadera reproducción. Podemos de hecho sugerir que hay "proyección" cuando falta una identidad ontológica entre entidad proyectante y entidad proyectada mientras que, por lo contrario, hay "reproducción" cuando existe una continuidad ontológica entre entidad reproductora y entidad reproducida. Este es, sin embargo, un tema que nos llevaría muy lejos respecto a los objetivos de este artículo.

Lo que todas estas observaciones nos pueden sugerir es que las reflexiones filosóficas sobre lo orgánico no pueden prescindir de reflexiones filosóficas sobre la tecnología. Hasta al momento, las interacciones entre filosofía de la tecnología y filosofía de la biología han sido muy esporádicas. Sin embargo, un aspecto importante de la hipótesis de la proyección orgánica es hacer esta interacción necesaria y productiva. Si los artefactos tecnológicos son una proyección de lo orgánico y si, viceversa, estos mismos artefactos se vuelven dispositivos epistémicos para entender lo orgánico, entonces la bio-filosofía y la tecno-filosofía deben complementarse. Desde un punto de vista histórico, cada tecnología ha creado las condiciones para nuevas posibilidades de representación y comprensión. Nos relacionamos con el mundo por medio de artefactos y por medio de estos artefactos también testeamos y comprendemos el medio que nos rodea. Por supuesto, no hay que olvidar que la relación entre máquina y artefacto es dinámica y variable. No es lo mismo entender un organismo como un autómata, una máquina a vapor, un sistema cibernético o un computador. Algunos artefactos mecánicos pueden imitar algunos aspectos estructurales, otros se refieren a ciertos otros elementos funcionales. Cada tecnología puede revelar propiedades distintas de la organización biológica, así como distintos sistemas experimentales revelan dominios específicos, y a veces complementares, de realidad.

Podemos decir entonces que la postura "organocéntrica" nos proporciona una perspectiva bastante más sofisticada de la postura "mecanocéntrica". Defender la idea que un organismo (o un órgano) se reduce a un mecanismo (o una máquina) es, como mínimo, una extrema simplificación por dos razones principales. En primer lugar, no hay la Máquina en general, así como no hay la Tecnología en general. Hay distintas máquinas que funcionan con tecnologías diferentes y que proporcionan miradas alternativas del mundo orgánico (ej. tecnologías mecánicas, termodinámicas o electromagnéticas). En segundo lugar, incluso si pudiéramos llegar a definir en términos muy generales - como intentó hacerlo Franz Reuleaux (Moon 2007), algunas de las características esenciales que una entidad debe necesariamente poseer para ser una máquina, estas propiedades serán muy probablemente propiedades orgánicas "proyectadas" en un artefacto tecnológico. Suponiendo que haya una definición univoca de máquina (o de mecanismo), dicha definición no nos serviría para reducir propiedades orgánicas a propiedades mecánicas por la razón que la representación de máquina presupondría una representación previa de organismo (Canguilhem 2000) ${ }^{10}$. Los artefactos más simples o los aparatos tecnológicos más sofisti-

${ }^{10}$ De hecho, Canguilhem sostenía la aparente paradoja segundo la cual no existe nada de más orgánico de

Revista de Humanidades de Valparaíso, 2019, No 14, 117-138

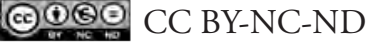


En el principio era la mano: Ernst Kapp y la relación entre máquina y organismo Maurizio Esposito

cados son imitaciones de la naturaleza y, como vimos en la primera sección del artículo, el primer modelo imitado es el mismo cuerpo humano. El brazo y la mano son el prototipo del martillo y el martillo es el prototipo de todos los artefactos que siguen. La empresa tecnológica, para Kapp, se basa sobre un bio-mimetismo inconsciente. Si aceptamos esta premisa tenemos que concluir que, en realidad, cualquier máquina o mecanismo es resultado de una imitación originaria y esta imitación puede interesar aspectos estructurales (organización de la máquina) o funcionales (actividades de la máquina).

Dado todo lo anterior, entendemos que la relación "organocéntrica" consiste precisamente en sostener que las máquinas son un subconjunto del conjunto del mundo orgánico. La discusión, por tanto, se desplaza desde una conexión sincrónica (si las máquinas representan fielmente a los organismos) a una conexión diacrónica (como las máquinas llegan a constituirse como dispositivos epistémicos en relación con los fenómenos orgánicos). De acuerdo a la hipótesis "organocéntrica", de hecho, la identidad entre máquinas y organismos no subsiste aunque cuando las primeras nos proporcionen conocimientos genuinos en biología. Un acercamiento a la filosofía de la tecnología de parte de los bio-filósofos, y viceversa, nos puede ayudar a entender mucho mejor las relaciones entre máquinas y organismos. Este acercamiento es hoy en día particularmente importante para entender como las nuevas tecnologías informáticas globales representan, definen y plasman nuestras concepciones del mundo orgánico (Stevens 2011). En suma, la hipótesis "organocéntrica" de Kapp hace la conjunción entre tecnología y biología imprescindible en la medida que la primera es un derivado de la segunda y la segunda se vuelve inteligible a partir de la primera.

\section{Conclusiones}

En arrojando luz sobre un autor poco conocido, el articulo ha explorado un enfoque alternativo sobre la relación entre máquina y organismo. En primer lugar, he sugerido que podemos diferenciar dos maneras principales de articular dicha relación. Por un lado, hay una manera tradicional que he llamado relación "mecanocéntrica". Este consiste en sugerir que existe un cierto grado de isomorfismo entre máquina y organismo y, por tanto, la máquina (y el mecanismo) puede ser principio de explicación del mundo orgánico. He argumentado que en la relación "mecanocéntrica" el mecanismo es anterior y primordial respecto al mundo orgánico en razón de que un organismo es un tipo de mecanismo y no lo contrario. En la historia de la relación entra máquina y organismo, esta postura ha sido

una máquina. Esto porque la máquina es por Canguilhem una "imagen residual” del organismo. En otras palabras, podemos considerar una máquina como una "caricatura" de un organismo en la medida que la “caricatura (máquina) exagera algunos de los elementos esenciales que caracterizan un ser orgánico: en una máquina todas las piezas tienen una función específica y todas contribuyen para que el conjunto trabaje por un fin definido (el fin del constructor). Lo anterior solo se aplica de una forma muy aproximada al mundo orgánico.

Revista de Humanidades de Valparaíso, 2019, No 14, 117-138

()ㅇㅇㅇㅛ CC BY-NC-ND 
En el principio era la mano: Ernst Kapp y la relación entre máquina y organismo Maurizio Esposito

la más exitosa o, por lo menos, la más representativa en las discusiones filosóficas. Hemos visto que, sin embargo, existe una alternativa menos representativa, aunque no menos fundamentada: la que he denominado relación "organocéntrica". Esta consiste en suponer que las máquinas son una imitación de un organismo o sus partes. Por ende, el dominio de lo mecánico es un subconjunto del conjunto del mundo orgánico y esto implica que, a diferencia de la relación "mecanocéntrica", el organismo es primordial respecto al mecanismo en razón de que este último es solo un tipo de organismo.

Lo que he tentativamente llamado relación "organocéntrica" es una generalización ligada a la hipótesis de la proyección orgánica propuesta de Kapp y a todas las hipótesis que consideran los artefactos mecánicos como entidades biomiméticas. Hemos visto que, de acuerdo a Kapp, el proceso de proyección se puede dividir en tres momentos; en primer lugar, hay una interacción practica entre organismo (ser humano) y medio ambiente. Esta interacción práctica, la cual nace a partir de algunas necesidades adaptativas, genera las condiciones para la producción de artefactos. El segundo momento consiste en la creación de artefactos funcionales que son, en realidad, entidades biomimética. En este estadio, el proceso de proyección comienza a ser consciente, es decir, el sujeto empieza a percibir que el artefacto es una imitación orgánica que proporciona una mejor integración con el medio ambiente. Sin embargo, es solo en el tercer momento que el sujeto realiza, conscientemente, que la máquina es, en realidad, una proyección orgánica. En virtud de este reconocimiento consciente, la máquina se vuelve un dispositivo epistémico eficaz para entender los procesos orgánicos. En otras palabras, los artefactos técnicos no solamente facilitan la integración entre organismo y medio ambiente, sino que también favorecen el conocimiento del mundo externo. De acuerdo a la hipótesis de Kapp, el artefacto y luego la máquina, considerados como mediadores eficientes entre sujetos y medio ambiente, producen las condiciones para la emergencia de la consciencia (evolución del cerebro), el comienzo de la historia y civilización.

He también sugerido que la hipótesis de la proyección orgánica nos orienta hacia una integración estratégica entre bio-filosofía y tecno-filosofía. Esta integración nos permite articular una postura más sofisticada respecto a la visión "mecanocéntrica": es decir, nos lleva a defender la hipótesis que los organismos y las máquinas son entidades ontológicamente distintas, aunque cuando las últimas nos pueden entregar conocimientos genuinos y confiables sobre los segundos. Todo esto en virtud del hecho que los artefactos y las máquinas son, en esencia, una expresión del organismo, y, más en lo específico, son una derivación del órgano/herramienta primordial y prototípico: la mano. Finalmente, hemos visto que la hipótesis "organocéntrica" nos puede liberar de la discusión interminable (y probablemente sin posibilidad de solución) respecto a si los organismos son máquinas. La discusión, de hecho, está basada sobre un prejuicio "mecanocéntrico" motivado más de una intuición implícita (ej. Que las máquinas se parecen a los organismos) que de una reflexión explicita (ej. En qué sentido y como las máquinas se relacionan con los organismos). Entonces, en continuidad con la hipótesis kappiana, las tareas que nos quedan hacer

Revista de Humanidades de Valparaíso, 2019, No 14, 117-138

(ㄷ)(1)(8) CC BY-NC-ND 
En el principio era la mano: Ernst Kapp y la relación entre máquina y organismo Maurizio Esposito

hoy en día son principalmente dos: 1) Como, y hasta qué punto, los artefactos tecnológicos han influido sobre las diferentes concepciones de vida y organismo en la historia de la biología. 2) Averiguar cómo y en qué medida las nuevas tecnologías, mucho más globales y ubicuas que las tecnologías del siglo XIX, están plasmando los nuevos conocimientos sobre el mundo de lo vivo, así como el mundo inorgánico. De hecho, nuevas formas de interacción con el mundo crean las condiciones para la generación de nuevos artefactos tecnológicos, y por tanto, nuevas representaciones. La hipótesis "organocéntrica" nos sugiere que la historia de la biología no es solamente la historia de sus ideas sino que es también (y sobretodo) la historia de artefactos que se han trasformado en dispositivos epistémicos que, a su vez, produjeron nuevas formas de mirar, interpretar, y entender los seres vivos.

\section{Agradecimientos}

Este trabajo ha sido redactado en ejecución del proyecto de investigación Fondecyt N. 1171017.

\section{Referencias bibliográficas}

Aristóteles (2003). Acerca del Alma. Madrid: Editorial Gredos.

Canguilhem, G. (2000). La connaissance de la vie. Paris: Vrin.

Duchesneau, F. (1998). Les Modèles du vivant de Descartes à Leibniz. Paris: Vrin.

Espinas, A. (1897). Les origines de la technologie: étude sociologique. Paris: Felix Alcan.

Espinas, A. (1903). L'organisation ou la Machine Vivante en Grèce, au IV siècle avant J.C. Revue de Métaphysique et de Morale, 11(6): 703-71.

Gehlen, A. (1989). Man in the Age of Technology. New York: Columbia University Press.

Hacking, I. (1998). Canguilhem amid the Cyborgs. Economy and Society, 27: 2-3, 202-216.

Hartmann, F. (2014). Of Artefacts and Organs: World Telegraph Cables and Ernst Kapp's Philosophy of Technology. En W. Boyd Rayward (ed.), Information beyond Borders. Burlington: Ashgate.

Heudin, J. (2008). Les Créatures artificielles: Des automates aux mondes virtuels. Paris: Odile Jacob.

Holmes, W.L. (2014). Cable Theory: Overview. En D. Jaeger, R. Jung (eds.), Encyclopedia of Computational Neuroscience. Springer, New York, NY.

Kant, I. (2014). Antropologia en Sentido Pragmatico. México: Fondo de Cultura Económico.

Kapp, E. (1849). Der konstituierte Despotismus und die konstitutionelle Freiheit. Hamburg: Hoffmann und Campe.

Revista de Humanidades de Valparaíso, 2019, No 14, 117-138

()ㅇㅇㅇㅛ CC BY-NC-ND 
En el principio era la mano: Ernst Kapp y la relación entre máquina y organismo Maurizio Esposito

Kapp, E. (1870). Essay review: Philosophy of the Unconscious. Journal of Speculative Philosophy, 4(1): 84-94.

Kapp, E. (1877). Grundlinien einer Philosophie der Technik. Braunschweig: Druck und Verlag von George Westermann.

Kapp, E. (2018). Elements of a Philosophy of Technology: On the Evolutionary History of Culture. Minneapolis: University of Minnesota Press.

Mitcham, C. (1994). Thinking through Technology: The Path between Engineering and Philosophy. Chicago: Chicago University Press.

Moon, F. (2007). Franz Reuleaux: Contributions to 19th Century Kinematics and Theory of Machines. Appl. Mech. Rev., 56(2): 261-285.

Nicholson, D. (2012). The concept of mechanism in biology. Studies in History and Philosophy of Biological and Biomedical Sciences, 43: 152-163.

Riskin, J. (ed.) (2007). Genesis Redux: Essays in the History and Philosophy of Artificial Life. Chicago: Chicago University Press.

Ryle, G. (1945). Knowing How and Knowing That: The Presidential Address. Proceedings of the Aristotelian Society, 46: 1-16.

Ortega y Gassett, J. (1965). Meditación de la Técnica. Madrid: Espasa-Calpe.

Simondon, G. (2012). Du mode d'existence des objets techniques. Paris: Aubier.

Spengler, O. (2015). Man and Technics: A Contribution to a Philosophy of Life. London: Arktos Media.

Stevens, H. (2011). Life out of sequence: a data-driven history of informatics. Chicago: Chicago University Press.

von Hartmann, E. (1884). Philosophy of the Unconscious. London: Trubner \& Co.

Wood, G. (2002). Living dolls: a magical history of the quest for mechanical life. London: Faber and Faber. 


\title{
The question of animal technical capacities
}

\section{La cuestión de las capacidades técnicas de los animales}

\author{
Ana Cuevas Badallo \\ Universidad de Salamanca, España \\ acuevas@usal.es
}

\begin{abstract}
The ability to use and make technical artifacts has been considered exclusive to human beings. However, recent findings in ethology in light of observations made in nature and in laboratory show the opposite. In the area of philosophy of technology there are few exceptions that take into account the ability of some non-human animals to manufacture and use tools. In this paper I want to show some reasons to reconsider other possibilities. It seems that capacities such as intentionality, culture or even the complexity of the structures of manufactured object are not exclusive to human beings. I will suggest a different way of analyzing objects created by non-human animals, one that tries to explain the gradualness of the structure, but also the plasticity of the behavior exhibited by non-human animals. These two elements (structure and behavioral plasticity) allow a deeper understanding of the great variety of objects that other animals also manufacture and use.
\end{abstract}

Keywords: artifact, animal tools, intentionality, ethology, behavioral plasticity.

\section{Resumen}

La habilidad para usar y hacer artefactos técnicos se ha considerado como una actividad exclusivamente humana. Sin embargo, recientes descubrimientos realizados en estudios etológicos tanto en la naturaleza como en cautividad en el laboratorio han mostrado que esto no es del todo cierto. En el área de la filosofía de la tecnología hay muy pocas excepciones que tiene en cuenta la habilidad de animales no humanos para manufacturar y usar herramientas. En este artículo se pretenden mostrar algunas razones por las que merece la pena reconsiderar este asunto. Al parecer, capacidades tales como la intencionalidad, la cultura o incluso la complejidad de las estructuras de los objetos creados no son característi-

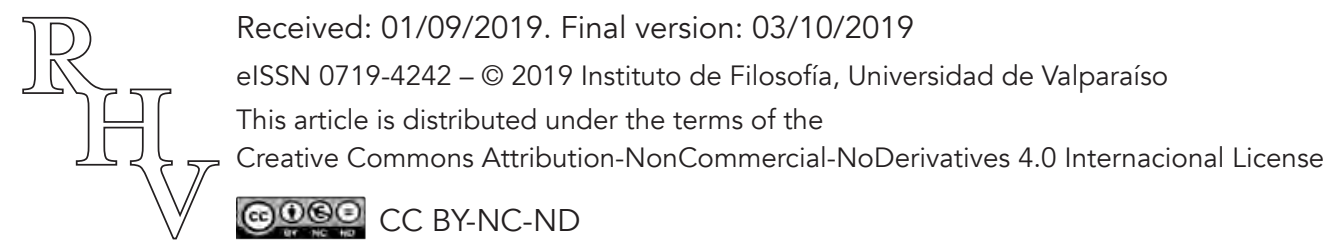


The question of animal technical capacities

Ana Cuevas Badallo

cas exclusivas de los seres humanos. Se sugerirá una forma diferente de analizar objetos creados por animales no humanos, que intente explicar la gradualidad en la complejidad de la estructura, pero que también tenga en cuenta la plasticidad del comportamiento que desarrollan esos animales. Esos dos elementos, estructura y plasticidad del comportamiento permiten una mejor comprensión de la gran variedad de objetos creados y usados por otros animales.

Palabras clave: artefacto, herramientas animales, intencionalidad, etología, plasticidad del comportamiento.

\section{Introduction}

Research on the behavior of non-human animals is a flourishing scientific area and an attractive topic of media attention. Almost every month, new information is published on the capabilities that humans seem to share with other species. Just a few examples: dolphins (Tursiops truncatus) use "learned identity signal" as labels when addressing conspecifics, i.e. they use names to refer to each other (King and Janik 2013); Wild bearded capuchin monkeys (Sapajus libidinosus) in Brazil deliberately break stones, producing flakes and cores that have the characteristics and morphology of intentionally exhibited in hominid tools (Proffitt et al. 2016); dogs (Canis lupus familiaris) can understand both words and intonation of human speech (Andics et al. 2016); pigeons (Columba livia) can learn to distinguish real words from non-words by visually processing their letter combinations (Scarf et al. 2016); sheep recognize familiar and unfamiliar human faces from two-dimensional images (Knolle et al. 2017); ravens (Corvus corax) can plan for events unrelated up to 17 hours, exert self-control, and consider temporal distance to future events (Kabadayi and Osvath 2017).

These new scientific discoveries support good reasons to believe that, characteristics such as awareness or sensitivity, self-awareness, knowledge of the mental states of others, sense of humor, sense of the past or future, language, intentionality, personality or even the ability to develop a culture, or to make artifacts (Glock 2009, 160), are no longer exclusive to human beings. Actually, the thesis of the continuity of capacities between non-human animals and human beings could be considered a good explanation of the existence of those capacities.

Taking into account recent developments and discoveries in studies on animal capacities, the definition of what an artifact is, a central theme in technology philosophy, must be reconsidered. Artifacts are considered the cornerstone of the ontology of technological productions, and since the distinction of Randall Dipert (1993) between instruments, tools and artifacts, many other definitions and categories have been suggested. Almost all definitions assume an anthropocentric point of view, considering that only human beings

Revista de Humanidades de Valparaíso, 2019, No 14, 139-170

(ㄷ)(1)(8) CC BY-NC-ND 
make artifacts or, in other words, because they are an artifact, the object must be made or manufactured by a human being. The arguments to defend human agency are based on the necessary "intentionality" and / or "cultural" or "social" human singularity.

The ability to use and make tools, considered exclusive to the human repertoire, has also been reconsidered in ethology in light of observations made in nature and in the laboratory. However, from the philosophy of technology there are few exceptions that take into account the ability of some animals to manufacture and use tools. Among those exceptions stand out the contributions of Beth Preston (1998), James L. Gould (2007), and Stefano Borgo, Noemi Spagnoletti, Laure Vieu, and Elisabetta Visalberghi (2013).

Here I will analyze these contributions and explore a new way of understanding objects created by non-human animals. The first part of the document summarizes the main definitions of artifacts in philosophy of technology so far, to distinguish the main characteristic that an object must have to be considered a technological artifact. The second part is dedicated to analyzing the contributions of Preston, Gould, and Borgo et al. about no-human animal capacities for making artifacts, and we will discuss its main merits and weaknesses. The third section analyzes whether anthropomorphism is necessarily a fallacious argument, as well as some criticisms of the uniqueness of intentionality and cultural features as human capabilities. The last section will be dedicated to developing an alternative interpretation, based on the behavioral plasticity of non-human animals for the manufacture of complex tools and structures.

\section{Artifacts in philosophy}

The idea that human beings are exceptional for making and using tools is linked to another attempt to identify the specificity of human characteristics: the uniqueness of the structure and capabilities of the hands. The pre-Socratic philosopher, Anaxagoras, considered that the prehensile hand preceded and gave rise to the development of human mind. Centuries later but in the same vein Ernst Haeckel (1889) upheld that the uprising of the human beings ancestors left the hands free for manipulating or handling the environment, causing the increasing of brain size. Friedrich Engels even considered that the development of the ability to manipulate objects and manufacture tools was prior to the manual labor which is the basis of human society. The thesis of incremental brain size and the manipulation and manufacture of tools was discussed in anthropology, and many British anthropologists (Landau 1993) supported the hypothesis about the priority of large brains before the ability to use and manufacture tools. The debate is still ongoing and there are good reasons to state that "large brains followed the tool". At the same time, the connection between the tools and the evolution of the brain and the specific capabilities in paleoanthropology is on the basis of distinguishing between different stages in the evolution of human ancestors, and even between different stages in the evolution of human history.

Revista de Humanidades de Valparaíso, 2019, No 14, 139-170

(ㄷ)(1)(8) CC BY-NC-ND 
This historical connection between human hands and the development of technology leads to the definition of technological artifacts as a human (and only human) result. It is not surprising that the definitions of tools and, in general, of artefacts in philosophy of technology take human agency for granted.

Several definitions of artifacts in philosophy of technology have been raised over the past three decades. After a long period of focusing on the (exceptional) nature of technological knowledge, or the analysis of the relationships between science and technology, some philosophers turned their attention to the ontological realm and tried to identify what technological creations are. There is a general agreement to refer to these objects as "artifacts", using the term in a general sense and labeling with it a broader and confusing set of concepts, such as tools, machines or instruments. This section focusses on a brief analysis of the most representative proposals.

Almost all definitions of "artifact" in philosophy assume human agency and the intentionality of that agency. Randall Dipert (1993; 1995) distinguished between instruments, tools, and artifacts.

An "instrument" is an object that does not need to have been modified but has a property (recognized by someone) and can be used intentionally as a means to achieve a goal due to that property. "Tools" are objects with intentionally modified properties whose objective is to fulfill a goal, or to make them more effective in fulfilling that goal. Tools have a relational content: the new modified features must be recognized by an agent different from the one who made the modification. "Artifacts" are sophisticated tools that share properties with tools and the ability to communicate their properties. The difference between tools and artifacts is less common in more recent philosophical definitions, where tools are generally considered as a simple type of artifacts.

Riso Hilpinen considers that an object is an artifact if and only if it has an author (Hilpinen 1993, 156-157). The object must be produced by someone. In 1993 Hilpinen the "producer" has to be a human being, with intentions and concepts. However, in 2011 Hilpinen opens the possibility for some animals, using the example of Betty, a New Caledonia crow known for its ability to make hooks using wires. Nevertheless, Hilpinen does not delve into the question and in the rest of the paper continues to deal with artefacts produced by human beings. Amie Thomansson expressly defines artifacts as the result of human intentions to produce something of a specific type (Thomasson 2007). And, in the same vein, defenders of the "dual nature" of artifacts insist on the relevance of human intentionality: technological artifacts are defined by their physical structure, designed for specific purposes, but at the same time, they have functional capabilities. related to human Intentionality (Vermaas and Houkes 2006). Ruth Baker suggests that the uniqueness of the artifacts depends on the intentionality of those who produce them with a specific 
The question of animal technical capacities

Ana Cuevas Badallo

function (Baker 2006, 132). Functions define and constitute the identity of artifacts and make them as recognizable and distinguishable objects. On the other hand, these functions cannot be reduced to the material properties of the object.

Another group of definitions emphasizes the social aspect of artifacts, a characteristic that is generally considered exclusive to human beings. According to Trevor Pinch and Wiebe Bijker, artifacts can only exist in social collectives (Bijker et al. 2012). In their famous example of the development of bicycle design, they show how the construction of technological artifacts is the outcome of a social process that is affected by the interests of different social groups: users, designers, producers, etc. John Searle (1995) defended that a physical entity has a status of artifact if and only if its institutional state is accepted, which is based on the intentional use of its functions. Marcel Scheele (2006) suggests that in order to understand the functions of artifacts we need to include the social environment, otherwise it is difficult to distinguish between proper and accidental use of artifacts. And Maarten Franssen (2006) analyzes social aspects of artifacts from a normative point of view: an artifact is a good artifact if it works correctly and can be used for the purposes for which it was designed. The normative judgment for being a good artifact depends on an institutionalized fact.

According to these definitions, the main requirements for an object to become an artifact are: (i) some mental abilities (mainly intentionality) of those who create those objects; (ii) social or cultural organizations that allow a normative interpretation of the functions of these objects; (iii) and a production process (in the sense of a chain of actions) that results in the object. That said, are those characteristics exclusively related to human beings?

\section{Non-human animals artifacts}

There are very few exceptions to this traditional consideration about technological artifacts as products of human agency. In this section I will analyze the contributions of Preston, Gould and Borgo et al.

\subsection{Preston: equipment}

Preston (1998) considers the definitions of "tools" and "use of tools" as they are conventionally used among ethologists, and suggests a different theoretical framework based on the notion of Martin Heidegger's equipment (Zeug) as a substitute for which she considers "popular categories". Preston maintains an explanation that does not isolate the object or behavior associated with the use of the object, but rather connects them with a history and context of use (Preston 1998, 516). For example, identifying a stone as a tool will depend on the previous use of the stone. If someone takes a specific stone and uses it to open a nutshell or nail a nail, the stone has become a hammer. As soon as the stone is

Revista de Humanidades de Valparaíso, 2019, No 14, 139-170

(ㄷ)(1) $\mathrm{CC}$ BY-NC-ND 
discarded, it becomes a natural object again. However, if the user decides that the stone meets some requirements and maintains it for future use, the stone will remain a hammer, because "the actual use determines what kind of tool it is" (Preston 1998, 517). In the case of artifacts, to the extent that they are manufactured, designed for a specific use and with a standardized form, they can be identified as tools, even if they are never used. But, to identify those objects in the category of artifacts (to individuate them, in Preston's terms) it is necessary to know what people do with things of a certain type.

Preston criticizes the definition of tool use proposed by Benjamin Beck in 1980, well known among ethologists ${ }^{1}$. From Beck's perspective, the use of tools is a behavior that involves an external object that must be manipulated and effectively oriented by the animal when using it. However, from Preston's perspective, the notion of tool use is not a good starting point. She suggests a different possibility, based on Heidegger's framework of equipment and practical activity. Heidegger strongly opposes the distinction between subject and object that comes from the Cartesian tradition, as well as that some mental abilities such as intentionality or representability close the gap between subject and object. From Heidegger's perspective the subject-object relationship has to be understood in terms of being-in-the-world. Being is divided into two: human-being (Dasein), and non-human being. The non-human being in turn is divided into Zuhandenheit and Vorhandenheit, "readiness-at-hand" and "presence-at-hand". Those things that human beings encounter in everyday practical activities, like tools or materials, are called in Heidegger terms Zeug, commonly translated as "equipment". The equipment is functionally constituted, is something useful and is used to do something.

So, there is nothing like an equipment, or a useful thing, but "useful things always are in terms of their belonging to other useful things. [...] A totality of useful things is always already discovered before the individual useful thing" (Heidegger 1927/2010, 69). In order that an object actually functions as a useful thing, it has to fit into the context of a meaningful activity. Things become equipment on the basis of their functionality, therefore functionality is a defining feature of equipment, and equipment is what it is only when is actually used.

Function can only be understood by manipulation, and for Heidegger to understand something is impossible without the prior use of a thing. Therefore, "even though the

\footnotetext{
${ }^{1}$ Beck, in a more recent reedition of his 1980 book (2011), has slightly changed the definition: "Our present definition of tool use is: The external employment of an unattached or manipulable attached environmental object to alter more efficiently the form, position, or condition of another object, another organism, or the user itself, when the user holds and directly manipulates the tool during or prior to use and is responsible for the proper and effective orientation of the tool." (Shumaker, Walkup and Beck 2011, 5) (in Italics the differences)
}

Revista de Humanidades de Valparaíso, 2019, No 14, 139-170

(ㄷ)(1)(2) CC BY-NC-ND 
functioning of a piece of equipment becomes available through manipulation, our understanding of equipment also depends on social norms and conventions for how things are normally used" (Susi and Ziemke 2005, 10).

Preston is aware that the application of Heidegger's proposal of equipment to non-human animals has to face some difficulties. First of all, Heidegger's Dasein refers only to human beings, setting aside (in the same category) stones, plants, or non-human animals. Secondly, the "they" responsible of cultural norms are other human beings. And, even if today the idea that animal culture exists is controversial, in Heidegger's works it is not even a possibility. However, Preston considers that Heidegger's notion of equipment can also be applied to the case of other animals, because the difference between human beings and animals is a matter of degree and not an absolute difference. (Preston 1998, 537-538). Actually, many ethological studies have shown that "at least some non-human animals may have rudimentary cultures in exactly the same sense that humans do" (Preston 1998, 538). And, about norms, Preston points out that philosophers and scientists in biology and behavioral sciences often use the concept of function, a normative term.

On the other hand, if something can be part of the equipment, to the extent that it is used that way, and the notion of equipment is not limited to portable things, then if a hammer is part of the equipment, the anvils are too. But Heidegger was thinking about Dasein, so the equipment is always relative to the functions attributed to manipulation and culture, and those things that animals use are not equipment in the same sense. An anvil is always an anvil, even when an elephant uses it as a hammer (Preston 1998, 542).

Another consequence of the notion of equipment is that everything that is used for a purpose is part of the equipment, therefore, if houses are equipment, then nests are equipment. So far so good. But if trees are used for climbing, then "the ground you walk on and the air you breath must also qualify as equipment on this account. This difficulty is due to the tendency of any function-based theory to generate continua" (Preston 1998, 543).

\subsection{Gould: Artifact}

Another author who deals explicitly with artifacts and animals is Gould (2007). In a collective book about the creations of the mind, Gould begins his contribution by asking "What is an animal artifact?" Gould does not use any of the different definitions proposed, but he raises his own definition "I will take an artifact to be any creation on the part of an animal, using/or modifying available material, which is useful to it or its offspring." (Gould 2007, 249). Not every kind of creation is taken into consideration, but those "that most human find impressive" (Gould 2007, 149). All of them "creations of the mind", or better said, "created by instinct" (Gould 2007, 149).

Gould distinguishes between three main categories depending on the purpose of the animals (common among the ethologists' classifications of "tool use"): (i) artifacts used 
for hunting, foraging, or processing food; (ii) artifacts employed for protection or as homes; and (iii) artifacts used to attract members of the opposite sex. Gould's classification also addresses two other criteria in addition to the purpose: the phylogenetical order, and the materials used for constructing the artifact (animals' secretions like silk, wax, saliva; stones, shells, dried mud/clay; and vegetation). But those criteria are used carelessly.

It also includes tools such as a different category among artifacts used to hunt and search for food, again using the Merriam and Webster dictionary for the meaning of "tools".

He does not consider the definition anthropomorphic (although the instrument must be used or worked by hand, or at least used to perform an operation or necessary to practice a vocation or profession). Gould concludes that eyes, fingernails, teeth and Wernike's area in the brain qualify as tools. Actually, as Gould points out:

$[\ldots]$ if we hold tool artifacts to a stricter standard for animals [...], and require that the tools be modified in some non-trivial way [...], then the list becomes dramatically shorter. [...] I know of only one clear case: the hook and the step-cut tools carefully crafted by the crows on New Caledonia for removing insect larvae from branches. (Gould 2007, 252) ${ }^{2}$

Gould's examples are controversial and are generally discarded by many ethologists, to the extent that they can be slippery slopes, leading to accepting as artifacts some hard-to-classify by-products.

For example, Gould considers a spider web or the cocoon of silkworm as artifacts, one for hunting and the other one for protection. These things are not considered artifacts or even tools among ethologist, as far as the object has to be inanimate, not internally manufactured, and unattached to the environment, to be a tool. If we consider spiders' web or caterpillar cocoons as artifacts, then the nails could be considered artifacts when they are used for screwing, or the eggs shell, or even the placenta, are artifacts for protecting the embryos.

Another problematic question on Gould's paper is his consideration about the cognitive capabilities of those animals able to use and made artifacts. Whereas he considers that "methods of artifact production in animals and in humans are to some degree linked, rather a result of a separate creation" (Gould 2007, 266), he deals merely in the conclusions with the difference between innate and inborn instructions, and more flexible, goal-oriented systems. Arranging into the same broad category every kind of artifact manufactured or used by a non-human animal.

\footnotetext{
${ }^{2}$ Actually, the list is longer than Gould presupposes, and at the list ethologist have add chimpanzees (Pan troglodytes), orangutans (Pongo pygmaeus), and woodpecker finches (Camarhynchus pallidus), that will be discussed latter.
}

Revista de Humanidades de Valparaíso, 2019, No 14, 139-170

()ㅇㅇㅇ CC BY-NC-ND 


\subsection{Borgo et al.: Naturefacts}

Borgo et al. (2013) explore if a philosophically-inspired definition of physical artifact developed by human could be applicable for some tools used by Capuchin monkeys (New World monkeys of the subfamily Cebinae). Those monkeys are famous for their ability to use hammers and anvils to open nuts. Borgo and Vieu (2009) suggest a definition for physical artifacts that goes beyond the usual definitions of artifacts, including "objects of nature" as those objects intentionally selected for use with a purpose, while to be an artifact, the object must be physically modified. Spagnoletti and Visalberghi study Capuchin monkeys on the wild and in captivity as well. The main argument of the paper is that the notion of artifact is not specific to the human being, a conclusion reached on the basis of behavioral studies, since capuchin monkeys show behaviors that could be interpreted as intentional.

The main limitation, in their own words, is the "behavioral" point of view. If the essence of the artifacts depends on the intentionality, necessary when selecting, modifying and using objects for a purpose, then it is necessary to face the problems associated with the attribution of intentionality to non-human animals.

Capuchins are well known for their use of hammers and anvils to break shells, however, they generally do not manufacture those objects: they choose among the different possibilities those that are most suitable for the operation. Among the monkeys they are the best tool users, their abilities being similar to those of chimpanzees. (Pan troglodytes). Actually, and as Borgo et al. point out, they have been shown capable of transferring relations from one situation or set of objects to a different one, using analogical reasoning, applying relational structures in tool using tasks and being sensitive to the function properties of the tools (Borgo et al. 2013, 378). The observations of tool use by capuchins in the wild suggest that "the ability is acquired, requires intentionality and can be taken as cultural trait of some groups" (Borgo et al. 2013, 379). And even more than that: anticipate future needs, remember items that are out of sight and plan the course of action (ibid). The evidence of the intentionality of Capuchins comes from the observed behavior, for example, when they select stones of the appropriate material and the weight considering the purpose: cracking open nuts, or other encased foods, less resistant than the nuts. Capuchins need to acquire these skills during their lives, that is, these are not innate behaviors: Capuchins have to learn by practicing to select the right object.

Among them "efficiency in cracking nuts with tool varies widely among wild capuchins" (Visalberghi and Fragaszy 2013, 210). They are able to classify artifacts, distinguishing between anvils and hammers, and between them by functional and non-functional characteristics, by their purpose and even by the context.

In this sense the theory of naturefacts upheld by Borgo and Vieu of attributing capacities to objects and not necessarily manufacturing them could be applied to the case of

Revista de Humanidades de Valparaíso, 2019, No 14, 139-170

(ㄷ)(1)(8) CC BY-NC-ND 
the Capuchins. However, they say, there are other characteristics of the artifacts that are lost in the case of the Capuchins, such as the transmission of skills information among the conspecifics, that is, teaching, essential in the case of human artifacts.

On the one hand, both Preston and Gould maintain a very open categorization of non-human animal artifacts: all kinds of objects used by them with a function, including some parts of the organism or parts of the environment. In that big category Preston and Gould do not distinguish, for instance, those objects that are crafted from those that are just used without modification; or those that are crafted or mastered after long periods of trial and error learning process from those that are made instinctively in a parsimonious way; or those that are crafted by a community instead only by a single individual. On the other hand, Borgo et al. (2013) apply the notion of naturefacts in a very limited way. This characterization, based on the observation of the behavior of Capuchins using tools, is restricted to a single species and to those objects selected and not designed to perform a technical action.

\section{Exclusive features?}

With the exception of these three papers, philosophical definitions of artifact avoid the consideration of those objects used or made by non-human animals. This oblivion, more or less conscious, shows an anthropocentric prejudice, originated by the philosophical assertion that the behavior of animals, however complex, is never the result of a mental process. On the ethologists side the situation is slightly different: the strategy of including every object used or made by non-human animals in the same broad category, probably tries to avoid an accusation of anthropomorphism. In any case, the defense of the human exclusiveness of certain characteristics it is being challenged. The following sections summarize the main arguments in favor of the supposedly human capabilities that seem to be shared with other species.

\subsection{Anthropomorphism and Anthropocentrism}

The claim that anthropomorphism is a fallacious argument was made in order to identify and rule out anecdotalism, such as when Darwin and Romanes were trying to establish the continuity of human and non-human traits and proposed that some non-human traits should be understood using traits possessed by humans. Anthropomorphism is defined as "the attribution of human traits, specifically human psychological traits, no non-human." (Fitzpatrick 2008, 235), or more precisely "the attribution of human psychological, social, or normative properties to non-human animals" (Andrews and Huss 2014, 711).

However, in principle there is nothing wrong with attributing human properties to nonhuman animals. As Keeley (2004) has pointed out "we simply cannot know a priori whether a given human trait is or is not uniquely human, or whether a given species shares

Revista de Humanidades de Valparaíso, 2019, No 14, 139-170

(c) (1) 8 (을 CC BY-NC-ND 
any human traits" (Keeley 2004, 533). In the same vein Fitzpatrick points "This [anthropomorphism] in itself, is not a mistake, since humans surely do share many psychological traits with other species." (Fitzpatrick 2008, 235). The problem arises when we attribute human psychological characteristics to non-human animals with lack of evidence, that is, when it is possible to maintain a better explanation backed by non-anthropomorphic evidence.

On the other side, considering that human mental properties are not shared with of other animals has received different names: anthropocentrism (Fisher 1996, 7), reverse anthropocentrism (Keeley 2004, 535), anthropodenial (Sober 2005, 85), theoretical conservatives (Fitzpatrick 2008, 228), and anthropectomy (Andrews and Huss 2014, 720). Fisher identifies Donald Davidson as a tough anthropocentrist, as far as Davidson suggests "those who are inclined to ascribe thought to animals on the basis of their purposive behavior are anthropomorphic." (Fisher 1996, 7). All of them agree with cognitively sophisticated anthropomorphic explanations instead of accepting cognitively unsophisticated explanations that can be equally backed by data. (Sober, 1998).

Morgan's Canon was suggested to avoid the anthropomorphic fallacy. It is widely defended in animal psychology, and states that: "In no case may we interpret an action as the outcome of the exercise of a higher psychical faculty, if it can be interpreted as the outcome of the exercise of one which stands lower in the psychological scale" (Morgan 1894, 53). The Canon has generally defended by the simplicity it poses. However, some authors (Fitzpatrick 2008; Sober 1998, 2005) have criticized by arguing that Morgan's canon is not really a principle of simplicity. The Canon cannot connect with the principles of parsimony (posting fewer things): "Morgan's Canon, however, asks us to prefer theories that posit processes that come lower in the hierarchy of cognitive sophistication rather than theories that posit fewer things" (Fitzpatrick 2008, 230). On the other hand, Morgan argued that the simplest explanation for the behavior of an animal is the most anthropomorphic one (Morgan 1894, 53-54), since it is simpler to explain animal behavior in the same terms as we would do if the behavior were exhibited by a human being. Another criticism against Morgan's Canon comes from the idea that there are "higher" and "lower" psychical faculties. Today, modern theorists prefer to refer to the relative sophistication of the cognitive processes (Buckner 2013).

As an alternative to Morgan's Canon, Fitzpatrick suggests evidentialism:

in no case should we endorse an explanation of animal behavior in terms of cognitive process $\mathrm{X}$ on the basis of the available evidence if that evidence gives us no reason to prefer it to an alternative explanation in terms of a different cognitive process $\mathrm{Y}$-whether this be lower or higher on the psychical scale. (Fitzparitck 2008, 242)

And Buckner proposes to recover Hume, when he detected the bias in rationalists like Descartes. Buckner names Hume recommendation "Hume's Dictum", which argues that 
when assessing whether a certain psychological capacity is shared between humans and animals, we must adopt competence criteria that can be applied fairly to both (Buckner 2013, 865).

\subsection{Intentionality}

Philosophers have usually argued against the mental capabilities of non-human animals. The main argument about the lack of intentionality in other animals depends on our unique capacity for a symbolic and articulated language. Davidson $(1985,1999)^{3}$, argues that in order to have intentional states it is necessary to be able to have internal representations, i.e. intentional states happen in an intensional context. Therefore, since animals cannot have propositional attitudes, they cannot have intentional states.

Malcolm, in a classical defense of the attribution of intentional behavior to another animal (Malcolm 1972-1973, 13), suggested the following example: let's suppose that we see the dog of our neighbor chasing our cat. The cat runs at full speed to the garden's oak, but suddenly and surreptitiously she changes her trajectory and climbs to a close maple. The dog does not see the maneuver and when he arrives to the oak puts his front paws on the oak and barks to the branches over him. Malcom defends that if we have been seeing the scene, then we are justified to think, "the dog believes that the cat has climbed the oak". Nevertheless, Davidson admits it could look like a plausible explanation, but insists that sensu stricto the dog cannot believe anything, because he has not language.

Other philosophers, as Daniel Dennett and Fred Dretske, have claimed the intentionality of the behavior of some animals. Dennett distinguishes between different orders of intentionality or intentional attributions, going from zero-order intentionality, when the creature does not have any intentional states like beliefs or desires at all; first-order intentionality, when the creature possesses beliefs, desires or hopes, but the content of the states does not contain intentional components - i.e. they are only about behavior-; second order intentionality, when the creature has beliefs and desires about beliefs and desires; and third order intentionality, when the systems have intentional states like "a wants $b$ to believe that a believes that he is alone". Dennett adopts the strategy known

\footnotetext{
3 "Neither an infant one week old nor a snail is a rational creature [...] we may say of the infant from the start that he is a rational creature because he will probably become rational if he survives, or because he belongs to a species with this capacity. Whichever way we talk, there remains the difference, with respect to rationality, between the infant and the snail on one hand, and the normal adult person on the other [...] The difference consists in the having of propositional attitudes such as belief, desire, intention and shame. This raises the question how to tell when a creature has propositional attitudes; snails, we may agree, do not, but how about dogs or chimpanzees? The question is not empirical; the question is what sort of empirical evidence is relevant to deciding when a creature has propositional attitudes [...] language is a necessary concomitant of any of the propositional attitudes [...] belief depends on having the concept of objective truth, and this comes only with language." (Davidson 1982,317)
}

Revista de Humanidades de Valparaíso, 2019, No 14, 139-170 
as "intentional stance", which consists "of treating the object whose behavior you want to predict as a rational agent with beliefs and desires and other mental stages exhibiting what Brentano and other call intentionality." (Dennett 1981, 151). Dretske considers that some animals are agents because they act, not just behave. He uses the example of some foraging birds that distinguishes some nasty tasting butterflies, and even they can mistake different species of butterflies because of their similar appearance. Dretske maintains that to explain the bird's behavior in terms of what it believes:

it is natural because memory about some previously experienced object is so obviously implicated in why the birds behaves the way it does [...] Unlike the thermostats or the Scarlet Gilia [a kind of plant] things that happens to the particular system relating to the success of its behavior is relevant to its future behavior. (Dretske 1999, 28)

Hans-Johann Glock has also discussed Davidson's radical proposal, and he suggests another cannon (less demanding than Morgan's cannon): "we only should attribute higher order capacities to an animal if that is the best explanation of its behavioral capacities. That cannon rests on a gradual classification of the mental capacities, which go from those of higher order to the lower ones" (Glock 2009, 79). Glock prefers to refer to "thoughts" instead of "propositional attitudes", and defends that some animals without language may have concepts, these being of a simple type. And instead of "mental representations", he suggests using "cognitive abilities", among which the cognitive ability to "discriminate" stands out, something that many non-human and languageless animals have. The Malcolm example dog recognizes the tree and distinguishes it from other objects, and this is where the concepts arise in the Glock argument: if the dog is able to recognize the tree (taking into account some of its features), it is because he has a "tree" concept. On the other hand, if an animal has the capacity to be right or wrong about the world, it is because that animal has beliefs. Since animals have no language, they cannot offer expressions that express their beliefs, but we can infer those beliefs on the basis of some behavioral attitudes, even some facial expressions that some animals share with us. Concepts are discriminatory principles (between different possibilities), therefore having concepts is the same as having the capability to recognize between different kinds of things (Price 1953, 355; Dupré 1996, 331), something that we can confirm with observations of animals' behavior in the wild and also in captivity. Animals have the ability to distinguish between colors, flavors, noises, shapes, quantities, types of creatures, etc., skills they need to learn, they are not innate (Tomasello and Call 1997, caps. 4-5). On the other hand, we must establish gradual differences between different species. Although some species have the ability to distinguish between different objects, this does not mean that they all have the same abilities to possess discriminatory or classifying concepts (for example, bees have the ability to distinguish between different flowers, but it is not the same as saying that they have the concept of different flowers). 
The difference between the ability to distinguish and the ability to discriminate conceptually between different things can be useful to understand the difference between the use of objects and the manufacture and use of artifacts by some animals. The ability to use objects that distinguish between different possibilities could be explained as simple mechanisms, innate dispositions or skills acquired by trial and error or more complex learning processes.

\subsection{Culture}

The other main reason to defend that artifacts are the exclusive result of human agency is the social and cultural uniqueness of human beings. Culture has traditionally been considered as one of the most important characteristics of humankind, and as intentionality, exclusive of human beings. However, the thesis on the existence of animal culture has attracted some adherents. The tradition of considering some animal capacities as social has a long history. For example, Aristotle points out that birds learn socially to sing. Charles Darwin on The Decent of man (1871) argues that animals learn by experience, but also by imitating the behavior of other animals. And in the same vein, C. L. Morgan, believes that organisms can survive in challenging environments because they acquire knowledge and skills learned from others. However, the real debate about animal culture begins in the mid-twentieth century, when some Japanese researchers began to document traditions among free-living animals ${ }^{4}$. Since then, the number of documented examples of socially learned behaviors among non-human animals has increased exponentially.

Nevertheless, there is no agreement between specialists if the capacity for social learning is sufficient to establish that a group of animals of a species has culture. As Laland and Galef (2009) suggest, there are several reasons for different opinions. "Part of the disagreement over animal culture reflects definitions issues. Biologists [...] seemingly tend to employ less exacting definition that do anthropologists [...], and psychologists often take an intermediate position between the two" (p. 9). For instance, John Tyler Bonner defined culture as "the transfer of information by behavioral means" (Bonner 1980, 9), and considered that invertebrates exhibit rudimentary culture. Another example of this broad consideration of culture is the one advocated by Charles Lumsden and Edward Wilson (1981), who attributed culture to some 10.000 species (including bacteria). On the other hand, there are researchers (such as Galef or Tomasello) who demand traits similar to those exhibited by humans, such as teaching, specific group norms or even ethnic markers to have a culture. With such demanding requirements, it is difficult to maintain that there are other species, different from human beings, with culture.

\footnotetext{
${ }^{4}$ Such as Imo, a Japanese macaque that started to wash sand-covered sweet potato in freshwater on Koshima Island. Twelve years later, other macaques from the Imo's group showed the same behavior, a clear example of socially learned behaviors.
}

Revista de Humanidades de Valparaíso, 2019, No 14, 139-170

(ㄷ)(1)(2) CC BY-NC-ND 
Another reason for disagreement:

concerns the kinds of evidence sufficient to establish that differences in the behavior of geographically separated populations of species result from social learning rather than from genetic differences between populations or differences in the way diverse ecologies shape behavioral development of individuals. (Laland and Galef 2009, 9)

For instance, McGrew and Tutin (1978) were the first to show different cultural patterns between a troop of chimpanzees in Kasoge (western Tanzania) and another troop observed at Gombe, 50 kilometers from Kasoge. Years later, McGrew with some other colleagues, edited Chimpanzees Cultures (1992), where they showed a large number of examples of variations in chimpanzee behavior repertoires. In the same line, but with other species, go Schaik, Ancrenaz et al. (2003) (orangutans); Perry, Panger et al. (2003) (white-faced capuchin monkeys), or Krützen et al. (2005) (bottlenose dolphins), showed evidence of behavioral repertoires of many large-brain mammals that lived in different places, which they explain with the hypothesis of being species with culture. But, in any case, there is enough evidence to maintain, that there are at least many other species capable of learning and imitating socially, and human culture and animal behavior traditions, if not homologous, are at least analogous (Galef 2009).

\section{Animal tools}

Of the three characteristics that an object has to fulfill in order to become an artifact, the materiality of the object remains essential: the result of the production process must be an object. In the case of objects produced by non-human animals, specialists refer to them as "tools".

There are several definitions and classifications of "tool use" in ethology. Everyone agrees that the tools have to be external objects to the animal that uses them, avoiding the possibility of using the animal's own organs, even when they use them functionally (like, for example, aye-aye's amazing finger Daubentonia madagascarensis, used as a hook to hunt worms inside tree barks). Boswall and Beck explicitly say so: tools have to be an unattached (or manipulable attached) environmental object (Boswall 1977a; 1977b; 1978; 1983; and Beck 1980). Most definitions agree that the object has to be dynamic (Van Lawick-Goodall 1970, 195; Alcock 1972, 464; St. Amant and Horton 2008, 1203 ; Bentley-Condit and Smith 2010; Shumaker, Walkup and Beck 2011, 5), i. e. the animal has to use it dynamically. However, those who wish to include things like bird or insects nests do not agree with this feature (Pierce 1986, 96). Similarly, there is a general agreement that internally produced objects, such as spider webs or silkworm cocoons, cannot be considered tools sensu stricto (except Gould 2007, which defend otherwise). The most comprehensive classifications of "tool use" have been done by Bentley-Condit and Smith (2010), and Shumaker, Walkup and Beck (2011). Bentley-Condit and Smith suggest a

Revista de Humanidades de Valparaíso, 2019, No 14, 139-170

(ㄷ)(1)(8) CC BY-NC-ND 
The question of animal technical capacities

Ana Cuevas Badallo

classification of ten categories, which distinguishes between different activities that can be done with these tools. Therefore, tools are classified taking into account their function and not their shape, structure or physical characteristics. Similarly, Shumaker, Walkup and Beck, classify using the same argument, but their classification is broader and suggest 22 ways to use tools.

There is a general agreement between the different definitions and classifications: an object becomes a tool when used with a purpose and a function. Nevertheless, considering the purposiveness of an action creates many difficulties. Is it possible to distinguish between the "use with a purpose" of a chimp and the "use with a purpose" of an ant or a wasp? Is purposiveness the same as intentionality? And, in that case, is every "tool use" behavior be intentional?

But there is another way to address this problem: consider the relationships of living beings and their environment on an ongoing basis. All living things are part of an environment and exchange energy, as well as other products and by-products with their environments. In that sense, each living being is an agent in their respective media. In those exchanges, the media and the agent modify each other ${ }^{5}$. In some cases, these exchanges with the media are carried out using and modifying the media for a specific purpose. Establishing whether the purpose is technical or not is a matter of the agent, how this agent uses the object and for what purposes. For example, the difference between a technical artifact and an artistic artifact depends mainly on the use of the object: a ceramic vase can be a container for transporting liquids, or a work of art if the same vase is contemplated inside a cabinet in a museum. The environment of use of the object has changed, and also the agents that use the object. In that sense, the physical object can be the same, but the relationship of the object with the agent or agents, as well the purpose of the object, are different.

Here I would like to explore this approach, taking into account the idea of the agency of living beings in their media, to have a better understanding of the artifacts used and manufactured by non-human animals. Based on this explanation, I suggest a gradual differentiation between the different types of objects used and manufactured by non-human animals. This gradual differentiation is based on two axes: one is the "complexity of the structure" of the object and the second the "behavioral plasticity" of the agent to modify

\footnotetext{
${ }^{5}$ Just two examples to illustrate those changes: "the origin of oxygenic photosynthesis in Cyanobacteria led to the rise of oxygen on Earth $\sim 2.3$ billion years ago, profoundly altering the course of evolution by facilitating the development of aerobic respiration and complex multicellular life." (Soo et al. 2017, 1436). Or the modification of the landscape by beavers: "beaver dams can create a series of impoundments in streams that stretch for kilometers in otherwise dry landscapes, dramatically altering streamside and floodplain vegetation." (Pilliod et al. 2018, 58). Human beings also altered the environment, in larger scale than beavers but not than Cyanobacteria.
}

Revista de Humanidades de Valparaíso, 2019, No 14, 139-170

(c) (1) 8 (을 CC BY-NC-ND 
The question of animal technical capacities

Ana Cuevas Badallo

the environment. Some artifacts may exhibit a very complex structure, but they have been manufactured on the basis of a fixed and innate behavior, while other artifacts with a simpler structure are produced by a more flexible behavior developed by the agent.

\subsection{Axis 1: The structure}

Taking into account the first axis of the structure, for an object to become a technical artifact, it is necessary for an agent (or a group of agents) to identify that object by its special structure to perform a specific function. There are three possibilities: (i) the object is not structurally modified, that is, it is only discriminated between other objects due to its special characteristics (a naturefact in terms of Borgo and Vieu); (ii) the object is an artifact created by the modification of materials found in the environment; (iii) the object is an assembled structure that uses different types of materials (nests).

(i) Examples of objects used as artifacts but non structurally modified:

- Small pieces of soil or small pebbles thrown by the two-colored Conomyrma ants at the entrance of their rival ants' nests.

- Small pieces of soil thrown by the ants Tetramorium caespitium to the entrance of the Nomia melanderi bees' nests that are attacked and eliminated when they go out of the nest.

- Stones that sea otters (Enhydra lutris) put in their thorax to open mollusks like mussels (observed by Hall and Schaller in 1964).

- Rock used as an anvil to open a cockleshell by black spot tuskfish (Choerodon schoenleinii) (Jones et al. 2011, 865).

- Stones, pieces of land, branches and grass that elephants (Loxodonta africana and Elephus maximas) throw to attack, explore and, perhaps, play.

- Pieces of bread or other discarded food (which humans throw away) that herons (Butorides virescens and Butorides striatus) use as bait to fish for fish (in this case, these objects have been made by another species, Riehl 2001).

- Sponges from the bottom of the sea that the dolphins in western Australia select and put on their rostrum for foraging on the sand looking for food (Krützen et al. 2005).

- It is worth mentioning those naturefacts that are used repeatedly by the same animal, and saves it for future use. Tai chimpanzees, for example, use some stones to break nuts, and those that fit especially well for that purpose are kept for future uses. (Boesch and Boesch 1990, 97). And similarly, those capuchin monkeys analyzed by Borgo et al. 2013.

Revista de Humanidades de Valparaíso, 2019, No 14, 139-170

(c) (1) $\mathrm{O}$ (을 BY-NC-ND 
(ii) The second type of objects are the result of materials that have been modified (manufactured) to be used for technical purposes. So far, ethologists have identified four species of non-human animals that can manufacture tools: chimpanzees (Pan troglodites), orangutans (Pongo pygmaeus), New Caledonian Crows (Corvus moneduloides), and Woodpecker finches (Cactospiza pallida).

- Chimpanzees were the first non-human animals observed in freedom using objects made by themselves. Goodall in 1964 saw a group of chimpanzees in Gombe using modified tree branches to fish termites. Later, other groups of chimpanzees (in Gomeb, Mahale, Täi, Bossou and Goualougo) were also observed using other kind of tools, like stone hammers and anvils, tree branches for dipping honey, or leaf sponges for drinking water (Sugiyama and Koman 1979; Boesch and Boesh 1990; Sanz et al. 2004). There are differences between the groups in terms of the type of tools used, depending on the family and the environment in which they live. Some researchers (Boesch 1996; Möbius et al. 2008) conclude that these differences are based on cultural features.

- Another species that have been studied are the orangutan (van Schaik et al. 1996). A population of Sumatran orangutan modify and use trees branches to access to insects and to the Neesias seeds (a kind of fruit with hard and irritating shell).

- Hunt and Gray (Hunt 1996; 2000; Hunt and Gray 2002; 2003; 2004) have studied the Crows of New Caledonia, impressive users and creators of tools. They have the ability to make some objects to extract worms from bark trees. They select among the branches and leaves of the trees and give them three-dimensional shape. They are able to perform these actions in a very similar way to hominids, with a high level of standardization in manufacturing, high levels of skill in production and cumulative changes in the design of objects:

They (i) selected a fork formed by, usually, two twigs; (ii) broke off one twig just above the junction (side twig), then discarded it; (iii) broke off the remaining twig just below the junction (tool twig); and (iv) carried out fine sculpting of the hook on the tool twig with the bill, in between removing the compound leaves. The sculpting removed small pieces of wood from the hook, which refined and sharpened it. (Hunt and Gray 2004)

- The Woodpecker finches also manufacture objects. In this case, those birds modify twigs and prickles for extracting arthropods from holes or cracks in the barks. They shape these objects, shortening or cleaning them from the lateral branches that prevent proper and efficient use (Tebbich and Bshary 2004). $50 \%$ of the food that they eat during the dry season is obtained with the use of those hooks.

Revista de Humanidades de Valparaíso, 2019, No 14, 139-170

()ㅇㅇㅛ CC BY-NC-ND 
(iii) As I mentioned, the most common classifications of animal tools do not include nests. The reason argued is that "nests are not manipulable" (Shumaker et al. 2011, 9). I agree that to consider an object as a "tool", it must not only be used for a purpose, but must also be manipulable to modify the environment with it. However, if we expand the category to include sets of materials, which have a specific structure to fulfill some functionalities, then nests must be included. Opening the door to nests as artifacts built by non-human animals results in a large number of cases in many different subgroups: from the best-known examples of nest built by birds and insects, but also by mammals, amphibians, fishes, reptiles, and spiders. An interesting feature that the nest can have - and almost none of the tools mentioned so far - is that many nests are built by more than one agent. Nests generally involve the collaborative work of more than one agent and, in many cases, a large number of agents. Only a few examples are described below:

- The Potter wasp (in the family of Eumeninae) are solitary wasps that can build nest with the shape and appearance of pots. Those nests can have one or several individual brreding cells. The building material usually is mud made of a mixture of soil and regurgitated water, but other species also use chewed plant material. "Their nests have unusually thick outer walls that might function both as waterproofing and as fortification against predation and females will assiduously repair experimentally induced damage" (Matthews et al. 2018, 93).

- The nest of the honey bee (Apis mellifera), is built by the workers of the colony, and the internal structure is very complex: a densely packed group of hexagonal prismatic cells made of beeswax. Those cells are used to store food (honey and pollen) and to house the brood. "The honeybee hive retains heat and moisture and, during winter, can maintain a temperature differential as great as $+59^{\circ}$ " (Pierce 1986, 100).

- The nests of Macrotermes termites of Africa:

the labyrinthine internal structure of these termitaries has been designed in the course of evolution to guide a regular flow of air from the central fungus gardens, where it is heated and rises by convection [...] the architecture is so efficient that the temperature within the fungus garden remains within one degree of $30^{\circ}$ and the carbon dioxide concentration varies only slightly, around 2.6 percent. (Wilson 1975, 11-12)

Revista de Humanidades de Valparaíso, 2019, No 14, 139-170

()ㅇㅇㅇㅛ CC BY-NC-ND 
- The Leaf-Curling Spider (Phonognatha graeffei) weaves a leaf or other object in the center of its nets as a hiding place for birds and other predators. The leaves curl to form a funnel that the spider uses to hide inside (Thirunavukarasu et al. 1996, 187).

- The male of the three spine stickleback fish (Gasterosteus aculeatus) builds nests with small pieces of plants woven into round nests with an opening on one side. They are held together by a secretion of the male's kidneys. Sometimes the nest is built on plants that are fixed to the substrate (Sargent 1982).

- Among non-human animals, birds are among the most impressive nest builders: "Bird nests include the best and the most highly evolved nests known among vertebrate animals" (Collias and Collias 1984, 3). In a recent paper of 2016 Alexis J. Breen, Lauren M. Guillette, and Susan D. Healy asked: "What Can Nest-Building Birds Teach Us?", where they pointed out that:

The techniques with which birds build their nests [...] range from the sculpting of burrows or cavities from substrate excavation, through the moulding of mud or salivary mucus by vibrating head and/or shaping breast and feet movements, the piling up of materials where subsequent bill manipulations, coupled with side-to-side shaking movements, may be made in order to entangle or intertwine nest components, to the weaving of hanging nest baskets using intricate tuck, looping, interlocking, winding, and knotting bill-made stitches to fasten and secure grassy materials. (Breen et al. 2016, 84)

- Just a few examples to illustrate the many possibilities that birds can display as nest builders: "The nests built by the Hornero birds (Furnarius rufus) have an elaborated architecture." (Zyskowski and Prum 1999). Those nests are made with a mixture of clay, leaves and grass. The Hornero couple builds an oven-like nest every year, the enclosed space is U-shaped, with a hall separating the nest chamber from the outside. The incubation chamber is safe from inclement weather, particularly storms and winds.

- The long-tailed tit (Aegithalos caudatus) construct their nest from four materials - lichen, feathers, spider egg cocoons and moss - with over 6,000 pieces used for a typical nest. The nest is a flexible bag with a small entrance on top. The structural firmness of the nest is provided by moss and spider silk netting together.

- The colorful displays built by Bowerbirds males (Ptilonorhynchidae) to attract females. Those bowers usually "include stick towers up to $3 \mathrm{~m}$ high or huts up to $4 \mathrm{~m}$ in diameter, decorated with as many as several hundred or thousand flowers, fruits, mushrooms, snail shells, butterfly wings, stones, and other natural objects." (Diamon 1986, 31). Males can spend hours arranging 
the display, and it takes "several years before males build typically adult bowers. During these years [...] males may learn how to build bowers by watching older males, and females may learn which males to choose by watching older females." (Diamon 1986, 33-34).

- The Sociable Weaver (Philetuirus socius), a species of gregarious bird, that built a massive nest together that can work for many years:

The nest mass can be divided into two main structural regions: the superstructure or roof, and the substructure or living area which contains the chambers. A typical well-established nest mass which has been in use for several years consists of an extensive superstructure of small sticks $10 \mathrm{~cm}$ to $30 \mathrm{~cm}$ long and often thorny, and an even more extensive substructure of grass straws extending below the supporting branch on which the mass is built. The number of chambers varies with the size of the nest mass from five to 50 . Each chamber consists of an entrance tunnel up to $25 \mathrm{~cm}$ in length and 6-7 cm diameter leading vertically into a nest chamber measuring some $15 \mathrm{~cm}$ in diameter and set to one side of the tunnel. The chambers are all separate and do not interconnect with one another inside the substructure. (Maclean 1973, 194)

- And for finishing this list of examples, just some made by mammals:

Prairie dogs (genus Cynomys) excavate their nests by digging burrows from the ground. Their habitat, the Great Plains of North America, has extreme variations in the weather from one season to another, and for that reason the nests are built to withstand extreme temperatures, as well as floods and fires (Hoogland 1996, 6). The internal structure of the nest is composed of different cameras located at different depths and serve different purposes. There are cameras used as a refuge for predators, other cameras for storing food or listening to predators, and there are also nurseries, usually located deep in the ground where temperatures are more stable. The size of the loan varies, but it can be as large as 65,000 square kilometers (discovered in Teas in 1900 and the home to an estimated 400 million prairie dogs).

- Beavers (genus Castor), modify the environment using massive logs, branches (cut by themselves) and mud structures to block streams and create ponds where they build their shelters, also built with branches and mud. These shelters are usually found in the middle of the ponds and can only be reached by underwater entrances. Beavers build dams in areas with shallowand mobile waters. They avoid currents of more than $60 \mathrm{~cm}$ deep or strong currents, and place the dams where there are restrictions in the flow of the current. They usually use objects such as rocks or tree stumps to secure their prey. Some-

Revista de Humanidades de Valparaíso, 2019, No 14, 139-170

()ㅇㅇㅛ CC BY-NC-ND 
The question of animal technical capacities

Ana Cuevas Badallo

times they can dig channels to bring water to their favorite trees and swim near the trees. Once they have built the dam, the family builds a shelter. The lodge is made of sticks, mud and rocks. They do not apply mud to the top of the shelter, creating a ventilation well.

\subsection{Axis 2: Behavioral plasticity}

Another feature that must be taken into account is the ability to exhibit adaptive phenotypic plasticity, defined as "the ability of a genotype to vary its phenotype across environments, and thus maintain high performance across that environmental gradient" (Snell-Rood 2013, 1004). Here I will use the distinction proposed by Snell-Rood between "developmental and activational behavioural plasticity":

Developmental behavioural plasticity corresponds to the traditional definition of phenotypic plasticity, where a genotype expresses different behavioural phenotypes in different environments as a result of different developmental trajectories triggered by those environments. Developmental behavioural plasticity encompasses all of what is generally defined as 'learning', or any change in the nervous system as a result of experience $[\ldots]$ Developmental behavioural plasticity is different from 'activational' behavioural plasticity [...] Here, the external context results in the expression of a particular behaviour such that a individual expresses different behaviours as it encounters different environments or conditions. [...]. Activational behavioural plasticity is an immediate response to the environment. Developmental behavioural plasticity, by definition, requires developmental changes such as neuron or muscle growth. These processes take time. (Snell-Rood 2013, 1004-1005)

Not all users of nest tools or builders show behavioral plasticity of development, but even the most basic type of agents can guide their behavior and react to external inputs (active behavioral plasticity). Here I suggest a gradual classification:

(i) Agents with activational behavioral plasticity: agents can identify similar stimuli (even during time), discriminate between (some) different stimuli and manifest similar behaviors after similar stimuli. The answers are innate behavioral responses: responses that are invariably induced by a particular stimulus. (Dupré 1996, 328). A type of physical stimulus produces a fixed type of behavioral response. With Dupré we can say that these behaviors are "mere differential reaction to causal inputs." (Dupré 1996, 328). They develop actions that can be described as active behavioral plasticity based on internal models, typically oriented by evolution. We can rephrase this with Saidel:

if it is performed in the right environment, it will lead to a goal. A representation of the goal does not play a role in causing goal-oriented behavior. [...] If evolution had

Revista de Humanidades de Valparaíso, 2019, No 14, 139-170

(ㄷ)(1)(8) CC BY-NC-ND 
so structured the organism that it lacked distinct representations of its goals and the means to achieve those goals, then the organism would not be able to abandon a particular behavior - a means to a goal - while retaining the goal. (Saidel 2009, 38-39)

Although at the most basic level, they even show the capacity of learning: "some learning does not implicate representation, of means or of goals, at all. [...] They are merely filling in gaps in an evolutionarily pre-programmed behavioral pattern" (Saidel 2009, 39). Here, the appropriate environment would be an environment with favorable (positive) conditions for the agent, and the actions of that agent would produce unintentional changes in the environment. dig:

Examples of this type would be the females of the Ammophilia and Sphex wasps that

$[\ldots]$ subterranean burrows to deposit eggs and a prey insect (a cricket like in the next example) for their larvae to feed on as they develop. When the female pace prey in the borrow, she fills the entrance with pebbles and soil. When the burrow is closed for the final time, the female sometimes holds and object in her mandibles and uses it to press the soil, compacting it and making it less conspicuous. (Shumaker, Walkup and Beck 2011, 24)

Sphex's behavior is a complex routine that is invariably caused by a particular stimulus.

(ii) Agents with basic behavioral plasticity of development: agents that can classify (not only discriminate) into positive and negative actions (so that they know something about the current state of the environment). Some of them show "(1) the capacity to identify and reidentify objects and properties, (2) the (relative) independence of stimuli, and (3) the fact that an adequate level of abstraction is involved in the classification" (Newen and Bartels 2007, 295).

They have the ability to learn and improve their actions. Therefore, some agent responses to a certain stimulus may be "driven" by that stimulus, but may generate a generalization of the stimulus. These agents develop actions aimed at achieving a goal. In some cases, agents may even create desirable conditions, therefore, if the environment is not favorable, they modify it to create the possibilities of meeting some objectives.

Living beings that fit this type are, for example, some kind of ants, termites, many kinds of birds, and Beavers (genus Castor). They all build nests, which can vary greatly between species in their shape, size and composition (Healy, Walsh and Hansell 2008). These animals perceive the environment in terms of positive and negative situations, and 
The question of animal technical capacities

Ana Cuevas Badallo

change the environment to build a new one more suitable for their interest, build nests or even, as in the example of beavers, build dams with water to a level that allows the construction of the nest.

(iii) Agents with medium developmental behavioral plasticity: agents that develop flexible response behaviors (Allen and Hauser 1991) aimed at achieving a goal that is considered and conceptualized as desirable.

Having distinct representations allows an organism to abandon one behavior and to adopt another while still retaining the goal that the previous behavior was aimed at achieving, and toward which the new behavior is now directed. Having distinct representations of goals and means to achieve them is thus a prerequisite for behaving in a goal-directed fashion. (Saidel 2009, 39)

They have the capacity to form new associations of objectives and the means to achieve those objectives. It is a type of learning that cannot be explained by conditioning or by filling behaviors in evolutionarily present patterns.

In this case, agents can create new conditions to meet some objective. The main difference with the previous group is that these creations are based on an internal utility function that tries to agree with external performance, that is, they can identify some parts of the environment as prototypes and modify them to create new conditions. Chimpanzees, orangutans, New Caledonian crows, woodpecker finches, and capuchin monkeys, fit in this type.

New Caledonian crows have impressive plastic manufacturing capabilities (Hunt 1996, 2000; Hunt and Gray 2002; 2003). For example, they appear to have diversified and cumulatively evolved the objects that form from the edges of Pandanus spp. leaves (Hunt and Gray 2003).

Chimpanzees demonstrate complex plasticity in the use of tools and can easily use complex sets of objects when necessary. Some of the sequential actions include:

an appreciation of the quality of the raw material, sometimes before even being at the food source; material selectivity; transport of raw material and tools; reduction and shaping of raw material before use (reduction in length, removal of lateral branches and leaves, and intentional shaping of brush in some cases); retouching during usage; a notion of order when using sequential tools; a notion of geometry; uniformity of tool forms; and an important cultural component in tool use (e.g., Loango chimpanzees live in a forest full of Coula edulis and Panda oleaso nuts, but do not crack them open with tools as Tai" chimpanzees do in Co^te d'Ivoire). (Boesch, Head and Robbins 2009, 567)

Wild capuchin monkeys generally open fruits, nuts and invertebrates with a hard shell, and for this they can use stones and anvils (Fragaszy, Izar, et al. 2004). In the laboratory they can develop a very complicated use of objects.

Revista de Humanidades de Valparaíso, 2019, No 14, 139-170

(ㄷ)(1)(8) CC BY-NC-ND 
The question of animal technical capacities

Ana Cuevas Badallo

Capuchins possess behavioral characteristics that are less widely shared with other primates and that are particularly relevant to using objects as tools. Both wild and captive capuchins reliably and spontaneously combine objects with substrates and with other objects by pounding and rubbing; they also insert their hands and objects in holes and crevices. (Visalberghi and Fragaszy 2009, 546)

Carpenter's finches are famous for their spontaneous behavior when they use objects in nature. They use twigs or cactus spines to remove arthropods from cracks and use this ability more than any other species other than humans. Tebbich and colleagues (Tebbich et al. 2001) discovered that young woodpecker finches developed competent skills in the use of implements even when raised with adults who do not use tools. Young finches showed a strong spontaneous tendency to use sticks, and refined and consolidated the habit by their own experience.

If we want to analyze the complexity of artifacts made and used by non-human animals, these two axes (structure and behavioral plasticity) must be taken into account. Establishing all tools and nests in a large category does not allow us to understand the variability of complex structures and behaviors that nonhuman animals show as agents in their environment. The strategies to modify their environment are very diverse and, in many cases, can be carried out in a flexible way. Many non-human animals learn during their lives how to make these artifacts in a more appropriate way. The manufacture of an artifact can also be a collective problem, where many agents of the same species perform a specific task during the manufacturing process. Therefore, differences with human-made artifacts are more a matter of degree.

There are strong differences between artifacts manufactured by humans and non-humans. Human beings have exceptional capabilities that result in highly complex technology. Among those capabilities stands out several abilities: (i) the ability to reason in terms of non-observable and / or hidden causes (Waldmann and Hagmayer 2005; Kushnir et al. 2005; Saxe et al. 2005), (ii) the ability to distinguish between "genuine" and "spurious" causes (Lien and Cheng, 2000); (iii) the ability to reason the link between the effects and their possible causes (Waldmann and Holyoak 1992) and planning their own interventions in a quasi-experimental way to elucidate ambiguous causal relationships (Hagmayer et al., 2007). On the other hand, human beings can learn from the conspecifics by perceiving their goals and then try to reproduce the strategies that the other being uses to try to achieve those goals.

This difference in learning process leads to a huge difference in cultural evolution; specifically, only cultural learning leads to cumulative cultural evolution in which the culture process artifacts - both material artifacts, such as tools, and symbolic artifacts, such as language and Arabic numbers - that accumulate modifications over historical time. Thus,

Revista de Humanidades de Valparaíso, 2019, No 14, 139-170

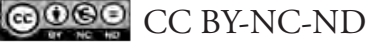


The question of animal technical capacities

Ana Cuevas Badallo

one person invents something, other persons learn it and then modify and improve it, and then this new and improved version is learned by a new generation - and so on across generations. (Tomasello 2000, 38)

The ratchet effect seems to be exclusive to humans: "some individual or group of individuals first invented a primitive version of the artifact or practice, and then some later user or users made a modification, an "improvement," that others then adopted perhaps without change for many generations, at which point some other individual or group of individuals made another modification, which was then learned and used by others, and so on over historical time in what has sometimes been dubbed "the ratchet effect" (Tomasello, Kruger, and Ratner 1993). The process of cumulative cultural evolution requires not only a creative invention but also, and most importantly, a faithful social transmission that can function as a ratchet to prevent backward slippage, so that newly invented implements or practices retain their new and improved form at least a little faithfully until a new modification or improvement arrives (Tomasello 2000, 5).

\section{Conclusions}

Artifacts have generally been considered objects created by intentional human actions. Objects manufactured by non-human animals have been excluded from that category. However, this separation is based on a limited and anthropomorphic perspective on the capabilities of nonhuman animals. In this article I have shown some reasons to consider otherwise. Capacities such as intentionality, culture or even the complexity of the structures of the manufactured object are not exclusive to human beings.

I have suggested a different way of analyzing objects created by non-human animals, one that attempts to explain the gradualness of the structure, but also the plasticity of the behavior exhibited by the non-human animal. These two elements (structure and behavior of plasticity) allow a deeper understanding of the great variety of objects that other animals also manufacture. Humans create amazing technological structures, but that does not mean they are the only animals with technical capabilities.

\section{References}

Alcock, J. (1972). The evolution of the use of tools by feeding animals. Evolution, 464-473.

Allen, C., Hauser, M. D. (1991). Concept attribution in nonhuman animals: Theoretical and methodological problems in ascribing complex mental processes. Philosophy of Science, 58(2), 221-240.

Andics, A., Gábor, A., Gácsi, M., Faragó, T., Szabó, D., Miklósi, Á. (2016). Neural mechanisms for lexical processing in dogs. Science, 353(6303): 1030-1032.

Revista de Humanidades de Valparaíso, 2019, No 14, 139-170

(ㄷ)(1)(8) CC BY-NC-ND 
Andrews, K., Huss, B. (2014). Anthropomorphism, anthropectomy, and the null hypothesis. Biology, Philosophy, 29(5): 711-729.

Baker, L. R. (2006). On the twofold nature of artifacts. Studies in History and Philosophy of Science Part A, 37(1): 132-136.

Beck, B. B. (1980). Animal Tool Behavior. New York: Garland STPM Pub.

Bentley-Condit, V., Smith, E. O. (2010). Animal tool use: current definitions and an updated comprehensive catalog. Behaviour, 147(2): 185-221, A1-A32.

Bijker, W. E., Hughes, T. P., Pinch, T. (2012). The Social Construction of Technological Systems: New Directions in the Sociology and History of Technology. Cambridge, Massachusetts: The MIT Press.

Boesch, C., Boesch, H. (1990). Tool use and tool making in wild chimpanzees. Folia primatologica, 54(1-2), 86-99.

Boesch, C. (1996). The emergence of cultures among wild chimpanzees. Proceedings British Academy, 88, 251-268.

Boesch, C., Tomasello, M. (1998). Chimpanzee and human cultures. Current Anthropology 39: 591-614.

Boesch, C., Head, J., Robbins, M. M. (2009). Complex tool sets for honey extraction among chimpanzees in Loango National Park, Gabon. Journal of Human Evolution, 56(6): 560569 .

Bonner, J. T. (1980). The Evolution of Culture in Animals. Princeton, NJ: Princeton University Press.

Borgo, S., Vieu, L. (2009). Artifacts in formal ontology. In Anthonie Meijers (ed), Philosophy of Technology and Engineering Sciences. Handbook of The Philosophy of Science Series, Vol. 9, pp. 273-308. Amsterdam: North Holland, Elsevier.

Borgo, S., Spagnoletti, N., Vieu, L., Visalberghi, E. (2013). Artifact and artifact categorization: comparing humans and capuchin monkeys. Review of Philosophy and Psychology, 4(3): 375-389.

Boswall, J.(1977a). Notes on tool-using by Egyptian Vultures. Bulletin of the British Ornithologists' Club, 14(2): 74-76.

Boswall, J. (1977b). Tool using by birds and related behaviour. Aviculture Maazine, 83: 88-97.

Boswall, J. (1978). Further notes on tool-using by birds and related behaviour. Aviculture Magazin, 8: 162.

Boswall, J. (1983). Tool-using and related behaviour in birds: More notes. Aviculture Magazine, 89: 94-108

Breen, A., Guillette, L. M., Healy, S. D. (2016). What can nest-building birds teach us? Comparative Cognition \& Behavior Reviews. 11: 83-102. 
The question of animal technical capacities

Ana Cuevas Badallo

Buckner, C. (2013). Morgan's Canon, meet Hume's Dictum: avoiding anthropofabulation in cross-species comparisons. Biology \& Philosophy, 28(5): 853-871.

Collias, E.C., Collias, E.N. (1984) Nest building and bird behaviour. Princeton University Press, Princeton.

Darwin, C. (1981[1871]). The Descent of Man, and Selection in Relation to Sex. Princeton: Princeton UP.

Davidson, D. (1982). Rational animals. Dialectica, 36(4): 317-327

Davidson, D. (1985). Incoherence and irrationality. Dialectica, 39(4): 345-354.

Davidson, D. (1999). The emergence of thought. Erkenntnis, 51(1): 511-521.

Dennett. D. (1981). True believers: The intentional strategy and why it works. In AF Heath (ed.), Scientific Explanation: Papers Based on Herbert Spencer Lectures Given in the University of Oxford. Clarendon Press: 150-167.

Dipert, R. R. (1993). Artifacts, art works, and agency. Journal of Aesthetics and Art Criticism, 52(3): 367-369.

Dipert, R. R. (1995). Some issues in the theory of artifacts. The Monist, 78(2): 119-135.

Dretske, F. I. (1999). Machines, plants and animals: the origins of agency. Erkenntnis, 51(1): 523-535.

Dupré, J. (1996). The mental lives of non-human animals. In M. Bekoff and D. Jamieson (eds.), Readings in Animal Cognition, pp. 323-336. Cambridge, Massachusetts: The MIT Press.

Fisher, J. A. (1996). The myth of anthropomorphism. In M. Bekoff and D. Jamieson (eds.), Readings in Animal Cognition, pp. 3-16. Cambridge, Massachusetts: The MIT Press.

Fitzpatrick, S. (2008). Doing away with Morgan's canon. Mind, Language, 23(2): 224-246.

Fragaszy, S., Izar, P., Visalberghi, E., Ottoni, E. B., de Oliveira, M. G. (2004). Wild capuchin monkeys (Cebus libidinosus) use anvils and stone pounding tools. American Journal of Primatology: Official Journal of the American Society of Primatologists, 64(4): 359-366.

Franssen, M. (2006). The normativity of artifacts. Studies in History and Philosophy of Science Part A, 37(1): 42-57.

Galef, B. G. (2009). Culture in animals?. In K. N. Laland and B. G. Galef, (eds.), The question of animal culture, pp. 222-246. Harvard University Press.

Glock, H.-J. (2009). Can animals act for reasons? Inquiry, 52(3): 232-254.

Gould, J. L. (2007). Animal artifacts. In E. Margolis and S. Laurence (eds.), Creations of the Mind: Theories of Artifacts and their Representation, pp. 249-266. Oxford: Oxford University Press.

Haeckel, E. (1889). Natürliche schöpfungsgeschichte: Gemeinverständliche wissenschaftliche vorträge über die entwickelungslehre im allgemeinen und diejenige von Darwin, Goethe und Lamarck im besonderen. Berlin: G. Reimer. 
The question of animal technical capacities

Ana Cuevas Badallo

Hagmayer Y., Sloman S.A., Lagnado D.A., Waldmann M.R. (2007). Causal reasoning through intervention. In A Gopnik and L Schulz. Causal Learning: Psychology, Philosophy and Computation, pp. 86-100. Oxford, UK: Oxford Univ. Press.

Healy, S., Walsh, P., Hansell, M. (2008). Nest building by birds. Current Biology, 18(7): R271-R273.

Heidegger, M. (2010). Being and Time. New York: SUNY Press.

Hilpinen, R. (1993). Authors and artifacts. Proceedings of the Aristotelian Society, 93: 155-178.

Hoogland, John L. (1996). Cynomys ludovicianus. Mammalian species, 535: 1-10.

Hunt, G. R. (1996). Manufacture and use of hook-tools by new caledonian crows. Nature, 379 (6562): 249-251.

Hunt, G. R. (2000). Human-like, population-level specialization in the manufacture of pandanus tools by new Caledonian crows corvus moneduloides. Proceedings of the Royal Society of London. Series B: Biological Sciences, 267(1441): 403-413.

Hunt, G. R., Gray, R. D. (2002). Species-wide manufacture of stick-type tools by New Caledonian crows. Emu, 102(4): 349-353.

Hunt, G. R., Gray, R. D. (2003). Diversification and cumulative evolution in New Caledonian crow tool manufacture. Proceedings of the Royal Society of London. Series B: Biological Sciences, 270(1517): 867-874.

Hunt, G.R., Gray,R.D.(2004). The crafting ofhook tools by wild NewCaledoniancrows. Proceedings of the Royal Society of London. Series B: Biological Sciences, 271(suppl_3): S88-S90.

Jones, A. M., Brown, C., Gardner, S. (2011). Tool use in the tuskfish choerodon schoenleinii? Coral Reefs-Journal of the International Society for Reef Studies, 30(3): 865.

Kabadayi, C., Osvath, M. (2017). Ravens parallel great apes in flexible planning for tool-use and bartering. Science, 357(6347): 202-204.

Keeley, B. L. (2004). Anthropomorphism, primatomorphism, mammalomorphism: understanding cross-species comparisons. Biology and Philosophy, 19(4): 521-540.

King, S. L., Janik, V. M. (2013). Bottlenose dolphins can use learned vocal labels to address each other. Proceedings of the National Academy of Sciences, 110(32): 13216-13221.

Knolle, F., Goncalves, Rita P., Morton, J. (2017). Sheep recognize familiar and unfamiliar human faces from two-dimensional images. Open Science, 4(11): 171228.

Krützen, M., Mann, J., Heithaus, Michael R., Connor, R. C., Bejder, L., Sherwin, W. B. (2005). Cultural transmission of tool use in bottlenose dolphins. Proceedings of the National Academy of Sciences, 102(25): 8939-8943.

Laland, K. N., Galef, B. G. (eds.) (2009). The Question of Animal Culture. Cambridge, MA: Harvard University Press.

Landau, M. (1993). Narratives of Human Evolution. New Haven: Yale University Press.

Revista de Humanidades de Valparaíso, 2019, No 14, 139-170

()ㅇㅇㅇㅛ CC BY-NC-ND 
Lien, Y., Cheng, P. W. (2000). Distinguishing genuine from spurious causes: a coherence hypothesis. Cognitive Psychology, 40(2): 87-137.

Lumsden, C. J., Wilson, E. O. (1981). Genes, mind, and ideology. The Sciences, 21(9): 6-8.

Maclean, G. L. (1973). The sociable weaver, Part 2: nest architecture and social organization. Ostrich: Journal of African Ornithology, 44(3-4): 191-218.

Malcolm, N. (1972-1973). Thoughtless brutes. Proceedings and Addresses of the American Philosophical Society 46: 5-20.

Matthews, J. R., Matthews, R. W. (2018). Nesting biology of an australian potter wasp, Delta latreillei (Saussure) (Hymenoptera: Vespidae: Eumeninae). Australian Entomologist, 45(1): 93-104.

McGrew, W. C., Tutin, C. E. (1978). Evidence for a social custom in wild chimpanzees? Man, 13(2): 234-251.

Morgan, C. L. (1894). An Introduction to Comparative Psychology. London: Walter Scott.

Newen, A., Bartels, A. (2007). Animal minds and the possession of concepts. Philosophical Psychology, 20(3): 283-308.

Perry, S., Panger, M., Rose, L. M., Baker, M., Gros-Louis, J., Jack, K., Pyle, K. (2003). Traditions in wild white-faced capuchins. In D. M. Fragaszy, and S. Perry, (eds.), The Biology of Traditions: Models and Evidence, pp. 391-425. Cambridge University Press, Cambridge, New York.

Pierce Jr., J. D. (1986). A review of tool use in insects. Florida Entomologist. 69(1): 95-104.

Pilliod, D. S., Rohde, A. T., Charnley, S., Davee, R. R., Dunham, J. B., Gosnell, H., Nash, C. (2018). Survey of beaver-related restoration practices in rangeland streams of the western USA. Environmental management, 61(1): 58-68.

Preston, B. (1998). Cognition and tool use. Mind and Language, 13(4): 513-547.

Price, H. H. (1953). Thinking and Experience. Hutchinson, London.

Proffitt, T. et al. (2016). Wild monkeys flake stone tools. Nature, 539(7627): 85-88. doi:10.1038/ nature 20112

Riehl, C. P. (2001). Black-crowned Night Heron fishes with bait. Waterbirds, 24(2):285-286.

Saidel, E. (2009). Attributing mental representations to animals. In R. W. Lurz (ed.), The philosophy of animal minds, pp. 35-51. Cambridge: Cambridge University Press.

Sargent, R. C. (1982). Territory quality, male quality, courtship intrusions, and female nest-choice in the threespine stickleback, Gasterosteus aculeatus. Animal Behaviour, 30(2): 364-374.

Scarf, D., Boy, K., Reinert, A. U., Devine, J., Güntürkün, O., Colombo, M. (2016). Orthographic processing in pigeons (Columba livia). Proceedings of the National Academy of Sciences, 113(40): 11272-11276. 
The question of animal technical capacities

Ana Cuevas Badallo

Scheele, M. (2006). Function and use of technical artifacts: social conditions of function ascription. Studies in History and Philosophy of Science Part A, 37(1): 23-36.

Searle, John R. (1995). The construction of social reality. New York: The Free Press, Simon and Schuster.

Shumaker, R. W., Walkup, K. R., Beck, B. B. (2011). Animal tool behavior: the use and manufacture of tools by animals. Baltimore, Maryland: JHU Press.

Snell-Rood. E. C. (2013). An overview of the evolutionary causes and consequences of behavioural plasticity. Animal Behaviour, 85(5): 1004-1011.

Sober, E. (1998). Innate knowledge. Routledge encyclopedia of philosophy, 4: 794-797.

Sober, E. (2005). Comparative psychology meets evolutionary biology. In L. Daston and G. Mitman (eds.), Thinking with Animals: New Perspectives on Anthropomorphism, pp. 8599. New York: Columbia University Press.

Soo, R. M., Hemp, J., Parks, D. H., Fischer, W. W., Hugenholtz, P. (2017). On the origins of oxygenic photosynthesis and aerobic respiration in Cyanobacteria. Science, 355(6332): 1436-1440.

St. Amant, R., Horton, T. E. (2008). Revisiting the definition of animal tool use. Animal Behaviour, 75(4): 1199-1208.

Susi, T., Ziemke, T. (2005). On the subject of objects: Four views on object perception and tool use. tripleC: Communication, Capitalism, Critique. Open Access Journal for a Global Sustainable Information Society, 3(2): 6-19.

Tebbich, S., Taborsky, M., Fessl, B., Blomqvist, D. (2001). Do woodpecker finches acquire tooluse by social learning? Proceedings of the Royal Society of London. Series B: Biological Sciences, 268(1482): 2189-2193.

Tebbich, S., Bshary, R. (2004). Cognitive abilities related to tool use in the woodpecker finch, Cactospiza pallida. Animal behaviour 67(4): 689-697.

Thirunavukarasu, P., Nicolson, M., Elgar, M. A. (1996). Leaf selection by the leaf-curling spider Phonognatha graeffei (Keyserling) (Araneoidea: Araneae). Bulletin of the British Arachnological Society 10(5): 187-189.

Thomasson, A. (2007). Ordinary objects. Oxford: Oxford University Press.

Tomasello, M. (2000). Culture and cognitive development. Current Directions in Psychological Science, 9(2): 37-40.

Tomasello, M., Call, J. (1997). Primate cognition. Oxford University Press.

Tomasello, M., Kruger, A. C., Ratner, H. H. (1993). Cultural learning. Behavioral and brain sciences, 16(3): 495-511

van Lawick-Goodal, J. (1970), Tool-using in primates and other vertebrates. Advances in the Study of Behavior, 3: 195-249.

Revista de Humanidades de Valparaíso, 2019, No 14, 139-170

(c) (1) $\mathrm{O}$ (ㄱ BY-NC-ND 
van Schaik, C. P., Fox, E. A., Sitompul, A. F. (1996). Manufacture and use of tools in wild Sumatran orangutans. Naturwissenschaften, 83(4): 186-188.

Vermaas, P. E., Houkes, W. (2006). Technical functions: A drawbridge between the intentional and structural natures of technical artifacts. Studies in History and Philosophy of Science Part A, 37(1): 5-18.

Visalberghi, E., Fragaszy, D. (2009). What is challenging about tool use? The capuchin's perspective. In E. A. Wasserman and T. R. Zentall (eds.). Comparative cognition: Experimental explorations of animal intelligence, pp. 529-552. Oxford: Oxford University Press.

Visalberghi, E., Fragaszy, D. (2013). The Etho-Cebus Project: Stone-tool use by wild capuchin monkeys. In C. Sanz, J. Call, and C. Boesch (eds.), Tool Use in Animals: Cognition and Ecology, pp. 203-222. Cambridge: Cambridge University Press.

Waldmann, M. R., Holyoak, K. J. (1992). Predictive and diagnostic learning within causal models: asymmetries in cue competition. Journal of Experimental Psychology: General, 121(2): 222-236.

Waldmann, M. R., Hagmayer, Y. (2005). Seeing versus doing: two modes of accessing causal knowledge. Journal of Experimental Psychology: Learning, Memory, and Cognition, 31(2): 216-227.

Wilson, E. O. (1975). Sociobiology: The new synthesis. Cambridge, Massachusetts: Belknap Press.

Zyskowski, K., Prum, R. O. (1999). Phylogenetic analysis of the nest architecture of Neotropical ovenbirds (Furnariidae). The Auk, 116 (4): 891-911. 


\title{
Centros celulares nutritivos e espumas microscópicas como formas elementares dos seres viventes
}

\author{
Nutritious cell centers and microscopic foams as elementary forms \\ of living beings
}

\author{
Mauricio de Carvalho Ramos \\ Universidade de São Paulo, Brasil \\ maucramos@gmail.com
}

\begin{abstract}
Resumo
No presente artigo comparo duas concepções de elementos ou unidades básicas dos organismos vivos da segunda metade do século XIX: os centros celulares de Goodsir e o protoplasma de Bütschli. A comparação será feita a partir da proposição de uma forma nucleoplasmática, sendo as referidas concepções expressões históricas dessa forma geral. $\mathrm{O}$ centro de nutrição é uma forma que combina as funções de nutrição, germinação e reprodução, responsável pela produção de tecidos (texturas), órgãos, tumores e a totalidade do organismo a partir do ovo fecundado. As espumas microscópicas produzem a diferenciação orgânica por meio de estabilizações dinâmicas da tensão superficial existente entre os alvéolos. Concluirei criticamente discutindo a relação dessas duas expressões em termos de sua continuidade ou esgotamento como realizações científicas da biologia do período citado.
\end{abstract}

Palavras-chave: protoplasma, morfologia, forma nucleoplasmática, Goodsir, Bütschli.

\begin{abstract}
In this paper I will compare two conceptions of basic elements or units of living organisms from the second half of the nineteenth century: Goodsir's cellular centers and Bütschli's protoplam. The comparison will be made from the proposition of a nucleoplasmic form, and the referred conceptions are historical expressions of this general form. The nutrition center is a form that combines the functions of nutrition, germination and reproduction, responsible for the production of tissues (textures), organs, tumors and the whole organism
\end{abstract}

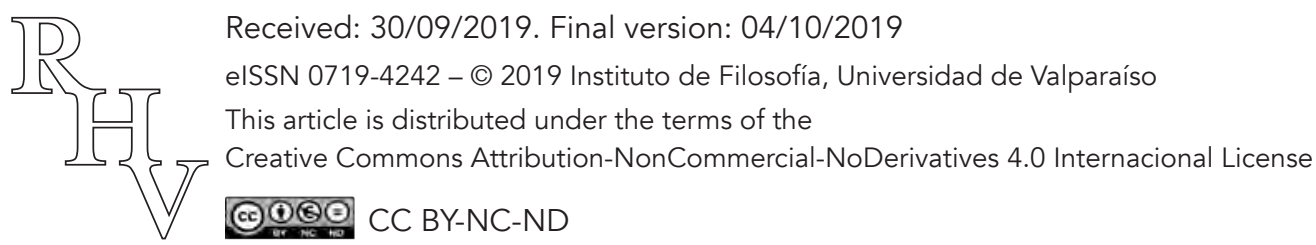


Centros celulares nutritivos e espumas microscópicas como formas elementares dos seres viventes

Mauricio de Carvalho Ramos

from the fertilized egg. Microscopic foams produce organic differentiation through dynamic stabilization of the surface tension between the alveoli. I will conclude critically by discussing the relationship of these two expressions in terms of their continuity or exhaustion as scientific achievements of the biology of the period cited.

Keywords: protoplasm, morphology, nucleoplasmatic form, Goodsir, Bütschli.

\section{Introdução: as formas nucleoplasmáticas elementares de vida dos seres viventes}

No presente artigo, examinarei comparativamente duas expressões históricas da tentativa de conceber as estruturas e as funções elementares de vida. A primeira é o conceito de centro de nutrição, proposto pelo anatomista escocês John Goodsir (18141867) na obra Anatomical and pathological observations (1845). Um centro de nutrição é uma célula especial responsável pela germinação e nutrição de tecidos e órgãos. A segunda encontra-se na obra Untersuchungen über microskopische Schäume und die struktur des Protoplasmas (1892) (utilizarei a tradução de 1894, Investigations on microscopic foams and on protoplasm), do zoólogo alemão Johann Adam Otto Bütschli (1848-1920), que propõe e fundamenta experimentalmente um modelo físico-químico de protoplasma como uma microespuma composta por uma rede fluida de alvéolos. Para obter os resultados que almejo, minha comparação será feita articulando essas duas realizações científicas como expressões históricas de um conceito de forma nucleoplasmática especificamente proposto para esse fim.

A forma nucleoplasmática provém de minha comparação de várias proposições do que são as formas mais elementares da vida encontradas na história das ciências dos seres orgânicos e vitais para uma série de casos históricos presentes entre a segunda metade do século XVII, o século XVIII e a segunda metade do século XX. Tais formas associam as unidades estruturais e funcionais e, abandonando o antagonismo estrutura-função, visam compreender a busca pelo conhecimento das formas mais elementares da vida como não fundamentadas primariamente ou essencialmente em entidades estruturais, nem em processos fluidos funcionais. Em outras palavras, a avaliação epistemológica da história dos conceitos de forma de vida elementar não se dá recorrendo a esquemas estruturalistas ou funcionalistas puros. Com isso, minha avaliação é morfológica, desde que a forma seja compreendida como estruturas permanentemente integradas a funções. Para que essa compreensão aconteça de fato, as formas elementares dos seres viventes que desejo investigar historicamente devem ser pensadas como uma forma complexa na qual um corpúsculo ou núcleo central está em continuidade com um pleno ou plasma periférico. A estrutura nuclear possui uma função de estabilização e a estrutura plasmática a de expansão da forma elementar em sua totalidade. Como ambas estão em continuidade, por mais concentrado e atomizado que seja o organismo (seres unicelulares, por exemplo) ou a forma orgânica que opera como elemento fundamental de constituição (as células

Revista de Humanidades de Valparaíso, 2019, No 14, 171-185

(ㄷ)(1)(8) CC BY-NC-ND 
Centros celulares nutritivos e espumas microscópicas como formas elementares dos seres viventes

Mauricio de Carvalho Ramos

de um organismo multicelular, por exemplo), elas nunca perdem seu caráter de uma continuidade fluídica. Do mesmo modo, a fase plasmática da forma elementar nunca é imaginada como carente de uma força ou afinidade de atração para um núcleo ou centro. Com tal concepção geral, posso agora apresentar de modo mais preciso o objetivo deste artigo: considerar os centros nutritivos de Goodsir e as unidades protoplasmáticas de Butschli como dois tipos históricos e em continuidade de formas nucleoplasmáticas. Tal procedimento racional é o item principal de um método que venho elaborando e aplicando no desenvolvimento de um projeto intitulado Epistemologia histórica do conceito de morfologia. Os primeiros resultados que obtive foram a identificação de algumas expressões históricas de metamorfoses nucleoplasmáticas nos conceitos de mônada orgânica, inspirado no conceito de substância composta leibniziana (Ramos 2012), de parte seminal, presente na teoria da geração de Maupertuis (Ramos 2015), de citoblasto vegetal de Mathias Schleiden e de animal elementar da anatomia comparada de Robert Grant (Ramos 2013). O presente estudo é o primeiro passo para a possível inclusão de mais duas dessas metamorfoses epistemológicas históricas da forma nucleoplasmática.

\section{Os centros nutritivos}

Para Goodsir, os centros de nutrição são "certas partes celulares diminutas existentes nas texturas e nos órgãos" $(1845,1)$. Eles são entidades orgânicas complexas que combinam funções e estruturas normais e patológicas que acumulam funções gerativas e fisiológicas ou germinativas e somáticas em diferentes níveis ontogenéticos. Na verdade, nesse conceito de unidade elementar da vida o antagonismo entre soma e germe é diluído (ou talvez inexistente), pois a nutrição é ao mesmo tempo uma forma de crescimento e de desenvolvimento onde um centro nutritivo é "meramente uma célula cujo núcleo é uma fonte permanente de sucessivas progênies de células jovens" (Goodsir 1845, 2, itálicos meus). $\mathrm{O}$ aumento da quantidade destas células preenche a cavidade da célulamãe, expandindo sua parede. Nesse processo, células mães e filhas realizam movimentos integrados de expansão em direções determinadas cuja resultante é a diferenciação de entidades, partes ou unidades orgânicas mais complexas, as texturas (ou tecidos; manterei o termo original, textura) e os órgãos. Outra função dos centros nutritivos é extrair alimento de uma fonte, como os vasos sanguíneos, e distribuí-lo aos órgãos e às texturas, para que cresçam e se desenvolvam $(1845,1)$. Os centros nutritivos também são concebidos por Goodsir como centros ou manchas germinais, de modo que manifestam a referida integração estrutural-funcional de geração e de manutenção orgânicas.

Podemos obter uma visão de conjunto das diferentes dimensões do conceito acompanhando a descrição que o autor faz de um tumor cístico lingual (Goodsir $1845,107)$ (Figura 1.). A capa que encista o tumor é composta por três membranas. A externa é constituída por fibras elásticas e aureolares contendo vasos sanguíneos que cresceram anomalamente (não representada na figura). A membrana média (1a) contém

Revista de Humanidades de Valparaíso, 2019, No 14, 171-185

(ㄷ)(1)(8) CC BY-NC-ND 
células achatadas cujos núcleos são descritos como manchas germinais, ou seja, o que a caracteriza como uma membrana germinal, um tipo especial de textura em que as funções de desenvolvimento e de crescimento dos centros de nutrição se manifestam integradamente - mais um elemento da diluição da distinção soma-germe. A terceira, mais interna, é uma camada de pequenas células esféricas contendo grânulos (1b).

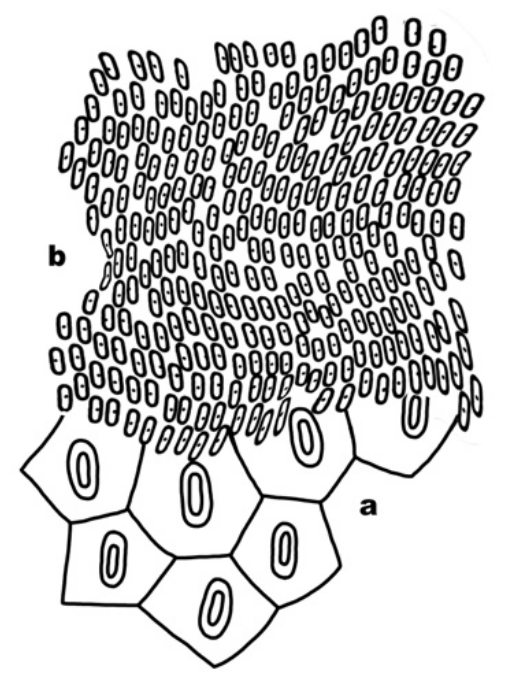

Figura 1. (a) membrana média germinal do cisto tumoral exibindo células achatadas contendo centros de nutrição; (b) membrana interna constituída por pequenas células ovais. (Com exceção da Figura 4, as demais foram feitas com modificações a partir das originais do texto pelo desenhista Alberto Cordeiro de Sá, a quem sou profundamente grato); (modificado a partir da Figura 1, prancha I do texto original).

A massa interna do tumor contém duas camadas (Figura 2.). A primeira é branca e possui células que podem ser anucleadas (2a); a segunda, de cor cinza avermelhada, é composta por células com "núcleos em vários estágios de desenvolvimento" (Goodsir $1845,107)$. Esse desenvolvimento ocorre pela fragmentação do núcleo original que produz o referido aumento de células-filhas, grande o bastante para distender a célulamãe para além de seu tamanho médio (2b). 


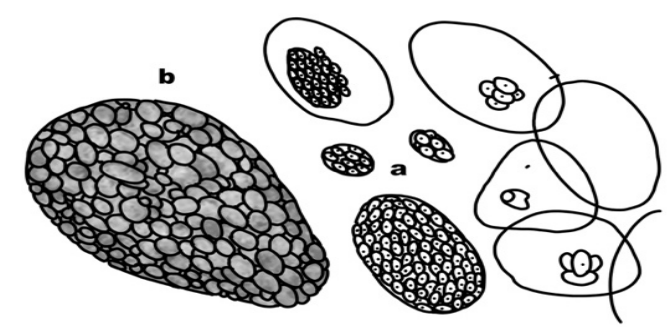

Figura 2. (a) células da massa mais interna do tumor com centros nutritivos já divididos em núcleos com diferentes quantidades de células-filhas e em diferentes estágios de desenvolvimento; (b) uma célula totalmente preenchida com volume bem maior que o da célula mãe original; (modificado a partir da Figura 2., prancha I do texto original).

Vejamos agora como o tumor "funciona" em sua totalidade morfológica. Suas duas partes principais, diz Goodsir, "realizam dois tipos distinto de ações". O cisto é a parte ativa, pois "remove matérias nutritivas para si mesmo e para seus componentes a partir dos vasos que se ramificam em sua túnica" (Goodsir 1845, 108). Os centros nutritivos, aqui descritos como manchas germinais da membrana germinativa, são os órgãos que cumprem tal função. Isso é possível graças à existência, em cada centro, de forças de atração que "selecionam e removem dos vasos capilares a matéria necessária para a formação das células da camada interna", as células ovais representadas na Figura 2a. Estas células passam para o interior da massa tumoral, que é a porção passiva, transportando alimento para as células que lá estão. Como vimos, elas são de dois tipos e, na sequência de sua descrição, Goodsir explica mais detalhadamente suas funções. Nas células da porção branca, a atividade dos núcleos está ligada mais à nutrição, enquanto as mais internas "atuam como indivíduos reprodutivos do crescimento mórbido total" da massa tumoral. A Figura 3 mostra esses dois tipos de células em uma mesma textura. Aqui o germinativo, o reprodutivo e o nutritivo encontram-se associados, já que a reprodução das células causa a germinação que, ao receber alimento, faz o tumor crescer e desenvolver-se. 


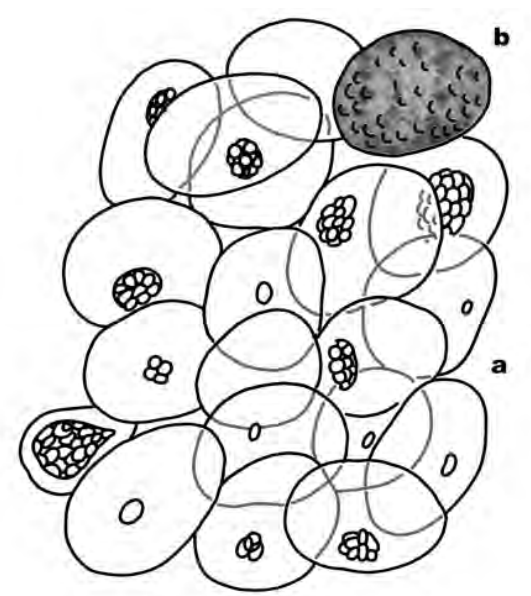

Figura 3. (a) células ovais em vários estágios de desenvolvimento que correspondem a centros germinais ou nutritivos em diferentes graus de fragmentação; (b) uma célula totalmente preenchida que, segundo Goodsir, estão mais ligadas a uma função germinativa e reprodutiva; (modificado a partir da Figura 5, prancha I do texto original).

Encerrando sua descrição, Goodsir faz uma analogia de especial significado para minha perspectiva morfológica de estudo:

Em uma massa mórbida deste tipo, como ocorre geralmente nas texturas e nos órgãos de um animal, certas partes são preservadas como reprodutoras e as restantes realizam as funções da totalidade da massa, da textura ou do órgão, tal como em certas comunidades de animais em que certos indivíduos são reservados para reproduzir o enxame e os demais se devotam às obrigações da colmeia. (Goodsir 1845, 109)

A atividade que organiza a gênese e a manutenção de uma entidade orgânica especial como um tumor pode estar, em princípio, presente na organização de qualquer entidade orgânica normal ou regular. Um mesmo padrão de divisão de trabalho que se encontra em animais sociais (abelhas) aparece nas unidades que integram a totalidade do plano morfológico do organismo. Para mim, nos cnidários coloniais essa divisão é ainda mais interessante para a compreensão do conceito de tumor de Goodsir. Uma unidade desses invertebrados morfologicamente simples e os tumores seriam colônias contendo zooides com funções reprodutivas e nutritivas separadas, mas em continuidade em uma mesma massa orgânica. Tal divisão de trabalho é apenas um dos efeitos da integração de fragmentações, deslizamentos, proliferações, expansões, contrações, extrações e outras ações que conduzem à formação de unidades orgânicas bem distintas. Menciono sem aprofundar que esta morfologia é muito semelhante ao esquema monadológico no qual o centro ativo da colônia representaria a mônada principal e os insetos sociais individuais e os zooides da colônia de cnidários representariam as mônadas subalternas (Ramos 2012). 
Centros celulares nutritivos e espumas microscópicas como formas elementares dos seres viventes

Mauricio de Carvalho Ramos

A compreensão dos fenômenos exibidos pelas texturas e órgãos já formados e pelas neoformações começa por uma construção morfológica empírico-teórica que parte de centros de nutrição isolados, como na membrana germinal, formando um sistema. Mas, essa mesma construção poderia partir dos primórdios de formação do organismo completo, ou seja, de um centro de nutrição geral identificável à mancha germinativa existente nas fases embriogênicas mais iniciais dos ovos fecundados. Como diz Goodsir, "o centro de nutrição que nos é mais familiar é aquele do qual o todo do organismo deriva sua origem - a mancha germinal do ovum". Todos os demais centros do organismo dela derivam, mas, apesar de toda diferenciação que sofrem, dois níveis básicos são conservados: há as células individuais com sua "vitalidade peculiar independente" e as que "mantém certas relações com uma célula capital central, em torno da qual todas as outras derivam sua origem" (Goodsir 1845, 2). Desde a mancha germinativa inicial do ovo, cada célula é um centro nutritivo-germinativo em potencial, mas, no desenrolar da ontogênese, há centros que são ativos apenas durante o período necessário à formação de uma parte orgânica e centros que mantém sua atividade morfológica por toda a vida do organismo:

Os centros da nutrição são de dois tipos: os que são peculiares às texturas e os que pertencem aos órgãos. Os centros nutritivos das texturas são, em geral, permanentes. Os dos órgãos são, na maior parte dos casos, peculiares à sua etapa embrionária e, no final, desaparecem ou dividem-se nos vários centros das texturas que compõem os órgãos. (Goodsir 1845, 2)

Tanto as neoformações tumorais como a própria dinâmica de cada unidade orgânica normal revelam a manutenção do caráter germinativo-nutritivo de todas as células quando concebidas pela morfologia de Goodsir. Se pudermos visualizar os primeiros estágios da embriogênese de uma ave perceberemos uma mancha contendo um corpúsculo vivo central pulsante associado a uma rede de vasos vermelhos que se inserem na massa amarela do vitelo. Essa ação orgânica atrai o alimento que permitirá a formação de todas as massas, texturas e órgãos do organismo em gestação. Algo morfologicamente muito semelhante ocorre com um tumor (Figura 4.). 


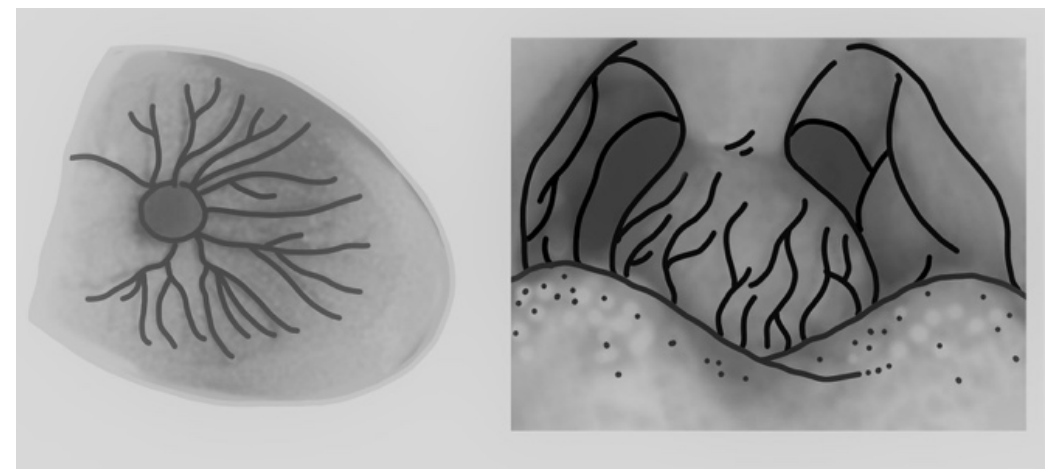

Figura 4. desenhos simplificados feitos por Alberto Cordeiro de Sá de (a) um embrião semelhante ao de uma ave em seus primeiros dias de vida comparado com (b) um tumor lingual. Além de ilustrar o que Goodsir nos explica, essa comparação também serve para estimular o raciocínio morfológico para que associemos a ação germinativa-nutritiva de todos centros orgânicos que, nas formas estruturalistas e funcionalistas de raciocínio, seriam incomparáveis.

Farei a seguir as primeiras correlações do conceito de centro nutritivo com o de forma nucleoplasmática. Esse tipo de centro é uma forma composta por um núcleo cuja ação principal é a de fragmentação e um plasma formado pela proliferação e aglutinação de unidades nucleoplasmáticas de segunda ordem. Ambos formam um contínuo cuja coesão e expansão são sustentadas graças à formação de um fluxo que vai do centro para a periferia. A totalidade dialética dessa forma permite objetivar fenômenos nos quais as partes genéticas ativas e as fisiológicas passivas são incompreensíveis se forem substancialmente isoladas.

O caráter nucleoplasmático de um centro nutritivo torna-se mais evidente quando pensado em sua integridade orgânica. A expansão do núcleo gera imediatamente dois níveis morfológicos, empiricamente expressos pelas células mãe e filha, que se encontram intimamente integrados para qualquer nível dessa expansão. Eles correspondem a dois níveis morfológicos que determinam objetivamente uma relação entre nucleoplasmas centrais e periféricos, de modo que todo "nucleoplasma-filho" pode transformar-se em um "nucleoplasma-mãe", mas não o contrário. Para mim, isso corresponde ao que Goodsir disse sobre a diferença de autonomia da vitalidade das células conforme sua localização morfológica no organismo, em texturas ativas ou em órgãos passivos. A esse respeito ele também diz algo cujo sentido revela-se mais plenamente neste ponto da discussão: a célula-mãe é "mãe de todas aquelas contidas em seu próprio território" (Goodsir 1845, 2). Determinado pela forma nucleoplasmática, tal território torna-se uma espécie de "plasma virtual" que se estende continuamente a partir do núcleo e corresponde empiricamente à existência e a persistência de uma célula-mãe ativa "por trás" de todas as partes orgânicas (normais ou patológicas) unificadas por uma "célula capital central". Em sua unidade morfológica, a célula-mãe é o núcleo e seu território é o plasma. 
Centros celulares nutritivos e espumas microscópicas como formas elementares dos seres viventes

Mauricio de Carvalho Ramos

\section{Unidades elementares de vida como centros morfodinâmicos em protoplasmas alveolares contínuos}

Farei a próxima etapa de minha proposta relacionando as últimas linhas do ensaio de Goodsir com as primeiras linhas do livro de Bütschlii sobre as espumas microscópicas:

Sobre as forças que existem em conexão com os centros da nutrição, nada se pode ainda afirmar de muito definido. Quando este ramo de investigação tiver sido explorado, esperaremos estar na posse de uma ciência das forças orgânicas que mantenha relações diretas com a anatomia, ou ciência das formas orgânicas. (Bütschli 1894, 3)

Referindo-se ao prefácio de uma de suas obras, de 1876 (ela não é citada explicitamente, mas provavelmente trata-se de seu Studien über die ersten Entwicklungsvorgänge der Eizelle, die Zelltheilung und die Conjugation der Infusorien. Abhidl. der Senckenberg. naturf. Gesellsch. Bd. X. 1876), Bütschli afirma, na introdução do Investigations on microscopical foams, como a relação entre forças e formas orgânicas, imaginada por Goodsir, poderia realizar-se: "o método de exame morfológico que conduzira a [...] brilhantes resultados para a compreensão de organismos multicelulares, não nos serve quando tentamos penetrar mais profundamente a natureza essencial do organismo elementar - a célula". Citando a referida obra de 1876, acrescenta: "os fenômenos exibidos por e no organismo elementar não poderia assumir uma forma inteligível senão através das condições físicas e químicas de sua origem e cessação" (Bütschli 1894, 1). Com isso, à ciência das forças orgânicas é atribuída a capacidade de explicar causalmente os fenômenos morfológicos e, assim, a interação entre anatomia e físico-química conduziria a algum tipo de redução da primeira à segunda.

O autor apresentou e sustentou a hipótese de que a matéria viva do protoplasma possui uma estrutura alveolar, mais precisamente, a de uma espuma diminuta cujos alvéolos formavam uma malha semelhante a um favo de abelha. Sua proposta rivalizava com outros modelos, mas não os incluirei em minha discussão. Bütschli foi um profundo conhecedor das formas mais elementares da vida animal, os protozoários, bem como de outras formas de vida unicelular e pluricelular que investigou sob a perspectiva morfológica que, posteriormente, pareceu-lhe limitada. O problema específico que conduziu à passagem da morfologia à físico-química foi a explicação "do fenômeno da divisão do corpo celular protoplasmático" levando em consideração "as propriedades dos corpos fluidos - isto é, a tensão superficial" (Bütschli 1894, 1). Nessa direção, a espuma microscópica aparece, em primeiro lugar, como o modelo geométrico ou, mais precisamente, geométrico-físicoquímico que poderá explicar a essência do fenômeno de divisão que, desde as primeiras segmentações do ovo fecundado, comparece na determinação de todas as entidades orgânicas delimitadas por membrana. Mas, além disso, ela também está apta a explicar como as forças das superfícies mantêm unidas as unidades estruturalmente definidas. Por fim, tais explicações serão obtidas a partir de um modelo particularmente apropriado à experimentação: "Se tais espumas microscópicas forem sucessivamente manufaturadas,

Revista de Humanidades de Valparaíso, 2019, No 14, 171-185

()ㅇ요요 CC BY-NC-ND 
Centros celulares nutritivos e espumas microscópicas como formas elementares dos seres viventes

Mauricio de Carvalho Ramos

não poderiam mostrar certas peculiaridades do protoplasma e seu acurado estudo não poderia oferecer uma contribuição essencial na direção de confirmar ou corrigir minha visão?" (Bütschli 1894, 4).

Para cumprir suas funções, a composição das espumas artificiais deveria conferirlhes uma sutileza material tão próxima quanto possível da existente no protoplasma vivo (Bütschli 1894, 5). Bütschli inicialmente sintetizou espumas agitando uma mistura de solução de sabão comercial com benzina ou xileno. Elas podem ser comparadas com espumas ordinárias de sabão em que as bolhas de benzina são análogas (termo não utilizado pelo autor) às de ar (Bütschli 1894, 6). O autor afirma que "a durabilidade de espumas deste tipo é impressionante", tendo as conservado por dois anos sem alteração (Bütschli 1894, 6). Posteriormente, passou a utilizar espumas produzidas pela difusão de fluidos aquosos (solução salina) em óleos graxos (óleo de oliva). Elas manifestavam propriedades semelhantes às anteriores mesmo quando manipuladas para observação e experimentação (Bütschli 1894, 46). Pequenas amostras dessas espumas eram fabricadas diretamente em uma lâmina e observadas ao microscópio (Bütschli 1894, 8).

A largura da malha das espumas que produziu era, aproximadamente, entre 0,001 e $0,005 \mathrm{~mm}$. Quando deixadas em repouso por algumas semanas, os alvéolos gradualmente se dispunham, por efeito natural da gravidade, em camadas tão mais finas e cujos alvéolos eram tão menores quanto mais próximos da superfície. Isso mostrou para o autor que, contrariamente a outros modelos, as espumas alveolares eram completamente fluidas (Bütschli 1894, 31), já que seus alvéolos podiam deslocar-se livremente pela trama. Esse arranjo revelou-se teoricamente importante, pois poderia encerrar a base físico-química para a compreensão de um importante fenômeno de diferenciação do protoplasma: a delimitação de unidades orgânicas a partir de bordas (membranas) com funções especiais. A esse respeito diz Bütschli "Um fenômeno de especial importância é exibido pela superfície de espumas de mesma composição e preparadas com êxito. Com ampliação moderada, elas aparecem circundadas por uma borda delicada e algo mais clara". Vistas sob aumento ainda maior, esta tênue borda apresenta-se diminutamente estriada verticalmente em direção à superfície (Bütschli 1894, 32). Bütschli designou tal superfície uma membrana alveolar (Figura 5). 


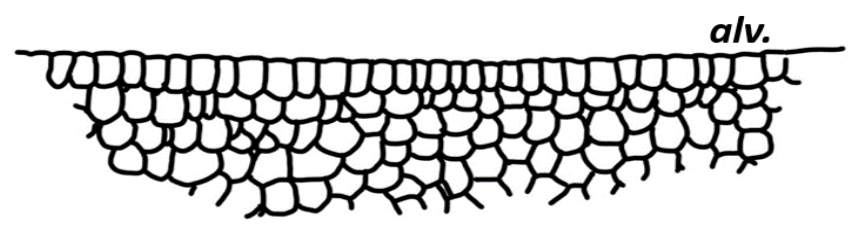

Figura 5. "Seção óptica da porção marginal de uma gota de espuma oleosa preparada com óleo de oliva e $\mathrm{NaCl}$ contendo uma camada alveolar (alv) bem distinta e relativamente alta" (Bütschli 1894, 352); (modificado a partir da Figura 4, prancha $\mathrm{V}$ do texto original).

A camada alveolar é apenas a camada mais superior da espuma, no sentido de que "sua origem é facilmente explicada uma vez que é apenas uma consequência das leis que o arranjo das lamelas da espuma obedece" (Bütschli 1894, 32). Essa diferenciação regional da borda, formando uma camada estruturalmente diferente das inferiores, é uma consequência do equilíbrio de forças de tensão superficial específico para cada região (Figura 6). O caráter substancialmente estrutural do modelo é evidente, pois o que seriam diferenças morfológicas primariamente funcionais são reduzidas a diferenças na geometria de sistemas mantidos por forças físico-químicas.
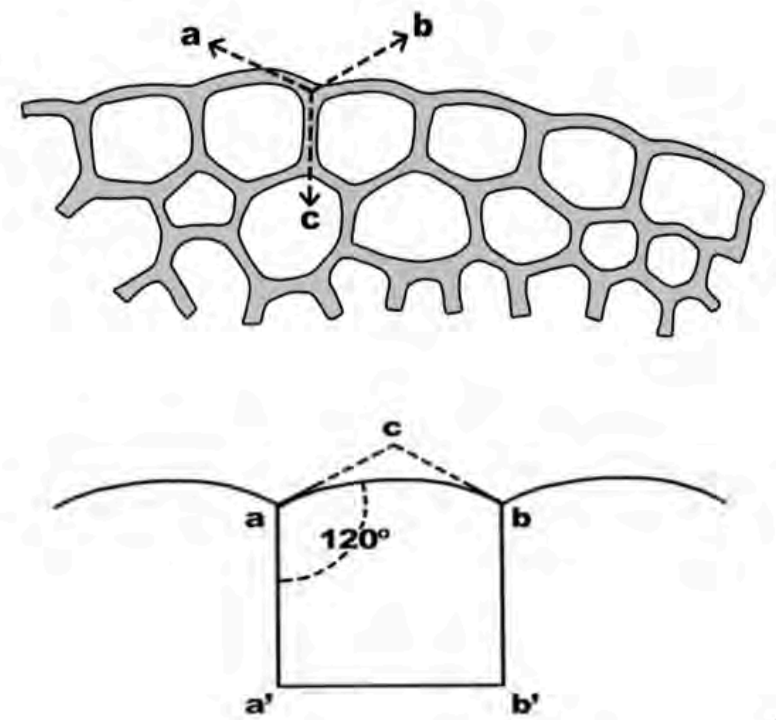

Figura 6. A estrutura específica e regular da camada mais superior de alvéolos (a membrana alveolar) é determinada pela formação de ângulos de $120^{\circ}$ no ponto de junção de três superfícies ou lamelas; esse ponto é diferenciado pelo simples fato de situar-se no contorno da espuma que dá para o exterior; modificados a partir das figuras 3 , p. 33 e 1, p. 35 do texto original. 
Deve-se ressaltar agora que, como já foi dito, tais estruturas são completamente fluidas, ou seja, tanto os componentes da camada alveolar como os da estrutura completa da espuma estão intercambiando-se ativamente. Assim, a parte fixa dessa estrutura, a que confere unidade à rede de alvéolos, pode ser compreendida como uma estrutura geométrica cujas propriedades são (ou poderão ser) plenamente compreensíveis como ações reguladas físico-quimicamente. Bütschli apresenta vivamente essa descoberta nos seguintes termos:

\begin{abstract}
É bastante assombroso ver o quão facilmente tais gotas, juntamente com suas bordas, fluem amplamente e como estas últimas, apesar da sua natureza fluídica, mantém-se integras. Isto mostra de novo e precisamente que ele deve sua origem às leis físicas que continuam a agir durante o movimento de fluxo. (Bütschli 1894, 36)
\end{abstract}

Os diagramas vetoriais são a expressão simbólica de sistemas de força concebidos por uma racionalidade essencialmente geométrica e, como tais, podem representar o que há de mais universal ou essencial nas estruturas protoplasmáticas. As observações e os experimentos serviram basicamente para indicar quais sistemas de força específicos operam na produção da estrutura do protoplasma ou da matéria viva. De fato, para Bütschli, a razão principal para tais investigações está em passar aos modelos físicoquímicos sem retornar ao esquema estrutural: "Na descrição das gotas de espuma, eu evitei intencionalmente entrar no que era o ponto de partida de meus experimentos, a saber, a imitação e a possível explicação das estruturas protoplasmáticas" (Bütschli 1894, 85). Assim, os dados que podem confirmar o sucesso dessa imitação e das explicações que dela decorrem originam-se da observação direta de organismos vivos. Bütschli conta nesse sentido com a imensa quantidade de observações que obteve em seus estudos da morfologia microscópica em várias categorias de seres vivos, bactérias, fungos, plantas, protozoários, invertebrados e vertebrados, submetidos a uma série de condições de observação in vivo e in vitro. A seguir, examinarei uma série de figuras presentes no Investigation de Bütschli com o objetivo de capturar o modo de diferenciação e de organização através da ação físico-química.

Na Figura 8 combinei três tipos específicos do processo geral de diferenciação estrutural a partir de ações físico-químicas. A primeira (7a, a mesma da Figura 5) mostra a formação artificial de uma membrana alveolar em uma gota de espuma oleosa acima apresentada. Eu a dispus aqui como modelo experimental a ser comparado com duas formas naturais do mesmo processo de diferenciação: (i) a que ocorre nos protozoários (no foraminífero miliolídeo, Figuras 5b e 5c) e em Gromia (5d) como representantes de formas elementares de vida unicelulares livres; (ii) a que ocorre nas células de metazoários pluricelulares (a minhoca Lumbricus terrestris (5e)). Comparando as quatro amostras de protoplasma, a artificial e as três naturais, vemos claramente que a unidade celular é constituída por unidades sub-celulares $\mathrm{O}$ que temos aqui são três amostras de protoplasma exibindo a mesma forma alveolar geral e o nível mais elementar de diferenciação, que se dá entre 
os meios extra e intracelulares com a formação da membrana alveolar. O primeiro ponto que destaco é que a célula como base morfológica dos organismos também possui internamente uma morfologia análoga, pois seu protoplasma é constituído pelos alvéolos que poderiam ser pensados como células de um nível inferior.
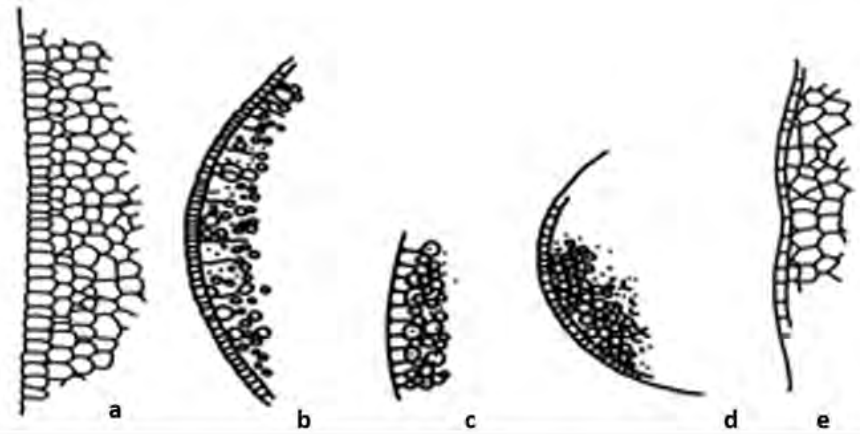

Figura 7. Em (a) a mesma espuma artificial da Figura 5 comparada com estruturas protoplasmáticas naturais. Na sequência: duas figuras ("b" e "c" com diferentes ampliações) representando a borda de uma gota de protoplasma vivo isolado por compressão de um protozoário foraminífero miliolídeo (uma família de foraminífero) (Bütschli 1894, 346); em (d) uma gota de protoplasma fixado e corado do protozoário Gromia Dujardini M. Schultze, liberada livremente pela abertura oral através da compressão do exemplar (Bütschli 1894, 346); em (e), borda de uma célula nervosa de minhoca (Lumbricus terrestris) macerada em iodina-álcool (Bütschli 1894, 358). É nítida a presença da camada alveolar mais externa, com seu típico arranjo estriado uniforme, integrada internamente à malha ou retículo de alvéolos com estrutura comparativamente mais variável (modificados a partir, na sequência, das Figura 4-prancha V; 5a e 5b-Prancha II; 1-Prancha II; 3-Prancha III).

Além da formação da membrana alveolar externa que cria o contorno da célula, o protoplasma interno com suas unidades alveolares também sofreria processos de morfogênese produtores das formas subcelulares. Vemos isso mais conspicuamente na Figura 8, que representa o protozoário do gênero Acineta no qual a diversidade da forma interna é exibida com detalhe bem maior. Trata-se de um exemplar vivo no qual vemos a membrana alveolar formar o macronúcleo cujo conteúdo é análogo ao do plasma celular. Uma forma globular menor na parte superior mostra novamente como se dá a formação de vesículas por uma membrana alveolar circundante. Bütschli descreve outros detalhes (1894, 87-88) da morfologia que não puderam ser representados na figura simplificada que apresentamos. Considerando o conjunto das observações anteriormente descritas, podemos concluir que a forma completa da célula é o produto de diferentes níveis de organização alveolar sempre integrados em uma rede dinâmica semelhante a uma espuma. A diversidade das formas celulares completas produz a forma total do organismo. 


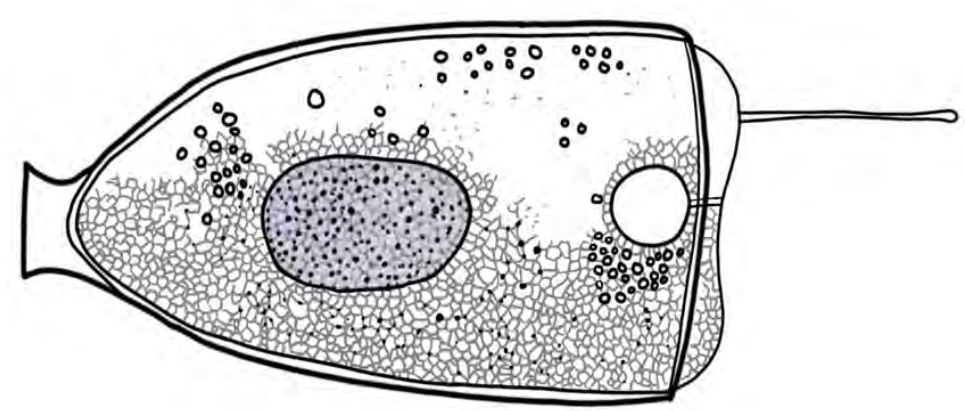

Figura 8. Exemplar do protozoário Acineta observado vivo. Esta imagem do todo celular mostra a expansão da estrutura alveolar como fundamento da diferenciação e da organização das várias unidades subcelulares (modificado a partir da Figura 5, prancha III do texto original).

\section{Conclusão}

Nesta parte conclusiva de meu estudo, articularei os resultados obtidos por Bütschli ao conceito de nucleoplasma comparando-os diretamente aos obtidos por Goodsir. Os centros de nutrição de Goodsir são nucleoplasmas com um evidente núcleo fisiológicogerminativo cuja expressão plasmática se dá pela fragmentação desse núcleo que gera e organiza texturas e órgãos sem perda da unidade original. Sendo a mancha germinativa do ovo fecundado um centro nutritivo primordial, o organismo completo, suas células e todas as unidades orgânicas hierarquicamente organizadas possuem seus respectivos centros, repetindo a mesma unidade morfológica básica. Esses centros são verdadeiramente morfológicos, pois conduzem ativamente e funcionalmente os desdobramentos da estrutura.

A fragmentação dos núcleos de uma célula-mãe produz células-filhas que preenchem e distendem a região interna da primeira, produzindo uma trama que, em princípio, poderia ser morfologicamente análoga a uma espuma alveolar de Bütschli. Para que essa comparação seja válida, as diferenciações geométricas-dinâmicas do protoplasma alveolar devem ser pensadas como morfológicas, o que implica realizar uma interpretação que cria a continuidade entre ambas. O núcleo de uma forma protoplasmática de Bütschli encontra-se nos três vetores em equilíbrio dinâmico que aparecem na fronteira entre três alvéolos (Figura 6). Assim comparadas e interpretadas, as duas estruturas aliadas às suas funções são duas formas nucleoplasmáticas em continuidade histórica expressas em diferentes obras, por diferentes autores e separadas por aproximadamente 50 anos. Contudo, penso que, como forma de realização científica histórica concreta, essa possibilidade se expressa apenas parcialmente, já que a analogia entre as duas estruturas não é acompanhada por uma analogia que sustente algum compartilhamento funcional. 
Isso se torna claro se compararmos a membrana germinal de Goodsir (Figura 1a) com a camada alveolar de Bütschli (Figuras 5 e 7). A primeira é uma unidade orgânica dotada de atividade proliferativa, cuja fonte é a ação coordenada dos centros de nutrição. Tais propriedades fenomênicas as tornam compreensíveis como formas naturais determinadas como objetos do que, utilizando os termos de Goodsir, é uma ciência das formas orgânicas. Já a membrana alveolar de Bütschli é, fenomenicamente, uma entidade que se objetiva na diluição das fronteiras do natural e do artificial. Como estruturas manufaturadas, as espumas microscópicas são entidades empíricas projetadas para reunir propriedades dinâmicas que sejam plenamente inteligíveis pela físico-química. À luz dessa segunda possibilidade de comparação, tais espumas são concebidas como objetos de uma ciência dinâmico-geométrica reguladas por forças, mas que não são formas, no sentido que as defini na introdução deste artigo. Isso porque a atividade dinâmica do protoplasma não é uma atividade funcional internamente e permanentemente ligada a uma estrutura. Colocando lado a lado a conceitualização do protoplasma como forma nucleoplasmática e como estrutura geométrica-dinâmica temos uma transição que pode significar duas coisas: ou bem continua em curso a continuidade do modelo nucleoplasmático e podemos esperar novas expressões nas realizações científicas posteriores às de Bütschli ou temos um esgotamento histórico desse modelo e uma consequente extinção ou deslocamento do pensamento morfológico para a periferia da biologia. Consegui sustentar a primeira possibilidade nos estudos que realizei sobre o processo de plasmogenia, concebido pelo biólogo mexicano Alfonso Luiz Herrera (1868-1943) (Ramos 2016). Contudo, dado que esse projeto plasmogenético, vigoroso entre o final do século IX e início XX, praticamente desapareceu na ciência oficial posterior, ainda faz parte de meus estudos futuros um exame mais detido da validade e do alcance da segunda possibilidade.

\section{Referências bibliográficas}

Bütschli, J. A. O. (1894). Investigations on microscopic foams and on protoplasm. London: Adam and Charles Black.

Goodsir, J., Goodsir, H. D. S (1845). Anatomical and pathological observations. Edinburgh: Myles Macphail.

Ramos, M. de C. (2012). O conceito de mônada orgânica. Methateoria, 3(1): 1853-2322.

Ramos, M. de C. (2013). Morfologia genética em Scheliden e Grant: a célula vegetal e o animal elementar. Revista de Filosofia Aurora, 36(25): 217-237. doi: http://dx.doi.org/10.7213/ revistadefilosofiaaurora. 7772

Ramos, M. de C. (2015). Organic monadology in Maupertuis. Advances in Historical Studies (4): 17-28. doi: 10.4236/ahs.2015.41003

Ramos, M. de C. (2016). A plasmogenia e a sintese conceitual e artificial do protoplasma. São Paulo: LiberArs.

Revista de Humanidades de Valparaíso, 2019, No 14, 171-185

(ㄷ)(1)임 CC BY-NC-ND 



\title{
Perspectivas darwinistas sobre la mente y la conducta humanas: alcances, limitaciones e implicancias educativas
}

\author{
Darwinian perspectives on the human mind and behavior: scope, \\ limitations and educational implications
}

\section{Leonardo González Galli}

Universidad de Buenos Aires, Argentina

leomgalli@gmail.com

\begin{abstract}
Resumen
En este trabajo caracterizo las aproximaciones darwinistas a la conducta y mente humanas, especialmente la psicología evolucionista, y analizo las principales críticas que dichas aproximaciones han recibido. A tal fin recurro a la crítica de Jean Marie Schaeffer a la tesis de la excepcionalidad humana y a la perspectiva semántica de las teorías científicas de Ronald Giere. Concluyo que las principales críticas (reduccionismo, determinismo y sesgo ideológico) no son aplicables a la psicología evolucionista en tanto programa de investigación. Concluyo también que no se puede sostener a priori que el enfoque darwiniano no sea aplicable a la mente y conducta humanas. Finalmente discuto algunas implicancias educativas de estos debates.
\end{abstract}

Palabras clave: selección natural, psicología evolucionista, enseñanza de la biología.

\begin{abstract}
In this work I characterize Darwinian approaches to human behavior and mind, especially evolutionary psychology, and analyze the main criticisms that these approaches have received. To this end I resort to Jean Marie Schaeffer's criticism of the thesis of human exceptionality and the semantic perspective of scientific theories of Ronald Giere. I conclude that the main criticisms (reductionism, determinism and ideological bias) are not applicable
\end{abstract}

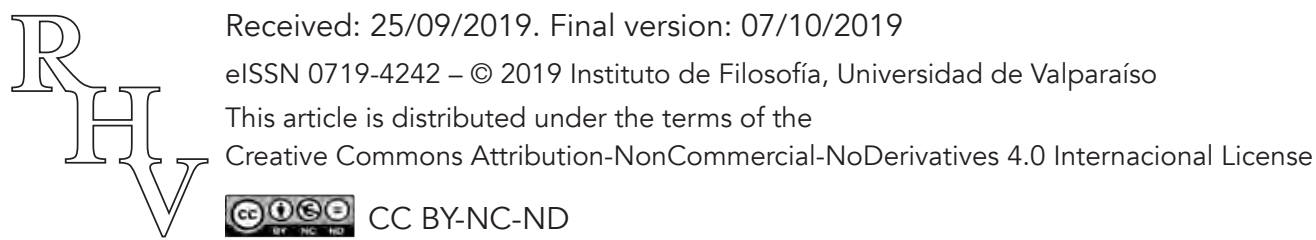


Perspectivas darwinistas sobre la mente y la conducta humanas: alcances, limitaciones e implicancias educativas

Leonardo González Galli

to evolutionary psychology as a research program. I also conclude that it cannot be held a priori that the Darwinian approach is not applicable to the human mind and behavior. Finally, I discuss some educational implications of these debates.

Keywords: natural selection, evolutionary psychology, biology teaching.

\section{Introducción}

La discusión sobre la importancia relativa de los factores biológicos y los socioculturales en la determinación de los rasgos mentales y comportamentales de los humanos es muy antigua. Con frecuencia, el problema se ha planteado en términos dicotómicos ("naturaleza versus crianza", "genes versus ambiente", etc.), y en distintas épocas y contextos el péndulo de las opiniones se movió hacia uno u otro extremo. Tras la segunda guerra mundial la posición antibiológica1 ganó fuerza y se estabilizó. Por oposición al "biologicismo" denominaré "socioculturalismo" a dicha postura (Alcock 2001, habla de "determinismo cultural"). En las últimas dos décadas, sin embargo, los avances en diversas áreas de investigación fueron dejando en claro que estos planteos dicotómicos son inconducentes. En este sentido, hay un fuerte consenso sobre el hecho de que tanto los factores biológicos como los socioculturales tienen un rol causal importante. Así, las discusiones de los últimos años versan sobre cómo se produce la interacción entre factores biológicos y ambientales durante el desarrollo. Tal como señaló Steven Pinker hace ya casi veinte años "es posible que el tema naturaleza frente a educación se encuentre agotado" (Pinker 2003, 11).

La preocupación que me motiva a revisitar este tema es que, a pesar de lo dicho en el párrafo precedente, en el ámbito de la educación el péndulo permanece fijo en el extremo antibiológico. Según argumentaré, tal situación obedece a supuestos que son cuestionables y tiene consecuencias que considero negativas. Cuando hablo del "ámbito de la educación" lo hago en un doble sentido. En primer lugar, me refiero al mundo académico de la investigación en didáctica de la biología. En segundo lugar, me refiero al mundo de las prácticas educativas en todos los niveles (especialmente secundaria, profesorados de biología y licenciaturas en biología). En todos estos ámbitos se tiende a asumir un "socioculturalismo" que va de la mano del supuesto según el cual cualquier aplicación de la biología a lo humano ${ }^{2}$ es a priori ilegítima. Más específicamente, los programas de investigación que se basan en la biología para explicar (algunos aspectos de) lo humano reciben tres críticas principales: (1) reduccionismo biológico, (2) determinismo biológico

\footnotetext{
${ }^{1}$ Hablo de posición "antibiológica" y no "antibiologicista" porque si bien la oposición al biologicismo (entendido como la reducción total de lo humano a la biología) está más que justificada, lo que encontramos con frecuencia es una oposición a la aplicación de la biología per se a lo humano.

${ }^{2}$ Utilizaré la expresión "lo humano" para referirme abreviadamente a la mente y la conducta humanas.
}

Revista de Humanidades de Valparaíso, 2019, No 14, 187-222

(c) (1) 8 (을 BY-NC-ND 
Perspectivas darwinistas sobre la mente y la conducta humanas: alcances, limitaciones e implicancias educativas

Leonardo González Galli

y (3) sesgo ideológico. Así, la enseñanza suele orientarse a mostrar a los/as estudiantes que la biología no es pertinente para la comprensión de la mente y la conducta humanas y que, por lo tanto, deben sospechar de toda mirada biológica y deben buscar las explicaciones exclusivamente en modelos de las ciencias sociales.

Estas acusaciones han recaído sobre todas las áreas de la biología que amenazan con tener algún valor explicativo para la mente y la conducta. Curiosamente, asumiendo alguna forma de dualismo, se reconoce habitualmente la legitimidad de la biología cuando de la anatomía y fisiología humanas se trata (Soler 2009, 29). Así, la genética, el darwinismo $^{3} \mathrm{y}$, más recientemente, las neurociencias, han sido acusadas de mala ciencia al servicio de los poderosos.

Por supuesto, no se trata de negar aquí el hecho histórico evidente de que muchos han recurrido a la biología (y a otras disciplinas científicas, como la antropología) para justificar un determinado orden socioeconómico (Alexander y Numbers 2010). No se trata tampoco de negar que la ciencia es una empresa humana y que, como tal, está necesariamente atravesada por la ideología. Se trata, en cambio, de elaborar una perspectiva mínimamente sofisticada que evite las falsas dicotomías y la sobresimplificación con que, con demasiada frecuencia, se plantean estas cuestiones. Se trata también de tender a una mejor comprensión de la naturaleza de la ciencia que ayude a entender los alcances y limitaciones de lo que la biología pueda decir sobre estas cuestiones. Es entonces la insatisfacción que como educador e investigador en didáctica de la biología experimento frente a la postura dominante que acabo de caracterizar lo que me motiva a elaborar estas reflexiones.

En este trabajo defenderé la necesidad y legitimidad de las perspectivas biológicas y, más específicamente, darwinistas sobre lo humano (para una introducción general y accesible a este tema puede consultarse Castro, López-Fanjul y Toro 2003). Para tal fin, me serviré de dos ideas de la filosofía de la ciencia que no suelen considerarse en este debate. La primera de estas ideas es la crítica a la "tesis de la excepción humana", desarrollada por el filósofo francés Jean Marie Schaeffer (2009). Tras presentar dicha crítica sugeriré que su aceptación implica rechazar la deslegitimación a priori de las miradas darwinistas sobre lo humano. Además, sostendré que el modo de lidiar con este problema depende fuertemente de qué idea tengamos sobre la naturaleza de las teorías científicas $\mathrm{y}$, más específicamente, intentaré mostrar que la adopción de la denominada perspectiva semántica (esta es la segunda idea a la que recurriré) ofrece una caracterización de las teorías científicas que, en cierto grado al menos, "diluye" buena parte de los problemas asociados a la aplicación de la biología a lo humano. Armado con estas dos ideas abor-

\footnotetext{
${ }^{3}$ Con el término "darwinismo" me referiré al enfoque teórico de la actual biología evolutiva que asume que el principal mecanismo evolutivo es la selección natural.
} 
Perspectivas darwinistas sobre la mente y la conducta humanas: alcances, limitaciones e implicancias educativas Leonardo González Galli

daré las respuestas a las habituales acusaciones de reduccionismo, determinismo y sesgo ideológico. Finalmente, discutiré algunas implicancias de estos análisis, volviendo a mis preocupaciones educativas.

\section{Crítica del excepcionalismo humano y perspectiva semanticista de las teorías científicas}

\subsection{Crítica de la perspectiva excepcionalista sobre el ser humano}

¿Cómo es posible que los avances importantes en el conocimiento del ser humano aportados por la biología [...] no hayan sido acogidos por todos los investigadores en ciencias sociales ni por todos los filósofos y los investigadores en el campo de los hechos culturales [...] como algo que volvía factible el desarrollo de un modelo integrado del estudio de lo humano?

Schaeffer $(2009,14)$

Según Schaeffer (2009), la "tesis de la excepción humana" se compone de cuatro afirmaciones. De acuerdo con la primera, existe una diferencia de naturaleza entre el humano y el resto de los seres vivientes. Se postula así una ruptura óntica al interior de lo viviente. Esto supone más que afirmar que hay rasgos propios del humano (una afirmación más bien trivial, ya que vale para cualquier especie), supone, en cambio, afirmar que en su mismo ser el humano es irreductible a la vida animal como tal. La segunda afirmación, implica una particular interpretación del dualismo ontológico para postular la existencia de dos planos del ser: el material y el espiritual. Esto constituiría una suerte de segunda expresión de la ruptura óntica, pero en este caso al interior de lo humano. La tercera afirmación radica en una concepción gnoseocéntrica del humano, de acuerdo con la cual lo que hay de propiamente humano en nuestra especie es la capacidad de conocer. Finalmente, la cuarta afirmación consiste en el ideal cognitivo anti-naturalista, de acuerdo con el cual el conocimiento de lo que es propiamente humano exige una vía de acceso y un tipo de conocimiento radicalmente diferentes de aquellos que nos permiten conocer las demás entidades. Tanto las ciencias naturales como las sociales son igualmente deslegitimadas por este ideal: ambas adoptan la vía cognitiva externalista ${ }^{4}$ (así, aunque las ciencias sociales suelen declararse anti-naturalistas solo serían anti-biologicistas).

Schaeffer dedica su libro a cuestionar todos los componentes de esta tesis. Por razones de espacio no me extenderé sobre dicha crítica y remito al lector a dicho texto para profundizar en esta cuestión. Me limitaré a señalar aquí que, con respecto a la prime-

\footnotetext{
${ }^{4}$ En este contexto, el externalismo se refiere al modo objetivista de indagar el mundo, "en tercera persona", propio de las ciencias (tanto sociales como naturales). La tesis de la excepción humana, por el contrario, sostiene que el conocimiento de lo que es propiamente humano reclama un tipo de conocimiento radicalmente distinto del que nos permite conocer a todas las demás entidades naturales (incluidos los seres vivos no humanos). Este rechazo del externalismo lleva a un ideal cognitivo antinaturalista.
}

Revista de Humanidades de Valparaíso, 2019, No 14, 187-222

()ㅇㅇㅇㅇ CC BY-NC-ND 
Perspectivas darwinistas sobre la mente y la conducta humanas: alcances, limitaciones e implicancias educativas

Leonardo González Galli

ra afirmación, la aceptación del evolucionismo implica un rechazo de la ruptura óntica. En relación con la segunda afirmación, resulta evidente que una perspectiva basada en las ciencias naturales implica el rechazo del dualismo cuerpo/mente. La tercera afirmación pierde importancia cuando se rechaza la primera: la cuestión de en dónde reside la "esencia humana" solo tiene sentido dada la aceptación de la ruptura óntica. Rechazado dicho supuesto, desde una perspectiva biológica (que no es la única posible y que debería complementarse con otros enfoques), solo se puede discutir qué rasgos tiene el humano en tanto especie biológica, análisis que vale por igual para cualquier otra especie. De hecho, el enfoque evolucionista cuestiona toda mirada esencialista (Mayr 2006): no existe tal cosa como la "esencia humana" (pero, como veremos más adelante, esto no implica negar la existencia de una "naturaleza humana"). Finalmente, en relación con la cuarta afirmación, dado que lo que aquí pretendo es defender la legitimidad de un particular programa de investigación de la biología es claro que asumo una perspectiva externalista y naturalista sobre el humano.

Las críticas a la validez de la perspectiva darwinista de lo humano asumen la primera afirmación (ruptura óntica) y, en ocasiones, parecen asumir también la segunda (dualismo ontológico). En efecto, estas críticas se basan en una perspectiva rupturista según la cual la aparición, en algún momento de nuestra evolución, de la cultura habría vuelto irrelevante el sustrato biológico del que dicha cultura emergió. Esta es la postura expresada en el llamado "modelo estándar de las ciencias sociales", según el cual la cultura es un sistema autónomo, causalmente independiente del sustrato cognitivo y biológico de las mentes individuales (Pinker 2003, 112) ${ }^{5}$. Así, tal como hacía el conductismo, el "socioculturalismo" solo reconoce como biológicamente dado un sustrato psicofísico que otorga al desarrollo de la mente y la conducta una flexibilidad virtualmente ilimitada. Esta perspectiva ha sido denominada "tabla rasa" (Pinker 2003). Debe quedar claro que es perfectamente legítimo, y eventualmente muy útil, desarrollar modelos de solo consideran los factores socioculturales; no cuestiono la validez de dichos modelos sino la censura a priori de aquellos modelos que se centran en los factores biológicos. En este sentido, desde el punto de vista científico, no hay margen para dudar del origen evolutivo de los humanos, y esto supone una tesis fundamental de continuidad: lo que somos no es más que la última versión de un linaje, producto de un proceso de cambio continuo a partir de alguna versión de primate anterior. Así, si aceptamos que en los demás animales operan ciertos factores causales, el supuesto de partida (que, desde ya deberá luego validarse empíricamente) debe ser que dichos factores causales operarán también en nosotros. De modo análogo, si ciertos modelos científicos han probado ser muy iluminadores en relación con algunos aspectos de la conducta de los animales no humanos, el supuesto de

\footnotetext{
${ }^{5}$ Un enfoque como este es legítimo y puede resultar muy fructífero. El problema es que dicho enfoque (o cualquier otro) se proponga como totalizador y excluyente. Lo que sugiero es que, en línea con la mirada perspectivista adoptada en este trabajo, este enfoque centrado en lo sociocultural debería ser parte, junto con otros que aporten otras perspectivas, de un marco general de pluralismo teórico.
}

Revista de Humanidades de Valparaíso, 2019, No 14, 187-222

(c) (1) 8 (을 CC BY-NC-ND 
partida debería ser que dichos modelos también podrían, en principio, iluminar algunos aspectos importantes de nuestra conducta. En este sentido, como veremos, la sociobiología (SB) y la psicología evolucionista (PE) no son más que la aplicación al humano de un programa de investigación cuyo valor explicativo para los animales no humanos es innegable. El poder heurístico y explicativo de este enfoque es notable, y solo una severa confusión entre lo que es y lo que debería ser (según los ideales epistémicos de ciertos autores) podría llevar a negar este hecho que queda en evidencia en la ingente producción académica del área y la resolución (desde ya, nunca total ni definitiva) de algunos viejos enigmas teóricos (Alcock 2001; Carranza 2016; Davies, Krebs y West 2012).

Lo que aquí estoy defendiendo es la legitimidad de los enfoques darwinistas. Esto no supone la defensa de ninguna de las hipótesis específicas sostenidas por unos u otros autores. Es más, queda abierta la posibilidad de que, aunque legítimo, el enfoque darwinista resulte -tras una extensa investigación empírica- poco iluminador en relación con los asuntos humanos que nos interesan. Lo importante es que, una vez establecido que no se puede negar a priori la legitimidad del programa de investigación, el valor global de dicho programa, o de cualquiera de sus hipótesis específicas, deberá evaluarse a partir del análisis de datos empíricos, y no a partir de posturas apriorísticas como aquellas basadas en la idea de que, en tanto seres culturales, los factores biológicos son irrelevantes.

Los enfoques darwinistas del comportamiento animal son actualmente una parte importante y bien establecida de la biología evolutiva. Esto se debe al enorme poder explicativo y heurístico de dicho enfoque. Si asumimos una continuidad histórico-evolutiva entre el humano y los demás animales, entonces, la aplicación de estos modelos explicativos a lo humano no debería considerarse a priori ilegítima, incluso debería considerase prometedora. Para decirlo de otro modo, la negación de tal legitimidad debería argumentarse con base en algún hito evolutivo que marcara una discontinuidad flagrante entre el humano y sus antepasados. Habitualmente, la cultura, o algunos de los rasgos cognitivos que la hacen posible (principalmente, el lenguaje), se ha postulado como ese factor de quiebre entre humanos y no humanos. Sin embargo, dicha perspectiva siempre estuvo reñida con la perspectiva evolucionista dominante que desconfía de los "saltos evolutivos". De hecho, la investigación de las últimas décadas sobre la conducta social de animales no humanos, especialmente de los grandes simios, no ha hecho más que socavar aún más dicho enfoque rupturista (Laland y Galef 2009).

Los enfoques que no atienden a lo biológico no asumen necesariamente una postura discontinuista sino que, simplemente, se centran legítimamente en factores socioculturales. La tesis discontinuista sí es asumida, en cambio, por quienes niegan a priori la validez de los modelos biológicos. De acuerdo con lo que sostendré en la siguiente sección, ningún modelo puede dar cuenta de todos los aspectos de un fenómeno, por lo que nada hay de cuestionable en aquellos modelos que se enfocan en los factores socioculturales. Lo que cuestiono es la pretensión de que los modelos que sí consideran lo biológico, en particular aquellos basados en la selección natural, no son a priori, por razones ideológi-

Revista de Humanidades de Valparaíso, 2019, No 14, 187-222

(ㄷ)(1)(8) CC BY-NC-ND 
Perspectivas darwinistas sobre la mente y la conducta humanas: alcances, limitaciones e implicancias educativas

Leonardo González Galli

cas o de otra índole, aplicables a lo humano. Contra dicha pretensión, he sostenido que el evolucionismo en general pone en cuestión la tesis de discontinuidad y excepcionalidad y que, como consecuencia, la aplicación de los modelos evolucionistas a lo humano resulta legítima a priori.

\subsection{La perspectiva semántica de las teorías científicas}

[...] todas las afirmaciones teóricas permanecen perspectivas en el sentido de que se aplican a aspectos del mundo y luego, en parte porque se aplican solo a algunos aspectos del mundo, nunca con total precisión.

Ronald Giere (2006, 15, traducción propia)

Tal como he adelantado, argumentaré que la forma que toma el debate en torno de la SB y la PE depende en gran medida de la concepción de teoría científica que adoptemos. Describiré brevemente la perspectiva semántica de las teorías científicas, más específicamente la denominada "teoría cognitiva de la ciencia" de Ronald Giere (1992; 2006), que constituye una corriente epistemológica específica dentro de la "familia semanticista" (Díez y Moulines 2008).

La perspectiva semanticista parte de la afirmación de que lo importante en una teoría científica es su significado, esto es, qué dice acerca de qué aspectos del mundo. Por contraste, las perspectivas sintácticas enfatizan la importancia de los aspectos formales de la teoría, tales como las definiciones y las fórmulas matemáticas (Díez y Moulines 2008). De acuerdo con esta perspectiva, lo más importante de una teoría son sus modelos. El modelo es una entidad abstracta. Un aspecto fundamental de este enfoque es la afirmación de que los modelos guardan una relación analógica con los sistemas reales que representan. Así, un modelo solo se parece en cierto grado y aspectos al sistema representado. Según Giere, por tal motivo, no tiene sentido preguntarse si un modelo es verdadero o falso. De acuerdo con lo dicho, si adoptamos un concepto fuerte de verdad por correspondencia, todo modelo resultará falso, ya que nunca tendremos un ajuste total entre el modelo y la realidad. Por tal motivo, la cuestión interesante no es si un modelo es verdadero o falso sino si es adecuado o no. Por supuesto, la evaluación de la adecuación solo se puede hacer en función de ciertas metas. Así, desde esta perspectiva, se asume que los modelos se construyen con la intención de intervenir en el mundo de acuerdo con ciertos fines. Y es en función de esos fines que se evalúa la adecuación del modelo.

La adopción de esta perspectiva epistemológica supone renunciar desde el principio a toda pretensión explicativa totalizadora. Tal como señalamos, en el mejor de los casos, un modelo puede reclamar para sí el mérito de iluminar ciertos aspectos del fenómeno de interés. Así, si tomamos, por ejemplo, la agresión intergrupal (guerra), los modelos darwinianos podrán, eventualmente, dar cuenta de ciertos aspectos de dicho fenómeno, pero en ningún caso de su totalidad. Seguramente, algunos aspectos de la guerra podrán ser

Revista de Humanidades de Valparaíso, 2019, No 14, 187-222

()ㅇㅇㅛ CC BY-NC-ND 
Perspectivas darwinistas sobre la mente y la conducta humanas: alcances, limitaciones e implicancias educativas

Leonardo González Galli

explicados por ciertos modelos de las ciencias sociales. Según los críticos Hilary y Steven Rose (2000), la PE afirma explicar todos los aspectos del comportamiento humano. Aún en caso de que algún psicólogo evolucionista afirmara tal cosa (no me consta), tal pretensión no estaría justificada. Más allá de las eventuales pretensiones de algún investigador particular, un modelo solo estaría, en el mejor de los casos, explicando algunos aspectos del comportamiento humano. Por otro lado, lo que un modelo dice sobre cierto fenómeno siempre es relativo a la perspectiva teórica e instrumental adoptada (perspectivismo). En síntesis, lo que, en nuestro caso, la PE pueda decir sobre lo humano siempre será parcial (iluminará ciertos aspectos y no otros) y perspectivo (solo válido en relación con ciertas perspectivas teóricas y metodológicas adoptadas). Las mismas conclusiones valen para cualquier otro modelo, incluyendo los de las ciencias sociales.

Así, la intención de lograr una comprensión profunda de cualquier fenómeno nos obliga al pluralismo teórico. Tal como discutiré más adelante, muchas discusiones sobre los enfoques darwinianos de lo humano, especialmente la discusión en relación con el problema del reduccionismo biológico, pierden sentido cuando se adopta este enfoque. Espero mostrar que este cambio de perspectiva es de gran valor, sobre todo porque evita enfrentamientos estériles y nos permite concentrarnos en lo que, según creo, debería ser la discusión más interesante: qué modelos explican qué aspectos de los fenómenos de interés.

\section{Perspectivas darwinistas sobre lo humano}

La psicología se basará seguramente sobre los cimientos [...] de la necesaria adquisición gradual de cada una de las facultades y aptitudes mentales. Se proyectará mucha luz sobre el origen del hombre y sobre su historia.

Charles Darwin (1876, 428, traducción propia)

De acuerdo con el enfoque semanticista adoptado, resulta fundamental enunciar con claridad qué dicen sobre los fenómenos de interés los modelos teóricos en que se basan la $\mathrm{SB}$ y la PE. Intentaré mostrar que si hacemos este ejercicio constataremos que muchas de las críticas que se dirigen contra dichos programas carecen de sustento, simplemente porque atribuyen a estos programas supuestos teóricos que no forman parte de los modelos que los sustentan. Muchas veces, esas críticas se basan en citas acotadas de algún texto de algún investigador particular. Sin embargo, si lo que se pretende es cuestionar un programa de investigación, semejante procedimiento no es adecuado. Los dichos de investigadores individuales pueden ser de interés para un análisis sociológico de la disciplina, pero no para un análisis epistemológico del programa de investigación. Y si la crítica se basa exclusivamente en análisis sociológicos debe tenerse presente que, por más interesantes que sean, dichos análisis son incapaces de evaluar la validez de una teoría.

Revista de Humanidades de Valparaíso, 2019, No 14, 187-222

(c) (1) 8 (을 CC BY-NC-ND 
Perspectivas darwinistas sobre la mente y la conducta humanas: alcances, limitaciones e implicancias educativas

Leonardo González Galli

A continuación, reseñaré los modelos teóricos en que se basan la SB y la PE, procediendo desde los modelos más generales hacia los más específicos.

\subsection{Selección natural y adaptacionismo}

El modelo central común a todos los enfoques darwinistas de la mente y la conducta humanas es, desde ya, el modelo de evolución por selección natural ${ }^{6}$. Comenzaremos, entonces, caracterizando dicho modelo. Siguiendo a Bergstrom y Dugatkin $(2012,60)$ podemos decir que la selección natural es la consecuencia inevitable de tres condiciones:

(1) Variación. Los individuos dentro de la población difieren en sus rasgos.

(2) Herencia. Algunas de las diferencias interindividuales son heredables.

(3) Éxito reproductivo diferencial. Los individuos con ciertas variantes de un rasgo dejan, en promedio, más descendientes que aquellos con otras variantes.

La consecuencia, la evolución por selección natural, es el cambio en la proporción de las diferentes variantes heredables en la población a través de las generaciones.

Este modelo es válido para cualquier rasgo biológico, sea morfológico o comportamental. Muchas personas son reticentes a reconocer la influencia de los genes en la personalidad y la conducta y, por lo tanto, tienden a negar que dichos rasgos puedan evolucionar por selección (Buss 2019; Ridley 2004; Soler 2009). Sin embargo, negar la validez de este modelo para los rasgos conductuales supondría adherir al dualismo que hemos mencionado como parte de la tesis de la excepción humana y que resulta insostenible a la luz de los conocimientos actuales (Plomin et al. 2002) ${ }^{7}$.

Habitualmente, se denominan "adaptaciones" aquellos que rasgos que, por ser producto de la selección, mejoran el ajuste entre el organismo y su medio. El término "adaptacionismo" se utiliza con diversos significados. De acuerdo con Lewens (2007) podemos distinguir:

a. Adaptacionismo empírico: la mayoría de los rasgos son adaptaciones, esto es, son producto de la selección natural.

\footnotetext{
${ }^{6}$ Estrictamente hablando, de acuerdo con la propuesta de Giere, la selección natural sería, por su alto grado de generalidad, más un "principio" que un modelo. A este principio se le agregarían luego algunas condiciones específicas para formular modelos cuya mayor especificidad los haría aplicables a ciertos sistemas reales. Pero estas distinciones no son relevantes para nuestra discusión.

${ }^{7}$ Aquellos modelos sobre la personalidad y la conducta que dejan afuera los factores biológicos no suponen una adhesión al dualismo que estoy criticando. Dichos modelos, simplemente, ponen el foco en otros factores, lo que constituye una decisión perfectamente legítima y potencialmente fructífera. No estoy cuestionando estos modelos: estoy cuestionando el dualismo.
}

Revista de Humanidades de Valparaíso, 2019, No 14, 187-222

(c) (1)을 CC BY-NC-ND 
Perspectivas darwinistas sobre la mente y la conducta humanas: alcances, limitaciones e implicancias educativas Leonardo González Galli

b. Adaptacionismo metodológico: con independencia de qué tan cierto resulte ser el adaptacionismo empírico, el modo más fructífero de indagar el mundo biológico es asumir hipotéticamente el carácter adaptativo de los rasgos estudiados.

c. Adaptacionismo explicativo: el objetivo más importante de la biología evolutiva es dar cuenta de la adaptación (en este caso "adaptación" se refiere al ajuste entre los organismos y su entorno).

d. Adaptacionismo epistemológico: disponemos de métodos fiables para establecer la validez o no validez de las hipótesis sobre la adaptación.

Los investigadores que se enmarcan en el "programa adaptacionista" adhieren en grado variable a estas diversas formas de adaptacionismo. En cualquier caso, ningún investigador cree, como quiere la caricatura construida por los críticos, que todos los rasgos sean adaptativos. En efecto, cualquier manual de biología evolutiva (Futuyma y Kirkpatrick 2018) deja en claro que existen mecanismos evolutivos no selectivos (la deriva genética, por ejemplo) y que, por lo tanto, siempre está abierta la posibilidad de que el rasgo estudiado no constituya una adaptación. Como programa de investigación el adaptacionismo ha sido criticado (Gould y Lewontin, 1979) y defendido con igual fervor (Dennett 1995). En cualquier caso, incluso los principales críticos del programa adaptacionista reconocen la importancia del concepto de adaptación (Lewontin 1978). En la actualidad un gran porcentaje de las investigaciones que se llevan a cabo sobre la conducta animal se enmarcan en el enfoque adaptacionista (Carranza 2016; Davies, Krebs y West 2012).

\subsection{Ecología del comportamiento}

De acuerdo con Alcock (2001, 9, traducción propia), la ecología del comportamiento (EC) es "el estudio de las relaciones evolucionarias entre el comportamiento de un animal y su entorno". Buller (2007, 263, traducción propia) la define como "el estudio de cómo el comportamiento permite al animal responder adaptativamente a las condiciones de los ambientes físicos y sociales". Sin embargo, este enfoque no supone simplemente la aplicación del darwinismo al estudio del comportamiento animal, sino que implica algunos otros supuestos teóricos más específicos. Un aspecto teórico central para comprender esta especificidad reside en qué respuesta se dé al denominado problema del altruismo. Se dice que una conducta es altruista, en sentido biológico, cuando reduce el éxito reproductivo de que quien la ejecuta al tiempo que incrementa el de otro individuo (Davies, Krebs y West 2012, 307). La razón por la cual este tipo de comportamientos ha resultado problemático para el darwinismo es que, en una primera lectura al menos, la selección no podría favorecer su evolución.

Después de que el propio Darwin considerara que la selección podía explicar la evolución de la conducta tanto como la de la morfología o fisiología, el primer programa de investigación que buscó analizar la conducta desde la perspectiva de la selección natural,

Revista de Humanidades de Valparaíso, 2019, No 14, 187-222

()ㅇㅇㅛ CC BY-NC-ND 
Perspectivas darwinistas sobre la mente y la conducta humanas: alcances, limitaciones e implicancias educativas Leonardo González Galli

en las primeras décadas del siglo XX, fue la etología de Europa continental, representada por investigadores como Konrad Lorenz y Niko Tinbergen (De la O-Rodríguez y Montoya 2011; Lorenz 1986; Thorpe 1982, Tinbergen 1985). En relación con el problema del altruismo, tanto Darwin como estos primeros etólogos asumieron que este problema podía resolverse mediante el concepto de selección de grupos (Sober y Wilson 2000). La idea básica es que los grupos formados por individuos altruistas tendrían un mayor éxito reproductivo que aquellos formados por individuos egoístas. De este modo, a largo plazo, la conducta altruista podría incrementar su frecuencia en la población. Luego, tuvieron lugar importantes desarrollos teóricos en la etología anglosajona que resultaron en respuestas radicalmente diferentes al problema del altruismo.

A comienzos de la década de 1960, William Hamilton desarrolló el concepto de fitness inclusivo. De acuerdo con este concepto, un alelo (una variante de un gen) que tenga como efecto una conducta altruista puede pasar copias de sí mismo a la siguiente generación mediante la producción de descendientes (fitness directo) o mediante una ayuda a parientes cercanos que resulte en un incremento en la supervivencia o reproducción de dichos parientes (fitness indirecto). El fitness inclusivo de dicho gen sería la suma de su fitness directo y su fitness indirecto (Futuyma y Kirkpatrick 2018, 300 y ss.). De acuerdo con esta teoría, las conductas altruistas deberían ser dirigidas preferencialmente hacia parientes cercanos ("selección por parentesco") (Davies, Krebs y West 2012). Esta perspectiva fue luego popularizada por Richard Dawkins (2017a) como la teoría del "gen egoísta”.

Un segundo hito en esta historia lo constituye la publicación, en 1966, de "Adaptation and natural selection" de George Williams (1966). Además de presentar de un modo más accesible la teoría de Hamilton, y de analizar cómo llevar a cabo el estudio científico de la adaptación, en este libro Williams desarrolló una crítica demoledora de la idea de selección de grupos. Aunque teóricamente posible, la selección de grupos sería una fuerza débil en la evolución, principalmente porque la selección de individuos al interior de cada grupo tendería a favorecer el egoísmo, y dado que la selección de individuos es más rápida que la de grupos, se impondrían las variantes egoístas (este tipo de altruismo no sería "evolutivamente estable"). Posteriormente, Robert Trivers (1971; 1972) desarrolló los modelos de altruismo recíproco, de inversión parental y de conflicto paterno-filial. La primera de estas ideas permitió comprender de qué modo la selección podría favorecer conductas altruistas entre individuos no emparentados.

Estamos ahora en condiciones de definir en qué cosiste la especificidad del enfoque teórico de la EC. Esta corriente teórica puede definirse como una variante del programa adaptacionista, aplicado al estudio del comportamiento animal, basado en los principios desarrollados por Hamilton (fitness inclusivo), Williams (rechazo de la teoría de la selección de grupos) y Trivers (altruismo recíproco, inversión parental, conflicto pater- 
Perspectivas darwinistas sobre la mente y la conducta humanas: alcances, limitaciones e implicancias educativas

Leonardo González Galli

no-filial). Además, la EC ha recurrido a la teoría de los juegos para desarrollar modelos de optimalidad, a partir de los cuales derivar hipótesis específicas sobre cómo deberían comportarse los animales dadas ciertas condiciones (Bautista y Fernández-Juricic 2016).

\subsection{Sociobiología humana}

El hecho de que la SB llegara a tener nombre propio se debe más a cuestiones histórico-sociológicas que a cuestiones conceptuales. El nombre deriva del libro "Sociobiología: la nueva síntesis" que Edward O. Wilson publicó en 1975 (citado aquí como Wilson 1980; Ruse 1980). Dado el clima intelectual y político en Estados Unidos de América a mediados de la década de 1970, el hecho de que Wilson dedicara el último capítulo de su libro a nuestra especie generó un áspero debate. Sin embargo, desde el punto de vista teórico hay poco de original en el libro de Wilson. A pesar de esto, se ha popularizado la idea errónea según la cual la SB es una teoría sobre el comportamiento humano propia de Wilson (Alcock 2001, 5). La definición del propio Wilson $(1980,5)$, según la cual la SB es "el estudio sistemático de las bases biológicas de todo comportamiento social" es engañosamente amplia y oculta algunos rasgos fundamentales del campo, como el hecho de que quienes se autodenominan "sociobiólogos" están invariablemente interesados en analizar las conductas sociales desde el punto de vista evolutivo (causas últimas) y no, por ejemplo, desde el punto de vista fisiológico (causas próximas). Los sociobiólogos estudian la conducta social desde una perspectiva darwinista y, más específicamente, se distancian de la etología clásica europea para basarse en los supuestos teóricos de la EC. Así, la SB podría definirse como la EC aplicada a la conducta social de los animales, incluido Homo sapiens. El término "sociobiología" es muy poco utilizado en la actualidad.

\subsection{Psicología evolucionista}

De acuerdo con Buller (2007, 255 y ss.), la PE constituye un programa de investigación específico que tiene su origen en las obras de los antropólogos John Tooby y Donald Symons y los psicólogos Leda Cosmides y David Buss. Estos autores parten de una crítica a la EC según la cual no sería conveniente estudiar el carácter adaptativo de las conductas. Dado que la conducta es el output de un sistema de procesamiento de información cognitivo operando en cierto entorno no serían las conductas en sí las que fueron seleccionadas, sino, más bien, el sistema de procesamiento de la información. Así, la PE se propone investigar los sistemas cognitivos que generan las conductas, y no las conductas mismas. Para semejante programa de investigación adoptan los siguientes supuestos teóricos. En primer lugar, se asume que la cognición está adaptada al estilo de vida del pleistoceno y no al entorno actual. Desde hace más de un millón de años, y hasta hace apenas unos diez mil años, los humanos vivimos en pequeñas hordas de cazadores-recolectores. Esto no significa, desde ya, que nuestras adaptaciones cognitivas hayan surgido de novo en el

Revista de Humanidades de Valparaíso, 2019, No 14, 187-222

()ㅇㅇㅇㅇ CC BY-NC-ND 
Perspectivas darwinistas sobre la mente y la conducta humanas: alcances, limitaciones e implicancias educativas

Leonardo González Galli

pleistoceno. En efecto, nuestros rasgos cognitivos tienen un origen remoto, es solo que el pleistoceno representa la última etapa de nuestra evolución en que los humanos vivimos al modo ancestral, antes de que la agricultura y otros cambios culturales modificaran rápida y drásticamente nuestro entorno y estilo de vida. Por el poco tiempo transcurrido desde entonces, los psicólogos evolucionistas consideran improbable que hayan evolucionado nuevas adaptaciones cognitivas al estilo de vida posterior al pleistoceno. En segundo lugar, como la supervivencia supone múltiples problemas particulares, es esperable que se hayan seleccionado rasgos psicológicos específicos que resultaran adaptativos en relación con dichos problemas. Dichos sistemas cognitivos adaptativos específicos son llamados "módulos" (Pinker 2000). Los psicólogos evolucionistas tienden a asumir que disponemos de cientos de módulos específicos ("tesis de la modularidad masiva"). Estos módulos serían dominio-específicos, esto es, incluirían una gran cantidad de conocimiento innato sobre cada dominio y surgirían como parte del desarrollo normal. En tercer lugar, se asume que esta arquitectura cognitiva es común a toda la especie. Por último, dado que para la mayoría de los humanos el ambiente actual es radicalmente distinto del entorno ancestral en que se seleccionaron los módulos, no es esperable que las conductas actuales sean en sí mismas adaptativas.

De acuerdo con Buller (2007 269 y ss.), las principales diferencias entre la EC y la PE son: (1) mientras la PE investiga adaptaciones psicológicas al entorno del pleistoceno, la EC humana investiga adaptaciones conductuales a las condiciones ambientales (incluidas las actuales), (2) mientras la PE espera que las conductas sean con frecuencia maladaptativas en los entornos actuales, la EC espera que sean adaptativas, (3) la PE propone que se debe estudiar la adaptación de la mente al entorno pleistocénico, mientras la EC propone que se debe estudiar el ajuste adaptativo de las conductas al entorno actual, (4) mientras la PE sostiene la tesis de la modularidad masiva, la EC permanece agnóstica en relación con el tipo y número de mecanismos psicológicos que causan las conductas y, finalmente, (5) la PE busca investigar una estructura cognitiva universal, mientras que la EC busca estudiar cómo las diferencias ambientales producen diferencias conductuales entre los individuos. En cualquier caso, no es claro en qué medida ambos programas de investigación son compatibles (Buller 2007, 271).

Como ya señalé, el término "sociobiología" está en desuso por haber quedado asociado al nombre y a las particulares opiniones de Edward. O. Wilson. Por esta razón, se suele hablar de EC humano, cuando se analizan las conductas, o de PE, cuando se analizan los mecanismos cognitivos. Para abreviar, de aquí en adelante hablaré directamente de PE, pero mis análisis son igualmente válidos para la EC.

\section{Las críticas}

Se han planteado numerosas críticas a la SB y la PE, entre ellas que estas disciplinas suponen determinismo biológico, reduccionismo biológico, un sesgo ideológico conser-

Revista de Humanidades de Valparaíso, 2019, No 14, 187-222

(ㄷ)(1)(8) CC BY-NC-ND 
Perspectivas darwinistas sobre la mente y la conducta humanas: alcances, limitaciones e implicancias educativas

Leonardo González Galli

vador, falencias metodológicas, uso abusivo de analogías, exceso de especulación, hipótesis no refutables (Diéguez 2012, cap. 12). Dado que por cuestiones de espacio es imposible analizar todas estas críticas, me limitaré a discutir las tres acusaciones más frecuentes y más generales: determinismo, reduccionismo y sesgo ideológico. Para sostener sus objeciones contra la PE los críticos suelen recurrir a la metodología de identificar frases específicas que pueden entenderse como la expresión de, por ejemplo, una postura reduccionista. Sin embargo, siempre resulta sencillo encontrar frases que parezcan apoyar prácticamente cualquier postura. En cambio, para juzgar si estas acusaciones tienen o no fundamento, sugiero que es más adecuado examinar los supuestos de los modelos teóricos en cuestión para ver si implican o no lo que se les adjudica. Para tal fin recurriré a libros de algunos de los autores más reconocidos de las disciplinas analizadas.

\subsection{Reduccionismo y determinismo}

La idea de determinismo genético es en gran medida irrelevante, porque nadie adhiere a ella, al menos ningún biólogo evolucionista competente lo hace.

John Maynard Smith (1997, 522, traducción propia)

Dos críticas principales que han recibido todos los enfoques biológicos sobre lo humano es que se trata de perspectivas reduccionistas y deterministas. Un problema no menor es que ambos términos tienen más de un significado, y no siempre es claro cuáles de esos significados están en juego en las críticas en cuestión.

En el caso del reduccionismo existen, al menos, tres significados (Diéguez 2012, 189 y ss.; Dobzhansky et al. 1980, 487 y ss.). En primer lugar, habría un reduccionismo ontológico que supone que todos los aspectos y propiedades de un organismo son producto exclusivamente de la interacción de sus componentes mínimos. Luego, habría un reduccionismo metodológico según el cual la investigación debe orientarse a los niveles inferiores de organización. Finalmente, está el reduccionismo epistemológico o teórico que se refiere a la reducción de una teoría a otra (para una discusión de este complejo asunto véase Díez y Moulines 2008, 391 y ss.), en el que la teoría reducida pasar a ser un caso particular de otra teoría de mayor alcance. Los reduccionismos ontológico y metodológico no son muy problemáticos (al menos para el tema que me ocupa aquí). En relación con el primero, ningún científico sugiere que desde el punto de vista ontológico haya algo más que átomos y otras entidades estudiadas por los físicos y sus interacciones. En relación con el segundo, en qué nivel de organización se pone el foco del análisis es una cuestión pragmática, dada por los objetivos de la investigación. Es el reduccionismo epistemológico, que amenaza con un reemplazo de las ciencias sociales por la biología, el que es más problemático.

Ahora bien, ¿En qué sentido dicen los críticos que la SB o la PE son reduccionistas? Por ejemplo, Lewontin, Rose y Kamin $(1996,16)$ afirman que:

Revista de Humanidades de Valparaíso, 2019, No 14, 187-222

()ㅇㅇㅇ CC BY-NC-ND 
Perspectivas darwinistas sobre la mente y la conducta humanas: alcances, limitaciones e implicancias educativas

Leonardo González Galli

los reduccionistas intentan explicar las propiedades de conjuntos complejos [...] en términos de las unidades de que están compuestas estas moléculas o sociedades [y que] [...] sostendrían que las propiedades de una sociedad humana [...] son la suma de los comportamientos y tendencias individuales de los seres humanos de que se compone esa sociedad. Las sociedades son agresivas, por ejemplo, porque los individuos que las componen son agresivos.

No es claro a qué forma de reduccionismo se refieren estos autores. Pareciera que denuncian alguna forma de reduccionismo metodológico y/o epistemológico que implicaría la desaparición de las ciencias sociales porque, presuntamente, todos los fenómenos sociales podrían explicarse en términos de genes y selección natural. Sin embargo, los psicólogos evolucionistas no se proponen tal reemplazo disciplinar, sino que, más bien, buscan ofrecer explicaciones ancladas en niveles de análisis diferentes de los de las ciencias sociales e, incluso, en ocasiones, intentan conectar esos diversos niveles de análisis (Pinker 2003, 115 y ss.). La PE tampoco supone un reduccionismo que, como el denunciado en la cita de Lewontin et al., niegue la existencia de fenómenos propios de niveles superiores de organización (Dennett 1995, 80 y ss.). Así, es difícil ver que el avance de estas disciplinas biológicas implique una reducción o una sustitución teóricas en relación con las ciencias sociales. Sí es esperable, y seguramente positivo, que tengan lugar influencias recíprocas (Ruse 1980, 235 y ss.).

En cuanto al determinismo ${ }^{8}$, se trata de una doctrina según la cual a iguales condiciones se obtendrán iguales resultados. Presumiblemente, el determinismo genético supone que los genes son los únicos factores causales relevantes y que, por lo tanto, a iguales genes, iguales estructuras cognitivas y conductas. Citemos nuevamente a Lewontin et al. (1996, 16-17):

Esencialmente, los deterministas se preguntan: ¿Por qué son los individuos como son? ¿Por qué hacen lo que hacen? Y responden que las vidas y las acciones humanas son consecuencias inevitables de las propiedades bioquímicas de las células que constituyen al individuo. Por último, todo comportamiento humano $-\mathrm{y}$, en consecuencia, toda la sociedad humana- está regido por una cadena de determinantes que van del gen al individuo, y de éste, a la suma de los comportamientos de todos los individuos. Los deterministas afirmarían, pues, que la naturaleza humana está determinada por nuestros genes.

\footnotetext{
${ }^{8}$ Es frecuente que el miedo al determinismo se vincule con la cuestión del libre albedrío y de la responsabilidad individual: si los genes determinan mi conducta, entonces, yo no puedo ser responsable de mis actos. Sin embargo, este problema atañe a toda forma de determinismo y no solo, ni especialmente, al genético. Así, si creemos que nuestra conducta está determinada por nuestra crianza y nuestra cultura estamos frente al mismo problema. Por lo tanto, señalar que los genes tienen algún poder causal (una de las premisas de cualquier interpretación darwinista) en el desarrollo de nuestra conducta tiene exactamente las mismas consecuencias, en relación con el problema del libre albedrío y de la responsabilidad individual, que señalar que la crianza lo tiene.
}

Revista de Humanidades de Valparaíso, 2019, No 14, 187-222 
Perspectivas darwinistas sobre la mente y la conducta humanas: alcances, limitaciones e implicancias educativas Leonardo González Galli

Esta idea de determinismo genético supone, además, que la existencia de un "gen para X" implica que no es posible eludir el desarrollo de X (Alcock 2001, 41). Por ejemplo, de acuerdo con Stephen Gould (2010, 266): "Si estamos programados para ser lo que somos, entonces estos rasgos constituyen algo ineluctable. En el mejor de los casos, podemos canalizarlos, pero no cambiarlos, ni por medio de la voluntad, ni de la educación, ni de la cultura".

La cuestión del determinismo genético está directamente ligada a la pregunta sobre el rol que los genes cumplen en el desarrollo. Analizaré esta cuestión para concluir que, desde el punto de vista de los modelos científicos vigentes, el determinismo genético es un sinsentido. Dado esto, ni la PE ni ninguna otra disciplina que pretenda ser tenida por ciencia respetable podría asumir el determinismo genético y, de hecho, ninguna disciplina adopta ese supuesto suicida. Además, insistiré en que la PE no asume ninguna forma de determinismo genético porque no precisa de tal supuesto: la PE (el igual que todo el darwinismo) requiere que los genes influyan en el desarrollo de los rasgos, no que lo determinen.

Abordemos entonces la cuestión de qué hacen (y qué no) los genes. Con frecuencia, los psicólogos evolucionistas, al igual que todos los biólogos, utilizan expresiones con la forma "el gen de o para X", siendo X cualquier rasgo fenotípico, incluidos los rasgos conductuales y cognitivos. Lo primero que hay que señalar es que estas expresiones no suponen que $\mathrm{X}$ exista como consecuencia exclusiva de la existencia de dicho gen, es decir, no suponen una relación de determinación. Por ejemplo, la afirmación de que existe un "gen Z para (o de) el color blanco" en una especie de roedor significa que, en promedio, y manteniéndose constantes las demás variables (ambientales y genéticas) que influyen en este rasgo, será más probable que el pelaje sea blanco en aquellos individuos que poseen $\mathrm{Z}$ que en aquellos que poseen un alelo diferente. Sin embargo, la posesión de $\mathrm{Z}$ no supone el desarrollo inexorable del color blanco. Esto se debe a que lo más probable es que la producción del color blanco requiera la concurrencia de otros factores causales (genéticos y ambientales). Así, siempre podría suceder que alguno o varios de dichos factores estuvieran ausentes en el desarrollo de un individuo particular, de modo que ese individuo no desarrollaría el pelaje blanco aún en caso de portar el gen Z. Cabe señalar aquí que, por la mirada que supone de los sistemas biológicos, la genética considerará especialmente relevante el rol causal de los genes, lo que no quita que otras teorías enfaticen el rol de causal de otros factores.

Es importante detenerse en la expresión "en promedio" del párrafo anterior. Esta expresión significa que la afirmación según la cual el gen $\mathrm{Z}$ produce pelaje blanco es una afirmación probabilística, lo que, por definición, excluye relaciones de determinación fuertes. Lejos de ser una curiosa excepción, esto es la norma en la biología. En efecto, dada la multicausalidad implicada en todo sistema biológico solo podemos aspirar a hacer afirmaciones probabilísticas (Mayr 1998, 88). Este aspecto epistemológico de las afirmaciones de la biología es sumamente relevante y suele ser ignorado en este debate. Es

Revista de Humanidades de Valparaíso, 2019, No 14, 187-222

(ㄷ)(1) $\mathrm{CC}$ BY-NC-ND 
Perspectivas darwinistas sobre la mente y la conducta humanas: alcances, limitaciones e implicancias educativas

Leonardo González Galli

cierto que, con frecuencia, quienes hablan desde la biología no hacen explícito el carácter probabilístico de sus afirmaciones (lo mismo cabe para quienes hablan desde las ciencias sociales). Sin embargo, sería engorroso estar continuamente aclarando el carácter probabilista de las afirmaciones y, además, tal explicitación no debería ser necesaria porque, como dije, no se trata de un curioso aspecto de alguna explicación particular sino de un rasgo de toda explicación biológica.

Siguiendo con nuestro ejemplo, la posesión del gen $\mathrm{Z}$ no supone tampoco que sea imposible modificar el color del pelaje a partir de la manipulación de otros factores causales, incluidos los ambientales. Podría suceder, por ejemplo, que el color del pelaje fuera sensible a la dieta del animal, en cuyo caso cabría la posibilidad de modificar el pelaje manipulando la dieta. Nótese que, aunque un gen (o cualquier otro factor causal) no puede determinar un rasgo, sí puede determinar una diferencia en dicho rasgo. En este ejemplo, aunque la coloración de la piel en el roedor fuera resultado de múltiples factores causales, podría suceder que dos individuos tuvieran distinta coloración solo porque uno de ellos tiene el gen $\mathrm{Z}$ y el otro tiene un alelo alternativo. Del mismo modo, podría ser la dieta lo que explicara la diferencia fenotípica. Y, desde ya, la diferencia en cuestión podría deberse a una compleja interacción de factores causales genéticos y ambientales.

En los análisis de la genética conductual de animales no humanos está claro que el ambiente cumple un rol causal importantísimo en el desarrollo. Por ejemplo, un concepto central de la genética del comportamiento es el de heredabilidad (Plomin et al. 2002, 108 y ss.). Dicho término se refiere a la proporción de la varianza de un rasgo que puede atribuirse a la variabilidad genética subyacente para una dada población y en un momento dado. De más está decir que aquella proporción de la varianza que no es explicada por la variabilidad genética es explicada por la variabilidad ambiental (o por una interacción entre los factores genéticos y ambientales), otro ejemplo de lo evidente y rutinario que es en estos análisis el reconocimiento de la importancia del ambiente. Más específicamente, en la definición de heredabilidad la aclaración "para una dada población y en un momento dado" implica que el efecto de la variabilidad genética detectado solo es válido en un ambiente dado. Esto se debe a que los efectos que un gen tiene sobre un rasgo suelen variar con las condiciones ambientales: es frecuente que existan interacciones genes-ambiente (Sapolsky 2018, 366 y ss.). Los genes influyen, sí, pero el modo en que lo hacen suele depender del ambiente. A esto se refiere Matt Ridley (2004) con la frase - que da título a su libro - "naturaleza por vía del ambiente" (nature via nurture). Del mismo modo, el ambiente influye, sí, pero el modo en que lo hace suele depender de los genes. Por ejemplo, un experimento ya clásico muestra que en ciertas condiciones ambientales cierto genotipo resulta en una mayor "inteligencia" (en realidad, un menor número de errores al resolver un laberinto) en ratas. Sin embargo, en otras condiciones ambientales ese mismo genotipo tiene el efecto inverso: una menor "inteligencia". ¿Influyen los genes en la "inteligencia" de las ratas? Sí, pero el modo en que lo hacen depende del ambiente, a tal punto que en 
Perspectivas darwinistas sobre la mente y la conducta humanas: alcances, limitaciones e implicancias educativas

Leonardo González Galli

ambientes diferentes esos genes pueden tener efectos antagónicos (Plomin et al. 2002, 182). En palabras de Dawkins $(2017 b, 41)$ — un presunto determinista genético, según sus críticos-:

[...] la varianza genética es una causa significativa de una gran parte de la varianza fenotípica en las poblaciones observadas, pero sus efectos pueden ser anulados, modificados, aumentados o invertidos por otras causas [...] Los sucesos ambientales, tanto internos como externos, pueden modificar los efectos de los genes y pueden modificar los efectos de otros sucesos ambientales.

Podemos pensar que existe un continuo en la sensibilidad del desarrollo de los rasgos en relación con la influencia ambiental. En un extremo, algunos rasgos son muy sensibles a dicha influencia (por ejemplo, en nuestra especie, el peso corporal), mientras que, en el extremo opuesto, otros son muy poco sensibles (por ejemplo, el color de ojos). Sin embargo, en cualquier caso, incluido el color de ojos, sería erróneo decir que el rasgo está determinado genéticamente. En relación con esta cuestión, todo etólogo, ecólogo del comportamiento o psicólogo evolucionista sabe que los rasgos cognitivos y conductuales suelen encontrarse cerca del extremo de máxima sensibilidad del desarrollo ante las variables ambientales. Los textos de estas disciplinas declaran explícitamente los múltiples modos en que el ambiente influye en el desarrollo de la mente y la conducta al exponer sus modelos teóricos, y hacen referencia rutinariamente a dicha influencia en sus análisis. Buss (2019, 50-51), por ejemplo, explicita claramente tres modos en que el ambiente ejerce su influencia. En términos evolutivos, fue el ambiente el que determinó qué rasgos se seleccionaron (este no es el punto conflictivo). Además, tanto la emergencia durante el desarrollo individual de cada mecanismo cognitivo como su eventual activación requieren de ciertos inputs ambientales. En el mismo sentido, un concepto importante en EC es el de "estrategia condicional" (Alcock 2001, 157), según la cual los animales poseen sistemas de toma de decisiones que les permiten ejecutar distintas conductas adaptativas según las circunstancias. De este modo, la conducta en sí es producto de la interacción entre las circunstancias ambientales y el sistema cognitivo de toma de decisiones. Una analogía ayuda a transmitir la idea de la imposibilidad de toda forma de determinación, sea genética o ambiental (Harris 2015, 73; Sapolsky 2018, 370). Observemos un rectángulo y preguntémonos si su área se debe a la base o a la altura. ¿Absurdo verdad? Del mismo modo, es absurdo preguntar si un rasgo "es genético" o si "es ambiental". Sin embargo, la diferencia en el área de dos rectángulos podría deberse exclusivamente a una diferencia en la base, exclusivamente a una diferencia en la altura o, desde ya, a una diferencia simultánea en ambas variables (aparentemente, esta analogía se debe al gran neurobiólogo Donald Hebb). Observemos también que esta analogía ayuda a comprender que - contra lo que muchos críticos afirman - los efectos de ambas variables pueden separarse a los fines del análisis (Plomin et al. 2002, 108). 
Perspectivas darwinistas sobre la mente y la conducta humanas: alcances, limitaciones e implicancias educativas

Leonardo González Galli

Dado todo lo dicho en los párrafos precedentes, sería realmente curioso que los psicólogos evolucionistas defendieran para el estudio de la conducta humana un enfoque que ningún biólogo se atrevería a defender a la hora de estudiar, por ejemplo, el desarrollo de las estructuras florales de las plantas. El hecho de que el determinismo genético sea un sinsentido biológico hace que esta acusación sea especialmente insostenible (Dawkins 2017 b, 35 y ss.). En síntesis, es ya un lugar común señalar que cualquier rasgo biológico es producto de un proceso de desarrollo en el que influyen tanto factores genéticos como ambientales (De Waal 2000; Harris 2015; Meaney 2006; Plomin et al. 2002; Ridley 2004; Sapolsky 2018; 2007).

El punto importante para nuestra discusión es que los psicólogos evolucionistas o los ecólogos del comportamiento no sostienen ninguna hipótesis idiosincrática en relación con la cuestión de cómo influyen los genes en el fenotipo. Por el contrario, asumen los conocimientos estándar, bien establecidos y poco problemáticos sobre qué son los genes y qué hacen. Cuando los investigadores de estas disciplinas afirman, por ejemplo, que la tendencia a dirigir los actos altruistas preferentemente hacia parientes cercanos es producto de la selección natural están asumiendo que ha existido variabilidad heredable para dicho rasgo. Es decir, se asume que han existido diferentes alelos que producían una diferencia estadística, entre los individuos que tenían uno u otro alelo, en la tendencia a preferir a los parientes. Por una cuestión de economía del lenguaje se habla de "el gen del o para el nepotismo". Así, la acusación según la cual la PE supone una relación de determinación entre un gen y un rasgo constituye un claro ejemplo de la confusión que reina en este debate ${ }^{9}$. En este sentido, deberíamos preguntarnos por qué los psicólogos evolucionistas, cuyo programa consiste en aplicar el modelo de selección natural al análisis de la conducta y la mente humanos, asumirían el determinismo genético, siendo que tal supuesto no es una condición necesaria para la aplicación del modelo de selección a ningún rasgo de ningún organismo, y siendo que dicho supuesto es un caso flagrante de mala biología. La condición para la aplicación del modelo de selección natural es que exista variabilidad heredable para el rasgo analizado. Esto, a su vez, requiere que existan distintas versiones de los genes (alelos) que influyan diferencialmente en el desarrollo del rasgo en cuestión, no que lo determinen (Alcock 2001, 43; Dawkins 2017b, 49 y ss.; Maynard Smith 1997, 524). En el caso que nos ocupa, las evidencias de que los genes influyen en la personalidad y la conducta humana son abrumadores (Harris 2015; Plomin

\footnotetext{
${ }^{9}$ El número y magnitud de estos errores es tal que su refutación demandaría un libro entero. Solo a modo de ejemplo, menciono otros dos errores que aparecen en muchas críticas a la PE. Según el primero de ellos, esta ciencia atribuiría conciencia y otros atributos humanos a los genes. Según el segundo, no tiene sentido sugerir, por ejemplo, que existen diferencias genéticas en relación con la capacidad para leer porque la lectura no formó parte de nuestro amiente evolutivo. El hecho de que estos errores sean tan groseros, y de que se sigan repitiendo, es francamente curioso y demanda, en sí mismo, una explicación. Dejo al lector o a la lectora el ejercicio de argumentar por qué estos cuestionamientos son erróneos.
}

Revista de Humanidades de Valparaíso, 2019, No 14, 187-222

(ㄷ)(1)(8) CC BY-NC-ND 
Perspectivas darwinistas sobre la mente y la conducta humanas: alcances, limitaciones e implicancias educativas

Leonardo González Galli

et al. 2002; Sapolsky 2018). Más adelante reseñaré brevemente un análisis reciente de Steven Pinker sobre la violencia que me permitirá mostrar que la PE de hecho no asume determinismo ni reduccionismo.

Terminaré esta sección con unas palabras sobre la noción de "naturaleza humana". En general, el rechazo de los críticos a este concepto se basa en el supuesto de que el mismo supone que dicha naturaleza consta de una colección de rígidos instintos genéticamente programados. Sin embargo, quienes actualmente hablan de "naturaleza humana" (por ejemplo, Buss 2019 o Pinker 2003) no se refieren a tal cosa porque, tal como expliqué, semejante determinismo es mala biología y es un supuesto innecesario. La "naturaleza humana" podría definirse como el conjunto de rasgos que, estadísticamente, caracterizan a la especie Homo sapiens. Es bastante curioso que alguien niegue totalmente la existencia de tales rasgos universales. El gregarismo, la cultura y el lenguaje son tres ejemplos evidentes de universales humanos. Si reconocemos que estos rasgos son universales, entonces, estamos reconociendo que existe algo así como una "naturaleza humana". A partir de este reconocimiento surge la discusión verdaderamente interesante: ¿Qué otros rasgos son universales y cómo se explica su existencia? (Brown 1999, 2000). Es frecuente también que la afirmación de la existencia de una naturaleza humana se interprete como incompatible con el reconocimiento de la evidente flexibilidad de la conducta humana. Sin embargo, ambos aspectos de lo humano son más bien evidentes: algunos rasgos son casi universales, algo inexplicable si se asume una flexibilidad total, un desarrollo no sesgado ni limitado por el sustrato biológico (determinismo socio-cultural) $\mathrm{y}$, a su vez, todos los rasgos presentan cierta variabilidad, algo inexplicable si se asume un determinismo biológico.

Finalmente, se ha señalado críticamente que la idea de naturaleza humana supone adoptar un enfoque esencialista incompatible con el evolucionismo (Diéguez 2017; 2012). Sin embargo, dicha crítica es otro ejemplo del problema que mencioné antes en relación con la ignorancia por parte de los críticos del carácter estadístico de todas las afirmaciones que se hacen en biología. No existe ninguna esencia inmutable de la especie humana (¡ni de ninguna otra!) sino un conjunto de rasgos que estadísticamente nos permiten caracterizar a nuestra especie. Ontogenéticamente, dichos rasgos son sensibles (en mayor o menor grado según el caso) a las influencias ambientales. Filogenéticamente, dicho conjunto de rasgos es producto del proceso evolutivo y, por lo tanto, no es inmutable. Tal como señala Diéguez (2017), “[...] los rasgos que pueden considerarse como característicos de la naturaleza humana son productos contingentes de la evolución biológica y, por ende, están sujetos a posibles nuevos cambios evolutivos". Del mismo modo, la naturaleza de la especie león se refiere a esa caracterización estadística que podemos encontrar en los libros de zoología. Dicha descripción incluye, por ejemplo, la afirmación de que los leones viven en manadas. Pero, ¿todos los leones son necesariamente gregarios? Seguramente no. Lo más probable es que haya cierta proporción de leones muy poco propensos a la vida en manada. ¿Es entonces incorrecto que el libro de zoología afirme que los leones son gre- 
Perspectivas darwinistas sobre la mente y la conducta humanas: alcances, limitaciones e implicancias educativas

Leonardo González Galli

garios? No, no es incorrecto, es solo otra afirmación probabilística más, como todas las afirmaciones de la biología. Nuestra especie no es la excepción: todas las especies tienen su "naturaleza" (Buss 2019, 43). Si no podemos hacer afirmaciones de este tipo sobre nuestra especie no podemos hacerlas sobre ninguna otra $\mathrm{y}$, simplemente, no podríamos decir absolutamente nada sobre los sistemas biológicos.

\subsection{Darwinismo e ideología}

Rechazar a Darwin porque algunas de sus ideas provienen de una analogía con la sociedad capitalista en la cual vivió es, precisamente, la clase de cosa que no deberíamos permitir que nuestros prejuicios nos lleven a hacer.

John Maynard Smith (1997, 523, traducción propia)

Para los intelectuales [...] resulta muy conveniente creer la gente 'carece de naturaleza', que es completamente maleable. Eso elimina toda barrera moral para la manipulación y el control [...] La doctrina es tan sumamente estúpida que uno ha de buscar una explicación. Esta es la que a mi juicio nos da a entender la historia social e intelectual.

Noam Chomsky (citado en Barsky 2005, 258)

En relación con esta compleja cuestión me limitaré a discutir algunas simplificaciones groseras (pero frecuentes). La acusación de sesgo ideológico esconde varios supuestos relacionados. En primer lugar, se suele señalar que una disciplina es "mala ciencia" y que lo único que explica su existencia es su función ideológica. Pero ¿Por qué una teoría particular funcionaría exclusivamente como sostén de cierta ideología? Aquí lo que se sugiere es que la teoría en cuestión implica intrínsecamente, de algún modo, supuestos propios de la ideología que presuntamente avala y que ello hace que las eventuales aplicaciones o usos de la teoría estén necesariamente sesgados a favor de esa ideología. Examinaré (brevemente, estas cuestiones requerirían un análisis extenso) entonces estas dos cuestiones: ¿Es a PE “mala ciencia”? ¿Favorece de hecho la PE alguna ideología en particular?

Con respecto a la primera cuestión, la PE ha recibido muchas críticas (Buller 2009; McKinnon 2012). A este respecto, cabe preguntarse si es legítimo exigir a esta disciplina estándares epistémicos diferentes de los que se imponen a otras ciencias (Ruse, 1980, 44). Kitcher (1985) ha defendido la necesidad de que aquellas hipótesis que encierran un gran peligro político sean tratadas con más rigor y precaución, y ha señalado que la SB ha fallado en ese punto. Alcock (2001) ha rechazado este doble estándar en cuanto al tratamiento de las diferentes ciencias. Aunque la observación de Kitcher parece razonable, se basa en el supuesto de que las hipótesis biológicas son especialmente peligrosas desde el punto de vista político. Los ejemplos que comentaré más adelante sobre las consecuencias negativas de diversas hipótesis "ambientalistas" (el caso del autismo y el del "efecto Cenicienta") deberían llevarnos a reflexionar sobre la validez de dicho supuesto. 
Perspectivas darwinistas sobre la mente y la conducta humanas: alcances, limitaciones e implicancias educativas Leonardo González Galli

Siguiendo con la crítica de la PE en tanto ciencia, McKinnon $(2012,30)$ cuestiona el uso de ciertas metáforas por parte de los psicólogos evolucionistas como, por ejemplo, la personificación de la selección natural. Sin embargo, dicha metáfora no es más que una expresión de la metáfora del diseño que permea toda la teoría darwiniana (Ruse 2003, 2000). Del mismo modo, esta autora cuestiona el uso de la metáfora computacional de la mente (McKinnon 2012, 36), pero, en este caso, el problema es el mismo, dado que dicha metáfora es fundacional de toda la ciencia cognitiva (Gardner 1988; Pugh 2017). Así, para impugnar la PE sobre estas bases McKinnon debería impugnar también el darwinismo en general y todo el cognitivismo. En relación con los cuestionamientos metodológicos, me limitaré a señalar que la claridad con la que los psicólogos evolucionistas explicitan sus supuestos teóricos y los criterios que utilizan para formular y evaluar sus hipótesis (Alcock 2001, 57 y ss.; Buss 2019, 37 y ss.; Schmitt 2008; Tybur, Miller y Gangestad 2007) no es fácil de encontrar en todos los campos disciplinares.

En cuanto a la posibilidad de que la PE sirva de hecho a una ideología reaccionaria debemos señalar que es innegable que las teorías biológicas, y más específicamente el evolucionismo darwinista, han sido utilizadas para todo tipo de fines políticos (algunos podrían considerase reaccionarios y otros progresistas). Sin embargo, la relación entre estas teorías y esas ideologías dista de ser directa y necesaria (Bowler 2003; Girón Sierra 2005). Para rechazar esta acusación no es necesario adherir a la idea de que las teorías son en sí mismas neutrales y que luego pueden utilizarse de diversos modos (el llamado modelo de la "ciencia martillo", Heler 1996). Podemos reconocer que las teorías se relacionan con las ideologías, por ejemplo, en el sentido de que dichas teorías pueden haber surgido parcialmente de razonamientos analógicos que incluyen ciertos valores no epistémicos. También podría reconocerse que un sesgo ideológico podría estar implicado en el hecho de que una teoría haga más probables ciertas intervenciones en el mundo que otras (Lacey 2005a). Sin embargo, reconocer estos posibles modos de relación entre ciencia e ideología no debería impedirnos reconocer al mismo tiempo el hecho evidente de que suele existir un amplio margen para diversos usos y aplicaciones. Por ejemplo, la genética ha sido utilizada tanto para avalar el racismo como para cuestionarlo. Así, Lewontin (1972) se basó en la genética para cuestionar el concepto tradicional de raza humana ${ }^{10}$. Del mismo modo, entre las aplicaciones de la biología molecular se encuentran tanto los cultivos transgénicos, con diversas consecuencias negativas asociadas, como las técnicas que hicieron posible la identificación de víctimas del terrorismo de Estado (Penchazadeh 2012; Wulff 2014).

Un ejemplo notable de cómo la biología puede tener un efecto progresivo y liberador lo constituye el caso de las explicaciones sobre el autismo. Durante muchos años predominaron explicaciones totalmente ambientalistas de inspiración psicoanalítica (Brose 2009;

${ }^{10}$ Por supuesto, clasificar a la humanidad en razas no es lo mismo que ser racista: el racismo requiere, además, una jerarquización de esas razas.

Revista de Humanidades de Valparaíso, 2019, No 14, 187-222

(ㄷ)(1)(8) CC BY-NC-ND 
Perspectivas darwinistas sobre la mente y la conducta humanas: alcances, limitaciones e implicancias educativas

Leonardo González Galli

Hacking 2001; Pollak 2011). Así, psicoanalistas como Bruno Bettelheim y Leon Kanner afirmaron que la principal causa del autismo era una carencia de afecto materno $\mathrm{y}$, en una muestra de crueldad notable, acuñaron incluso el término "madre nevera" para referirse a las madres de niños autistas. No cuesta mucho imaginar el sufrimiento (gratuito, podemos decir retrospectivamente) que estas ideas deben haber generado a miles madres con hijos autistas (además de reforzar los roles de género estereotipados). Luego, la investigación en ciencias biomédicas fue dejando en claro que existen factores estrictamente biológicos (neurológicos, genéticos) implicados en el desarrollo de la condición autista (Brose 2009; Cormand 2015). Según Brose (2009), "Hoy, los padres de los niños autistas han dejado de encontrarse bajo sospecha: las teorías de Kanner y de Bettelheim han sido superadas hace tiempo y rechazadas en múltiples ocasiones". Los estudios biomédicos actuales permiten descartar la hipótesis de que la condición autista esté determinada exclusivamente por factores ambientales y según Brose (2009) actualmente "los médicos consideran el autismo un trastorno congénito de la función cerebral que obedece, sobre todo, a causas genéticas". El "sobre todo" implica que, como siempre, hay lugar para un rol causal de los factores ambientales ${ }^{11}$. Es claro que, en este caso, la aplicación de la biología a lo humano ha tenido un gran efecto liberador.

Hay muchos ejemplos de los costos potenciales de no tener en cuenta la perspectiva biológica sobre lo humano (véase, por ejemplo, Elgarte, 2019 para un análisis de esta cuestión en relación con el diseño de políticas e instituciones). Un caso especialmente interesante, relacionado específicamente con los enfoques darwinistas de lo humano, lo constituye el llamado "efecto Cenicienta". Daly y Wilson (2000) mostraron, con abrumadoras evidencias empíricas, que la presencia en el hogar de un adulto que no sea progenitor biológico, es decir, una madrastra o un padrastro (esta categoría excluye a los padres y madres adoptivos), constituye el factor epidemiológico más importante a la hora de estimar el riesgo de malos tratos graves a menores. Desde la PE se predice que la presencia de padrastros o madrastras sería un factor de riesgo debido a que es esperable que los individuos estén bien predispuestos a invertir recursos en sus descendientes biológicos, pero no en los descendientes de otros individuos. El cuidado de hijos ajenos sería un costo que los individuos estarían obligados a afrontar como consecuencia de formar pareja con personas que ya son padres o madres. La poca predisposición a invertir recursos en hijos ajenos, junto con la obligación de hacerlo debido a que la pareja tiene ya hijos, generaría tensiones que harían más probables todas las formas de maltrato. Desde ya, la explicación que Daly y Wilson dan de este hallazgo es discutida por quienes rechazan toda explicación biológica de lo humano y se han reportado casos en que la predicción de este modelo aparentemente no se cumple (Daly y Wilson 2008; Temrin, Buchmayer y Enquist 2000; Temrin, Nordlund y Sterner 2004). Sin embargo, dado lo dicho en la sección sobre cómo los genes ejercen sus efectos en interacción con el entorno, la eventual comprobación de

${ }^{11}$ Dicho sea de paso, jentre esos factores ambientales no se encuentran las vacunas!

Revista de Humanidades de Valparaíso, 2019, No 14, 187-222

(ㄷ)(1)(8) CC BY-NC-ND 
Perspectivas darwinistas sobre la mente y la conducta humanas: alcances, limitaciones e implicancias educativas Leonardo González Galli

alguna excepción no debería sorprender a nadie, y no invalidaría las principales conclusiones de Daly y Wilson. En cualquier caso, parece claro que Daly y Wilson evidenciaron un factor de riesgo principal hasta entonces ignorado (Buss 2019). Esto último ilustra, al menos, el poder heurístico del adaptacionismo aplicado a lo humano y los posibles riesgos de no tener en cuenta dicho enfoque.

Así, el supuesto en que se basa buena parte de la crítica a la PE según el cual las explicaciones biológicas de lo humano tienen necesariamente implicancias políticamente reaccionarias es falso (Tybur, Miller y Gangestad 2007). Por lo tanto, no parece razonable condenar cierta disciplina por el hecho de que haya servido a fines espurios en ciertos contextos. De hecho, si estuviéramos dispuestos a hacer semejante cosa deberíamos condenar a prácticamente a todas disciplinas, incluyendo no solo a las ciencias naturales sino también a las ciencias sociales y la filosofía (Ruse 1980, 113 y ss.). La contracara del supuesto según el cual las explicaciones biológicas de lo humano tienen necesariamente implicancias reaccionarias la constituye el supuesto de que las explicaciones socioculturales tienen necesariamente implicancias progresistas. Sin embargo, la historia muestra que ese no es el caso (Pinker 2003, 229 y ss.). Por ejemplo, el conductismo sirvió de sustento para la tecnología de la propaganda y el adoctrinamiento (a eso se refiere la cita de Chomsky al comienzo de esta sección). Por otro lado, y más allá de los ejemplos antes comentados, no está de más recordar que las hipótesis deberían evaluarse por sus méritos epistémicos con independencia de qué tanto nos simpaticen sus presuntas implicancias ideológicas. Es decir, si una hipótesis bien establecida tuviera implicancias ideológicamente antipáticas deberíamos lidiar con ese hecho.

Hay una cuestión más específica en relación con estos problemas que se refiere a la relación entre el darwinismo en general con la ideología capitalista. En general se reconoce la influencia de los teóricos de la economía política capitalista en Darwin (Bowler 2003; Muñoz 2008; Schweber 2008). Sin embargo, una cosa es reconocer estas relaciones analógicas de influencia recíproca entre dos campos del saber (la economía y la biología) y algo muy distinto es afirmar que el darwinismo no es más que la ideología capitalista proyectada en la naturaleza. Contra esta crítica caben, al menos, tres observaciones. La primera es que este tipo de relaciones analógicas no son exclusivas del darwinismo. En efecto, hoy se reconoce que las metáforas y analogías son una parte esencial de la ciencia en general (Bradie 1999). La segunda es que, a la hora de evaluar la adecuación de una hipótesis debería ser irrelevante qué analogías inspiraron dicha hipótesis, de lo que se trata, en cambio, es de que la hipótesis en cuestión sea puesta a prueba de un modo honesto mediante los procedimientos legitimados por la comunidad de expertos (Ruse 1980, 125-126). La tercera cuestión es que la teoría de la selección natural contiene elementos conceptuales originales que no tienen un análogo evidente en las doctrinas políticas que, parcialmente, le pueden haber servido de inspiración a Darwin. Esta independencia entre ambos campos conceptuales queda en evidencia, por ejemplo, en el hecho de que la teoría darwiniana derivó hacia desarrollos que contradicen directamente algunos aspectos

Revista de Humanidades de Valparaíso, 2019, No 14, 187-222

(). (18) CC BY-NC-ND 
Perspectivas darwinistas sobre la mente y la conducta humanas: alcances, limitaciones e implicancias educativas

Leonardo González Galli

de la ideología capitalista. Por ejemplo, mientras que la ideología capitalista enfatiza la competencia entre individuos, el darwinismo actual, sobre todo en la perspectiva del "gen egoísta", al poner el foco en los genes no predice que los individuos tengan conductas necesariamente competitivas y egoístas: en la medida en que convenga a los genes, los individuos serán cooperativos y altruistas. Además, si se acepta la hipótesis de selección de grupos (Sober y Wilson 2000) la competencia interindividual pierde aún más peso relativo.

También es pertinente mencionar aquí que la idea de selección natural fue muy rechazada tras ser propuesta por Darwin en 1859. En efecto, aunque Darwin tuvo gran éxito en convencer a la comunidad científica de que las especies evolucionaban, tuvo mucho menos éxito en convencerla de que la selección era el principal mecanismo responsable de dicho cambio. Fue recién con el advenimiento de la Teoría Sintética de la Evolución (alrededor de 1930) que la idea de selección gozó de amplia aceptación. El período que va desde 1859 a 1930, aproximadamente, fue llamado por tal razón "el eclipse del darwinismo" (Bowler 2005, 1985). El hecho de que una teoría que, presuntamente, era tan conveniente para el establishment político fuera rechazada durante tantos años pone en evidencia que la relación entre darwinismo (más específicamente, la selección natural) y capitalismo es más compleja de lo que los críticos sugieren. Esta independencia entre los campos analogados tiene otras implicancias más importantes para esta discusión, en especial el hecho de que la teoría biológica no incluye los aspectos normativos de la teoría de la economía política (Ruse 1980, 124). Finalmente, la eventual aceptación de una de las teorías no implica la validez de la otra. Así, el darwinismo podría ser una excelente teoría sobre la evolución biológica y, al mismo tiempo, el capitalismo podría ser un modo desastroso de concebir la sociedad.

Como ya señalé, nada de lo dicho supone negar que existan relaciones entre la ciencia en general, y la biología en particular, y las ideologías (Alexander y Numbers 2010). Por el contrario, reconocemos que las ciencias (¡todas!) son parte de la sociedad y, por lo tanto, los valores, epistémicos y no epistémicos (si aceptamos tal distinción), influyen en dichas ciencias (Echeverría 2002; Gómez 2014; Lacey 2005a; 2005b). Pero este reconocimiento general no basta para impugnar ningún programa de investigación particular, porque se aplica por igual a todas las ciencias. Por lo tanto, señalar la influencia de la ideología es decir poco y nada. Así, se deberían ofrecer buenas razones para concluir que un programa de investigación no es más que una empresa ideológica. Y mostrar las opiniones personales de cierto autor o algunos casos de usos indebidos no son razones de peso. En los casos particulares, habría que mostrar, por ejemplo, que en cierta disciplina se sostiene alguna hipótesis que resulta epistémicamente inadecuada solo por el hecho de que dicha hipótesis favorece ciertos valores no epistémicos.

Revista de Humanidades de Valparaíso, 2019, No 14, 187-222

(ㄷ)(1)(8) CC BY-NC-ND 
Perspectivas darwinistas sobre la mente y la conducta humanas: alcances, limitaciones e implicancias educativas Leonardo González Galli

\section{El declive de la violencia según Steven Pinker como caso testigo}

Para apoyar mis argumentos reseñaré brevemente un análisis sobre la violencia del psicolingüista Steven Pinker, unos de los principales autores de la PE.

En uno de sus últimos libros, Pinker (2012) documenta la reducción de diversas formas de violencia y la explica como resultado una interacción entre ciertos cambios socio-culturales y la estructura cognitiva universal cuya existencia postula la PE. Este autor analiza un cambio a nivel conductual, a saber, una reducción de diversas formas de violencia, y como todo psicólogo evolucionista asume que dicho cambio no puede explicarse por un cambio de la estructura cognitiva de base ni de su sustrato genético. Podría terminar aquí la reseña del texto de Pinker y lo poco que he dicho debería alcanzar para que quedara claro que este autor no puede estar incurriendo en determinismo ni reduccionismo genéticos. $\mathrm{Si}$, como pide el reduccionismo y el determinismo, las conductas analizadas se explicaran exclusivamente (reduccionismo) por la existencia de ciertos genes que obligan (determinismo) a la ejecución de dichas conductas, entonces, los niveles de agresión se deberían haber mantenido invariables, dado el escaso número de generaciones abarcado por el período analizado por Pinker. Por el contrario, este autor atribuye este declive de la violencia a cambios socioculturales. Más específicamente, identifica cinco "fuerzas históricas" que serían responsables de este proceso de pacificación. Estas "fuerzas" son: "El Leviatán" (los Estados que monopolizan el uso de la fuerza), el comercio (que generaría un "juego de suma positiva" en el que todos ganan más comerciando que haciendo la guerra), la "feminización" de la sociedad (la importancia creciente de las mujeres en la toma de decisiones), el "cosmopolitismo" (que habría facilitado el ponerse en el lugar de los demás y, de ese modo, ampliar el "círculo solidario") y, por último, la "escalera mecánica de la razón" (que permite evaluar racionalmente las consecuencias de la violencia y considerarla un problema a resolver). Así, Pinker (2012) propone explicaciones basadas en el análisis de la interacción entre ciertos factores socioculturales y una estructura cognitiva universal producto de la selección que excluyen toda forma de reduccionismo o determinismo biológicos.

Por último ¿Es el análisis de Pinker especialmente conveniente para los sectores políticos conservadores? Varios de los factores socioculturales que Pinker identifica como (parcialmente) responsables del declive de la violencia son parte de la agenda política del progresismo clásico. El caso de la creciente participación femenina en la toma de decisiones políticas es un claro ejemplo de ello: no parece que semejante análisis sea conveniente para el patriarcado. Cabe, en este punto, decir algo sobre la idea de "naturalización", una noción frecuentemente asociada a las críticas ya analizadas. Por ejemplo, según McKinnon $(2012,25)$ la PE “[...] ha naturalizado categorías y jerarquías sociales, en particular las de sexo, género y parentesco". Presuntamente, la "naturalización" supondría presentar algo que ha sido "socialmente construido" (Hacking 2001, para un análisis de las complicaciones de la idea de construcción social) como "naturalmente dado". Nuevamente, basta con recurrir al análisis de Pinker para desacreditar esta crítica. Este autor asume que

Revista de Humanidades de Valparaíso, 2019, No 14, 187-222

()ㅇㅇㅇ CC BY-NC-ND 
Perspectivas darwinistas sobre la mente y la conducta humanas: alcances, limitaciones e implicancias educativas Leonardo González Galli

la violencia tiene un fundamento biológico, pero ¿En qué sentido Pinker estaría "naturalizando" la violencia al sugerir que la misma ha disminuido gracias a ciertos cambios sociales en interacción con cierta estructura cognitiva de base biológica? Por el contrario, Pinker está mostrando que los niveles de violencia que una sociedad particular padece son en gran medida consecuencia de los particulares procesos socio-históricos que atravesó dicha sociedad: no parece que eso implique la "naturalización" de nada. Más aún, al identificar esos factores socioculturales y analizar cómo interactúan con la estructura cognitiva humana, Pinker está dando pistas sobre cómo modificar nuestro entorno para tender a una sociedad mejor. Por otro lado, la perspectiva evolucionista continuista aquí adoptada nos invita a desconfiar de la dicotomía natural / no natural. La capacidad de producir cultura es un rasgo propio de nuestra especie, es parte de la naturaleza humana, tan natural como cualquier otro rasgo y, por lo tanto, los productos de la cultura también lo son. En este sentido, si queremos comprender, por ejemplo, el altruismo humano, preguntarse si es natural o no lo es (en tal caso, ¿Sería no-natural, anti-natural, sobre-natural? ¿Qué significan exactamente esas expresiones?) no ayudará en nada a nuestra comprensión. Mejor habríamos, en cambio, en preguntarnos qué factores (tanto genéticos como no genéticos, incluidos los culturales, todos naturales) contribuyen y de qué modo en el desarrollo de ese aspecto de nuestra mente y conducta.

\section{Recapitulación y conclusiones}

En esta sección final recapitularé brevemente mis argumentos para luego analizar algunas de sus implicancias educativas.

El adaptacionismo aplicado a la conducta animal, más específicamente la ecología del comportamiento, constituye un programa de investigación muy activo desde hace unos cuarenta años. No se trata de un área de investigación marginal ni de un programa idiosincrático de uno o dos autores. Dado este contexto, y aceptando que nuestra especie tiene un origen evolutivo, lo más razonable es asumir que el adaptacionismo tiene, legítimamente, mucho para decir sobre nuestra mente y conducta. Así, solo la adopción de un enfoque abiertamente excepcionalista, en el que se asuma un hiato entre nosotros y el resto de las especies, nos permitiría excluir a priori a nuestra especie de este tipo de análisis. El análisis de Schaeffer (2009), presentado en la sección 2.1, me lleva a rechazar esas pretensiones excepcionalistas. Por otro lado, muchos autores están bien dispuestos a recurrir al adaptacionismo cuando de explicar la anatomía y fisiología humanas se trata, pero, sin embargo, consideran que dicho enfoque no es legítimo ni pertinente cuando lo que estamos analizando es la mente o la conducta. Dicha distinción supone adherir a un dualismo difícil de sostener desde una perspectiva naturalista: la conducta y la mente son funciones de un sistema fisiológico-anatómico influido (no determinado) por los genes y que, por lo tanto, debe haber evolucionado por selección natural. En síntesis, el rechazo de la tesis de la excepcionalidad humana y la adopción de una perspectiva evolucionista

Revista de Humanidades de Valparaíso, 2019, No 14, 187-222

(ㄷ)(1)(8) CC BY-NC-ND 
Perspectivas darwinistas sobre la mente y la conducta humanas: alcances, limitaciones e implicancias educativas

Leonardo González Galli

nos lleva a asumir la pertinencia y legitimidad del enfoque adaptacionista aplicado a la mente y la conducta humanas. Actualmente, son la psicología evolucionista y la ecología del comportamiento humano los programas de investigación que encarnan dicho enfoque. Así, eventualmente, lo que requiere una argumentación especial no es la aplicación de esta perspectiva a nuestra especie sino su rechazo a priori.

Por otro lado, muchos autores (y educadores) denuncian que la PE (como el resto de las disciplinas biológicas aplicadas a lo humano) constituye un caso de reduccionismo biológico y determinismo genético. Además, se trataría de "mala ciencia" al servicio de una ideología reaccionaria. En relación con estas críticas intenté mostrar que los modelos teóricos en que se fundamenta la PE no suponen reduccionismo ni determinismo y que no puede afirmarse que haya una relación fuerte, necesaria o evidente entre dicha disciplina y una ideología en particular. Por otro lado, la perspectiva semántica de las teorías científicas (Giere 2006) supone que ninguna teoría puede pretender ofrecer una explicación total de un fenómeno y que, por lo tanto, la comprensión de cualquier fenómeno demanda un pluralismo teórico que excluye por principio toda forma de reduccionismo. El enfoque adaptacionista aplicado a la mente y la conducta humanas solo puede, por lo tanto, captar ciertos aspectos de dichos fenómenos desde una perspectiva particular. Estas afirmaciones valen para todo modelo científico, más allá de las pretensiones de algunos autores particulares. La perspectiva semántica nos recuerda, además, que lo importante de una teoría es qué dicen sus modelos sobre el mundo. En relación con esta cuestión, el principal modelo en que se basa la PE es la selección natural, modelo que tiene entre sus supuestos el de variabilidad heredable. Dicho supuesto implica asumir que los genes influyen en el desarrollo de los rasgos analizados, no que lo determinan. De hecho, tal como ya analicé in extenso, la idea misma de determinación genética es simplemente incompatible con todo lo que sabemos de biología. Ninguno de los modelos más específicos en que se basa la PE, por ejemplo, el de una mente modular, implica tampoco ninguna relación de determinación genética.

En síntesis, el rechazo de la tesis de la excepción humana y la adopción de una perspectiva evolucionista y de un enfoque semántico sobre las teorías científicas me llevan a concluir que el adaptacionismo encarnado por la PE es un enfoque teórico legítimo y prometedor para aportar a la comprensión de ciertos aspectos de la mente y la conducta humanas, y que no implica una perspectiva reduccionista y determinista ni un sesgo ideológico particular. Permitiéndome un pequeño ejercicio de normativismo epistemológico diré que sería deseable que los propios científicos, tanto aquellos que aplican la biología a lo humano como aquellos que cuestionan dicho programa, comprendieran que sus eventuales pretensiones de explicaciones totales no tienen mayor sustento y que reconocieran explícitamente que sus aproximaciones son necesariamente perspectivas (Giere 2006). Todos ganaríamos en esta discusión si reconociéramos lo limitado del propio enfoque (sea cual fuere) y la necesidad del pluralismo teórico, ajustando nuestros discursos en consecuencia.

Revista de Humanidades de Valparaíso, 2019, No 14, 187-222

(c) (1) 8 (을 CC BY-NC-ND 
Perspectivas darwinistas sobre la mente y la conducta humanas: alcances, limitaciones e implicancias educativas Leonardo González Galli

Para concluir este trabajo quisiera volver a las preocupaciones que motivaron su escritura. Tal como señalé antes, en el ámbito educativo (la investigación en didáctica de la biología y las prácticas educativas) impera actualmente una perspectiva "socioculturalista" antibiológica que lleva a rechazar todo enfoque biológico de lo humano. En la práctica, esta perspectiva se traduce en una de dos actitudes por parte de docentes e investigadores: la no mención de las perspectivas darwinianas de lo humano o su mención y condena sin matices. Como ejemplo de la primera actitud, si revisamos textos recientes de didáctica de la biología evolutiva tales como Understanding evolution (Kampourakis 2014) o Evolution challenges (Rosengren et al. 2012) no encontramos ni una sola mención a la PE o la EC humana. Como ejemplo de la segunda actitud, De Vecchi y Giordan (2006, 43-44) reiteran las críticas aquí discutidas y, lo que es un notable sinsentido, emparentan la SB con el racismo. La asociación de la SB, que afirma una unidad biológica de la especie humana, con el racismo, que afirma exactamente lo contrario, no es más que otra muestra de la confusión que reina en estos debates. Tal como señala David S. Wilson $(2010,12)$, “Algunos intelectuales emulan a los 'creacionistas de la Tierra joven' en su rechazo a la evolución cuando se llega a los asuntos humanos". Este rechazo en la comunidad educativa de toda perspectiva biológica de lo humano obedece, sin dudas, a múltiples factores. La experiencia personal sugiere que entre dichos factores se encuentra la gran prédica que han tenido entre el profesorado los textos de Stephen Gould y Richard Lewontin. Muchos se han formado una imagen de la SB humana, la PE y la EC humana exclusivamente a partir de los textos de estos críticos (entre dichos textos se destacan, Gould 2010, 1997 y Lewontin, Rose y Kamin 1996).

Ahora bien ¿Por qué considero que es un problema que esta sea la perspectiva dominante sobre estos temas en el ámbito educativo? Por, al menos, dos razones. En primer lugar, por una razón básica: dicha perspectiva asume todos los supuestos que he cuestionado en este trabajo, por lo que en ningún caso puede ser positivo asumirla. En segundo lugar, por una razón específicamente didáctica. Para decirlo brevemente, sugeriré que el mejor modo de fomentar el pensamiento crítico en los estudiantes en relación con temas complejos como estos es abordar directamente el estudio de los modelos científicos implicados, así como su aplicación a los casos más peliagudos. Más allá de lo que realmente impliquen los modelos científicos que he analizado, no hay dudas de que en la comunicación de estos temas al público general es frecuente un discurso biologicista. Por lo tanto, es razonable que uno de los objetivos de la enseñanza general obligatoria sea ayudar a los estudiantes a cuestionar dicho biologicismo (Castéra y Clément 2012; Jiménez Aleixandre 2012). Acuerdo plenamente con dicho objetivo. El desacuerdo radica en cuál es el mejor modo de alcanzar dicho objetivo. Como ya señalé, muchos educadores ignoran totalmente la aplicación de la biología a los asuntos humanos o bien limitan el abordaje del tema a denunciar como mala ciencia ideológicamente sesgada dicha aplicación. Sin embargo, la primera estrategia deja a los estudiantes indefensos frente a los discursos biologicistas tan frecuentes en los grandes medios de comunicación. La segunda estra- 
Perspectivas darwinistas sobre la mente y la conducta humanas: alcances, limitaciones e implicancias educativas Leonardo González Galli

tegia, por su parte, solo deja a los estudiantes, como única mirada posible de lo humano, una perspectiva socioculturalista, tan reduccionista y determinista como el biologicismo. Desde ya, quienes adoptan esta segunda estrategia no ven problema alguno en esta consecuencia porque, como ya he comentado (y cuestionado), asumen que el socioculturalismo tiene necesariamente implicancias políticas progresistas.

Por el contrario, un tratamiento educativo adecuado de estos temas en las clases podría contribuir a la formación de ciudadanos que pudieran analizar críticamente los mensajes, esta vez sí, reduccionistas y deterministas, que reciben desde los medios de comunicación. Ese "tratamiento educativo adecuado" debería implicar dos cuestiones, la primera científica y la segunda metacientífica: (1) ayudar a los estudiantes a comprender qué dicen y qué no dicen, qué explican y qué no explican, los modelos teóricos en cuestión y (2) ayudar a los estudiantes a comprender que cualquier modelo solo puede iluminar ciertos aspectos y desde ciertas perspectivas del fenómeno analizado y que, por lo tanto, es imprescindible adoptar un pluralismo teórico. El primer punto supone un sólido aprendizaje de los modelos científicos y un análisis profundo de su aplicación a lo humano. Esto se debe a que es ingenuo creer que un modelo aprendido a partir de casos paradigmáticos como el melanismo industrial o el cuello de las jirafas luego podrá ser aplicado con éxito por los estudiantes a casos tales como la conducta humana. Por su parte, el segundo punto demanda un análisis explícito de la naturaleza de los modelos científicos (en relación con este punto considero especialmente adecuado el enfoque semántico que ya he comentado).

Sugiero entonces que una adecuada discusión de qué dice la PE (o la genética o las neurociencias) sobre nuestra mente y conducta ayudaría a que los estudiantes detectaran las distorsiones de las versiones pop de estas teorías y pondría en evidencia las limitaciones de dichas perspectivas. Por otro lado, la comprensión de qué no explica la biología ayudaría a comprender la necesidad de otras explicaciones complementarias ofrecidas por disciplinas como las ciencias sociales. Solo quien comprende qué dice un modelo puede comprender qué aspectos del mundo no son explicados por dicho modelo. Así, lo que podría prevenir la difusión y consolidación de los discursos reduccionistas y deterministas no es la evitación de la biología aplicada a lo humano sino, por el contrario, la apropiación crítica de dichos marcos teóricos. Y tal apropiación no tendrá lugar mientras en el ámbito educativo domine una actitud de rechazo acrítico y sin matices de estos enfoques.

En síntesis, la formación de ciudadanos/as críticos/as requiere que se les enseñe con rigor y libertad lo que todos los modelos científicos vigentes tienen para decir sobre lo humano. Esto implica, además, discutir explícitamente las controversias asociadas a dichos modelos. Por el contrario, la actitud que muchos docentes adoptan, basados en las críticas de los enfoques biológicos que aquí he cuestionado, constituyen una forma de adoctrinamiento, es decir, exactamente lo contrario de una formación para una ciudadanía crítica. Dada la complejidad del tema, cada docente deberá evaluar en qué cursos es viable introducir estas discusiones. En cualquier caso, considero que estos temas no pueden ser

Revista de Humanidades de Valparaíso, 2019, No 14, 187-222

(ㄷ)(1)(8) CC BY-NC-ND 
Perspectivas darwinistas sobre la mente y la conducta humanas: alcances, limitaciones e implicancias educativas Leonardo González Galli

eludidos en la formación del profesorado de biología y de biólogos. Espero que este texto contribuya a la reflexión de docentes e investigadores en relación con cómo introducimos, o no lo hacemos, estos temas en las aulas.

\section{Agradecimientos}

El autor agradece al Consejo Nacional de Investigaciones Científicas y Técnicas (CONICET) y a la Universidad de Buenos Aires (Proyecto UBACyT 20020170200207BA) por el apoyo financiero. También agradece especialmente al Dr. Santiago Ginnobili y al Mg. Joaquín Suárez por la lectura crítica del artículo y las pertinentes sugerencias realizadas.

\section{Referencias bibliográficas}

Alcock, J. (2001). The Triumph of Sociobiology. Oxford: Oxford University Press.

Alexander, D., Numbers, R. (eds.) (2010). Biology and Ideology from Descartes to Dawkins. Chicago: The University of Chicago Press.

Barsky, R. (2005). Noam Chomsky. Una vida de discrepancia. Barcelona: Península.

Bautista, L., Fernández-Juricic, E. (2016). Optimización del comportamiento. En J. Carranza (ed.), Etología adaptativa. El comportamiento como producto de la selección natural, pp. 155-194. Córdoba: Editorial Universidad de Córdoba / Universidad de Extremadura.

Bergstrom, C., Dugatkin, L. A. (2012). Evolution. Nueva York: W. W. Norton \& Company.

Bowler, P. (1985). El eclipse del darwinismo. Teorías evolucionistas antidarwinistas en las décadas en torno a 1900. Barcelona: Labor.

Bowler, P. (2003). Evolution. The History of an Idea. Berkeley: University of California Press.

Bowler, P. (2005). Revisiting the Eclipse of Darwinism. Journal of the History of Biology, 38(1): 19-32. doi: 10.1007/s 10739-004-6507-0

Bradie, M. (1999). Science and metaphor. Biology and Philosophy, 14(2): 159-166. doi: https:// doi.org/10.1023/A:1006601214943

Brown, D. (1999). Human universals. En R. Wilson, F. Keil (eds.), The MIT Encyclopedia of the Cognitive Sciences, pp. 382-384. Cambridge: The MIT Press.

Brown, D. (2000). Human Universals and their Implications. En N. Roughley (ed.), Being Humans. Anthropological Universality and Particularity in Transdisciplinary Perspectives, pp. 156-174. Berlin: de Gruyter.

Buller, D. (2007). Varieties of Evolutionary Psychology. En D. Hull, M. Ruse (eds.), The Cambridge Companion to The Philosophy of Biology, pp. 255-274. Cambridge: Cambridge University Press.

Revista de Humanidades de Valparaiso, 2019, No 14, 187-222

()ㅇㅇㅇㅛ CC BY-NC-ND 
Perspectivas darwinistas sobre la mente y la conducta humanas: alcances, limitaciones e implicancias educativas Leonardo González Galli

Buller, D. (2009). Cuatro falacias de la psicología evolutiva popular. Investigación y Ciencia, 388: 58-65.

Buss, D. (2019). Evolutionary psychology. The New Science of the Mind. Nueva York: Routledge.

Brose, N. (2009). Autismo. Mente y Cerebro, 38: 36-41.

Carranza, J. (ed.) (2016). Etología adaptativa. El comportamiento como producto de la selección natural. Córdoba: Editorial Universidad de Córdoba / Universidad de Extremadura.

Castéra, J., Clément, P. (2012). Teachers' Conceptions About the Genetic Determinism of Human Behaviour: A Survey in 23 Countries. Science \& Education, 23(2): 417-443. doi:10.1007/ s11191-012-9494-0

Castro, L., López-Fanjul, C., Toro, M. A. (2003). A la sombra de Darwin. Las aproximaciones evolucionistas al comportamiento humano. Madrid: Siglo XXI.

Cormand, B. (2015). El paisaje genético del autismo. Mente y Cerebro, 72: 44-46.

Daly, M., Wilson, M. (2000). La verdad sobre Cenicienta. Una aproximación darwiniana al amor parental. Barcelona: Crítica.

Daly, M. y Wilson, M. (2008). Is "Cinderella Effect" Controversial? A Case Study of Evolution-Minded Research and Critiques Thereof. En C. Crawford, D. Krebs (eds.), Foundations of evolutionary psychology, pp. 383-400. Nueva York: Taylor \& Francis Group/ Lawrence Erlbaum Associates.

Darwin, C. (1876). The Origin of Species by Means of Natural Selection or the Preservation of Favoured Races in the Struggle fot Life. Sixth Edition with Addittions and Corrections to 1872. Londres: John Murray.

Davies, N., Krebs, J., West, S. (2012). An Introduction to Behavioral Ecology. Chichester: Wiley-Blackwell.

Dawkins, R. (2017a). El gen egoista extendido. Edición especial $40^{\circ}$ aniversario. Madrid: Salvat.

Dawkins, R. (2017b). El fenotipo extendido. El largo alcance del gen. Madrid: Capitán Swing.

De la O-Rodríguez, C., Montoya, B. (2011). Biología del comportamiento animal: la etología como un puente en el estudio del comportamiento. En G. Gutiérrez, M. Papini (eds.), Darwin y las ciencias del comportamiento, pp. 137-158. Bogotá: Universidad Nacional de Colombia / Colegio Colombiano de Psicólogos.

De Vecchi, G., Giordan, A. (2006). Guía práctica para la enseñanza científica. Sevilla: Díada.

De Waal, F. (2000). Bases genéticas y ambientales de la conducta. Investigación y Ciencia, 280: 48-53.

Dennett, D. (1995). Darwin's dangerous idea: Evolution and the meanings of Life. Nueva York: Simon and Schuster.

Diéguez, A. (2012). La vida bajo escrutinio. Una introducción a la filosofia de la biología. Barcelona: Buridán.

Revista de Humanidades de Valparaíso, 2019, No 14, 187-222

(ㄷ) (1)임 CC BY-NC-ND 
Perspectivas darwinistas sobre la mente y la conducta humanas: alcances, limitaciones e implicancias educativas Leonardo González Galli

Diéguez, A. (2017). Transhumanismo y naturaleza humana. Contribuciones a congresos científicos. Universidad de Málaga. URL: https:/riuma.uma.es/xmlui/bitstream/handle/10630/14245/Resumen\%20Transhumanismo\%20y\%20naturaleza\%20humana.pdf?sequence $=3 \&$ isAllowed $=\mathrm{y}$

Díez, J., Moulines, C. U. (2008). Fundamentos de filosofía de la ciencia. Barcelona: Ariel.

Dobzhansky, T., Ayala, F., Stebbins, G., Valentine, J. (1980). Evolución. Barcelona: Omega.

Echeverría, Javier (2002). Ciencia y valores. Barcelona: Destino.

Elgarte, J. (2019) Usos legítimos y necesarios de la ciencia en el diseño de políticas e instituciones: algunos ejemplos. En D. Busdygan (coord.), Rostros del igualitarismo: discusiones y desafíos filosóficos. Buenos Aires: Teseo Press. En prensa.

Futuyma, D., Kirkpatrick, M. (2018). Evolution. Oxford: Oxford University Press.

Gardner, H. (1988). La nueva ciencia de la mente. Historia de la revolución cognitiva. Barcelona: Paidós.

Giere, R. (1992). La explicación de la ciencia. Ciudad de México: Consejo Nacional de Ciencia y Tecnología.

Giere, R. (2006). Scientific Perspectivism. Chicago: The University of Chicago Press.

Girón Sierra, A. (2005). Darwinismo, darwinismo social e izquierda política (1859-1914). Reflexiones de carácter general. En M. Miranda, M., G. Vallejo (comp.), Darwinismo social y eugenesia en el mundo latino, pp. 23-58. Buenos Aires: Siglo XXI de Argentina Editores.

Gómez, R. (2014). La dimensión valorativa de las ciencias. Bernal: Universidad Nacional de Quilmes Editorial.

Gould, S. (1997). La falsa medida del hombre. Barcelona: Crítica.

Gould, S. (2010). Desde Darwin. Reflexiones sobre historia natural. Barcelona: Crítica.

Gould, S., Lewontin, R. (1979). The spandrels of San Marco and the Panglossian paradigm: a critique of the adaptationist programme. Proceedings of the Royal Society of London. B. doi: http://doi.org/10.1098/rspb.1979.0086

Hacking, I. (2001). ¿La construcción social de qué? Barcelona: Paidós.

Harris, J. (2015). No hay dos iguales, Individualidad humana y naturaleza humana. Madrid: Editorial Funambulista.

Heler, Mario (1996). Ética y ciencia: la responsabilidad del martillo. Buenos Aires: Biblós.

Jiménez Aleixandre, M. (2012). Determinism and Underdetermination in Genetics: Implications for Students' Engagement in Argumentation and Epistemic Practices. Science \& Education, 23(2): 465-484. doi: 10.1007/s11191-012-9561-6

Kampourakis, K. (2014). Understanding evolution. Nueva York: Cambridge University Press.

Kitcher, P. (1985). Vaulting Ambition: Sociobiology and the Quest for Human Nature. Cambridge: The MIT Press.

Revista de Humanidades de Valparaíso, 2019, No 14, 187-222

()ㅇㅇㅇㅛ CC BY-NC-ND 
Perspectivas darwinistas sobre la mente y la conducta humanas: alcances, limitaciones e implicancias educativas Leonardo González Galli

Lacey, H. (2005a). Values and Objectivity in Science. The Current Controversy about Transgenic Crops. Lanham: Lexington Books.

Lacey, H. (2005b). Is science value free? Values and scientific understanding. Nueva York: Taylor $\&$ Francis.

Laland, K., Galef, B. (ed.) (2009). The Question of Animal Culture. Cambridge: Harvard University Press.

Lewens, T. (2007). Adaptation. En D. Hull, M. Ruse (eds.), The Cambridge Companion to The Philosophy of Biology, pp. 1-21. Cambridge: Cambridge University Press.

Lewontin, R. (1972). The apportionment of human diversity. En T. Dobzhansky, M. Hecht, W. Steere (eds.), Evolutionary Biology, 6: 381-398. New York: Appleton-Century-Crofts.

Lewontin, R. (1978). Adaptation. Scientific American, 239(3): 212-230.

Lewontin, R., Rose, S., Kamin, L. (1996). No está en los genes. Críticas del racismo biológico. Barcelona: Grijalbo.

Lorenz, K. (1986). Fundamentos de etología. Estudio comparado de las conductas. Barcelona: Paidós.

Maynard, S. J. (1997). Commentary. En P. Gowaty (ed.), Feminism and Evolutionary Biology, pp. 522-526. Nueva York: Chapman \& Hall.

Mayr, E. (1998). Así es la biología. Madrid: Debate.

Mayr, E: (2006). Por qué es única la biología. Consideraciones sobre la autonomía de una disciplina cientifica. Buenos Aires: Katz.

Meaney, M. (2006). Nature, Nurture, and the Disunity of Knowledge. Annals of the New York Academy of Sciences, 935(1): 50-61. doi:10.1111/j.1749-6632.2001.tb03470.x

McKinnon, S. (2012). Genética neoliberal. Mitos y moralejas de la psicología evolucionista. Ciudad de México: Fondo de Cultura Económica.

Muñoz, J. (2008). El concepto darwiniano de escasez: la extensión de la ideología capitalista al mundo vivo. En J. Llorente, R. Ruiz, G. Zamudio, R. Noguera, R. (comp.), Fundamentos históricos de la biología, pp. 617-638. Ciudad de México: Universidad Nacional Autónoma de México.

Penchazadeh, V. (comp.) (2012). Genética y derechos humanos. Encuentros y desencuentros. Buenos Aires: Paidós.

Pinker, S. (2003). La tabla rasa. La negación moderna de la naturaleza humana. Barcelona: Paidós.

Pinker, S. (2012). Los ángeles que llevamos dentro. El declive de la violencia y sus implicancias. Barcelona: Paidós.

Pinker, S. (2000). Cómo funciona la mente. Barcelona: Destino.

Revista de Humanidades de Valparaiso, 2019, No 14, 187-222

(c) (1) 8 (을 BY-NC-ND 
Perspectivas darwinistas sobre la mente y la conducta humanas: alcances, limitaciones e implicancias educativas Leonardo González Galli

Plomin, R., Defries, J., McClearn, G., Mcguffin, P. (2002). Genética de la conducta. Barcelona: Ariel.

Pollak, R. (2011). Bettelheim, el impostor. En C. Meyer (dir.); M. Borch-Jacobsen, J. Cottraux, D. Pleux, V. Rillauer (eds.), El libro negro del psicoanálisis. Vivir, pensar y estar mejor sin Freud, pp. 409-419. Buenos Aires: Sudamericana.

Pugh, K. (2017). Computers, Cockroaches, and Ecosystems: Understanding Learning through Metaphor. Charlotte: Information Age Publishing.

Ridley, M. (2004). Qué nos hace humanos. Ciudad de México: Santillana.

Rose, H., Rose, S. (eds.) (2000). Alas. Poor Darwin. Arguments Against Evolutionary Psychology. Londres: Vintage. Random House.

Rosengren, K., Brem, S., Evans, E. M., Sinatra, G. (eds.) (2012). Evolution Challenges. Integrating research and practice in teaching and learning about evolution. New York: Oxford University Press.

Ruse, M. (1980). Sociobiología. Madrid: Cátedra.

Ruse, M. (2000). Teleology: Yesterday, today, and tomorrow? Studies in History and Philosophy of Biological \& Biomedical Sciences, 31(1): 213-232.

Ruse, M. (2003). Darwin and design. Does evolution have a purpose? Cambridge: Harvard University Press.

Sapolsky, R. (2007). El mono enamorado y otros ensayos sobre nuestra vida animal. Barcelona: Paidós.

Sapolsky, R. (2018). Compórtate. La biología que hay detrás de nuestros mejores y peores comportamientos. Madrid: Capitán Swing Libros.

Schaeffer, J. M. (2009). El fin de la excepción humana. Buenos Aires: Fondo de Cultura Económica.

Schmitt, D. (2008). Evolutionary Psychology Research Methods. En C. Crawford, D. Krebs (eds.), Foundations of evolutionary psychology, pp. 215-238. Nueva York: Taylor \& Francis Group/Lawrence Erlbaum Associates.

Schweber, S. (2008). Darwin y los economistas políticos: la divergencia de caracteres. En J. Llorente, R. Ruiz, G. Zamudio, R. Noguera (comp.), Fundamentos históricos de la biología, pp. 533-616. Ciudad de México: Universidad Nacional Autónoma de México.

Sober, E., Wilson, D. S. (2000). El comportamiento altruista. Evolución y psicología. Madrid: Siglo XXI.

Soler, M. (2009). Adaptación del comportamiento: comprendiendo al animal humano. Madrid: Síntesis.

Temrin, H., Buchmayer, S. Enquist, M. (2000). Step-parents and infanticide: new data contradict evolutionary predictions. Proc. Biol. Sci., 267(1446): 943-945. doi: 10.1098/rspb.2000.1094

Revista de Humanidades de Valparaíso, 2019, No 14, 187-222

(c) (1) $\mathrm{O}$ (을 BY-NC-ND 
Perspectivas darwinistas sobre la mente y la conducta humanas: alcances, limitaciones e implicancias educativas Leonardo González Galli

Temrin, H., Nordlund, J., Sterner, S. (2004). Are stepchildren overrepresented as victims of lethal parental violence in Sweden? Proceedings of the Royal Society of London B, 271(3): S124-S126.

Thorpe, William (1982). Breve historia de la etología. Madrid: Alianza.

Tinbergen, Niko (1985). El estudio del instinto. Ciudad de México: Siglo XXI.

Trivers, R. (1971). The evolution of reciprocal altruism. Quarterly Review of Biology, 46: 35-57. doi: $10.1086 / 406755$

Trivers, R. (1972). Parental investment and sexual selection. En B. Campbell (ed.), Sexual selection and the descent of man: 1871-1971, pp. 136-179. Chicago: Aldine.

Tybur, J., Miller, G., Gangestad, S. (2007). Testing the Controversy: An Empirical Examination of Adaptationists' Attitudes Toward Politics and Science. Human Nature, 18(4): 313-28. doi: 10.1007/s12110-007-9024-y

Williams, G. (1966). Adaptation and natural selection; a critique of some current evolutionary thought. Princeton, N.J.: Princeton University Press.

Wilson, D. S. (2010). Evolución para todos. De cómo la teoría de Darwin cambia nuestro pensar. Xalapa: Universidad Veracruzana.

Wilson, E. (1980). Sociobiología. La nueva síntesis. Barcelona: Omeba.

Wulff, G. (2014). Las abuelas y la genética. El aporte de la ciencia en la búsqueda de los chicos desaparecidos. Buenos Aires: Abuelas de Plaza de Mayo. 


\title{
París, California y la búsqueda por una teoría del cambio cultural
}

\author{
Paris, California and the quest for a theory of cultural change
}

\author{
Lorenzo Baravalle \\ Centro de Ciências Naturais e Humanas, Universidade Federal do ABC, Brasil \\ Centro de Filosofia das Ciências, Universidade de Lisboa, Portugal \\ lorenzo_baravalle@yahoo.it
}

\begin{abstract}
Resumen
El debate sobre la posibilidad de una teoría evolutiva del cambio cultural se ha acalorado, a lo largo de los últimos años, debido a las supuestas incompatibilidades entre dos de las principales propuestas teóricas en ese ámbito disciplinar: la teoría de la doble herencia (o de la herencia dual) y la epidemiología cultural. La primera, formulada a partir de los años 1980 por un grupo de biólogos y antropólogos situados principalmente en universidades californianas, defiende una analogía entre herencia genética y transmisión cultural. La epidemiología cultural, más recientemente formulada por Dan Sperber y sus colaboradores (situados principalmente en universidades parisinas), niega que tal analogía sea sostenible y propone un modelo parcialmente alternativo. Pero ¿cuánto, en realidad, estas dos propuestas difieren entre sí? En este artículo defenderé que menos de lo que los epidemiólogos culturales suelen sostener.
\end{abstract}

Palabras clave: evolución cultural, genética de poblaciones, epidemiología, atractores culturales, niveles de causación.

\begin{abstract}
The debate on the possibility of an evolutionary theory of cultural change has heated up, over the last years, due to the supposed incompatibilities between the two main theoretical proposals in the field: dual inheritance theory and cultural epidemiology. The former, first formulated in the 1980's by a group of biologists and anthropologists mostly hosted at Californian universities, supports an analogy between genetic inheritance and cultural transmission. Cultural epidemiology, more recently formulated by Dan Sperber and his
\end{abstract}

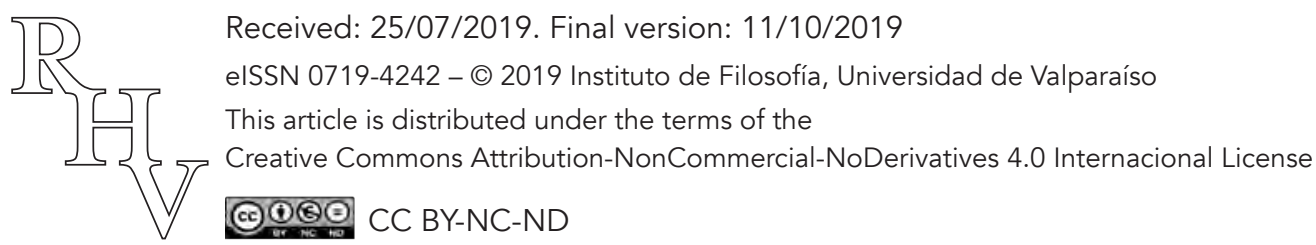


collaborator (mostly hosted at Parisian universities), denies the defensibility of such an analogy and put forward a partially alternative model. But how much do these proposals actually differ with each other? In this article, I shall argue that less than what cultural epidemiologists use to think.

Keywords: cultural evolution, population genetics, epidemiology, cultural attractors, levels of causation.

\section{Introducción}

En el contexto de los estudios sobre evolución cultural, dos propuestas teóricas han estado compitiendo para asegurarse un papel predominante en los futuros desarrollos de la disciplina: la teoría de la doble herencia (o de la herencia dual; Boyd y Richerson 1985) y la epidemiología cultural (Sperber 1996). El desacuerdo entre los sostenedores de las dos teorías se ha ido configurando, a lo largo de los últimos veinte años, aproximadamente de la siguiente manera. Por un lado, los epidemiólogos culturales han criticado la teoría de la doble herencia por presentar una imagen de los procesos de cambio cultural poco realista. Por el otro, los simpatizantes de la teoría de la doble herencia no descartan la epidemiología cultural como incorrecta, sino que la consideran compatible con la teoría de la doble herencia e insisten sobre la necesidad de integrarla a esta.

Aunque la discusión entre los "californianos" (los teóricos de la doble herencia) y los "parisinos" (los epidemiólogos culturales; según la denominación geográfica de Sterelny 2017) haya generado útiles aclaraciones sobre algunas de las tesis centrales de cada escuela (Richerson y Boyd 2005; Sperber y Claidière 2008; Acerbi y Mesoudi 2015; Morin 2016a), actualmente parece haber llegado a un estado de impasse. Entre los temas de desacuerdo, el que sobre más énfasis ha sido puesta por parte de los epidemiólogos cultural es el de la fidelidad de la transmisión de la información cultural (véase, para una discusión reciente, Morin 2016b). Mientras que para los californianos tal proceso, si bien menos fiel que la herencia genética, es suficientemente estable como para garantizar, a lo largo de las generaciones, la preservación de la información cultural, para los parisinos las cosas son más complicadas que eso. Durante cada instancia de comunicación, los sujetos reinterpretan la información cultural de manera tan idiosincrásica que no tiene sentido identificar alguna entidad que perdure en ese proceso de manera estable.

Claramente, los parisinos concuerdan sobre el hecho de que las culturas humanas exhiben acumulación de hábitos, tradiciones y técnicas. Sin embargo, a diferencia de los californianos, niegan que tal fenómeno pueda ser "substancializado" de manera análoga al proceso de herencia genética. Una sociedad no es, en última instancia, nada más que un conjunto de sujetos interactuando entre ellos y con el ambiente: lo que llamamos "acumulación cultural" es un epifenómeno resultante de tales interacciones. Los 
epidemiólogos culturales creen que esta es una explicación de las dinámicas culturales más naturalísticamente aceptable que la de los teóricos de la doble herencia (Scott-Phillips et al. 2018). Los teóricos de la doble herencia, por otro lado, se rehúsan a considerar tal propuesta como totalmente distinta de la de ellos mismos (Richerson 2017).

En este artículo, mi objetivo es ofrecer algunas consideraciones que contribuyan a entender mejor los términos de la controversia $y$, tal vez, indicar una manera para solucionarla. Por lo general, creo que los teóricos de la doble herencia estén en lo cierto. En mi opinión, la epidemiología cultural ofrece una caracterización de los procesos cognitivos involucrados en la comunicación humana que es, efectivamente, diferente de aquella de la teoría de la doble herencia (y puede que incluso mejor que esta). Sin embargo, no me parece que, en la práctica, tal caracterización deba llevarnos a considerar las dinámicas de acumulación y cambio cultural de manera diferente de como son representadas en el contexto de la teoría de la doble herencia.

El plan del artículo es el siguiente. En la segunda sección introduzco los que considero ser los dos explananda centrales de cualquier teoría de la evolución cultural y discuto las explicaciones proporcionadas, respectivamente, por la teoría de la doble herencia y la epidemiología cultural a cada uno de ellos. En la tercera sección intento entender en que aspectos los parisinos advierten mayor incompatibilidad entre su propia propuesta y la teoría de la doble herencia. En esta misma sección, digo algo más sobre el por qué los parisinos se autodenominan "epidemiólogos" y discuto supuestas diferencias entre los modelos empleados por ellos y los modelos empleados por los californianos, de alguna manera derivados de la genética de poblaciones. En la sección 4 argumento que, de un punto de vista formal, los modelos empleados por la epidemiología cultural y la teoría de la doble herencia son compatibles y complementarios. A partir de este resultado, muestro en la sección 5 que, si bien las quejas de los parisinos sobre de la teoría de la doble herencia puedan tener un cierto valor filosófico, ellas no tienen la relevancia científica que le suele ser atribuida. En la conclusión, resumo brevemente mi argumento, sus premisas y sus implicaciones.

\section{Lo que una teoría de la evolución cultural debería explicar}

Tanto la epidemiología cultural como la teoría de la doble herencia se presentan como teorías de la evolución cultural. Para entender mejor las diferencias entre las dos propuestas es, por lo tanto, provechoso preguntarse cuales son sus objetivos compartidos.

Aunque no sea un rasgo necesario de todas las teorías de la evolución cultural, la mayoría de ellas (o, por lo menos, las que han ido apareciendo a lo largo de los últimos 3040 años) tiende a considerar la cultura (principalmente humana, pero no necesariamente) tanto como un producto de la evolución biológica como un proceso evolutivo parcialmente independiente. Los dos fenómenos están relacionados; sin embargo, 
merecen consideraciones distintas. Como veremos más adelante, uno de los aspectos más importantes - pero también frecuentemente ignorado - del desacuerdo entre parisinos y californianos concierne en que medida consideraciones sobre la evolución de nuestras habilidades cognitivas deberían condicionar consideraciones sobre el cambio cultural. De momento, no obstante, vamos a concentrarnos sobre los dos fenómenos por separado.

Explicar la cultura como producto de la evolución biológica significa explicitar las condiciones bajo las cuales facultades cognitivas responsables por el aprendizaje social, la cooperación y la comunicación han evolucionado. También significa identificar, en la medida de lo posible, en que modo la evolución de nuestras facultades cognitivas condiciona la manera en la que, hoy en día, aprendemos información cultural de los demás y emulamos conductas ajenas de manera selectiva.

Con relación a este elemento de la teoría de la evolución cultural, los parisinos y los californianos, aunque en desacuerdo sobre aspectos específicos (Sperber y Claidière 2008), comparten varias tesis generales. Ambas escuelas se inspiran en la psicología evolucionista y, a la vez, se distancian de esta por razones similares. De la psicología evolucionista, parisinos y californianos adoptan la idea de que buena parte de nuestra psicología social evolucionó durante la era geológica conocida como Pleistoceno (entre 2,59 millones y 10 mil años atrás). Sin embargo, tanto los parisinos como los californianos tienen una concepción diferente de los psicólogos evolucionistas con relación al tipo de habilidades cognitivas que fueron seleccionadas durante esa época.

Mientras los psicólogos evolucionistas (por lo menos los más tradicionales) piensan que lo que evolucionó en el Pleistoceno fueron una serie de módulos cognitivos para tareas relativamente específicas (fabricación de herramientas, vida en grupo, relaciones estables de pareja etc.), los evolucionistas culturales creen que la selección natural premió, durante ese periodo, habilidades más genéricas relacionadas con la transmisión de la información aprendida. Estas diferentes concepciones fundamentan dos distintas interpretaciones de la cultura. Para los psicólogos evolucionistas (Tooby y Cosmides 1992), nuestros hábitos y tradiciones eran adaptativos en la época en la que los módulos cognitivos que permiten implementarlos fueron seleccionados; hoy en día, ellos son mayoritariamente disfuncionales. Para los evolucionistas culturales (tanto parisinos como californianos) la cultura es - en virtud del hecho de que nuestras habilidades cognitivas son más genéricas y flexibles - capaz de cambiar a lo largo del tiempo y, aunque a veces nuestros hábitos y tradiciones sean efectivamente disfuncionales, no deja de ser globalmente adaptativa.

Boyd y Richerson (1985; Richerson y Boyd 2005) identifican tres tipos de sesgos (biases) relacionados con el aprendizaje social: sesgos dependientes del contenido, conformismo, y sesgos dependientes del modelo (estos últimos dos son a veces denominados "sesgos dependientes del contexto"). La idea básica es que una cierta composición de creencias, hábitos, tradiciones y técnicas en una sociedad es el producto del hecho de que las personas tienden a adoptar, por razones evolutivas biológicas, actitudes y conductas que son: 
- atractivas de acuerdo con algún criterio psicológico, o cuya utilidad es evidente, o simples de entender (sesgos dependientes del contenido);

- adoptadas por la mayoría de los miembros de la población (conformismo);

- adoptadas por los miembros más prestigiosos de la población(sesgo dependiente del modelo).

Cada uno de estos sesgos es tendencialmente adaptativo, de un punto de vista biológico/genético, aunque ninguno es infalible, y puede fácilmente pasar que — como consecuencia de repetidas instancias de aprendizaje social conforme estos sesgos- en una población se difundan actitudes y conductas no adaptativas, o incluso maladaptativas (esto es, negativas del punto de vista de la fitness genética).

Los epidemiólogos culturales no tienen una propuesta tan detallada con respecto a los tipos de sesgos que actuarían en la transmisión de información aprendida. En los textos clásicos de los autores pertenecientes a esa tradición (en particular, Sperber 1996; Sperber y Claidière 2007), se puede percibir un énfasis sobre lo que Boyd y Richerson llaman "sesgos dependientes del contenido". De acuerdo con la posición defendida en textos más recientes (Claidière et al. 2014; Buskell 2017a), parecería que también sesgos más "contextuales" pueden condicionar la difusión de un hábito o una tradición. De cualquier manera, aquí voy simplemente a asumir que hay compatibilidad y solamente un desacuerdo menor entre parisinos y californianos. Probablemente, estrictamente hablando, la propuesta de Boyd y Richerson es aún algo programática, y ulteriores estudios necesitan ser realizados para corroborar o ampliar la taxonomía de sesgos que acabo de exponer. Sin embargo, ese trabajo ya está siendo realizado (véase Kendal et al. 2018 para una reseña actualizada), y los resultados son aparentemente coherentes tanto con la imagen defendida por los parisinos como aquella defendida por los californianos.

Las diferencias entre los epidemiólogos culturales y los teóricos de la doble herencia se hacen más evidentes con relación a la caracterización de la cultura como un proceso evolutivo en si mismo. Discutiendo la cultura como producto evolutivo, nos hemos concentrado sobre la dimensión psicológica/cognitiva del fenómeno cultural, con un énfasis sobre los mecanismos que hacen que un individuo adopte una actitud o una conducta en lugar que otra. Cuando una teoría de la evolución cultural pasa a considerar la cultura como un proceso evolutivo, el foco deja de ser el individuo y pasa a ser la población, o sociedad, de la cual el individuo forma parte. Lo que una teoría de la evolución cultural como teoría de los procesos de acumulación y cambio cultural pretende explicar es por qué, en una determinada población o sociedad, ciertas creencias, hábitos, tradiciones, técnicas etc. gozan de mayor difusión que otros.

Para los sostenedores de la teoría de la doble herencia, el fenómeno de difusión de creencias, hábitos, tradiciones, técnicas etc. debe ser concebido en estricta analogía con los fenómenos de evolución fenotípica. De hecho, podemos considerar las actitudes y las 
conductas derivadas de la adopción de ciertas creencias o tradiciones culturales como un subconjunto de rasgos fenotípicos, los cuales tienen, justamente, la peculiaridad de poder ser transmitidos por comunicación y aprendizaje social. Boyd y Richerson llaman tales rasgos fenotípicos "variantes culturales". Del punto de vista de la transmisión de las variantes culturales, el aprendizaje social funciona como si fuera un canal paralelo a la herencia genética. Es justamente en virtud de esta analogía que los californianos denominan a su propia teoría de teoría de la "doble herencia".

Obviamente, la transmisión cultural tiene diferencias significativas con respecto a la herencia genética. En particular, la herencia genética es principalmente vertical - la información genética es transmitida de padres a hijos (aunque transferencias de información genética horizontal sean comunes en bacterias) - mientras que la información cultural fluye en todas las direcciones (de padres a hijos, entre padres, entre hijos, entre adultos de la generación de los padres a niños que no son sus hijos, de hijos a padres etc.). Aún admitiendo estas diferencias, los sostenedores de la teoría de la doble herencia creen que es posible aplicar una serie de modelos matemáticos derivados de la genética de poblaciones - $\mathrm{y}$, más específicamente, de la genética cuantitativa - para determinar los factores que, en casos concretos, influyeron en una particular distribución de variantes culturales en una población. Tales factores son los factores evolutivos tradicionales selección natural, deriva genética, migración etc.- - más otros análogos, pero típicamente culturales, como la mutación dirigida (innovación cultural), factores de transformación de la variante, o diferentes tipos de selección cultural (Mesoudi 2011; Baravalle 2019).

Los epidemiólogos culturales, por otro lado, ven las diferencias entre transmisión cultural y herencia genética como fatales para la posible aplicación de modelos derivados de la genética de poblaciones a la difusión de ítems culturales. Eso los lleva a rechazar varios aspectos de la conceptualización de Boyd y Richerson, como veremos en más detalle en la próxima sección.

\section{Epidemiología y atractores culturales}

Para los epidemiólogos culturales, la transmisión cultural no es análoga a la herencia genética porque - con la excepción de unos casos específicos - la información cultural no se replica, simplemente, de individuo a individuo, sino que es continuamente reformulada (Sperber 1996; 2001). Esto es, cuando alguien comunica una información potencialmente transmisible (en el sentido de que podría influenciar la actitud o la conducta del interlocutor) es muy poco probable que lo haga de manera que la representación que tiene de tal información sea transmitida fielmente al interlocutor. El aprendizaje de información cultural involucra una constante reconceptualización, por parte del aprendiz, de la información aprendida. Tal reconceptualización es debida al hecho de que el aprendiz entra en contacto con la información cultural con su propio bagaje de conocimientos anteriores, habilidades inferenciales e intereses específicos. Por

Revista de Humanidades de Valparaíso, 2019, No 14, 223-240

()ㅇㅇㅇㅛ CC BY-NC-ND 
esta razón, la representación que dos personas elegidas al azar en una población tienen de un mismo ítem cultural (que sea un elemento fonético del lenguaje, un ritual religioso, una técnica de preparo de un alimento o una creencia científica) tiende a ser siempre levemente diferente e idiosincrásica.

Pero ¿como explicar, entonces, el hecho de que existen hábitos y tradiciones compartidas entre miembros de una sociedad, las cuales parecen perdurar a lo largo de las generaciones? Para ofrecer una respuesta a esta pregunta, los parisinos invocan la analogía entre procesos de difusión cultural y los procesos epidemiológicos. Los miembros de una sociedad son portadores de representaciones culturales, de manera similar a como los enfermos son portadores de una enfermedad. En sus interacciones diarias, los dos tienen una cierta probabilidad de transmitir los "gérmenes" de la representación o de la enfermedad. Cuando un nuevo sujeto es infectado, desarrolla su propia versión de la representación o de la enfermedad. Esta puede - y suele, como acabamos de ver- tener alguna diferencia respecto a la versión (o las versiones) de los individuos con los que entró en contacto. Sin embargo, tales diferencias no pueden superar un cierto umbral; si lo hacen, la nueva representación no es, estrictamente hablando, la "misma" representación o enfermedad. No podemos decir que alguien contrajo, efectivamente, el sarampión si de hecho carece de todos los síntomas característicos de esta enfermedad. De la misma manera, no podemos decir que alguien se convirtió realmente al Zoroastrismo si no exhibe una conducta coherente con la de esta religión.

Hay que aclarar en seguida, ya que es crucial para entender la perspectiva de los epidemiólogos culturales, que no hay nada de intrínseco a la representación cultural que impida que ella varíe incluso radicalmente a lo largo de los "contagios". Lo que hace que ella se mantenga relativamente estable en una población es el hecho de que los miembros de la población dejen de considerar representaciones aberrantes como posibles instancias de la representación original. Esta idea puede ser expresada más rigurosamente por medio de la noción de atractor. Un atractor es un área, en un espacio ideal de posibles variaciones subjetivas de una representación cultural, en el que las representaciones reales tienden a converger (véase Buskell 2017a y Scott-Phillips et al. 2018 para análisis detallados de este concepto).

Imagínese, por ejemplo, el espacio de posibles variaciones de la letra zeta en castellano. Como es sabido, en la mayoría del territorio español, la letra es pronunciada aproximadamente como la th inglesa, mientras que en Latinoamérica es comúnmente pronunciada como una $s$. Pequeñas variaciones (como, por ejemplo, en dirección al fonema $/ d z /$ ) son toleradas y entendidas. Sin embargo, un individuo que pronunciara la letra zeta de una manera radicalmente distinta (como una $k a$, por ejemplo) tendría serios problemas de comunicación. Eso puede ser expresado en términos de atracción cultural, con el auxilio de la figura 1, de la siguiente manera. Las zonas más obscuras del espacio de variación representan los fonemas correctos, los cuales, junto con los fonemas representados por las zonas grises representan los fonemas aceptados. Las zonas blancas 
representan los fonemas incorrectos. La representación cultural se transmite solo en los casos en los que el nuevo hablante sea capaz de elaborar una conducta (en este caso lingüística) correspondiente a la de las áreas más obscuras o grises.

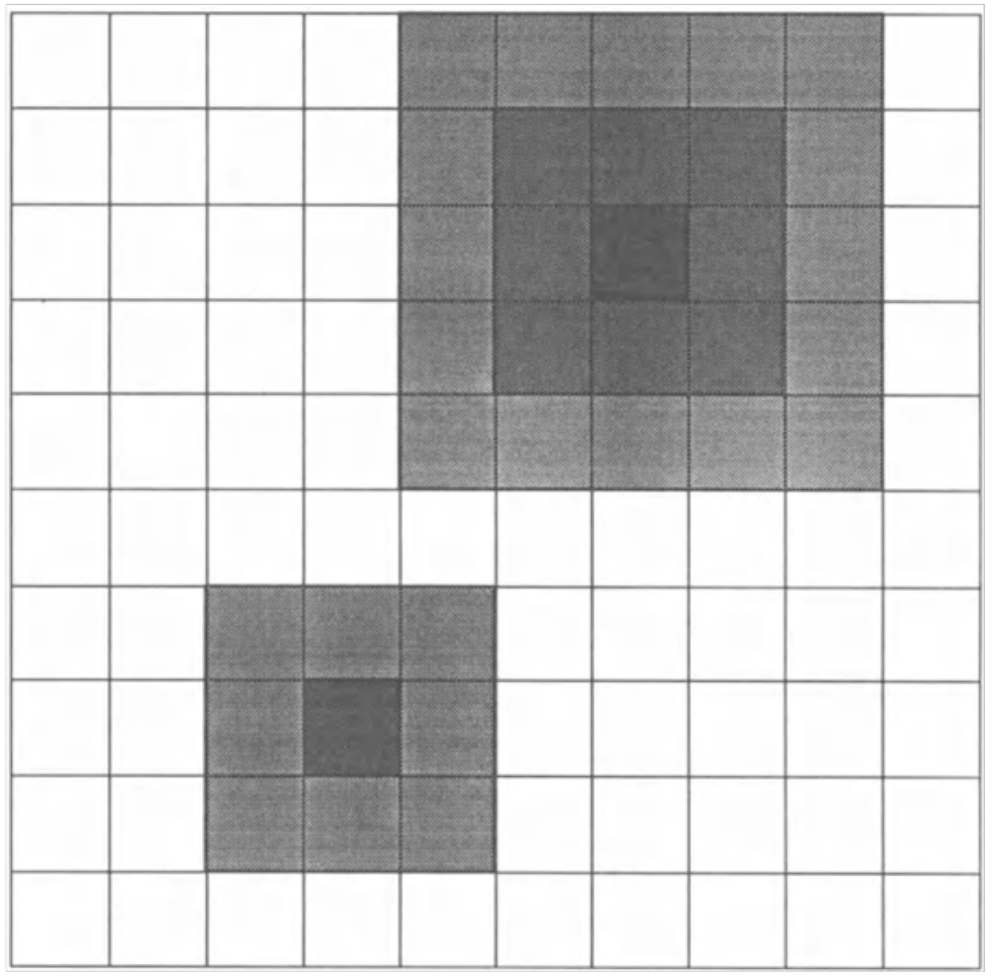

Fig. 1: Reconstrucción de un espacio de variación cultural con dos atractores (de Sperber 1996, 109).

Los atractores de una determinada representación pueden cambiar gradualmente a lo largo del tiempo, tanto por razones relacionadas con la adaptividad biológica de las conductas relacionadas con la representación, como de otro tipo (por sesgos "de contenido", contextuales u otros). El aspecto más importante a resaltar aquí es que, a diferencia del canal de herencia cultural postulado por los teóricos de la doble herencia, la noción de atractor cultural no tiene ninguna relevancia causal:

Un atractor, por como lo he caracterizado, es una construcción abstracta, estadística, como la tasa de mutación o la probabilidad de transformación. Decir que hay un atractor sólo quiere decir que, en un determinado espacio de posibilidades, las probabilidades de transformación forman un cierto patrón [...] (Sperber 1996, 111-112)

El espacio de variación no es, pues, nada más que un artefacto estadístico útil para representar la permanencia o el cambio de determinadas tradiciones o costumbres. 
El error de los teóricos de la doble herencia, desde esta perspectiva, sería el de por así decirlo_ "hipostasiar" el proceso de cambio cultural (Sperber 2001; Claidière et al. 2014): es incorrecto hablar de un "canal" de transmisión cultural porque en última instancia no hay nada, en la cultura, más allá que un conjunto de personas interactuando entre sí y con el ambiente de cierta manera. A diferencia de la analogía con la herencia genética, engañosa y simplista (porque reduce el proceso de transmisión cultural a mera replicación, ocultando la complejidad de las relaciones sociales) la analogía con la epidemiología sería más refinada y realista. Esta capturaría aspectos de la emergencia de patrones poblacionales a partir de agregados de interacciones individuales de manera que quedaría inaccesible a una perspectiva fundamentada en la analogía con la genética de poblaciones (Buskell 2017b).

\section{Epidemiología y genética de poblaciones: una comparación}

A partir de esta sección, voy a evaluar si los epidemiólogos culturales tienen razones válidas para justificar la realización de un programa de investigación significativamente distinto de aquel iniciado por los teóricos de la doble herencia. Procederé, aproximadamente, de la siguiente manera. En esta sección compararé algunos aspectos de la genética de poblaciones y de la epidemiología para averiguar si, como asumido por los epidemiólogos culturales, las analogías con estas dos disciplinas conducen a perspectivas genuinamente alternativas sobre los fenómenos culturales. Como veremos, no hay razones para pensar que ese sea el caso. En la próxima sección, entonces, consideraré una posible respuesta de los epidemiólogos culturales. Aunque la genética de poblaciones y la epidemiología sean, bajo muchos puntos de vista, equivalentes, se podría argumentar que el hecho de ver el fenómeno de cambio cultural como un proceso dinámico causalmente autónomo o, alternativamente, como meramente resultante de agregados de interacciones individuales debe hacer alguna diferencia. Con relación a esa cuestión, sostendré que, si bien la diferencia entre estas dos concepciones puede tener algún interés filosófico (similar a aquel suscitado por el debate entre causalistas y estadisticalistas en el contexto de la filosofía de la biología evolutiva; Sober 1984; Matthen y Ariew 2002; Walsh et al. 2002), queda para demostrar que tenga algún significado empírico.

En un sentido trivial, la genética de poblaciones y la epidemiología son teorías diferentes porque tienen dos objetos diferentes. La genética de poblaciones tiene como objetivo el de rastrear el cambio en las distribuciones genotípicas (o fenotípicas, en el caso de la genética cuantitativa), mientras que la epidemiología estudia la difusión de enfermedades infecciosas. Dada las diferencias entre los dos fenómenos, las dos teorías adoptan modelos matemáticos propios. Sin embargo, ambas teorías se dedican a estudiar fenómenos relacionados con dinámicas de poblaciones. Además, como observado por los biólogos Steve Peterson y Mark Viney, "hay [...] una clara analogía entre herencia — la transmisión de genes de una generación a otra - e infección — la transmisión de 
parásitos de un huésped a otro-y las consecuencias de ambos procesos en el nivel de las poblaciones" (Peterson y Viney 2000, 528). Si admitimos esa analogía, lo que distingue la genética de poblaciones y la epidemiología sería más el enfoque que cada una de estas disciplinas adopta respecto a fenómenos parecidos. Para Peterson y Viney, la genética de poblaciones estudiaría los fenómenos de transmisión directamente en el nivel de las poblaciones, mientras que la epidemiología se dedicaría a dar cuenta de la emergencia de patrones poblacionales a partir de agregados de instancias de transmisión.

En ese sentido, los epidemiólogos culturales identifican una diferencia real entre las dos disciplinas. Lo que está en cuestión, sin embargo, no es sólo si tal diferencia existe, sino si tiene las implicaciones que Sperber y los demás parisinos le atribuyen. Para soportar su postura "separatista", los parisinos necesitarían mostrar que los resultados obtenidos a partir de modelos de genética de poblaciones son sustancialmente divergentes de los resultados obtenidos a partir de modelos epidemiológicos. Es con relación a ese aspecto que, por lo que puedo ver, los parisinos fallan en ofrecer razones convincentes. Que los modelos de las dos teorías en cuestión sean compatibles, o incluso equivalentes, es algo que ya sostenían, casi 40 años atrás (en la "prehistoria" de la teoría de la doble herencia), los genetistas Luca Luigi Cavalli-Sforza y Marcus Feldman. En su clásico Cultural Transmission and Evolution: A Quantitative Approach, los autores notan:

La analogía de una enfermedad infecciosa con la difusión de una innovación en el ámbito de una generación es tal vez más acertada que aquella con una mutación exitosa. Sin embargo, las teorías matemáticas formulada por cualquier una de las tres variables número de individuos portadores de una enfermedad infecciosa, la proporción portadora de mutaciones ventajosas, o el número de individuos que han adoptado una innovación - son formalmente idénticas cuando estudiadas a este nivel elementar. (Cavalli-Sforza y Feldman 1981, 33; cursivo en el original)

Una opinión parecida tiene Aunger (2001), el cual imputa las diferencias formales entre genética de poblaciones y epidemiología más a factores contingentes debidos a la historia y a la agenda de cada disciplina que a reales diferencias conceptuales. La epidemiología, con su énfasis en la relación entre los agregados de individuos y las consecuencias poblacionales de las interacciones entre estos, privilegia un análisis espacial de las dinámicas de difusión. Para eso, recurre a varias herramientas formales derivadas de la teoría de redes - network theory - (Peterson y Viney 2000, 530), cuya relevancia no sea tal vez evidente para la genética de poblaciones. Por otro lado, la genética de poblaciones se enfoca sobre la dimensión temporal de los fenómenos de difusión. Es, plausiblemente, en virtud de tal enfoque diferente que los genetistas de poblaciones necesitan realizar una mayor abstracción con respecto al nivel de los individuos y concentrarse exclusivamente en el nivel de las poblaciones.

Lo que emerge de esta conceptualización es que, con respecto a un cierto dominio de fenómenos de distribución de variantes en una población, la genética de poblaciones y

Revista de Humanidades de Valparaíso, 2019, No 14, 223-240 
la epidemiología son dos disciplinas complementarias, y en ningún sentido en conflicto. En el contexto de una teoría de la evolución cultural, tal complementariedad podría ser entendida de la siguiente manera. Por un lado, tendríamos estudios de carácter epidemiológico, que conectan lo que sabemos sobre los sesgos humanos de aprendizaje social con la probable difusión espacial de una representación/variable cultural. La noción de atractor tendría, de acuerdo con lo que ha sido sostenido por varios epidemiólogos culturales (Buskell 2017b; Scott-Phillips et al. 2018), la función de monitorear los efectos agregativos de las interacciones culturales. La información obtenida a partir de estos estudios epidemiológicos constituiría una importante fuente para construir, por otro lado, modelos temporales de acumulación y cambio cultural, los cuales podrían beneficiarse de herramientas formales derivadas de la genética de poblaciones (como han sostenido los teóricos de la doble herencia).

Es interesante notar que, aunque nominalmente poco atraídos por tal proyecto compatibilista, algunos epidemiólogos culturales ya lo promueven tácitamente. Es el caso, por ejemplo, de Claidière et al. (2014). En ese artículo, los autores critican la teoría de la doble herencia etiquetándola como "seleccionista". De su punto de vista, el fallo de esa teoría sería que insiste demasiado sobre la adaptividad, genética o cultural, de las variantes culturales más difusas en una sociedad. En otras palabras, la teoría de la doble herencia sería culpable de una especie de "panadaptacionismo cultural". En contra de tal posición, Claidière y sus colaboradores elaboran un proto-modelo matemático — las "matrices evolutivas causales"- - que, a partir de una concepción no-replicativa de la información cultural, permitiría inferir procesos de distribuciones de representaciones culturales. El resultado es que, en la mayoría de escenarios, las distribuciones de representaciones culturales no coincidirían con las distribuciones previstas por un enfoque seleccionista.

Lo que Claidière y sus colaboradores parecen ocultar al lector es que el empleo de herramientas conceptuales derivadas de la genética de poblaciones no implica la adhesión a una perspectiva seleccionista. De hecho, los modelos de genética de poblaciones están explícitamente formulados para tomar en cuenta otras causas de los procesos evolutivos además que la selección natural, tales como deriva genética, mutación, migración etc. Es más, en la medida en que las matrices evolutivas causales son modelos que tienen como objetivo el de rastrear frecuencias de representaciones culturales - haciendo completa abstracción de como tales frecuencias son realizadas por agregados de interacciones individuales - ellas mismas podrían ser interpretadas como modelos derivados de la genética de poblaciones. Y no habría nada de lo que avergonzarse: la epidemiología tiene que dejar paso a la genética de poblaciones cuando se trata de observar una población "desde arriba”, para entender dinámicas de más larga escala y duración. 
París, California y la búsqueda por una teoría del cambio cultural

Lorenzo Baravalle

\section{Agregados y causas a nivel de poblaciones: el interés filosófico del debate entre parisinos y californianos}

Llegados a este punto, los simpatizantes de la epidemiología cultural podrían objetar que lo que he discutido en la sección anterior es irrelevante. Lo que está en discusión cuando se comparan el papel de la epidemiología y de la genética de poblaciones en el contexto de una teoría de la evolución cultural no es el uso de ciertas herramientas formales, sino que dos diferentes concepciones causales del cambio cultural. Como vimos en las secciones 2 y 3, parecería que la analogía entre transmisión cultural y herencia genética compromete los teóricos de la doble herencia con un cierto realismo con relación a causas actuando en un nivel sobre-individual (las presiones selectivas culturales y otros tipos de causas evolutivas). La analogía con la epidemiología, en cambio, dispensaría los parisinos de tal compromiso: de un punto de vista causal, todas las dinámicas evolutivas culturales son reducibles a interacciones individuales. Como dijimos, eso sería más naturalísticamente aceptable y constituiría una razón de peso para inclinarse a favor de la perspectiva epidemiológica (véase, por ejemplo, Scott-Phillips et al. 2018).

El problema que veo con esa estrategia argumentativa es que promete más de lo que puede ofrecer. Es cierto que la caracterización causal de los procesos de acumulación y cambio cultural son diferentes en la teoría de la doble herencia y en la epidemiología cultural. Sin embargo, no queda claro si tal diferencia tiene alguna significativa consecuencia testable o si — se me perdone la paráfrasis de una célebre expresión- es una diferencia que no hace (por lo menos empíricamente) ninguna diferencia.

¿Qué tipo de compromiso ontológico asumen los teóricos de la doble herencia cuando afirman que la transmisión cultural es un "canal" de herencia y que las variantes culturales están sujetas a presiones selectivas (o a otras fuerzas evolutivas; Baravalle 2019)? Para poder responder a esta pregunta, debemos antes entender mejor que tipo de relaciones causales sobre-individuales suelen ser postuladas en el contexto del estudio evolutivo de poblaciones en biología. Cuando un genetista de poblaciones dice que un cierto rasgo fue seleccionado (o evolucionó por deriva, o fue introducido por procesos migratorios etc.), lo que quiere decir es que un cierto conjunto de condiciones ambientales, bióticas y/o sociales hizo que la frecuencia de tal rasgo se incrementara en la población. Por supuesto, para que eso pueda ocurrir, es necesario que los individuos que componen la población se comporten de cierta manera: algunos morirán sin tener descendencia, mientras que otros serán muy prolíficos. Sin embargo, podría argumentarse, el proceso evolutivo no es simplemente el agregado de tales circunstancias individuales. Autores como Elliott Sober (1980; Shapiro y Sober 2007) o Roberta Millstein (2006) han insistido sobre el hecho de que lo que cambia en el proceso evolutivo - esto es, frecuencias de rasgos u otros aspectos demográficos, como la estructura démica de la población- son propiedades de poblaciones, no reducibles a propiedades de individuos. Por esa razón, es más correcto decir que es la población como un todo (y no un agregado de individuos) la que establece ciertas dinámicas causales con el ambiente, bioma, o contexto social.

Revista de Humanidades de Valparaíso, 2019, No 14, 223-240

(c) (1) 8 (을 CC BY-NC-ND 
Cuando los teóricos de la doble herencia comparan las variantes culturales a rasgos fenotípicos sujetos a factores evolutivos análogos a aquellos que influyen en las distribuciones de los rasgos fisiológicos o morfológicos, lo que plausiblemente quieren decir es que, a lo largo de las cadenas de transmisión culturales, actúan factores que, globalmente, producen cambios en la composición de la población. Como las dinámicas evolutivas dependientes de la herencia genética, también las dinámicas evolutivas culturales necesitan ser realizadas por individuos que interactúan de cierta manera. Sin embargo, como también en el caso de los procesos evolutivos dependientes de la herencia genética, puede sostenerse que el proceso evolutivo cultural no es solamente consecuencia del agregado de tales interacciones. Las frecuencias cambiantes de rasgos culturales, la estructura démica de la población y otras características sociales e institucionales de una población son todas propiedades de la población, no directamente reducibles a propiedades de sus miembros. Sería, por lo tanto, correcto considerar el proceso evolutivo cultural como un proceso causal en el nivel de la población.

En el contexto del debate filosófico sobre la estructura causal y explicativa de la teoría evolutiva en biología no han faltado los que han criticado la perspectiva presentada aquí arriba. Matthen y Ariew (2002) y Walsh et al. (2002) - los llamados estadisticalistashan objetado - en contra de la tesis llamada de causalista - que no es necesario postular un nivel de interacciones causales sobre-individuales para dar cuenta del lenguaje de los biólogos evolutivos. Desde el punto de vista de estos filósofos, los conceptos comúnmente usados para referirse a procesos evolutivos — como selección, deriva, migración etc.no se refieren a causas, sino que son solamente artefactos estadísticos. La única cosa que propiamente "existe" son individuos naciendo, interactuando de cierta manera, teniendo una mayor o menor descendencia y, finalmente, muriendo. Solo en ese nivel hay relaciones causales. El problema es que sería imposible, para un biólogo evolutivo, rastrear cada uno de estos individuos, dentro de una población y por varias generaciones, para entender como la composición de la población cambia. Es aquí donde intervienen los conceptos de selección, deriva etc.: ellos funcionan como instrumentos para "mantener la cuenta" de los nacimientos, reproducciones y muertes y, de esa manera, hacernos entender mejor las causas del cambio evolutivo. Sin embargo, estos conceptos no denotan ningún proceso "real", son constructos resultantes de la teoría; un poco como la "expectativa de vida" de la que hablan las aseguradoras.

Ahora, independientemente de las simpatías de cada uno, lo que en realidad está en cuestión en el debate entre causalistas y estadisticalistas - como ha notado justamente Glennan (2008) - son dos diferentes nociones de causa. Por un lado, los causalistas hacen referencia a una noción de causa como relevancia causal; por el otro, los estadisticalistas se refieren a una noción de causa como producción. La noción de relevancia causal (como es discutida, por ejemplo, en Woodward 2003) tiene que ver con la idea de que una causa es un difference maker, es decir, un evento o una propiedad que, de haber sido diferente, el efecto también habría sido diferente. En ese sentido, cuando un biólogo dice 
que la predominancia de una cierta variante mimética en una población de polillas es debida a la presión selectiva creada por las fábricas contaminantes limítrofes a su hábitat (como en el célebre caso de Biston betularia), expresándose así en términos causales poblacionales, lo que quiere decir es lo siguiente: ceteris paribus, si no hubiese habido fábricas contaminantes, las frecuencias de variantes se habrían mantenido constantes. Esa manera de referirse a causas, correcta y común en las ciencias especiales, no excluye otro uso de la noción de causa como producción (derivado de Salmon 1998; Dowe 2000), que hace referencia a las circunstancias individuales que han realizado y hecho posible el proceso poblacional.

De mi punto de vista, el énfasis puesto por los epidemiólogos culturales sobre el aspecto agregativo de las dinámicas culturales, si bien puede enriquecer conceptualmente la teoría de la evolución cultural, no pasa de tener un valor principalmente filosófico, similar a aquel de la interpretación estadisticalista de la biología evolutiva. Tanto los estadisticalistas como los parisinos son escépticos con respecto a la posibilidad de concebir procesos poblacionales de cambio evolutivo como dotados de características causales propias. Ambos sostienen la necesidad, para una caracterización más naturalísticamente aceptable de los procesos evolutivos, de descargar el peso de la descripción causal de tales procesos sobre los individuos que los realizan. Sin embargo, puede argumentarse, en contra de los parisinos, que su perspectiva, al igual que la de los estadisticalistas, es compatible con aquella de los que atribuyen un papel causal a los procesos evolutivos en el nivel de las poblaciones. Así como el desacuerdo entre causalistas y estatisticalistas puede ser imputado a diferentes interpretaciones — ambas absolutamente legítimas - de las nociones causales involucradas en la caracterización de los procesos evolutivos, algo análogo podría decirse con relación al desacuerdo entre parisinos y californianos.

Dicho esto, la cosa aquí más importante es que, tanto en el caso del debate causalistas/ estadisticalistas como en el presente caso, los científicos llamados a construir modelos evolutivos pueden tranquilamente ignorar la cuestión. Esta no influye directamente sobre cómo los modelos son construidos: es "empíricamente opaca", por decirlo de alguna manera. Claramente, los modelistas pueden elegir estrategias más agregativas o, alternativamente, centradas en propiedades de poblaciones (Illari y Russo 2014, cap. 5). Pero eso no implica la adopción, por parte de los modelistas, de presupuestos ontológicamente profundos sobre donde las causas de los procesos evolutivas están "realmente". En la practica, la elección de un modelo "realista" con respecto a causas al nivel de poblaciones, derivado de la genética de poblaciones, u otro "deflacionario", derivado de la epidemiología, depende de consideraciones instrumentales, similares a aquellas discutidas en la sección anterior. De hecho, en el contexto de la teoría de la evolución cultural, trabajos como el realizado por El Mouden et al. (2014), elaborado por autores cercanos a la epidemiología cultural, o incluso el proto-modelo de las matrices causales del que ya hemos hablado previamente (Claidière et al. 2014) podrían haber sido realizados por teóricos de la doble herencia. 
Para poder soportar las pretensiones de secesión de la teoría de la doble herencia, los epidemiólogos culturales deberían presentar evidencia de que los diferentes mecanismos de transmisión cultural postulados por las dos teorías tienen efectos poblacionales diferentes; $\mathrm{o}$, mejor aún, que las dinámicas evolutivas culturales reales pueden ser descritas y explicadas por el arsenal teórico de la epidemiología cultural, pero no con el de la teoría de la doble herencia. Desafortunadamente para ellos, no creo que los epidemiólogos culturales hayan conseguido hacer eso. En parte eso se debe, sin duda, al hecho de que más allá del énfasis sobre la analogía con la epidemiología y sobre la teoría de los atractores, muy pocos modelos matemáticos han empleado operacionalmente estos conceptos como admitido por los mismos epidemiólogos culturales- (Scott-Phillips et al. 2018, 171). Sin modelos de este tipo, es difícil corroborar si las consecuencias poblacionales previstas por la teoría epidemiológica son o no compatibles con las previstas por la teoría de la doble herencia. Más allá de eso, sin embargo, sospecho que hay una dificultad de principio en la realización de las ambiciones de los parisinos. Aunque estos estén en lo cierto con respecto a los mecanismos de transmisión cultural, dudo - por las razones esbozadas en la sección anterior- de que una teoría análoga a la genética de poblaciones como es la teoría de la doble herencia sería incapaz de adaptarse para dar cuenta de las consecuencias poblacionales de tales mecanismos de transmisión.

\section{Conclusión}

A lo largo de este artículo, mi objetivo ha sido el de mostrar que las dos principales propuestas teóricas en el contexto de los estudios sobre evolución cultural, esto es, la teoría de la doble herencia y la epidemiología cultural, son más compatibles de lo que a los epidemiólogos culturales les gustaría admitir. Mi argumento ha sido básicamente el siguiente. Dos tipos de consideración podrían justificar la interpretación de la teoría de la doble herencia y la epidemiología cultural como teorías por lo menos parcialmente incompatibles. El primero es de carácter formal. Por un lado, la teoría de la doble herencia se basa, en buena medida, sobre una analogía con la genética de poblaciones y emplea modelos derivados de esa disciplina. Por el otro, la epidemiología cultural (como el mismo nombre deja claro) se inspira en una analogía con la epidemiología. Si, por lo tanto, resultase que la genética de poblaciones y la epidemiología son teorías en cierto grado incompatibles, eso podría tener consecuencias también en el contexto de la teoría de la evolución cultural. Sin embargo, he mostrado en la sección 4 que ese no es el caso. La genética de poblaciones y la epidemiología son teorías formalmente compatibles, y hasta complementarias en algunas de sus aplicaciones.

El segundo aspecto que podría justificar una nítida demarcación entre epidemiología cultural y teoría de la doble herencia es de carácter causal. Las analogías con la epidemiología y con la genética de poblaciones parecen soportar dos distintas concepciones de la estructura causal de las dinámicas poblacionales: meramente agregativa en el caso de la

Revista de Humanidades de Valparaíso, 2019, No 14, 223-240 
epidemiología y realista con respecto a causas sobre-individuales en el caso de la genética de poblaciones. Si bien esta caracterización de diferentes concepciones de la estructura causal de las dinámicas poblacionales revela un rasgo genuino de la controversia entre epidemiólogos culturales y teóricos de la doble herencia, he argumentado en la sección 5 que se trata de una divergencia más filosófica que científica (esto es, relacionada con explicaciones o predicciones empíricamente testables).

Para concluir, me gustaría aclarar que mi argumento no tiene, en absoluto, el objetivo de disminuir el valor de los trabajos realizados en el contexto de la tradición epidemiológica. Por el contrario, es justamente porque creo que estos trabajos contribuyen, con una perspectiva original, al entendimiento de las dinámicas de acumulación y cambio cultural que insisto sobre la necesidad de integrarlos con los trabajos realizados por los teóricos de la doble herencia. Como Scott-Phillips y sus colaboradores reconocen:

un foco excesivo sobre el contraste entre estos enfoques sería contraproductivo. Hay un equilibrio a ser alcanzado aquí, entre la elucidación de genuinos malentendidos por un lado, y, por el otro, la apariencia de una pelea miope entre especialistas - una consecuencia que deseamos evitar. $(2018,168)$

En la práctica, sin embargo, esa consecuencia no siempre se ha conseguido evitar. No queda que esperar que, en futuro, haya mayor entendimiento y colaboración.

\section{Agradecimientos}

Esta investigación ha sido financiada por el Conselho Nacional de Desenvolvimento Científico e Tecnológico de Brasil (CNPq - beca $n^{\circ}$ 402619/2016-1) y por el Fondo Nacional de Desarrollo Científico y Tecnológico de Chile (FONDECYT REGULAR - beca $\left.n^{\circ} 1171017\right)$.

\section{Referencias bibliográficas}

Acerbi, A., Mesoudi, A. (2015). If we are all cultural Darwinians what's the fuss about? Clarifying recent disagreements in the field of cultural evolution. Biology \& Philosophy, 30(4): 481503. doi: 10.1007/s10539-015-9490-2

Aunger, R. (2001). Introduction. En R. Aunger (ed.), Darwinizing culture: The status of Memetics as a science, pp. 1-23. Oxford: Oxford University Press.

Baravalle, L. (2019). Cultural evolutionary theory as a theory of forces. Synthese, online-first. doi: $10.1007 / \mathrm{s} 11229-019-02247-0$

Boyd, R., Richerson, P. (1985). Culture and the evolutionary process. Chicago: The University of Chicago Press. 
Buskell, A. (2017a). What are cultural attractors? Biology \& Philosophy, 32(3): 377-394. doi: $10.1007 / \mathrm{s} 10539-017-9570-6$

Buskell, A. (2017b). Cultural Attractor Theory and explanation. Philosophy, Theory, and Practice in Biology, 13(9). doi: 10.3998/ptb.6959004.0009.013

Cavalli-Sforza, L. L., Feldman, M. (1981). Cultural Transmission and Evolution: a Quantitative Approach. Princeton (NJ): Princeton University Press.

Claidière, N., Scott-Phillips, T. C., Sperber, D. (2014). How Darwinian is Cultural Evolution? Philosophical Transactions of the Royal Society B, 369. doi: 10.1098/rstb.2013.0368

Dowe, Phil (2000). Physical Causation. Cambridge: Cambridge University Press.

El Mouden, C., André, J.-B., Morin, O., Nettle, D. (2014). Cultural transmission and the evolution of human behaviour: a general approach based on the Price equation. Journal of Evolutionary Biology, 27: 231-241. doi: 10.1111/jeb.12296

Glennan, S. (2008). Productivity, relevance and natural selection. Biology \& Philosophy, 24: 32539. doi: 10.1007/s10539-008-9137-7

Illari, P., Russo, F. (2014). Causality. Philosophical Theory meets Scientific Practice. Oxford: Oxford University Press.

Kendal, R. L., Boogert, N. J., Rendell, L., Laland, K. N., Webster, M., Jones, P. L. (2018). Social learning strategies: Bridge-building between fields. Trends in Cognitive Science, 22(7): P651-P665. doi: 10.1016/j.tics.2018.04.003

Matthen, M., Ariew, A. (2002). Two Ways of Thinking about Fitness and Natural Selection. Journal of Philosophy, 99(2): 55-83. doi: 10.2307/3655552

Mesoudi, A. (2011). Cultural Evolution: How Darwinian Theory Can Explain Human Culture and Synthesize the Social Sciences. Chicago: The University of Chicago Press.

Millstein, R. (2006). Natural Selection as a population-level causal process. British Journal for the Philosophy of Science, 57(4): 627-53. URL: www.jstor.org/stable/4489089

Morin, O. (2016a). Reasons to be fussy about cultural evolution. Biology \& Philosophy, 31: 44758. doi: 10.1007/s10539-016-9516-4

Morin, O. (2016b). How traditions live and die. Oxford: Oxford University Press.

Peterson, S., Viney, M. E. (2000). The interface between epidemiology and population genetics. Parasitology today, 16(12): 528-532. doi: 10.1016/S0169-4758(00)01776-2

Richerson, P. J. (2017). Recent critiques of dual inheritance theory. ESIC, 1, 203-11. URL: http:// www.des.ucdavis.edu/faculty/Richerson/Morin\%20Lewens\%20formatted\%20final.pdf

Richerson, P., Boyd, R. (2005). Not by Genes Alone: How Culture Transformed Human Evolution. Chicago: The University of Chicago Press.

Salmon, W. (1998). Causality and explanation. Oxford: Oxford University Press. 
Scott-Phillips, T., Blancke, S., Heintz, C. (2018). Four misunderstandings about cultural attraction. Evolutionary Anthropology, 27: 162-73. doi: 10.1002/evan.21716

Shapiro, L., Sober, E. (2005). Epiphenomenalism - The Do's and the Don'ts. En G. Wolters, P. Machamer (eds.), Thinking about causes: From greek philosophy to modern physics, pp. 235-264. Pittsburg: University of Pittsburg Press.

Sober, E. (1980). Evolution, population thinking, and essentialism. Philosophy of Science, 47(3): 350-383. URL: http://www.jstor.org/stable/186950

Sober, E. (1984). The Nature of Selection. Chicago: The Chicago University Press.

Sperber, D. (1996). Explaining culture. A naturalistic approach. Oxford: Blackwell.

Sperber, D. (2001). An Objection to the memetic approach to Culture. En R. Aunger (ed.) Darwinizing culture: The status of Memetics as a science, pp. 163-174. Oxford: Oxford University Press.

Sperber, D., Claidière, N. (2008). Defining and explaining culture (comments on Richerson and Boyd, Not by genes alone). Biology \& Philosophy, 23: 283-292. URL: http://www. dan.sperber.fr/wp-content/uploads/2008/09/NotByGenesAloneCommentary-SperberClaidiere.pdf

Sterelny, K. (2017). Cultural evolution in California and Paris. Studies in History and Philosophy of Biology and Biomedical Sciences, 62: 42-50. doi: 10.1016/j.shpsc.2016.12.005

Tooby, J., Cosmides, L. (1992). The Psychological Foundations of Culture. En J. Barkow, L. Cosmides, J. Tooby (eds.), The Adapted Mind: Evolutionary Psychology and the Generation of Culture, pp. 19-136. New York: Oxford University Press.

Walsh, D., Lewens T., Ariew A. (2002). The trials of life: Natural selection and random drift. Philosophy of Science, 69(3): 452-73. doi: 10.1086/342454

Woodward, J. (2003). Making things happen. A theory of causal explanation. Oxford: Oxford University Press. 


\title{
Una discusión en torno a los límites del concepto especie
}

\author{
A discussion about the limits of the species concept
}

\author{
Mariano Martín Villuendas \\ Universidad de Salamanca, España \\ mariano-zgz@hotmail.com
}

\begin{abstract}
Resumen
El dilema conceptual que envuelve a las especies ha dividido, desde su misma formulación, a los biólogos y filósofos en dos grandes sectores: aquellos que creen en la existencia de una categoría unificada de especie y aquellos que abogan por una pluralidad irreductible de conceptos igualmente legítimos. El objetivo del presente trabajo consistirá en analizar los problemas que rodean a la categoría especie con la única finalidad de determinar si existe una definición unívoca e irrestricta de especie. Para ello, se estructurará el trabajo en dos grandes secciones. En la primera sección se analizará en qué medida el esencialismo constituye una teoría antitética a la moderna teoría biológica. En la segunda sección se llevará a cabo una crítica detallada de los diversos conceptos propuestos de especie. De estas consideraciones se concluirán dos hechos. En primer lugar, consecuencia del derrumbe del esencialismo, que no existe una tal categoría especie sino una pluralidad irreductible de conceptos. En segundo lugar, consecuencia de la afirmación anterior, que la actitud más consecuente con la teoría de la evolución es la de abrazar un pluralismo ontológico y, por ende, un pluralismo taxonómico.
\end{abstract}

Palabras clave: taxonomía, evolución, taxón especie, categoría especie, pluralismo.

\begin{abstract}
The conceptual dilemma that species entail has divided, since its formulation, biologists and philosophers in two spheres: those who believe in the existence of a unified category of species and those who defend the unyielding plurality of equally legitimate concepts. The aim of this paper is to comprise the analysis of the problems that revolve around the species category with the only purpose being to determine the existence of only
\end{abstract}

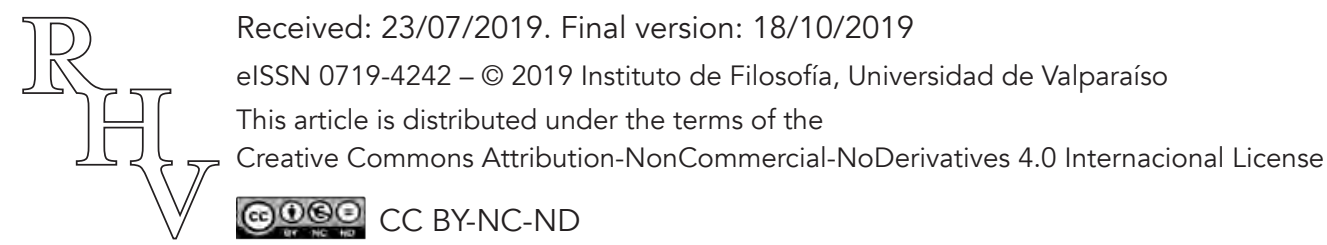


Una discusión en torno a los límites del concepto especie

Mariano Martín Villuendas

one univocal and unrestricted definition of species. For this reason, the paper will be divided into two sections. The first section will analyse the extent to which essentialism amounts to an antithetical theory to the modern biological theory. In the second section a detailed critique will be carried out on existing attempts to devise a definition of species. Two conclusions can be drawn from the previous statements. First and due to the fall of essentialism, that there is not only one single category of species but an uncompromising plurality of concepts. Secondly and following previous assertion, it can be stated that the most consistent viewpoint in the evolutionary theory is the one in which an ontological pluralism is embraced and, consequently, a taxonomical pluralism.

Keywords: taxonomy, evolution, species taxon, species category, pluralism.

\section{Introducción}

El profundo dilema conceptual y ontológico que subyace a la consideración de las especies ha sido una constante que ha llegado de forma intacta hasta nuestros días (Wilkins 2009). Si bien es cierto que este problema ha ido modificándose a lo largo de los años a consecuencia de las múltiples investigaciones llevadas a cabo en los diversos ámbitos de la biología, no es menos cierto que este interrogante sigue en la actualidad más vigente que nunca. La llegada del darwinismo y el consiguiente desarrollo del pensamiento poblacional ocasionó una redefinición en los términos en los cuales se debía definir a las mismas. Este hecho provocó, de forma indirecta, que el problema de las especies adquiriese su verdadera dimensión y significación. El motivo es claro: las especies ya no constituían el resultado de una simple creación divina, estas eran sencillamente el producto de la evolución por medio de la selección natural. Surgía así la tarea de tratar de encontrar cuáles eran los términos en los que debíamos definir a las especies, tarea de la que dependía la legibilidad de disciplinas tan fundamentales como la taxonomía.

El objetivo del presente trabajo consistirá en examinar el problema que envuelve a la categoría especie con la única finalidad de responder a la pregunta de si es posible aportar una definición unívoca y definitiva de especie. Para llevar a cabo esta tarea se dividirá el trabajo en tres secciones. En la primera sección se examinará cuáles son los principales motivos por los que es necesario abordar el problema que rodea a las especies. En la explicitación de tales motivos se revelará el aspecto eminentemente multidisciplinar que rodea a esta problemática. En la segunda sección se delineará en qué medida el esencialismo constituye una posición antitética a la moderna teoría biológica. En la tercera sección se abordará propiamente el problema de las especies usando como telón de fondo las consideraciones esbozadas hasta ese momento. Para ello, se analizarán los diversos conceptos de especie propuestos desde la biología, entreviendo su alcance y limitación. Esto

Revista de Humanidades de Valparaíso, 2019, No 14, 241-273

(ㄷ)(1)(8) CC BY-NC-ND 
permitirá concluir la necesidad de suspender el intento de aportar una definición unívoca de la categoría especie alzando la posibilidad de considerar una aproximación pluralista como la mejor forma de dar cuenta de la complejidad que rodea al mundo orgánico.

\section{2. ¿Por qué las especies?}

Existen numerosas razones para abordar el problema de las especies, razones que no han pasado desapercibidas a lo largo de los diversos debates en torno a la filosofía de la biología. Puesto que una consideración detallada de cada una de ellas llevaría la discusión demasiado lejos, aquí se señalarán únicamente tres motivos por los cuales resulta obligado tratar de arrojar luz a esta problemática.

\subsection{El problema de las especies en la historia}

Las especies han estado presentes en el centro de la discusión biológica ya desde Carl von Linné, empero podríamos rastrear su recorrido incluso hasta el mismo Aristóteles. El pensamiento predarwiniano consideraba que las especies se hallaban definidas por unas esencias intrínsecas, motivo por el cual la labor del biólogo debía consistir únicamente en tratar de descubrir dichas esencias. Esta situación cambio de forma drástica con la llegada del pensamiento de Darwin produciéndose, de esta forma, una profunda revolución conceptual. En El origen de las especies Darwin afirmó que las especies ya no constituían el resultado de una simple creación divina, tal y como Linné pensó, sino que estas eran el producto de la evolución por medio de la selección natural. Esto significaba, en última medida, que las diversas especies constituían entidades históricas con límites difusos.

El problema de las especies adquiría, de esta forma, su verdadero significado. ¿Por qué motivo? Tras el derrumbe del esencialismo, la identificación de las especies y, más aún, la definición de la propia categoría especie se tornaba en suma manera complicada y problemática. ¿Qué estatuto tenían las especies ahora? ¿Cuáles eran sus características definitorias? ¿Qué las diferenciaba de rangos como las familias o los géneros? Surgía de esta forma el problema de la categoría y del taxón especie. El problema de la categoría especie remite sencillamente al intento de lograr un concepto universal, un concepto que marque de forma perspicua cuál es exactamente la definición de especie. El problema del taxón especie hace referencia al problema de cómo identificar las diversas especies que pueblan el mundo. Este problema no es espurio, pues tal y como dice Richard Mayden (2002, 174): "It is impossible to predict the type and degree of character modification that will result from a speciation event. Thus, 'species characters' naturally do not exist any more than do characters for genera, families, orders, etc". Ya no existía una única forma incontrovertible de identificar a las diversas especies: "The plethora of ways in which 
different workers want to use the species category reflects an underlying plethora of valid ways of looking at biological diversity" (Mishler 1999, 307). Pero ¿por qué motivo es preciso clarificar este dilema conceptual?

Una posible respuesta podría ser porque las especies constituyen la unidad fundamental de disciplinas tan relevantes como la biología evolutiva, la ecología o la genética. Es a partir de la publicación de El Origen de las especies cuando estas fueron reconocidas como las unidades básicas de la evolución, pues eran ellas las que participaban de forma directa del proceso evolutivo. Tratar de comprender la diversidad y heterogeneidad del mundo orgánico sin apelar a las especies constituía una tarea condenada desde un principio al fracaso, pues eran ellas mismas las causantes de dicha heterogeneidad. Asimismo, resulta imposible lograr una comprensión plena del funcionamiento de un determinado ecosistema sin diseccionar las especies constituyentes del mismo, así como las relaciones que estas mantienen entre sí (Mayr 1982, 296). Incluso desde el punto de vista genético las especies constituyen una unidad de estudio fundamental, pues ya el pensamiento poblacional reconoció en su día la existencia de cierta unicidad en el programa genético de las mismas. Es por estas múltiples razones por las que Ernst Mayr afirma: "The species is the principal unit of evolution and it is impossible to write about evolution, and indeed about almost any aspect of the philosophy of biology, without having a sound understanding of the meaning of biological species" (Mayr 1996, 262). Sin embargo, el gran problema es que, como dice Jody Hey $(2001,326)$ : "Darwin killed species essentialism, but in so doing, he fostered rather than settled questions about what species really are".

\subsection{El problema de la categoría especie en la práctica taxonómica}

En segundo lugar, y en estrecha relación con lo mencionado anteriormente, se revela de extremada importancia clarificar el problema de la categoría especie debido a que este problema afecta a nuestro entendimiento de la disciplina taxonómica: "The clarification of the species concept has led to a clarification of many evolutionary problems as well as, often, to a simplification of practical problems in taxonomy" (Mayr 1963, 19). Si aceptamos, por ejemplo, que existe una única definición clara y perspicua de lo que es la especie y que existe, por tanto, una forma precisa de identificarlas, entonces nos veremos inclinados hacia una suerte de monismo taxonómico y, por tanto, hacia un monismo metafísico. El monismo metafísico alegaría, en pocas palabras, que el mundo se halla dividido y fragmentado de forma natural de una determinada manera. Si solo existe una división natural entonces el objetivo del científico solo puede consistir en tratar de desvelar cómo está organizado y delineado el mundo generando, de esta forma, clasificaciones y definiciones que sean capaces de reflejar la naturaleza misma del mundo. Esta sería la posición que habrían tomado personajes como John Locke, Carl von Linné, Hilary Putnam o Saul Kripke. Sin embargo, si quisiésemos ser más precisos, adjuntaríamos a estos autores la etiqueta de realistas taxonómicos (Dupré 1993, 27). ¿Por qué motivo?

Revista de Humanidades de Valparaíso, 2019, No 14, 241-273

(ㄷ)(1)(8) CC BY-NC-ND 
Sencillamente porque se puede ser monista taxonómico sin por ello ser un esencialista. El mismo Michael Ghiselin, defensor de la tesis de la individualidad y por ello detractor del esencialismo, es un claro defensor del monismo metafísico, eso sí, desde una perspectiva histórica (Ereshefsky 2001, 40).

El realista taxonómico nos diría que existen reglas y clasificaciones claras universalmente aceptadas por todos sencillamente porque los organismos se hallan delimitados de forma natural por unas esencias intrínsecas, esencias que marcan la partición de los organismos en los diversos taxones. El mismo número de niveles taxonómicos se hallaría, de esta manera, implícito en la propia naturaleza. Si por el contrario consideramos que existen diversas formas de dividir el mundo puesto que existen múltiples procesos o fuerzas evolutivas capaces de segmentar el árbol de la vida de muy diferentes maneras entonces estaremos optando por un pluralismo taxonómico y, quizás, por un pluralismo metafísico, pues es posible ser pluralista taxonómico y monista metafísico. Este sería el caso de los autores Mishler y Donoghue (1983) y Mishler y Brandon (1987).

Estos autores reconocen que la variabilidad ecológica, morfológica e incluso genética dentro de cada una de las especies es enorme. Existen múltiples discontinuidades en cada uno de los aspectos característicos de las especies, discontinuidades que nos impedirían establecer una única clasificación distintiva y arquetípica. Reconocer un pluralismo metafísico implicaría, por tanto, aceptar que no existe un único concepto de especie ya que cada uno de los diversos conceptos propuestos captaría una de las posibles divisiones del mundo natural. No existe ninguna razón, nos diría el pluralista metafísico, que nos lleve a creer que la evolución nos ha provisto de un único sistema clasificatorio privilegiado pues constituye un hecho demostrado ya desde el pensamiento poblacional que la variabilidad natural es sumamente significativa. Sería esta diversidad y complejidad orgánica así como las múltiples fuerzas que tallan el árbol de la vida-flujo genético, selección u homeostásis genética- la que nos impediría dar con un parámetro capaz de reducir todos los conceptos a uno solo, la que nos impediría generar una única clasificación arquetípica. El objetivo del presente trabajo consistirá en defender la pertinencia de ambas tesis, pertinencia que ya han tratado de mostrar filósofos de la biología como John Dupré o Marc Ereshefsky.

\subsection{El renacimiento del esencialismo}

La última razón por la que constituye un hecho obligado acercarse al problema de las especies se debe al renacimiento que ha experimentado, en los últimos años, el esencialismo dentro de la práctica biológica. Debido a la enorme confusión conceptual generada en torno al problema de las especies, y más específicamente en torno al problema de la categoría especie, reconocidos filósofos de la biología han apostado por recoger los presupuestos más fundamentales del esencialismo compaginándolos, eso sí, con la moderna disciplina biológica. Este ha sido el caso de filósofos como Richard Boyd y su teoría de los tipos homeostáticos (Boyd 1999). Sin embargo, uno de los apologetas más fervientes

Revista de Humanidades de Valparaíso, 2019, No 14, 241-273

(ㄷ)(1)(8) CC BY-NC-ND 
de la vuelta al esencialismo ha sido el filósofo Michael Devitt (2008). Para Devitt la necesidad de reavivar el esencialismo es clara. Hacemos constantes generalizaciones en torno a las especies, generalizaciones que involucran aspectos concernientes a la morfología, fisiología, comportamiento o composición genética de las diversas especies.

La cuestión central es que estas generalizaciones precisan de una explicación que nos permita responder a la pregunta de por qué motivo estas generalizaciones deben ser verdaderas. A juicio de Devitt, esa explicación debe estar necesariamente relacionada con la naturaleza esencial de cada especie particular. Las múltiples similitudes de los diversos miembros de una especie se explican por la naturaleza intrínseca que subyace al propio grupo, se explican por su esencia. Existe algo intrínseco al grupo, dice Devitt, algo en virtud de lo cual esas cosas son como son y no son de otra manera. Este es el principal motivo por el que conceptos tan fundamentales dentro de la práctica taxonómica como el concepto biológico o ecológico de especie deben considerar al esencialismo como su acompañante privilegiado pues, de lo contrario, estos conceptos se verían impotentes a la hora de dar una respuesta satisfactoria al problema de la categoría especie. La razón es clara para Devitt. Si bien estos conceptos afirman que ser miembro de una especie consiste en, por poner un ejemplo, pertenecer a una comunidad reproductiva, lo que no nos dicen es en virtud de qué esos individuos forman parte de dicha comunidad reproductiva. No nos dicen, en definitiva, en virtud de qué se da dicha conspecificidad. Estos conceptos explican cómo se puede identificar la membresía a una especie pero se ven impotentes a la hora de explicar por qué se da dicha membresía. Desde esta perspectiva, el esencialismo constituye el complemento perfecto pues, por su propia naturaleza, lleva aparejado la respuesta al porqué de la conspecificidad. Si los individuos pertenecen a una especie concreta esto se debe a que comparten ciertas propiedades intrínsecas.

\section{Esencialismo y darwinismo. ¿Por qué ya no podemos sostener el esencialismo?}

\subsection{La doctrina de los tipos naturales}

Fue John Stuart Mill el primer autor que hizo un empleo explícito de la palabra tipo (Kind) en 1843. No obstante, fue John Venn quien, en 1866, empleó la denominación que actualmente conocemos, tipo natural (Natural Kind). A pesar de que el uso de la palabra tipo natural se remonta al siglo XIX, podríamos rastrear la idea fundamental que subyace

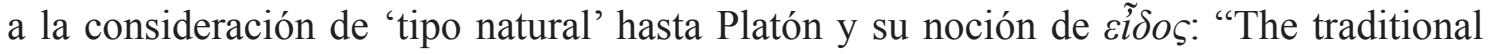
species concept going back to Plato's eidos is often referred to as the Typological Species Concept" (Mayr 2000, 18).

Pues bien, ¿qué es eso de 'tipo natural'? Los tipos naturales constituyen clases de objetos que se definen por la posesión de una propiedad o propiedades esenciales, generalmente microestructurales (Dupré 1981, 67). De esta manera las entidades pertenecientes a un tipo se parecerían de forma no accidental ya que estas compartirían una suerte de 
propiedades esenciales comunes y necesarias, propiedades que servían, a su vez, para declarar la membresía al tipo en cuestión. De esta manera se podría decir que los tipos naturales se hallan individuados por sus esencias, motivo por el cual estos dispondrían de una definición clara y precisa. Acudimos, de esta forma, a la caracterización del ya famoso concepto tipológico de especie. Este concepto consideraría a la especie como un agregado de organismos poseedores de un conjunto de propiedades esenciales (Mayr 1987, 148). La posesión de esas propiedades esenciales se vería como la condición necesaria y suficiente para que los diversos miembros del tipo fuesen lo que son y perteneciesen al tipo al que pertenecen. Ahora bien, ¿qué es eso de la esencia? La esencia consistiría en ese conjunto de propiedades intrínsecas y definitorias del tipo: "According to the traditional notion of definition, class terms are defined by sets of traits which are severally necesary and jointly sufficent for membership in the class" (Hull 1976, 178). Esas esencias, por definición, deben ser inmutables pues si estas tuviesen la potestad de modificarse entonces el individuo ya no sería lo que es, este sencillamente cambiaría y se convertiría en otra cosa diferente (Ereshefsky 2001, 97). Esto haría que la suma de variación autorizada por el esencialismo fuese mínima pues las especies, por definición, deben permanecer constantes a través del tiempo ${ }^{1}$.

Este concepto tipológico podría identificarse con el concepto esencialista de especie, un concepto que vería a los diversos organismos como manifestaciones o instanciaciones de un mismo eidos: "It was referred to as the typological species concept, which treats species as random aggregates of individuals that have in common the essential properties of the type of the species" (Mayr 1987, 148). Vemos ahora de qué manera esencialismo y tipologismo se relacionan. Cuando se describe la esencia lo que se está describiendo, en última medida, es el tipo, o mejor aún, las propiedades que hacen del tipo lo que es (Dupré 1993, 65). La cuestión esencial es, ¿cómo podemos identificar esa esencia? La esencia se identificaría por medio de la similitud morfológica general. Es precisamente por este motivo por el cual Mayr (1982) ha asociado el pensamiento tipológico al pensamiento morfológico. Esta perspectiva ontológica, como no puede ser de otra manera, condiciona en gran medida la práctica biológica pues si el biólogo asume esta visión del mundo entonces su objetivo no puede consistir más que en tratar de descubrir los diversos tipos naturales, tipos delineados por sus esencias. Vemos, por tanto, la prescripción metodológica que lleva aparejado el esencialismo: el científico debe construir clasificaciones que estructuren a las diversas entidades naturales de acuerdo a su esencia ${ }^{2}$. Es necesario

\footnotetext{
${ }^{1}$ Este es el motivo por el que se ha relacionado el concepto tipológico con las clases. Las clases no tendrían limitación en el espacio ni en el tiempo, motivo por el cual no podrían entender a las especies como entidades genealógicas.

${ }^{2}$ Linné sería el perfecto ejemplo. Linné tejió su sistema taxonómico empleando el creacionismo y el esencialismo como herramientas.
}

Revista de Humanidades de Valparaíso, 2019, No 14, 241-273 
Una discusión en torno a los límites del concepto especie

Mariano Martín Villuendas

reseñar una última característica fundamental del tipologismo. La condición de membresía al tipo, lo que se ha denominado como propiedades esenciales, es fundamentalmente explicativa:

The key idea, I think, is that the membership condition must be explanatory. The essentialist hypothesizes that there exists some characteristic unique to and shared by all members of Homo sapiens which explains why they are the way they are. A species essence will be a causal mechanism which works on each member of the species, making it the kind of thing that it is. (Sober 1980, 354)

\subsection{Darwin y el nacimiento del pensamiento poblacional}

La publicación de El Origen de las especies y la consiguiente difusión de sus planteamientos generó una profunda revolución conceptual dentro de la disciplina biológica. Pero ¿por qué motivo? Sencillamente por dos razones. En primer lugar, El Origen de las especies dejaba entrever que las especies ya no constituían el producto de la creación divina tal y como Linné pensó, estas eran el simple resultado de la evolución por medio de la selección natural. Esta idea atentaba contra el núcleo duro del creacionismo. Asimismo, Darwin dibujó una consecuencia secundaria de este planteamiento. Las especies ya no constituían entidades estáticas, motivo por el cual estas no disponían de unas esencias atemporales e inmutables. La razón era clara para Darwin, las especies debían ser entidades que evolucionaban, entidades sometidas al cambio. Sobre estas dos bases levantó Darwin la nueva y revolucionaria teoría de la evolución por medio de la selección natural. La cuestión fundamental es que para que la selección pudiese actuar y para que, en última instancia, se pudiese producir la evolución, era preciso que se diese la variación. Además, se exigía que la variación fuese transmisible hereditariamente pues, de lo contrario, las múltiples diferencias no se podrían acumular y no se podría originar la evolución. Esta idea requería, por tanto, que las especies estuviesen conectadas causalmente entre sí, constituyendo entidades genealógicas.

A eso se le sumaba que la evolución fomentaba una amplia variedad y diversidad tanto morfológica como genética dentro de cada especie. Esto hacía que los miembros de las diversas especies mostrasen una amplia divergencia intraespecífica tanto fenotípica como genotípica (Ruse 1987, 229). De esta manera, la teoría de Darwin atentaba directamente contra el núcleo del esencialismo. ¿Por qué motivo? En primer lugar, ya no existían las esencias. En segundo lugar, las especies evolucionaban. En tercer lugar, para que las especies pudiesen evolucionar era necesario que se diese la variación, la desviación del tipo, lo cual hacía que las especies constituyesen entidades históricas y no clases espaciotemporalmente irrestrictas. En cuarto lugar, debido al motivo anterior, existía una amplia divergencia intraespecífica (Mayr 1963, 22).

Revista de Humanidades de Valparaíso, 2019, No 14, 241-273

(ㄷ)(1)(8) CC BY-NC-ND 
Este programa de investigación sufrió un revulsivo con la llegada del pensamiento poblacional, disciplina que permitió unir los logros del mendelismo con las ideas centrales de Darwin en torno a la evolución. El pensamiento poblacional tenía como premisa fundamental que el estudio de las especies se debía llevar a cabo por medio de las poblaciones y no por medio de los tipos. Las especies ya no consistían en tipos naturales con esencias fijas sino en poblaciones consistentes en una colección heterogénea de individuos cuyas frecuencias alélicas iban modificándose con el tiempo a causa de diferentes procesos biológicos: deriva genética, mutación, migración o selección. Esto obligaba a definir a las especies por medio de propiedades relacionales y no ya por medio de propiedades intrínsecas. Los principales motivos por los que la aceptación del pensamiento poblacional condujo al abandono del esencialismo y del tipologismo fueron los siguientes:

1. En primer lugar, porque existe una amplia variación fenotípica intraespecífica ${ }^{3}$. El genotipo se despliega siempre de acuerdo a un ambiente específico. ¿Qué ocurre si se modifica el ambiente? Que la expresión fenotípica se modifica. Esto es algo que mostraron en 1948 Clausen, Keck y Hiesey a través del experimento llevado a cabo con la especie Achillea millefolium (Lewontin 2000, 28). Este experimento demostró cómo una misma especie era capaz de desplegar fenotipos divergentes en función de las condiciones ambientales en las que esta se veía inmersa.

2. En segundo lugar, se podría argüir que la variación fenotípica es irrelevante pues la esencia real reside en el material genético. La cuestión central es que ningún individuo posee el mismo genotipo que otro. Si bien distintos individuos pueden concordar en el $80 \%$ e incluso $90 \%$ de su material genético jamás podremos encontrar dos individuos que compartan el $100 \%$ de dicho material genético. La razón es clara, cada genotipo es el producto de la contribución específica de los progenitores. Incluso en el hipotético caso de que los miembros de una especie compartiesen ciertas características, estas de ningún modo podrían ser declaradas como esenciales pues podrían modificarse a través de numerosos procesos biológicos como la deriva meiótica, las mutaciones, la deriva genética o la recombinación genética. Propiedad común no es equivalente, por tanto, a propiedad esencial y esto es algo que hay que tener presente. El tipologista requiere de una esencia inmutable, incambiada, el problema es que, como se ha visto, lo que es propio para una especie en un determinado momento puede dejar de serlo en otro. A esto se le suma el hecho de que la variación genética es, de por sí, enorme. Se podrían señalar tres ideas que refrendan tal aserción. En primer lugar, existe una enorme reserva de variación genética. Es precisamente esta reserva la que permite a los individuos estar adaptados a una amplia variedad de ambientes divergentes (Mayr 1963, 95). En segundo lugar, el pensamiento poblacional

${ }^{3}$ A esto se le suman las diversas causas de plasticidad fenotípica.

Revista de Humanidades de Valparaíso, 2019, No 14, 241-273

(ㄷ)(1)(8) CC BY-NC-ND 
reconoce que los heterocigotos están mejor adaptados que los homocigotos, esto hace que la heteorcigosis tienda a extenderse en las poblaciones haciendo que exista más variación genética que fenotípica ${ }^{4}$. Además, se ha demostrado que la importancia de los mecanismos de desarrollo homeostático es crucial. Estos mecanismos harían que diferentes combinaciones de genes produjesen el mismo fenotipo, lo cual abriría la posibilidad a considerar que la variación genética pudiese exceder a la variación fenotípica (Dupré 1993, 55).

3. En último lugar, porque las especies constituyen entidades espaciales y temporales a diferencia de los tipos. Para el pensamiento tipológico los miembros de las especies eran capaces de instanciarse en el momento que fuera, cabía incluso la posibilidad de que no existiesen siquiera instanciaciones del tipo. Esto para el pensamiento poblacional constituye una imposibilidad conceptual, básicamente porque una vez que el linaje se halla extinto este no puede volver a surgir (Dupré 1993, 41). Además, para que se pueda dar la evolución es preciso que las especies constituyan linajes genealógicos. Como bien es sabido, las especies se alzan por medio de la evolución gradual a partir de las especies parentales, evolución que no consiste más que en la constante acumulación de cambios. Es por esta razón por la que no se puede afirmar que las especies constituyan entidades espaciotemporalmente irrestrictas. Además, la especiación es un proceso vago, razón por la cual ningún conjunto de características estable marca cuándo podemos considerar a una población como una nueva especie.

¿Cómo puede abordar el esencialista la evolución? ¿Cómo es capaz de explicar fenómenos fenotípicos tan relevantes como el polimorfismo del desarrollo o el dimorfismo sexual? ¿Cómo es capaz de explicar fenómenos genéticos tan relevantes como la recombinación, la mutación o la deriva? ¿Cómo es capaz el tipologista de identificar las especies politípicas, esto es, poblaciones de organismos fenotípicamente diferentes pero que pertenecen a la misma especie? (Dobzhansky 1970, 356). ¿Cómo es capaz de identificar las especies hermanas (Sibling species), esto es, especies diferentes morfológicamente indistinguibles? Los esencialistas no saben cómo responder a estos interrogantes pues para ellos, por definición, todos los miembros de una especie deben compartir la misma esencia (Sober 1980, 351).

\footnotetext{
${ }^{4}$ Los heterocigotos que heredan un alelo de la hemoglobina s, siendo portadores de la enfermedad de la célula falciforme, son más resistentes a la malaria que los homocigotos.
}

Revista de Humanidades de Valparaiso, 2019, No 14, 241-273

(c) (1) 8 (을 CC BY-NC-ND 
Una discusión en torno a los límites del concepto especie

Mariano Martín Villuendas

\section{El problema de las especies}

\subsection{Hacia la clarificación del problema: la categoría especie y el taxón especie}

Antes de abordar propiamente el problema de las especies es necesario realizar una aclaración previa pues de no hacerlo se corre el riesgo de malentender el núcleo mismo del asunto. Esta aclaración remite a la distinción entre el problema de la categoría especie y el problema del taxón especie. La pertinencia de esta distinción ha sido reseñada por autores tan ilustres como el biólogo evolutivo Mayr (1963).

Antes de adentrarse en el problema del taxón es necesario clarificar qué es eso del taxón especie. El taxón hace referencia a un objeto, sea este zoológico o botánico, el cual puede ser identificado y clasificado por biólogos expertos (Mayr 1982, 254). En pocas palabras, el taxón haría referencia a una población clasificable y delimitable de organismos que se diferenciaría de otros grupos de organismos o poblaciones. Como ejemplo podríamos tomar las siguientes especies: Homo sapiens, Solanum tuberosum o Drosophila melanogaster. Dobzhansky ha definido al taxón especie de la siguiente manera: "In short, a species is the most inclusive Mendelian population" (Dobzhansky 1970, 357). El problema del taxón es, desde esta perspectiva, un problema esencialmente de delimitación, un problema de cómo reconocer la multiplicidad de objetos zoológicos y botánicos que pueblan el mundo. El esencialismo entendería este problema a través de las siguientes preguntas, ¿qué significa ser miembro de una especie particular? ¿Cuáles son las propiedades esenciales de un organismo? Vemos el carácter fundamentalmente explicativo que subyace a las preguntas planteadas por el esencialista. Esto se deriva, como ya se vio en la sección anterior, de su motivación principal, responder al porqué. La moderna teoría biológica entendería este problema como un sencillo problema de delimitación pues ya no existen características esenciales.

En resumidas cuentas, este problema se ceñiría a dos preguntas. La primera, cómo asignar individuos a un taxón especie particular. La segunda, cómo delimitar a estos taxones especie frente a otros taxones especie. El gran problema es que existe una enorme variabilidad tanto en los animales como en las plantas lo cual dificulta en suma manera la identificación y clasificación de los diversos organismos. A este respecto, existen dos creencias en lo relativo al taxón especie. En primer lugar, existen aquellos que piensan que los diversos taxones especie poseen una característica unificadora, característica que permitiría identificar a todos los taxones por igual. Es por este motivo por el que los partidarios de esta primera opción defenderían un único concepto de especie. Aquí tendríamos a figuras como Mayr y su concepto de comunidad reproductiva (Mayr 2000). Por otro lado, existiría otro bloque que consideraría que las diversas especies no poseen una característica unificadora por lo que sería necesario sostener una pluralidad de conceptos operacionales para poder reconocer a las diversas especies. Los partidarios de esta última posición reconocerían, por tanto, que las diversas especies son unificadas por medio de diversos procesos biológicos, procesos como el flujo genético, la selección o la homeos-

Revista de Humanidades de Valparaíso, 2019, No 14, 241-273

(c) (1) 8 (을 CC BY-NC-ND 
tasis genética. Antes de pasar al problema de la categoría especie es necesario matizar que nadie ha puesto en duda la existencia del taxón especie. Ningún biólogo sería capaz de poner en tela de juicio la existencia de los diversos taxones especie que pueblan el mundo pues son precisamente estos objetos los que se encarga de estudiar el naturalista de campo (Mayr 1987).

¿Qué es la categoría especie? La categoría especie remitiría al rango de la jerarquía de Linné: "A category designates a given rank or level in a hierarchic classification. Such terms as species, genus, family and order designate categories. A category, thus, is an abstract term" (Mayr 1963, 13). Esta categoría constituiría la clase de todos los taxones especie, es decir, sería la clase que tendría como miembros a los diversos taxones especie. Esta categoría, de existir, debe cumplir dos requerimientos esenciales. En primer lugar, esta categoría debe estar unificada, esto es, debe señalar una característica o características comunes a todas las especies. En segundo lugar, esta categoría debe ser esencialmente explicativa, es decir, debe señalar un mecanismo por el cual las especies puedan garantizar su integridad y coherencia. ¿Cuál es el problema de la categoría especie? Este es un problema esencialmente de definición (Mayr 1982, 254). De ahí que la categoría especie sea una categoría fundamentalmente explicativa, pues remite a una suerte de mecanismos causales, mecanismos que hacen que las especies sean lo que son. No basta con señalar las propiedades comunes que todos los miembros de una especie comparten, es necesario proceder a la identificación del mecanismo que hace que la especie sea lo que, de hecho, es.

Si se tuviese que encarnar el problema de la categoría especie en unas pocas preguntas estas serían las siguientes. ¿Cuál es la definición de especie? ¿Qué distingue al taxón especie de la jerarquía de Linné de taxones mayores como las clases u ordenes? Existen dos creencias en torno al problema de la categoría especie. Un primer sector afirmaría que tal categoría especie existe realmente. De esta forma, estos autores estarían apoyando un monismo, tanto taxonómico como metafísico. Los partidarios más reconocidos de esta postura serían Kevin de Queiroz (2007) y Mayr (1963). Un segundo bloque consideraría que no existe tal categoría especie pues lo que existe, más bien, sería una pluralidad irreductible de conceptos igualmente legítimos. Existen diferentes aproximaciones al mundo orgánico, aproximaciones que nos dotan de diferentes patrones de jerarquización del mundo (Ereshefsky 2001, 139). De esta manera, se estaría apoyando un pluralismo metafísico. Esta sería la posición que sostendrían autores como Dupré (1993) o Ereshefsky (2001). El mismo Darwin se situaría dentro de este último bloque. Influenciado en gran medida por las investigaciones botánicas, Darwin sostuvo en varios pasajes de El Origen de las especies que tal categoría especie era una simple conveniencia taxonómica. ¿Dónde basó el grueso de su argumentación? Darwin consideró que las especies, al evolucionar, no podían ser delimitadas a través de unos contornos definidos. No existían un conjunto de características primordiales o esenciales que pudiesen marcar la definición de las mismas, tampoco existía un mecanismo unitario que las dotase de estabilidad: 
Una discusión en torno a los límites del concepto especie

Mariano Martín Villuendas

In short, we shall have to treat species in the same manner as those naturalist treat genera, who admit that genera are merely artificial combinations made for convenience. This may not be a cheering prospect; but we shall at least be freed from the vain search for the undiscovered and undiscoverable essence of the term species. (Darwin 1964, 485)

La literatura acerca de las especies ha considerado que de resolver el problema de la categoría especie se estaría resolviendo, de manera indirecta, el problema del taxón especie. ¿Por qué? Si consiguiésemos captar lo esencial de las especies, el mecanismo que hace que estas sean lo que son, entonces ya no tendríamos ningún tipo de problema en poder identificar satisfactoriamente a las diversas especies. Pero ¿qué resuelve el problema de la categoría especie? El concepto especie, pues el concepto especie constituye la definición de lo que son las especies (Ereshefsky 2001, 80). Es necesario, por tanto, analizar si existe tal concepto unitario capaz de atrapar la definición de especie.

\subsection{Conceptos de especie}

\subsubsection{Conceptos categoriales de especie}

En primer lugar, es preciso considerar los dos conceptos categoriales propuestos por los biólogos de Queiroz y Mayr. Estas aproximaciones se presentarán de forma independiente a las demás por dos motivos. El primero, porque han sido los únicos conceptos propuestos con la explícita finalidad de dar respuesta directa al problema de la categoría especie. El segundo, porque estos conceptos se caracterizan por su no-dimensionalidad y no-operatividad, hecho que los distancia del resto.

A juicio de Mayr, la categoría especie no constituye una simple construcción humana, esta refleja un aspecto genuinamente existente de la realidad. Lo que esconde Mayr bajo esta consideración es un profundo rechazo al pluralismo metafísico $\mathrm{y}$, por ende, al pluralismo taxonómico. Existe un único concepto de especie, una única clasificación válida, una clasificación que remitiría a cómo está estructurado el mundo. El concepto que propone Mayr es, por estas razones, no-dimensional. El objetivo de Mayr no consiste en tratar de construir una forma de identificar a los diversos taxones especie, consiste en tratar de armar una definición de qué es ser una especie. Es por este motivo por el que Mayr acude a una situación no-dimensional. Las consideraciones dimensionales solo valen en la medida en la que se tiene por objetivo delimitar los diversos taxones especie en la práctica. Además, desde una situación dimensional las especies solo pueden ser determinadas por inferencia y este proceso es sumamente problemático: "More interesting to the evolutionist are the difficulties that are introduced when the dimensions of time and space are added" (Mayr 1963, 16).

Es preciso acudir a una situación no-dimensional si queremos delinear un concepto adecuado de especie $(1963,15)$. Mayr resume esta reflexión en la siguiente frase: "Analogously, an individual belongs to species X not because it has the same species specific

Revista de Humanidades de Valparaíso, 2019, No 14, 241-273

(c) (1) 8 을 $\mathrm{CC}$ BY-NC-ND 
characters as other individuals of species $\mathrm{X}$, but it has these species specific characteristics because, like other conspecifics, it is part of species" (Mayr 1996, 274). ¿Cuál es pues la definición de especie? En su famoso libro, Populations, Species, and Evolution Mayr aporta su definición de especie: "Species are groups of interbreeding natural populations that are reproductively isolated from other such groups" (Mayr 1963, 12). Esta definición da a entender que las especies son pool de genes armoniosos y estables protegidos de la influencia de genes potencialmente desestabilizadores. Como podemos observar, la idea de comunidad reproductiva juega un rol secundario en la definición de especie, esta idea será relevante, eso sí, cuando abordemos su vertiente operacional. El elemento de verdadera importancia en la vertiente no-operacional del concepto biológico es el de mecanismos de aislamiento, pues son estos los que permiten a las especies sostener su integridad y coherencia interna (Mayr 1942, 247). La crítica de este concepto se llevará a cabo cuando se esboce su vertiente operacional pues es ahí donde se podrán observar las dificultades prácticas que dicho concepto arrastra. No obstante, quedémonos con la definición de especie que nos propone Mayr (2000, 24): "The species is a device for the protection of harmonious, well-integrated genotypes. It is this insight on which the Biological Species Concept is based".

De Queiroz ha propuesto otro concepto categorial de especie siguiendo la estela marcada por Mayr. A juicio de de Queiroz, el problema de las especies se ha resuelto desde hace tiempo. La resolución de este conflicto radica en la identificación del elemento común a los diversos y múltiples conceptos propuestos por los biólogos y taxonomistas. A juicio de de Queiroz (2007) las especies constituirían metapoblaciones de linajes, o mejor dicho, segmentos de tales linajes, los cuales evolucionan de forma separada los unos de los otros ${ }^{5}$. La clave para la solución del problema de las especies reside, por tanto, en la identificación de un concepto general, de un concepto categorial, el concepto de linaje poblacional: "The general concept to which I refer equates species with separately evolving metapopulation lineages, or more specifically, with segments of such lineages" (de Queiroz 2007, 880-881). Este concepto, al igual que el de Mayr, es un concepto no-operacional, es decir, es un concepto que no tiene por objetivo especificar qué criterios son relevantes a la hora de identificar a los diversos taxones especies, este sencillamente dice cuál es el elemento común que subyace a los diversos conceptos de especie. Los diversos criterios propuestos por los restantes conceptos de especie, criterios como el aislamiento reproductivo o la zona adaptativa mínima, harían referencia a las diferentes propiedades adquiridas por los diversos linajes durante el transcurso de la especiación, motivo por el cual estos constituirían simples criterios operacionales de identificación.

La divergencia entre los diversos conceptos de especie se explicaría debido a que al poner el énfasis en diferentes propiedades lo que estarían haciendo estos conceptos es

\footnotetext{
${ }^{5}$ El linaje constituiría una línea ancestro-descendiente. El linaje se diferencia de la población por un simple criterio temporal.
} 
señalar distintos estadios temporales del proceso de especiación. Lo que no tienen en cuenta sus proponentes, dice de Queiroz, es que los cambios en aspectos como el cruce, la morfología o la ecología no acaecen todos al mismo tiempo ni siquiera en un orden regular. La cuestión esencial es que estos no constituyen definición alguna de la categoría especie, lo que recalcan son propiedades constituyentes, no propiedades fundamentales. No es preciso que las especies dispongan de cada una de las características reseñadas por los diversos conceptos de especie. La ausencia de alguna de estas propiedades no constituye evidencia alguna en contra de la separación de dichos linajes ${ }^{6}$. Existen, no obstante, varios problemas con el concepto propuesto por de Queiroz. En primer lugar, al recurrir a una propiedad relacional, el ser descendiente de un ancestro común, el concepto de de Queiroz no parece poseer gran capacidad explicativa ni predictiva. ¿Por qué? En primer lugar, porque no se estarían señalando ni las propiedades características de las especies ni los mecanismos por los cuales estas se sustentan. En segundo lugar, en íntima relación con esto último, porque el concepto de de Queiroz no es capaz de dar cuenta de la diferencia que separa a los taxones especie de otros taxones más altos como las familias o los géneros, pues estos constituyen de igual forma linajes de poblaciones. Para intentar solventar este problema, de Queiroz propone diferenciar entre linaje y clado. Los rangos más altos como las familias constituirían clados mientras que las especies constituirían linajes. Aun así, el concepto de de Queiroz se vería incapaz de dar cuenta de los linajes parafiléticos, los cuales son reconocidos desde la aproximación de Mayr.

\subsubsection{Conceptos operacionales de especie}

Analizados los conceptos categoriales es necesario acercarse a la caracterización de los principales conceptos operacionales. Antes de comenzar con esta caracterización es preciso realizar tres apuntes. En primer lugar, todos estos conceptos son relacionales, estos no señalan propiedad intrínseca alguna (Mayr 1963, 14). En segundo lugar, estos conceptos dan cuenta de una multiplicidad irreductible de procesos responsables de la existencia y coherencia interna de las especies. En tercer lugar, existe una amplia variedad de conceptos no reducibles los unos a los otros. Mayden reconoce hasta veinticinco conceptos (Mayden 2002, 177). Por una sencilla cuestión de economía temporal aquí se explorarán únicamente los cinco más relevantes: el concepto fenético, ecológico, biológico, evolutivo y filogenético. Tras reseñar las características más primordiales de cada uno se llevará a cabo una crítica particular de los mismos para posteriormente pasar a ver de qué forma estos conceptos son irreductibles a un parámetro común.

\footnotetext{
${ }^{6}$ Sin embargo, la ausencia de todas sí que constituiría una evidencia en contra de tal separación.
} 


\subsubsection{Análisis de los conceptos}

El concepto fenético o morfológico de especie afirmaría que los organismos se agrupan en especies sobre la base de una similaridad general en sus características físicas. Esta similitud puede ser tanto comportamental, como fisiológica, morfológica o ecológica. La membresía a la especie se declararía, por tanto, sobre la base de una serie de características compartidas. Este concepto, procedente de los análisis predarwinianos (Mayr 1963), fue adaptado a la moderna teoría biológica en el siglo pasado por los autores Peter Sneath y Robert Sokal (1973). Estos autores tuvieron como objetivo primario el intentar basar los análisis taxonómicos sobre medidas objetivas de similaridad general usando, para ello, análisis computacionales de un gran número de características dispares. Puesto que su objetivo principal era lograr un análisis libre de teoría consideraron que ninguna de las características debía ser más primordial que otra (Dupré 1993, 45). ¿Qué ventajas tiene este concepto? En primer lugar, este concepto es bastante operacional puesto que, como es obvio, se puede aplicar a todos los organismos. En segundo lugar, y en estrecha conexión con lo anterior, este concepto destaca por su universalidad.

El concepto ecológico de especie fue propuesto de forma explícita en 1976 por Leigh Van Halen. Este concepto se basa en la idea de linaje poblacional, presupuesto, como se ha visto, absolutamente esencial si se pretende asumir el darwinismo. Pues bien, según el concepto ecológico las especies no serían otra cosa más que linajes que ocupan determinadas zonas adaptativas mínimas, o nichos ecológicos, explotando, de esta manera, ciertos recursos ambientales: "A species is a lineage (or a closely related set of lineages) which occupies an adaptive zone minimally different from that of any other lineage in its range and which evolves separately from all lineages outside its range" (Van Halen 1976, 233). El concepto ecológico se basa, por tanto, en la idea de ecologías divergentes. Los elementos clave en esta definición serían el de linaje y el de zona adaptativa. La zona adaptativa sería aquella parte del espacio ocupado por una determinada especie, espacio en el que se incrustarían las relaciones de depredación y parasitismo. Es ese nicho adaptativo y las fuerzas selectivas unidas al mismo el que permitiría mantener la coherencia interna de las especies pudiendo hablar de ellas como de taxones distintivos. Esto hace que el concepto ecológico considere el cruce como un mecanismo secundario. A juicio de Van Halen, la selección actúa fundamentalmente sobre el fenotipo, lo cual hace que los genes tengan una importancia relativa en el proceso evolutivo (Van Halen 1976, 233). Es la selección la que moldea a las especies. La segunda idea crucial es la de linaje. Las especies que ocupan estas zonas adaptativas mínimas deben formar parte de un mismo linaje. Van Halen llega de esta forma a un concepto crucial, el concepto de multiespecie. Las multiespecies constituirían grupos de especies pertenecientes a diferentes taxones cuyos miembros tendrían la capacidad de cruzarse pudiendo producir, de esta manera, una descendencia fértil. A pesar de cruzarse, estos individuos mantendrían su coherencia interna, 
esto es, seguirían constituyendo entidades taxonómicas diferentes. Esto demostraría la ineficiencia del flujo genético como mecanismo unificador. Un ejemplo de tal multiespecie sería la especie Quercus macrocarpa y la especie Quercus bicolor (Van Halen 1976, 235).

El concepto biológico de especie fue ampliamente popularizado por Mayr. El concepto biológico de especie, al igual que el concepto ecológico, asume que los taxones especie constituyen entidades históricas. En la sección anterior se esbozó el carácter no-dimensional del concepto de especie y se señaló que existía una variante dimensional y operacional del mismo. La clave de esta variante operacional residía en el concepto de comunidad reproductiva pues, a juicio de Mayr, las especies no constituían otra cosa más que el conjunto más inclusivo de individuos conectados de forma potencial entre sí en términos reproductivos (Mayr 2000, 22). Este concepto subraya dos ideas fundamentales estrechamente conectadas entre sí: la idea de aislamiento reproductivo y la idea de coherencia intraespecífica. El aislamiento no consiste más que en la protección de los pool de genes armoniosos y estables. Para lograr tal aislamiento reproductivo era crucial que los organismos pudiesen disponer de unos mecanismos de aislamiento adecuados que impidiesen la contaminación de su pool de genes estable.

De esta forma, Mayr pone el énfasis en la relación genética: "the biological species concept is a product of modern understanding of the genetic structure of Mendelian populations" (Dobzhansky 1970, 354). Las especies constituyen, sencillamente, un campo para la recombinación de genes. Esta idea se encarna en el calificativo "genetic fortresses" (Ereshefsky 2001, 82) o "device for the protection of harmonious well-integrated genotypes" (Mayr 2000, 24). Los mecanismos de aislamiento pueden ser, o bien precigóticos, o bien postcigóticos. Como ejemplos del primer caso tendríamos la exclusión ecológica, las propiedades temperamentales, la incapacidad de llevar a cabo el cruce o las incompatibilidades cromosómicas (Mayr 2000). Como ejemplos del segundo caso tendríamos la descendencia estéril o la inviabilidad del híbrido. Afirmar que la especie consiste en un arma de protección de genotipos estables no es, de por sí, suficiente para definir satisfactoriamente a la especie pues todavía es necesario esbozar el mecanismo que dota de coherencia interna a la especie. Se llega así a la segunda idea esencial del concepto biológico de especie: la idea de coherencia intraespecífica. ¿Cuál es el mecanismo biológico que dota de coherencia interna a las especies? Este mecanismo no es otro más que el flujo genético. El flujo genético sería el mecanismo que permitiría ocultar las características indeseables extendiendo las beneficiosas por medio del cruce entre los diversos miembros de la población.

En cuarto lugar tendríamos el concepto evolutivo de especie. Este concepto fue propuesto en 1951 por el paleontólogo George Gaylord Simpson a fin de poder salvar tanto la no-dimensionalidad del concepto biológico de especie pudiendo retratar, de esta forma, la existencia de las especies a través del tiempo como la inclusión de los organismos asexua- 
les dentro de la categoría especie (Simpson 1951, 290). Este concepto afirmaría que las especies constituyen linajes de ancestros-descendientes poseedores de sus propios roles evolutivos, tendencias y destinos históricos:

The following seems to be the strictly evolutionary criterion implied: a phyletic lineage (ancestral-descendent sequence of interbreeding populations) evolving independently of others, with its own separate and unitary evolutionary role and tendencies, is a basic unit in evolution. (Simpson 1951, 289)

Este concepto de especie es sumamente flexible pues permite acoger una amplia variedad de procesos biológicos responsables de dichas tendencias evolutivas, procesos como el cruce, la selección o la homeostasis interna.

En último lugar se hallaría el concepto filogenético de especie. Este concepto, al igual que los tres anteriores, tiene como base la idea de linaje, es decir, asume que los taxones especie constituyen entidades históricas. Existen muchas variantes de este concepto filogenético (Wheeler y Meier 2000), no obstante, se podría resumir la idea central del mismo de la siguiente manera: el concepto filogenético se basa en la proximidad de los descendientes, esto es, se basa en la idea de que un taxón especie debe contener a la especie ancestral así como a sus descendientes y solo a ellos. El concepto filogenético tendría a su base la idea de taxones monofiléticos. Que las especies sean monofiléticas quiere dar a entender que los miembros de una especie deben ser descendientes de un conjunto de ancestros comunes, es decir, un taxón es monofilético cuando comprende a todos y solo a los descendientes de un ancestro común. Aquí se desarrollará únicamente la caracterización llevada a cabo por Mishler y Donoghue (1983) y por Mishler y Brandon (1987).

Estos autores consideran que las especies no son otra cosa más que los taxones menos inclusivos reconocidos en una clasificación en la cual los organismos se agrupan por grado de monofilia. Asimismo, estos autores reconocerían dos criterios fundamentales: el criterio de agrupamiento y el de clasificación. El criterio de agrupamiento informaría acerca de qué organismos son candidatos a la conspecificidad. En relación al criterio de agrupamiento estos autores sostendrían un monismo centrado en la monofilia. El criterio de clasificación, por su parte, apelaría a los procesos causantes de que una especie sea esa especie. Estos autores sostendrían un pluralismo en lo relativo al criterio de clasificación pues considerarían que unos procesos tienen más importancia que otros dependiendo de la situación de cada especie particular. El pluralismo es así considerado superior al monismo pues es capaz de reflejar la amplia variedad de causas evolutivas. Eso sí, es necesario recalcar que el pluralismo que defienden Mishler y Donoghue y Mishler y Brandon es un pluralismo dentro del monismo. Si bien existen múltiples clasificaciones en función de la situación considerada, solo existe una única clasificación válida dentro de cada situación: "a single, optimal general-purpose classification exists for each particular situation, but that the criteria applied in each situation may well be different" (Mishler y Brandon 1987, 403). Brent Mishler y Michael Donoghue resumen su visión en la siguiente frase: 
Una discusión en torno a los límites del concepto especie

Mariano Martín Villuendas

Even when monophyletic groups are delimited, the problem of ranking remains since monophyletic groups can be found at many levels whithin a clade. Species ranking criteria could include group size, gap size, geological age, ecological or geographical criteria, degree of intersterility, tradition, and possible others. (Mishler y Donoghue 1983, 499)

\subsubsection{Crítica de los conceptos de especie}

Una crítica individual de cada uno de estos conceptos permitirá entrever de qué manera el alcance y la validez de los mismos son limitadas, mostrando, de esta manera, la imposibilidad de dar con un concepto general capaz de atrapar la enorme diversidad que rodea a las especies. Sin embargo, puesto que una crítica exhaustiva de estos conceptos de especie requeriría de un espacio del que aquí no se dispone, únicamente se esbozarán algunas de las principales deficiencias subyacentes a los mismos.

Vayamos con el concepto fenético de especie. Como ya se ha señalado en la sección 3.2. existe una numerosa variación intraespecífica en lo relativo a cualquier característica seleccionada dentro de cada una de las diversas especies que pueblan el mundo (Dupré 1981, 84-85). Esta variación, al constituir la pieza clave de la evolución, hace que sea sumamente difícil poder seleccionar un conjunto de características como las definitorias de una especie. A esto se le suma el problema ya mencionado de que, debido a la evolución, lo que puede ser definitorio en un determinado momento para una especie puede dejar de serlo en otro. Sin embargo, lo que verdaderamente pone al feneticismo contra las cuerdas son los casos prácticos que los biólogos han encontrado en la naturaleza. Un caso paradigmático sería el de las especies hermanas (Sibling species). Estos organismos, aun a pesar de ser morfológicamente indistinguibles, constituirían distintas especies pues serían genéticamente tan diferentes como dos especies cualesquiera. Por tanto, es posible que dos organismos sean similares fenotípicamente pero completamente distintos a nivel genético ${ }^{7}$. A esto se le suma la heterocigosis y los mecanismos homeostáticos de desarrollo. Ampliamente es reconocida la mejor adecuación del heterocigoto. Esto se debe, en parte, a que la heterocigosis constituye una forma de incrementar la diversidad de fuentes bioquímicas (Dupré 1981, 85). Por su parte, los mecanismos homeostáticos del desarrollo permitirían que diferentes combinaciones de genes produjesen el mismo fenotipo. Esto abriría la posibilidad a que la variación genética pudiese ser mucho mayor que la fenotípica.

En cuanto al concepto ecológico de especie se podrían señalar dos breves críticas. En primer lugar, es un hecho reconocido que muchas especies ocupan diferentes nichos ecológicos a lo largo de las diversas fases de su vida (Mayr 1982, 275). Esto supone un verdadero problema para el concepto ecológico de especie pues, si se recuerda, este basa-

\footnotetext{
${ }^{7}$ Véase los casos de Drosophila pseudoobscura y Drosophila persimilis o el de las especies que comprenden los géneros Salmo y Coregonus.
}

Revista de Humanidades de Valparaíso, 2019, No 14, 241-273 
ba su poder en la noción de nicho ecológico. A esto se le suma el problema de las especies politípicas $^{8}$, las cuales, a pesar de pertenecer a una misma especie, pueden ocupar nichos diferentes (Mayr 1988, 322). En segundo lugar, es bien conocido que muchos de los procesos de especiación son alopátricos. La cuestión es la siguiente, ¿se puede esperar que los procesos de especiación vayan acompañados de cambios ecológicos? Ciertamente, esta suele ser la regla general pero no tiene por qué ser necesariamente así. A esto se le sumaría la cuestión de la especiación simpátrica, la cual sí constituiría un verdadero problema para el concepto ecológico (Mayden 2002, 177).

Vayamos ahora con el concepto biológico de especie. Dupré (1993) ha considerado que la aplicabilidad del concepto biológico es limitada. ¿Por qué motivos? En primer lugar, el concepto biológico de especie no se puede aplicar a las especies asexuales y esto es algo que reconoce el propio Mayr (2000). A juicio de Mayr, solo los organismos sexuales forman poblaciones y, en última instancia, solo ellos constituyen verdaderas especies. La razón de ello se debe a que el genotipo de los organismos asexuales, debido a su propio sistema de reproducción, no requiere de tal protección puesto que este no se ve amenazado por la introducción de genes no armónicos procedentes de otros pool de genes: "Any endeavor to propose a species definition that is equally applicable to both sexually reproducing and asexual populations misses the basic characteristics of the biological species definition" (Mayr 2000, 23). El gran problema de esto es que de aceptar el reclamo de Mayr estaríamos negando el estatuto de especie al mayor número de organismos que pueblan la tierra.

Si queremos entender cómo ha evolucionado la vida en nuestro planeta, si queremos entender cómo se ha originado la innumerable heterogeneidad natural necesitamos incluir en nuestro estudio a los organismos asexuales (Ereshefsky 2010b, 412). A esto se le suman los análisis llevados a cabo por Mishler. Este autor ha señalado que el genus Tortula de Mosses incluye a más de 100 especies tanto sexuales como asexuales (Mishler 1990). La cuestión central aquí es que los organismos asexuales forman especies comparables a las reconocidas en otros linajes asexuales e incluso sexuales. Existen, por tanto, procesos de unificación comunes a las especies sexuales y asexuales, procesos como la selección o la homeostasis genética (Ereshefsky 2001, 115). ¿Por qué negar entonces que los organismos asexuales puedan formar especies? En segundo lugar, no se puede negar que existe la posibilidad de hibridación estable. Edgar Anderson introdujo el concepto de introgresión para poder explicar este hecho (Mayr 1982). La introgresión haría referencia a la introducción de genes de una especie en el pool de genes de otra especie. Esta rompería, en definitiva, los contornos de las mismas especies 9 . Es precisamente por este motivo por el que los botánicos se muestran tan reticentes a aceptar el concepto biológico de especie

\footnotetext{
${ }^{8}$ Un caso de tal especie politípica podría ser el de Passerella melodia, la cual comprende más de 30 subespecies.

${ }^{9}$ Un caso práctico es el que concierne a las especies de aves Passer domesticus y Passer hispanoliensis.
}

Revista de Humanidades de Valparaíso, 2019, No 14, 241-273

(ㄷ)(1)(8) CC BY-NC-ND 
como el concepto arquetípico (Mishler y Donoghue 1983, 493). Recordemos el ejemplo que concernía a las especies Quercus macrocarpa y Quercus bicolor. Este ejemplo, si recordamos, ponía en jaque la idea del flujo genético como mecanismo rector responsable de la unicidad y coherencia interna de las especies. Existen numerosos estudios tanto teóricos como empíricos que avalan esta conclusión. Los más relevantes, a este respecto, son los llevados a cabo por Ehrlich y Raven (1969) y Endler (1973).

Paul Ehrlich y Peter Raven demostraron en un importante artículo del año 1969 que el principal mecanismo integrador de las especies era la selección y no el flujo genético. De hecho, era el propio régimen selectivo el que determinaba el grado de influencia del flujo genético. ¿Existe algún hecho empírico que avale esta consideración? Ehrlich y Raven señalan cómo poblaciones aisladas geográficamente a lo largo de prolongados periodos de tiempo han mostrado poca o ninguna diferenciación morfológica o evolutiva. Este podría ser el caso de la especie Erebia theano. Las poblaciones asentadas en Alaska apenas se diferencian de aquellas que viven en Colorado (Ehrlich y Raven 1969, 1230). Otro caso reseñable es el del cangrejo de arena Emerita analoga, el cual se distribuye a lo largo de los hemisferios norte y sur. Tal distribución imposibilita el flujo genético. Lo más sorprendente de esto es que estas poblaciones no muestran grado alguno de diferenciación morfológica. ¿Cómo se explica entonces la similaridad? Debido a los regímenes selectivos. El intercambio de genes se muestra, desde esta perspectiva, como un mecanismo de menor importancia. El mismo John Endler señaló, a través de diversas comprobaciones experimentales, los efectos restringidos del flujo genético cuando actuaban los regímenes selectivos. Asimismo, se consideraba que la diferenciación de las especies era algo imposible si las poblaciones no se veían separadas por barreras geográficas pues, de lo contrario, el flujo genético se tragaría toda la diferencia que se hubiese podido alzar a raíz de las diversas presiones selectivas (Endler 1973).

Lo curioso del asunto es que los experimentos de Ehrlich y Raven $(1969,1231)$ demostraron cómo poblaciones sometidas a diferentes regímenes selectivos mostraban una marcada diferenciación aun intercambiando genes. Si existe diferencia selectiva, el flujo genético se ve incapaz de impedir la formación de clinas (Endler 1973, 248). En último lugar, tendríamos el problema del anillo de las especies. El problema del anillo diría sencillamente que si bien los organismos de poblaciones colindantes pueden cruzarse de forma satisfactoria, los organismos residentes en conexiones distantes del anillo se verían incapaces de cruzarse con éxito debido a que poseerían distintos mecanismos de aislamiento aun a pesar de pertenecer a la misma especie (Ereshefsky 2010a, 681).

Pasemos ahora con el concepto evolutivo de especie. Mayr señala tres críticas fundamentales a este concepto. El primer problema de este concepto es que solo es aplicable a las especies monotípicas pues este concepto requiere que toda población aislada geográficamente deba ser tratada como una especie, de lo contrario, se estaría incumpliendo la prescripción acerca de las tendencias y roles evolutivos: "every geographical isolate would, by implication, have to be treated as a different species" (Mayr 1996, 271). Esto 
excluiría la consideración de las especies politípicas, lo cual restringiría mucho su rango explicativo. El segundo problema es que no tenemos manera de saber qué es eso de los roles, tendencias y destinos históricos de las especies. Apelar a estos conceptos en nada ayuda a clarificar la práctica científica (Mayr 1996, 271). El tercer problema es que no está claro de qué manera este concepto permite introducir la dimensión temporal autorizando, de esta manera, la identificación de las cronoespecies (Mayr 1996, 271).

¿Qué deficiencias presenta el concepto filogenético? En primer lugar, existe un problema con las especies ancestrales pues estas poseen características simplesiomórficas y no sinapomórficas. La cuestión es que el defensor del concepto filogenético solo autoriza las apomorfías como criterio para reconocer a las especies. En segundo lugar, y en conexión con lo anterior, este concepto no reconoce a los taxones parafiléticos, lo cual genera profundos problemas conceptuales. El caso concreto de la clase Reptilia ejemplifica dicha confusión conceptual. Las aves constituirían un subgrupo de la clase Reptilia pues estas comparten un ancestro común con otra subclases de Reptilia como los cocodrilos. La cuestión es que los biólogos consideran que las aves constituyen un taxón diferente. No es suficiente con tener en cuenta el criterio de monofilia, es necesario atender al grado de divergencia evolutiva.

\subsubsection{Diversidad orgánica y multiplicidad conceptual}

A través de un análisis de los principales conceptos de especie se ha podido comprobar cómo ninguno de estos conceptos goza de una validez irrestricta, todos presentan serias limitaciones a tener en cuenta. Este hecho debería servir como un primer indicio para poner en duda la pertinencia de tal categoría especie. Recordemos que para que existiese esta categoría era preciso que existiese un concepto unificado y explicativo en torno a la noción de especie, algo que, hasta el momento, no parece existir. Para completar este análisis se llevará a cabo en esta sección una comparación de tres de los principales conceptos de especie: el concepto ecológico, filogenético y biológico. No obstante, antes de llevar a cabo esta tarea es preciso explicar una serie de conceptos taxonómicos básicos pues solo de esta forma se podrá percibir el trasfondo de esta profunda divergencia conceptual.

\subsection{Conceptos esenciales en biología y taxonomía}

La disciplina taxonómica puede ser entendida, a grandes rasgos, como la práctica biológica dedicada a la clasificación de los diversos organismos que pueblan el mundo. Ereshefsky reconoce tres escuelas taxonómicas distintivas: la escuela evolutiva, la fenética y la cladista (Ereshefsky 2001, 51). Aquí se resaltarán las diferencias que acontecen entre las escuelas evolutiva y cladista. No obstante, antes de observar estas divergencias es preciso definir los tres tipos de taxones más característicos: el monofilético, el parafilético y el polifilético. 
El taxón monofilético (Fig. 1) se caracterizaría por contener, como ya se ha visto, al ancestro y a todos sus descendientes. Por su parte, el taxón parafilético (Fig. 2) contendría al ancestro y solo a alguno de sus descendientes, no a todos. Este sería el caso de la clase Reptilia, la cual contendría a lagartos o cocodrilos pero no a las aves, aun a pesar de que estas compartan un ancestro común con los anteriores. La escuela evolutiva agruparía a las aves en un taxón distinto debido a que estas ocupan una zona adaptativa diferente. El taxón parafilético tendría en cuenta, por tanto, no solo al ancestro común sino también la cantidad de divergencia evolutiva. Los taxones polifiléticos (Fig. 3) constituirían linajes cuyos organismos comparten ciertas características no presentes en el ancestro común, características desarrolladas a través de un proceso evolutivo paralelo. Estas características reciben el nombre de homoplasias. Las homoplasias no se identifican con las homologías, de hecho, hacen referencia a características sumamente diferentes (Ereshefsky 2001, 69).

Si las homoplasias son características compartidas por diversos linajes no contenidas en el ancestro común, ¿qué son las homologías? Las homologías serían las características propias de los taxones monofiléticos y parafiléticos. Las homologías pueden ser de dos tipos, o bien apomorfías o bien plesiomorfías. Las apomorfías serían caracteres no presentes en el ancestro, caracteres que se alzan con posterioridad. Estas servirían como evidencia de la monofilia. Las apomorfías pueden ser, a su vez, autopomorfías o sinapomorfías. Las autopomorfías constituirían los caracteres exclusivos de un único taxón. Las sinapomorfías, sin embargo, constituirían caracteres apomorfos compartidos por más de un taxón. Las plesiomorfías, por su parte, remitirían a características presentes ya en el ancestro. Cuando estas acaecen en algunos descendientes hablamos de grupos parafiléticos. De esta manera, las simplesiomorfías serían las características que se hallan presentes en el ancestro pero no en todos los descendientes.

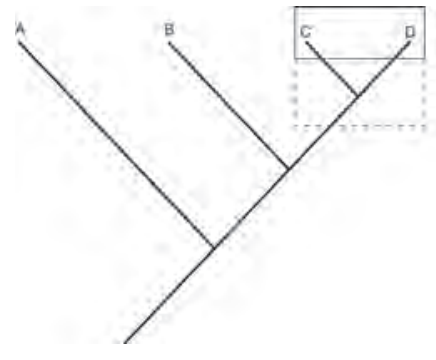

Fig. 1.

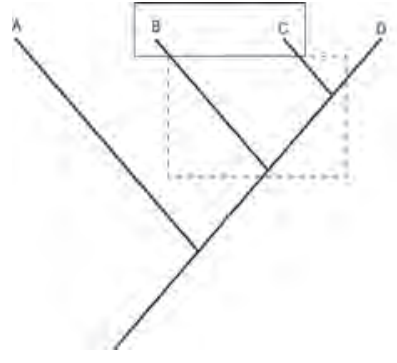

Fig. 2.

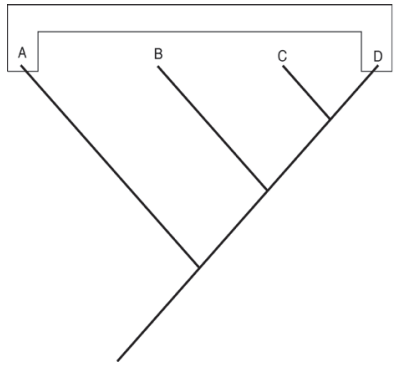

Fig. 3.

Esbozadas las características más relevantes de estos taxones podemos atender a las diferencias que separan a estas dos escuelas. La escuela evolutiva aceptaría tanto los taxones monofiléticos como los parafiléticos aceptando como evidencia tanto las sinapomorfías-autopomorfías como las simplesiomorfías. El ancestro común constituiría un criterio necesario pero no suficiente pues se precisa, además, de la suma de divergencia evolutiva. Ignorar los procesos evolutivos de cada uno de los grupos abocaría a oscurecer 
gran parte de la significación evolutiva de los mismos. Eso sí, esta escuela no aceptaría los taxones polifiléticos y, por ende, tampoco las homoplasias como criterio identificador, básicamente porque aquí no entra en juego el ancestro común. Por su parte, la escuela cladista reconocería únicamente los taxones monofiléticos aceptando únicamente las sinapomorfías-autopomorfías como criterios evidenciales. La razón de esto se debe a que, a juicio de los cladistas, las clasificaciones deberían reflejar únicamente la genealogía, algo que los taxones parafiléticos no logran cumplir del todo pues estos tienen en cuenta, como ya se ha dicho, la cantidad de divergencia evolutiva (Ereshefsky 2001, 55).

\subsection{Multiplicidad e irreductibilidad conceptual}

Las diversas consideraciones esbozadas a lo largo del trabajo han permitido observar dos hechos. El primero, que ninguno de los conceptos propuestos hasta el presente momento parece ser capaz de encerrar la enorme complejidad biológica del mundo orgánico. El segundo, que las dos escuelas taxonómicas más preponderantes de la actualidad divergen en lo relativo a los criterios de clasificación. Para poder concluir este análisis es preciso ver si tres de los principales conceptos de especie esbozados en la sección 4.2.2.1., el concepto ecológico, biológico y filogenético, permiten identificar la misma clase de taxones especie. Esta parece constituir la última esperanza del monista taxonómico: solo si estos tres conceptos permiten identificar de igual forma los diversos taxones especie del mundo orgánico podremos seguir sosteniendo la pertinencia de tal categoría especie ${ }^{10}$.

Analicemos la relación entre el concepto filogenético y el biológico. En primer lugar, el concepto biológico requiere que las especies constituyan entidades causalmente integradas, esto es, requiere que las especies se hallen conectadas entre sí por medio del cruce. Recordemos, era el flujo de genes el principal mecanismo integrador de las especies. Por su parte, el concepto filogenético no requiere de tal conexión e integración causal autorizando, de esta forma, a que las especies puedan vivir en poblaciones aisladas. Esto resolvería el problema planteado por Ehrlich y Raven acerca del cangrejo Emerita analoga pues el concepto filogenético podría recurrir a mecanismos de sostenimiento como la selección o la homeostasis genética (Ereshefsky 1998, 112). En segundo lugar, el concepto biológico y filogenético reconocen un número diferente de taxones especie, de ahí que muchas especies filogenéticas fallen en formar especies de cruce y que muchas especies de cruce fallen en formar especies filogenéticas (Ereshefsky 1998, 112).

Consideremos el primer caso. Como ya se ha visto, el concepto biológico se ve impotente a la hora de abordar el problema de las poblaciones aisladas geográficamente. El concepto filogenético, al reconocer la importancia de fuerzas como la selección o la homeostasis, abriría la posibilidad a poder dar cuenta de la situación de estas especies. Pero no solo eso, si se recuerda, el concepto biológico fallaba a la hora de reconocer a las

${ }^{10}$ La aproximación filogenética sería propuesta explícitamente por los cladistas.

Revista de Humanidades de Valparaíso, 2019, No 14, 241-273

(ㄷ)(1)(8) CC BY-NC-ND 
especies asexuales, algo que no le ocurría al concepto filogenético. La razón de ello era que para el concepto filogenético la importancia no radicaba en la reproducción sino en la monofilia (Ereshefsky 2010b, 410). Vayamos ahora con el segundo caso. El concepto biológico acepta de forma implícita la pertinencia de reconocer taxones parafiléticos, algo que es rechazado de forma taxativa por el concepto filogenético, pues este tiene como criterio esencial el grado de monofilia. Esto ocasiona que el concepto biológico no tenga por qué agrupar a todos los descendientes de un ancestro común en un único taxón.

Ereshefsky $(2001,91)$ pone el siguiente ejemplo. Imagínese por un momento que existen 6 especies emparentadas: A, B, C, D, E y F (Fig. 4). Imagínese ahora que las especies de $\mathrm{C}-\mathrm{F}$ muestran una aptitud para el cruce, aptitud que no despliegan las especies A-B. El concepto biológico reconocería a las especies de C-F como una única especie. ¿La razón? Formarían una comunidad reproductiva ${ }^{11}$. Esto sería tajantemente negado desde el concepto filogenético ya que, de tolerar esta división, lo que se estaría afirmando es la pertinencia de reconocer el taxón parafilético obviando, de esta forma, el ancestro común. Este análisis provoca, además, que el concepto filogenético y biológico disientan en lo relativo al resultado del proceso de especiación alopátrica. Mientras que el concepto biológico reconocería la existencia de la especie ancestral, el concepto filogenético la negaría. La razón de ello radica, de nuevo, en el conflicto entre los taxones monofiléticos y parafiléticos. De reconocer la existencia de la especie ancestral el concepto filogenético estaría autorizando la existencia de taxones parafiléticos, algo que sencillamente no puede hacer (Fig. 5). Habiendo esbozado las principales dificultades teóricas entre ambos conceptos, cabría preguntarse, ¿se materializa verdaderamente esta disensión en la práctica? Ereshefsky reseña un caso sorprendente estudiado por los biólogos Andrew Peterson y Adolfo Navarro-Sigüenza. Mientras que el concepto filogenético reconoció 249 especies endémicas de pájaro en México el concepto biológico reconoció únicamente 101 (Ereshefsky 2010b, 421).

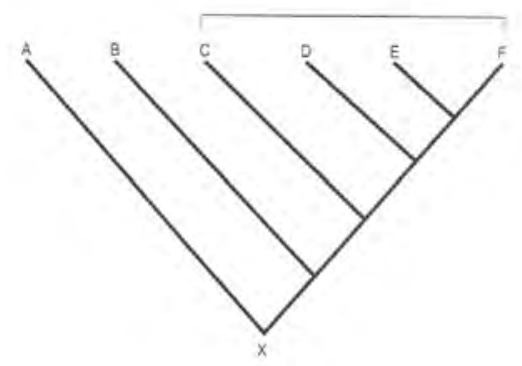

Fig. 4. Ereshefsky 2001, 91.

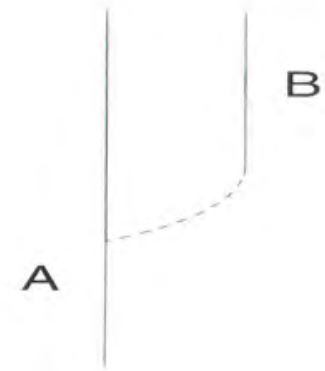

Fig. 5. Ereshefsky 2001, 137.

\footnotetext{
${ }^{11}$ Véase las especies del género Xiphophorus.
} 
Vayamos ahora con las diferencias concernientes al concepto ecológico y biológico de especie. El principal problema reside en que el concepto ecológico abre la posibilidad, al igual que el filogenético, a conformar especies asexuales pues este concepto se basaba en la idea de linajes que ocupaban la misma zona adaptativa mínima. Esta idea era negada tajantemente desde el concepto biológico de especie. Recurramos ahora a dos casos hipotéticos señalados por Ereshefsky (2001) para comprobar de qué forma estos dos conceptos divergen entre sí. Imagínese que se está considerando las especies A, B y C. Imagínese ahora que las especies A y B constituyen linajes que comparten una zona adaptativa mínima (Fig. 6). Sin embargo, supóngase ahora que B y C constituyen linajes sexuales capaces de cruzarse entre sí, siendo A asexual (Fig. 7). Ambos conceptos estarían reconociendo, desde esta perspectiva, distintos taxones especie. Considérese por un momento el concepto de multiespecies propuesto por Van Halen (1976). Para el concepto biológico estas especies constituirían una única especie pues sus miembros mostrarían una aptitud para el cruce. De esta forma, estas multiespecies se hallarían aisladas de otras multiespecies. La cuestión es que el concepto ecológico, por el contrario, sostiene que las especies que conforman dicha multiespecie sostienen su integridad propia.

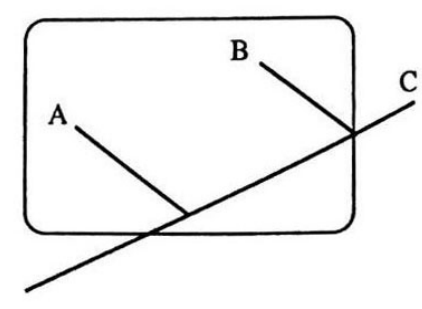

Fig. 6. Ereshefsky 2001, 134).

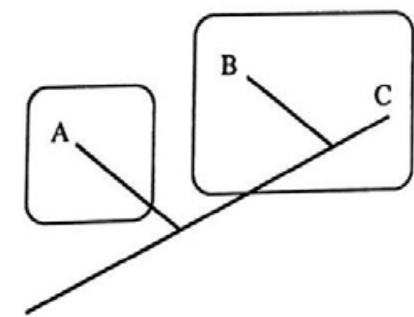

Fig. 7. Ereshefsky 2001, 134.

Consideremos ahora el último caso, el que concierne al concepto ecológico y filogenético. El mayor problema reside en la consideración de la especiación alopátrica. Imaginemos que una fracción de la población se adapta a una nueva zona ecológica diferente de la parental. Imagínese que la especie ancestral o parental permanece estable dentro de su propio nicho. Al igual que ocurría con el concepto biológico, el concepto ecológico de especie reconocería que la especie parental persiste como una especie ecológica (Fig. 5). ¿Cuál es la razón de ello? Sencillamente que el concepto ecológico acepta la pertinencia de los taxones parafiléticos. La cuestión, de nuevo, es que esto es negado de forma tajante por el concepto filogenético. Por este motivo, el concepto filogenético afirmaría que la especie parental se extingue en el momento en el que se produce el proceso de especiación. 
Una discusión en torno a los límites del concepto especie

Mariano Martín Villuendas

\subsection{Pluralismo metafísico y pluralismo taxonómico}

Como se ha podido apreciar, no existe forma alguna de unificar los diversos conceptos de especie. Cada concepto recalca un aspecto particular de la enorme heterogeneidad que rodea al mundo orgánico. Este hecho unido a los análisis llevados a cabo anteriormente debería conducir a un cuestionamiento de la categoría especie y, en última medida, a un cuestionamiento de la perspectiva monista. La enorme complejidad y variabilidad implicadas en las especies hace que únicamente una aproximación pluralista sea la adecuada si lo que se pretende es comprender el mundo orgánico en toda su extensión. Esto es algo que Darwin entendió ya en su día y que autores como Dupré (1993), Ereshefsky (2001) o Philip Kitcher (1984) se han encargado de recordar. Llegados a este punto es necesario exponer qué motivos existen para rechazar tal categoría especie.

En primer lugar, parece que tras la eliminación del esencialismo la pertinencia de la categoría especie queda en entredicho. Quizás Devitt (2008) tenga algo de razón en sus observaciones. Solo se puede explicar el porqué de la conspecificidad entre los diversos organismos, solo se puede explicar cuál es la verdadera definición de especie apelando al esencialismo, apelando a una suerte de propiedades ocultas y fundamentales. Eran esas propiedades esenciales las que permitían explicar las restantes propiedades del tipo, las causalmente responsables de las características del mismo. Este es el principal motivo por el cual las propiedades esenciales se hallan íntimamente ligadas al rol causal, al rol explicativo.

Desde esta perspectiva, parece existir una estrecha relación entre la necesidad de acoger una explicación causal y la pertinencia de sostener un esencialismo en lo relativo a las especies. El gran problema es que Darwin, con sus análisis, desterró del terreno de la biología al esencialismo al reconocer la enorme variación que los miembros de las especies presentaban así como la evolución de las mismas. Estos hechos ocasionaron que ya no se pudiese hablar de una tal propiedad universal instanciada provocando, de esta forma, que el rol causal se desplomase. Este es el motivo por el cual Mayr no es capaz de resolver el problema de la categoría por medio de su concepto biológico. Es imposible dar una respuesta única e incontrovertible al porqué de la conspecificidad sin apelar a esencias intrínsecas o mecanismos fundamentales. Mayr alega, las especies son armas de protección de genotipos bien integrados. Pero ¿cuáles son esos genotipos bien integrados? Mayr se ve incapaz de dar una respuesta incontestable. ¿Cuáles son los mecanismos que permiten proteger esos genotipos bien integrados? Mayr tampoco puede proporcionar una respuesta incontestable a esta pregunta pues, como se ha visto, existe una plétora de procesos causales responsables de dicha integridad. Esto provoca que los grupos definidos con respecto a un proceso no sean congruentes con los definidos respecto a otro proceso. Mishler y Brandon $(1987,401)$ dicen: "Furthermore, there is no reason to believe that reproductive processes and selective processes pick out the same units in nature".

Revista de Humanidades de Valparaíso, 2019, No 14, 241-273

(ㄷ)(1)(8) CC BY-NC-ND 
Entonces, ¿qué es lo que marca ser una especie? ¿Cuál es la definición de especie? Mayr se ve incapaz de aportar una única respuesta satisfactoria a tales preguntas y esto se debe a que solo se puede dar una respuesta satisfactoria al problema de la categoría recurriendo de una forma o de otra al esencialismo. Esta es la razón por la que autores como Samir Okasha han abogado por la eliminación del rol causal-explicativo. A juicio de este autor, debemos limitarnos al rol semántico, es decir, debemos limitarnos a ver las diversas características como simples indicadores de la conspecificidad (Okasha 2002, 204). Esto, por otra parte, no implica negar que existan ciertas propiedades comunes a todos los miembros de una especie, propiedades que nos permitan llevar a cabo ciertas generalizaciones en lo relativo a la unidad y coherencia de las mismas. La cuestión fundamental es que propiedades similares no equivale a propiedades esenciales. Estas propiedades compartidas pueden no ser compartidas por todos los miembros de una especie, incluso pueden modificarse con el tiempo dejando de ser propiedades típicas. Elliott Sober parece concordar con esta postura. A juicio de Sober, las definiciones constituyentes, a pesar de ser elementos completamente operativos en disciplinas como la química, son elementos que no funcionan demasiado bien dentro de la disciplina biológica: "it is no more reasonable to demand a species definition in terms of the properties of constituent organisms" (Sober 1980, 381).

A este hecho se le suman los análisis llevados a cabo a lo largo del presente trabajo en torno a la heterogeneidad de conceptos de especie. Ya no es que existan veinticinco conceptos de especie (Mayden 2002), pues quizás estos conceptos podrían agruparse en grupos más generales. El problema es que los cinco conceptos más generales de especie han demostrado tener una aplicabilidad limitada y lo que es aún peor, los tres conceptos más centrales de especie parecen delimitar los diversos taxones especie de maneras distintas. Estos conceptos hacen hincapié en distintos procesos biológicos, lo cual hace que no se pueda hablar de un mecanismo común y definitorio. Ereshefsky $(1998,113)$ afirma: "Species taxa are maintained by different so they lack a common type of unifying process".

La cuestión de fondo es que no podemos rechazar ninguno de estos conceptos pues todos se muestran relevantes a la hora captar los diversos matices del mundo orgánico (Mayden 2002, 179). El biólogo dedicado al estudio de las zonas híbridas encontrará el concepto biológico sumamente pertinente (bioespecie). El biólogo dedicado al estudio de los diversos nichos ecológicos encontrará que es el concepto ecológico el que mejor se adecua a sus propósitos (ecoespecie). Es posible que un organismo pueda pertenecer a una bioespecie o a una ecoespecie y que estas delimitaciones no sean conmensurables entre sí. No está tan claro qué es lo que divide de forma incontrovertible a unos taxones especie de otros. No está tan claro cuál es la definición única de la categoría especie. La cuestión es que si ya no existen unas características definitorias y un mecanismo causal responsable de las mismas, ¿qué razones tenemos para seguir sosteniendo la pertinencia 
de la categoría especie? ${ }^{12}$ Recordemos, con estos análisis no se buscaba poner en duda la existencia de los taxones especie, sencillamente lo que se pretendía era demostrar que el árbol taxonómico podía ser delineado de muchas y muy diversas maneras en función de los criterios seleccionados. Las especies son entidades reales, pero estas sencillamente carecen de características definitorias o privilegiadas que nos marquen cómo construir la taxonomía correcta. En esta aserción coincide Kitcher (1987, 190-191):

There are many important relations among organisms and, consequently, many sciences that study organisms and classify them from different points of view, taking different relations as the grounds of organismic diversity. No one of these relations - and, consequently, no one of these sciences - has the right to claim that it identifies the ground of organismic diversity.

Dupré parece resumir a la perfección esta intuición:

I am inclined to suspect that the persistence and intractability of the species problem has much to do with a tension between the assumption that science is concerned with dicovering the real essence and unique structure of nature [...] and the only slowly dawnig realization that Darwin has bequeathed us a nature with no such unique structure. (Dupré 1993, 51)

A lo que parecen conducir todas estas afirmaciones es a la pertinencia de considerar la posibilidad de un pluralismo metafísico. Si aceptamos que el mundo ya no está dividido de una forma esencial, si aceptamos que ya no existen tipos naturales impertérritos individuados por sus esencias, si aceptamos que el mundo orgánico evoluciona y se modifica constantemente, si aceptamos que existe una multiplicidad de fuerzas biológicas que segmentan el árbol de la vida de múltiples y muy diversas maneras, entonces resulta difícil poder sostener de manera incontrovertible un monismo metafísico. Indirectamente, al reconocer la posibilidad de abrazar un pluralismo metafísico lo que se está afirmando es la posibilidad de adoptar un pluralismo taxonómico. Rechazar de antemano la posibilidad de tal modelo ontológico y epistemológico supondría rechazar una amplia variedad de herramientas explicativas capaces de dar cuenta de la complejidad de los fenómenos biológicos. De hecho, resulta, cuando menos, paradójico que la biología evolutiva siga haciendo un uso sistemático del sistema taxonómico de Linné, un sistema basado en el esencialismo y el creacionismo. No es ya que este sistema sea inadecuado desde un punto de vista teórico, es que desde un punto de vista práctico este sistema se revela absolutamente deficiente ${ }^{13}$. La razón de ello es sencilla: el sistema de Linné, por sus mismos

\footnotetext{
${ }^{12}$ Quizás sea más útil hablar de ecoespecie, genoespecie, filoespecie o bioespecie.

${ }^{13}$ El sistema de Linné ha sufrido severas modificaciones, las cuales afectan a la inclusión de rangos -16 adicionales- $\mathrm{y}$ a la nomenclatura binomial -cambios e inclusión de nombres para dar cuenta de las subespecies.
}

Revista de Humanidades de Valparaíso, 2019, No 14, 241-273 
presupuestos, es incapaz de abarcar la complejidad de la vida orgánica. Parece pues que la única forma de abrazar en su totalidad los preceptos esbozados por Darwin pasa por suspender la necesidad de dar una respuesta incontrovertible y unívoca al problema de la categoría especie, un problema que parece hundir sus mismas raíces en un esencialismo todavía latente ${ }^{14}$ : "The is no God-given, unique way to classify the innmerable and diverse products of evolutionary process" (Dupré 1993, 57).

\section{Conclusión}

Los análisis llevados a cabo hasta el presente momento revelan la necesidad de replantearse la pertinencia de tratar de aportar una solución unívoca al problema que envuelve a la categoría especie. La enorme pluralidad y diversidad conceptual, así como la inexistencia de un parámetro común capaz de englobar a los diversos conceptos de especie deja entrever la incapacidad de responder de forma inequívoca y definitiva a una pregunta más propia del esencialismo que de la moderna teoría biológica. Como hemos podido observar, el mismo Charles Darwin reconoció la imposibilidad de aportar tal definición una vez aceptadas las ideas base de la evolución por medio de la selección natural. Quizás, lo más conveniente, sea aceptar que la categoría especie es una categoría eminentemente multidimensional, aspecto que se revela crucial a la hora de poder abarcar la enorme complejidad y heterogeneidad que rodea al mundo orgánico. Este hecho, a su vez, debería conducirnos a plantearnos si realmente es adecuado, tanto a nivel teórico como práctico, sostener un monismo tanto metafísico como taxonómico. Según lo esbozado en el presente trabajo, lo más consecuente sería plantearse la posibilidad de aceptar un pluralismo tanto metafísico como taxonómico. Esta opción teórica parece revelarse como la única opción congruente con los planteamientos llevados a cabo por el propio Darwin y con las evidencias empíricas que los mismos biólogos tan cuidadosamente se han molestado en demostrar.

\section{Referencias bibliográficas}

Boyd, R. (1999). Homeostasis, Species, and Higher Taxa. En R. Wilson (ed.), Species. New Interdisciplinary Essays, pp. 141-187. Cambridge: The MIT Press.

Darwin, C. (1859/1964). On the Origin of Species. A Facsimile of the First Edition. Cambridge: Harvard University Press.

\footnotetext{
${ }^{14}$ Ghiselin (1974) y Hull (1976), a través de la tesis de la individualidad, han reconocido que el abandono del pensamiento tipológico conlleva el abandono del intento de definir a las especies (poblaciones). Estas solo se pueden describir, no definir.
} 
de Queiroz, K. (1999). The General Lineage Concept of Species and the Defining Properties of the Species Category. En R. Wilson (ed.), Species. New Interdisciplinary Essays, pp. 49-91. Cambridge: The MIT Press.

de Queiroz, K. (2007). Species Concepts and Species Delimitation. Syst. Biol 56(6): 879-886. doi: https://doi.org/10.1080/10635150701701083

Devitt, M. (2008). Resurrecting Biological Essentialism. Philosophy of Science 75(3): 344-382. doi: $10.1086 / 593566$

Dobzhansky, T. (1970). Genetics of the Evolutionary Process. New York: Columbia University Press.

Dupré, J. (1981). Natural Kinds and Biological Taxa. The Philosophical Review 90(1): 66-90. doi: $10.2307 / 2184373$

Dupré, J. (1993). The Disorder of Things. Metaphysical Foundations of the Desunity of Science. Cambridge: Harvard University Press.

Ehrlich, P., Raven, P. (1969). Differentiation of Populations. Science 165(3899): 1228-1232. doi: https://doi.org/10.1126/science.165.3899.1228

Endler, J. (1973). Gene Flow and Population Differentiation. Science 179(4070): 243-250. doi: https://doi.org/10.1126/science.179.4070.243

Ereshefsky, M. (1998). Species Pluralism and Anti-Realism. Philosophy of Science 65(1): 103120. doi: $10.1086 / 392628$

Ereshefsky, M. (2001). The Poverty of Linnean Hierachy. A Philosophical Study of Biological Taxonomy. Cambridge: Cambridge University Press.

Ereshefsky, M. (2010a). What's Wrong with the New Biological Essentialism. Philosophy of Science 77(5): 674-685. doi: 10.1086/656545

Ereshefsky, M. (2010b). Darwin's Solution to the Species Problem. Synthese 172(3): 405-425. doi: https://doi.org/10.1007/s11229-009-9538-4

Ghiselin, M. (1974). A Radical Solution to the Species Problem. Systematic Zoology 23(4): 536544. doi: https://doi.org/10.1093/sysbio/23.4.536

Hey, J. (2001). The Mind of the Species Problem. Trends in Ecology and Evolution 16(7): 326329. doi: https://doi.org/10.1016/S0169-5347(01)02145-0

Hull, D. (1976). Are Species Really Individuals? Systematics Zoology 25(2): 174-191. doi: https:// doi.org/10.2307/2412744

Kitcher, P. (1984). Species. Philosophy of Science 51(2): 308-333.

Kitcher, P. (1987). Ghostly Whispers: Mayr, Ghiselin, and the Philosophers on the Ontological Status of Species. Biology and Philosophy 2: 184-192. doi: 10.1007/BF00057962.

Lewontin, R. (2000). Genes, organismo y ambiente. Las relaciones de causa y efecto en biología. Barcelona: Gedisa. 
Mayden, R. (2002). On Biological Species, Species Concepts and Individuation in the Natural World. Fish and Fisheries 3: 171-196. doi: https://doi.org/10.1046/j.14672979.2002.00086.x

Mayr, E. (1942). Systematics and the Origin of Species from the Viewpoint of a Zoologist. Cambridge: Harvard University Press.

Mayr, E. (1963). Populations, Species, and Evolution. Cambridge: Harvard University Press.

Mayr, E. (1982). The Growth of Biological Thought. Diversity, Evolution, and Inheritance. Cambridge: Harvard University Press.

Mayr, E. (1987). The Ontological Status of Species: Scientific Progress and Philosophical Terminology. Biology and Philosophy 2: 145-166. doi: https://doi.org/10.1007/BF00057959

Mayr, E. (1988). Toward a New Philosophy of Biology. Cambridge: Harvard University Press.

Mayr, E. (1996). What is a Species, and What is Not? Philosophy of Science 63(2): 262-277. doi: $10.1086 / 289912$

Mayr, E. (2000). The Biological Species Concept. En Q. Wheeler, R. Meier (ed.), Species Concept and Philogenetic Theory. A Debate, pp. 17-30. New York: Columbia University Press.

Mill, J. S. (1843/1963). A System of Logic. En J. M. Robson (ed.), The Collected Works of John Stuart Mill, vol. 8. Toronto: University of Toronto Press.

Mishler, B. (1990). Reproductive Biology and Species Distinctions in the Moss Genus Tortula, as Represented in Mexico. Systematic Botany 15(1): 86-97. doi: https://doi. org/10.2307/2419019

Mishler, B. (1999). Getting rid of Species? En R. Wilson (ed), Species. New Interdisciplinary Essays, pp. 307-317. Cambridge: The MIT Press.

Mishler, B., Donoghue, M. (1983). Species Concepts: A Case for Pluralism. Systematic Zoology 31(4): 491-503. doi: https://doi.org/10.1007/BF00127698

Mishler, B., Brandon, R. (1987). Individuality, Pluralism, and the Phylogenetic Species Concept. Biology and Philosophy 2: 397-414.

Okasha, S. (2002). Darwinian Metaphysics: Species and the Question of Essentialism. Synthese 131(2): 191-213. doi: https://doi.org/10.1023/A:1015731831011

Ruse, M. (1987). Biological Species: Natural Kinds, Individuals, or What? The British Journal for the Philosophy of Science 83(2): 225-245. doi: https://doi.org/10.1093/bjps/38.2.225

Simpson, G. G. (1951). The Species Concept. Evolution 5: 285-298. doi: https://doi. org/10.1111/j.1558-5646.1951.tb02788.x

Sneath, P., Sokal, R. (1973). Numerical Taxonomy: The Principles and Practice of Numerical Classification. San Francisco: W. H. Freeman.

Sober, E. (1980). Evolution, Population Thinking, and Essentialism. Philosophy of Science 47 (3): 350-383. doi: https://doi.org/10.1017/CBO9780511624940.012 
Van Halen, L. (1976). Ecological Species, Multispecies, and Oaks. Taxon 25(2/3): 233-239. doi: https://doi.org/10.2307/1219444

Venn, J. (1866). The Logic of Chance. London: Macmillan.

Wheeler, Q., Meier, R. (2000). Species Concepts and Phylogenetic Theory. A Debate. New York: Columbia University Press.

Wilkins, J. (2009). Species. A History of the Idea. London: University of California Press. 



\title{
El ideal de unificación en biología: el caso de la síntesis evolutiva extendida
}

\author{
The ideal of unification in biology: \\ the case of extended evolutionary synthesis
}

\begin{abstract}
Susana Gisela Lamas
Laboratorio de Investigación en Ontogenia y Adaptación (LINOA), Facultad de Ciencias Naturales y Museo. Universidad Nacional de La Plata, Argentina sglamas@yahoo.com.ar
\end{abstract}

\begin{abstract}
Resumen
En este artículo analizaré si la denominada Síntesis Evolutiva Extendida (SEE) representa una síntesis y una extensión respecto de su predecesora, la Síntesis Moderna (SM). Se argumentará que la SM propone un enfoque externalista de la evolución en tanto que la SEE considera necesario superar la dicotomía internalismo/externalismo proponiendo enfoques más integradores. Se concluirá que la SEE no puede ser considerada una extensión de la SM y que la apelación a esa extensión se relaciona con aspectos sociológicos y con el valor epistémico de la unificación teórica que siempre estuvo presente en el pensamiento evolutivo biológico.
\end{abstract}

Palabras claves: teoría evolutiva, externalismo/internalismo, perspectiva integradora, continuidad teórica, valor epistémico.

\begin{abstract}
In this article I will analyze whether the so-called Extended Evolutionary Synthesis (EES) represents a synthesis and an extension with respect to its predecessor, Modern Synthesis (MS). It will be argued that the MS proposes an externalist approach to evolution while the EES considers it necessary to overcome the internalism/externalism dichotomy by proposing more integrative approaches. It will be concluded that the EES cannot be considered an
\end{abstract}

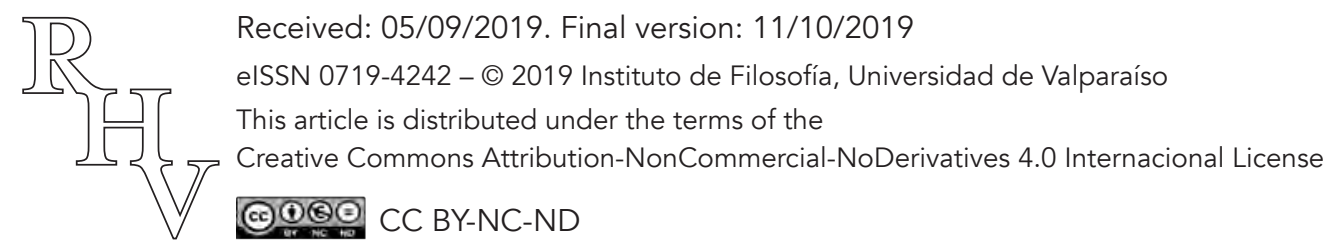


extension of MS and that the appeal to that extension is related to sociological aspects and the epistemic value of theoretical unification that was always present in biological evolutionary thinking.

Keywords: evolutionary theory, externalism/internalism, integrative approach, theoretical continuity, epistemic value.

\section{Introducción}

Julian Huxley en su libro La Evolución. Síntesis Moderna, describe cómo a finales del siglo XIX y principios del XX se proclamó la muerte del darwinismo a partir de la genética mendeliana y los trabajos en fisiología. A este periodo lo denomina el "eclipse" del Darwinismo ${ }^{1}$. Esta metáfora resulta interesante porque un eclipse es un ocultamiento transitorio y esto es exactamente lo que Huxley quiere conseguir con su libro, que el pensamiento de Darwin vuelva a vislumbrarse. Empezará, de este modo, un programa de investigación que conciba a la evolución a partir de los principios explicativos de la genética y la selección natural unificando sus datos y teorías; a esta unificación la denominará sintesis. En ese contexto plantea qué debería entenderse por darwinismo y lo define como una mezcla de inducción y deducción, ya que considera que fue Charles Darwin quien los aplicó por primera vez en el estudio de la evolución. Más adelante Huxley (1943) asevera que Darwin no sólo estableció el hecho de la evolución, sino que también descubrió su mecanismo sentando, así, las bases para continuar con un programa de investigación que se caracterizó por sus aspectos metodológicos y la selección natural como principio explicativo.

Cuando refiere al método de la inducción y la deducción utilizado por Darwin hace alusión a la propuesta de William Whewell en su libro History of the Inductive Sciences ${ }^{2}$. Whewell (1837) utiliza el término inducción para referirse a dos procesos distintos, el de coligación (colligation) y el de coinsilencia (consilience). Por coligación entiende el acto intelectual por el cual el entendimiento establece una conexión precisa entre los fenómenos y la caracteriza como una operación mental que permite unir muchos hechos (suprainducir) y expresarlos mediante una ley general. Mientras que a la coinsilencia la concibe como la capacidad de la hipótesis de explicar o predecir hechos diferentes a los usados cuando se la propuso. Whewell (1837) considera, no obstante, que para que exista inducción no alcanza con unificar muchos hechos, sino que debe proponerse un nuevo

\footnotetext{
${ }^{1}$ Peter Bowler (1985) retomando la noción de eclipse describe el desarrollo del pensamiento evolutivo de principios del siglo XX a cuyas teorías las caracteriza como evolucionistas y antidarwinistas.

${ }^{2}$ History of the Inductive Sciences es el primer tomo del libro Philosophy of Inductive Sciences (1840) escrito por William Whewell.
} 
concepto que haga referencia a este principio suprainducido. Así, siguiendo la lectura que Huxley hace de Darwin, podríamos afirmar que la selección natural representaría este nuevo concepto unificador.

Sin embargo, existen otras interpretaciones acerca del método usado por Darwin en El origen, por ejemplo, Ghiselin (1969) sostiene que Darwin usó un método hipotéticodeductivo. En tanto, Mayr (2001) propone que Darwin fue pragmático y utilizó diversos métodos, en este sentido afirma:

Darwin was a pragmatist and used whatever method he thought would bring him the best results. Darwin was a very keen observer, and there is no doubt that observation was his most productive approach. However, he was also a most skillful experimenter and, particularly in his botanical researches, he conducted numerous experiments. (Mayr 2001, 498)

También existen otros enfoques donde no se enfatiza en el método utilizado sino que se considera a las redes argumentativas a partir de lo existente y lo posible y, en base a ello, se amplía el ámbito de las explicaciones legítimas racionalmente sustentables sin que deban basarse necesariamente en un método (Regner 2002).

Pero, si bien ha habido controversias en este sentido y acerca de si Darwin habría leído el libro de Whewell previamente a escribir El Origen (Ruse, 1975; Thagard, 1977), en su obra explicitó el objetivo de encontrar leyes generales que expongan los mecanismos evolutivos existentes en la naturaleza. En efecto, lo primero que se lee en El origen de las Especies es un epígrafe de Whewell acerca de la importancia de establecer leyes generales en el mundo material, y la selección natural es postulada como esa ley o mecanismo natural:

But with regard to the material world, we can at least go to far as this-we can perceive that events are brought about not by insulated interpositions of Divine power, exerted in each particular case, but by the establishment of general laws. (Whewel, citado por Darwin $1859 / 1964,2)$

No obstante, tal como afirma Smocovities (1996), para los lectores de Darwin sólo había sido establecida la facticidad de la evolución, no su mecanismo o agente causal. En este sentido la interpretación de esta autora es distinta a la proporcionada por Huxley.

Cabe señalar que Darwin, además de la selección natural, también reconoce la importancia de otros medios de modificación que los postula como leyes de la variación ${ }^{3}$, entre los que podemos enumerar a los efectos del cambio de condiciones, el uso y desuso combinados con la selección natural, la aclimatación, la variación correlativa, la

\footnotetext{
${ }^{3}$ Me refiero al capítulo quinto de On the Origin of Species.
} 
compensación y economía del crecimiento, etc. Esto se refleja, asimismo, en la última oración de la Introducción de El Origen, donde explicita que está convencido de que la selección natural ha sido el medio más importante, pero no el único de modificación.

\section{La Síntesis Moderna (SM)}

La lectura que Huxley (1943) hace de Darwin y que, de alguna manera, fue la heredada en los libros de textos de biología, a la que podríamos llamar la historia oficial, supone que Darwin utilizó la metodología de Whewell, llevando a cabo la unificación de datos y postulados científicos provenientes de disciplinas externas a la biología (como la geología, la geografía, etc.) y disciplinas biológicas (como la embriología y otros postulados teóricos como los del uso y desuso, variación correlativa, etc.). Julian Huxley, tal como él mismo lo explicita, se siente heredero del darwinismo y por ello, para la comprensión de la evolución, busca "armonizar" los hechos y los instrumentos de trabajo de las disciplinas tanto biológicas como no biológicas. Dentro de las primeras destaca a la genética mendeliana, la embriología, la ecología, la sistemática, la paleontología y la anatomía comparada. Entre las no biológicas reconoce la importancia del análisis matemático, la geografía y la geología. A esta nueva propuesta la denomina Síntesis Moderna y afirma que consiste, básicamente, en la unificación de los conocimientos de estos campos disciplinares a través de una mirada evolucionista en la cual la selección natural sirva como principio explicativo o mecanismo general para dar cuenta del cambio. El criterio cuantitativo de ese mecanismo lo encuentra en la genética.

Sin embargo, Mayr y Provine (1980) reconocen que las expresiones Síntesis Moderna, Teoría Neo-darwiniana y Neodarwinismo, se utilizaron para referir a diferentes modos de entender el fenómeno evolutivo ofrecidos entre 1920 y 1950 que se basaron en datos y teorías provenientes de la botánica, la sistemática, la paleontología y la genética de poblaciones. Y, tal como lo reconoce Smocovities (1996, 56-57):

The unification of biology and the emergence of evolutionary biology took place just as the centenary of the publication of Darwin's Origin was approaching. Gathering to reexamine and reassess the work of this "great man of science," evolutionary biologists and historians would begin to contribute to the burgeoning literature of Darwin studies. Rereading the present into the past, they reinvented Darwin and Darwinism as neo- Darwinism, and reinterpreted his "theory of descent with modification" as evolution by means of natural selection. Darwin was to be reconstructed once again as the "founding father" of the discipline of evolutionary biology. Yet though Darwin was to be repeatedly hailed as the Newton of biology, it was the "modern synthesis" that would function as the biological analogue of the "Newtonian synthesis" in the grand narrative of the history of science.

De esta forma, la SM queda establecida como el nuevo conjunto de teorías "herederas" de Darwin, la selección natural como su principio unificador y la genética de poblaciones 
como la disciplina que permite mostrar mediante modelos matemáticos la evolución. Asimismo, no sólo se plantea la factibilidad de la selección natural sino que queda establecida como principio mecánico causal. A partir de la SM la evolución se definirá como el cambio en la composición genética de las poblaciones, lo que conlleva a restringir los procesos evolutivos sólo a aquellos que cambian directamente las frecuencias génicas, a saber, la selección natural, la deriva, el flujo genético y la mutación. De ahí que fenómenos relacionados con las limitaciones o canalizaciones del desarrollo no se considerarán causales de procesos evolutivos debido a que no modifican directamente las frecuencias génicas.

En el proceso de desarrollo de la SM, a pesar de lo expresado por Huxley (1943), varias disciplinas fueron dejadas de lado para dar cuenta de la evolución, entre ellas la embriología que devendrá en la biología del desarrollo y la fisiología. Más adelante veremos las consecuencias que estas ausencias ocasionaron al propio darwinismo. Así, podemos advertir cómo la SM propuso un "endurecimiento" del pensamiento de Darwin, al negligir la importancia de campos disciplinares por él aceptados para entender el fenómeno evolutivo (por ejemplo, la embriología, la fisiología, etc.) y ello devino en un modo mucho más pasivo de conceptualizar a los organismos en relación al ambiente. Esta división queda claramente expresada cuando Ernest Mayr (1998) propone una diferencia entre causas próximas y remotas, afirmando que sólo estas últimas pueden dar cuenta del proceso evolutivo.

\section{El internalismo y externalismo en la biología}

Kauffman (1993), parafraseando a Monod y desde un enfoque diferente, analiza cómo el pensamiento evolutivo busca entender el orden, y asegura que en el siglo XX ha habido dos perspectivas teóricas distintas que provienen de dos tradiciones que se fundamentan en dos enfoques diferentes, el de la selección y el de la auto-organización que él pretende relacionar. En esta misma línea García Azkonobieta (2005) caracteriza así a estos enfoques:

La visión externalista intenta comprender los sistemas vivos como producto de un proceso histórico adaptativo que puede interpretarse como el cambio de las frecuencias genéticas de las poblaciones en función de las presiones selectivas externas del entorno. La visión internalista, por su lado, considera la comprensión de la organización biológica como una condición previa necesaria e ineludible para poder entender la evolución, y es más, tiende a tratar la evolución como un factor secundario, no esencial de la vida. (García Azkonobieta 2005, 9)

En este sentido, el endurecimiento de la SM antes mencionado, supuso una mayor separación entre las visiones internalista y externalista, al proponer a la selección natural como el mecanismo del cambio evolutivo considerando, por tanto, a los organismos con 
un rol mucho más pasivo que el propuesto por Darwin. Así la SM iniciada por Huxley se caracterizó por dejar de lado disciplinas como la fisiología y la embriología vinculadas con los procesos internos de los organismos, a pesar de haberse expresado en sentido contrario en su libro.

En la década de los '90 se critica severamente a la visión externalista y a los enfoques centrados en la genética. Oyama (2000a) utiliza la expresión imperialismo genético para referirse a las explicaciones biológicas evolutivas basadas en el gen y reconoce que hay otros factores que influyen en la herencia como los factores físicos, químicos, biológicos, ambientales y comportamentales que participan en el desarrollo pre y postnatal. Asevera, asimismo, que genes y entorno son parte de los sistemas de desarrollo que producen los fenotipos (Oyama 2000a). De esta manera propone entender al proceso evolutivo desde la perspectiva de los sistemas de desarrollo dentro del cual estarían incluidos los genes, es decir cambia el gen-centrismo por una perspectiva más integradora. Así Susan Oyama et al. (2001) plantean llevar a cabo explicaciones evolutivas donde se analicen los sistemas de desarrollo desde diferentes enfoques con el objetivo de proponer no una teoría entendida como modelo teórico sino un programa de investigación. En este sentido afirma:

What we have come to term developmental systems theory is not a theory in the sense of a specific model that produces predictions to be tested against rival models. Instead, it is a general theoretical perspective on development, heredity and evolution, a framework both for conducting scientific research and for understanding the broader significance of research findings. (Oyama et al. 2001, 8-9)

Es por ello que se advierte la necesidad de relacionar diferentes campos disciplinares a fin de proporcionar una red teórica o programa amplio de investigación que permita entender las múltiples causas que intervienen en los procesos de herencia y evolución donde las nociones de natura/nurtura, biología/cultura, genes/ambiente, no se entiendan de modo dicotómico (Oyama 2000b; Oyama et al. 2001). Este programa se fue extendiendo a diferentes áreas de conocimiento y, en el pensamiento evolutivo, se desarrollaron campos disciplinares novedosos como evo-devo (evolution and development), la epigenética y la construcción del nicho que plantearon una mirada integradora de los fenómenos biológicos. De esta manera, la teoría de los sistemas de desarrollo permitió una superación en los enfoques internalistas y externalistas antes mencionados proveyendo explicaciones más abarcativas de los procesos evolutivos.

\section{La Síntesis Evolutiva Extendida (SEE)}

En este contexto y reconociendo no sólo las anomalías que presentaba la SM sino el marco desde el cual esa teoría analizaba la evolución, un grupo de científicos y filósofos de la ciencia se dieron cita en el Instituto Korand Lorenz en Altenberg, Austria para realizar 
un simposio en el año 2008. Manifestaron la necesidad de proponer una nueva teoría de la evolución a la que denominaron Síntesis Evolutiva Extendida (SEE) que posee muchos aspectos en común con la Teoría de los Sistemas de Desarrollo. En la denominación de esta teoría aparecen dos términos sobre los que vale la pena detenerse síntesis y extendida. Sus autores aseveran que es una síntesis porque reconocen que han reunido datos y teorías de diversos campos disciplinares para dar cuenta del proceso evolutivo desde una perspectiva más integrativa que la SM. Y esos campos estarán representados por la epigenética, evo-devo, la plasticidad del desarrollo y la teoría de la construcción del nicho (Laland at al. 2015).

No obstante, cuando los principales representantes de la SEE argumentan acerca de por qué utilizan la noción de extensión, afirman que en la SEE mantienen los postulados de la SM aunque se enfatice en el rol que cumplen otros procesos. Así Laland et al. (2015, 1) sostienen:

The latter, which we label the 'extended evolutionary synthesis' (EES), retains the fundaments of evolutionary theory, but differs in its emphasis on the role of constructive processes in development and evolution, and reciprocal portrayals of causation. In the EES, developmental processes, operating through developmental bias, inclusive inheritance and niche construction, share responsibility for the direction and rate of evolution, the origin of character variation and organism-environment complementarity.

Por otra parte Pigliucci (2007) reconoce que sigue la propuesta de Popper al considerar que la SM es la teoría de los genes y la SEE es la teoría de las formas y que se necesita de ambas para entender los procesos evolutivos, y de allí la necesidad de unificarlas. El problema de este argumento radica en que asimila la genética a la genética de poblaciones y esa identificación, en la actualidad, no es correcta; puesto que, la información proveniente de la genética ha influido en el pensamiento evolutivo más allá de la genética de poblaciones por ejemplo con Evo-devo o el Proyecto Genoma. Además la SM se basa en ciertos prerrequisitos, como la gradualidad, el adaptacionismo, la selección natural y el gencentrismo. Todos ellos contrarios a los prerrequisitos de la SEE (Müller 2017).

Si la SEE no posee un enfoque externalista sino que intenta superar estos enfoques dicotómicos y no es una teoría basada en la genética sino en una perspectiva más integradora para explicar la evolución, cabría preguntarnos por qué se la denomina extendida. ¿Qué se extiende? Para responder a estas preguntas primero analizaremos algunas de las afirmaciones de Laland et al. $(2015,3)$ :

We conclude that the EES is not just an extension of the MS but a distinctively different framework for understanding evolution, which, alongside more traditional perspectives, can be put to service constructively within the field.

Revista de Humanidades de Valparaíso, 2019, No 14, 275-286

(ㄷ)(1)임 CC BY-NC-ND 
Parecería ser contradictorio denominar a una teoría SEE y afirmar, por otro lado, que no es una extensión. ¿Por qué llamarla así, entonces? Considero que hay dos razones diferentes, una de orden sociológica y otra epistémica. Analizaré cada una por separado.

Llamaré razones sociológicas a aquellas relacionadas con los aspectos vinculados con la comunidad científica. En la comunidad científica hay diferentes criterios de credibilidad y de autoridad que se traducen no sólo en qué opiniones recibirán más crédito y gozarán de una mayor aceptación; sino también en los criterios editoriales para evaluar los trabajos en revistas científicas especializadas y en los grupos y líneas de pesquisa que recibirán los susidios de investigación. En el caso del pensamiento evolutivo los científicos formados en la SM siguen manteniendo gran parte de esa autoridad y, en mi opinión, esa es una de las razones por las que los proponentes de la SEE argumentan a partir de la continuidad y no de la ruptura conceptual. Este fenómeno ya ha sucedido otras veces con la SM, un ejemplo es el análisis de Gould (2004) acerca del endurecimiento que tuvo la SM respecto al adaptacionismo:

The community of evolutionary biologists is sufficiently small, and sufficiently stratified - a few lead and many follow, as in most human activities - that we need not necessarily invoke some deep and general scientific or societal trend to explain a change in opinion by a substantial community of evolutionists in different nations. A reassessment by a few key people, bound in close contact and mutual influence, might trigger a general response. The three leading exponents of hardening in America-Dobzhansky, Simpson, and Mayrworked together as colleagues in a "New York Mafia" centered at Columbia University and the American Museum of Natural History. (Gould 2004, 543)

Por otro lado, ya ha sido ampliamente discutido en la bibliografía filosófica el rol de la comunidad y los obstáculos para aceptar los cambios científicos. Y, en cierto sentido, aceptar la selección natural como mecanismo evolutivo por parte de los defensores de la SM y de la SEE da una idea de continuidad entre las teorías que permite interpretar de un modo acumulativo sus cambios conceptuales. Esto, de algún modo, está relacionado con el segundo factor antes mencionado, el epistemológico.

A lo largo de este artículo se expuso cómo en las diferentes teorías darwinistas se argumenta a favor de la nueva propuesta teórica apelando a la unificación. En el pensamiento evolutivo el ideal de unificación estuvo presente desde Darwin, proponiendo que cada teoría comprende a las demás y agrega nuevos postulados.

No obstante, lo que ha sucedido en diversas ocasiones es que se mantiene el término pero se modifica su significado, por lo cual la nueva teoría no refiere a lo mismo que la anterior. Pero, al utilizar los mismos términos y enseñar en los libros de textos este enfoque unificador, las rupturas se desvanecen. Esto puede verse, por ejemplo, con la noción de selección natural como la supervivencia del más apto en Darwin y como reproducción 
diferencial en la SM. Se habla de dos procesos diferentes, relacionados con distintos niveles de organización y con principios explicativos distintos. Pero parecería haber una continuidad entre uno y otro.

Lo mismo sucede con las denominadas Teorías Neo-Lamarckianas cuando aluden a caracteres adquiridos. Para Lamarck (1809) estos caracteres están estrechamente unidos al uso y desuso y son fenotípicos. En la actualidad no se apela al uso y desuso y uno de los indicadores de herencia epigenética son los grupos metilos que no representan un carácter fenotípico. Es decir, la utilización de un mismo término no es condición suficiente para afirmar que exista continuidad entre dos propuestas teóricas.

De algún modo considero que algo similar está sucediendo en la discusión entre la SM y la SEE, sus supuestos son diferentes. No obstante, los proponentes de la SEE señalan que hay procesos evolutivos que potencialmente pueden poseer la misma importancia que la selección natural. Considero que esta apelación constante a la selección natural es lo que permite interpretar a la SEE como una extensión de la SM; porque habría principios o supuestos explicativos que se mantienen. Y esa, en mi opinión, es la razón epistémica para entenderla en términos de unificación y acumulación cognitiva por autores que defienden a una u otra teoría.

Pigliucci y Müller (2010) no estarían de acuerdo con esta última interpretación. Ellos proponen un modelo que grafican en forma de elipses para concebir el cambio conceptual evolutivo que lo representan como una continua expansión de la teoría evolutiva en un diagrama con elipses inclusivas que comienza con tres principios de Darwin: Variación, herencia y selección natural. Continúa con los postulados de la SM: mutación genética, herencia mendeliana, genética de poblaciones, contingencia, especiación y tendencias. Y, finaliza con los de la SEE: evo-devo, plasticidad y acomodación, construcción del nicho, herencia epigenética, teoría del replicador, evolvabilidad, selección a multinivel y evolución genómica.

Pero algunas de estas disciplinas parten de supuestos distintos y, en algunos casos, contradictorios. Es importante tomar esto en consideración porque no se trata sólo de incluir a disciplinas o prácticas diversas sino que también es necesario reflexionar acerca de sus enunciados teóricos. Por ejemplo, si analizamos la genética de poblaciones en relación con la selección multinivel, la primera afirma el cambio en las frecuencias génicas (reproducción diferencial) como un indicador de la selección natural. Pero esto no sería aceptable para la selección a multinivel. Luego, entender al cambio acumulando disciplinas podría llevarnos a la aceptación de principios explicativos inconsistentes entre sí. 


\section{Conclusiones}

La SM propone a la selección natural como la principal fuerza evolutiva con un enfoque gen centrista y una estrecha vinculación con el adaptacionismo. Este último, a su vez, supone un enfoque gradual del cambio, reduccionista y externalista, en el cual el organismo es pasivo frente a los cambios ambientales.

La SEE, por otro lado, intenta vincular los enfoques internalista y externalista superando su modo dicotómico de comprender los procesos evolutivos. De esta manera, propone analizar los cambios a partir de una interrelación organismo-ambiente donde el ambiente modifica al organismo pero también el organismo modifica al ambiente. Uno de los pilares fundamentales de los procesos evolutivos es la herencia porque permite entender el cambio inter-generacional, proporcionando una perspectiva histórica. En este sentido, la SEE acepta cuatro sistemas de herencias que están vinculados a los campos disciplinares que desarrollaron esta teoría: el genético, el epigenético, el ambiental y el comportamental. Claramente los tres últimos no son aceptados por la SM pero ¿qué podemos decir respecto al primero? Los aspectos genéticos en la SEE fueron desarrollados fundamentalmente por los científicos pertenecientes a Evo-devo quienes llegaron a conclusiones bastante diferentes a las obtenidas por la SM. Esta última reconoce la necesidad de que exista variabilidad genética para explicar los cambios evolutivos. Evodevo, en cambio, considera que hay conservación de genes y que los mismos genes regulatorios son compartidos por animales con diferente plan corporal (ej: insectos y vertebrados). Y, además, que esos genes tienen roles conservados en el desarrollo.

Es por todo lo anteriormente dicho que considero que la SEE es una síntesis pero no es una extensión de la SM. Y, quizás, cuando las relaciones de poder sean modificadas en la comunidad científica, se apelará a los principios explicativos de la SEE - ya sean los actuales o algunos otros que se propongan en un futuro- sin necesidad de apelar a la selección natural como fuerza evolutiva.

\section{Agradecimientos}

Agradezco al Dr. Vicente Dressino por sus comentarios y ayuda. Esta investigación es llevada a cabo con el subsidio del Proyecto de Incentivos 11/N907 de la Universidad Nacional de La Plata.

\section{Referencias bibliográficas}

Bowler, P. (1985). El eclipse del darwinismo: teorías evolucionistas antidarwinistas en las décadas en torno a 1900. Barcelona: Ed. Labor.

Darwin, C. (1859/1964). On the Origin of Species. A Facsimile of the First Edition. Cambridge: Harvard University Press.

Revista de Humanidades de Valparaíso, 2019, No 14, 275-286

(c) (1) 8 (을 $\mathrm{CC}$ BY-NC-ND 
El ideal de unificación en biología: el caso de la síntesis evolutiva extendida

Susana Gisela Lamas

García Azkonobieta, T. (2005). Evolución, desarrollo y (auto)organización. Un estudio sobre los principios filosóficos de la evo-devo. Tesis doctoral. Donostia-San Sebastián: Universidad del País Vasco.

Ghiselin, M. T. (1969). The Triumph of the Darwinian Method. Berkeley: University of California Press.

Gould, S. J. (2004). The Structure of Evolutionary Theory. Massachusetts y Londres: The Belknap Press of Harvard University Press Cambridge.

Huxley, J. (1943). The Modern Synthesis. London: George Allen \& Unwin L.T.D.

Kauffman, S. (1993). The origins of order: self-organization and selection in evolution. Oxford: Oxford University Press.

Laland, K. N., Uller, T., Feldman, M. W., Sterelny, K., Müller, G. B., Moczek, A., Jablonka, E., Odling-Smee, J. (2015). The extended evolutionary synthesis: its structure, assumptions and predictions. Proc. R. Soc. B., 282(1813). doi: http://doi.org/10.1098/rspb.2015.1019

Lamarck, J. B. (1809). Philosophie zoologique. Paris: Dentu.

Mayr, E. (2001). The philosophical foundations of darwinism. Proceedings of the American Philosophical Society, 145(4): 488-495.

Mayr, E., Provine W.B (1980). The Evolutionary Synthesis: Perspectives on the Unification of Biology. Cambridge: Cambridge University Press.

Mayr, E. (1998). This Is Biology: The Science of the Living World. Cambridge, MA: Harvard University Press.

Müller, G.B. (2017). Why an extended evolutionary synthesis is necessary? Interface Focus 7: 20170015. doi: http://dx.doi.org/10.1098/rsfs.2017.001

Oyama, S. (2000a). Evolution's Eye: A Systems View of the Biology-Culture Divide. Durham, NC: Duke University Press.

Oyama, S. (2000b). The Ontogeny of Information: Developmental Systems and Evolution. Durham, NC: Duke University Press.

Oyama, S., Grifiths, P. E., Gray, R. D. (2001). Cycles of Contingency. Developmental Systems and Evolution. Massachusetts: The MIT Press.

Pigliucci, M. (2007). Do We Need an Extended Evolutionary Synthesis? Evolution, 61(12): 27432749. doi: https://doi.org/10.1111/j.1558-5646.2007.00246.x

Pigliucci, M., Müller, G. B. (2010). Evolution: The Extended Synthesis. Massachusetts: The MIT Press.

Regner, A. C. (2002). O «jogo do atual e do possível» e as manhas da razão: un estudo de caso. En F. Tula Molina y P. Lorenzano (eds.), Filosofía e historia de la ciencia en el Cono Sur. Quilmes. Argentina: Editorial UNQ.

Revista de Humanidades de Valparaíso, 2019, No 14, 275-286

(c) (1) 8 을 BY-NC-ND 
Ruse, M. (1975). Darwin's debt to philosophy: An examination of the influence of the philosophical ideas of John. W. Herschel and William Whewell on the development of Charles Darwin's theory of Evolution. Stud. Hist. Phil. Sci., 6(2): 159-181. doi: https://doi.org/10.1016/00393681(75)90019-9

Smocovities, V. B. (1996). Unifying Biology. The Evolutionary Synthesis and Evolutionary Biology. Princeton, New Jersey: Princeton University Press.

Thagard, P. R. (1977). Discussion Darwin and Whewell. Stud. Hist. Phil. Sci., 8(4): 353-356. doi: https://doi.org/10.1016/0039-3681(77)90026-7

Whewel, W. (1837). History of the Inductive Sciences. From the Earliest to the Present Times. London: J. W. Parker.

Whewel, W. (1840). Philosophy of the Inductive Sciences. Founded Upon Their History. London: J. W. Parker. 


\title{
Androcentrismo, ciencia y filosofía de la ciencia
}

\author{
Androcentrism, science and philosophy of science
}

\author{
Federico Nahuel Bernabé \\ Universidad Nacional Arturo Jauretche; \\ CEFHIC-Universidad Nacional de Quilmes, Argentina \\ fnbernabeblach@gmail.com
}

\begin{abstract}
Resumen
En este trabajo retomaremos los aportes de la filosofía feminista de la ciencia en torno al androcentrismo, con especial énfasis en la biología y las ciencias biomédicas. Propondremos que tales aportes pueden ordenarse atendiendo a tres sentidos distintos de androcentrismo, y que entre tales sentidos aparecen tensiones importantes. Siguiendo el camino trazado por Longino, el empirismo crítico contextual, defenderemos que la reconstrucción racional de teorías puede ayudarnos a precisar dónde se agazapan los vectores de decisión patriarcales en la práctica científica. Para ello, presentaremos un análisis alternativo al de Longino y lo utilizaremos como insumo para discutir la idea de cerebros tipo en el marco de la neuroendocrinología del comportamiento.
\end{abstract}

Palabras clave: androcentrismo, biología, feminismo, estructuralismo, filosofía.

\begin{abstract}
In this work we will take up again the contributions of the feminist philosophy of science around androcentrism, with special emphasis on biology and biomedical sciences. We will propose that such contributions can be ordered according to three different senses of androcentrism, and that important tensions appear between these senses. Following the path traced by Longino, contextual critical empiricism, we will defend that the rational reconstruction of theories can help us to specify where patriarchal decision vectors crouch in scientific practice. To this end, we will present an alternative analysis to Longino's and use it as an input to discuss the idea of type brains in the framework of the neuroendocrinology of behaviour.
\end{abstract}

Keywords: androcentrism, biology, feminism, structuralist view of theories, philosophy.

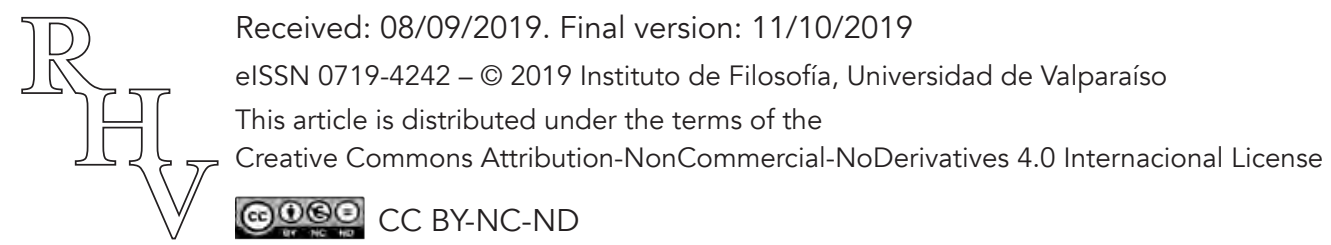




\section{La(s) filosofía(s) feminista(s) de la ciencia y la polisemia del androcentrismo}

Hablar de la filosofía feminista de la ciencia (FFC) como una corriente o escuela de pensamiento bien delimitada constituye una simplificación inaceptable. Consideramos más adecuado hablar de un movimiento filosófico, pues el rótulo FFC se aplica a líneas de pensamiento fuertemente heterogéneas, las cuales comparten a lo sumo una orientación general y algunas ideas centrales. Esa mínima común orientación puede precisarse como sigue:

1. La afirmación de la existencia de valores extracognitivos de naturaleza androcéntrica en ciencia.

2. La afirmación de que tales valores son ineliminables.

\section{Porque,}

3. los y las científicas son sujetos cognoscentes situados (situated knowers).

Ahora bien, la situacionalidad del conocimiento y la ineliminabilidad de los valores no son, por supuesto, aportes originales de la FFC, más bien es un lugar común en la filosofía de la ciencia postkuhneana (Gómez 2015). El primer rasgo propio y característico de la FFC es la atención al problema del androcentrismo, dentro del problema general de los valores. Además, los trabajos de la FFC y de la crítica feminista de la ciencia en general constituye el acervo de ejemplares más grande del modo en el que los valores (en este caso, androcéntricos) performan la actividad y los productos científicos. El segundo rasgo, es un fuerte compromiso militante con la transformación social y por ende con la transformación de la ciencia.

Hasta aquí las similitudes qua movimiento filosófico. Cómo presentar las distintas corrientes, sus divergencias y solapamientos, constituye en sí mismo un problema. Si bien la primera taxonomía propuesta por Sandra Harding (1986) que distingue entre empirismo, perspectivismo (standpoint theory) y posmodernismo, ha sido la más difundida, nos inclinaremos por la propuesta más reciente de Elizabeth Potter (2006). En concreto, sirve a nuestros fines pues propone ordenar las corrientes atendiendo no cuestiones de marco sino al modo en el que responden al desafío de la ciencia cargada de valores (patriarcales): de más normativas a más naturalistas.

Representado por Harding $(1986 ; 1993)$ en su versión clásica o estándar y por Alison Wylie (2003) en una versión revisada y más cercana al empirismo, el perspectivismo feminista hereda de la epistemología marxista el rechazo del sujeto ahistórico de conocimiento y la pretendida neutralidad respecto al punto de vista desde el que se construye el conocimiento. Así mismo, sostiene que la perspectiva del grupo social oprimido (las mujeres, pero no sólo, también la raza, la clase social etc.) aporta lo que se ha dado en llamar objetividad fuerte, frente a una objetividad débil de la perspectiva del opresor/dominante. Y esto, porque el oprimido ve todo lo que ve el opresor y además todo aquello que a aquél

Revista de Humanidades de Valparaíso, 2019, No 14, 287-313

()ㅇㅇㅇㅛ CC BY-NC-ND 
se le escapa. En este sentido, la standpoint theory defiende una epistemología sostenida desde los estilos cognitivos del grupo oprimido, que no sólo suponga un empoderamiento de este sino una mejora epistémica para el conjunto. Así, el perspectivismo es una teoría crítica al estilo de la escuela de Frankfurt, con un fortísimo componente pragmático y emancipatorio.

Empirismo contextual: fundamentalmente sostenido por Helen Longino (1994; 1997) es una de las posturas más fructíferas del feminismo en filosofía de la ciencia. Lo que Longino defiende es que la buena lógica y la evidencia empírica son necesarias pero no suficientes para dar cuenta de la justificación y el rechazo-aceptación de teorías. La actividad científica conlleva esencialmente supuestos de contorno, elementos volicionales sociales y políticos que juegan el rol de vectores de decisión. Hasta aquí, la propuesta es más o menos estándar a partir de la obra de Kuhn, pero lo profundamente original es la propuesta de objetividad de la autora: dado que siempre hay valores, la objetividad se construye a partir de la elucidación de aquellos valores operantes en las distintas teorías/ hipótesis y la discusión crítica intersubjetiva de los mismos. Esto permite garantizar el control de las teorías no sólo en el nivel fáctico o conceptual, sino también axiológico.

Empirismo feminista naturalizado: heredera directo de Quine, la propuesta de Lynn Hankinson Nelson $(1990 ; 1993)$ consiste en tomarse en serio el holismo empirista quineano: no hay diferencias fuertes entre observación y teoría, la filosofía y la ciencia son disciplinas cuya tarea es continua. La filosofía debe brindar una teoría acerca del modo en el cual se construyen teorías científicas mejores. La normatividad aquí es nula: por el holismo contrastacional sabemos que cuando una teoría es puesta a prueba, lo hace el sistema conceptual completo en el que ocurre, incluidas creencias de sentido común y valores epistémicos y no epistémicos. Dado que no hay una distinción interesante entre hechos y valores, no podemos decir que la comunidad de científicos que sostiene posiciones patriarcales hace mala ciencia. En términos de la acción filosófica, parece llamar a una especie de quietismo naturalista.

Dentro de esta riqueza de posiciones, en este trabajo nos ubicaremos en la órbita del empirismo contextual crítico de Longino. Las razones para ello son múltiples y no se presentarán en detalle, pero vale señalar nuestro argumento central: tiene la dosis justa de normativismo como para que el trabajo de análisis filosófico tenga sentido. Como ya señalamos, y por muy sugestivo que resulten las posiciones naturalizadas, subsiste el problema del quietismo filosófico, depositando sobre la sociedad y sus procesos la desaparición de los valores patriarcales de la labor científica. En la otra esquina, el perspectivismo dinamita toda idea de corrección parcial de la ciencia, tanto en su versión marxista como posmoderna: todo es ideología, por lo que el trabajo analítico y crítico de la filosofía de la ciencia sería estéril. Frente a estos tigris y éufrates, se extiende el camino de Longino, cuya posición metodológica parte de que "the logical and cognitive structures of scientific inquiry requires such interaction" (Longino 1990, 5.) No es que los valores no epistémicos como vectores de decisión sean contrabando indeseable en la actividad científica, 
sino que dada la infradeterminación de la teoría por los hechos, tales vectores de decisión valorativos son esenciales a la actividad científica. Justamente, lo interesante de la propuesta longiana es la aceptación positiva de los valores no epistémicos y la búsqueda de una salida al problema de la objetividad que no suponga en algún sentido la negación de estos. Pues es precisamente en la negación, la invisibilización de los valores no epistémicos donde reside la reproducción científica de la opresión.

La solución pasa entonces por la discusión racional de los valores presupuestos por las teorías en disputa. Para ello, se establecen cuatro condiciones básicas o normas para el empirismo contextual crítico (Borgerson 2011):

1. Espacios reconocidos para el criticismo, es decir, deben existir revistas académicas, congresos u otras instancias reconocidas por la comunidad científica en las que se generen discusiones críticas acerca del desarrollo de una disciplina dada.

2. El criticismo no debe ser ignorado, esto es, los y las científicas deben hacerse cargo de las revisiones críticas de sus pares.

3. Estándares públicos y compartidos. La crítica efectuada por los pares requiere la aceptación compartida de ciertas reglas que han de ser públicas para garantizar que todos y todas las participantes de la discusión hablan de lo mismo.

4. Razonable igualdad de autoridad, es decir, la aceptación o rechazo de teorías o hipótesis debe residir en la discusión intersubjetiva y no en la autoridad de quién propone tal o cual teoría.

Central al empirismo contextual crítico es, por tanto, la negación del científico individual y ahistórico como sujeto de la ciencia. En una clara herencia historicista, Longino revaloriza la práctica colectiva de la ciencia como instancia de decisión racional de los valores no epistémicos presupuestos en la práctica científica. Finalmente, lo más importante para nuestros intereses es que es un presupuesto para la práctica del FFC que los valores deben ser explicitados. Ahí es donde entendemos que la filosofía qua análisis elucidatorio y reconstructivo puede jugar un rol importante, tal y como la misma Longino dice y muestra.

\subsection{Los tres sentidos de androcentrismo}

Aun cuando aquí seguiremos el camino programático de Longino, la denuncia de la persistencia de sesgos androcéntricos o valores patriarcales en la práctica y en los productos científicos es un resultado general de la FFC en su conjunto. Ahora bien, defenderemos que androcentrismo se dice de al menos tres maneras, las cuales están estrechamente vinculadas, pero son distinguibles y en ciertos casos pueden generar tensiones internas. 
En primer lugar, androcentrismo se dice en un sentido sociológico y se evidencia en la escasez de mujeres y cuerpos feminizados en la ciencia. Esta escasez no es ni única ni principalmente numérica, sino respecto a los cargos y puestos de poder dentro de las comunidades. Así mismo, el sesgo androcéntrico sociológico se manifiesta en la feminización de ciertas áreas en detrimento de otras, el reparto de tareas en los laboratorios y en el trabajo de campo. Esta dimensión ha sido ampliamente explorada en los países centrales y se vinculó con los primeros pasos de la crítica feminista de la ciencia, e incluso con las primeras políticas inspiradas en estas críticas (incorporación de las mujeres a la ciencia, la idea de mujer científica). Para una revisión de literatura extensa y reciente, puede consultase Tacsir et al. (2014).

El segundo sentido de androcentrismo apunta a la línea de flotación de la objetividad científica, el androcentrismo conceptual/explicativo: la elección de teorías está sesgado en favor de aquellas que reproducen y naturalizan el estatus quo opresivo hacia las mujeres. Las comunidades científicas favorecen aquellas teorías que van mano a mano con el prejuicio sobre la inferioridad intelectual de las mujeres.

Este androcentrismo explicativo/conceptual ha resultado protagónico en los trabajos más importantes de la FFC, particularmente en áreas como la biología evolutiva, la arqueología (Wylie 1997), la neurociencia y las ciencias del comportamiento (Fausto-Sterling 1992). En cada una de esas áreas las autoras han mostrado cómo las teorías que mantenían una perspectiva favorable a la dominación masculina han sido mejor aceptadas que otras, incluso, han sobrevivido a abundante evidencia contraria. La posición general tomada a partir de estos hallazgos consiste en dudar de toda perspectiva científica que aborde, desde una perspectiva biológica, las diferencias entre machos y hembras de nuestra especie. Esta duda o sospecha va desde una lectura crítica de los resultados obtenidos por tales perspectivas biológicas, hasta la calificación de mera ideología de estos trabajos.

Finalmente, hay un tercer sentido de sesgo androcéntrico al que hemos dado en llamar subrogativo y consiste en la exclusión de las mujeres y la diversidad qua objetos de estudio de las ciencias. Particularmente potente en el área biológica y biomédica, el sesgo surrogativo toma como modelo para la producción del conocimiento al hombre. Lo más interesante es que este sesgo se extiende más allá de nuestra especie, y ocurre incluso en el trabajo experimental con animales (Bernabé y Giri 2019). Dicho de una vez, el macho de las especies es generalmente tomado como ejemplar de la especie, excepto cuando se estudia la reproducción. Aun cuando ha sido menos potente dentro de la FFC es una de las formas en que la perspectiva de género ha generado un fuerte efecto en el mainstream, apareciendo toda una nueva disciplina de gendered medicine (Wizemann y Pardue 2001; Legato 2004; Klinge y Wiesemann 2010; Regitz-Zagrosek 2012).

Mientras que la posición general tomada a partir del androcentrismo conceptual/explicativo es la sospecha respecto al estudio de las diferencias sexuales entre mujeres y 
hombres, la posición general tomada a partir del androcentrismo subrogativo parece ir en una dirección contraria, pues la solución a la medicina que toma como objeto modélico al hombre pasa por el estudio de las diferencias y la diferenciación sexuales.

\section{Neurosexismo, la forma contemporánea del androcentrismo explicativo}

En este apartado vamos a profundizar en el segundo sentido de androcentrismo apenas presentado, que en su versión más contemporánea toma el nombre de neurosexismo. El neologismo fue acuñado por la filósofa de la ciencia Cordelia Fine en su comunicación breve de 2008: "Will Working Mothers' Brains Explode? The Popular New Genre of Neurosexism" y posteriormente desarrollado en profundidad en su libro "Delusion of Gender" (Fine 2010). Si bien tomaremos como punto de partida para caracterizar la noción el trabajo de síntesis de Fine, debe notarse que el término por ella acuñado nombra un concepto que es resultado del trabajo mancomunado de distintas filósofas y científicas feministas.

\section{1 ¿De qué hablamos cuando hablamos de neurosexismo?}

En la obra de Fine $(2010 ; 2008)$, "neurosexismo" tiene al menos tres significados notablemente distintos, si bien no son correctamente diferenciados sino más bien presentados de forma ecléctica a través de ejemplos procedentes tanto de literatura científica como de publicaciones divulgativas. Veamos algunos ejemplos:

Como el mago que sabe que vas a elegir el siete de diamantes antes de incluso abrir el mazo, Sarah puede sorprender a su esposo a voluntad, gracias a su afortunada habilidad de saber lo que sientes antes incluso de que lo sienta. [...] Sarah no es ni una vidente de parque de atracciones ni la irresponsable dueña de una futurista máquina de interpretación de ondas cerebrales. Ella es simplemente una mujer que disfruta el milagroso don de leer la mente, que aparentemente les pertenece a todas las propietarias de un cerebro femenino [...] Sarah es solo uno de los muchos y curiosos personajes que pueblan los libros de divulgación científica acerca del género. Ella se encuentra en el libro El cerebro femenino de Louann Brizendine (2007), uno de los recientes e influyentes libros defendiendo la existencia de diferencias fundamentales en la psicología de hombres y mujeres, inscriptas en el hardware neural de estos. Desafortunadamente, la precisión científica y el sentido común son a menudo víctimas de la fealdad de acercarse al anticuado sexismo, formulado en el respetable y autoritario lenguaje de la neurociencia. (Fine 2008, 69)

Es decir, aquí neurosexismo se aplica al género de divulgación científica que utiliza nociones de la neuroendocrinología del comportamiento y de las neurociencias en general para establecer las diferencias entre el cerebro de las mujeres y los hombres, las cuales explican a su vez el instinto emocional femenino. Además, este género responde a la an-

Revista de Humanidades de Valparaíso, 2019, No 14, 287-313 
ticuada posición ideológica del sexismo. Ahora bien, Fine no sólo carga las tintas contra esta divulgación científica ideologizada, sino que además apunta directamente a la teoría organizacional Activacional (OR):

Tales descubrimientos condujeron a una idea brillantemente elegante conocida como la hipótesis organizacional-activacional [...] Y así, los neuroendocrinólogos han investigado la intrigante idea de que la testosterona prenatal organiza el cerebro. Manipulan los entornos hormonales de los animales durante el período crítico en el que se cree que tiene lugar la organización del cerebro, y ven qué les sucede a sus cerebros y su comportamiento. [...] ¿Podría la testosterona prenatal en los seres humanos crear diferencias sexuales permanentes en el cerebro que se encuentran detrás de las diferencias de género en la cognición y el comportamiento? [...] Los investigadores hipotetizan que los cambios que ven en el comportamiento son resultado de sus manipulaciones hormonales, es decir, que se producen por cambios inducidos por la testosterona en el cerebro del feto (o, en el caso de la rata, el cerebro neonatal). Y digo hipotetizan porque ha resultado más difícil de lo que se podría pensar $[\ldots]$ conectar los puntos entre las hormonas prenatales y los cambios cerebrales. (Fine 2010, 119)

En el tratamiento de la OR que hace Fine se presentan de modo notablemente simplificado los presupuestos de la teoría e inmediatamente se introduce la sospecha de cuán acertada sea esta teoría, particularmente en el caso de los humanos. La posición de Fine parece apuntar a una visión relativamente compartida con otras autoras críticas de la OR que podemos sintetizar como sigue: la teoría funcionaría razonablemente bien para algunas aves como los pinzones cebra y en mamíferos no humanos. En humanos, en cambio, la conexión causal entre hormonas, estructuras neurofisiológicas y conductas se pierde. Pero no es sólo eso lo que se señala respecto del estatus de la OR. Además de ser dudosa la aplicación del marco conceptual en el caso de los mamíferos de mayor volumen cerebral, algunos pasajes de la historia reciente de la disciplina parecen indicar que la neuroendocrinología tiende a sostener teorías incluso contra la evidencia fáctica Como ejemplo cita a Geschwind:

Norman Geschwind y sus colegas sugirieron una teoría muy compleja, que involucraba la idea de que el alto nivel de testosterona fetal experimentado por los hombres ralentiza el crecimiento del hemisferio izquierdo del cerebro. Geschwind llegó a sugerir que esto deja a los hombres con un mayor potencial para 'talentos superiores en el hemisferio derecho, como el talento artístico, musical o matemático’. (Fine 2010, 122)

Debe notarse aquí en primer lugar, que la posición de Greschwind no se corresponde con los casos paradigmáticos tratados en nuestra reconstrucción. La teoría bajo análisis trata de estructuras dimórficas discretas como la SDN-POA o el HV vinculadas con conductas bien delimitadas. El autor discutido por Fine, en cambio, apunta a un dimorfismo 
cerebral global que se corresponde con un dimorfismo cognitivo general. En segundo lugar, a lo que apunta la autora no es a que Greschwind o la OR sean o no la misma teoría, sino más bien a que ambas comparten cierta inmunidad respecto a las refutaciones:

La teoría de Geschwind es la sartén teflón de la literatura cientifica. Mientras que otras teorías se vuelven sucias e inutilizables cuando se arroja sobre ellas datos desconfirmantes, estos simplemente resbalan sobre teoría de Geschwind, que continúa sobreviviendo e inspirando a pesar de las críticas importantes que apuntan a la conclusión de que el estado actual de la teoría debería ser una ambiciosa-idea-que-no-funciona. (Fine 2010, 122)

El argumento entonces es que, teniendo claros casos en contra, la teoría no es descartada de forma inmediata por parte de la comunidad, y que inspira (asumimos que aquí Fine hace referencia a la heurística que genera) la investigación en el área. A lo que se apunta pues es que "[c]on todo, la idea de que mayores niveles de testosterona fetal de alguna manera crean los cerebros masculinos" que son, claro, superiores en actividades típicamente masculinas. Es decir, independientemente de que Gerschwind y la OR sean la misma teoría, lo que comparten (el recurso a la acción organizacional de las hormonas en períodos críticos del desarrollo fetal para explicar las conductas dimórficas) se sostiene pese a la evidencia en contra. Y esta irracionalidad por parte de la comunidad de endocrinólogos del comportamiento se explica porque se condice bien con ciertos prejuicios acerca de lo que significa ser hombre y ser mujer.

A la luz de lo apenas dicho, no es difícil ver que neurosexismo es polisémico en tanto se predica de distintas cosas:

A) En primer lugar, nombra una categoría literaria de divulgación científica en la cual se utiliza como insumo ciertos desarrollos neurocientíficos y su lenguaje para sostener que la desigualdad entre hombres y mujeres es resultado de sus diferencias biológicas.

B) En segundo lugar, nombra la posición ideológica que sostiene que la desigualdad entre hombres y mujeres es resultado de sus diferencias biológicas, particularmente las diferencias neuroendocrinas.

C) Por último, nombra la propia neuroendocrinología (la OR) en tanto sirve como dudoso sustento cientifico de A y B.

\footnotetext{
${ }^{1}$ Debe notarse que Fine utiliza la expresión "lay science" cuya traducción literal sería ciencia lega. En general, lay science hace referencia a aquellos artículos periodísticos u otras obras de divulgación escritas por periodistas y/o divulgadores profesionales. No obstante, algunas de las obras discutidas por la propia autora, aun siendo netamente divulgativas, son escritos por miembros de la comunidad científica. Por ello, hemos elegido traducirlo por el término más general de divulgación.
} 
Debe notarse que neurosexismo es auténticamente polisémico, en tanto las caracterizaciones propuestas A-C no son intercambiables en ningún sentido, dado que nombran realidades bien distintas: cierta literatura divulgativa, cierta posición ideológica y cierta área de experticia científica. Si bien la autora pretende enfatizar el modo en el cual estos tres elementos están vinculados, no cabe duda de que pueden ser atacados o defendidos de forma independiente. No es necesario, por ejemplo, aceptar el estatus dudoso de la neuroendocrinología para reconocer la existencia de una posición ideológica sexista, y lo mismo con el género de divulgación científica.

\subsection{La larga marcha de la opresión científicamente justificada}

Aun si tenemos razón en sostener que neurosexismo se dice de cosas distintas que son independientes entre sí, las ideas de Fine estarían solo pobremente presentadas si obviamos uno de sus puntos centrales: el neurosexismo vincula estos tres elementos, reeditando la conocida crítica feminista a la ciencia que la propia autora cita al inicio de la sección pertinente del libro:

Durante dos milenios, los "expertos imparciales" nos han dado ideas tan incisivas como el hecho de que las mujeres carecen de suficiente calor para hervir la sangre y purificar el alma, que sus cabezas son demasiado pequeñas, sus vientres demasiado grandes, sus hormonas demasiado debilitantes, que piensan con sus corazones o con el lado equivocado del cerebro. La lista nunca termina. (Hess 1990, 81)

Lo que Fine sostiene, a final de cuentas, es que la neuroendocrinología del comportamiento es un capítulo más de lo que podemos llamar la larga marcha de la opresión científicamente justificada. Si miramos al menos de forma breve esa historia a la que se refieren Hess, Fine y otras autoras y autores, encontramos convincente evidencia de que hay coincidencias entre las concepciones ideológicas sobre cuáles son las diferencias entre hombres y mujeres, y las explicaciones brindadas al respecto. Ya en la obra sobre la naturaleza de Aristóteles nos encontramos con propuestas explicativas acerca de las diferencias conductuales entre machos y hembras que cifran estas en la constitución biológica de los sujetos. En concreto, de acuerdo con Aristóteles es la capacidad diferencial de cocer la sangre de machos y hembras la que explica el desarrollo inferior de las hembras, asignándole no sólo determinadas funciones reproductivas sino además su carácter natural sumiso, débil y su escasa aptitud intelectual. Dando un súbito salto secular, en los últimos capítulos de El origen del hombre Darwin se ocupa de dejar en claro que las diferencias entre hombres y mujeres, en lo tocante a lo intelectual, se explican por la selección.

La principal distinción en la capacidad intelectual de los dos sexos queda demostrada porque el hombre alcanza una mayor eminencia, en cualquier cosa que emprenda, que la que pueda alcanzar la mujer [...] los machos han de defender a sus hembras, así como a sus jóvenes, de enemigos de todo tipo, y cazar para su subsistencia conjunta. Pero evitar a los

Revista de Humanidades de Valparaíso, 2019, No 14, 287-313 
enemigos o atacarlos con éxito, capturar animales salvajes y construir armas, requiere la ayuda de facultades mentales superiores, a saber, observación, razón, invención o imaginación. Estas diversas facultades se habrían puesto así continuamente a prueba y se habrían seleccionado durante el estado adulto [...] (Darwin 2009, 740-741)

Independientemente de que hoy exista un feminismo darwinista, parece claro que uno de los resultados que Darwin consideraba razonable a partir de sus teorías es la natural inferioridad de la mujer respecto de los hombres. El statu quo opresivo de las mujeres respecto de los machos es resultado de la evolución. Unos años más tarde, en 1915 el reputado neurólogo Dr. Charles L. Dana cargaría las tintas contra el movimiento sufragista, aduciendo que la constitución del sistema nervioso femenino las hace menos aptas para el ejercicio racional de la elección de representantes y la búsqueda del bien común. Es más, votarlas las pondría en un severo riesgo de padecer enfermedades psiquiátricas graves, por lo que el sufragismo atentaba contra la salud pública de esa "preciosidad inestable" (sic.) que es el sexo femenino. Como señala Hess, la lista parece nunca acabar.

Lo que se pone en juego en todos estos ejemplos es lo que Reinharz (1986) denomina low threshold for male dominance theorizing (bajo umbral para la teorización de la dominación masculina). Es decir, los mecanismos de aceptación o rechazo de teorías son sesgados en favor de aquellas teorizaciones que favorecen la posición ideológica de la superioridad masculina. Pensando ahora en términos de neurosexismo, la neuroendocrinología del comportamiento, al ser evaluada a la luz de esta crítica feminista de la ciencia, se muestra como mala ciencia o, como mínimo, dudosa. Con distintos grados de fortaleza, la idea de que la OR ha recibido un trato preferencial debido a que refuerza los prejuicios sexistas y discriminatorios hacia la mujer y otras minorías en términos de derechos, puede hallarse en van der Wijngaard (1997), Brookey (2002) Jordan-Young (2010) y Anne Fausto Sterlling (1992). No obstante, quien primero presenta un análisis concreto acerca de la neuroendocrinología del comportamiento es Helen Longino (1997).

El argumento central de Longino es el siguiente: dados los datos disponibles (al momento de realizar el análisis filosófico) podrían subsumirse en otro esquema conceptual que se condice al menos tan bien como la OR con los datos disponibles. Y si es así, si dos teorías pueden hacerse cargo igualmente bien de los datos disponibles, entonces se evidencia que el apoyo a uno u otro se debe a factores valorativos/ideológicos. Discutiremos en profundidad inmediatamente.

\subsection{La reconstrucción de Longino}

Longino llama modelo hormonal lineal a la OR en tanto se caracteriza por "ofrecer explicaciones en términos de caminos causales irreversibles y unidireccionales [..] desde los niveles hormonales en el útero, pasando por la organización cerebral, hasta llegar a la conducta" (Longino 1997, 76). De acuerdo con la autora, el modelo lineal se sustenta

Revista de Humanidades de Valparaíso, 2019, No 14, 287-313

()ㅇㅇㅛ CC BY-NC-ND 
sobre cuatro tipos de datos: experimentación animal, fisiológicos, anatómicos y conductuales. Con ellos, los miembros del programa neuroendocrino construyen el siguiente esquema explicativo:

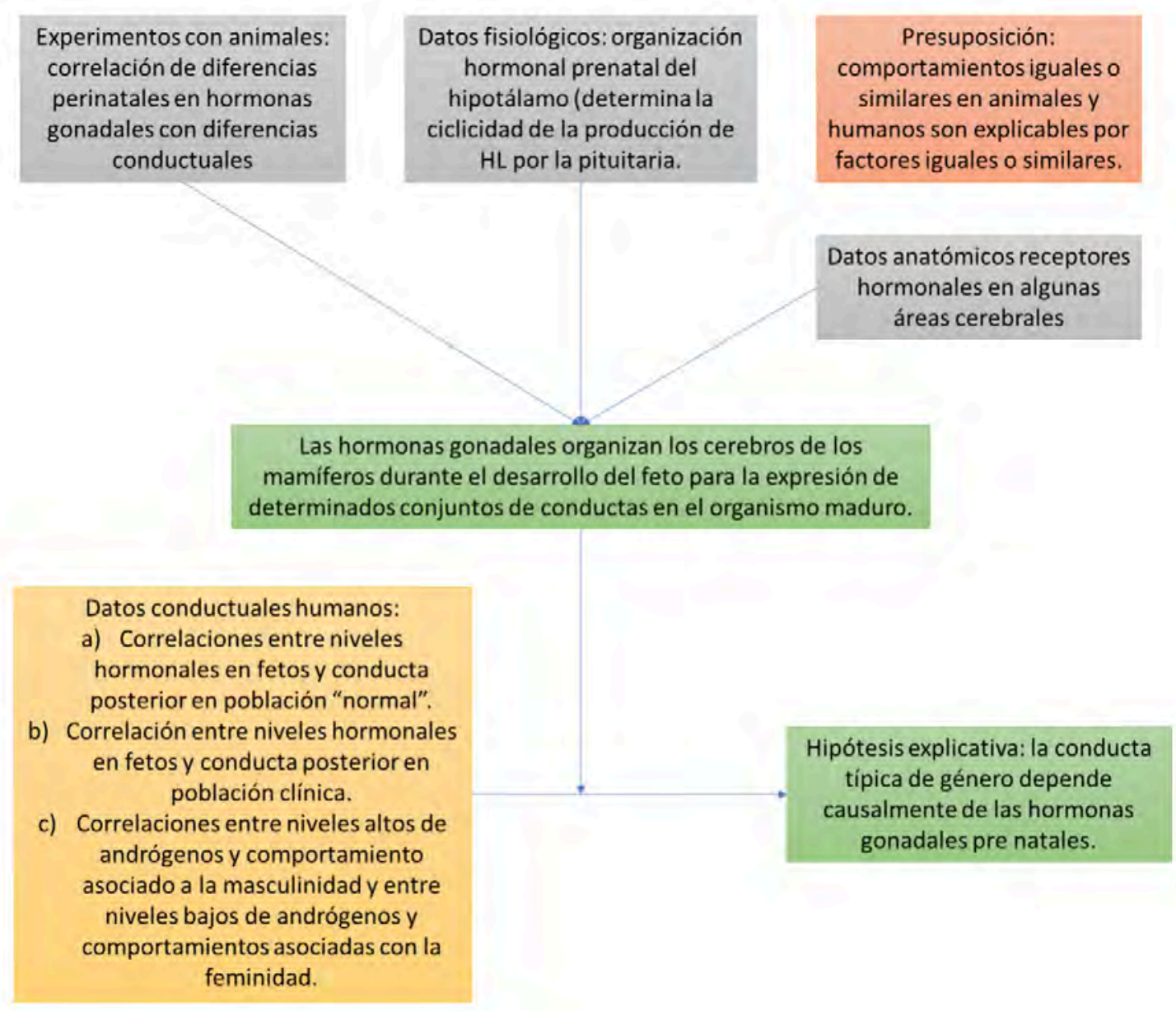

Fig. 1. Elaboración propia a partir del esquema reconstructivo propuesto por Hellen Longino $(1997,77)$.

Nótese que, de acuerdo con la estructura del esquema, los datos provenientes de la fisiología, anatomía y experimentación con animales conducen, junto con la presuposición de que comportamientos iguales o similares en animales y humanos son explicables por los mismos factores, a la afirmación central de la teoría. Posteriormente, dicha afirmación central es aplicada para explicar los datos de los seres humanos, clasificados aquí en función de su procedencia (correlaciones sobre población general y sobre población clínica 
entre hormonas y conductas), generando entonces una afirmación especial y concreta: la conducta típica de género depende causalmente de las hormonas gonadales prenatales que genera dos tipos de cerebros uno masculino y uno femenino.

Ahora bien, si todos estos elementos pudieran ordenarse en otro esquema conceptual, podrían decantarse los supuestos axiológicos subyacentes. Así pues, propone intentar aplicar otro esquema conceptual para ordenar los datos. En este caso, la idea básica es que la interacción de los sujetos humanos con el ambiente social en ciertos períodos especialmente críticos del desarrollo supone una selección (poda o desarrollo) de ciertas conexiones sinápticas, las cuales subyacen a las diferencias cognitivas y conductuales. Este es el nuevo esquema:

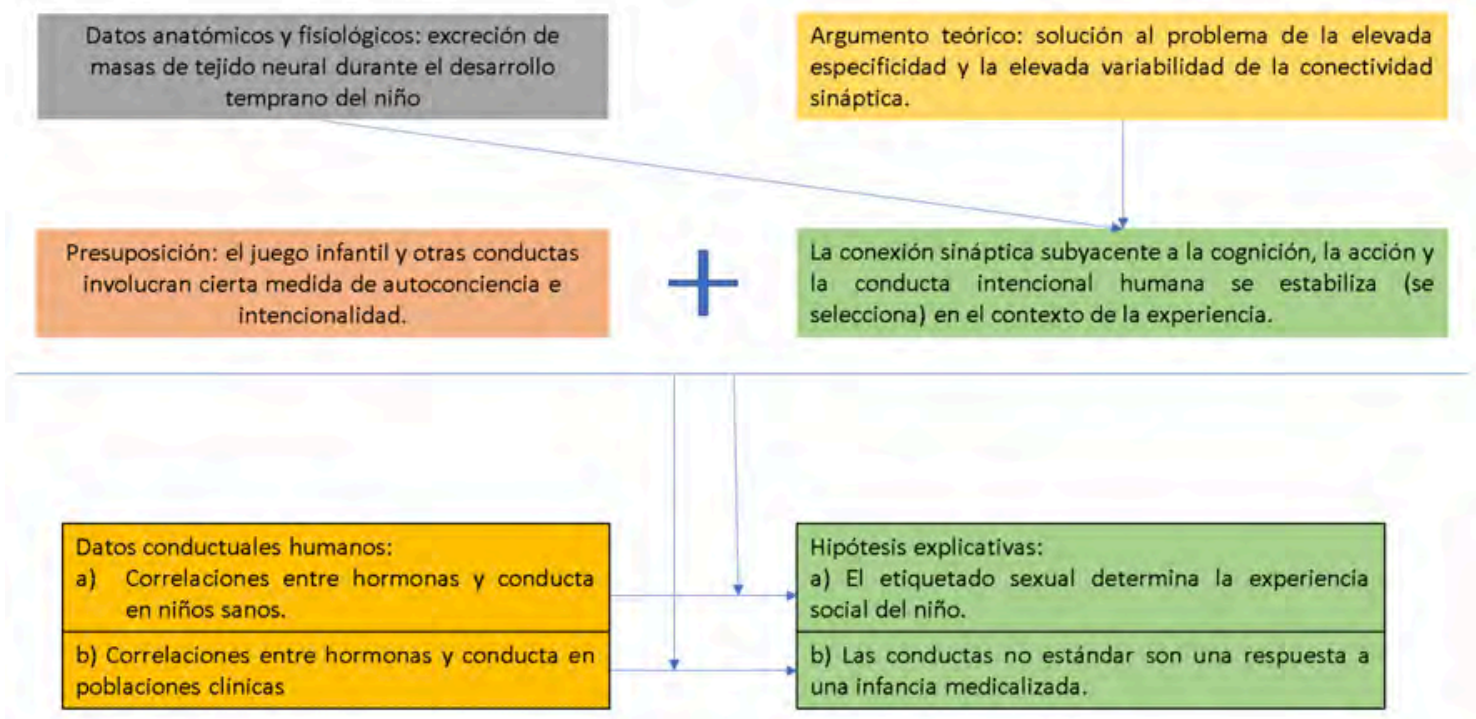

Fig. 2. Elaboración propia a partir del esquema reconstructivo propuesto por Hellen Longino $(1997,78)$.

Ahora bien, los cambios son los esperables a partir de la introducción de una nueva teoría: las aplicaciones específicas a las conductas humanas son distintas pues cifran en el etiquetado social y en la medicalización de la infancia las razones por las que las conductas de hombres y mujeres son distintas. No obstante, aquí hay otros cambios que deben revisarse y que, argumentaré, muestran la necesidad de introducir algunas modificaciones en la noción de empirismo contextual crítico propuesto por Longino. En primer lugar, no es que cambia el "contexto teórico" sino que cambian los datos de partida. En el segundo esquema explicativo se abandona no solo la OR sino también la consideración de los datos procedentes de la experimentación, la fisiología y la anatomía animal. Esto va de la mano con el cambio de presupuesto, en lugar de presuponer la continuidad/extrapolación desde otros mamíferos hacia seres humanos. En segundo lugar, es claro que entre 
el esquema conceptual alternativo propuesto por Longino y la OR no hay coincidencia total en sus aplicaciones pretendidas: mientras que la OR pretende explicar las conductas dimórficas de los mamíferos y al menos algunos vertebrados, la teoría propuesta como alternativa se aplica exclusivamente a los seres humanos.

Como fuere, con estos ingredientes, lo que Longino sostiene es que el éxito de la OR frente a otras alternativas, como la por ella propuesta, se debe a su connivencia con determinados prejuicios profundamente arraigados en la sociedad, al menos en el tratamiento de los seres humanos. No obstante, el análisis presentado por la autora parece mostrar más bien que lo que cambia es el presupuesto de continuidad entre el ser humano y otros mamíferos. Efectivamente, si presuponemos que los seres humanos no pueden ser tratados (en los aspectos relativos a las conductas dimórficas) como el resto de los mamíferos, parece razonable que la OR no se aplique a nuestra especie. Ahora bien, no es en absoluto obvio que adoptar o no tal presupuesto pueda achacarse de modo meridiano a determinados prejuicios ideológicos. Más bien parece un corolario esperable de la biología postdarwin en su conjunto. Si hay un valor ahí, en todo caso es claramente epistémico. Unos parágrafos más adelante, la autora precisa algo más esta idea:

Habiendo visto que los datos pueden recibir distintas interpretaciones en diferentes contex-
tos teóricos, es posible ver el papel de las presuposiciones en la selección y análisis de esos
datos. Los datos sobre comportamiento humano no consisten en correlaciones uniformes,
sino en conjuntos que se agrupan de forma más o menos bipolar. Tomar tal agrupamien-
to como significativo es, en parte, una expresión de la ideología del género, que toma el
género como correlato temperamental y conductual del dimorfismo sexual anatómico y
fisiológico, esto es, una ideología del género que trata el género dimórfico como un rasgo
genuino de la especie. (Longino 1997, 80)

Aquí el argumento cambia y apunta hacia el modo de conceptualizar los datos disponibles sobre la conducta humana. No obstante, este cambio es sólo aparente. De lo que se acusa a los y las científicas bajo la OR es de conceptualizar las conductas distintas entre machos y hembras humanas como "significativos" (como es significativo el canto de los pinzones cebra) y entonces explicar dichos datos ampliándolos conceptualmente y subsumiéndolos bajo el patrón nómico de la OR. Ahora bien, lo que se intenta señalar como ideología de género es, justamente, que los y las miembros del programa endocrino traten los datos sobre seres humanos del mismo modo en el que se tratan los datos provenientes de otras especies de mamíferos. Es decir, de nuevo, deberían darse argumentos independientes para ello. Y no los hay.

Nuestra principal crítica al abordaje es que del hecho bien asumido de que el mismo conjunto de fenómenos sea explicable por distintas teorías (infra determinación de la teoría por los hechos) no demuestra que las razones de proponer una teoría u otra sean ideológicas. En el caso particular de Longino además, hay varios elementos que desalientan esta lectura. Por un lado, elegir una teoría más general, con mayor poder de sistemati- 
zación que otra, parece una decisión guiada por valores epistémicos, no contextuales. Por otro, en el contexto particular de la biología, el "presupuesto de extrapolación" entre otros animales y los seres humanos difícilmente puede considerarse algo más que hacer ciencia después de la revolución darwinista. Finalmente, las teorías propuestas como alternativas no son incompatibles, la poda neural a partir de la etiquetación o la medicalización de la infantil no presenta, en principio, contradicción con la acción organizacional de las hormonas en fases críticas del período embrionario.

Con todo, el problema del neurosexismo y de los tipos de cerebros subsiste. ¿Cómo precisar dónde se agazapan los valores patriarcales en la neuroendocrinología?

\section{Una reconstrucción alternativa}

A continuación, presentaremos una reconstrucción alternativa a la ofrecida por Longino, pues creemos que utilizando otro andamiaje metateórico, podemos alcanzar algún grado de claridad respecto al problema discutido. Para ello recurriremos al estructuralismo metateórico, aunque en una versión eminentemente abreviada.

Para el estructuralismo, la noción mínima de teoría se corresponde con el par ordenado $\langle K, I\rangle$. $K$ representa el aparato conceptual, legal y matemático de la teoría, mientras que $I$ representa aquellos sistemas del mundo a los que la teoría pretende aplicarse. Aquí se presentará solo parcialmente $K$ (los modelos y los modelos potenciales) e $I$. Comenzaremos por un ejemplar paradigmático y luego presentaremos una reconstrucción informal y una formal ${ }^{2}$.

\subsection{Un ejemplar paradigmático}

Uno de los casos aplicativos que recorre las revisiones críticas e ilustra los manuales es la conducta reproductiva de las ratas, como podemos ver a continuación:

\footnotetext{
${ }^{2}$ Para una presentación concisa del enfoque, véase Díez y Lorenzano (2002). Para la presentación más completa y acabada, véase Balzer et al. (1987).
} 


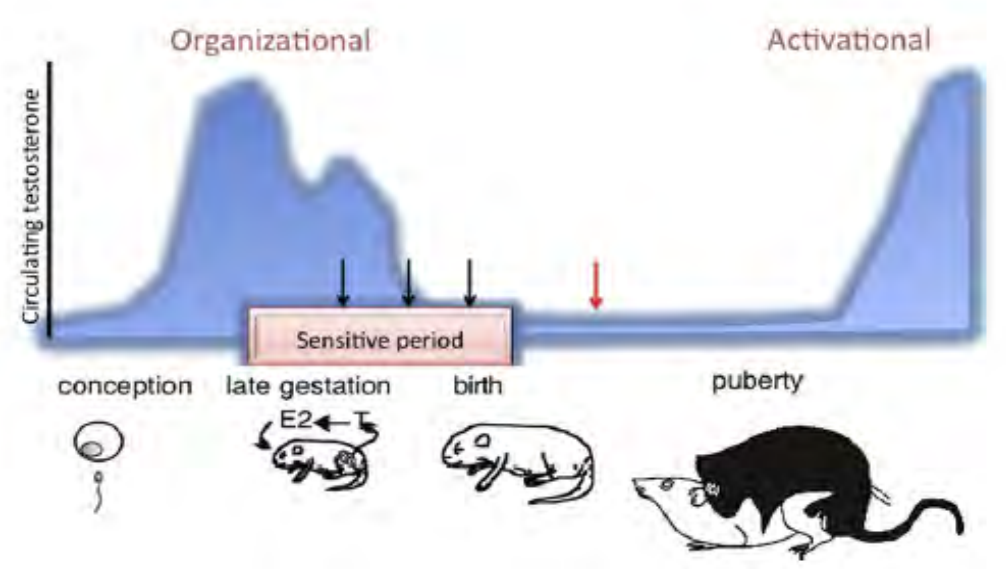

Fig. 3. Representación gráfica de la acción organizacional y activacional de las hormonas gonadales atendiendo al momento en el que se produce y las conductas resultantes en las wistar macho. (Extraído de Fink et al. 2011, 395)

El caso de las wistar macho tiene todos los componentes de ejemplar paradigmático de Kuhn. En primer lugar, ocupa un rol destacado entre los manuales con los cuales se forman las nuevas generaciones de científicos, constituyéndose en la referencia básica en el plano pedagógico. En segundo lugar, el ejemplo condensa todos los conceptos de la teoría, así como sus afirmaciones acerca del comportamiento de los sistemas de referencia, es decir, es un buen ejemplo de la teoría. Finalmente, y debido a ambas consideraciones previas, el ejemplar de la wistar macho tiene un rol heurístico fundamental, en tanto guía las nuevas aplicaciones a partir de las indicaciones que genera: si usted tiene una conducta dimórfica, busque la acción hormonal sobre el cerebro en distintos momentos del desarrollo.

Tomemos el artículo de Houtsmuller et. al (1994). En dicho trabajo se encuentra una aplicación del caso de las wistar macho:

Los machos fueron tratados prenatal o prenatal y neonatalmente con ATD. Los patrones de conducta sexual y elección de parejas fueron estudiados en la adultez. Luego, los animales fueron sacrificados y el volumen del SDN-POA fue medido. El volumen del SDN-POA resultó reducido en ambos grupos. La combinación de tratamiento pre y neonatal dio lugar a una frecuencia reducida de monta, intromisión y eyaculación, así como redujo la preferencia de hembras sobre machos. El tamaño del SDN-POA se correlaciona significativa y positivamente con la frecuencia de la conducta sexual masculina, así como con la preferencia por las hembras frente a los machos. (Houtsmuller et al. 1994, 535. La traducción es nuestra)

Nótese los componentes: conductas dimórficas (monta, intromisión, eyaculación, preferencia de hembras o machos), estructura neurofisiológica dimórfica (SDN-POA, núcleo 
sexualmente dimórfico del área preóptica por sus siglas en inglés) y hormonas (en este caso, ATD es un bloqueador de la aromatización de la testosterona a estradiol). Cuando un bloqueador de la aromatización de la testosterona es administrado a las wistar preñadas y a las crías macho recién nacidas, se obtienen machos con un descenso o desaparición de monta y eyaculación respecto del grupo control. Post morten, se observa que el SDNPOA de las wistar tratadas con el bloqueador tiene un volumen menor que el de las wistar control. Formulado de otra forma: La acción organizacional de la testosterona durante el período pre y perinatal, es responsable de la masculinización del SDN-POA, el cual es el responsable de las conductas de monta y eyaculación.

\subsection{Reconstrucción Informal}

\subsubsection{Aplicaciones pretendidas (explanandum)}

La OR es una teoría que pretende explicar cómo se originan y como se expresan las conductas sexualmente dimórficas $(B)$. $B$ es el conjunto todas las conductas que son dimórficas atendiendo al sexo, incluyendo en la noción de dimorfismo aquellas que son diferencias absolutas (un sexo tiene la conducta y el otro no), de forma (aquellas conductas que ambos sexos manifiestan, pero de forma distinta) o de frecuencia (aquellas conductas que ambos sexos manifiestan de forma idéntica pero en diferente cantidad). Como se ve, B presupone la existencia de dos sexos (y sólo dos) y todos los miembros del conjunto, es decir, toda conducta dimórfica, tiene tres valores posibles: si b pertenece a $B$, entonces $b$ puede ser $b_{i}$ (indiferenciada o prediferenciada), $b_{m}$ (masculina), $b_{f}$ (femenina).

\subsubsection{Núcleo conceptual y legal de la teoría (explanans)}

La OR sostiene que las conductas sexualmente dimórficas dependen de la interacción (INT) de las hormonas gonadales $(H)$ con el cerebro $(C)$ de un individuo $(I)$ durante los períodos relevantes de tiempo $(T)$. $\mathrm{H}$ es el conjunto de las hormonas gonadales, independientemente de si son estas son andrógenos o estrógenos. Notablemente, la OR no otorga relevancia a las distinciones usuales entre hormonas gonadales masculinas y hormonas gonadales femeninas en tanto unas pueden, eventualmente, transformarse en otras y la masculinización o feminización de las estructuras neurofisiológicas dimórficas no depende de qué hormona u hormonas actúen o de donde estas procedan, sino más bien de que $H$ y $C$ participen de la relación $I N T$ en un tiempo dado o no lo hagan (Principio de Adán).

Los períodos de tiempo que la teoría reconoce son tres $t_{1}, t_{2}, t_{3}$, que respectivamente están por indiferenciado, organizacional y activacional, suponiendo que los períodos son consecutivos en ese orden. Aquí deben señalarse que $t_{1}$ y $t_{2}$, es decir, el período organizacional, son fijos para cada especie y variables a través de las especies, mientras que $t_{2}$ es variable para cada y a través de las especies. Si bien esto no es explicitado en ningún pasaje de la literatura relevante, es evidente que los períodos organizacional y activacional 
no son conceptualmente simétricos: el auge hormonal que activa las conductas dimórficas puede ocurrir a lo largo de toda la vida post natal mientras que el auge hormonal que organiza las estructuras neurofisiológicas dimórficas solo puede darse en un momento específico del desarrollo, atendiendo a cada especie. Además, mientras que la ausencia de hormonas en el período organizacional conduce a la diferenciación masculina, la ausencia de hormonas en el período activacional implica la no manifestación de la conducta independientemente del sexo.

Las estructuras neurofisiológicas sexualmente dimórficas $(S)$ son el conjunto de aquellas áreas cerebrales que difieren entre machos y hembras y que son responsables de las conductas dimórficas. Al igual que en el caso de $B$, presuponen la existencia de dos y sólo dos sexos, y, si $s$ pertenece a $S$, entonces puede tener tres valores $s_{i}$ (indeferenciada), $s_{f}$ (femenino), $s_{m}$ (masculino). Como resultado de la investigación sistemática bajo la OR, se ha generado una profusa taxonomía acerca de qué estructuras son dimórficas y en qué sentido son dimórficas. Toda esta pluralidad, no obstante, no genera disparidades conceptuales relevantes: en el marco de la teoría, todas las distintas estructuras en todas las formas en que son dimórficas caben en $S$. Finalmente, la OR propone los conceptos de organización $O R G$ y activación $A C T$ para reflejar el modo en el cual las hormonas producen la diferenciación de las estructuras neurofisiológicas y las activan, dependiendo del período de tiempo en el que la interacción hormonal ocurra.

De modo informal, la ley fundamental de la OR se presenta de la siguiente manera:

1. En el periodo pre sexual, no hay ni estructuras ni conductas dimórficas.

2. Para toda estructura dimórfica y para todo individuo, existen cerebros y hormonas tales que,

2.1 se organiza una estructura neurofisiológica masculina si el cerebro interacciona con las hormonas en $t_{1}$;

2.2 si no interaccionan, entonces se organiza una estructura neurofisiológica femenina;

2.3 las estructuras que el cerebro adquiere en $t_{1}$ son resultado de la organización;

2.4 la conducta exhibida en $t_{2}$ por un individuo es el resultado de la activación o de la organización del cerebro de este. 


\subsection{Reconstrucción formal}

\subsubsection{Modelos potenciales}

Los modelos potenciales son el tipo de estructura del que tiene sentido preguntarse si cumplen o no con las leyes de la teoría. Es decir, los $M_{p}$ representan el aparato conceptualizador de la teoría. Los $M_{p}$ se componen de los dominios de objetos (conjuntos) y de las relaciones y funciones:

\section{Dominios de objetos}

- $B$ : es el conjunto tipos de conductas que pueden tener tres valores: indiferenciada, masculina y femenina.

- I es el conjunto de individuos de la misma especie, asumiendo que dicha especie está sexualmente dividida.

- $C$ es el conjunto de los cerebros.

- $S$ es un conjunto de estructuras neurofisiológicas que pueden tener tres valores: indiferenciada, masculina y femenina.

- $H$ es el conjunto de hormonas gonadales.

- $\quad T$ y > están por los tres períodos que la teoría reconoce, prediferenciado, organizacional y activacional y su sucesión temporal (se asume que $t_{0}, t_{1}, t_{2}$ se suceden en el tiempo de forma ordenada)

\section{Relaciones y funciones}

- INT es una relación de cerebro y hormonas en un tiempo.

- $C E R$ es función y asigna cerebros a individuos.

- $\quad S T R$ es función y asigna estructuras a cerebros en un cierto tiempo.

- $C O D$ es función y asigna conductas a individuos cierto tiempo.

- $O R G$ es función y asigna estructuras a cerebros.

- $A C T$ es función y asigna conductas a un cerebro.

Con estos elementos podemos brindar la primera definición de la reconstrucción: 


\section{Definición 1}

$M_{p}(\mathrm{OR}): x$ es un modelo potencial de la teoría organizacional $\left(x \in M_{p}(\mathrm{OR})\right)$ sí y solo sí existen $B, I, C, S, H, T,>, I N T, C E R, S T R, C O D, O R G, A C T$ tal que

(0) $x=\langle B, I, C, S, H, T,>, I N T, C E R, S T R U C T, C O D, O R G, A C T\rangle$

(1) $B$ es un conjunto de cardinalidad $3\left(B=\left\{b_{i}, b_{f}, b_{m}\right\}\right)$

(2) $I$ es un conjunto finito no vacío

(3) $C$ es un conjunto finito, no vacío

(4) $S$ es un conjunto de cardinalidad $3\left(S=\left\{s_{i}, s_{m}, S_{f}\right\}\right)$

(5) $H$ es un conjunto finito y no vacío

(6) $T$ es un conjunto de cardinalidad $3\left(T=\left\{t_{0}, t_{1}, t_{2}\right\}\right)$

(7) $>\subseteq t_{2}$

(8) $I N T \subseteq C \times T \times P o t(H)$

(9) $C E R: I \rightarrow C$

(10) STR: $C \times T \rightarrow S$

(11) $C O D: I \times T \rightarrow B$

(12) $O R G: C \rightarrow S$

(13) $A C T: C \rightarrow B$

\subsubsection{Los modelos actuales}

Habiendo caracterizado los dominios de objetos, relaciones y funciones de la teoría, al introducir el predicado conjuntista que define los modelos potenciales, podemos preguntarnos ahora cuáles de las estructuras que cumplen con estos axiomas impropios, cumplen además con los axiomas propios, es decir, con las leyes de la teoría.

\section{Definición 2}

$M(\mathrm{OR}): x$ es un modelo de la teoría organizacional $(x \in M(\mathrm{OR}))$ syss existen $B, I, C$, $S, H, T,>, I N T, C E R, S T R, C O D, O R G, A C T$, tal que

(0) $x \in M_{p}(\mathrm{OR})$

(1) $\forall c \in C, \operatorname{STR}\left(c, t_{0}\right)=s_{i} \wedge \forall i \in I, C O D\left(i, t_{0}\right)=b_{i}$

(2) $\forall b_{k} \in B, \forall i \in I, \exists c \in C, \exists h \in H$, tal que: 
(2.1)

(2.2) $\left\langle c, t_{l}, h\right\rangle \notin I N T \rightarrow O R G(c)=s_{f}$

(2.3) $\operatorname{STR}\left(c, t_{1}\right)=O R G(c)$

(2.4) $C E R(i)=c \wedge C O D\left(i, t_{2}\right)=A C T(c) \vee O R G(c)$

\section{Cerebros tipo o cerebros mosaico}

Ya discutimos cómo la asignación de un cerebro masculino o femenino a partir de la bifurcación hormonal es uno de los argumentos centrales contra la OR. Hasta ahora, lo hemos discutido en el marco de la metaciencia, pero el problema de los cerebros-tipo es también un problema científico que puede plantearse como la siguiente pregunta ¿Cómo se deben conceptualizar las diferencias cerebrales entre hombres y mujeres? Además, la discusión ha traspasado las fronteras de lo académico en general para llegar a instalarse en los medios de comunicación masiva.

Sin dudas, el artículo que más ha agitado el avispero del debate es "Sex beyond the genitalia: The human brain mosaic" (151 veces citado al momento de escribir este párrafo) de Daphma Joel et al. y su equipo de Tel Aviv. En torno a este y a las respuestas al mismo, desarrollaremos nuestro análisis. Bien, los términos de la polémica son los siguientes: habida cuenta del hallazgo de diferencias neuroanatómicas relacionadas con el sexo a partir de la aplicación sistemática de la OR y del estudio en general del cerebro humano ¿estamos legitimados a conceptualizar los cerebros de hombres y mujeres como perteneciendo a tipos distintos? La respuesta afirmativa a esa pregunta puede encontrarse en autores como Glezerman (2016), Arnold (2009), Cahill (2006), Baron Cohen (2005). Todos ellos asumen que la existencia de estructuras neurofisiológicas dimórficas legitima la distinción entre cerebro-tipo-femenino y cerebro-tipo-masculino. Por el lado de la respuesta negativa, las representantes más destacadas son Joel $(2011 ; 2012)$, Joel et al. (2015) y Anne Fausto-Sterlling (1992).

Sobre un total de 1400 cerebros, Joel y su equipo realizan diversas mediciones (volumen total del cerebro, distribución de materia gris, comparación de las estructuras más claramente dimórficas etc.). Frente a la visión clásica (OR) pretenden mostrar que el cerebro no puede ser catalogado como dimórfico. Para ello, debe mostrar que hay escasa consistencia interna entre las características típicamente masculinas y las características típicamente femeninas. Además, debe mostrar que existe un fuerte solapamiento entre dichas características, esto es, que hay más cerebros con características de ambos tipos. Las conclusiones son sólidas:

Nuestro estudio demuestra que aunque existen diferencias de sexo / género en la estructura cerebral, los cerebros no se dividen en dos clases, una típica de los hombres y la otra típica de las mujeres, ni están alineadas a lo largo de un continuo "cerebro masculino-cerebro 
femenino". Por el contrario, incluso considerando solo el pequeño grupo de características cerebrales que muestran las mayores diferencias sexo / género, cada cerebro es un mosaico único de características, algunas de las cuales pueden ser más comunes en las mujeres en comparación con los hombres, otras pueden ser más comunes en los hombres en comparación con las mujeres, y aún otros pueden ser comunes tanto en mujeres como en hombres. (Joel et al. 2015, 5. La traducción es nuestra)

Nótese que en ningún momento se niega que existan diferencias sexuales en el cerebro, lo que se pretende mostrar es que tales diferencias muestran una fuerte variabilidad y pobre consistencia interna, haciendo más razonable conceptualizar los cerebros como mosaicos individuales que como tipos dimórficos como las gónadas. Lo que los y las autoras muestran es que, en promedio, tomando un cerebro cualquiera y analizándolo exhaustivamente, no podríamos determinar a qué sexo pertenece.

El trabajo de Joel ha generado, además, grandes repercusiones. Se han presentado objeciones sustantivas a la metodología para distinguir dimorfismos (Del Giudice et al. 2016) como al enfoque morfológico de la propuesta mosaico de Joel (Glezerman 2016). La discusión ha seguido con sucesivas respuestas por parte de Joel et al. (2016a, 2016b) y con nuevas revisiones críticas de la metodología original (Rosenblatt 2016; Chekroud et al. 2016). Aquí, el debate metodológico resulta de escaso interés para el tema que nos ocupa. Lo que nos interesa aquí es si efectivamente, y como Joel y las críticas de la OR sostienen, nuestra teoría objeto favorece la visión tipológica de los cerebros.

Retomemos nuestra reconstrucción de la OR. Allí establecimos que los $M_{p}$ establecen la clase de estructuras de las que cabe preguntarse si cumplen además las constricciones nómicas de la teoría. En el caso de la OR establecimos que tales estructuras son del siguiente tipo: $\langle B, I, C, S, H, T\rangle,, C E R, S T R, C O D, O R G, A C T\rangle$ y caracterizamos cada uno de los dominios que la componen y las relaciones y funciones sobre tales dominios

Lo primero que resulta obvio, si nuestra reconstrucción es correcta, es que la parte conceptualizadora-tipificadora de la teoría no incluye ninguna referencia a cerebros-tipo. Es decir, la teoría no exige que los individuos a las cuales se va a aplicar posean cerebros tipo femenino o cerebros tipo masculino. Se podría aducir que esta afirmación es tramposa, en tanto las S pueden tomar tres valores: masculino, femenino o indiferenciado y la función ORG asigna tales estructuras a los cerebros de los individuos. Es decir, se podría afirmar que la noción de cerebro-tipo está conceptualizada de tal manera que evita el término, pero permanece conceptualmente: un cerebro al que la organización ha asignado estructuras de tipo masculino sería un cerebro-tipo-masculino. Ahora bien, recordemos que la polémica no es en torno a la existencia de diferencias relativas al sexo en el cerebro, sino más bien a si tales diferencias favorecen la conceptualización de los cerebros como perteneciendo a tipologías distintas o más bien como mosaicos variables de estructuras dimórficas. 
Para contestar prolijamente a esta cuestión debemos referirnos ahora a la ley de la OR. Lo que la ley establece que (1) En el periodo pre sexual, no hay ni estructuras ni conductas dimórficas y (2) Para toda estructura dimórfica y para todo individuo, existen cerebros y hormonas tales que (2.1) Se organiza una estructura neurofisiológica masculina si el cerebro interacciona con las hormonas en $\mathrm{t}_{1},(2.2)$ si no interaccionan, entonces se organiza una estructura neurofisiológica femenina. (2.3) las estructuras que el cerebro adquiere en $t_{1}$ son resultado de la organización (2.4) la conducta exhibida en $t_{2}$ por un individuo es el resultado de la activación o de la organización del cerebro de este. Es decir, si hay interacción hormonal en el período organizacional, entonces se organiza una estructura de tipo masculino y si no la hay, femenino. Aquí no se establece que las conductas dimórficas se expliquen por un determinado tipo de cerebro. Más bien se establece el modo por el cual se diferencian ciertas estructuras que entonces resultan explicativas de tales conductas.

Siendo así ¿cuál es nuestro punto? El estructuralismo propone una noción clara de identidad de una teoría: la entidad más simple que puede ser catalogada como tal es el par ordenado $\langle K, I\rangle$ donde $K$ es el aparato conceptual-legal de la teoría e $I$ el conjunto de los sistemas del mundo a los que la teoría pretende aplicarse. En general, además, las teorías son redes jerárquicas de elementos teóricos de este tipo. Justamente por su ser jerárquico, todo lo que la teoría dice está contenido en el elemento teórico básico. Así pues, para determinar si una teoría efectivamente dice algo debemos analizar los elementos contenidos en la dupla $\langle K, I\rangle$. Si nuestra interpretación de la teoría es correcta, el concepto de cerebros-tipos no forma parte de lo que la teoría pretende explicar, es decir, no está incluido en las las aplicaciones pretendidas, entendidas como $I$. Por otro lado, tal concepto es ajeno al aparato legal de la teoría: nada hay en la ley que sea equiparable a la introducción de cerebros-tipo. Al menos desde el punto de vista analítico, la OR es ajena a la noción discutida.

Ahora bien, lo que acabamos de decir no es suficiente para despejar todas las dudas. Es cierto que la OR no habla sobre tipos de cerebros, pero eso no satisface las dudas al respecto. Al fin y al cabo, aun cuando la OR pueda sostenerse independientemente de que se muestre poco razonable la distinción tajante de tipos de cerebros, en algún sentido parece que el dimorfismo cerebral es una consecuencia de la OR: si aplicamos la teoría de forma iterada sobre distintos individuos de una dada especie, entonces obtendríamos una imagen global de las diferencias neurofisiológica de dicha especie, lo que nos permitiría determinar cómo es el cerebro de los machos y cómo el de las hembras de la especie. Aquí lo que se pone en juego es si el programa de investigación bajo la OR conduce a tal visión dicotómica del cerebro.

Esta es justamente la postura de Glezerman, Baron-Cohen y Cahill entre otros. La teoría, en su uso sistemático y repetido, legitima hablar de cerebros femeninos y masculinos. Ahora bien, lo que queremos mostrar no es que tal lectura de las consecuencias del programa neuroendocrino sea errada, sino más bien que no son las únicas posibles. De hecho, la OR trata a las conductas dimórficas y a las estructuras neurofisiológicas dimórficas

Revista de Humanidades de Valparaíso, 2019, No 14, 287-313 
que las explican como independientes de otras, lo cual se evidencia en algunos ejemplos citados: el timing y la cantidad de testosterona administrada a una conejilla de indias preñada, produce efectos distintos en la descendencia respecto a las conductas dimórficas, pudiendo coexistir (como de hecho ocurre, incluso en el taller de la naturaleza) conductas dimórficas de valor distinto en el mismo individuo. Estos ejemplos podrían favorecer entonces más bien una visión mosaica de las consecuencias de la OR. De hecho, algunas de las más reputadas figuras de la disciplina han tomado este camino, por ejemplo, Margaret McCarthy (Joel et al. 2017)

Nuestro análisis nos lleva a dos cuestiones ulteriores, muy interesantes para el problema discutido. Por un lado, nuestra elucidación nos permite señalar de modo más preciso dónde están los valores no epistémicos, comparado con el análisis informal y deficitario de Longino: no es que la OR presuponga los viejos cánones ideológicos del sexismo, sino más bien que la interpretación que hagamos de sus consecuencias qua programa de investigación puede estar guiada o no por tales valores u otros. El hecho de que algunos científicos (Brizendine 2007) y divulgadores profesionales tomen el camino de la tipología frente al mosaiquismo, parece indicar algo relevante acerca de ciertas presuposiciones no puramente teóricas. A partir de la interpretación dicotómica del cerebro, defienden la naturalidad del statu quo opresivo hacia las mujeres y otras lindezas, como la educación segregada (Sax 2006). Al margen de cómo la elucidación de la OR nos permite determinar que la polémica de los cerebros tipo no afecta a dicha teoría, no quiere decir que la polémica no sea interesante o relevante, ni que sea indigna de análisis filosófico. Es interesante que Joel misma señale que su preocupación sobre la legitimidad de la categorización surge de la obvia relevancia social que tiene la posibilidad de que exista un sexo cerebral y que ello sea utilizado como baza científica en favor de, por ejemplo, la educación segregada por sexos:

En el plano social, adoptar una visión que reconozca la variabilidad y la diversidad humanas tiene implicaciones importantes para los debates sociales sobre cuestiones de larga data, como la conveniencia de la educación de un solo sexo y el significado de sexo / género como categoría social. (Joel et al. 2015, 15472. La traducción es nuestra)

Pese a que consideramos que Joel erra al caracterizar la conceptualización de los cerebros-tipo como un resultado natural de la OR, coincidimos en que la discusión es relevante y que tiene una obvia dimensión social. De hecho, consideramos que hemos mostrado que tal debate es preminentemente ideológico: el programa neuroendocinológico del comportamiento puede subsistir sin pronunciarse al respecto. Sin embargo, sería útil aquí adelantar alguna de las conclusiones del presente capítulo. Nótese que Joel subordina el significado de su trabajo a mostrar que no hay tal cosa como cerebro femenino y cerebro masculino, porque ello desterraría para siempre de la neurociencia las posiciones ideológicamente deleznables de Brizendine, Sax y otros. A esta afirmación subyace una idea como mínimo peligrosa: que las decisiones acerca de cosas como la educación mixta, el 
desarrollo de políticas públicas orientadas a la erradicación de la desigualdad histórica sufrida por parte de la mujer, a la discriminación positiva etc. dependen de las teorías vigentes en una dada (o en varias) disciplinas. De hecho, es la misma posición de Sax, pero en sentido contrario: "si tenemos una teoría que avala que las mujeres y los hombres tienen cerebros distintos, entonces la educación segregada es deseable" frente a "si tenemos una teoría que avala que el cerebro humano es un mosaico, entonces la educación mixta es deseable". Ambas posturas son erradas, aun cuando una encarne valores progresistas con los que nos sentimos mucho más identificados.

\section{Conclusiones}

Al tomarnos en serio la propuesta del ECC de Longino, hemos descubierto que los análisis informales o superficiales no son suficientes para determinar dónde se agazapan esos valores que deben ser explicitados para poderlos discutir racional e intersubjetivamente. La reconstrucción propuesta como alternativa a la de Longino, nos permite evitar el error de calificar de valores patriarcales a lo que son valores netamente epistémicos (como la generalidad) y nos posiciona mejor para señalar dónde están los valores entreverados en la práctica de la neuroendocrinología: no es en la teoría misma, sino en el modo en el que se presenta y en el modo en el que se utiliza como ariete ideológico para legitimar posiciones del orden conservador.

Es por ello por lo que consideramos importante discutir y clarificar la noción de neurosexismo. Lo que hemos mostrado es que al menos en el caso presentado (no necesariamente en todos los que se puedan presentar) el sentido de neurosexismo que ocurre es el del género de divulgación o de ciencia Lega protagonizado por Brizendine, Sax y otros. Eso nos permite mantenernos en una posición feminista de repudio al neurosexismo sin rechazar por ello el estudio de las diferencias y la diferenciación sexual.

Esta revisión nos permite además navegar la tensión entre los dos sentidos de androcentrismo que presentamos al principio. Al no rechazar de plano los estudios de las diferencias sexuales, sino más bien su utilización como excusa para defender el patriarcado, estamos en mejores condiciones para defender el desarrollo de la medicina que no ponga al hombre en el centro y que reconozca las especificidades de las mujeres y las disidencias. No sólo las socioambientales, sino también las referidas a la constitución biológica.

Nuestra postura podría entenderse como un modo de salvar los muebles frente a los valores no cognitivos, sacándolos de las teorías y volviendo a una versión aggiornada de la ciencia libre de valores. Tal lectura nos parece errada, pues cuando decimos que los valores no están en la teoría, no queremos decir que en la neuroendocrinología como disciplina no haya valores en juego, sino que no están allí donde se los busca. Las reconstrucciones racionales no pueden reflejar la complejidad y riqueza de la práctica científica, sino cierto aspecto de esta. Que no esté en la teoría, en nuestro caso, significa que los 
conceptos que se consideran típicamente androcéntricos (como tipos de cerebro) no son conceptos propuestos por la teoría entendida como el par ordenado $\langle K, I\rangle$. Eso no quiere decir que la práctica científica no ponga en juego valores. De hecho, hemos propuesto dónde están y cómo atacarlos siguiendo a algunas autoras feministas.

\section{Referencias bibliográficas}

Arnold, A. P. (2009). The organizational-activational hypothesis as the foundation for a unified theory of sexual differentiation of all mammalian tissues. Hormones and Behavior, 55(5): 570-578. doi: 10.1016/j.yhbeh.2009.03.011

Balzer, W., Moulines, C. U., Sneed, J. (1987). An architectonic for science. The structuralist program. Dordrecht: Reidel.

Baron-Cohen S., Knickmeyer R.C., Belmonte M.K. (2005). Sex differences in the brain: implications for explaining autism. Science, 310: 819-823.

Bernabé, F., Giri, L. (2019). It's a Male World: el sesgo sexual de los modelos animales en biología. Arbor, 195(791): a492. doi: https://doi.org/10.3989/arbor.2019.791n1005

Borgerson, K. (2011). Amending and defending Critical Contextual Empiricism. European Journal of Philosophy of Science, 1(3):435-449.

Brizendine, L. (2007). The female brain. London: Bantam Press.

Brookey, R. A. (2002). Reinventing the Male Homosexual: The Rhetoric and Power of the Gay Gene. Bloomington: Indiana University Press.

Cahill, L. (2006). Why sex matters for neuroscience. Nature Review Neurosciesce, 7(6): 477-484. doi: 10.1038/nrn1909

Chekroud, A. M., Ward, E. J., Rosenberg, M. D., Holmes, A. J. (2016). Patterns in the human brain mosaic discriminate males from females. PNAS, 113(14): E1968. doi: https://doi. org/10.1073/pnas. 1523888113

Darwin, C. (2009). El origen del hombre. Madrid: Crítica.

Del Giudice, M., Lippa, R. A., Puts, D. A., Bailey, D. H., BAiley, J. M., Schmitt, D. P. (2016). Joel et al.'s method systematically fails to detect large, consistent sex differences. PNAS, 113(14): E1965. doi: https://doi.org/10.1073/pnas.1525534113

Diez, J. A., Lorenzano, P. (eds.) (2002). Desarrollos actuales de la metateoría estructuralista: Problemas y discusiones. Bernal: Universitat Rovira i Virgili y Universidad Nacional de Quilmes.

Fausto-Sterling, A. (1992). Myths of Gender. Nueva York: BasicBooks.

Fine, C. (2008). Will working mothers' brains explode? The popular new genre of neurosexism. Neuroethics, 1(1): 69-72. 
Fine, C. (2010). Delusions of Gender: How Our Minds, Society, and Neurosexism Create Difference. New York: W. W. Norton.

Fink, G., Pfaf, D., Levine, J. (2011). Handbook of Neuroendocrinology. Oxford: Academic Press.

Glezerman, M. (2016). Yes, there is a female and a male brain: Morphology versus functionality. PNAS, 113(14): E1971. doi: https://doi.org/10.1073/pnas.1524418113

Gómez, R. (2015). La dimension valorativa de las ciencias. Bernal: Universidad Nacional de Quilmes.

Hankinson Nelson, L. (1990). Who Knows: From Quine to Feminist Empiricism, Philadelphia:Temple University Press.

Hankinson Nelson, L. (1993). Epistemological communities. En Linda Alcoff and Elizabeth Potter (eds), Feminist Epistemologies, pp. 121-59. New York and London: Routledge.

Harding S. (1986). The Science Question in Feminism. Ithaca: Cornell University Press.

Harding, S. (1993). Rethinking standpoint epistemology: what is 'strong objectivity'? En Linda Alcoff y Elizabeth Potter (eds.), Feminist Epistemologies, pp. 49-82. New York and London: Routledge.

Hess, B. B. (1990). Beyond dichotomy: Drawing distinctions and embracing differences. Sociological Forum, 5(1): 75-93. http://www.jstor.org/stable/684582.

Houtsmuller E. J., Brand, T., de Jonge F. H., Joosten, R. N., van de Poll, N. E., Slob, A. K. (1994). SDN-POA Volume, Sexual Behavior, and Partner Preference of Male Rats Affected by Perinatal Treatment with ATD. Physiology \& Behavior, 56 (3): 535-541.

Joel, D. (2011). Male OR female? Brains are intersex. Frontiers in Integrative Neuroscience, 5: 57. doi: https://doi.org/10.3389/fnint.2011.00057

Joel, D. (2012). Genetic-gonadal-genitals sex (3G-sex) and the misconception of brain and gender, or, why 3G-males and 3G-females have intersex brain and intersex gender. Biology of Sex Differences, 3: 27.

Joel, D., Berman, Z., Tavor, I., Wexler, N., Gaber, O., Stein, Y., Shefi, N., Pool, J., Urchs, S., Margulies, D. S., Liem, F., Hänggi, J., Jäncke, L., Assaf, Y. (2015). Sex beyond the genitalia: The human brain mosaic. PNAS, 112(50): 15468-15473. doi: https://doi.org/10.1073/ pnas. 1509654112

Joel, D., Hänggi, J., Pool, J. (2016). Reply to Glezerman: Why differences between brains of females and brains of males do not 'add up' to create two types of brains. Proc Natl Acad Sci USA (Letter).

Joel, D., Persico, A., Hänggi, J., Pool, J., Berman, Z. (2016). Reply to Del Guidice et al., Chekroud et al., and Rosenblatt: Do brains of females and males belong to two distinct populations? Proc Natl Acad Sci USA (Letter). 
Joel, D., McCarthy, M. M. (2017). Incorporating Sex as a Biological Variable in Neuropsychiatric Research: Where Are We Now and Where Should We Be? Neuropsychopharmacology, 42(2): 379-385.

Jordan-Young, R. (2010). Brain Storm. Cambridge, Massachusetts: Harvard University Press.

Klinge, I., Wiesemann, C. (2010). Sex and Gender in Biomedicine. Göttingen: Universitätverlag Göttingen.

Legato, M. (2004). Principles of Gender-Specific Medicine. San Diego: Elsevier Academic Press.

Longino, H. (1994). In Search of Feminist Epistemology. The Monist, 77(4): 472-485.

Longino, H. E. (1997). Feminismo y filosofía de la ciencia. En Marta González García et. al (eds.), Ciencia, tecnología y sociedad, 71-83. Barcelona: Ariel.

Potter, E. (2006). Femminism and Philosophy of Science. Routledge: New York.

Regitz-Zagrosek, V. (2012). Sex and gender differences in health. EMBO Reports, 13(7): 596603. doi: 10.1038/embor.2012.87

Reinharz, S. (1986). Patriarcal Pontifications. Society, 23(6): 23-29. doi: https://doi.org/10.1007/ BF02697107

Rosenblatt, J. D. (2016). Multivariate revisit to "sex beyond the genitalia". Proc. Natl. Acad. Sci. USA, 113(14): E1966-E1967. doi: 10.1073/pnas.1523961113

Sax, L. (2006). Why gender matters: What parents and teachers need to know about the emerging science of sex differences. New York: Broadway Books.

Tacsir, E., Grazzi, M., Castillo, R. (2014). Women in Science and Technology: What Does the Literature Say? Inter-American Development Bank, Technical Note No. IDB-TN-637. https://publications.iadb.org/publications/english/document/Women-in-Science-andTechnology-What-Does-the-Literature-Say.pdf

van der Wijngaard, M. (1997). Reinventing the Sexes: The Biomedical Construction of Femininity and Masculinity. Bloomington: Indiana University Press.

Wizemann T. M., Pardue, M. (2001). Exploring the Biological Contributions to Human Health. Does Sex Matter? Washington: National Academies Press.

Wylie, A. (1997). The engendering of archaeology: refiguring feminist science studies. Osiris, 12: 80-99. http://www.jstor.org/stable/301900

Wylie, A. (2003). Why standpoint matters. En Robert Figueroa and Sandra Harding (eds.), Science and Other Cultures: Issues in Philosophies of Science and Technology, pp. 26-48. New York: Routledge. 



\title{
Un enfoque inferencial y dinámico de la modelización y la comprensión en biología
}

\author{
An inferential and dynamic approach to modeling and \\ understanding in biology
}

\author{
Rodrigo Lopez-Orellana*; Juan Redmond**; David Cortés-García ${ }^{\dagger}$ \\ *CONICYT, Chile / Instituto de Estudios de la Ciencia y la Tecnología, \\ Universidad de Salamanca, España \\ rodrigo.lopez@usal.es \\ ${ }^{* *}$ Universidad de Valparaíso, Chile \\ juan.redmond@uv.cl \\ †Universidad del País Vasco, España \\ davidcortesgarcia.dcg@gmail.com
}

\section{Resumen}

El objetivo del presente trabajo es proponer un enfoque inferencial y dinámico de la comprensión con modelos en biología. La comprensión cumple un papel central en la práctica de la modelización. A partir de su vinculación con los otros dos elementos centrales de la investigación científica, experimentación y explicación, mostramos su relevancia epistémica para el caso de la explicación en biología. Además, gracias a la introducción de la noción de comprensión, proponemos una perspectiva no referencialista de los modelos científicos, que está determinada por su uso.

Palabras clave: comprensión, modelos, explicación, representación, experimentación, inferencias, razonamiento subrogativo, biología.

\section{Abstract}

This paper aims to propose an inferential and dynamic approach to understanding with models in biology. Understanding plays a central role in the practice of modeling. From its links with the other two central elements of scientific research, experimentation,

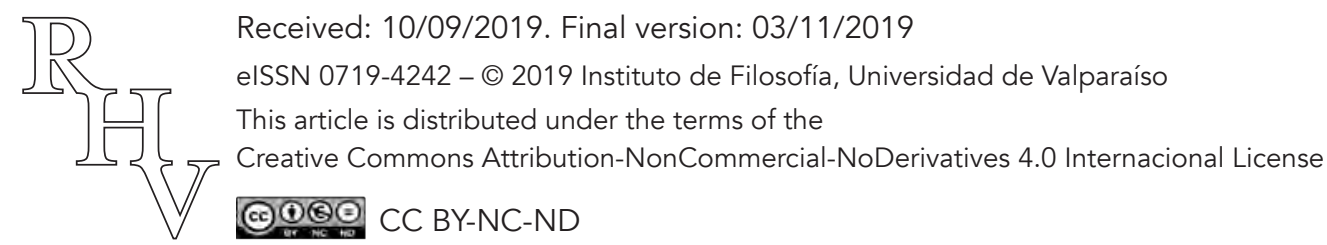


Un enfoque inferencial y dinámico de la modelización y de la comprensión en biología

Rodrigo Lopez-Orellana; Juan Redmond; David Cortés-García

and explanation, we show its epistemic relevance to the case of explanation in biology. Furthermore, by including the notion of understanding, we propose a non-referentialist perspective on scientific models, which is determined by their use.

Keywords: understanding, models, explanation, representation, experimentation, inferences, surrogate reasoning, biology.

\section{Introducción}

En filosofía de la ciencia se ha argumentado que los modelos científicos cumplen dos funciones que no son excluyentes: 1) representan una porción de la realidad (sistema-dia$n a$; sistema de fenómenos); $\mathrm{y}, 2$ ) representan una teoría en el sentido de que interpretan las leyes o axiomas de esta (Frigg y Nguyen 2016; Frigg y Hartmann 2018). Es en el primer sentido, principalmente, que la práctica de modelización en nuestros días tiene un gran protagonismo en la literatura filosófica. En este artículo ofrecemos algunos elementos de discusión al respecto, centrándonos en el punto 1) dentro del ámbito de la biología: nuestro objetivo general es profundizar en cómo los modelos representan sus sistemas-diana (target-systems) de tal modo que la práctica de modelar se ajuste a la evidencia científica.

Nuestro enfoque está alineado con las perspectivas que critican la suposición de que la representación es una relación diádica de correspondencia entre el vehículo representativo (el modelo) y su sistema-diana (v. g., Cartwright, Shomar y Suárez 1995; Morrison y Morgan 1999; Suárez 2003; Suárez 2004; Knuuttila y Merz 2009). Por ello, nos distanciamos de cualquier noción de representación como 'espejo', 'especulo' o 'replicación' (mirroring), que tienen que ver con conceptos como isomorfismo, similitud (likeness) o semejanza (resemblance) entre las propiedades del vehículo de representación y las de su sistema-diana. Nada parece más alejado de esto último que la práctica misma de la modelización en biología.

Uno de los objetivos principales que trata de satisfacer la modelización científica es proporcionar explicaciones acerca de los fenómenos que representan. En términos generales, se entiende por 'explicación científica' la acción o el proceso de establecer y especificar relaciones (causales, funcionales, mecanicistas, históricas, etc.) entre fenómenos, principalmente a través de teorías científicas. Sin embargo, en el caso concreto de la biología son los modelos los que son usados como las herramientas explicativas preferidas: "la explicación en biología se obtiene siempre a través de la intervención directa sobre modelos del fenómeno a explicar" (Leonelli 2009, 192). La característica singular de la biología es que explica esencialmente con modelos. Distinto es el caso de la física o la química donde los modelos comparten ese rol junto con las leyes científicas (en sentido propio; Lorenzano 2008), porque se insiste en las relaciones fenoménicas de tipo causal. En biología, explicación y representación están fuertemente entrelazadas.

Revista de Humanidades de Valparaíso, 2019, No 14, 315-334

(c) (1) 8 (을 CC BY-NC-ND 
Un enfoque inferencial y dinámico de la modelización y de la comprensión en biología

Rodrigo Lopez-Orellana; Juan Redmond; David Cortés-García

En los últimos años ha existido una rica discusión filosófica acerca de las funciones representacional y explicativa de los modelos. Por ejemplo, según Cassini $(2016,25)$, uno de los aspectos más interesantes de esta discusión es que - en general - los modelos científicos no siempre comportan un mecanismo causal para la producción de los fenó$\operatorname{menos}^{1}$ que se intentan representar. Aunque la mayoría de los modelos no son causales, sí muchos de ellos logran proporcionar explicaciones satisfactorias. Por esta razón, la discusión filosófica se ha ampliado para considerar otros tipos de explicaciones científicas que pueden ser aceptadas como legítimas (v. g., Woodward 2003; Kitcher 1989, 1981). De esta manera, el problema no queda reducido a las explicaciones causales - en un sentido fuerte-, especialmente para el caso de la biología. En esta ciencia abundan explicaciones funcionales, mecanicistas y también históricas-evolutivas. Aunque las más estudiadas por los filósofos de la biología han sido las explicaciones funcionales. Según Braillard y Malaterre $(2015,13)$, este tipo de explicaciones son problemáticas porque implican la noción de fin y por lo tanto de teleología, nociones que atraviesan tanto las explicaciones de la estructura de los organismos y de sus rasgos, como de sus características y organización. Además, la misma noción de función es muy compleja, se involucra en aquellas explicaciones que no tratan de dar cuenta de relaciones causa-efecto, sino que pretenden explicar las relaciones entre elementos como, por ejemplo, las ventajas asociadas a la aparición de un determinado carácter fenotípico en un contexto histórico y ambiental particular. Sin embargo, en biología sí es posible capturar con modelos este tipo de relaciones.

Junto con esto, cabe preguntarse también si en biología es necesario ampliar la perspectiva de la noción de representación o, más específicamente, preguntarse por cuál ha de ser la noción de representación estrictamente involucrada. Una forma de comenzar sería revisando el aspecto de intencionalidad que comporta la modelización, tal como se expresa en la cita anterior de Leonelli (2009), que se traduce en el uso que un agente (el científico) hace de un modelo para realizar una acción determinada sobre los fenómenos. En efecto, el componente intencional apremia a dirigir el análisis de los modelos hacia el estudio de las propias prácticas científicas: en cómo los biólogos realizan su investigación (experimentación) y construyen y utilizan modelos para representar o explicar los fenómenos.

En este trabajo ofrecemos entonces 1) algunos argumentos a favor de ampliar la perspectiva de la explicación con modelos incorporando la noción de comprensión, que actualmente se ha vuelto de gran interés para la filosofía de las ciencias naturales en el debate acerca de la modelización científica (de Regt y Dieks 2005; de Regt et al. 2009). Sin duda,

\footnotetext{
${ }^{1}$ Entiéndase por 'producción de fenómenos' la generación, creación o recreación de fenómenos a través de técnicas o procedimientos científicos, generalmente dentro de un laboratorio, para su estudio o descripción. Esta producción se da en el experimento científico, entendido como "un conjunto de dispositivos, mecanismos, sistema de métodos que mezclan sustancias con máquinas, seres vivos producidos por cría selectiva [...]" (Santesmases 2002, 267), entre otros elementos, y que se usan con el propósito de producir fenómenos en un laboratorio como fenómenos naturales.
}

Revista de Humanidades de Valparaíso, 2019, No 14, 315-334 
Un enfoque inferencial y dinámico de la modelización y de la comprensión en biología

Rodrigo Lopez-Orellana; Juan Redmond; David Cortés-García

esta noción ofrece una forma interesante de abordar el componente intencional de la modelización científica. En efecto, sostenemos que la comprensión tiene una relevancia epistémica para el caso de la explicación con modelos en biología. Además, gracias a la introducción de la noción de comprensión, 2) proponemos una perspectiva no referencialista sobre la modelización científica, determinada por el uso de modelos, la experimentación y la producción de fenómenos.

Pero antes de exponer nuestro enfoque, conviene tener presente lo siguiente. Frigg y Nguyen (2016) argumentan que - en términos generales - toda perspectiva sobre la representación científica, que pretenda estar bien definida, debe dar cuenta de los siguientes ítems:

(1) El problema de la demarcación representacional: la pregunta acerca de cómo las representaciones científicas difieren de otros tipos de representaciones (criterios de representación científica).

(2) Si el propósito que se tiene es establecer la demarcación entre representaciones científicas y las que no lo son, entonces se debe abordar el problema de la representación cientifica: cómo llenar el espacio en blanco en ' $R$ es una representación científica del sistema-diana $S D$ sys __'2. En cambio, si se parte del rechazo al problema de la demarcación representacional, tendrá que abordarse el problema de la representación epistémica: cómo llenar el espacio en ' $R$ es una representación epistémica de $S D$ sys ' (ER-Scheme).

(3) El problema de estilo: ¿qué estilos de representación existen y cómo se pueden caracterizar?

(4) Formular estándares de precisión (accuracy): ¿cómo identificamos lo que constituye una representación precisa o fiable (an accurate representation)?

(5) El problema ontológico: ¿cuáles son los tipos de objetos que sirven como representación?

Además, Frigg y Nguyen nos dicen que junto con estos problemas también tenemos las siguientes condiciones de adecuación o de suficiencia, que deben cumplirse satisfactoriamente:

(6) Razonamiento subrogativo (surrogate reasoning): las representaciones científicas nos permiten generar hipótesis sobre sus sistemas-diana.

\footnotetext{
${ }^{2}$ Hemos cambiado ' $S$ ' (representation) por ' $R$ ', y también ' $T$ ' (target system) por ' $S D$ ' (sistema-diana), del esquema original de Frigg y Nguyen (2016).
} 
Un enfoque inferencial y dinámico de la modelización y de la comprensión en biología

Rodrigo Lopez-Orellana; Juan Redmond; David Cortés-García

(7) Posibilidad de distorsión (misrepresentation): si $R$ no representa exactamente a $S D$, entonces se trata de una distorsión pero no de una no-representación (Redmond et al. 2017).

(8) Modelos sin diana (targetless): dar respuesta a la pregunta ¿qué debemos hacer con las representaciones científicas que carecen de targets, pero que son exitosas de igual manera?

(9) Requisito de direccionalidad: las representaciones científicas se refieren a sus targets, pero los targets no se refieren a sus representaciones.

(10) Aplicabilidad de las matemáticas: ¿cómo el aparato matemático utilizado en algunas representaciones científicas se vincula o enlaza con el mundo físico?

En nuestro artículo solo nos focalizaremos en aquellos aspectos y condiciones que consideramos más determinantes para la práctica de modelización en biología. Especialmente aquellos aspectos y condiciones que se orientan a proponer una nueva definición de representación incluyendo la noción de comprensión. Es en este sentido que nos ocuparemos del problema de la representación (2) y lo resolveremos en términos inferenciales desde el razonamiento subrogativo (6) como condición de suficiencia. Ejemplificaremos nuestro punto, muy brevemente, a partir de aplicaciones matemáticas (10) en modelos metapoblacionales.

\section{Comprensión científica a partir de modelos}

En primer lugar, afirmamos que la comprensión — en términos generales - debe entenderse como un estado subjetivo en el cual se construyen significados y/o conocimientos acerca de hechos o ideas y que pertenece a un dominio cognitivo como pensamiento inferencial. La comprensión permite de una manera fiable organizar, interpretar, comparar, traducir, describir la información o sacar conclusiones generales o resolver problemas a partir de ella. Por este motivo, no solo es un estado, sino que también es una acción. Pero esta acción no es reducible a tipos de razonamiento deductivos o inductivos, sino que se configura por medio de un tipo de disposiciones y relaciones de distinto carácter ${ }^{3}$.

En el caso del razonamiento científico, la información involucrada en la comprensión es el resultado de la investigación, teorización y experimentación científica. En este caso podemos distinguir entre comprensión y explicación científicas en cuanto a que la primera es una acción subjetiva, de un agente (el científico), aunque basada en una información acerca de los fenómenos del mundo (como información relevante, no trivial) obtenida a partir de la propia práctica científica. En cambio, la segunda siempre es intersubjetiva:

\footnotetext{
${ }^{3}$ Para un análisis acerca del razonamiento subrogativo, especialmente sobre los problemas de utilizar lógica clásica en este tipo de razonamiento, véase Redmond y Lopez-Orellana (2018a).
}

Revista de Humanidades de Valparaíso, 2019, No 14, 315-334 
Un enfoque inferencial y dinámico de la modelización y de la comprensión en biología

Rodrigo Lopez-Orellana; Juan Redmond; David Cortés-García

es llevada a cabo por un agente pero involucra de forma directa el reconocimiento de su éxito y aceptación por parte de una comunidad de agentes (la comunidad científica), en relación con ciertos procedimientos y criterios que esa comunidad ha establecido explícitamente. Por ello, la explicación científica ha estado fuertemente relacionada a tipos de razonamiento deductivos, inductivos, probabilísticos o, por lo menos, de acuerdo con ciertas reglas generalmente explícitas y aceptadas por dicha comunidad.

Según de Regt et al. $(2009,7)$, en la filosofía de la ciencia la comprensión se ha visto como un subproducto de la explicación, relegada a un segundo plano. Creemos que esto se debe, por un lado, a la necesidad de evitar consecuencias innecesarias de hipótesis psicologistas sobre el conocimiento científico; y, por otro lado, se debe a la exagerada importancia que se le ha dado al papel de las teorías y las leyes. Hoy en día, distintos autores limitan ese papel de las teorías a su utilidad como instrucciones para la construcción de modelos (principalmente de modelos explicativos) y ponen el foco en cuestiones tales como la autonomía de los modelos (respecto de las teorías), su manipulabilidad o sus usos, la producción de conocimiento y de fenómenos, o la comprensión acerca de los fenómenos que se gana con su uso (Knuuttila y Merz 2009, 153-154).

En la práctica científica es posible reconocer una variedad de relaciones entre sujeto cognoscente y fenómenos que caben bajo la forma de la comprensión (Wilkenfeld 2013, 999), razón por la cual la elaboración de una explicación 'unificada' de la comprensión científica puede resultar un tanto difícil. Sin embargo, de ello no se sigue que la noción de comprensión carezca de relevancia epistémica y que no pueda darse una definición más o menos general. En efecto, un esfuerzo de caracterización general dentro del debate de la explicación lo realizan de Regt et al. (2005; 2009), a partir de un criterio esencialmente contextual para la inteligibilidad de las teorías científicas.

Respecto a la cuestión de la relevancia epistémica, sabemos que los modelos pueden ofrecer una mejor comprensión de los fenómenos. Como argumenta Newman $(2017,574)$, dicha comprensión en ningún caso es modesta o superficial. Debemos reconocer que en la comprensión se garantiza - de alguna manera - un logro cognitivo efectivo: 'el sujeto $S$ comprende un sistema de fenómeno $f$ por medio del modelo $M$ '. Si esto no fuera así, es decir, si $S$ comprendiera $f$ solo de una manera superficial, observaríamos - por ejemploque $S$ no sería capaz de usar $M$ para ejecutar acciones o resolver problemas relativos al estudio de $f$. Pero, como argumenta Newman, sí vemos que en la propia práctica de la modelización - y, sobre todo, de la experimentación - los científicos son capaces de resolver esos problemas o ejecutar acciones significativas; incluso, evaluar la plausibilidad de $M$ o de la teoría $T$ involucrada, y ganar conocimiento respecto de $T$.

Una buena definición de la noción de comprensión ha sido elaborada por Elgin (2009, 327):

Revista de Humanidades de Valparaíso, 2019, No 14, 315-334

(ㄷ)(1)(8) CC BY-NC-ND 
Un enfoque inferencial y dinámico de la modelización y de la comprensión en biología

Rodrigo Lopez-Orellana; Juan Redmond; David Cortés-García

La comprensión es la captación [grasp] de un cuerpo general y amplio de información que está basada en los hechos, que responde debidamente a la evidencia y nos capacita para realizar inferencias no triviales, argumentos, y quizás acciones relacionadas con el asunto al que la información pertenece. (Elgin 2009, 327, traducción nuestra)

Además, esta noción

[...] se aplica a la comprensión como el producto final de la actividad explicativa ${ }^{4}$ (el estado cognitivo alcanzado, el objetivo de la explicación), porque es el estado de un sujeto cognitivo. Y se aplica aún más a la comprensión de las teorías y modelos utilizados en estas actividades explicativas: tal comprensión se refiere a la utilidad y a la manipulabilidad de las teorías y modelos evaluadas por un grupo específico de pares. (de Regt et al. 2009, 3, traducción e itálicas nuestras)

Esta idea supone que la comprensión pertenece no solo a un dominio cognitivo, sino también al dominio de la pragmática: un análisis acerca de los modelos debe incluir cuestiones como los propósitos del científico y los recursos materiales y abstractos que emplea para conseguirlos.

Cabe advertir que no entraremos aquí en la discusión respecto a los términos 'captación' (grasp) e 'información', que son por sí mismos bastante problemáticos. Remitimos a los trabajos de Newman (2017), Elgin (2009) y de Regt et al. (2009). Sí insistiremos en la inclusión de las nociones de 'utilidad' (también 'uso') y 'manipulación' (usefulness and tractability) señaladas en la cita anterior. Para el caso que nos interesa, esto es, sobre el papel que ocupa la comprensión en biología, lo que se pone en juego es que la manipulación tiene un valor epistémico central. El ámbito primordial de esa manipulación es el experimento. El objetivo de esa manipulación es conseguir una explicación de los fenómenos. Pero el objeto de esa manipulación es un modelo. Leonelli (2009) entiende este tipo de manipulación de modelos como "intervención directa":

Por "intervención directa" me refiero a la modificación de un modelo para investigar el fenómeno biológico que ese modelo representa. Esto puede suceder a través del razonamiento, como cuando se cambian mentalmente los términos de una ecuación usada para representar la dinámica evolutiva, o a través de movimientos físicos, como cuando

\footnotetext{
${ }^{4}$ Debemos advertir que la comprensión no siempre resulta ser el producto final de la explicación. Podemos tener explicaciones científicas exitosas sobre los fenómenos y, sin embargo, no lograr comprensión alguna sobre esos fenómenos o sus detalles. Por ejemplo, Darwin admitía que, si bien su teoría era una explicación muy exitosa de la evolución biológica a través de la selección natural, no había logrado comprender del todo algunos de sus mecanismos (cf. Darwin 1859, 194-195, Capítulo VI, sobre las dificultades de su teoría). Obviamente, explicación y comprensión son dos actividades intelectuales muy distintas, pero que pueden complementarse. Juntas pueden producir una mayor ganancia de conocimiento, pero va a depender de cuestiones como la inteligibilidad de las teorías o de los modelos. Un análisis detallado al respecto puede encontrarse en de Regt (2009, 30-38).
}

Revista de Humanidades de Valparaíso, 2019, No 14, 315-334 
Un enfoque inferencial y dinámico de la modelización y de la comprensión en biología

Rodrigo Lopez-Orellana; Juan Redmond; David Cortés-García

se cambia el orden de las bolas que representan los nucleótidos en una representación plástica de la doble hélice del ADN. Ya sea que se exprese en pensamientos o gestos, la agencia humana constituye una condición ineludible para producir explicaciones del mundo natural. (Leonelli 2009, 192, traducción e itálicas nuestras)

Por tanto, el 'uso' de un modelo implica siempre una manipulación o intervención directa sobre los modelos de los fenómenos a explicar, y la comprensión juega un rol central en esta acción. En este sentido, "[1]a comprensión es un término de éxito cognitivo" (Elgin 2009, 327), ya que nos permite decir con propiedad algo acerca de los fenómenos e inferir nuevas consecuencias acerca de ellos, a la vez que nos permite actuar sobre los propios modelos y sus sistemas-diana. Este tipo de comprensión obedece al interés por parte del científico de ofrecer una información relevante y pertinente sobre los fenómenos estudiados y con la intención de que pueda ser considerada dentro del marco teórico general de una ciencia. En este proceso, los experimentos tienen un papel fundamental, como mostraremos más adelante.

\section{Enfoque inferencial y dinámico de la comprensión y del uso de los modelos}

El esquema que hemos visto anteriormente, 'el sujeto $S$ comprende un sistema de fenómenos $f$ pormedio del modelo $M$ ', puede traducirse de la siguiente manera (en un segundo nivel de comprensión):

El sujeto $S$ comprende $M$, que habla acerca de $f$, cuando usa $M$.

Pero ¿qué estamos entendiendo por uso? Nuestra definición está inspirada en el enfoque inferencial presentado por Suárez (2004) y en la caracterización de Mäki (2009) acerca de la representación por sistemas subrogativos o sustitutos ${ }^{5}$ :

Decimos que un sujeto $S$ usa un modelo $M$ cuando:

(i) M apunta a un sistema-diana $S D$ (a un sistema de fenómenos); y

\footnotetext{
${ }^{5}$ Según a Mäki (2009, 32-33), debe entenderse que un modelo es un modelo de algo, específicamente de un sistema de fenómenos. Lo que, en estricto rigor, no es una perogrullada. Un modelo representa ese sistema de fenómenos como su sustituto. Un modelo $M$ representa un sistema-diana $S D$ en el sentido de que $M$ es representativo de $S D$ : en otras palabras, $M$ es el sistema sustituto/subrogante de $S D$. Para Mäki, la función epistémica de los modelos como sustitutos se traduce en conseguir conocimiento no examinando directamente a $S D$, sino más bien examinando directamente a $M$ (conocimiento indirecto de $S D$ ), siempre y cuando $M$ se parece o corresponde al sistema de destino $R$ en aspectos adecuados y en grados suficientes. Como hemos señalado anteriormente, en nuestro artículo analizamos cuál es la forma más ajustada a la evidencia científica en la que se relacionan $M$ y $S D$, como sistema de fenómenos biológicos, y cómo conseguimos conocimiento de $S D$ a través de $M$. Para alternativas ficcionalistas de esta relación véase Redmond y Valladares (2018a; 2018b) y Redmond, Valladares y Lopez-Orellana (2017).
}

Revista de Humanidades de Valparaíso, 2019, No 14, 315-334

()ㅇㅇㅇㅇ CC BY-NC-ND 
Un enfoque inferencial y dinámico de la modelización y de la comprensión en biología

Rodrigo Lopez-Orellana; Juan Redmond; David Cortés-García

(ii) $S$ genera hipótesis (inferencias subrogativas) sobre el $S D$ a partir de $M$.

El primero (i) es la relación que se establece por la capacidad de una fuente (que es $M)$ para llevar a un usuario competente e informado $(S)$ a considerar dicho sistema-diana $(S D)$. Se trata de una propiedad relacional y contextual de $M$, fijada y mantenida en parte por los usos previstos por parte de los agentes. No se puede decir que ningún modelo apunte intencionalmente a un sistema-diana en ausencia de tales usos. En este sentido, se trata de un acto intencional de $S$ que establece una relación entre $M$ y el $S D$.

También, si $M$ apunta a su sistema-diana, el requerimiento de direccionalidad queda garantizado ( $M$ apunta a $S D$ pero no al revés) y asegura al mismo tiempo (ii), esto es, la dinámica de inferencias subrogativas entre $M$ y $S D$.

Por razonamiento subrogativo o sustituto (surrogate reasoning) debe entenderse aquella función que cumple un modelo de generar hipótesis sobre su sistema-diana. Sustituto en el sentido de que las conclusiones que se obtengan por esta vía en $M$ serán consideradas como hipótesis formuladas sobre su sistema-diana. Lo que infiero en $M$ lo 'traslado' al sistema-diana.

Lo anterior nos permite definir inferencialmente una noción de comprensión que llamaremos aquí 'comprensión efectiva' (Lopez-Orellana y Cortés-García 2019):

El sujeto $S$ comprende efectivamente el modelo $M$, que habla acerca de un sistemadiana $S D$, cuando usa $M$ generando subrogativamente hipótesis que permiten manipular $S D$ mediante acciones o procesos de control y la generación de nuevos fenómenos $S D^{\prime}$.

Nuestra definición es entonces una definición inferencial y dinámica; 'comprensión efectiva' debe entenderse aquí como una noción de este tipo. Se ajusta a la definición de Elgin (citada más arriba) en la medida en que, para definir uso, nos focalizamos en las inferencias no triviales y argumentos que nos llevan a generar un conjunto de acciones o procesos para el control de los fenómenos. Y también, sobre todo en biología, para la generación de nuevos fenómenos. Afirmamos que esas acciones o procesos para el control de fenómenos (manipulación) tienen lugar en el experimento, como definiremos a continuación.

Así mismo, según la definición de comprensión de Elgin (2009), $M$ puede entenderse también como algún tipo de información (básica o muy elaborada o refinada) relativa a un fenómeno o sistema de la realidad $S D$, que en nuestro caso es la realidad biológica, y que puede ser transmitida o compartida con la comunidad científica. El éxito cognitivo de $S$ en la comprensión de $M$ (que habla acerca de $S D$ ), puede ser evaluado gracias a que logra manipular o usar satisfactoriamente $M$. En efecto, el éxito de la comprensión guarda relación, en última instancia, con el logro de $S$ en la transmisión o comunicación de $M$ y en la respectiva aceptación de sus pares. Con ello se sugiere que en dicho proceso cognitivo

Revista de Humanidades de Valparaíso, 2019, No 14, 315-334

(). (18) CC BY-NC-ND 
Un enfoque inferencial y dinámico de la modelización y de la comprensión en biología

Rodrigo Lopez-Orellana; Juan Redmond; David Cortés-García

el sujeto logra — en primera instancia - establecer relaciones y construir conocimientos efectivos y exitosos acerca de los hechos relativos a $S D$. De esta manera, se pone énfasis en el ámbito contextual y de aplicación de la comprensión. En el proceso de la comprensión, el científico usa o manipula la información en instancias donde necesite que sea más relevante, gracias a que ha 'captado' y logrado compartir su contenido. Entonces, una comprensión de este tipo debe ser entendida también como una cognición intersubjetiva acerca de un determinado fenómeno de estudio, que logra compartirse por el conjunto de la comunidad científica y que tiene como base epistémica la experimentación y la representación científicas asociadas al fenómeno.

Este modo de definir la comprensión en términos de uso, y el uso de los modelos a partir de su condición de generadores de hipótesis sobre $S D$, nos ubica en una clara perspectiva inferencialista y, por tanto, dinámica de la práctica de modelización en biología. Poner el peso en el uso aleja la modelización en biología de todo compromiso representacionalista, esto es, de una perspectiva estática de la modelización. No hay ningún compromiso realista: no se asume ningún isomorfismo o similaridad entre $M$ y $S D$.

\section{Noción de experimentación}

De acuerdo con nuestra definición de uso, "el científico usa un modelo cuando (i) apunta efectivamente con el modelo a un sistema-diana y (ii) genera hipótesis (inferencias sustitutas) sobre este sistema de fenómenos a partir del modelo", debe resultar claro el rol protagónico que posee la noción de experimento en nuestro enfoque, ya que hemos asumido que el ámbito primordial del uso de un modelo es el experimento. En este sentido, asumimos también que la noción de experimentación que está estrechamente relacionada con la comprensión es la de Ian Hacking (1983). En efecto, Hacking considera la experimentación como una práctica dinámica, como acción, basada en la intervención —o manipulación - y transformación de fenómenos, con cierta autonomía respecto de la(s) teoría(s) en cuestión ${ }^{6}$. Principalmente porque, al igual que con los modelos, la función de los experimentos no está reducida a la confirmación o refutación de esas teorías, aunque sí interactúa con la teorización y la modelización (Hacking 1983, 263-264).

En la concepción del realismo experimental (experimentalismo) de Hacking, realidad y experimentación están estrechamente vinculadas; en otras palabras, sostiene que la función principal de un experimento es crear fenómenos. Hacking habla de 'crear' y no de 'descubrir' atendiendo a la complejidad propia de la naturaleza, ya que generalmente es difícil tanto acceder a los fenómenos como producirlos de una manera estable y contro-

\footnotetext{
${ }^{6}$ Para Hacking, las relaciones entre teoría y experimento difieren en diferentes estadios de desarrollo, muchas veces los experimentos preceden a teorías importantes - como en el caso de las teorías de la óptica(Hacking, 1983, 159-160). Para una lectura complementaria sobre experimentación pueden verse Redmond y Lopez-Orellana (2018b) y Redmond y Valladares (2018b).
}

Revista de Humanidades de Valparaíso, 2019, No 14, 315-334

(ㄷ)(1)(8) CC BY-NC-ND 
Un enfoque inferencial y dinámico de la modelización y de la comprensión en biología

Rodrigo Lopez-Orellana; Juan Redmond; David Cortés-García

lada. Con ello entendemos por qué es común para los científicos que sus experimentos fallen: "[i]gnorar este hecho es olvidar lo que la experimentación está haciendo [...] la verdadera destreza de los científicos es saber cuándo el experimento está funcionando" (Hacking 1983, 230).

Experimentar es entonces crear, producir, refinar y estabilizar fenómenos (Hacking 1983, 229-230). Es a través de esta práctica ordenada que el científico consigue el éxito en su investigación. Pero esto no quiere decir que Hacking asuma un antirrealismo científico acerca de las entidades o fenómenos del mundo. Según Hacking, el trabajo experimental proporciona la mejor evidencia para el realismo científico, no solo porque podamos poner a prueba las teorías acerca de esas entidades o fenómenos, sino más bien porque logramos manipular aquellas entidades que no pueden ser 'observadas' y porque logramos con ello producir nuevos fenómenos y comprender los aspectos de la naturaleza. Para Hacking, las entidades teóricas (como el electrón) o las relaciones fenoménicas supuestas por las teóricas (como la plasticidad fenotípica), son vistas en este enfoque como herramientas, es decir, se convierten en entidades experimentales o 'entidades para el experimentador' (Hacking 1983, 262-266).

En efecto, es esa manipulación la que nos permite acercarnos a una comprensión efectiva de los fenómenos de la realidad. Por ejemplo:

La entidad teórica favorita del filósofo es el electrón [...] los electrones se convierten en entidades experimentales, o en entidades para el experimentador. En los primeros estadios del descubrimiento de una entidad podemos poner a prueba la hipótesis de que existe. Incluso esto es rutina. Cuando J.J. Thomson se dio cuenta en 1897 de que lo que había llamado "corpúsculos" estaban saliendo de los cátodos calientes, casi la primera cosa que hizo fue medir la masa de estas partículas cargadas negativamente. Hizo una estimación cruda de $e$ y de la carga, y midió $e / m$. El valor que obtuvo de $m$ era bastante correcto. Millikan elaboró algunas de las ideas que ya se discutían en el laboratorio Cavendish, y en 1908 determinó la carga del electrón, esto es, la unidad mínima probable de carga eléctrica. Así, desde un principio, la gente ponía menos atención en probar la existencia del electrón que en el hecho de interactuar con ellos. Cuanto mejor sea nuestra comprensión acerca de los poderes causales del electrón, mejor podremos construir aparatos que logren efectos bien comprendidos en otras partes de la naturaleza. Cuando se logra usar el electrón para manipular otras partes de la naturaleza de una manera sistemática, el electrón deja de ser un ente hipotético o inferido. Ha dejado de ser teórico y se vuelve experimental. (Hacking 1983, 262, traducción nuestra)

En relación con esta perspectiva de Hacking, ya a principios del siglo XX, el biólogo Jacques Loeb había propuesto una epistemología específica para la biología basada en la idea del control y producción del conocimiento. Para Loeb, comprender un fenómeno es ser capaz de controlarlo y, por ende, de producirlo: 
Un enfoque inferencial y dinámico de la modelización y de la comprensión en biología

Rodrigo Lopez-Orellana; Juan Redmond; David Cortés-García

[...] la biología moderna es fundamentalmente una ciencia experimental y no descriptiva; [...] sus resultados no son retóricos, pero siempre asumen una de estas dos formas: o bien es posible controlar un fenómeno de la vida hasta el punto de que podamos producirlo a voluntad (como, v. g., la contracción de un músculo extirpado); o bien conseguimos encontrar la relación numérica entre las condiciones del experimento y el resultado biológico (v.g., la ley de herencia de Mendel). La biología, en la medida en que se basa en estos dos principios, no puede retroceder sino que debe avanzar. (Loeb 1912, 3-4)

En otras palabras, el objetivo primordial del biólogo es controlar o producir fenómenos, antes que representarlos. El conocimiento exitoso que nos ofrece la biología radica en esta cuestión. Loeb definía la biología como investigación centrada en el control de los organismos; de esta manera, la experimentación obviamente juega un papel central (Pauly 1987, 5). Toda justificación del conocimiento biológico viene dada por el éxito de ese control, y esto se hace a través de experimentos. Una prueba de ello, según Loeb, fue su desarrollo de la partenogénesis artificial (fertilización química o activación del óvulo) en 1899, con la cual se puede comprender cuáles fueron las condiciones para el desarrollo evolutivo del óvulo — entre otras cuestiones-. Este éxito le llevó a considerar y valorar la forma en la cual los científicos deben generar un conjunto de acciones o procesos para el control y la generación de nuevos fenómenos (Loeb 1903; 1904).

Ahora bien, este tipo de manipulación involucrada en la experimentación es distinta que en el caso de los modelos. En la experimentación el objeto de esa manipulación o intervención son los propios fenómenos. Como señalamos anteriormente, el ámbito de la manipulación directa de los modelos es el experimento, pero el objeto de esa manipulación es un modelo. No se debe confundir ambas instancias de manipulación, aunque por supuesto estas están relacionadas. Como lo muestran Morgan y Morrison (1999), los modelos en conjunto con los experimentos son los que actúan como efectivos mediadores entre los fenómenos y las teorías. Pero los modelos cumplen un rol primordial en cuanto a que uno de sus principales objetivos es la explicación de los fenómenos.

En efecto, y siguiendo a Cartwright et al. (1995, 138-139), ambos son instrumentos exitosos de investigación. Nos permiten - por un lado- intervenir en el dominio conceptual de interpretaciones y representaciones del mundo, y - por otro lado- nos permiten la intervención sobre el dominio fenoménico. Por ello, ambos elementos deben considerarse como las herramientas para la comprensión cientifica. Aunque la perspectiva de Hacking exagere el papel del experimento, es totalmente compatible con los enfoques de Morgan y Morrison (1999) y de Cartwright et al. (1995), en vistas de la noción de comprensión científica. Por supuesto, debemos reconocer que, a favor del experimentalismo de Hacking, los experimentos nos permiten poner a prueba las hipótesis subrogativas que puedan darse acerca de la existencia de los fenómenos en cuestión y — de esta maneranos blindan para no caer en un realismo ingenuo sobre esos fenómenos. 
Un enfoque inferencial y dinámico de la modelización y de la comprensión en biología

Rodrigo Lopez-Orellana; Juan Redmond; David Cortés-García

\section{Modelos metapoblacionales: comprensión e idealización matemática}

Por estas razones, afirmamos también que el éxito de la comprensión tiene una estrecha relación con el hecho de estar en posesión de un modelo. Generalmente, un modelo comporta en una primera instancia una estructura simple o básica de información, pero que puede ir mejorándose o refinándose a partir de la interpretación de los fenómenos o de los resultados de la experimentación en su uso o aplicación exitosa. Una forma de entender esto es poniendo atención sobre las clases de modelos que existen en biología y el grado de idealización que entrañan. Dar cuenta de la gran diversidad de modelos que se utilizan en biología - que se encuentra en estrecha relación con los usos de estos y con los objetivos epistémicos particulares de los investigadores - es muy relevante para la interpretación de las estructuras de información (o conocimiento). Los modelos en biología pueden ser clasificados de distintas maneras; pero aquí distinguimos dos clases de modelos atendiendo a su carácter:

(a) Modelos matemáticos. Aquellos modelos integrados parcial o totalmente por elementos matemáticos. Dentro de estos, podemos distinguirlos en relación con contenido de idealización que comportan:

(i) Modelos matemáticos ideales. Consisten en formulaciones matemáticas aplicadas a la biología, por lo que son modelos a priori, sin carga empírica (o con una carga empírica muy restringida). Son, en muchas ocasiones, construidos como modelos falsos. Por ejemplo: el modelo de competencia interespecífica de Lotka-Volterra, los modelos matriciales predictivos de sucesión ecológica, los modelos clásicos de genética poblacional y el modelo de biogeografía insular de McArthur y Wilson.

(ii) Modelos matemáticos empíricos. Son modelos que poseen una carga matemática importante, al incluir en su propia constitución funciones gráficas, ecuaciones, algoritmos, etc.; sin embargo, y a diferencia de los anteriores, parten de mediciones u observaciones empíricas. Pueden ser reconfigurados en modelos falsos. Por ejemplo: el modelo de la cinética enzimática de Michaelis-Menten, los modelos gráficos para los efectos Bohr y Haldane de la saturación de la hemoglobina y los modelos computacionales basados en la teoría de redes.

Esta distinción entre modelos ideales y modelos empíricos es una clasificación continua, establecida en base al grado de idealización que un modelo particular comporte, y siendo, generalmente, inversamente proporcional a su carga empírica. De esta manera, un modelo particular, en su desarrollo, puede alterar su grado de idealización y de carga empírica, como reflejaremos más adelante en esta misma sección.

Revista de Humanidades de Valparaíso, 2019, No 14, 315-334

(c) (1) $\mathrm{O}$ (을 BY-NC-ND 
Un enfoque inferencial y dinámico de la modelización y de la comprensión en biología

Rodrigo Lopez-Orellana; Juan Redmond; David Cortés-García

(b) Modelos descriptivos. Son de carácter fundamentalmente descriptivo. Por lo general son menos abstractos que los modelos matemáticos, aunque su elaboración comporta siempre un cierto grado de abstracción y de idealización, aunque no en un sentido matemático. Por ejemplo: los modelos de los operones lac y trp, el modelo de Singer de la bicapa lipídica, los modelos-organismo ${ }^{7}$ y los modelos $3 \mathrm{D}$ computacionales o físicos de estructuras anatómicas.

Incluso podemos encontrar diferentes modelos con distintos grados de idealización para un mismo sistema de fenómenos. Por ejemplo, para el caso de la predicción de la dinámica de metapoblaciones se han propuesto sucesivos modelos (Hanski 1998; Smith y Smith 2007, 255-269) que van incorporando progresivamente una carga empírica mayor, al tiempo que se reduce su grado de idealización y cuya 'precisión' representacional resulta incrementada. Ejemplos como estos permiten abordar el problema de los estándares de precisión representacional de los modelos y de la aplicabilidad de las matemáticas; esto es, el problema número (4) y la condición de suficiencia número (10) de Frigg y Nguyen (2016). En efecto, los modelos metapoblacionales tratan de predecir las variaciones a lo largo del tiempo en los tamaños de las subpoblaciones en casos de hábitat discontinuo, es decir, en poblaciones cuya distribución geográfica atiende a una conformación en parcelas. Aquellas poblaciones que se encuentras geográficamente fragmentadas, pero entre cuyas subpoblaciones se mantiene un flujo génico (migración) se denominan metapoblaciones. En la siguiente figura se representa un esquema de una metapoblación clásica con distribución parcelada:

\footnotetext{
${ }^{7}$ Denominamos modelo-organismo a aquellos modelos que se corresponden con un organismo biológico. El mismo individuo (o grupo de individuos) funcionan efectivamente como un modelo.
} 
Un enfoque inferencial y dinámico de la modelización y de la comprensión en biología

Rodrigo Lopez-Orellana; Juan Redmond; David Cortés-García

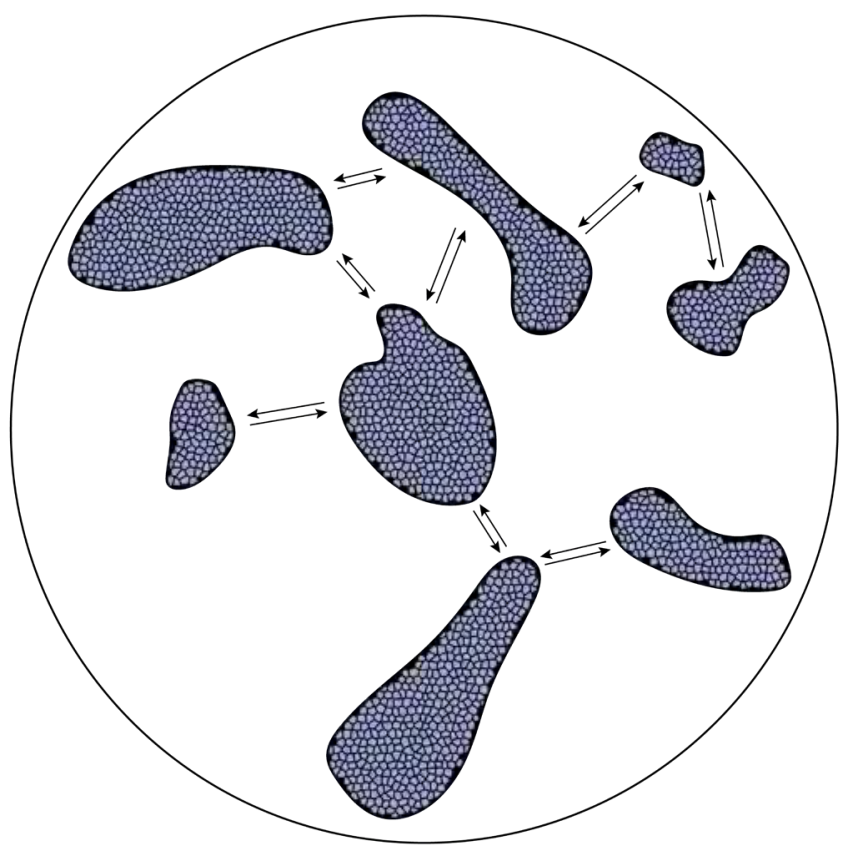

Fig. 1. Esquema de una metapoblación clásica con distribución parcelada. Los espacios coloreados (parcelas) representan el área de ocupación de una subpoblación, es decir, las regiones cuyas características bióticas y abióticas pueden mantener una subpoblación de la especie de interés, mientras que los espacios en blanco (matriz) es toda sección del terreno cuyas características las hacen inhabitables para una población determinada. Se corresponde con los espacios vacíos entre parcelas ocupadas. A diferencia de otros modelos metapoblacionales, el modelo clásico no distingue entre parcelas ocupadas y parcelas ocupables. Las flechas representan el flujo génico entre subpoblaciones, es decir, la migración entre parcelas.

De hecho, el modelo básico de metapoblaciones $\left(\mathbf{e}_{1}\right)$ pertenecería a la clase de modelos matemáticos ideales, mientras que podríamos considerar las sucesivas elaboraciones y refinamientos de este $\left(\mathbf{e}_{2} \mathrm{y}_{\mathbf{3}}\right)$ como modelos matemáticos empíricos. El modelo original parte de una serie de asunciones teóricas, consistiendo el mismo en la aplicación de una ecuación a un problema biológico real: las dinámicas demográficas en poblaciones geográficamente fracturadas. Su formulación matemática es la siguiente:

$$
\begin{array}{ll}
\mathbf{e}_{1} \quad \frac{d p}{d t}=I(p)-E(p) \quad \begin{array}{l}
\text { donde } p \text { es la probabilidad de persistencia (fracción de } \\
\text { espacios ocupados), } I(p) \text { la tasa de inmigración y } E(p) \text { la } \\
\text { tasa de extinción. }
\end{array}
\end{array}
$$


Un enfoque inferencial y dinámico de la modelización y de la comprensión en biología

Rodrigo Lopez-Orellana; Juan Redmond; David Cortés-García

Otra versión posterior es el modelo 'isla-continente' o 'lluvia de propágulos', que considera un núcleo mucho mayor en el que la población nunca llega a extinguirse (continente). Esta nueva formulación supone un refinamiento de la ecuación anterior al incorporar nuevas presuposiciones empíricas:

$$
\mathbf{e}_{2} \quad \frac{d p}{d t}=i(1-p)-e p \quad \begin{aligned}
& \text { donde } i \text { es la probabilidad de inmigración y } e \text { es la } \\
& \text { probabilidad de extinción. }
\end{aligned}
$$

Una versión que se ajusta mejor a las dinámicas poblacionales es el modelo de Levins, que considera que la tasa de inmigración no es constante sino proporcional a la fracción de parcelas ocupadas y a la fracción de parcelas vacías:

$$
\mathbf{e}_{3} \quad \frac{d p}{d t}=i(1-p) \cdot \mathrm{p}-e p
$$

Este es un modelo mucho más simple. Nos permite comprender la relación entre la tasa de colonización de parcelas y la tasa de extinción de subpoblaciones. Ambos casos dependen de las características observadas de las especies, específicamente, de la habilidad de las especies para migrar: cuanto más hábil sea una especie para migrar, mayor será la tasa de ocupación (colonización) de una parcela; y, cuanto mayor sea la tasa de extinción, mayor será la tasa de desocupación (Levins 1969; 1970).

A pesar de que el modelo de Levins $\left(\mathbf{e}_{3}\right)$ se aproxime mejor a la dinámica poblacional observada en la naturaleza, cabe señalar que no tiene en consideración otros aspectos relevantes tales como el efecto rescate, las características de la matriz, la importancia de los corredores ecológicos ${ }^{8}$, los factores ambientales regionales, la no-linearidad de las relaciones en la naturaleza, las sinergias causales, los efectos antropogénicos, etc. (Laurance 2008). La incorporación de estos factores abre la posibilidad de elaborar modelos de mayor precisión representacional para casos experimentales particulares, atendiendo a las características propias la metapoblación concreta a modelar (incluyendo las características del entorno) y de los objetivos epistémicos particulares de los investigadores. Esto nos muestra que, en muchos casos, los modelos ideales difícilmente son capaces de capturar la complejidad de los fenómenos que tratan de explicar o predecir, principalmente porque en esta ciencia predominan las causas multifactoriales. Aunque debemos destacar que el valor de los modelos metapoblacionales viene dado por su poder predictivo, puesto que estos son elaborados con el fin de comprender las dinámicas poblacionales en hábitats fragmentados para desarrollar programas de gestión del territorio y de conservación de la biodiversidad más eficientes.

\footnotetext{
${ }^{8}$ Los corredores ecológicos son fracciones de terreno que unen diferentes parcelas y que, no formando parte del espacio habitable, favorecen el movimiento de los individuos entre parcelas y, por lo tanto, el flujo génico.
} 
Un enfoque inferencial y dinámico de la modelización y de la comprensión en biología

Rodrigo Lopez-Orellana; Juan Redmond; David Cortés-García

\section{Conclusiones}

Con el ejemplo anterior, el modelo metapoblacional de Levins, podemos confirmar que el éxito asociado a un modelo particular viene dado por su uso. En efecto, el incremento de la carga empírica asociada a un modelo particular - fruto de la incorporación de nuevos elementos causales, factores, o variables - supone un aumento en la precisión de la representación (ejemplificada en el paso de $\mathbf{e}_{\mathbf{1}}$ a $\mathbf{e}_{3}$ ). Esto supone la obtención de una mejor comprensión de los fenómenos involucrados, ya que nos permite inferir mejores hipótesis acerca de los mismos. De esta manera, podemos afirmar que el poder predictivo de un modelo viene dado por el carácter inferencial de la comprensión que nos ofrece.

En efecto, si enfocamos esta cuestión a nuestra definición de comprensión efectiva, podemos reconocer que un sujeto $S$ usa el modelo $M$ (por ejemplo, $\mathbf{e}_{1}$ o $\mathbf{e}_{2}$ ) generando hipótesis que permiten manipular $S D$ (en nuestro ejemplo, un conjunto de poblaciones próximas que intercambian individuos de la misma especie), mediante acciones o procesos de control (por ejemplo, manipulando genéticamente a un grupo de sus individuos o interviniendo en su ecosistema ${ }^{9}$ ). Estas acciones y procesos de control están alineados con las predicciones basadas en las inferencias realizadas subrogativamente a partir de $M$ y el correspondiente testeo en la experiencia. Este testeo confirma las predicciones aumentando la comprensión efectiva y permitiendo un margen de mejora en el que aumenta la capacidad predictiva. Todo esto se traducirá en la obtención de un mejor modelo $M^{\prime}$ (en nuestro ejemplo, gracias a la inclusión de la tasa de inmigración proporcional en $\mathbf{e}_{3}$ ).

De este modo, podemos ver también que la noción de predicción, como conjunto inferencias exitosas, nos permite pensar en una versión dinámica de la comprensión científica. En efecto, se trataría un proceso que nos ayuda a explicar cómo el modelo va mejorando. Incluso, podemos decir que el modelo como representación científica es más preciso o adecuado solo a la luz de las inferencias exitosas que, como predicciones, son el resultado de una comprensión efectiva que un usuario generó al usar el modelo prediciendo y realizando acciones con éxito sobre su sistema-diana.

Con todo esto, podemos ver el importante rol epistémico que tiene la comprensión para la explicación con modelos en biología, esto es, definida inferencial y dinámicamente como comprensión efectiva.

\footnotetext{
${ }^{9}$ Para un ejemplo exhaustivo de manipulación de un sistema de fenómenos sobre metapoblaciones, véase el famoso experimento de Klassen et al. (1970). Se trata de la manipulación de los caracteres hereditarios de una especie, como la Anthonomus grandis o gorgojo del algodón, para generar rasgos condicionales letales con el fin de destruir un porcentaje importante de individuos de esa especie y medir su respuesta de sobrevivencia global.
}

Revista de Humanidades de Valparaíso, 2019, No 14, 315-334 
Un enfoque inferencial y dinámico de la modelización y de la comprensión en biología Rodrigo Lopez-Orellana; Juan Redmond; David Cortés-García

\section{Referencias bibliográficas}

Braillard, P.-A., Malaterre, C. (2015). Explanation in Biology: An Introduction. En P.-A. Braillard, C. Malaterre (eds.), Explanation in Biology. An Enquiry into the Diversity of Explanatory Patterns in the Life Sciences, Vol. 11, pp. 1-28. Dordrecht: Springer. doi: https://doi. org/10.1007/978-94-017-9822-8

Cartwright, N., Shomar, T., Suárez, M. (1995). The Tool Box of Science. Tools for the Building of Models with a Superconductivity Example. En W. E. Herfel, W. Krajewski, I. Niiniluoto, R. Wójcicki (eds.), Theories and Models in Scientific Processes, pp. 138-149. Amsterdam: Editions Rodopi B.V.

Cassini, A. (2016). Modelos científicos. Diccionario Interdisciplinar Austral. Retrieved from: http://dia.austral.edu.ar/Modelos

Darwin, C. (1859). On the Origin of Species by Means of Natural Selection, or, The Preservation of Favoured Races in the Struggle for Life. London: John Murray.

de Regt, H. W. (2009). Understanding and scientific explanation. En H. W. de Regt, S. Leonelli, K. Eigner (eds.), Scientific Understanding. Philosophical Perspectives, pp. 21-42. Pittsburgh: University of Pittsburgh Press.

de Regt, H. W., Dieks, D. (2005). A contextual approach to scientific understanding. Synthese, 144(1): 13-170. doi: https://doi.org/10.1007/s11229-005-5000-4

de Regt, H. W., Leonelli, S., Eigner, K. (2009). Focusing on scientific understanding. En H. W. de Regt, S. Leonelli, K. Eigner (eds.), Scientific Understanding. Philosophical Perspectives, pp. 1-17. Pittsburgh: University of Pittsburgh Press.

Elgin, C. Z. (2009). Is Understanding Factive? In A. Haddock, A. Millar, D. Pritchard (eds.), Epistemic Value, pp. 322-330. Oxford University Press.

Frigg, R., Hartmann, S. (2018). Models in Science. The Stanford Encyclopedia of Philosophy. Retrieved from: https://plato.stanford.edu/archives/sum2018/entries/models-science/

Frigg, R., Nguyen, J. (2016). Scientific Representation. The Stanford Encyclopedia of Philosophy. Retrieved from: https://plato.stanford.edu/archives/win2018/entries/scientificrepresentation

Hacking, I. (1983). Representing and intervening. Introductory topics in the philosophy of natural science. Cambridge: Cambridge University Press.

Hanski, I. (1998). Metapopulation dynamics. Nature, 396(6706): 41-49. https://doi. org/10.1016/0169-5347(89)90061-X

Kitcher, P. (1981). Explanatory Unification. Philosophy of Science, 48(4): 507-531.

Kitcher, P. (1989). Explanatory Unification and the Causal Structure of the World. En P. Kitcher, W. Salmon (eds.), Scientific Explanation, pp. 410-505. Minneapolis: University of Minnesota Press. 
Un enfoque inferencial y dinámico de la modelización y de la comprensión en biología

Rodrigo Lopez-Orellana; Juan Redmond; David Cortés-García

Klassen, W., Creech, J. F., Bell, A. (1970). The potential for genetic suppression of insect populations by their adaptations to climate. Miscellaneous Publication, USDA, 1178: 1-77.

Knuuttila, T., Merz, M. (2009). Understanding by Modeling An Objectual Approach. En H. W. de Regt, S. Leonelli, K. Eigner (eds.), Scientific Understanding. Philosophical Perspectives, pp. 146-168. Pittsburgh: University of Pittsburgh Press.

Laurance, W. F. (2008). Theory meets reality: How habitat fragmentation research has transcended island biogeographic theory. Biological Conservation, 141(7): 1731-1744. https://doi. org/10.1016/j.biocon.2008.05.011

Leonelli, S. (2009). Understanding in Biology: The Impure Nature of Biological Knowledge. En H. W. de Regt, S. Leonelli, K. Eigner (eds.), Scientific Understanding. Philosophical Perspectives, pp. 189-209. Pittsburgh: University of Pittsburgh Press.

Levins, R. (1969). Some demographic and genetic consequences of environmental heterogeneity for biological control. Bulletin of the Entomological Society of America, 15(3): 237-240. doi: https://doi.org/10.1093/besa/15.3.237

Levins, R. (1970). Extinction. En M. Desternhaber (ed.), Some mathematical problems in biology. Lectures on Mathematics in the Life Sciences, Vol. 1, pp. 77-107. Providence, Rhode Island: American Mathematical Society.

Loeb, J. (1912). The Mechanistic Conception of Life. Biological Essays. Chicago: The University of Chicago Press.

Lopez-Orellana, R., Cortés-García, D. (2019). On Understanding and Modeling in Evo-Devo. An Analysis of the Polypterus Model of Phenotypic Plasticity. In A. Nepomuceno, L. Magnani, F. Salguero, C. Barés and M. Fontaine (eds.), Model-Based Reasoning in Science and Technology. Inferential Models for Logic, Language, Cognition and Computation, pp. 138-152. SAPERE Series. Cham: Springer. doi: https://doi.org/10.1007/978-3-030-327224_9

Lorenzano, P. (2008). Lo a priori constitutivo en la ciencia y las leyes (y teorías) científicas. Revista de Filosofia, 33(2): 21-48.

Mäki, U. (2009). MISSing the world. Models as isolations and credible surrogate systems. Erkenn, 70: 29-43. doi:10.1007/s10670-008-9135-9

Morrison, M., Morgan, M. S. (1999). Models as Mediating Instruments. En Mary S. Morgan and Margaret Morrison (eds.), Models as Mediators. Perspectives on Natural and Social Science, pp. 10-37. Cambridge: Cambridge University Press.

Newman, M. P. (2017). Theoretical understanding in science. British Journal for the Philosophy of Science, 68(2): 571-595. doi: https://doi.org/10.1093/bjps/axv041

Pauly, P. J. (1987). Controlling Life. Jacques Loeb and the Engineering Ideal in Biology. Oxford: Oxford University Press.

Redmond, J., Lopez-Orellana, R. (2018a). Lógica clásica y esquizofrenia: por una semántica lúdica. Revista de Filosofia, 74: 197-223. doi: 10.4067/S0718-43602018000100215. 
Un enfoque inferencial y dinámico de la modelización y de la comprensión en biología

Rodrigo Lopez-Orellana; Juan Redmond; David Cortés-García

Redmond, J., Lopez-Orellana, R. (2018b). Revisando las prácticas científicas de Galileo. En D. Salatino, G. Cuadrado y L. Gómez (eds.), Creatividad, investigación y lógica transcursiva, pp. 345-354. Mendoza: Facultad Regional Mendoza Universidad Tecnológica Nacional.

Redmond, J., Valladares, D. (2018a). Ficción en ciencia. Por una lectura artefactual de los modelos en ciencia. En Olga Pombo (ed.), Modelos e Imagens, pp. 45-73. Lisboa: Fim de Século Edições.

Redmond, J., Valladares, D. (2018b). Revisiting the Bohr Model from an artefactual perspective. En O. Pombo, A. Pato y J. Redmond (eds.), Epistemologia, Lógica e Linguagem, pp. 85106. Colecção Documenta. Lisboa: CFCUL.

Redmond, J., Valladares, D. L., Lopez-Orellana, R. (2017). Modelizaciones galileanas y objetos ideales. En Guillermo Cuadrado y L. E. Gómez (eds.), Ciencias de la Ingeniería en el Siglo XXI. Nuevos enfoques en su lógica, enseñanza y práctica, pp. 51-61. Mendoza: Universidad Tecnológica Nacional.

Santesmases, M. J. (2002). ¿Artificio o naturaleza? Los experimentos en la historia de la biología. Theoria, 17(2): 265-289.

Smith, T. M., Smith, R. L. (2007). Ecología. Madrid: Pearson Educación.

Suárez, M. (2003). Scientific representation: against similarity and isomorphism. International Studies in the Philosophy of Science, 17(3): 225-244.

Suárez, M. (2004). An inferential conception of scientific representation. Philosophy of Science, 71(5): 767-779.

Wilkenfeld, D. A. (2013). Understanding as representation manipulability. Synthese, 190(6): 9971016. doi: https://doi.org/10.1007/s11229-011-0055-x

Woodward, J. (2013). Making Things Happen: A Theory of Causal Explanation. New York: Oxford University Press. 


\title{
Individuación colectiva y emergencia de la organismalidad
}

\author{
Collective individuation and emergence of organismality
}

\author{
Isaac Hernández*; Davide Vecchi** \\ *Laboratoire de recherche ERRAPHIS, Département de philosophie, Université Toulouse Jean \\ Jaurès, France \\ hernandez.isaac@gmail.com \\ ${ }^{* *}$ Centro de Filosofia das Ciências, Departamento de História e Filosofia das Ciências, Faculdade \\ de Ciências, Universidade de Lisboa, 1749-016 Lisboa, Portugal \\ davide.s.vecchi@gmail.com
}

\begin{abstract}
Resumen
En este artículo nos centramos en la emergencia de la individualidad biológica por asociación, tratando de formular algunas condiciones teóricas para pensar el proceso de individualización colectiva. El punto de partida de nuestro análisis es el concepto de "transición evolutiva mayor". Una transición evolutiva mayor es el resultado de la integración de un cierto número de entidades biológicas, inicialmente independientes, que logran organizar sus interacciones, convirtiéndose en un colectivo de componentes que tiene una identidad orientada hacia un objetivo común. Cuando se trata de organismos, una transición mayor corresponde a un fenómeno de fusión entre organismos que, a veces, pertenecen a linajes diferentes. Así, el surgimiento de un nuevo nivel de individualidad biológica implica el establecimiento de relaciones constitutivas entre los individuos que cambia su estatuto de entidades autónomas. Como resultado, la aparición de un nuevo tipo de entidad en el mundo viviente implica que los individuos entablen relaciones que los transforman intrínsecamente, una transformación suficiente para que un "todo" se convierta en una "parte" que forma otro "todo", es decir; un nuevo nivel de organismalidad.
\end{abstract}

Palabras clave: individuación biológica, asociación, emergencia, organismalidad, complejidad biológica.

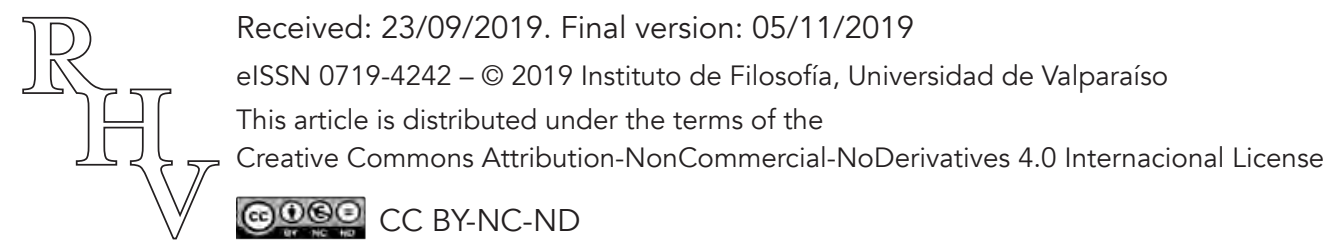


Individuación colectiva y emergencia de la organismalidad

Isaac Hernández; Davide Vecchi

\begin{abstract}
In this article we focus on the emergence of biological individuality by association, trying to formulate some theoretical conditions to think about the process of collective individualization. The starting point of our analysis is the notion of "major evolutionary transition." A major evolutionary transition is the result of the integration of a multiplicity of initially independent biological entities that, by managing to organize their interactions, become a collective of components having an identity oriented towards a common goal. When biological organisms (sometimes belonging to different lineages) are concerned, a major transition corresponds to a phenomenon of fusion between them. We shall argue that the emergence of a new biological level of individuality implies the establishment of constitutive relationships between individuals that change their status as autonomous entities. As a result, the emergence of a new type of entity in the living world implies that individuals enter into relationships that intrinsically transform them, a transformation sufficient for a "whole" to become a "part" that forms another "whole", that is, a new level of organismality.
\end{abstract}

Keywords: biological individuation, association, emergence, organismality, biological complexity.

\title{
1. Introducción
}

Todos los sistemas vivos poseen una dimensión interactiva que es indispensable para su auto-mantenimiento y existencia en un medio ambiente preciso. El conjunto de estas interacciones involucra la coexistencia con otros organismos. De hecho, desde el comienzo de la vida en la tierra, los organismos se han reagrupado o asociado, constituyendo grupos con distintos niveles de agregación y organización que aumentan, bajo ciertas circunstancias, las posibilidades de sobrevivencia de esos organismos (Ruiz-Mirazo y Moreno 2012). De esta forma, los organismos siempre han formado asociaciones de diferentes tipos, que poseen variados niveles de integración u organización que llevan a la creación de alianzas de distinto orden.

Ciertamente, podemos mencionar una variedad de colonias bacterianas, cuya dinámica opera bajo distintos niveles de complejidad que van desde agregaciones simples hasta agregaciones que poseen un gran nivel de complementariedad y coordinación de funciones. Tales ejemplos pueden referir a:

communities such as biofilms (which may be single or multi-taxa), as well as some populations of unicellular organisms, exhibit well-defined cell organization and a functional division of labour that includes specialized cell-to-cell interactions, the suppression of cellular autonomy and competition, metabolic collaboration, combined defense and attack strategies, and the coordination of movement, growth and reproduction. (Dupré y O'Ma1ley 2009, p.11)

Revista de Humanidades de Valparaíso, 2019, No 14, 335-362

(c) (1) 8 (을 CC BY-NC-ND 
Podemos referirnos también a las macro-interacciones ecológicas, en donde encontramos intercambios funcionales entre los organismos que comparten los recursos disponibles de un nicho común. De esta forma, podemos decir que la interacción entre organismos puede crear nuevos niveles de organización biológica, a partir del momento en que estas asociaciones logran anclar un nivel de integración importante.

Sin embargo, aunque existe un sinnúmero de ejemplos de comportamientos o fenómenos de asociación en el mundo vivo, los ejemplos de fenómenos de asociación que ven nacer un nuevo tipo de individuo biológico son más escasos. Podemos decir que una de las características más notables de este tipo particular de asociación es que las partes (organismos) que constituyen la organización actúan de manera coordinada, pudiendo eventualmente movilizar un proceso de selección natural al nivel de la organización. En efecto, la emergencia de un individuo biológico implica la existencia de un ritmo coordinado de actividad entre sus partes, una fenomenología única compuesta de entidades que fueron, en algún momento de la historia natural, entidades autónomas. De esta forma, comprender este fenómeno de asociación radica en el hecho de comprender cómo un grupo de individuos autónomos llega a hacer emerger un solo individuo autónomo.

En este artículo pretendemos profundizar conceptualmente en este fenómeno de integración particular, enfocándonos más específicamente en el problema de la emergencia de la individualidad biológica, a fin de comprender si y cómo un tipo particular de agregación de individuos pueden formar un solo individuo biológico.

\section{Transición evolutiva mayor}

Maynard Smith y Eörs Szathmáry en su libro The Major Transitions in Evolution introducen la idea de "transición" para denotar un cambio importante en la historia natural que no solamente puede alterar los tipos de entidades biológicas existentes, sino que también transforma el proceso evolutivo en sí mismo, abriendo así las puertas a la emergencia de nuevas formas de organización biológica, es decir, de complejidad biológica ${ }^{1}$.

En grandes rasgos, los autores sostienen que la evolución de la complejidad se ha canalizado, en varios momentos de la historia natural, a través de un puñado de grandes transiciones en los cuales encontramos grandes cambios en la manera en que la información se transmite de generación en generación. Así,

the evolution of new levels of biological organization, such as chromosomes, cells, multicelled organisms, and complex social groups radically changed the kinds of individuals

\footnotetext{
${ }^{1}$ Es importante precisar que las primeras tres transiciones postuladas por Maynard Smith y Szathmary (2010), no corresponden a asociaciones entre organismos, sino que a la evolución bioquímica de la biosfera. En este artículo, nos enfocamos en la evolución de nuevas formas de organismos por asociación y en la evolución de la organismalidad (Pepper y Herron 2008; Queller y Strassmann 2009).
}

Revista de Humanidades de Valparaíso, 2019, No 14, 335-362 
natural selection could act upon. Many of these events also produced revolutionary changes in the process of inheritance, by expanding the range and fidelity of transmission, establishing new inheritance channels, and developing more open-ended sources of variation. (Calcott et al. 2011, p1)

La evolución de la complejidad, al menos en este puñado de casos, sería una consecuencia de este particular fenómeno de transición, en donde la emergencia de un nuevo nivel de organización biológica implica la emergencia de novedad cualitativa.

Antes de continuar, es importante preguntarse por qué es necesario hablar de una transformación del proceso evolutivo. El hecho es que la teoría darwiniana de la evolución explica la variación de los organismos mediante un proceso de mutación aleatoria que se transmite de padres a hijos. La metáfora del árbol de la vida de Darwin pretende ilustrar las relaciones de parentesco entre grupos de seres vivos, teniendo cuidado en no considerar ningún tipo de proceso horizontal; ¡no se salta de una rama del árbol a otra! De esta manera, la novedad cualitativa que aparece a través del tiempo se explica únicamente en el espacio de la filogénesis de un clado siempre transmitida por descendencia directa. Podemos entender entonces por qué una transición mayor, en el sentido de Maynard Smith y Szathmary, podría cambiar nuestra visión del proceso evolutivo: de acuerdo con la visión darwiniana, el origen de los organismos que forman la especie proviene de la diferenciación de un organismo anterior que pertenece a la misma rama del árbol o al mismo linaje histórico, y no a un proceso de fusión entre organismos de diferentes orígenes. Sin embargo, en la idea de una transición mayor, la variación cualitativa puede ser impulsada también por fenómenos particulares de asociación entre individuos de diversos orígenes, cuando se asocian a tal punto que logran hacer emerger un nuevo nivel de individualidad. Así, la noción de transición mayor intenta capturar un fenómeno más general de evolución de la complejidad que podría tomar un camino diferente al de la evolución darwiniana clásica por descendencia común ${ }^{2}$.

El punto de partida de Maynard Smith y Eörs Szathmary para desarrollar la idea de transición evolutiva mayor es el reconocimiento de tres características principales de este fenómeno:

1. Las entidades que inicialmente fueron capaces de replicación autónoma pierden, después de la transición, esta autonomía replicativa en beneficio de una replicación dependiente de un conjunto más amplio.

\footnotetext{
${ }^{2}$ Se debe al mismo tiempo subrayar que Maynard Smith y Szathmáry (2009, p. 107) defienden la "excepcionalidad" de las fusiones por simbiogénesis: "The motorbike is a symbiosis between the bicycle and the internal combustion engine. It works fine, if you like that kind of thing, but someone had to invent the bicycle and internal combustion." El punto aquí es que la selección natural es más importante para entender la emergencia de las novedades evolutivas, y en consecuencia las transiciones mayores, que la simbiogénesis.
} 
2. Una transición mayor a menudo se asocia con la división del trabajo y la especialización de funciones.

3. Una transición mayor a menudo implica un cambio en la forma en que la información se transmite entre generaciones (Maynard Smith y Szathmáry 2010).

En este sentido, la aparición de la célula eucariota es un ejemplo paradigmático de este fenómeno. Hoy en día, el origen simbiogenético de la célula eucariota se impone frente a las otras teorías sobre la aparición de los eucariontes (Taylor 1976). Las mitocondrias y los cloroplastos (orgánulos semiautónomos de la célula eucariota) se definen como tipos de procariotas que han evolucionado especializaciones funcionales que les permiten generar y almacenar energía. Estas especializaciones se distribuyen, transmiten y heredan, inicialmente a través de la endo-simbiosis, luego como una función constitutiva de un nuevo organismo más complejo. En este punto, Lynn Margulis, una de las autoras de la teoría simbiogenética, especifica que los procesos de asociaciones que dieron lugar a la aparición de nuevas formas de vida a partir de la simbiosis (o en general a las sinergias entre las formas de vida existentes) son un motor fundamental en la transformación de la vida, en particular de su complejidad. Así, "long-term stable symbiosis that leads to evolutionary change is called 'symbiogenesis'. These mergers, long-term biological fusions beginning as symbiosis, are the engine of species evolution" (Margulis y Sagan 2002, 12). Como resultado, la teoría simbiogenética sostiene que las relaciones simbióticas que impulsan los procesos simbiogenéticos son responsables de gran parte de las novedades evolutivas, lo que puede ser consistente con la noción de transición evolutiva mayor, suponiendo que en cada transición hay un proceso de integración endógeno entre componentes de diferentes orígenes.

La idea de Margulis es en nuestra opinión fundamental para estructurar la noción de transición mayor. Un fenómeno de este tipo implica un flujo de fusión de individuos que, siendo profundamente afectados por los resultados de sus asociaciones, pierden su autonomía individual frente a un nuevo dominio de organización más complejo. De esta forma, una transición mayor podría definirse como el resultado de la integración de un grupo de organismos, inicialmente independientes, que hacen emerger un sistema unitario capaz de organizar sus interacciones como un colectivo de componentes que tiene una identidad orientada hacia un objetivo común. Es así como el resultado de cada evento de transición mayor es la aparición de un nuevo nivel de organización biológica con un nuevo nivel de complejidad. Es así también que el surgimiento de una nueva organización biológica autónoma implica la apertura de nuevos caminos de complejidad en los que las entidades emergentes son cualitativamente diferentes de sus predecesores. 


\subsection{Transición, complejidad y jerarquización}

Para entender mejor la relación entre la emergencia de la novedad cualitativa y el fenómeno de agregación de organismos asociado a una transición mayor, es importante entender el tipo de noción de complejidad que está en juego. En el caso de una transición mayor, esta complejidad se teoriza poniendo énfasis en los fenómenos de interacciones entre organismos, dentro de los cuales un conjunto de organismos logra estabilizar sus relaciones dando origen a un nuevo individuo biológico. Es importante entonces explicitar las conexiones teóricas entre el concepto de "nivel" en biología y la noción de "jerarquía", siendo estas nociones capitales para entender el proceso de emergencia de la complejidad que denotan las transiciones mayores.

Como decíamos, la complejidad está vinculada a la noción de "transición" y este vínculo se expresa a través de una jerarquización creciente en la historia de los seres vivos. En efecto, es común observar que los sistemas vivos tienen una estructura anidada o jerárquica que ha emergido a lo largo de la historia evolutiva. En términos generales, una jerarquía corresponde a una clasificación en la que los términos clasificados están en una relación de subordinación. De esta forma, una jerarquía expresa un tipo de relación de orden en el que hay elementos restringidos por otros elementos. En una organización, por ejemplo, la jerarquía se basa en un orden de prioridad entre los elementos o en las relaciones de subordinación entre los miembros de la organización ${ }^{3}$. Cuando decimos que la vida se nos aparece bajo una estructura jerárquica, decimos entonces que la vida tiene un tipo de arreglo u organización en el que los elementos están en una relación de subordinación. Cuando pensamos en esta relación desde la historia evolutiva, podemos decir que la evolución ha tendido a producir sistemas más complejos agregando progresivamente más niveles jerárquicos. Por ejemplo, si partimos desde las moléculas, estas moléculas se transforman posteriormente en biomoléculas, células, organismos multicelulares y grupos de organismos. Estas distintas etapas, caracterizadas por la aparición de un nivel mayor de complejidad, se pueden representar en una especie de escala en la que el elemento anterior se incluye dentro del nivel posterior.

Decíamos sin embargo que una jerarquía implica una subordinación de unos elementos respecto a otros. Una jerarquía entonces debe poder constreñir los niveles inferiores. Esto nos permite hacer una distinción teórica entre "jerarquía" y "nivel"4. En la idea de una

\footnotetext{
${ }^{3}$ Por ejemplo, en el ejército encontramos una disposición jerárquica de elementos, los soldados, donde el orden de prioridad de los elementos, los grados, es constitutivo de la organización.

${ }^{4}$ Esto es importante aclararlo para no confundir una jerarquía con un nivel de organización. Si el criterio utilizado para definir una jerarquía se basa únicamente en la inclusión de un nivel en el otro, en el que el nivel superior contiene entidades de nivel inferior al incluirlas como partes, el número de niveles jerárquicos existentes puede aumentar considerablemente. De hecho, un criterio como este, que puede considerarse a diferentes escalas, ya sea a nivel de los átomos hasta la biosfera, puede fácilmente volverse demasiado extenso, incluso ilimitado.
}

Revista de Humanidades de Valparaíso, 2019, No 14, 335-362 
transición mayor, dado que en cada transición surge un nivel de organización más complejo, podemos reconocer un número limitado de transiciones mayores $\mathrm{y}$, por lo tanto, de jerarquías bajo constricción. Por ejemplo, uno de los criterios de Maynard Smith y Szathmáry para definir una transición mayor es el hecho de que la entidad inferior pierde su autonomía replicativa o reproductiva durante la transición. Esto se ejemplifica en el caso de la transición de un nivel unicelular a un nivel multicelular, dado que el nivel superior restringe al nivel inferior a través de la pérdida de control de la función reproductiva del nivel inferior. Esta dependencia replicativa o reproductiva implica que el nivel superior constriñe el nivel inferior, lo que quiere decir que el nivel inferior está funcionalmente subordinado al nivel superior. En consecuencia, podemos decir que una transición mayor es la manifestación de un proceso de jerarquización en el que el número de niveles contenidos (o anidados) en la organización coexiste en una especificación jerárquica causal (McShea Daniel W. 2017), lo que Salthe llama "hierarchical process complexity" (Salthe, 1993). Por un lado, la jerarquización biológica obedece a una lógica de complejidad estructural (Heylighen 1999) en la que un sistema se compone de subsistemas acumulados, y las partes de un sistema estructuran el siguiente nivel, lo que también puede describirse como un aumento cuantitativo en los niveles organizacionales a lo largo del tiempo evolutivo. Por otro lado, en una transición mayor existe también una complejidad cualitativa que se constata al analizar los cambios y novedades biológicas, como cuando el sistema sufre un cambio fundamental en la forma en que almacena y transmite la información hereditaria (Szathmáry 2015).

Así, podemos decir que, en un proceso de individualización colectiva, existe un fenómeno de constricción en donde el nivel emergente se define por la constricción sistemática de sus elementos. De esta manera, la formación de un nuevo nivel de complejidad, en el sentido de una transición mayor, coincide con la formación de un nuevo nivel jerárquico. Así, la complejidad creciente de la vida se produce bajo un número limitado de transiciones evolutivas mayores, cuya particularidad es que el nuevo dominio relacional (el nivel superior) ejerce una determinación sobre los elementos que lo componen ${ }^{5}$. Como veremos más adelante, es también en este sentido que Maynard Smith y Eörs Szathmáry hablan de complejización durante la evolución, sugiriendo, entre otras condiciones, la pérdida de funciones de los individuos que componen la nueva organización.

Podemos resumir conceptualmente lo anterior diciendo que una transición evolutiva implica una fusión de individuos que permite la aparición de un nuevo tipo de individuo biológico. Este individuo representa un dominio biológico de organización distinto al de los individuos que se fusionaron. La aparición y persistencia de este nuevo dominio de

\footnotetext{
${ }^{5}$ Como podemos ver, existen distintas caracterizaciones de la noción de complejidad. Nosotros hemos hablado de complejidad jerárquica, cuantitativa y cualitativa en conexión con el tema de la emergencia de novedades biológicas. Lo importante es entender que todas estas nociones se encuentran imbricadas en una transición mayor.
} 
organización biológica depende, sin embargo, de la subordinación de las partes al nuevo nivel o dominio organizacional. Por lo tanto, si los individuos que componen este dominio están necesariamente subordinados para la realización de sus ontogénesis a las restricciones relativas de la organización del nivel superior del cual forman parte, entonces hay una nueva unidad, o individuo, que emerge ${ }^{6}$. Si este nuevo nivel de organización se estabiliza, el sistema puede ser seleccionado como un individuo en el que la evolución de las unidades componentes está necesariamente subordinada a la evolución de la nueva unidad compuesta. Finalmente, la estabilidad de este nuevo dominio biológico producido por la fusión entre individuos de orígenes a veces diferentes, se da cuando la fenomenología de los componentes está orientada hacia el mantenimiento de la organización de la unidad global, siendo esta una condición del mantenimiento y persistencia de la organización de los componentes.

\subsection{La composición de una jerarquía}

Para articular la noción de jerarquía con la noción de transición evolutiva, podemos centrarnos en la acumulación de los niveles de organización presentes en las jerarquías más complejas, o recientes, de la vida. Esto conecta también con la idea de tendencia a la complejidad creciente observada a lo largo de la historia de la vida ${ }^{7}$, en el sentido que la inclusión de un nivel en otro implica que este último es más complejo que el primero, en términos de los niveles incorporados en su estructura. Al mismo tiempo, una tendencia a la complejidad en la vida, de manera abstracta, también implica una tendencia a la jerarquización, es decir, una tendencia en "structural hierarchy, or the number of levels of nestedness of lower-level entities within higher-level individuals, of parts within wholes" (McShea 2001, p. 405). Así, la noción de jerarquía y de complejidad se encuentran en una relación directa $^{8}$.

\footnotetext{
${ }^{6}$ Es de precisar que una subordinación causal implica la aparición de una nueva norma biológica: todos los individuos que pertenecen a la organización colectiva dependen, para existir, de la organización global. Con el término "norma" se entiende una dinámica de asociación estabilizada. Por ejemplo, la normatividad fisiológica se manifiesta cuando las funciones de la asociación dependen las unas de las otras. En el sentido de Kaneko et al. se asocia la norma a una sociedad organizada en donde cada elemento se armoniza en conjunto y coexiste; en este caso Kaneko trata más bien la emergencia de la norma como orden colectivo (Furusawa y Kaneko 1998b).

${ }^{7}$ Justificar teóricamente que la vida tiene una tendencia a la complejidad es polémico. Solo podemos decir que hasta ahora la vida ha mostrado una tendencia a la complejidad lo suficientemente obvia como para movilizar varias hipótesis que intentan explicar esta tendencia (Bedau 2009).

${ }^{8}$ Si bien la existencia de una tendencia creciente a la complejidad por acumulación permanece controvertida en la literatura, sobre todo relativamente a la existencia de tendencias muy fuertes a la reducción genómica (O’Malley et al. 2016; Wolf y Koonin 2013). Se ha argumentado que, a pesar de la tendencia a la simplificación de la morfología, la tendencia a la complejización permanece creciente. La idea detrás de esta última posición es que la tendencia a la complejidad no siempre ocurre a través de la «acumulación» de
} 
Si nos centramos en un criterio estructural de la complejidad, podemos establecer un criterio teórico y operativo para comprender la misma. Los aspectos estructurales de la jerarquía consisten en especificar de cuántos tipos de entidades se compone el nivel jerárquico, así "by this criterion, a multicellular eukaryote contains more levels than a solitary prokaryotic cell; a society of multicellulars, more levels than a solitary multicellular individual" (McShea y Brandon 2010, 47). Es así como Daniel McShea propone un criterio cuantitativo para abordar la complejidad, basado en una descomposición del número de niveles entrelazados de la estructura jerárquica y el grado de individualización de la entidad de nivel más alto. Esto supone un principio de inclusión, en donde la entidad de nivel más alto incluye el nivel inferior como sus partes. Materialmente hablando, el nivel superior está compuesto de las partes del nivel inferior. Al mismo tiempo, para evitar la posibilidad de establecer jerarquías biológicas de forma ilimitada, es necesario agregar la condición siguiente: "lower-level entities [...] must be homologous with organisms in a free-living state, either extant or extinct" (McShea 2001, p. 408). Esto permite establecer un criterio más preciso en la definición de jerarquía biológica que limita el número de niveles jerárquicos que corresponden a las transiciones evolutivas. Así, por ejemplo, si la célula procariota ocupa el primer nivel de análisis jerárquico, el segundo nivel correspondería a la célula eucariota, dado que esta célula es una composición de procariontes. El siguiente nivel jerárquico sería los multicelulares, siendo estos una composición de eucariontes, así como los organismos coloniales serían una composición de los multicelulares. En todos estos casos, cada nivel jerárquico está compuesto del anterior, cuyos elementos son homólogos, en estado de libertad y autonomía, con el nivel superior que componen. A partir de este criterio, un órgano del organismo (el corazón, por ejemplo) no es homólogo a un organismo en estado de libertad, precisamente porque un órgano no puede concebirse por separado del organismo, es decir como organismo autónomo y libre ${ }^{9}$ La mayoría de las caracterizaciones de la jerarquía biológica se basan implícitamente en este requisito de existencia en autonomía y libertad; sin ellas, no habría límite teórico sobre la profundidad jerárquica discernible en los sistemas biológicos (Pigliucci 2010).

En esta sección, hemos querido establecer un sustrato conceptual para pensar en las condiciones para la emergencia de un nivel de individualidad. Al respecto, es importante enfatizar que la especificación apropiada de un nivel jerárquico se justifica cuando nos

partes y tipos de partes (por ejemplo, por diversificación funcional), sino que, a veces, a través de la perdida de ellas. Nótese también que esta posición es coherente con la idea extrapolada de la mereología formal; cuando el todo se vuelve más complejo, las partes se vuelven más simples (Varzi 2016).

${ }^{9}$ Esto parece ser un ejemplo similar al de las mitocondrias o el cloroplasto, que se han convertido en órganos especializados en el metabolismo de la energía celular. Incluso si en este caso reconocemos una cierta autonomía, sus orgánulos ya no pueden sobrevivir fuera de la maquinaria celular. En efecto, usando el criterio de homología de McShea, la mitocondria o el cloroplasto, siendo homólogos a organismos libres del pasado, no son análogos al corazón: el hecho de llamar a la mitocondria y el cloroplasto «organelos» no significa que son análogos a órganos en este sentido (McShea y Hordijk 2013).

Revista de Humanidades de Valparaíso, 2019, No 14, 335-362 
encontramos, como veremos a continuación, con el problema de especificar los niveles pertinentes para pensar en la individualidad biológica que supone la selección darwiniana. En este caso, los niveles relevantes de individualidad biológica se limitan a los niveles análogos a los organismos autónomos, evitando así estructuras y niveles intermedios. Así, contrariamente a una visión de la individualidad biológica en la que cada nivel de organización puede concebirse teóricamente como un nivel de selección, se puede sostener que los niveles relevantes para hablar de individualidad corresponden únicamente a los niveles expresados en las transiciones evolutivas. Es decir, en las que un conjunto de organismos ha logrado estructurarse bajo un espacio de interacción estructural/organizacional, de manera que sus comportamientos están correlacionados. Es así que la disposición de un conjunto de individuos que han establecido relaciones constitutivas con sus pares resulta en una agrupación que toma la forma de un nuevo dominio relacional que difiere de otros dominios relacionales del mundo exterior.

A su vez, hemos insistido que, en el marco de una transición evolutiva mayor, los organismos pierden gradualmente su autonomía fisiológica y reproductiva en provecho de una organización mayor de la cual ellos forman parte. El punto central es que las partes "renuncian" a ciertas funciones que permiten su autonomía. Como veremos a continuación, nuestra interpretación es que, en un proceso de individuación colectivo, debe haber una transferencia de autonomía por parte de los individuos que se ajustan al nuevo dominio colectivo.

\section{De una multiplicidad a una unidad: la transición}

El enfoque teórico del programa de investigación de "transiciones mayores" se centra en los episodios de creación de los nuevos tipos de agentes evolutivos, investigando cómo la individualidad biológica se transforma a través de la historia natural. En esta sección, mostraremos cómo es posible concebir, desde un punto de vista evolutivo, la aparición de un agente evolutivo.

\subsection{La composición del individuo biológico darwiniano}

El tema de la individualidad biológica se ha convertido en una unidad teórica fundamental desde el desarrollo de la teoría de la evolución por selección natural. De hecho, la explicación evolutiva requiere individuos, a menudo en competencia, que constituyan poblaciones en evolución. La explicación evolutiva también introduce una perspectiva diacrónica. Los individuos son concebidos como productos de la evolución, y estos pueden, al parecer, identificarse en muchos niveles de la jerarquía biológica (Lewontin 1970). David Hull define el individuo biológico como "spatiotemporally localized cohesive and continuous entities (historical entities)" (Hull 1978, p.336). El aspecto histórico de esta definición nos coloca directamente en el tiempo evolutivo. En este tiempo, el proceso de

Revista de Humanidades de Valparaíso, 2019, No 14, 335-362

()ㅇㅇㅛ CC BY-NC-ND 
selección natural representa la fuerza motriz de la evolución, la misma fuerza que Darwin anunció en términos de la "lucha por la existencia" de los individuos en un entorno de recursos limitados. Desde la teoría de la evolución por selección natural, y especialmente a través de su formulación contemporánea conocida como "la nueva síntesis" (Mayr 1998), el enfoque evolutivo de la individualidad biológica es dominante en las discusiones teóricas de la individualidad biológica. Así, la cuestión del individuo biológico ha sido absorbida por la noción de "unidad de selección" (Hull 1980; Godfrey-Smith 2009; Clarke 2010, Wilson 2005; Ghiselin 1971). Esta es la noción más ampliamente utilizada para definir un individuo biológico, subrayando su carácter evolutivo (Clarke 2010). Un individuo biológico corresponde, según esta noción, a una entidad sujeta a la fuerza de la selección natural, cuyo poder causal actúa sobre esta entidad-unidad discreta y continua. En consecuencia, podemos decir que el criterio ampliamente utilizado sobre la individualidad biológica se basa en la posibilidad de ser un objeto de selección (Mayr 1997).

Sin embargo, si bien la teoría de la evolución darwiniana a menudo se ha interpretado poniendo énfasis más bien en la competencia que en los fenómenos de cooperación, parece difícil negar que muchos organismos, para competir más eficazmente con sus pares, establecen nichos cooperativos. Basta pensar en el mutualismo establecido entre la célula huésped y las mitocondrias/cloroplastos que forman las células eucariotas, o al mutualismo de los biofilmes, o al mutualismo de los holobiontes, o a la co-evolución entre las plantas y sus polinizadores. En efecto, los ecosistemas no son sólo lugares de competencia, sino también de redes de interdependencia y de comunidades de las cuales depende la integridad de todos los miembros (Leigh and Vermeij 2002). Por lo tanto, si bien el criterio mayoritario para pensar la individualidad biológica se basa en la posibilidad de ser una unidad de selección, la cuestión de la emergencia de un nuevo individuo biológico, en el contexto de una transición mayor, se ha abordado a través de la siguiente pregunta: ¿cómo un grupo de individuos se vuelve un solo individuo, susceptible de desencadenar un proceso de selección al nivel de la colectividad, sin que la selección individual impida tal colectividad? (Michod and Nedelcu 2003a). De hecho, como señala Richard Michod, desde una perspectiva evolutiva, los individuos son "conjuntos" integrados e indivisibles que tienen un valor selectivo (fitness) que puede ser heredable; por lo tanto, pueden evolucionar y adaptarse a su propio nivel de organización (Michod 2007).

Para pensar en la evolución de grupos de organismos en grupos bien integrados y organizados, podemos suponer una organización robusta, un comportamiento social particular que conduzca a la estabilidad del grupo. Como explicaremos más adelante, esto significa que las relaciones entre los individuos en el grupo deben ir más allá de los beneficios individuales. El problema en cuestión es si la selección puede actuar a un nivel diferente al de los individuos, cuando estamos en presencia de tales comportamientos sociales. Si este es el caso, debe postularse que la selección actúa, no solo al nivel del individuo, sino que también puede actuar, bajo ciertas circunstancias, al nivel del grupo, lo que permitiría considerar una selección "multinivel” (Martens 2012; Okasha 2008). Por otro lado, la 
idea de que los grupos de organismos pueden hacer emerger propiedades que pertenecen exclusivamente al grupo y que son análogas a las de los individuos que conforman el grupo - lo que permitiría que estos grupos puedan ser concebidos como unidades de selección - nunca ha sido fácil de justificar. De hecho, la supuesta incompatibilidad de la selección con la cooperación ha provocado una serie de conflictos entre detractores y defensores de Darwin (Leigh 2010). Es Darwin en persona quién reconoce explícitamente en "El origen de las especies" que hay al menos un fenómeno biológico, los insectos sociales, que plantea "una dificultad muy especial lo suficientemente [...] insuperable como para derrocar" (Darwin 2008, p. 299) su teoría, sabiendo que en este tipo de sociedades la selección natural no parece ser aplicable a todos los individuos de la misma manera ${ }^{10}$. Sin embargo, incluso si Darwin postula, en el caso particular de las sociedades de insectos, la acción de una selección a nivel del conjunto, recordando que "la selección se aplica tanto a la familia como al individuo" (Darwin 2008, p. 301), la biología de la evolución ha dedicado mucho tiempo a teorizar la selección de los organismos paradigmáticos que pertenecen en particular al mundo-macro. Se piensa a menudo que la selección natural actúa ineludiblemente en organismos individuales, ya que la selección natural presupone, independientemente del nivel en cuestión, una replicación diferencial de entidades discretas. Por supuesto, esta es una condición que los grupos no satisfacen a primera vista. Es desde esta perspectiva que podemos entender la exclusión sistemática de un enfoque que piensa la selección a un nivel diferente al del organismo individual (Leigh 2010).

Para pensar una tal problemática, es interesante remitirse al origen simbiótico de la célula eucariota, que de hecho ha permitido modificar la representación que anteriormente se hacía de los mecanismos de evolución. El hecho es que este evento particular de la historia evolutiva pertenece a un proceso de fusión de linajes, y no al resultado de la variación de un linaje fisionado, como lo requiere la síntesis moderna. En efecto, la apertura al micro-mundo muestra claramente que la biología evolutiva, centrándose durante mucho tiempo en los procesos evolutivos de organismos individuales del macro-mundo, ignoró la importancia de los procesos horizontales. En particular, ha omitido la posibilidad de que los linajes puedan fusionarse para formar un sistema organizado completo que logre generar un nuevo individuo biológico (Doolittle y Bapteste 2007).

\subsection{Una correlación inversa de fuerzas}

Las interacciones entre individuos, en las cuales el surgimiento de un individuo evolutivo es uno de los resultados posibles, a menudo parecen motivadas por los beneficios que aporta su asociación, mostrando así características y propiedades adicionales, donde los intercambios han podido evolucionar desde la formación de grupos, hacia la formación, en el extremo, de verdaderos "super-organismos". De hecho, tan pronto como se evoca un

\footnotetext{
${ }^{10}$ Con toda certeza debido a la imposibilidad de propagación de los miembros estériles.
} 
proceso de individualización colectiva, examinamos la evolución de estos intercambios. Entre estos intercambios, la cooperación aparece como un elemento central de una organización colectiva que va más allá de los intercambios puramente individuales.

El surgimiento de la cooperación, bajo su faceta estratégica, la podemos entender como el "bien común". Sin embargo, tal bien común representa una complejización de las relaciones entre dos tipos de selección: la selección natural individual y la que tiene lugar al nivel del grupo en lo que esta última parece optimizada en comparación con los individuos aislados. De hecho, una población compuesta por individuos que dedican sus acciones a la preservación de sus estados individuales se sitúa es un proceso de selección individual donde la competencia se impone frente a la colaboración entre individuos. Por otro lado, tan pronto como tenemos una población que establece relaciones de interdependencia, nos movemos al otro lado del fenómeno de selección, con una fuerza selectiva que se desplaza hacia el lado del grupo, dejando espacio para la colaboración como vector de orden. Nos gustaría expresar esto por el término correlación negativa. Esto implica que la optimización de una colectividad pasa por una especie de inversión de la fuerza de selección individual, en donde el peso de la fuerza de selección es mayor a nivel de la comunidad que a nivel de los individuos que componen el grupo. Así, se da una correlación negativa entre la fuerza de selección del nivel de integración del colectivo y la fuerza de la selección individual de los elementos que componen el colectivo.

Este fenómeno de inversión entre la selección individual y la selección de grupos ha estado en el centro de la investigación sobre el comportamiento social, estableciendo la cooperación y su evolución como una forma de resolver el problema de la coexistencia de los varios niveles de organización biológica (Sober y Wilson 2003; Wilson 1997; Wilson y Sober 1989). Si pensamos en el problema de la compatibilidad de varios niveles de organización biológica, podemos suponer que el nivel inferior debe favorecer la cooperación a expensas de la competencia, lo que permite una disminución en la fuerza de selección individual y un aumento en la fuerza de selección a nivel de grupo. La evolución de la cooperación representa un paso crucial en el diseño de la transición efectiva de un estado individual a un estado de poblaciones estructuradas en grupos altamente organizados. Esta es la razón por la cual una transición evolutiva implica la formación de grupos cooperativos que se convierten, en ciertas circunstancias, en entidades integradas y vinculadas que pueden considerarse como nuevos niveles de individualidad.

Sin embargo, no es fácil teorizar la colaboración como condición para el surgimiento de una comunidad organizada. $\mathrm{Si}$, por un lado, la cooperación tiende a maximizar los beneficios selectivos de los grupos cuyos miembros actúan en coordinación (optimizando sus relaciones como grupo), por otro lado, la cooperación implica un costo para ciertos individuos que pertenecen a este grupo. Este costo puede atribuirse simplemente a su compromiso o al esfuerzo requerido durante la cooperación. Por ejemplo, el producir en exceso un elemento funcional para el grupo, proteger al grupo, prevenir posibles peligros, todos estos comportamientos benefician al conjunto, pero les cuestan a los cooperadores 
individuales sus inversiones energéticas en estas tareas. Así, la problemática de pensar en la cooperación como una fuerza impulsora de optimización de grupos hacia un estado de individualidad colectiva puede formularse de la siguiente manera: por un lado, la cooperación emerge como un proceso que reúne los intereses de todos, en el sentido en que un grupo que posee muchos colaboradores recolecta lógicamente un beneficio selectivo de cada individuo de ese grupo; por otro lado, el efecto lógico del costo de la colaboración recae en los miembros colaboradores y peligra el riesgo de propagación de la deserción. En este último caso, la selección natural debería causar una disminución de la frecuencia de estos cooperadores, lo que llevaría a una reducción de la viabilidad promedio de los grupos y, paradójicamente, a la pérdida de la posibilidad de generar un nuevo nivel estable de organización ${ }^{11}$.

Como podemos ver, este problema no es fácil de abordar. Esta problemática ha estado en el centro del debate sobre los estudios del altruismo biológico, ya que este rasgo es uno de los pilares fundamentales para pensar en la aparición de grupos sociales estables que creen un nuevo dominio biológico. En el contexto de una transición mayor, la mayoría de los niveles jerárquicos (genes, redes genéticas, células, células eucariotas, organismos multicelulares, super-organismos, etc.) evolucionaron a partir de un proceso de individualización colectivo que se caracteriza por un proceso de fusión entre individuos, ya que estos individuos se vuelven interdependientes. Esto se estudia en el enfoque de las transiciones mayores como resultado de la evolución de la cooperación. En consecuencia, si bien la evolución de la cooperación ha demostrado que el hecho de cooperar, incluso si a veces implica que ciertos individuos sacrifican sus beneficios individuales, hace posible favorecer al grupo en detrimento de los grupos menos colaboradores, es posible que la selección natural haya favorecido la permanencia de los rasgos altruistas en grupos cuyos beneficios selectivos promedio fueron mayores. De hecho, los grupos altruistas son más aptos, en el sentido de que cuentan con ventajas selectivas más importantes que los grupos no altruistas, lo que puede favorecer la evolución de este rasgo a pesar de las desventajas individuales en los grupos (Sober y Wilson 2003). Esto puede explicarse por el hecho de que la cooperación, aunque implica un cierto costo no despreciable dentro de los grupos, también tiene ventajas que explicarían por qué persisten estas asociaciones: en los grupos colaboradores, hay funciones que emergen que los miembros no pueden desarrollar por sí mismos. Por lo tanto, parece razonable decir que el nacimiento de la colaboración, a veces expresado como un sacrificio de autonomía individual, representa un paso crucial en el camino hacia la individualización de un grupo. Así, el tratamiento de la problemática de la cooperación requiere una comprensión del altruismo y su evolución dentro de los grupos, siendo esto la clave para entender cómo funciona la colaboración como principio de optimización.

\footnotetext{
${ }^{11}$ En la literatura este problema teórico es llamado "subversion from within" (Baron, 2013).
} 


\section{Condiciones teóricas para pensar la individuación biológica}

Como decíamos anteriormente, la consecuencia lógica de la cooperación dentro de los grupos radica en el hecho de que, para superar las dificultades teóricas planteadas por la selección individual en un contexto de individuación colectivo, necesitamos que la cooperación evolucione. Esto establece las condiciones para pensar en el surgimiento de una colectividad organizada: los individuos deben trabajar juntos con altos niveles de cooperación y bajos niveles de conflicto. Esta condición retoma la noción de organismo de Queller y Strassmann; "the organism is simply a unit with high cooperation and very low conflict among its parts" (Queller y Strassmann 2009). Esto significa que un proceso de individualización colectivo pasa por una adaptación en la que el conjunto ha logrado disminuir la competencia y aumentar la colaboración. Esto se traduce en el organismo a través de la supresión (idealmente) de la perturbación de las adaptaciones a niveles inferiores. En una transición mayor, encontramos mecanismos a través de los cuales un grupo de organismos se convierte en un solo organismo, es decir, un grupo que tiene un nivel muy bajo de conflicto y un nivel muy alto de cooperación entre sus miembros.

A continuación, expondremos algunas hipótesis de las condiciones para la formación de comunidades optimizadas y organizadas como agentes evolutivos. Estas condiciones están principalmente asociadas con la evolución de la cooperación y el control de conflicto entre los miembros.

\subsection{Especialización y control de conflictos}

Hemos dicho que una transición mayor se puede interpretar como un escenario en el que los individuos que antes eran autónomos se vuelven dependientes del nivel superior, es decir, de la red de interacciones que se han formado entre los individuos. Esta dependencia consiste en el hecho de que estos individuos se convierten en partes especializadas de un nuevo nivel de organización. Esta especialización se traduce en la conversión de los individuos previamente autónomos en elementos funcionales de un nuevo dominio biológico. Esto también puede entenderse como un proceso de transferencia de funciones al nivel superior, lo que no es otra cosa que la evolución de la especialización ${ }^{12}$. Es así que la idea de dependencia funcional observada durante una transición mayor encaja bien con la noción de indivisibilidad contenida en la noción de individuo. Cuando se produce una especialización de individuos de nivel inferior en funciones vitales (como la reproducción o funciones somáticas en organismos multicelulares), la organización general se vuelve, en última instancia, indivisible, es decir, se convierte en un verdadero individuo. Por lo tanto, la división del trabajo, resultante de la especialización de los individuos, también termina estableciendo una dependencia mutua: los individuos se vuelven tan especializados que pierden la capacidad de realizar otras tareas de manera autónoma (West et al.

\footnotetext{
${ }^{12}$ Este punto lo tratamos en la sección 4.2.
} 
2015). La especialización así es crucial en un proceso de individualización colectivo. En efecto, se pueden distinguir dos tipos de especializaciones: por un lado, está la división del trabajo fisiológico; por otra, la división del trabajo reproductivo. Cuando ambas se actualizan, se reúnen las condiciones para la emergencia de un nuevo individuo biológico. Si pensamos en la aparición de una unidad a partir de un conjunto heterogéneo de individuos, como es el caso de la aparición de la célula eucariota o de los primeros organismos multicelulares ${ }^{13}$, podemos comprender mejor la importancia de los dos tipos de especialización. La interdependencia funcional fisiológica, es decir, el hecho de que la función fisiológica de otro se vuelve indispensable para la estabilidad de uno y vice-versa, parece esencial para estabilizar (por ejemplo, para la emergencia de normas) un grupo que mantiene relaciones constitutivas. Si agregamos la interdependencia funcional reproductiva, podemos entender lo que Queller parece decirnos:

if independent units are to come together into successful new organismal entities, there must be some means of controlling the conflicts between them, some means of ensuring that the old units do not continue to pursue their individual reproduction at the expense of the group. (Queller 2000, 1650)

La división del trabajo fisiológico y reproductivo se enlaza con la emergencia de mecanismos de control de conflicto. Un ejemplo interesante de control de conflicto es el fenómeno del desarrollo embriológico. La aparición de mecanismos de control de conflicto ha podido evolucionar hacia mecanismos precisos de desarrollo observables en los complejos organismos actuales ${ }^{14}$. La aparición de mecanismos de desarrollo en el fenómeno de la multicelularidad puede entenderse como una consecuencia general de la interacción entre la dinámica interna y externa de las sociedades celulares (Furusawa y Kaneko 1998a; Kaneko y Furusawa 2000; Kaneko y Yomo 1999). En otros términos, puede entenderse como un mecanismo general de diferenciación espontánea de unidades biológicas que, al replicarse, se diferencian por interacción con otras células, desde el momento en que sus números aumentan por divisiones (Furusawa y Kaneko 1998a). Así, el origen de las organizaciones multicelulares puede describirse como una consecuencia posible de la dinámica interactiva de las células, sin que sea necesario postular un mecanismo genético o preformado que limite el comportamiento celular (Vecchi y Hernández 2014). La evolución de los mecanismos de control que supone una organización multicelular, corresponde originalmente a un fenómeno espontáneo y aleatorio de diferenciación funcional asociado con el comportamiento interactivo de las células. Estos mecanismos pueden haber evolucionado hacia la aparición de funciones del desarrollo embriológico

\footnotetext{
${ }^{13}$ Véase algunos interesantes aportes teóricos sobre el surgimiento de la multicelularidad en: Newman et al. (2006), Furusawa y Kaneko (2002).

${ }^{14}$ Sobre este punto, consultar las ideas de Newman y Bhat (2009).
}

Revista de Humanidades de Valparaíso, 2019, No 14, 335-362 
muy sofisticadas y complejas ${ }^{15}$. Este "orden", producido a partir de la interacción entre las células y su dinámica intracelular, conduce a la aparición de normas. Su producción ocurre espontáneamente en la aparición de funciones que ordenan poco a poco las interacciones celulares, alcanzando con el tiempo un proceso de desarrollo robusto que mantiene un grado de orden en una sociedad celular (Furusawa y Kaneko 1998b). Finalmente, en el caso de grupos multicelulares, el control del conflicto puede implicar la propagación de mediadores de conflictos que conducen al autocontrol, el control materno del destino celular, la disminución del tamaño de los propágulos, el crecimiento determinado del organismo, respuestas apoptóticas o el secuestro de la línea germinal (Michod y Nedelcu, 2003b).

Llegado a este punto, podemos pensar que la aparición de mecanismos de mediación de conflicto, en grupos colaboradores, corresponde a las primeras funciones que hacen posible convertir un grupo en una unidad. El surgimiento de la individualidad, por lo tanto, depende del surgimiento de funciones colectivas, incluidas las funciones que restringen el conflicto al garantizar la estabilidad y la armonía de las unidades de nivel inferior. Entonces, una de las diferencias cruciales entre un grupo de individuos y una unidad compuesta de individuos radica en el hecho de que el segundo posee, entre otras cosas, funciones que aseguran la persistencia de los miembros que componen el nuevo dominio biológico. En este sentido, decimos que el poseer mecanismos que conducen a la armonía multinivel ${ }^{16}$ corresponde finalmente a una de las funciones de nivel superior que surgen durante el comportamiento relacional de la vida. Por lo tanto, la emergencia de propiedades colectivas, como la función del desarrollo, puede servir como un criterio de distinción entre los verdaderos sistemas individualizados, que ponen de manifiesto las funciones colectivas, y los agregados de individuos que no han establecido relaciones constitutivas y que, por lo tanto, no corresponden a individuos reales.

\subsection{Transferencias y distribución de funciones}

En la sección 3.2 señalamos que una correlación negativa entre las partes y el todo hace posible pensar en la forma en que se armonizan los niveles de organización que conforman una comunidad. Al mismo tiempo, esta correlación negativa se presenta como una condición necesaria para que un conjunto de individuos se estabilice como unidad. También explicamos que, detrás de esta correlación negativa, existen mecanismos o funciones colectivas que gestionan la competencia entre los miembros de un grupo, lo que permite

\footnotetext{
${ }^{15}$ Este tema se estudia en relación al comportamiento de los sistemas complejos, especialmente porque durante las interacciones celulares, la célula, como sistema complejo lejos del equilibrio termodinámico, describe condiciones iniciales que conducen a la aparición de un orden del caos. Véase: (Goodwin 2001; Newman y Bonner 2016; Solé y Goodwin 2000).

${ }^{16}$ Creemos que los mecanismos de desarrollo son un muy buen ejemplo de control de conflicto. Se trata de una función que permite manejar una multiplicidad de individuos en un solo dominio organizacional.
}

Revista de Humanidades de Valparaíso, 2019, No 14, 335-362 
una armonización del nivel inferior con el nivel superior. Esto se debe a que el control de la competencia y del conflicto hace posible dirigir la fuerza selectiva hacia el grupo; la comunidad puede desencadenar un proceso de selección natural a nivel de conjunto. Por lo tanto, un proceso de individualización colectiva depende del surgimiento de funciones de nivel superior que limitan la posibilidad de confrontaciones entre los miembros, asegurando que la cooperación continúe entre las unidades de nivel inferior. Controlar el conflicto conduce, a través de la evolución de las adaptaciones que lo reducen, a una mayor individualidad y una mayor armonía para el organismo (Michod y Roze 2001).

Para explicar lo anterior en términos más concretos, Leo Buss (Buss 1987) propone el proceso de secuestro temprano de la línea germinal como mediador del conflicto durante la transición de la multicelularidad. Esto se debe a que dicha adaptación corresponde a un tipo de especialización funcional que hace que los miembros del grupo sean interdependientes y, por lo tanto, el sistema que constituyen indivisible. En este sentido, el secuestro de la línea germinal, como un caso de adaptación específica de la multicelularidad, supone la división funcional reproductiva entre las células somáticas y germinales (Huneman 2013). Una consecuencia interesante de esta división funcional es la interdependencia funcional que presupone. Un sistema dividido en funciones imprescindibles, como la reproducción y las funciones somáticas (el metabolismo, por ejemplo), conduce a una dependencia funcional vital, en el sentido de que cada individuo (o tipo de célula) necesita la función del otro para existir. En otras palabras, una división funcional conduce a una dependencia constitutiva irreversible.

Al mismo tiempo, el problema central que surge cuando se investiga la aparición de un nuevo nivel biológico es entender cómo puede haber una conciliación de varios niveles de organización en los que cada nivel está sujeto a las fuerzas de la selección natural en su propia escala. Richard Michod sugiere la transferencia de fitness ${ }^{17}$ como un medio para conciliar los varios niveles de organización biológica. Michod apunta que el pasar de un estado de selección individual a un estado de selección colectivo puede llevarse a cabo sobre la base de una transferencia de fitness entre el nivel inferior (los organismos individuales que estructuran la colectividad) y el nivel superior (la colectividad que contiene los individuos cuya aptitud diferencial disminuye respecto a la aptitud diferencial de la colectividad). La fitness o "aptitud" de cualquier unidad evolutiva puede entenderse de acuerdo con dos componentes básicos: fertilidad (reproducción) y viabilidad (mantenimiento y

\footnotetext{
${ }^{17}$ La fitness o "aptitud" es una herramienta descriptiva útil para los estudios de selección natural y se asocia con la tasa de supervivencia y el éxito reproductivo de un individuo o población. Los diferentes genotipos/ fenotipos de una población nunca tienen las mismas capacidades reproductivas ni las mismas tasas de supervivencia. En consecuencia, los individuos mejor adaptados a un entorno tendrán una mejor oportunidad de reproducirse en ese entorno; producirán por esta razón más descendientes. La importancia de esta noción en el análisis de la individualidad biológica radica en el hecho de que una de las condiciones indispensables para que una entidad sea considerada como individuo es que esta entidad pueda tener una fitness propia. Esto la convierte en una entidad que puede ser seleccionada.
}

Revista de Humanidades de Valparaíso, 2019, No 14, 335-362 
supervivencia). ${ }^{18}$ La transferencia de fitness implica que los elementos o funciones que tienen un vínculo directo con la aptitud de los individuos, y por lo tanto tienen un vínculo directo con las funciones reproductivas y de supervivencia, deben "exportarse" al siguiente nivel. Esta "exportación" se entiende como la forma en que opera la conciliación entre dos niveles de organización. Para los estudios sobre transición evolutiva, la cooperación es fundamental justamente porque permite la exportación de la fitness desde nivel inferior en beneficio del nivel superior (Michod y Herron 2006). Es así que podemos unirnos a la idea que Michod propone a partir de una correlación negativa de fitness; para que un grupo pueda coordinarse como un agente evolutivo, la fitness de los individuos debe disminuir proporcionalmente al aumento de la fitness del grupo. Esto puede pensarse como una transferencia de funciones de un nivel al otro. En efecto, decíamos que, al concebir la acción simultánea de la selección natural a más de un nivel, suponemos de hecho una coexistencia de esos niveles, sin los cuales todos estos se verían perturbados y no se estabilizarían como grupo. Sin embargo, esta coexistencia puede justificarse como consecuencia de la transferencia de las funciones de fitness desde el nivel inferior al superior.

Los eventos de las transiciones mayores se interpretan, bajo la tesis de Michod, como transiciones de la individualidad, enfocándose en los mecanismos de transferencia de esta individualidad al nivel superior. En este caso, la transferencia de fitness permite conciliar un nivel de organización con otro, a través de una disminución en la aptitud individual de los miembros y un aumento en la aptitud global del grupo (Hanschen et al. 2015). La lógica de esta tesis se basa en el hecho de que, si uno piensa en funciones que pueden representar la aptitud (por ejemplo, la función reproductiva o las funciones de supervivencia somática), una transferencia de estas funciones a un contexto grupal podría entonces mover las fuerzas de selección individuales al grupo. Por un lado, porque los individuos que han transferido funciones que tienen un vínculo directo con la aptitud diferencial, ya no tendrán su independencia individual, por lo que su aptitud individual dependerá absolutamente de las relaciones que entrega en el grupo. Por otro lado, una transferencia de funciones al grupo permite que este grupo sea seleccionado como grupo, lo que define su estatuto de individuo susceptible de ser seleccionado.

Conjuntamente, la transferencia de funciones, que es el resultado de la especialización, es un buen ejemplo de la distribución de funciones en un dominio biológico más amplio. De hecho, la especialización de los individuos en elementos reproductivos y elementos somáticos puede interpretarse como una redistribución funcional, en el sentido de que las funciones de desarrollo, reproducción y supervivencia se redistribuyen a través del grupo y, más concretamente, en el organismo multicelular, a través de linajes celulares. Así,

\footnotetext{
${ }^{18}$ Esta diferencia entre viabilidad y fertilidad grafica la diferencia entre especialización y división del trabajo funcional fisiológico y reproductivo.
} 
division of labor among lower level units specialized in the basic fitness components of the group enhances the individuality of the group. Once cells are specialized in one of the necessary components of fitness, say reproduction or viability, they can no longer exist outside of the group and the fitness of the group is no longer the average fitness of the cells belonging to the group. (Hanschen et al. 2015, p. 167)

Por ejemplo, en el caso de los organismos sociales actuales, una vez que se lleva a cabo la división del trabajo entre los miembros, los miembros que corresponden al linaje somático ahora se ven obligados a cooperar para el correcto funcionamiento del conjunto. Así, la distribución funcional de los linajes celulares parece ser un buen ejemplo de dependencia constitutiva derivada de la especialización. Finalmente, la diferenciación funcional, como principio fundamental para establecer una dependencia fuerte entre los miembros de un dominio biológico discreto, también se encuentra en grupos de organismos formados por diferentes especies, como en muchos casos de mutualismo y simbiosis a lo largo de la historia evolutiva ${ }^{19}$. Esto corresponde bien al caso de las mitocondrias, que han perdido la función de replicación totalmente independiente, pero en su lugar ha asumido la función de proporcionar energía a partir de la producción de ATP en el ensamblaje celular ${ }^{20}$.

\section{Consideraciones finales}

Volvamos a una de las preguntas centrales de la armonía entre niveles: si suponemos que una correlación negativa entre la parte y el todo es indispensable para la conciliación entre dos niveles de organización, ¿qué interés tienen los individuos en delegar una parte de sus funciones mientras estas funciones los hacen libres y autónomos? Se supone, por supuesto, que la colaboración, que implica una pérdida de autonomía individual, implica ciertos beneficios para las entidades de una comunidad. Pero quizás también sea posible responder de manera amplia, suponiendo que cuando cada unidad subordina parte de su autonomía al mantenimiento de una organización general, también facilita su propia realización individual, ya que el conjunto de relaciones le proporciona funciones que luego no tiene que realizar él mismo. Esta última sugerencia asume un principio mereológico común: cuando el todo se vuelve más complejo, las partes se vuelven más simples (Varzi 2016). Esta lógica mereológica coincide con la idea de Michod, y que nosotros hemos expresado bajo una correlación negativa: "during a transition from a lower to a higher level, we expect the fitness of the higher level to increase and the fitness of the lower level to decrease" (Michod 2011, p.170). Ciertamente, una transferencia de funciones conduce a

\footnotetext{
${ }^{19}$ Otros modelos de transición los tratamos en Hernandez y Vecchi (2019).

${ }^{20}$ Se debe notar que la perdida de la autonomía reproductiva de la mitocondria es parcial. No obstante, si bien la mitocondria todavía se reproduce por fisión (como la mitocondria ancestral), necesita de los recursos de la célula huésped (en particular de los genes que codifican para las polimerasas que regulan la replicación del ADN y la transcripción). Por esta misma razón, la distinción entre la división del trabajo a través de la especialización fisiológica y reproductiva no es dicotómica.
}

Revista de Humanidades de Valparaíso, 2019, No 14, 335-362 
una simplificación de los individuos, pero al mismo tiempo permite la complejización del conjunto compuesto por individuos (véase nota 18). Si uno interpreta una transferencia de funciones como una especialización de las partes, la especialización de una parte es indudablemente más beneficiosa para el "todo", aunque la parte deba realizar acciones que no le sirvan directamente (por ej. sobre-producir un componente en particular o exponerse a peligros). A su vez, "el todo" trae cosas a la parte que ya no tiene que producir por sí sola (por ejemplo, el hecho de que las partes pueden verse favorecidas por un entorno más estable o que ciertos individuos puedan transmitir los genes de la comunidad).

Podemos tomar estas reflexiones para comprender un proceso de individualización colectivo: el fenómeno de la individualización colectiva pasa por un fenómeno de subordinación en el que las partes "delegan", hacia el nivel superior, funciones que las hacían autónomas. Hemos visto que este fenómeno puede interpretarse como un proceso de transferencia de funciones a un nivel superior, que se concreta, de acuerdo con los enfoques de las transiciones de la individualidad, mediante una transferencia de las funciones vitales. Esta transferencia de funciones restringe a los individuos a que pertenezcan a la nueva estructura para lograr su ontogénesis. Es por eso que una conciliación entre dos niveles pasa por una jerarquización que toma forma de constricción del todo hacia las partes. De ahora en adelante, interpretamos este fenómeno como una transferencia de autonomía.

También hemos visto que este proceso de transferencia de funciones se traduce concretamente en un fenómeno de especialización. Este fenómeno consiste en la especialización de individuos en elementos funcionales indispensables. El ejemplo de la multicelularidad nos proporciona una representación muy instructiva: la especialización funcional que destaca la multicelularidad consiste en separar las células dedicadas a la supervivencia y al mantenimiento del organismo, de las células dedicadas a la reproducción y la herencia ${ }^{21}$. De hecho, este fenómeno de división funcional hace posible comprender la estabilidad del grupo de individuos a partir de una interdependencia irreversible entre estos individuos: las unidades independientes que eran capaces de reproducirse y sobrevivir por si solas, sólo pueden hacerlo en un contexto relacional específico. En otras palabras, decimos que las unidades se han vuelto dependientes del nuevo dominio biológico del que ahora forman parte. La especialización de las funciones, establecida como una etapa crucial para que un conjunto de individuos se convierta en un solo individuo, se ha estudiado a través de la evolución de la cooperación, y esto presupone la aparición y la evolución de mecanismos que restringen la posibilidad de conflicto entre individuos en un grupo. Así, un grupo de individuos se convierte en un solo individuo estable, susceptible de sufrir los impactos de la selección natural a su nivel de organización.

\footnotetext{
${ }^{21}$ Es importante señalar que, justamente en este caso, se debe hablar más bien de transferencia parcial y no total (como sería el caso de transferencia de funciones de los insectos eusociales, en donde una casta se vuelve estéril y en donde la reproducción ocurre totalmente a nivel del grupo). En efecto, las células de la línea somática pueden seguir haciendo mitosis y reproduciéndose. Sin embargo, la especialización de línea germinal implica que ésta es la única capaz de reproducir al grupo.
}

Revista de Humanidades de Valparaíso, 2019, No 14, 335-362 
De lo anterior, podemos agregar lo siguiente:

En primer lugar, cuando tenemos un sistema en proceso de individualización, podemos establecer un criterio de robustez de la relación entre las partes a través de la irreversibilidad de sus asociaciones. En una organización donde los intercambios funcionales son más débiles, encontraremos relaciones que son menos dependientes: su nivel de acoplamiento será más reversible. Sin embargo, en los sistemas donde existe una irreversibilidad en sus relaciones, las partes tienen más dificultades para vincularse fuera de este dominio relacional específico, debido a la dependencia establecida con sus pares. Por lo tanto, creemos que las transiciones evolutivas corresponden a un caso de irreversibilidad funcional mayor, por el cual las partes han entablado relaciones constitutivas irrevocables.

En segundo lugar, nos gustaría asociar la noción de irreversibilidad con la noción de organismalidad (organismality) propuesta por Queller y Strassmann (Queller and Strassmann 2009). En efecto, los niveles de organización pueden establecerse por los grados de cooperación y ausencia de conflicto entre las partes, cuyos altos niveles de dependencia entre las partes demuestran una irreversibilidad de las relaciones. De esta manera, la organismalidad, como principio normativo que impone dos condiciones al organismo - alta colaboración y muy bajo nivel de conflicto-, nos permite pensar en grados de interacción $^{22}$ en el sentido de que las comunidades pueden tener diferentes niveles de conflicto, colaboración e irreversibilidad relacional. De esta manera, los altos niveles de colaboración y los bajos niveles de conflicto implican una irreversibilidad de los intercambios funcionales que mantienen los individuos, en los que los altos niveles de dependencia obligan a los individuos a colaborar en el mismo dominio relacional.

Tercero, nos gustaría recordar que los mecanismos que explican cómo se pueden controlar los conflictos involucran funciones colectivas. Todos los elementos que hemos considerado aquí (la división del trabajo, las separaciones funcionales en tipos de células, la interdependencia irreversible entre individuos, etc.) requieren la emergencia de funciones específicas de control de conflicto. Uno de los ejemplos representativos de la aparición de estos tipos particulares de funciones es algo que podemos llamar "constricciones del desarrollo". Este tipo de constricciones pueden haber surgido a partir de la interacción entre organismos a través de un proceso de agregación gradual. De hecho, aunque la evolución de la multicelularidad ha permitido la adaptación de la función del desarrollo hacia mecanismos precisos y complejos de fragmentación de una sola célula madre (división celular), no debemos olvidar que este fenómeno es el resultado inconfundible de un proceso histórico de agregación para lo cual todavía tenemos ejemplos vivos, como la familia de algas Volvox. Volvox es un alga que cubre un gran rango de complejidad organizacional. Encontramos algas de tipo unicelular y colonial, así como de tipo multicelular con una división del trabajo de tipo germen-soma. Estas algas son organismos modelo ideales para

${ }^{22}$ Esto implica que la organismalidad es una propiedad gradual, no categórica, del "todo" durante el proceso de individuación colectivo).

Revista de Humanidades de Valparaiso, 2019, No 14, 335-362 
abordar los problemas fundamentales relacionados con la transición a la multicelularidad y para construir principios teóricos que caracterizan esta transición (Hallmann 2011). Por ejemplo, Volvox carteri tiene dos tipos de células en su estado maduro; células reproductivas de tipo germinal, que no tienen senescencia (o muerte celular programada) conocida hasta la fecha, y células somáticas que corresponden a la motilidad de la colonia (Kirk 1988). El ejemplo de Volvox puede interpretarse como una transición evolutiva viva, y la variedad de comportamientos de este género de algas ha servido como modelo para comprender la transición mayor de la vida unicelular a la vida multicelular, así como la evolución de la multicelularidad y los mecanismos de diferenciación celular, lo que toca varias cuestiones fundamentales en la biología evolutiva (Herron 2016).

La importancia de este ejemplo es que resalta la necesidad de desarrollar funciones que controlen la agregación celular, a través de la división funcional, para lograr un ajuste comunitario. La agregación, un fenómeno que podemos claramente asociar con la naturaleza dinámica y social de la vida (y de su evolución química), es el sustrato fundamental del proceso de individualización colectiva. Por lo tanto, proponemos interpretar los procesos de desarrollo actual, incluidos los organismos sociales multicelulares, como un proceso de agregación o composición controlada. En otros términos, el fenómeno del desarrollo, como función emergente de una colectividad, no es más que un proceso de agregación bajo constricción; a saber, una optimización del fenómeno de agregación a partir de la autoproducción controlada de una gran parte del material biológico para organizar el organismo durante la embriogénesis. De hecho, todos los mecanismos de control que observamos actualmente (selección parental, proliferación unicelular, especialización, etc.) han sido optimizaciones de las agregaciones colectivas, cuyo ejemplo más representativo lo encontramos bajo la forma de constricciones del desarrollo.

Finalmente, es natural cuestionar también el motor final que impulsa a individuos a asociarse. Nuestro propósito es más humilde. Hemos querido mostrar simplemente las diversas facetas que incluyen el fenómeno de la asociación, dejando sus causas, por el momento, a los estudios de ecología evolutiva. Estos estudios abordan los fenómenos de conformación de nichos asociativos que responden a necesidades específicas: la ventaja que la asociación permite frente a los depredadores, el refugio o el control de un espacio ecológico, la resistencia a las condiciones adversas, la optimización del sistema o rendimiento en general, etc. Así, la explicación de las causas que llevan a los individuos a asociarse pertenece a los estudios y reflexiones más profundas sobre las "motivaciones", siempre en términos de selección y procesos no adaptativos, que encontramos detrás de estos organismos y comportamientos. En los casos de asociaciones sinérgicas, todas las variedades de posibles causas, ya sean contingentes o genéricas, explican la persistencia de tales asociaciones a lo largo del tiempo por el beneficio que implica la asociación. En este artículo, hemos mostrado cómo pueden tener lugar estas asociaciones, sin entrar en teorizaciones sobre las causas de la complejización de la naturaleza por parte de la asociación. 


\section{Agradecimientos}

Davide Vecchi agradece el suporte financiero de FCT - Fundação para a Ciência e a Tecnologia (DL57/2016/CP1479/CT0072; Grant N. UID/FIL/00678/2019; R\&D Project Grant PTDC/FER-HFC/30665/2017 "Emergence in the Natural Sciences: Towards a New Paradigm") y del Fondo Nacional de Desarrollo Científico y Tecnológico de Chile (Grant N. 1171017).

\section{Referencias bibliográficas}

Baron, C. (2013). The handicap principle and the argument of subversion from within. Studies in History and Philosophy of Biological and Biomedical Sciences, 44(3): 347-355.

Bedau, M. A. (2009). The Evolution of Complexity. En Anouk Barberousse, Michel Morange, Thomas Pradeau (eds.), Mapping the Future of Biology. Coll. Boston Studies in the Philosophy of Science, pp. 111-130. Dordrecht: Springer.

Buss, L. W. (1987). The Evolution of Individuality. Princeton, N.J.: Princeton University Press.

Calcott, B., Sterelny, K., Szathmáry, E. (eds.) (2011). The Major Transitions in Evolution Revisited. Coll. Vienna Series in Theoretical Biology. Cambridge, Mass.: MIT Press.

Clarke, E. (2010). The problem of biological individuality. Biological Theory, 5(4): 312-325.

Darwin, C. (2008). L'origine des espèces, Paris: Flammarion.

Doolittle, W. F., Bapteste, E. (2007). Pattern pluralism and the Tree of Life hypothesis. Proceedings of the National Academy of Sciences, 104(7): 2043-2049.

Dupré, J., O'Malley, M. A. (2009). Varieties of Living Things: Life at the Intersection of Lineage and Metabolism. Philosophy and Theory in Biology, 1(20170609).

Furusawa, C., Kaneko, K. (1998a). Emergence of multicellular organisms with dynamic differentiation and spatial pattern. Artificial Life, 4(1): 79-93.

Furusawa, C., Kaneko, K. (1998b). Emergence of rules in cell society: Differentiation, hierarchy, and stability. Bulletin of Mathematical Biology, 60(4): 659-687.

Furusawa, C., Kaneko, K. (2002). Origin of multicellular organisms as an inevitable consequence of dynamical systems. The Anatomical Record, 268(3): 327-342.

Ghiselin, M. T. (1971). The individual in the Darwinian revolution. New Literary History, 3(1): 113-134.

Godfrey-Smith, P. (2009). Darwinian populations and natural selection. Oxford: Oxford University Press.

Goodwin, B. C. (2001). How the Leopard Changed Its Spots: The Evolution of Complextiy. Princeton, NJ: Princeton University Press.

Hallman, A. (2011). Evolution of reproductive development in the volvocine algae. Sexual Plant Reproduction, 24(2): 97-112. doi: 10.1007/s00497-010-0158-4

Revista de Humanidades de Valparaíso, 2019, No 14, 335-362

(c) (1) 8 (을 CC BY-NC-ND 
Hanschen E., E. Shelton, D., Michod, R. (2015). Evolutionary Transitions in Individuality and Recent Models of Multicellularity. En Inaki Ruiz Trillo, Aurora Nedelcu (eds.), Evolutionary Transitions to Multicellular Life, pp. 165-188. London: Springer.

Hernandez, I., Vecchi, D. (2019). The Interactive Construction of Biological Individuality Through Biotic Entrenchment. Frontiers in Psychology 10:2578. doi: 10.3389/fpsyg.2019.02578

Herron, M. D. (2016). Origins of multicellular complexity: Volvox and the volvocine algae. Molecular Ecology, 25(6): 1213-1223.

Heylighen F. (1999). The Growth of Structural and Functional Complexity during Evolution. En F. Heylighen, J. Bollen, A. Riegler (eds.), The Evolution of Complexity, pp. 17-44. Dordrecht: Kluwer Academic.

Hull, D. L. (1980). Individuality and selection. Annual Review of Ecology and Systematics, 11(1): 311-332.

Hull, D. L. (1978). A Matter of Individuality. Philosophy of Science, 45(3): 335-360.

Huneman P. (2013). Adaptations in transitions: how to make sense of adaptation when beneficiaries emerge simultaneously with benefits? En Philippe Huneman, Frédéric Bouchard (eds.), From Groups to Individuals: Evolution and Emerging Individuality, pp. 141-172. Cambridge: MIT press.

Kaneko, K., Furusawa, C. (2000). Robust and irreversible development in cell society as a general consequence of intra-inter dynamics. Physica A: Statistical Mechanics and its Applications, 280(1-2): 22-33.

Kaneko, K., Yomo, T. (1999). Isologous diversification for robust development of cell society. Journal of Theoretical Biology, 199(3): 243-256.

Kirk, D. L. (1988). The ontogeny and phylogeny of cellular differentiation in Volvox. Trends in Genetics, 4(2): 32-36.

Leigh, G. (2010). The group selection controversy. Journal of Evolutionary Biology, 23(1): 6-19.

Leigh, E. G., Vermeij, G. J. (2002). Does natural selection organize ecosystems for the maintenance of high productivity and diversity? Philosophical Transactions of the Royal Society B: Biological Sciences, 357(1421): 709-718.

Lewontin, R. C. (1970). The units of selection. Annual Review of Ecology and Systematics, 1(1): $1-18$.

Margulis, L., Sagan, D. (2002). Acquiring Genomes: A Theory of the Origins of Species. New York, NY: Basic Books.

Martens, J. (2012). L'évolution des organisations biologiques : vers une théorie unifiée de la coopération et du conflit. Paris: Paris 1.

Maynard Smith, J., Szathmáry, E. (2010). The Major Transitions in Evolution. Oxford: Oxford University Press. 
Maynard Smith, J., Szathmáry, E. (2009). The Origins of Life: From the Birth of Life to the Origin of Language. Oxford: Oxford University Press.

Mayr E. (1997). The objects of selection. Proceedings of the National Academy of Sciences, 94(6): 2091-2094.

Mayr, E. (ed.) (1998). The Evolutionary Synthesis: Perspectives on the Unification of Biology. Cambridge, Mass.: Harvard University Press.

McShea, D. W. (2017). Perspective metazoan complexity and evolution: is there a trend? Evolution, 50(2): 477-492.

McShea, D. W. (2001). The hierarchical structure of organisms: a scale and documentation of a trend in the maximum. Paleobiology, 27(2): 405-423.

McShea, D. W., Brandon, R. N. (2010). Biology's First Law: The Tendency for Diversity and Complexity to Increase in Evolutionary Systems. Chicago, London: University of Chicago Press.

McShea, D. W., Hordijk, W. (2013). Complexity by subtraction. Evolutionary Biology, 40(4): 504-520.

Michod, R. E. (2011). Evolutionary Transitions in Individuality: Multicellularity and Sex. En Brett Calcott, Kim Sterelny (eds.), The Major Transitions in Evolution, pp. 169-198. Cambridge, Mass.: MIT Press.

Michod, R. E. (2007). Evolution of individuality during the transition from unicellular to multicellular life. Proceedings of the National Academy of Sciences, 104(1): 8613-8618.

Michod, R. E, Nedelcu, A. M. (2003). On the reorganization of fitness during evolutionary transitions in individuality. Integrative and Comparative Biology, 43(1): 64-73.

Michod, R. E, Roze, D. (2001). Cooperation and conflict in the evolution of multicellularity. Heredity, 86(1): 1-7.

Michod, R. E, Herron, M. (2006). Cooperation and conflict during evolutionary transitions in individuality. Journal of evolutionary biology, 19: 1406-1409; discussion 1426.

Newman, S. A., Bhat, R. (2009). Dynamical patterning modules: a "pattern language" for development and evolution of multicellular form. The International Journal of Developmental Biology, 53(5-6): 693-705.

Newman, S. A., Bonner, J. T. (2016). Multicellularity: Origins and Evolution. Cambridge, Mass.: MIT Press.

Newman, S. A., Forgacs, G., Muller, G. B. (2006). Before programs: the physical origination of multicellular forms. The International Journal of Developmental Biology, 50(2-3): 289-299.

Okasha, S. (2008). Evolution and the levels of selection. Oxford, New York: Clarendon Press, Oxford University Press. 
O’Malley, M. A., Wideman, J. G., Ruiz-Trillo, I. (2016). Losing Complexity: The Role of Simplification in Macroevolution. Trends in Ecology \& Evolution, 31(8): 608-621.

Pepper J. W., Herron. M. D. (2008). Does biology need an organism concept? Biological Reviews of the Cambridge Philosophical Society, 83(4): 621-627.

Pigliucci, M. (2010). Okasha's evolution and the levels of selection: toward a broader conception of theoretical biology. Biology \& Philosophy, 25(3): 405-415. doi: https://doi.org/10.1007/ s10539-010-9197-3

Queller, D. C. (2000). 13. Philosophical Transactions of the Royal Society of London B: Biological Sciences, 355(1403): 1647-1655.

Queller, D. C., Strassmann, J. E. (2009). Beyond society: the evolution of organismality. Philosophical Transactions of the Royal Society B: Biological Sciences, 364(1533): 3143-3155.

Ruiz-Mirazo, K., Moreno, A. (2012). Autonomy in evolution: from minimal to complex life. Synthese, 185(1): 21-52.

Sober, E., Wilson, D. S. (2003). Unto Others: The Evolution and Psychology of Unselfish Behavior. Cambridge, Mass.: Harvard University Press.

Solé, R. V., Goodwin, B. C. (2000). Signs of Life: How Complexity Pervades Biology. New York, NY: Basic Books.

Szathmáry, E. (2015). Toward major evolutionary transitions theory 2.0. Proceedings of the National Academy of Sciences, 112(33): 10104-10111.

Taylor, F. J. R. (1976). Autogenous theories for the origin of eukaryotes. Taxon, 25(4): 377.

Varzi, A. (2016). Mereology. En Edward N. Zalta (ed.), The Stanford Encyclopedia of Philosophy. Stanford: Metaphysics Research Lab, Stanford University. https://plato.stanford.edu/ entries/mereology/

Vecchi, D., Hernández, I. (2014). The epistemological resilience of the concept of morphogenetic field. En Alessandro Minelli y Thomas Pradeu (eds.), Towards a Theory of Development, pp. 79-94. Oxford: Oxford University Press.

West, S. A., Fisher, R. M., Gardner, A., Kiers E., T. (2015). Major evolutionary transitions in individuality. Proceedings of the National Academy of Sciences of the United States of America, vol. 112(33): 10112-10119.

Wilson, D. S., Sober, E. (1989). Reviving the superorganism. Journal of theoretical Biology, 136(3): 337-356.

Wilson, D. S. (1997). Altruism and Organism: Disentangling the Themes of Multilevel Selection Theory. The American Naturalist, 150(S1): S122-S134.

Wilson, R. A. (2005). Genes and the Agents of Life: The Individual in the Fragile Sciences Biology. Cambridge: Cambridge University Press. 
Individuación colectiva y emergencia de la organismalidad

Isaac Hernández; Davide Vecchi

Wolf, Y. I., Koonin, E. V. (2013). Genome reduction as the dominant mode of evolution. BioEssays: News and Reviews in Molecular, Cellular and Developmental Biology, 35(9): 829-837.

Revista de Humanidades de Valparaíso, 2019, No 14, 335-362

(9) 100 CC BY-NC-ND 


\title{
The synthetic thesis of truth helps mitigate the "reproducibility crisis" and is an inspiration for predictive ecology
}

\author{
La tesis sintética de la verdad ayuda a mitigar \\ la "crisis de reproducibilidad" e inspira a la ecología predictiva
}

Luis Marone*; Javier Lopez de Casenave**; Rafael González del Solar ${ }^{\dagger}$

*ECODES, Instituto Argentino de Investigaciones de las Zonas Áridas, CONICET /

Facultad de Ciencias Exactas y Naturales, Universidad Nacional de Cuyo,

Mendoza, Argentina

lmarone@mendoza-conicet.gob.ar

${ }^{* *}$ ECODES, Departamento de Ecología, Genética y Evolución, Facultad de Ciencias Exactas y Naturales, Universidad de Buenos Aires / IEGEBA (UBA-CONICET), Buenos Aires, Argentina

casenave@ege.fcen.uba.ar

†ECODES, C. Amílcar 143, ático 2, 08032, Barcelona, Spain

rafael.gonzalezd@e-campus.uab.cat

\begin{abstract}
There are currently serious concerns that published scientific findings -including biological results- often fail to be reproducible, and that some solutions may be gleaned by attending the several methodological and sociological recommendations that could be found in the literature. However, researchers would also arrive at some answers by considering the advice of the philosophy of science, particularly semantics, about theses on truth related to scientific realism. Sometimes scientists understand the correspondence thesis of truth (CTT) as asserting that the next unique empirical confirmation of a hypothesis suffices to attribute truth to it provisionally. Such empiricist bias is not necessarily at the core of CTT, but Mario Bunge proposed the synthetic thesis of truth (STT), based on CTT, to explicitly avoid the bias. STT requires considering a hypothesis corroborated both by purely empirical confirmation and external consistency or compatibility with the bulk of existing background knowledge (systemicity). While a capricious understanding of CTT could be rigged to recommend the "one shot game" in hypothesis testing, STT clearly demands the
\end{abstract}

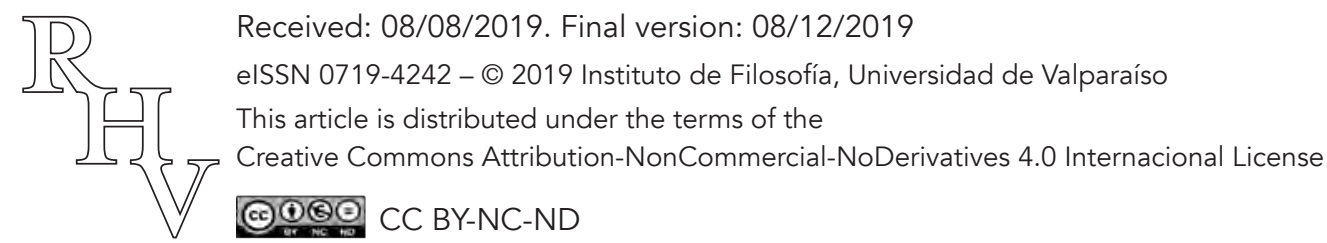


The synthetic thesis of truth helps mitigate the "reproducibility crisis" and is an inspiration for predictive ecology

Luis Marone; Javier Lopez de Casenave; Rafael González del Solar

use of multiple approaches, empirical as well as theoretical, and it asserts that a scientific test is effective to the extent to which it is neither purely empirical, nor viewed in isolation. Pattern consistency (empirical control) together with an understanding of causal relations (rational together with empirical control) make confirmed hypotheses robust and more reliable. The militancy of the double mechanism of hypothesis control can help mitigate the reproducibility crisis in biological research. Earl Werner's research program in community ecology is an example of the (implicit) use of STT criteria, which leads to the development of reliable, cross-checked, ecological results, with high predictive capacity.

Keywords: philosophy and methodology of science, scientific realism, truth criteria, empirical and rational support, causal mechanisms, ecology.

\section{Resumen}

Parte de los resultados de investigación publicados -incluyendo numerosos hallazgos en biología- no se han podido replicar en estudios posteriores, lo que preocupa a científicos y editores, quienes han recomendado valiosas sugerencias metodológicas y sociológicas para mitigar el problema. En mucha menor medida, los investigadores han evaluado sugerencias de la filosofía de la ciencia. En particular, qué enfoques semánticos sobre las tesis de la verdad en ciencia y tecnología resuelven mejor la "crisis de reproducibilidad". Numerosos científicos interpretan que la clásica tesis de la verdad por correspondencia (CTT) implica que la próxima corroboración empírica de una hipótesis a través de un único experimento es suficiente para confirmarla provisionalmente. Aunque ese sesgo empirista y simplista no surge necesariamente de la CTT, el empleo de dos criterios de verdad en forma explícita está dirigido a corregirlo: la tesis sintética de la verdad de Mario Bunge (STT) requiere, para considerar una hipótesis confirmada, que tanto la mayoría de la evidencia empírica disponible (consistencia interna) como del resto del conocimiento confiable actualizado (consistencia externa) corroboren la hipótesis en cuestión. Mientras que una lectura caprichosa de la CTT puede emplearse para manipularla y dar fundamento a competencias "de un solo tiro" en la investigación, la STT requiere el empleo de múltiples aproximaciones, tanto empíricas como teóricas, y afirma que la prueba científica será efectiva en la medida en que no sea puramente empírica ni única. La consistencia de patrones (control empírico) junto con la comprensión de las relaciones causales que los generan (control racional y empírico) hacen más robustas y confiables a las hipótesis confirmadas, mitigando la crisis de reproducibilidad en la investigación biológica. El programa de investigación en ecología de Earl Werner es un ejemplo de uso (implícito) de los criterios de STT para aumentar la capacidad predictiva de la ecología.

Palabras clave: filosofía y metodología de la ciencia, realismo científico, criterios de verdad, apoyo empírico y teórico, mecanismos causales, ecología.

Revista de Humanidades de Valparaíso, 2019, No 14, 363-376

(ㅇ)(@) CC BY-NC-ND 
The synthetic thesis of truth helps mitigate the "reproducibility crisis" and is an inspiration for predictive ecology

Luis Marone; Javier Lopez de Casenave; Rafael González del Solar

\section{Introduction}

There are currently serious concerns that published research findings in several scientific disciplines -including biology- often fail to be reproducible, which has given rise to the so called "reproducibility crisis" (Ioannidis 2005a; Lehrer 2010; Editors 2016). The lack of reproducibility means that different results, or even opposite results, are often obtained during the test of the same scientific hypothesis with the same type of experiment (or a different, although equally pertinent, one). The ability to reproduce observations or experiments is integral to science, however failure to do so also appears to be a routine part of research (Editors 2016). Some amount of irreproducibility is inevitable, since sources of variability in nature and society are infinite (Ives 2018), and are thus rather difficult to anticipate. Yet, according to a survey carried out by Baker (2016), there is a "bigger issue" that needs to be fixed. One-third of the survey respondents expressed that they think about the reproducibility of their own research daily, and more than twothirds discuss it with colleagues at least monthly. The bigger issue arises because some researchers think that the test of a hypothesis is a "one shot game" (i.e. a matter of a single, purely empirical test), especially if the test corroborates a novel and charismatic hypothesis and, therefore, facilitates rapid publication (Cohen 2017).

From a philosophical point of view, the reproducibility crisis is associated to the criteria of truth and the ways truth can be established in science provisionally. Several philosophers are skeptical about scientific realism, the doctrine that suggests that the goal of science is to give an account of reality (Lombardi 2018; Mahner 2001), but practicing scientists are used to the idea that their main goal is to search for truth, and that truth is correspondence between an assertion about nature or society and the way nature or society is or works. That is the correspondence thesis of truth (CTT), an idea that may be traced back to Aristotle, Plato, and Aquinas, and that was carefully elaborated in the last century by philosophers and logicians (e.g. Russell 1918; Tarski 1983; Bunge 2012). In a simple way, it asserts that truth corresponds to, or with, a fact: "a proposition (e.g. a prediction) asserting that fact $f$ is the case is true if, and only if, $f$ is actually the case" (Bunge 1999; 2012).

From a methodological perspective, which is more familiar to researchers, the reproducibility crisis is linked to the dilemmas related to scientific hypothesis testing. In factual science and technology, where the adoption of CTT has been of great use, hypothesis testing requires controlled observations or experiments. Although some practicing scientists may act automatically during such tests, most of them are often willing to follow some methodological advice. For example, they consider that hypotheses and theories are not confronted directly with facts (which are sometimes unobservable) but with data or empirical indicators that describe those facts indirectly (Marone and Galetto 2011). Scientists are also willing to admit that the establishment of the truth value of hypotheses and theories via the establishment of the truth value of some of their genuine predictions is a nonlogical but seductive (Bunge 1999) inference that only

Revista de Humanidades de Valparaíso, 2019, No 14, 363-376

(ㄷ)(1)(8) CC BY-NC-ND 
The synthetic thesis of truth helps mitigate the "reproducibility crisis" and is an inspiration for predictive ecology

Luis Marone; Javier Lopez de Casenave; Rafael González del Solar

suggests the truth of those hypotheses and theories. Furthermore, and regarding the lack of reproducibility of results, several methodological and practical actions, such as refining the experimental design, increasing sample size, improving data collection and statistical inference, are advised and followed by scientists.

However, researchers are less inclined to follow philosophical advice despite the implications it may have on science practice. This is unfortunate because some truth criteria may contribute a better foundation than other criteria to research programs that look for robust, replicable results. The CTT does not necessarily invite the testing of a hypothesis using a single, purely empirical approach (e.g. one correlation with a high number of points, or a single statistical test with a very small $p$-value), but researchers that practice the "one shot game" may be promoting the most empiricist heart of the CTT: the idea that a hypothesis can be proven provisionally to be true merely if the next (single, restricted) data set confirms one prediction genuinely deduced from it. This is a weak interpretation of CTT that, unfortunately, is often practiced and could be encouraging the report of contingent, unreproducible results.

The philosopher of science Mario Bunge has proposed a subtle (although powerful) modification of CTT that may help circumvent its purely empirical, weak interpretation. Bunge explicitly divided the correspondence criterion of truth into two complementary criteria. The synthetic thesis of truth (STT, Bunge 2006, 261) asserts that empirical confirmation (i.e. the one provided by the next controlled observation or experiment) is necessary, but not sufficient, to assign a truth value to a hypothesis, since external consistency, or compatibility with the bulk of the background knowledge, is needed as well (Bunge 2006; 2017). The explicit advice of simultaneous empirical and rational controls of scientific hypotheses may help prevent the "slipperiness of empiricism" (Lehrer 2010; Bunge 2017) that lies behind the reproducibility crisis. Our hypothesis is that if both kinds of control were carefully used before spreading the results in specialized journals, at least some nonreplicable findings would not reach the literature, avoiding subsequent confusion. But, let's begin by assessing the theses of truth in some detail.

\section{The correspondence and synthetic theses of truth: an in-depth assessment}

CTT and STT refer to factual statements and they capture the intuition that factual truth consists in adequacy to reality, unlike their formal (e.g. mathematical) counterpart. But the CTT is sometimes used to assess adequacy in a way that leaves out systemicity or external consistency (Bunge 1999). However, this problem is corrected by the STT approach (Bunge 2006), an embryonic theory compressed into a definition and two criteria. The definition is the same as CTT (i.e. a proposition $p$ asserting that fact $f$ is the case is true if, and only if, $f$ is actually the case). Yet, as it was advanced, the two criteria of synthetic truth are (a) that $p$ is compatible with (and exceptionally equivalent to) the

Revista de Humanidades de Valparaíso, 2019, No 14, 363-376

(ㄷ)(1)(8) CC BY-NC-ND 
The synthetic thesis of truth helps mitigate the "reproducibility crisis" and is an inspiration for predictive ecology

Luis Marone; Javier Lopez de Casenave; Rafael González del Solar

relevant empirical evidence (internal consistency), and (b) that $p$ is consistent with the bulk of the pertinent background knowledge (external consistency: a more rational, not purely empirical, criterion) (Bunge 2006; 2017).

Some examples on how people establish the truth in ordinary life and profession may highlight the everyday use of the STT criteria. When some parents decide to send their young daughter to learn to swim in a gymnasium, they will usually consider that there were no antecedents of serious accidents in the gymnasium as evidence in favor of their decision (a purely empirical support), as well as the results of a detailed inspection of its facilities showing that all necessary security measures that could eliminate the main causes of accidents (i.e. unfit mechanisms of several types) had been taken. When a physician prescribes a certain medicine to a given patient, the patient could take it simply because he trusts the physician. However, a curious and skeptical patient would only be willing to consider that the therapy is reliable after an in-depth inquiry. For example, after knowing that 100,000 patients had previously taken the drug and the drug was $99.9 \%$ effective (a purely empirical support), and that researchers could correctly describe the action mechanism of the medicine, discarding, above reasonable doubt, side effects through several possible metabolic pathways (a more rational as well as empirical support).

Bunge (1998) showed that external consistency is a key requisite for assessing the degree of truth (or untruth), for example, of pseudoscientific assertions. Pseudoscience can eventually predict facts correctly by chance, but its assertions suffer from lack of compatibility with the bulk of the up to date background knowledge, especially wellestablished causal mechanisms that explain the occurrence of such facts. Further, when a researcher attempts to solve some unsolved scientific question, external consistency invites a careful assessment of the background knowledge before producing a plausible hypothesis (i.e. a hypothesis that has not yet been empirically tested, but is deemed verisimilar and deserving of empirical testing in the light of some well-established body of knowledge; Bunge 1999). In fact, plausibility checks are an essential component of Bunge's scientific methodology because they allow the assessment of alternative hypotheses a priori in an objective manner to decide which of them is a better candidate for investing our resources in their empirical testing, discarding wild or insufficiently grounded conjectures. Thus, the external consistency criterion allows the researcher to allocate finite resources in a more efficient fashion.

But what background knowledge is relevant for such a plausibility assessment? According to Bunge (1999), a hypothesis may be said to be empirically plausible with respect to a set of relevant data, if the overwhelming majority of such data confirms it, and a hypothesis may be said to be theoretically or rationally plausible if it is consistent with the bulk of the background knowledge relevant to it. Thus, the plausibility of a new hypothesis is sustained on both empirical and theoretical backgrounds, which coincide with the two criteria of synthetic truth for hypotheses in general. In sum, the weighting of the degree of truth of a hypothesis has two empirical instances (one previous and

Revista de Humanidades de Valparaíso, 2019, No 14, 363-376

(). (18) CC BY-NC-ND 
The synthetic thesis of truth helps mitigate the "reproducibility crisis" and is an inspiration for predictive ecology

Luis Marone; Javier Lopez de Casenave; Rafael González del Solar

one during the test), and two theoretical instances (one previous and one after the test). But what characterizes the theoretical support of a new hypothesis? Bunge proposes all possible serious candidates ("the bulk of background knowledge") but, based on his ontology and epistemology (Bunge 1997; Marone and Bunge 1998), the knowledge of causal mechanisms is a key candidate:

[while assessing a hypothesis] We have got used to the idea of multiple controls, both empirical and theoretical ... In short, theorification and independent cross-checking make up for the weakness of every single empirical test, which by itself is or can be made circular. An empirical test is effective to the extent to which it is neither single nor purely empirical. (Bunge 1998)

In sum, in Bunge's philosophy of science, theoretical as well as empirical support is needed for assessing new hypotheses and provisionally establishing their truth. The CTT may be rigged as demanding only empirical support, but the STT explicitly requires both empirical and theoretical support. So, what consequences would adherence to, and the epistemic militancy of, STT have for the reproducibility crisis in science, and what kind of research program is developed under the inspiration of STT?

\section{The synthetic thesis of truth and the reproducibility crisis}

Ioannidis et al. (2001) evaluated 370 studies by meta-analysis addressing 36 genetic associations for various outcomes of disease. They showed that lack of reproduction is frequent in genetic epidemiology: the results of the first study, which often suggested a stronger genetic effect, correlated only modestly with subsequent research on the same association. A few years later, Ioannidis (2005b) examined all the original clinical research studies published in major general clinical journals in 1990-2003 which had received at least 1000 citations in the literature. These results were compared with subsequent studies on the same topic of similar or larger sample size and similar or better controlled designs. Contradiction (19\% of the 36 studies were challenged by subsequent ones) and initially stronger effects (another 19\%) were found in the survey. The high public impact of these meta-analyses on clinical research attracted the interest of other scientists and editors on the topic, increasing the number of articles and editorials on a subject that, notwithstanding, had woken interest long ago (e.g., Smith 1920; Hairston 1989; Polis et al. 1998; Werner 1998).

Both bias and genuine natural variability might explain why early studies tend to produce more false positives than subsequent ones. Several articles have revised the main [non-fraudulent] causes of the reproducibility crisis. Ioannidis (2005a) blamed studies of small sample and effect size, and flexible designs (technical causes), together with the attraction that hotter or fashionable ideas have in several scientific fields (mostly sociological causes). More recently, Ioannidis (2014) summarized the research

Revista de Humanidades de Valparaíso, 2019, No 14, 363-376

(c) (1) 8 (을 CC BY-NC-ND 
The synthetic thesis of truth helps mitigate the "reproducibility crisis" and is an inspiration for predictive ecology

Luis Marone; Javier Lopez de Casenave; Rafael González del Solar

practices that may help increase the proportion of true research findings: the adoption of reproducibility practices, standardization of definitions and analyses, better statistical methods, more appropriate statistical thresholds, improvement in study design standards (technical practices), together with the recording and sharing of results, large-scale collaborative research, and improvement of peer reviews (mostly mixed, sociological and technical practices). Moreover, Young et al. (2008) called attention to the responsibility of journals since the small proportion of results chosen for publication may be clearly unrepresentative of the real world because the process of selectivity is based on a weak assumption, that selectivity is equivalent to quality. Higginson and Munafó (2016) reinforced the idea indicating that researchers acting to maximize their publication rate should spend more of their effort seeking novel results and conducting small studies that have only $10 \%-40 \%$ statistical power. They suggested that if such figures were true, half of the published studies would report erroneous conclusions. Not surprisingly then, editors of Science (McNutt 2014) and Nature (Editors 2014) have declared that the journals want to do their part in raising publication standards for the benefit of scientists and of society, avoiding publication of unreproducible results. Most of editors' initiatives coincide with the recommendations cited above and are directed to increase transparency by improving design and statistics (e.g. the articles should describe criteria for defining sampling size, the exclusion of outliers, randomization), and strengthening sociological practices, such as all data and materials necessary for understanding, assessing, and extending conclusions of a manuscript must be available to any reader, as well as the possibility that research groups not involved with the original study replicate selected findings (Berg 2018).

Important and valuable as the proposed corrective initiatives may be (Editors 2014; Ioannidis 2014; McNutt 2014; Berg 2018; Ives 2018), they could be insufficient to tackle the reproducibility crisis because they only focus on the most empirical aspects of hypothesis testing, on the improvement of the next test (e.g. refining the experimental design, increasing sample size, improving data collection, randomization, and statistical inference). This is despite Ioannidis (2005a) had offered a comprehensive criticism and accurate diagnosis of the main causes of the reproducibility crisis early on when he stated that "it is a consequence of the convenient, yet ill-founded strategy, of claiming conclusive research findings solely based on a single study assessed by formal statistical significance, typically for a $p$-value less than 0.05 ". Ioannidis (2005a) was blaming the "one shot game", and the empiricist heart of CTT. Despite this early warning, the assessment of the mechanisms causing real patterns, as a rational control of the reproducibility of those patterns, is often missing in the specialized literature. Ironically, the use of putative mechanisms as a means of controlling the degree of truth of disparate phenomenological results is absent from the search of the mechanisms causing the reproducibility crisis.

Systemicity may also help, since an unwise bias towards novelty may be another factor that is increasing the reports of false positive results (Higginson and Munafó 2016; Cohen 2017). External coherence is indispensable for discarding wild conjectures whose 
The synthetic thesis of truth helps mitigate the "reproducibility crisis" and is an inspiration for predictive ecology

Luis Marone; Javier Lopez de Casenave; Rafael González del Solar

main -and perhaps sole- virtue is novelty, while being at odds with the bulk of updated background knowledge. External coherence, however, does not hinder innovative science, since it only demands consistence with most -not all- scientific knowledge (Bunge 1998). Further, it promotes innovation through the search of the usually unknown mechanisms that underpin clear natural or sociological patterns. "We can have greater confidence in our findings if they are consistent with mechanisms that are both reasonable and supported by other kind of evidence" (Johnson 2002). In his idea of a research program in wildlife science, Johnson (2002) emphasized the STT, without using the concept: we have greater confidence in our ideas if they are consistent with the output of our most recent observations or experiments, as well as correspond with plausible mechanisms whose existence was established by using independent, usually experimental, evidence (Bunge 1997; 2017; Werner 1998; Marone et al. 2000).

Certainly, a great number of researchers employ -although sometimes in a tacit way- both criteria of STT. For example, Munafó and Smith (2018), in trying to fix the reproducibility crisis, recently proposed that sheer repetition of the same experiment is not enough. They recalled an extant tradition in the philosophy of science (e.g. Bunge 1998; Stegenga 2009) that can be traced to William Whewell and that is also present in practicing science (Smith 1920; Marone et al. 2000; Johnson 2002). The core of such tradition is what Munafó and Smith (2018) called "triangulation", perhaps more widely known as "consilience" or "robustness". It consists in the strategic use of multiple approaches to address the same question. Each approach has its own assumptions and, thus, the results that agree from different approaches (and assumptions) are less likely to be artifacts. Munafó and Smith (2018) also emphasized the always important sociological aspects of scientific enterprise when they assert that, although triangulation is supposedly how science is meant to operate, in today hyper-competitive environment scientists often lose sight of the need to pursue distinct strands of evidence. Triangulation is a particular kind of redundancy and cross-check of hypotheses embedded in the STT tradition: by changing the kind of experiment (and its contingent assumptions), robustness is not merely inductive consistence between repetitions but redundancy under different assumptions. The robust result is sustained by inductive, as well as deductive, foundations (several predictions, founded on different assumptions, hold). It is a modest way of using background knowledge (assumptions in this case) to give multiple support to the working hypothesis, but it is an important way.

To conclude we will review examples of the practical application of STT to research questions in ecology and environmental sciences. In doing so, we will put the research program on community ecology, proposed and carried out by Earl Werner (1998) and colleagues, under the spotlight.

Revista de Humanidades de Valparaíso, 2019, No 14, 363-376

(ㄷ)(1)(8) CC BY-NC-ND 
The synthetic thesis of truth helps mitigate the "reproducibility crisis" and is an inspiration for predictive ecology

Luis Marone; Javier Lopez de Casenave; Rafael González del Solar

\section{The synthetic thesis of truth and the research program in community ecology}

The idea of employing multiple controls, empirical and theoretical, to reliably predict and explain natural phenomena is implicit in the way several natural scientists conduct research. One outstanding example is Earl Werner's research program in community ecology because of its balanced epistemological, methodological, and scientific components. In Werner's (1998) words: “The research program that I discuss here emphasizes the importance of integrating descriptive/comparative, experimental, and theoretical work to approach ecological questions. It is the iteration among theory, experiments, and a specific field pattern that is so valuable". According to Werner (1998), reliable knowledge requires descriptive, experimental, and theoretical evidence simultaneously. Such a research program accomplishes the three main goals of science (i.e. the description, explanation, and prediction of phenomena; see Bunge 1998). But a key component to make the program function is the integration of evidence, and Werner (1998) remarks that a clear view of how to integrate the different aspects of the scientific process into a successful research program is what is lacking in most discussions.

Particularly interested in prediction, Werner (1998) found that experiments that make no contact with a given research program may fall far short of providing a predictive basis because of the lack of integration with a strong theoretical foundation, even more if the experiments are not directed at uncovering mechanisms. The theoretical component would be the glue that holds these studies together at various levels. But more than this, to prevent a program from being deflected into unrealistic avenues, such a program must be related to the context provided by a field pattern, and the self-correcting steps that pattern avails. The attempt to take predictions from highly controlled studies back to more natural conditions is a critical step in a predictive research program: "Specifically, studies must be integrated in such a way that the artifacts introduced by experimental control are eventually cancelled out by the guiding hand of reality, and the intractableness of reality must be whittled away by the surgical knife of control" (Werner 1998). The incorporation of theoretical components based on mechanisms at the individual level, sometimes called "natural history" although they are often measured experimentally (e.g. morphological, physiological, behavioral mechanisms), allows the establishment from individual ecology of quantitative predictions at the community level. Such predictions are especially valuable because they are constructed independently of the community-level phenomena or pattern. By means of integrating theoretical, experimental and descriptive elements in a research program, hypothesis testing is an exercise embedded into Bunge's STT: the researcher aspires to build a functional whole (predictive and explanatory theory), based on the assumptions and hypotheses sustained on natural history, especially about causal mechanisms identified by experimentation, all of them controlled by a realistic pattern in the field (descriptions or comparative studies). The hypotheses in the program are supported not only by the data at hand (internal consistency) but also by theoretical expectations and data coming from alternative disciplines (external consistency). It

Revista de Humanidades de Valparaíso, 2019, No 14, 363-376

(). (18) CC BY-NC-ND 
The synthetic thesis of truth helps mitigate the "reproducibility crisis" and is an inspiration for predictive ecology

Luis Marone; Javier Lopez de Casenave; Rafael González del Solar

clearly sounds much more complex and labor intensive than the "one shot game", but the program would probably produce the most robust, trustworthy and reproducible results that community ecologists can offer.

Werner (1998) gave out numerous examples on how he and his colleagues have explained and predicted several ecological patterns in artificial as well as natural settings of northern USA, and to conclude we will contribute an own ecological example on the interplay of observational, experimental, and theoretical approaches. Domestic grazing is the main economic activity in the central Monte desert of Argentina, which affects several components of the flora and fauna (Pol et al. 2014). For example, it consistently reduces the production and abundance of grass seeds (and more inconsistently of forb seeds too) in the soil seed bank of that semiarid region. In a comparative assessment of three different Monte locations, Sagario et al. (2020) reported that the abundance of two seed-eating bird species (Saltatricula multicolor and Zonotrichia capensis) decreases systematically under heavy grazing. Previous (descriptive) studies of the diet of those species in grazed (Marone et al. 2017) and ungrazed habitats (Marone et al. 2008) suggested that whereas S. multicolor is an obligate grass-seed specialist, Z. capensis is an opportunistic seedeater, with a generalized diet that includes both grass and forb seeds (Marone et al. 2008; Ríos et al. 2012). Given that species that consume grass together with forb seeds have a higher resource base in grazed habitats than species that only consume grass seeds, the "theory" based on the specialist against opportunistic behavior of consumers was unable to explain and predict the reductions observed in the density of $Z$. capensis. This bird, with a broader potential diet, should not be affected by grazing or should be affected to a lesser extent than S. multicolor. Experiments on seed preferences by both bird species confirmed that $S$. multicolor is an obligate grass-seed specialist, but they also showed that $Z$. capensis is not a proper opportunistic feeder but an expanding grass-seed specialist (i.e. a species that prefer large and medium-sized grass seeds but also consume less-preferred seeds like tiny grass or forb seeds when the preferred seeds are scarce or absent in its habitat). Descriptive studies are unable to detect the expanding specialist behavior, but it arose in preference trials where the amount and disposition of seeds are experimentally controlled. Experiments led us to introduce changes in our theoretical background, incorporating the expanding specialist strategy, and such changes allowed us to explain the reductions (initial observation) in the abundance of $Z$. capensis in the grazed habitats. This species would also have been tracking its preferred grass seeds, even though it can consume other seeds and, therefore, it abandoned heavily grazed areas. This interplay of observations, experiments and theory produced a reliable, reproducible scenario, where prediction was founded on both rational and empirical grounds. 
The synthetic thesis of truth helps mitigate the "reproducibility crisis" and is an inspiration for predictive ecology

Luis Marone; Javier Lopez de Casenave; Rafael González del Solar

\section{Conclusions}

At the end of a revealing article on the lack of reproducibility of research results in various disciplines, Lehrer (2010) suggested that researchers like to pretend that their experiments quickly define the truth for everyone, and that this is the reason why the decline effect (i.e. the reproducibility crisis) is so troubling. But, according to Lehrer (2010), it is not troubling because it reveals the human fallibility of science or because it reveals that many of our most exciting theories will soon be rejected. The decline effect is troubling, Lehrer (2010) said, because it reminds us how difficult it is to prove anything. The emphasis STT makes on the worth that both rational and empirical support have when used simultaneously to test scientific ideas could leave "the proof" as close to truth as it is humanly possible.

\section{Acknowledgments}

We wrote this assay to celebrate Mario Bunge's 100 birthday on September 2019. Bunge has been considered "the philosopher of the practicing scientist" because he applied himself to the commendable task of associating both traditions in fertile ways. Philosophers attracted by the comfortable project of radically criticizing the foundation of scientific knowledge usually look at Bunge's work with suspicion, blaming him of having avoided the "true" complexity of the development of human knowledge. Criticism is a philosophical duty always welcomed, and the invitation to avoid automatisms is an essential contribution of the philosophy of science to practicing scientists. However, criticism is in better company when it is accompanied by positive proposal. Criticism and construction of a philosophical foundation for science and technology have been the passions of Mario during his life, a life full of intellectual courage. Contribution 109 of the Desert Community Ecology Research Team (Ecodes), of IADIZA-CONICET, and FCEyN Universidad de Buenos Aires. CONICET (PIP 12-469) contributed to the development of this project.

\section{References}

Baker, M. (2016). Is there a reproducibility crisis? Nature, 533: 452-454. doi: https://doi. org/10.1038/533452a

Berg, J. (2018). Progress on reproducibility. Science, 359: 9. doi: https://doi.org/10.1126/science. aar8654

Bunge, M. (1997). Mechanism and explanation. Philosophy of the Social Sciences, 27: 410-465. doi: https://doi.org/10.1177/004839319702700402

Bunge, M. (1998). Philosophy of Science. Volume 2, From Explanation to Justification. New York: Routledge. doi: https://doi.org/10.4324/9781315126388

Revista de Humanidades de Valparaíso, 2019, No 14, 363-376

(c) (1) 8 (을 BY-NC-ND 
The synthetic thesis of truth helps mitigate the "reproducibility crisis" and is an inspiration for predictive ecology

Luis Marone; Javier Lopez de Casenave; Rafael González del Solar

Bunge, M. (1999). Dictionary of Philosophy. New York: Prometheus Books.

Bunge, M. (2006). Chasing reality: Strife over Realism. Toronto: University of Toronto Press. doi: https://doi.org/10.3138/9781442672857

Bunge, M. (2012). The correspondence theory of truth. Semiotica, 188: 65-75. doi: https://doi. org/10.1515/sem-2012-0004

Bunge, M. (2017). Evaluating scientific research projects: The units of science in the making. Foundations of Science, 22: 455-469. doi: https://doi.org/10.1007/s10699-015-9474-3

Cohen, B. A. (2017). How should novelty be valued in science? eLife, 6 (art. e28699). doi: https:// doi.org/10.7554/elife.28699

Editors (2014). Journals unite for reproducibility. Nature, 515: 7. doi: https://doi. org/10.1038/515007a

Editors (2016). Reality check on reproducibility. Nature, 533: 437. doi: https://doi. org/10.1038/533437a

Hairston, N. G. (1989). Ecological experiments: Purpose, design, and execution. Cambridge: Cambridge University Press. doi: https://doi.org/10.1017/cbo9780511608513

Higginson, A. D., Munafó, M. R. (2016). Current incentives for scientists lead to underpowered studies with erroneous conclusions. PLoS Biology, 14 (art. e2000995). doi: https://doi. org/10.1371/journal.pbio.2000995

Ioannidis, J. P. A., Ntzani, E. E., Trikalinos, T. A., Contopoulos-Ioannidis, D. G. (2001). Replication validity of genetic association studies. Nature Genetics, 29: 306-309. doi: https://doi.org/10.1038/ng749

Ioannidis, J. P. A. (2005a). Why most published research findings are false. PLoS Medicine, 2 (art. e124). doi: https://doi.org/10.1371/journal.pmed.0020124

Ioannidis, J. P. A. (2005b). Contradicted and initially stronger effects in highly cited clinical research. JAMA, 294: 218-228. doi: https://doi.org/10.1001/jama.294.2.218

Ioannidis, J. P. A. (2014). How to make more published research true. PLoS Medicine, 11 (art. 1001747). doi: https://doi.org/10.1371/journal.pmed.1001747

Ives, A. R. (2018). Informative irreproducibility and the use of experiments in ecology. BioScience, 68: 746-747. doi: https://doi.org/10.1093/biosci/biy090

Johnson, D. H. (2002). The importance of replication in wildlife research. Journal of Wildlife Management, 66: 919-932. doi: https://doi.org/10.2307/3802926

Lehrer, J. (2010). The truth wears off. Is there something wrong with the scientific method? The New Yorker, December, 13: 52-57.

Lombardi, O. (2016). Carta abierta: acerca del mundo, los mundos y el papel de la filosofía. Revista de Humanidades de Valparaíso, 8: 129-145. doi: https://doi.org/10.22370/rhv.2016.8.501

Mahner, M. (2001). Scientific Realism. New York: Prometheus Books.

Revista de Humanidades de Valparaíso, 2019, No 14, 363-376

()ㅇㅇㅇㅛ CC BY-NC-ND 
The synthetic thesis of truth helps mitigate the "reproducibility crisis" and is an inspiration for predictive ecology

Luis Marone; Javier Lopez de Casenave; Rafael González del Solar

Marone, L., Bunge, M. (1998). La explicación en ecología. Boletín de la Asociación Argentina de Ecología, 7: 35-37.

Marone, L., Galetto, L. (2011). El doble papel de las hipótesis en la investigación ecológica y su relación con el método hipotético deductivo. Ecología Austral, 21: 201-216.

Marone, L., Lopez de Casenave, J., Cueto, V. R. (2000). Granivory in southern South American deserts: Conceptual issues and current evidence. BioScience, 50: 123-132. doi: https://doi. org/10.1641/0006-3568(2000)050[0123:gissad]2.3.co;2

Marone, L., Lopez de Casenave, J., Milesi, F. A., Cueto, V. R. (2008). Can seed-eating birds exert top-down effects on grasses of the Monte desert? Oikos, 117: 611-619. doi: https://doi. org/10.1111/j.0030-1299.2008.16506.x

Marone, L., Olmedo, M., Valdés, D. Y., Zarco, A., Lopez de Casenave, J., Pol, R. G. (2017). Diet switching of seed-eating birds wintering in grazed habitats of the central Monte desert, Argentina. Condor: Ornithological Applications, 119: 673-682. doi: https://doi. org/10.1650/condor-17-61.1

McNutt, M. (2014). Reproducibility. Science, 343: 229. doi: https://doi.org/10.1126/science. aaa1724

Munafó, M. R., Smith, G. D. (2018). Repeating experiments is not enough. Nature, 553: 399-401. doi: https://doi.org/10.1038/d41586-018-01023-3

Pol, R. G., Sagario, M. C., Marone, L. (2014). Grazing impact on desert plants and soil seed banks: implications for seed-eating animals. Acta Oecologica, 55: 58-65. doi: https://doi. org/10.1016/j.actao.2013.11.009

Polis, G. A., Wise, D. H., Hurd, S. D., Sánchez-Piñero, F., Wagner, J. D., Jackson, C. T., Barnes, J. D. (1998). The interplay between natural history and field experimentation. In W. j. Resetarits, J. Bernardo (eds.), Experimental ecology. Issues and perspectives, pp. 254-280. Oxford: Oxford University Press. doi: https://doi.org/10.2307/1447995

Ríos, J. M., Mangione, A. M., Marone, L. (2012). Effects of nutritional and anti-nutritional properties of seeds on the feeding ecology of seed-eating birds of the Monte Desert, Argentina. Condor, 114: 44-55. doi: https://doi.org/10.1525/cond.2012.110043

Russell, B. (1918/1998). Philosophy of Logical Atomism. Chicago: Open Court.

Sagario, M. C., Cueto, V. R., Zarco, A., Pol, R., Marone, L. (2020) Predicting how seed-eating passerines respond to cattle grazing in a semi-arid grassland using seed preferences and diet. Agriculture, Ecosystems and Environment, 289 (art. 106736). doi: https://doi. org/10.1016/j.agee.2019.106736

Smith, E. F. (1920). An introduction to bacterial diseases of plants. Philadelphia: WB Saunders Company. doi: https://doi.org/10.5962/bhl.title.13485

Stegenga, J. (2009). Robustness, discordance, and relevance. Philosophy of Science, 76: 650-661. doi: https://doi.org/10.1086/605819

Tarski, A. (1983). Logic, Semantics, Metamathematics. Indianapolis: Hackett Publishing Co.

Revista de Humanidades de Valparaíso, 2019, No 14, 363-376

()ㅇㅇㅇㅛ CC BY-NC-ND 
The synthetic thesis of truth helps mitigate the "reproducibility crisis" and is an inspiration for predictive ecology Luis Marone; Javier Lopez de Casenave; Rafael González del Solar

Werner, E. E. (1998). Ecological experiments and a research program in community ecology. In W. J., Resetarits, J. Bernardo (eds.), Experimental ecology. Issues and perspectives, pp. 3-26. Oxford: Oxford University Press. doi: https://doi.org/10.2307/1447995

Young, N. S., Ioannidis, J. P. A., Al-Ubaydli, O. (2008). Why current publication practices may distort science. PLoS Medicine, 5 (art. e210). doi: https://doi.org/10.1371/journal. pmed.0050201

Revista de Humanidades de Valparaíso, 2019, No 14, 363-376

(c) (1) 8 (을 BY-NC-ND 


\title{
Sobre la legitimidad de la interrogación meta-filosófica en filosofía de la biología
}

\author{
On the legitimacy of the meta-philosophical interrogation \\ in philosophy of biology \\ E. Joaquín Suárez-Ruíz \\ Universidad Nacional de La Plata, Argentina \\ ernestojoaquinsuarez@gmail.com
}

\begin{abstract}
Resumen
Una de las líneas de investigación más polémicas y actualmente desarrolladas en filosofía de la biología es aquella en la que los/las filósofos/as examinan los supuestos pre-darwinianos que aún estarían presentes en la base de otras sub-disciplinas filosóficas, como ser la ética, la gnoseología, la filosofía del lenguaje, etc. Este tipo de indagación, que aquí denominaré "interrogación meta-filosófica", puede pensarse como un abordaje complementario al epistemológico, el cual permite ampliar el enfoque crítico de la disciplina en cuestión. El objetivo de este artículo será explicitar las características de la "interrogación meta-filosófica" y argumentar sobre su legitimidad en tanto un modo de análisis propio de la Filosofía de la biología.
\end{abstract}

Palabras clave: filosofía de la biología, naturalismo filosófico, meta-filosofía, antropocentrismo.

\begin{abstract}
One of the most controversial and currently developed lines of research in philosophy of biology is that in which philosophers investigate pre-Darwinian assumptions that would still be present at the base of other philosophical sub-disciplines, such as ethics, epistemology, philosophy of language, etc. This type of inquiry, which I will call here "meta-philosophical interrogation," can be thought as a complementary approach to the epistemological one, which allows us to broaden the critical approach of the discipline in
\end{abstract}

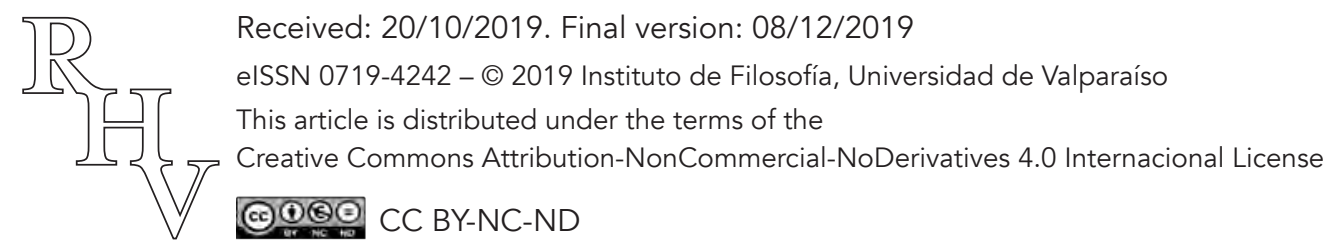


question. The objective of this article will be to analyze the characteristics of the "metaphilosophical interrogation" and to argue about its legitimacy as a way of inquiry proper to the philosophy of biology.

Keywords: philosophy of biology, philosophical naturalism, meta-philosophy, anthropocentrism.

\section{Introducción}

$\mathrm{Al}$ tomar como referencia las producciones actuales de investigadores reconocidos del campo de la filosofía de la biología, el vínculo actual entre filosofía y biología muestra no ser ya exclusivamente el de una aproximación epistemológica. Por señalar algunos ejemplos, cuando Daniel Dennett problematiza la pertinencia del concepto de "libre albedrío" a la hora de comprender el origen y fundamento de la moral (2004), cuando Michael Ruse realiza su crítica meta-ética a las morales sustantivas afirmando que no son sino ilusiones afectivas (2002) o cuando Philip Kitcher (2011) analiza el pasado evolutivo de los seres humanos para desarrollar su Ethical Project, estos filósofos de la biología parten de teorías y estudios biológicos para analizar problemas filosóficos de otras sub-disciplinas, en este caso, de la ética. Todos ellos comparten la convicción de que la visión post-darwiniana $^{1}$ de la evolución de la vida posee profundas implicancias no sólo en la biología sino también en la filosofía.

Este tipo de indagación es realizada por cada vez más filósofos de la biología, pero parece poseer dos puntos problemáticos. En primer lugar, se aleja la convicción de que el único tipo de análisis válido en filosofía de la biología es el de un distanciamiento epistemológico, ya que, para realizar exploraciones de este tipo, el/la filósofo/a precisa comprometerse con conocimientos empíricos a la hora de justificar sus aserciones. Podría argumentarse, por tal, que este compromiso impregnaría dichas investigaciones de un punto de vista acrítico, dogmático y/o reduccionista a la investigación filosófica. El segundo punto problemático reside en que su interrogación avanza no sólo hacia teorías y problemas ajenos a la disciplina de la que parten, sino también hacia los cimientos mismos de esas otras sub-disciplinas que exploran. Por ejemplo, si la crítica de Dennett al concepto de "libre albedrio" pone en duda los fundamentos de la deontología kantiana, el escepticismo meta-ético argumentado por Ruse pone en duda los cimientos mismos de la ética normativa en general.

\footnotetext{
${ }^{1}$ Distingo entre "darwiniano/a" y "post-darwiniano/a" para contemplar, a través de esta última denominación, los múltiples debates actuales en filosofía de la biología que problematizan los principios de la teoría darwiniana clásica.
} 
A pesar de estos dos puntos problemáticos, es a través de este tipo de interrogación que la filosofía de la biología muestra ser capaz de dar cuenta de los posibles aportes y modificaciones que una perspectiva evolutiva de la vida introducen en la filosofía en sentido amplio. Filósofos de la biología como los mencionados, al realizar interrogaciones más osadas con aquellos conceptos y modelos biológicos que en una primera instancia analizaron a través de una lente epistemológica, posibilitan echar nueva luz sobre la serie de problemas y soluciones que constituyen a las diferentes sub-disciplinas filosóficas. De allí que resulte perentorio hallar el modo en que los dos puntos problemáticos mencionados no conduzcan necesariamente a un desprecio absoluto de este tipo de investigaciones.

Así, teniendo presente esta tendencia actual en las producciones vinculadas a la filosofía de la biología, la intención de este artículo será la de exponer una idea, ya esbozada en otros trabajos (Suárez-Ruíz 2017; 2018; 2019), que consiste en lo siguiente: cuando filósofos de la biología como los recién mencionados parten de estudios y teorías provenientes de disciplinas biológicas con el fin de analizar problemas que tradicionalmente pertenecieron al ámbito específico de otras sub-disciplinas filosóficas, exceden el perímetro epistemológico de la filosofía de la biología tradicional para así señalar problemas de tipo meta-filosófico. Es decir, permiten reconocer, examinar y problematizar supuestos pre-darwinianos en otras disciplinas filosóficas y/o tradiciones filosóficas, que quizás estuvieron siendo acarreados a lo largo de su historia canónica.

Este tipo de interrogación meta-filosófica no es nueva en la filosofía contemporánea, dado que pensadores como John Dewey la han realizado ya en las primeras décadas del siglo XX (Dewey 1911). De hecho, según argumenta el especialista Jerome Popp, el pragmatista consideró las implicancias de la teoría darwiniana no sólo en la ética, sino también en la gnoseología (epistemology) y la Política (Popp 2007). Lo novedoso aquí es que, justamente, la interrogación es realizada por filósofos de la biología con una fuerte formación tanto en Epistemología como también (generalmente) en Antropología y Sociología de las ciencias, que los habilitaría a partir de teorías y modelos biológicos con el fin de señalar resabios pre-darwinianos presentes en otras sub-disciplinas, sin por ello perder un enfoque filosófico crítico.

Por tal, este trabajo tiene por objetivo explicitar la existencia de esta interrogación de tipo meta-filosófica generalmente excluida por la ortodoxia en filosofía de la biología, así como también ofrecer argumentos que contribuyan a justificar su legitimidad. Para ello procederé a matizar los dos puntos problemáticos mencionados más arriba. En el segundo apartado analizaré en qué consiste la interrogación meta-filosófica a través de las discusiones vinculadas al "naturalismo filosófico". En el tercero, dado que mi campo de investigación específico es la ética, y que fue a través de los desarrollos ligados a la evolución de la moral por filósofos como los mencionados más arriba que me introduje en las diferentes aristas de la filosofía de la biología, traeré a colación algunas afirmaciones de Michael Ruse respecto de las implicancias meta-éticas del altruismo en términos evo-

Revista de Humanidades de Valparaíso, 2019, No 14, 377-393 
lutivos. Finalmente, en el cuarto apartado argumentaré por qué la filosofía de la biología muestra poseer un rol distinguido en estas interrogaciones de tipo meta-filosóficas a partir del debate filosófico actual en torno al "antropocentrismo".

\section{2. "Naturalismo filosófico" o el punto ciego tras el análisis epistemológico}

Más allá de que existan exploraciones osadas como las que indiqué en la introducción, en filosofía de la biología parece haber una máxima normativa, en muchos casos no justificada y/o formulada de manera manifiesta, que presume que sus investigaciones deben limitarse exclusivamente al análisis epistemológico. Según esta legalidad implícita, aquella investigación filosófica que tomase lo empírico como supuesto para analizar problemas, por ejemplo, éticos, no sería un análisis propiamente filosófico sino uno perteneciente a las ciencias o, incluso, un desvío inconducente. Este supuesto normativo hunde sus raíces en las características de la tradición analítica de la filosofía, centrada ante todo en la clarificación conceptual de las nociones utilizadas en las ciencias. Dicho modo de aproximación tiene la ventaja de evitar comprometer el análisis crítico propio de la filosofía con la carga dogmática de los saberes científicos, pero al mismo tiempo, cuando se supone como el único abordaje filosófico considerado legítimo, tiene la desventaja de vetar al análisis filosófico de los posibles aportes provenientes de las disciplinas científicas.

Para ir a un caso más concreto, la forma en cómo se traduce en filosofía de la biología la tensión recién mencionada es a través de las discusiones en torno al "naturalismo filosófico". Según Michael Ruse, este último podría definirse como el "usar los métodos de las ciencias empíricas o las conclusiones de ellas en nuestras inquisiciones filosóficas" $(2005,96)$. Desde este enfoque, la filosofía se serviría de las ciencias para enriquecer sus investigaciones. Otra definición, ofrecida por el filósofo francés Nicolas Baumard, es la de "una forma de explicar un fenómeno psicológico, social o cultural que sea compatible con las ciencias naturales"” (Baumard 2016, 2). Esta última es más amplia y, sobre todo, más aventurada que la de Ruse, por el hecho de que implica no sólo un uso de los métodos y conclusiones de las ciencias biológicas, sino que, al aseverar que la explicación de los niveles de complejidad de los seres humanos deben coincidir con dichos métodos y conclusiones, podría interpretarse como una propuesta cercana a un reduccionismo de tipo biológico. Esto es, a la pretensión de explicar fenómenos psicológicos, sociales y culturales exclusivamente en términos biológicos (Blackburn 2005, 43). En defensa de la definición propuesta por Baumard (2016), podría argumentarse que, más que advertencias, este tipo de señalamientos representan una falacia de la pendiente resbaladiza (Volokh 2003), por el hecho de que el procurar compatibilidad no supone una exclusividad de la explicación biológica.

\footnotetext{
${ }^{2}$ Las citas seguidas de un asterisco (*) indicarán que la traducción es mía.
} 
Más allá de cualquier definición posible, hay autores que afirman que todo abordaje naturalista de los problemas filosóficos es una empresa desacertada desde un principio. El filósofo de la biología Gustavo Caponi, por ejemplo, afirma:

[...] cuando se habla de 'ética naturalizada' o de 'ética evolucionista', se incurre o bien en un error categorial o bien en un equívoco. El error categorial sería el de confundir cuestiones filosóficas con temas de biología, como sería el caso del estudio de la evolución de nuestras categorías cognitivas y de nuestras pautas morales más básicas. El equívoco, aparentemente menos pernicioso que el error, sería el de aludir a un área de investigación empírica, usando el nombre con el que se designa una reflexión que tiende a la justificación, a la evaluación y a la fundamentación de normas y decisiones. Lo cierto, de todos modos, es que el equívoco es solidario del error y, además, también puede inducirnos a creer que estamos ante una revolución meta-filosófica, cuando en realidad sólo estamos ante un abuso de lenguaje. Lo correcto es hablar, simplemente, de naturalización del pensamiento, de la cognición, de la emotividad, de la sociabilidad, de la moralidad y del gusto. Con ello sólo podríamos entender el estudio biológico de esos temas (Caponi 2018, 186).

Según el filósofo argentino, el abordaje "naturalista" es propio de las ciencias biológicas, por lo que pretender una "naturalización" de la filosofía conlleva los dos desaciertos aquí mencionados: el error categorial del naturalismo filosófico, por un lado, sería el de confundir el ámbito de la filosofía con el de las ciencias naturales y el equívoco, por otro lado, consistiría en confundir el nivel de lo empírico con el de lo epistemológico. Así, apelando a Wittgenstein, el rosarino afirma que un análisis filosófico que procure introducir estudios biológicos como parte integral de su investigación no incurriría sino en un "abuso del lenguaje". Retomaré las aseveraciones categóricas de Caponi en la conclusión.

Sumado a comparar definiciones diversas, otro modo complementario de matizar lo que se entiende por "naturalismo filosófico" es analizar primero el concepto de "naturalismo". Según el filósofo de la biología Antonio Diéguez, no habría algo así como "el" naturalismo ${ }^{3}$, sino que podría hablarse de al menos tres tipos: un naturalismo ontológico, uno epistemológico y uno metodológico. Dado que los dos primeros tienen la desventaja de comprometerse, por un lado, con el supuesto de que es posible conocer de manera invariable las entidades naturales cual esencias fijas (esencialismo en el naturalismo ontológico), y, por otro lado, con el supuesto de que el conocimiento científico permanece constante independientemente de los cambios socio-históricos (cientificismo en el naturalismo epistemológico), Diéguez opta por el naturalismo metodológico como la opción más atinada en la comprensión de cómo y en qué medida reconocerle pertinencia a los conocimientos científicos en el análisis de problemas filosóficos, es decir, a la hora de caracterizar un "naturalismo filosófico". En palabras del filósofo:

\footnotetext{
${ }^{3}$ De hecho, tal como afirma Daniel Andler $(2017,30)$, el conjunto "Naturalistas" podría incluir filosofías tan heterogéneas como las de Leucipo, Aristóteles, Hobbes, Spinoza, Rousseau, Hume, Mill, Dewey, Quine, Strawson, Lewis, Armstrong, Jackson, Dretske o McDowell.
} 
Sobre la legitimidad de la interrogación meta-filosófica en filosofía de la biología

E. Joaquín Suárez-Ruíz

El naturalismo metodológico no sólo es hoy la única opción viable en la ciencia, sino que es visto además por muchos filósofos (entre los que me encuentro) como una opción saludable en la propia práctica de la filosofía. El filósofo que así lo estime, tenderá a creer [...] que no hay diferencias metodológicas que marquen una separación absoluta entre la filosofía y la ciencia —o si se quiere que la filosofía también debe tomar la evidencia empírica como piedra de toque de sus propuestas teóricas, que a su vez han de interpretarse como hipótesis revisables. Aceptará, pues, que en la filosofía puede también aplicarse de forma fructífera un principio de parsimonia - Ronald Giere lo ha bautizado como "principio de prioridad naturalista"- que manda no explicar de forma no naturalista lo que puede ser explicado de forma naturalista (Diéguez 2014a, 40).

Por tal, el naturalismo metodológico tendría siempre presente la advertencia de no perder de vista tanto las limitaciones socio-históricas del cocimiento científico como la imposibilidad de acceder a algo así como "esencias", por lo que abordaría dichos conocimientos siempre a través de un "como si" fuesen ciertos, tendiendo a un principio de parsimonia que busca una complementariedad entre las afirmaciones filosóficas y las investigaciones biológicas del presente. Como puede verse, este enfoque es similar al propuesto por Baumard (2016), sólo que enfatiza las precauciones epistemológicas para con los conocimientos científicos. De modo que, a la luz del desarrollo de Diéguez, gran parte del problema de la "naturalización" de la filosofía parece surgir cuando se supone que sólo hay una manera de comprender el concepto "naturalismo".

La perspectiva del malagueño posibilita, por un lado, conservar un punto de vista crítico en el abordaje de los conocimientos científicos que escapa del esencialismo y/o el cientificismo, al mismo tiempo que, por otro lado, incluye la posibilidad de que dichos conocimientos puedan servir como fundamento a la hora de analizar problemas filosóficos. Desde esta perspectiva, la denominación "ética naturalista", en tanto una disciplina que se incluiría dentro del enfoque del "naturalismo filosófico", no parece ser en sí misma problemática, ya que, siendo que depende de lo que se comprenda por el adjetivo "naturalista", cuando se sigue la vía metodológica defendida por Diéguez esta no converge necesariamente en una visión acrítica, dogmática y/o reduccionista de los conocimientos científicos.

Justamente, un ejemplo de interrogación meta-filosófica a partir de un punto de vista naturalista de la filosofía es el realizado por el filósofo malagueño para el libro Naturaleza animal y humana (Diéguez y Atencia 2014). Allí, Diéguez toma como referencia la filosofía de Donald Davidson para problematizar la idea de que toda creencia tiene contenido proposicional y que, en consecuencia, no habría pensamiento sin lenguaje, analizándola a la luz de la evidencia que permite justificar sólidamente la existencia, al menos en grado, de pensamiento conceptual en primates no humanos. Aludiendo a estudiosos como el psicólogo cognitivo Michael Tomasello (2000) o el biólogo del comportamiento James L. Gould (2002), el filósofo afirma: "No son pocos los investigadores en cognición animal que piensan que para tener conceptos no hace falta tener lenguaje. Para estos investigado-

Revista de Humanidades de Valparaíso, 2019, No 14, 377-393

(c) (1) 8 (을 CC BY-NC-ND 
res no sólo tendría sentido atribuir algún tipo de proto-pensamiento a los animales, sino pensamiento conceptual en toda regla" (Diéguez 2014b, 91). Este sería un ejemplo en el que un filósofo de la biología se aleja del abordaje estrictamente epistemológico, tomando como base evidencias de pensamiento conceptual en animales no-humanos para analizar un supuesto ligado, en este caso no a la ética, sino a la filosofía del lenguaje y a la filosofía del conocimiento.

De hecho, la corrosión de la interrogación que se abre aquí parece ir más lejos: siendo que la idea davidsoniana señalada por Diéguez de la relación entre pensamiento y lenguaje aún puede encontrarse presente como si fuese un supuesto aproblemático en no pocas producciones vinculadas a la tradición analítica ${ }^{4}$, su horizonte de discusión se extiende aún más allá de los fundamentos de una sub-disciplina filosófica particular para llevarla hacia los cimientos de una tradición filosófica. En el cuarto apartado continuaré con este punto.

Para profundizar en las características de la indagación meta-filosófica, en la sección siguiente analizaré un caso en el que un filósofo de la biología analiza cuestiones de ética a la luz de una perspectiva evolutiva post-darwiniana.

\section{Un ejemplo de interrogación meta-filosófica en ética}

La interrogación que subyace al artículo de Michael Ruse denominado Altruismo: una perspectiva naturalista darwiniana es la pregunta sobre el vínculo entre ética normativa, la cual busca determinar qué es lo correcto y qué es lo incorrecto a nivel moral, y meta-ética, la cual analiza los orígenes y características de dicha normatividad, a la luz de una perspectiva naturalista (filosófica). Para ello, Ruse parte del concepto de altruismo desde una perspectiva post-darwiniana ${ }^{5}$. Según él, para comprender el vínculo entre las dos disciplinas mencionadas en el párrafo anterior, es necesario dividir entre un altruismo real, definido como aquel que es percibido en la vida diaria por los seres humanos, es decir, la acción de priorizar a los otros por sobre el beneficio individual (Ruse pone como ejemplo clásico a la Madre Teresa de Calcuta), y un altruismo biológico, esto es, una visión evolutiva del altruismo según la cual este emergió porque de algún modo fue favorecido por la selección natural (Ruse 2005, 99).

A partir de centrar su desarrollo en las características del altruismo biológico en seres humanos, Ruse describe tres formas posibles de comprender los orígenes del altruismo en los seres humanos. La primera forma pone el énfasis en la continuidad, y supone la idea del altruismo como una función innata, similar a cómo se presenta en otras especies fi-

\footnotetext{
${ }^{4}$ Véase, por ejemplo, Lepore y Ludwig (2013).

${ }^{5}$ Dado que mucho se ha debatido ya sobre este concepto desde un enfoque evolutivo, me voy a centrar aquí en los argumentos específicos que aporta el filósofo de la biología, suponiendo cierto conocimiento básico del tópico.
}

Revista de Humanidades de Valparaíso, 2019, No 14, 377-393

()ㅇㅇㅇㅛ CC BY-NC-ND 
logenéticamente distantes (el comportamiento altruista entre las hormigas, por ejemplo). La segunda forma pone el énfasis en la discontinuidad, es decir, en las características propiamente humanas. Esta definición comprende al altruismo como un evento surgido exclusivamente por el hecho de que beneficia a los individuos que lo llevan a cabo. Esto es, individuos que a través de un cálculo racional optan por actuar de manera altruista porque es la mejor manera en que garantizan su propia supervivencia. En tercer lugar, y esta es la opción que señala como la más coherente con una perspectiva evolutiva contemporánea, es un punto medio entre las dos anteriores: hay buenas razones para suponer que los individuos no son máquinas súper-calculadoras ni máquinas puramente instintivas sino que, más bien, teniendo en cuenta la influencia fundamental de la cooperación social en la evolución humana, podría afirmarse que existe una base común instintiva, un instinto moral que hace tender hacia el altruismo, pero que permite cierta flexibilidad según el contexto de riesgo y la cercanía parental, y que contempla cierto grado de libertad en el individuo a través de su capacidad racional (Ruse 2005, 101).

Como puede verse, aunque Ruse propone esta tercera vía intermedia como la adecuada a la hora de interpretar evolutivamente el altruismo, su acento está puesto en la continuidad. Ya no de manera desmesurada como sí ocurría en la primera vía, dado que subraya la existencia de una particular flexibilidad en el altruismo de los seres humanos que los diferencias del tipo de cooperación que puede verse presente en otras especies, pero su fundamento es un instinto. Las modificaciones que podrían generar las construcciones racionales se generan siempre variando sobre esta base constante. De allí que relativice la relevancia de los sistemas éticos normativos afirmando que "de hecho, la moral en su mayor parte es justamente una moral del sentido común, más que un sistema bien articulado tal como es producido por filósofos" (Ruse 2005, 104).

Esta concepción instintiva de la moral lo acercaría a una perspectiva humeana. Justamente, otro modo en que señala el instinto fundamental del altruismo en los seres humanos es como un sentido moral (Ruse 2005, 102). Al igual que el filósofo escocés, Ruse ve problemas a la hora de justificar una normatividad fuerte en ética, es decir, al ser la base de la moral un "sentido" proveniente de un instinto y no una capacidad racional consciente, no puede dar cuenta de un criterio incondicional que permita diferenciar de manera unívoca lo moralmente incorrecto de lo correcto. De allí que su análisis converja en un escepticismo ético, según el cual no existirían bases necesarias de la normatividad ética sino que, una vez que se considera con seriedad las consecuencias de un enfoque evolutivo de la moral, buscar un sistema ético objetivo y absolutamente fundado en la razón se presenta como una empresa inviable (Ruse 2005, 106).

Ahora bien, más allá de que la base meta-ética post-darwiniana desarrollada por el filósofo conduce a darle un rol limitado a la racionalidad en la constitución de sistemas éticos, no implica que dicha construcción deje de poseer un efecto importante incluso a pesar de su alcance restringido. Según sus palabras, la posición a la que llega consiste en: "un escepticismo, por favor notar, acerca de fundamentos más que acerca de preceptos

Revista de Humanidades de Valparaíso, 2019, No 14, 377-393

(). (18) CC BY-NC-ND 
sustantivos. Lo que estoy diciendo, por lo tanto, es que, debidamente entendida, la aproximación darwiniana a la ética nos lleva a una clase de no-realismo moral"* (Ruse 2005, 106). De modo que su punto de vista de la moral es ante todo descriptivo, vinculado a un planteo meta-ético que matiza la posibilidad de postular morales sustantivas pero sin negarla.

Entonces, su señalamiento de las profundas limitaciones de las construcciones racionales en ética normativa tiene el propósito de sentar las bases de un nuevo comienzo para reiniciar dicha búsqueda. De allí que afirme "[...] defiendo mi noción de altruismo contra la noción algo idealizada que uno encuentra en algunos sistemas morales" (Ruse 2005, 105). Al mismo tiempo, su planteo tampoco elimina la posibilidad de un altruismo radical, como sería, siguiendo su ejemplo, el de la Madre Teresa de Calcuta, sino que, de hecho, tendiendo al extremo quizás se puedan vencer hasta cierto punto las limitaciones (Ruse 2005, 106). A su vez, también rechaza caer cerca de una meta-ética emotivista. Según sus palabras:

Hay una buena razón biológica por la cual hacemos las cosas como las hacemos y sentimos como sentimos. Si, de acuerdo con los emotivistas, pensáramos que la moral es sólo una simple cuestión de emociones sin una sanción o justificación detrás de ellas, entonces la moral muy pronto colapsaría en su futilidad [...] La moral sustantiva se mantiene en su lugar como una ilusión efectiva porque pensamos que no es una ilusión sino algo real. De ese modo, sostengo que el fundamento epistemológico de la ética evolucionista es una clase de no-realismo moral, pero también que una parte importante de la ética evolucionista consiste en que pensemos que es una clase de realismo moral. Ser altruista es una obligación. No es una obligación que existe más allá de la naturaleza humana [...] (Ruse 2005, 107).

Desde una perspectiva idealizada de la ética, es decir, que supone una base absolutamente racional de los juicios morales, afirmar que las razones son "ilusiones efectivas" implicaría caer en un relativismo o un escepticismo total. No obstante, su escepticismo meta-ético no destruye la posibilidad de pensar una moral sustantiva. Si bien la reducción de la jurisdicción de la racionalidad posee importantes consecuencias en lo que respecta a la normatividad, esta capacidad humana aún tendría la posibilidad de, al menos hasta cierto punto, encauzar el sentido moral. De modo que, las características post-darwinianas de la moral no deberían llevar a la comprensión de que todo debate ético es irrelevante, como sí sucedería desde una base emotivista, justamente, por el hecho de que esas "ilusiones" poseen efectos concretos que favorecen la existencia del altruismo real.

Finalmente, hay otro aspecto interesante de su planteo meta-ético post-darwiniano, y es que "sortea" la falacia naturalista de un modo curioso: "no tanto negando que se trata de una falacia sino, por así decirlo, esquivándola. ¡No hay falacia al apelar a la evolución como fundamento porque no hay fundamento al cual apelar! En últimas, el altruismo no tiene bases que lo justifiquen" (Ruse 2005, 107). Nuevamente, la crítica a los sistemas éticos tradicionales no comporta eliminar la normatividad en ética, sino que, de hecho, el 
señalar sus limitaciones podría facilitar su factibilidad o, dicho en otros términos, el "hacerse cargo" de las características evolutivas del altruismo posibilitaría partir de una base más firme a la hora de buscar construcciones racionales efectivas. Por tal, su descripción no-realista de la moral termina por ratificar la relevancia de mantener una pretensión de racionalidad fuerte en ética normativa.

Este análisis de Ruse fue publicado en el año 2002. Desde entonces mucho se ha escrito sobre estos tópicos. Por ejemplo, otra propuesta con la cual se emparenta la perspectiva de Ruse es la del intuicionismo social del psicólogo moral Jonathan Haidt. Este psicólogo es crítico con el modelo racionalista de la moral, según el cual la formación de los juicios morales surge exclusivamente del razonamiento. A través de la inclusión de estudios que suponen una base evolutiva post-darwiniana como los de Frans de Waal (1991) y Antonio Damasio (1994), Haidt gestó el modelo intuicionista social como alternativa al racionalista. Continuar suponiendo en ética, argumenta el psicólogo, que los juicios morales son exclusivamente producto del razonamiento moral implica estar de espaldas a numerosas investigaciones que explicitan la influencia de las intuiciones morales, vinculadas a las emociones, y la relación inter-personal (Haidt 2001, 830). Curiosamente, este psicólogo publicó su primera formulación del modelo un año antes de que Ruse publicara el suyo, no obstante el intuicionismo social es un modelo vigente y próspero en debates actuales (por ejemplo, Brand 2016; Sapolsky 2017).

Otra propuesta emparentada con la propuesta de Ruse es la del filósofo Joshua Greene en su libro Moral Tribes (2013), quien afirma que resulta erróneo reducir toda la dimensión ética humana a una "moral del sentido común" (asimilable al "sentido moral"), más bien, este tipo de moral evolutivamente heredada es la que genera la mayor cantidad de conflictos ético-políticos, por el hecho de que si bien facilita el vínculo Yo-Nosotros, genera grandes dificultades para garantizar el vínculo Nosotros-Ellos. De allí que proponga una ética normativa fundada en una meta-moral que exceda la moral por default a través de la capacidad racional (Green 2013, 25). Más allá de que Ruse ponga el acento en la continuidad a la hora de plantear su escepticismo meta-ético y Greene lo ponga en la discontinuidad en su propuesta normativa meta-moral, ambas teorías resultan, al menos hasta cierto punto, complementarias. Así, la perspectiva de este filósofo sería un ejemplo de cómo una teoría ética que parte de una base evolutiva puede realizar una propuesta normativa.

Teniendo en cuenta estas investigaciones actuales, resulta evidente que el planteo de Ruse sigue poseyendo vigencia, particularmente en cuanto a la pertinencia de pensar una meta-ética post-darwiniana que posibilite generar una ética normativa desde una base "sólida". En la siguiente sección me centraré en las discusiones actuales en torno al "antropocentrismo", dado que este concepto me permitirá resaltar por qué la filosofía de la biología posee un rol fundamental a la hora de realizar indagaciones de tipo meta-filosóficas. 


\section{Antropocentrismo: un "tabú disciplinario"}

Actualmente están en boga las discusiones filosóficas en torno al "antropocentrismo". En ellas, este concepto ya no es tomado en el sentido escolar de la transición renacentista del teocentrismo al antropocentrismo, sino en tanto una antigua idea que se ha convertido en una herencia problemática: la idea de que existe una superioridad de la especie humana que marca una discontinuidad absoluta entre esta y el resto de los seres vivos (Butchvarov $2015,1)$. Aunque a primera vista las perspectivas críticas del antropocentrismo podrían considerarse como fundadas en una preocupación anacrónica, son numerosos los investigadores que argumentan lo contrario.

Gran parte de la producción filosófica vinculada a este concepto se relaciona con la ética animal, particularmente con el concepto de "especismo" popularizado por Peter Singer (2009). Ahora bien, hay otras líneas de investigación ligadas a la crítica al antropocentrismo que no se centran en la ética inter-específica, sino en la intra-especifica. Es decir, aquellas que señalan que el antropocentrismo no sólo impide ver relevancia moral en el resto de los seres vivos, sino que también obstaculiza una comprensión en profundidad de las características humanas (de Waal 2007; Boddice 2011; Butcharov 2015).

En sintonía con esta vía de investigación, hay autores que afirman que el antropocentrismo se manifiesta, a su vez, como un obstáculo epistemológico, el cual dificulta la precisión de las explicaciones científicas. Un ejemplo de ello proviene de la discusión en torno al concepto de "cultura" tal como es utilizado en las Humanidades. Los críticos al antropocentrismo señalan que, a pesar de que actualmente se acepta la posibilidad de afirmar la existencia de cultura en animales no humanos (Ingmanson 1996; McGrew 1998; Sapolsky 2004), aún continúa suponiéndose en las disciplinas humanísticas una dicotomía con fuerte carga esencialista. Como bien resume la investigadora Sabrina Tonutti, el enfoque propio de las Humanidades:

a. considera los rasgos culturales humanos bajo una lente de aumento, mientras reduce todos los rasgos animales en una sola categoría, sin tener en cuenta diferencias filogénicas inherentes;

b. ignora / niega elementos de continuidad entre humanos y otras especies animales, etiquetando los signos de la cultura en otros animales como 'proto-cultura', 'pre-cultura', etc., con el objetivo de subrayar la singularidad y superioridad de la especie humana, mientras ignora que cada especie es única y diferenciada según sus particularidades;

c. ignora los vínculos filogénicos entre nuestra especie y otros animales (principalmente primates) [...] Esta oposición se basa en una perspectiva esencialista intrínseca, que supone la existencia de una característica compartida por todos los seres humanos (en este caso la cultura), que es capaz de distinguir cualitativamente a los humanos de todas las demás especies animales.* (Tonutti 2011, 185).

Revista de Humanidades de Valparaíso, 2019, No 14, 377-393 
Según Tonutti, habría un resabio esencialista que traza una diferencia radical entre, por un lado, la cultura de todos los seres humanos y, por otro lado, la cultura de todos los animales no humanos ${ }^{6}$. Por lo que, más allá de que incluso al interior de las Humanidades pueda llegar a aceptarse la presencia de cierto tipo de cultura no humana, permanecería una suerte de tabú disciplinario que impide profundizar en ello (Tounutti 2011, 198). Según el punto de vista antropocéntrico, el sólo hecho de poner el acento explicativo en la continuidad inevitablemente conllevaría caer en un reduccionismo biológico (nuevamente, la falacia de la pendiente resbaladiza pareciese ser una "justificación" recurrente cuando se aspira a problematizar la tendencia antropocéntrica de las disciplinas humanísticas). El obstáculo epistemológico reside en que, justamente, esta aversión a la continuidad en las Humanidades termina perpetuando el supuesto pre-darwiniano de una separación radical entre dos ámbitos homogéneos.

Vinculado a la crítica epistemológica, el filósofo contemporáneo Jean-Marie Schaeffer caracteriza al antropocentrismo como una "Tesis de la excepción humana" (TEH), cuya matriz fue forjada en la modernidad (particularmente a partir de la filosofía cartesiana), y que es aún reproducida al interior de las Humanidades (Schaeffer 2009). Dicha tesis estaría constituida por cuatro postulados que proliferan de manera constante e implícita en el análisis humanístico. De manera resumida, estos se caracterizan por: 1 - Una "ruptura óntica" que separa radicalmente a los seres humanos de las otras formas de vida; 2 - Un dualismo entre un orden "natural" y otro "espiritual", según el cual los seres humanos quedarían exclusivamente en el segundo ámbito; 3 - Una concepción gnoseocéntrica que instaura la actividad racional como la característica humana por excelencia; 4 - Y, finalmente, un "ideal cognitivo anti-naturalista", esto es, la ruptura y el dualismo instauran la idea de que es posible prescindir de todo "lo natural" en la pregunta por "lo humano" (Schaeffer 2009, 24-25).

Para un filósofo de la biología ortodoxo, particularmente aquel formado en la tradición analítica, la advertencia de Schaeffer sonaría como algo sumamente forzado, por el hecho de que el filósofo francés estaría señalando un extravagante problema "metafísico" donde en realidad no existe. La TEH, si se la considerase a la luz de disciplinas científicas como la biología evolutiva, mostraría ser más un "abuso del lenguaje" que una advertencia relevante. Paralelamente, seguramente le llamaría la atención que el "antropocentrismo" sea un tópico tan en boga en las producciones filosóficas de la actualidad. Siendo que la teoría de la evolución, al menos en sus aspectos más básicos, es aceptada por toda (o casi toda) la comunidad académica, el suponer que subsiste la idea de una discontinuidad absoluta, análoga a la que suponían los naturalistas pre-darwinianos, no tendría ninguna vigencia.

En defensa del enfoque de Schaeffer es posible afirmar que esa lectura no hace justicia de su análisis, dado que lo interpreta desde una concepción disciplinal que, justamente,

\footnotetext{
${ }^{6}$ La costumbre extendida en las producciones humanísticas a entrecomillar la palabra "naturaleza" y sus derivados, pero no la de "cultura", parece ser otro indicio de ello.
} 
no puede ver el dogma que perpetua. El aporte principal del filósofo francés reside en que no plantea la TEH como un problema empírico o científico, sino que libra la discusión en los fundamentos mismos de la disciplina "filosofía", es decir, propone una pesquisa que problematice los supuestos pre-darwinianos que aún podrían seguir siendo reproducidos a nivel disciplinal. Su análisis pone el foco en las Humanidades en general y en la filosofía en particular como disciplinas herederas y reproductoras de supuestos aún no problematizados, institucionalmente perpetuados, de los cuales el principal es la idea de una discontinuidad radical de lo humano. Lo que sucede con el concepto de "cultura" desarrollado por Tonutti, sería un ejemplo de esta tenacidad a nivel institucional.

Tomando nuevamente como ejemplo el desarrollo de Diéguez, la visión davidsoniana del pensamiento conceptual elimina ya desde su punto de partida la posibilidad de que exista pensamiento sin lenguaje y, por tal, de pensamiento conceptual en animales no humanos. Actualmente numerosas investigaciones permiten problematizar la validez de este supuesto (Sterelny 2006; Toribio 2010; Toda y Platt 2015), por lo que la filosofía de este autor norteamericano, al menos en lo que respecta al aspecto mencionado, muestra poseer algunos dogmas que hoy se reconocen como obsoletos o, como mínimo, dudosos. Por tal, continuar reproduciendo ese aspecto del enfoque davidsoniano como aproblemático tiene como consecuencia mantener una visión pre-darwiniana del vínculo entre pensamiento y lenguaje. A pesar de ello, y como se mencionó en la primera sección, aún suele considerarse que este punto de vista posee aún perfecta vigencia.

Llegados a este punto, me permito arriesgar una hipótesis: la ortodoxia en filosofía de la biología que considera como único análisis legitimo el epistemológico, corre el riesgo de perpetuar supuestos pre-darwinianos en otras sub-disciplinas e, incluso, en tradiciones filosóficas a las cuales los mismos filósofos de la biología podrían estar adscribiendo de manera acrítica. Dichos supuestos pre-darwinianos suelen ser reproducidos sin otra justificación más que la apelación a una tradición y/o a autores canónicos (Wittgenstein, Davidson o Carnap serían algunos ejemplos de ello). De modo que, tras el pretendido "purismo" de lo epistemológico que niega pertinencia a la interrogación meta-filosófica podrían estar siendo perpetuados y/o reproducidos supuestos dogmáticos no reconocidos como tales. Según lo que se desarrolló en este artículo, la carga de la prueba quedaría del lado, no de los/las filósofos/as de la biología que se aventuran en el análisis de problemas éticos o gnoseológicos desde una perspectiva evolutiva, sino de los representantes de la ortodoxia que, a través del hábito anquilosado de una constante apelación a la autoridad, implícita o explícita, corren el riesgo de perpetuar supuestos pre-darwinianos por detrás de la idea de una legitimidad exclusiva de lo epistemológico.

Yendo aún un poco más lejos podría decirse que escrutinios como los realizados por Diéguez, Ruse, Tonutti o Schaeffer permiten poner en duda el concepto de "naturalismo filosófico", pero esta vez no para rechazarlo, sino para examinar si acaso se trata de un enfoque más, como pueden ser el de la "fenomenología" o el del "existencialismo". Es decir, teniendo en cuenta las profundas implicancias que muestra poseer la interrogación 
meta-filosófica, de lo que se trata aquí no es ya de una corriente filosófica entre otras, sino de un tipo de interpelación profunda que explicita supuestos problemáticos presentes en la base de las múltiples sub-disciplinas filosóficas y, aún más, de las tradiciones filosóficas en sí mismas. El "naturalismo filosófico" se revela, en realidad, como meta-filosofía.

Antes de finalizar preciso mencionar una posible objeción a la interrogación meta-filosófica, la cual, expresada en forma de pregunta, sería algo como ¿Por qué la filosofía de la biología debería comprenderse, a su vez, como una suerte de "biofilosofía"? La respuesta sería que, justamente, una investigación filosófica no puede nunca dejar de poseer un distanciamiento crítico para con el objeto que analiza, ya que, de otra manera, se convertiría en un ámbito propicio para la reproducción de dogmas. De allí que la interrogación meta-filosófica sea complementaria del análisis epistemológico, por el hecho de que suponer este tipo de indagación como independiente de la lente problematizadora propia de la filosofía de la biología implicaría correr el riesgo de perder de vista las múltiples limitaciones del conocimiento científico. Es decir, siendo que resulta imprescindible cierto compromiso para con estudios y modelos científicos en la búsqueda de supuestos dogmáticos pre-darwinianos, resulta imprescindible la lupa crítica de lo epistemológico.

Así, al considerar que tanto el análisis epistemológico como la interrogación meta-filosófica forman parte de una sola disciplina, es la capacidad crítica de la filosofía de la biología la que se enriquece. No sólo por el aumento de complejidad con el cual puede abordar su objeto (la biología), sino porque uno funciona como precaución metodológica del otro. Esto es, así como el análisis epistemológico habilita una visión crítica de los estudios empíricos y las teorías biológicas, la interrogación meta-filosófica permite una revisión de los supuestos de neutralidad e imparcialidad que podrían estar siendo reproducidos de forma subyacente en las sub-disciplinas y/o tradiciones filosóficas.

\section{Conclusiones}

Soy consciente de que en este artículo introduje varias ideas arriesgadas y heterodoxas: la "interrogación meta-filosófica", el naturalismo filosófico en tanto meta-filosofía y la TEH como perpetuada por la filosofía de la biología seguramente sean los planteos que más mohines podrían generar. Tal como señalé en la introducción, mi propósito es ante todo práctico: por un lado explicitar la existencia del tipo de interrogaciones meta-filosóficas realizadas por filósofos de la biología como Diéguez y Ruse y, por otro lado, argumentar sobre su legitimidad como un modo de indagación propio de la filosofía de la biología en tanto disciplina.

A la luz de lo desarrollado, se resuelven los dos puntos problemáticos mencionados en la introducción. En relación con el primero, la interrogación meta-filosófica muestra no sólo escapar del dogmatismo, sino también ampliar el enfoque crítico. Es decir, a través del potencial meta-filosófico de investigaciones biológicas que fundamentan el 
pensamiento conceptual en primates no humanos o el origen evolutivo del altruismo, es posible señalar críticamente dogmatismos pre-darwinianos no reconocidos como tales al interior de las sub-disciplinas y/o tradiciones filosóficas. Dada su relevancia fundamental, y en relación con el segundo punto problemático, esta indagación "entrometida" de la filosofía de la biología debería salir de su rol marginal en notas al pie o en especulaciones recreativas de filósofos reconocidos. Utilizando una analogía, si el análisis epistemológico puede entenderse como un reflector que se dirige hacia los estudios, teorías y modelos científicos, la interrogación meta-filosófica sería la que permite girar su farol $180^{\circ}$ para así echar luz sobre los supuestos dogmáticos que podrían permanecer impertérritos en la base de la filosofía misma.

Volviendo al planteo de Caponi mencionado en la primera sección, ni el equívoco ni el error categorial muestran ser tales. Respecto del primero, si acaso se pretende poseer una visión crítica y problematizadora tanto de la biología como de la filosofía misma, el análisis epistemológico y la indagación meta-filosófica deberían comprenderse como abordajes complementarios e interdependientes entre sí. Respecto del segundo, y como consecuencia de lo recién afirmado, continuar suponiendo una distinción radical entre los ámbitos de la filosofía y de la biología, particularmente en lo referido al análisis filosófico de las características de la evolución humana, conlleva perpetuar y/o reproducir supuestos pre-darwinianos que aún pueden encontrarse en la base de las sub-disciplinas y/o tradiciones filosóficas. Es decir, el no comprometerse en absoluto para con modelos y teorías biológicas a la hora de hacer filosofía, incluye la posibilidad de sí comprometerse con dogmatismos más vetustos, afincados y menos obvios que esos modelos y teorías.

Finalmente, habiendo evidenciado las características corrosivas de la indagación meta-filosófica y teniendo en cuenta que es un tipo de análisis presente incluso desde las primeras décadas del siglo XX, es posible afirmar que no se trata de una "revolución meta-filosófica" o una tendencia pasajera, sino de una inquietud propiamente filosófica de larga data que actualmente se encuentra en proceso de afianzamiento disciplinal. Es por ello que resulta capital que los filósofos y las filósofas de la biología, en lugar de considerar este tipo de interrogaciones como pasatiempos especulativos o como no dignos de su disciplina, se comprometan en este tipo de discusiones, justamente, tanto para continuar con el análisis crítico de las ciencias biológicas como también para descomprometerse de dogmatismos filosóficos arcaicos que quizás se encuentren persistiendo en la base de sus investigaciones.

\section{Agradecimientos}

El autor agradece al Consejo Nacional de Investigaciones Científicas y Técnicas (CONICET) y a la Universidad Nacional de La Plata por el apoyo financiero. También agradece especialmente al Dr. Martín Daguerre y al Dr. Leonardo González Galli por la revisión crítica del artículo. 
Sobre la legitimidad de la interrogación meta-filosófica en filosofía de la biología

E. Joaquín Suárez-Ruíz

\section{Referencias bibliográficas}

Andler, D. (2016). La silhouette de l'humain. Quelle place pour le naturalisme dans le monde d'aujourd'hui? Paris: Gallimard.

Baumard, N. (2016). The origins of fairness, how evolution explains our moral nature. Oxford: Oxford University Press.

Blackburn, S. (2005). The oxford dictionary of philosophy. Oxford: Oxford University Press.

Boddice, R. (ed.) (2011). Humans, animals, environments. Leiden: Brill.

Brand, C. (ed.) (2016). Dual-process theories in moral psychology. Wiesbaden: Springer.

Butcharov, P. (2015). Anthropocentrism in philosophy. Berlin: De Gruyter.

Caponi, G. (2018). ¿Qué quiere decir “naturalizar”? Ludus Vitalis, XXVI(50): 185-188.

Damasio, A. (1994). Descartes'error: emotion, reason, and the human brain. New York: Putnam.

Dennett, D. (2004). La evolución de la libertad. Barcelona: Paidos.

Dewey, J. (1911). The influence of Darwin on Philosophy. The Philosophical Review, 20(2): 219221.

Diéguez, A. (2014a). Delimitación y defensa del naturalismo metodológico (en la ciencia y en la filosofía). En R. Gutierrez-Lombardo, J. Sanmartín (eds.), La filosofía desde la ciencia, pp.21-49. México DF: Centro de Estudios Filosóficos, Políticos y Sociales Vicente Lombardo Toledano.

Diéguez, A. (2014b). Pensamiento conceptual en animales. En A. Diéguez, J. M. Atencia, Naturaleza animal y humana, pp. 83-114. Madrid: Biblioteca nueva.

Diéguez, A., Atencia, J. M. (2014). Naturaleza animal y humana. Madrid: Biblioteca nueva.

Gould, J. L. (2002). Learning instincts. En J. Wixted, H. Pashler (eds.), Steven's handbook of experimental psychology: Learning, motivation, and emotion, pp. 239-257. New Jersey: John Wiley \& Sons. doi: https://doi.org/10.1002/0471214426.pas0306

Greene, J. (2013). Moral tribes. Nueva York: The Penguin Press.

Haidt, J. (2001). The emotional dog and its rational tail: a social intuitionist approach to moral judgment. Psychological Review, 108: 814-834.

Ingmanson, E. (1996). Tool-using behavior in Wild Pan Paniscus: Social and Ecological Considerations. En A. Russon et al. (eds.), Reaching into Thought: The Minds of the Great Apes, pp. 190-210. Nueva York : Cambridge University Press.

Kitcher, P. (2011). The ethical Project. Cambridge: Harvard University Press.

Lepore, E., Ludwig, K. (eds.) (2013). A companion to Donald Davidson. Oxford: Wiley-Blackwell.

McGrew, W. (1998). Culture in nonhuman primates? Annual Review of Anthropology, 27: 301-28.

Revista de Humanidades de Valparaíso, 2019, No 14, 377-393

()ㅇㅇㅇㅛ CC BY-NC-ND 
Popp, J. (2007). Evolution's first philosopher, John Dewey and the continuity of nature. Nueva York: State University of New York Press.

Ruse, M. (2005). Altruismo: una perspectiva naturalista darwiniana. Saga, 10: 95-110. Traducción: Maximiliano Martínez y Fernando Melo. El texto original puede hallarse en S. Post, et al. (eds.) (2002), Altruism and altruistic love. Oxford: Oxford University Press.

Schaeffer, J. M. (2009). El fin de la excepción humana. Barcelona: Marbot.

Sapolsky, R. (2017). Behave: the biology of humans at our best and worst. Nueva York: Penguin.

Sapolsky, R., Share, L. (2004). A pacific culture among wild baboons, its emergence and transmission. Public Library of Science Biology, 2: e106-13.

Singer, P. (2009). Liberación Animal. Madrid: Trotta.

Sterelny, K. (2006). Folk logic and animal rationality. En S. Hurley, M. Nudds (eds.), Rational Animals? pp. 293-311. Oxford: Oxford University Press.

Suárez-Ruíz, E. J. (2017). Filosofía post-darwiniana: sobre la relevancia de la continuidad evolutiva en la comprensión de la moral. Tesis de licenciatura, Dpto. de Filosofía, FaHCE, UNLP.

Suárez-Ruíz, E. J. (2018). Para una caracterización filosófica de la continuidad evolutiva. Revista Latinoamericana de Estudios Críticos Animales, 2: 139-158.

Suárez-Ruíz, E. J. (2019). El otro lado de la filosofía de la biología: una problematización de lo epistemológico como límite disciplinar. Nuevo Itinerario, 15: 58-74.

Toda, K., Platt, M. L. (2015). Animal cognition: monkeys pass the mirror test. Current biology, 25(12): 64-66.

Tomasello, M. (2000). Primate cognition: introduction to the issue. Cognitive science, 24(3): 351-361.

Toribio, J. (2010). The animal concepts debate: a metaphilosophical take. Teorema, XXIX(2): 11-24.

Tonutti, S. (2011). Anthropocentrism and the Definition of 'Culture' as a Marker of the Human/ Animal Divide. R. Boddice (ed.), Humans, Animals, Environments, pp.183-199. Leiden: Brill.

Volokh, E. (2003). The mechanisms of the slipperly slope. Harvard Law Review, 116(4): 10261137.

Waal, F. de (1991). The chimpanzee's sense of social regularity and its relation to the human sense of justice. American Behavioral Scientist, 34: 335-349.

Waal, F. de (2007). Primates y filósofos. Barcelona: Paidos. 



\title{
La evolución de la biología y la biología evolucionista: especie y finalidad
}

\section{The evolution of biology and the evolutionist biology: species and finality}

\author{
Daniel Labrador Montero \\ Universidad de Salamanca, España \\ danilabra@usal.es
}

\begin{abstract}
Resumen
¿Son las especies categorías reales o meras convenciones? ¿Son las especies clases naturales? ¿Son los enunciados teleológicos un rasgo distintivo de la biología como ciencia? Estas preguntas y otras muchas son una constante en la filosofía de la biología. En este artículo se pretende mostrar que difícilmente se puede dar respuesta a alguna de ellas sin adquirir una posición respecto a las otras, pues existe una relación histórica entre las cuestiones acerca del concepto de especie y las cuestiones acerca de la finalidad. Para escenificar dicho vínculo se acudirá a una perspectiva histórica, donde se indagará en el desarrollo de esta ligazón entre las nociones de especie y finalidad. El centro y desembocadura de este trabajo será la teoría darwinista. El objetivo, por tanto, es realizar dicho análisis hasta la teoría de Darwin.
\end{abstract}

Tras realizar este trayecto centrado en el pensamiento de Aristóteles, Linneo, Buffon y Lamarck, se examinará la peculiar postura de Darwin acerca de la teleología y la relación que esto tiene con sus ideas acerca de las especies. A pesar de que Darwin inicia la caída de los grandes esencialismos teleológicos dentro de la reflexión sobre lo vivo, hay rastros de un finalismo en su obra.

Palabras clave: teleología, adaptación, transformismo, selección natural, Darwin.

\begin{abstract}
Are species real categories or just conventions? Are species natural kinds? Are teleological statements a distinctive feature of biology? Can life sciences escape from teleology? These are common issues in philosophy of biology. This paper aims to show that in order to
\end{abstract}

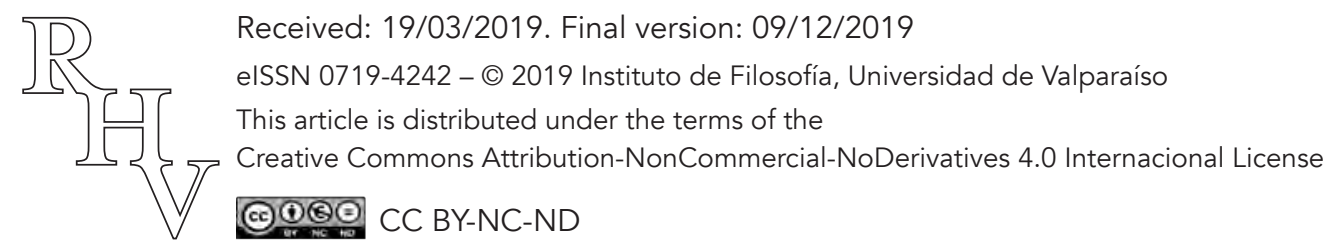


answer to each of these questions it is inevitable to take a position respecting the others. Therefore, there is a historical relation between the concept of species and teleological issues. In order to analyse such relation, I will take a historical perspective.

After making such historical reconstruction focused on the Aristotle, Linnaeus, Buffon and Lamarck thoughts, I will analyse the Darwinian peculiar view respect teleology and his ideas about species. Although Darwin set out the collapse of teleological essentialisms in biology, there are important vestiges of teleology in his theory.

Keywords: teleology, adaptation, transformism, natural selection, Darwin.

\section{Introducción}

El propósito de este artículo es analizar la relevancia histórica que ha tenido la relación entre las nociones de especie y de finalidad en el pensamiento biológico-filosófico hasta Darwin. Se intentará mostrar que la predilección por una teleología no (pre)determinada implica la apertura a la posibilidad de un transformismo que no dependa de teleologías fuertes. Es, por ello, que, en primer lugar, hay que detenerse en qué se considerará teleología y las diferentes formas que esta puede adoptar.

Es oportuno recalcar que el desarrollo de toda la argumentación está orientado a culminar con el pensamiento de Darwin y que, por tanto, no se irá más allá del siglo XIX. Analizar dichas relaciones en el neodarwinismo y la teoría evolutiva actual requeriría un artículo por sí solo. De esta forma, cualquier afirmación que se realice acerca de la teoría darwinista no tiene por qué ser aplicable a la biología actual, donde el panorama teórico es mucho más complejo.

\section{Las dicotomías teleológicas}

En la mayor parte de los campos del saber Aristóteles se mantuvo como referente durante siglos, autor finalista por excelencia. Toda su filosofía tiene como núcleo central una teleología naturalizada. Su derrumbe provino de la propuesta mecanicista, con el final del contemplativismo. Ya no era interesante admirar el inmenso plan de la naturaleza, sino saber cómo se desarrollaban sus procesos para poder reproducirlos artificialmente. La belleza de la naturaleza parecía desvanecerse de la mente científica con el rechazo de cualquier orden natural que aparentara una imposición antropomorfa. Así, formas y fines pasaron a ser ficciones que el hombre impone a la naturaleza ${ }^{1}$ (cf. Bacon 1984), pues la contemplación pasiva, predicaban, no ayuda a comprender el mundo, sino solo a admirarlo (Gilson 1980, 64).

\footnotetext{
${ }^{1}$ Cf. $\S 51$ del libro I de Novum Organum.
}

Revista de Humanidades de Valparaíso, 2019, No 14, 395-426

(ㅇ) $@ 0$ CC BY-NC-ND 
Las ciencias de la vida, en cambio, no se deshicieron de la finalidad. Hoy siguen sin poder hacerlo, aunque no por falta de partidarios de su erradicación. ¿Por qué la teleología parece razón de ignominia dentro de las ciencias naturales? Tomando como base el trabajo de Ernst Mayr (1988), Antonio Diéguez resume a la perfección cuáles son los presupuestos que hay detrás del resquemor epistemológico hacia la teleología en las ciencias naturales:

1. Las explicaciones teleológicas introducen elementos antropomórficos en la explicación. Es como si se atribuyera a la naturaleza una especie de propósito o deliberación consciente que la lleva a poner los medios adecuados para la consecución de sus fines $[\ldots]$

2. El discurso teleológico invierte el orden causal aceptable científicamente, situando en el futuro la causa y en el presente el efecto. [...]

3. Los enunciados teleológicos no pueden ser contrastados empíricamente.

4. La teleología no está más que en la mente del observador. (Diéguez 2012, 175-176)

Sin embargo, pueden mantenerse explicaciones teleológicas sin recurrir a un agente externo o a causas finales. Además, como infiere Michael Ruse (1973, 213), "la biología tiene, en un sentido más amplio, un elemento teleológico intraducible (aunque quizá eliminable). De manera muy real, los biólogos alcanzan una intelección explicativa refiriéndose al futuro". Ruse se refiere a un finalismo sin causas finales, a una "teleología poco sólida", lo que supone abrir los ojos ante los diferentes modos de teleología.

Se argumentará, que el paso hacia un transformismo "científico" (sin suponer fuerzas especulativas) y hacia un nuevo concepto de especie en el siglo XIX implicó el paso de una teleología interna (pre)determinada a una indeterminada, es decir, de una finalidad en la que el estado final está predeterminado sin importar los eventos circunstanciales e históricos a otra en la que el estado final no está prefijado. En relación con esto, también se puede distinguir entre teleología intra-orgánica, propia de cada organismo en sí mismo "causalmente dirigida a la consecución de un objetivo predeterminado", y teleología adaptativa, esto es, la de un individuo para con su entorno (Caponi 2002, 59) ${ }^{2}$. Caponi toma la diferenciación de von Uexkull: "en los seres vivos adultos distinguimos una doble conformidad a fin: de un lado, cada organismo está construido conforme a un fin en sí mismo, y del otro, el organismo está adaptado conforme a fin a su entorno" (von Uexkull 1945, 175). El paso continuo al segundo tipo de teleología a partir del siglo XVIII allanará el camino a un transformismo y a un evolucionismo en el que las causas principales del cambio no sean impulsos teleológicos internos de los organismos o un telos externo predeterminado, lo que tendrá consecuencias radicales para el concepto de especie.

\footnotetext{
${ }^{2}$ Caponi utiliza esta dicotomía en referencia a la distinción de Ernst Mayr entre biología funcional y evolutiva. Espero que se me permita usar esta dicotomía para los fines expuestos.
} 
Lamarck no fue capaz de desarrollar una teoría transformista sin renunciar a la teleología fuerte o "sólida", pero la apertura al adaptacionismo que él llevo a cabo implicaba el primer reconocimiento de que los factores circunstanciales cumplían un papel en la evolución. Y es que parece inviable abrazar el transformismo sin otorgar al entorno algún rol en la causación y motivación de dichas transformaciones - a no ser que se establezca la intervención divina como fuente de una mutabilidad que armoniza las formas de los seres con sus entornos concretos-. Con esto no se quiere decir que el cambio hacia la teleología adaptativa sea un paso previo para impulsar el salto al transformismo, sino que son dos aspectos que se dan conjuntamente.

Mostrar esta imbricada unión entre teleología y todo lo que abarca el concepto de especie - el realismo y antirrealismo, el fijismo y transformismo, los principios sobre los que se sostiene, etc. - hasta Darwin será la tarea del presente texto. Para ello, haciendo honor a De Aristóteles a Darwin (y vuelta) de Etienne Gilson, se irá desde el autor griego al biólogo inglés, pasando principalmente por las figuras de Linneo, Buffon y Lamarck.

\section{La biofilosofía de Aristóteles: eidos, finalidad y realismo moderado}

La discusión acerca del concepto de especie en Aristóteles $^{3}$ ha sido ampliamente debatida. Fue a partir del artículo de David Balme (1962) que se llegó a cierto consenso acerca de la flexibilidad de los conceptos de género y especie. De acuerdo con Marjorie Grene (1974), el uso de los términos 'genos' y 'eidos' es, en cierto sentido, caótico, ligado al lenguaje común y cotidiano (Jiménez Sánchez-Escariche 2000, 15). Tampoco había en Aristóteles un proyecto complejo de ordenación taxonómica universal (Pellegrin 1987). Sus diferentes clasificaciones dependían, más bien, del objeto de estudio (morfología, fisiología, etc.). Cierto es que, en cuanto a ordenación lógico-sistemática, genos está por encima de eidos (cf. Aristóteles 2000, IA I, 486a24-26), y esto es algo que parece corresponderse con la actual relación entre las categorías de género y especie, que se instaló con facilidad en las ciencias naturales gracias a las ventajas que conllevaba para los fines clasificatorios (Jahn et al. 1990; Barberá 1994).

Esto no significa que se haya alcanzado algún tipo de acuerdo más allá de lo anteriormente expuesto, sobre todo en lo relativo a las consecuencias filosóficas y ontológicas de su propuesta. Lo que sí parece evidente es que Aristóteles utiliza el concepto de eidos en sus tratados biológicos fundamentalmente como forma (Balm, 1962), para designar un conjunto de rasgos característicos y comunes, esto es, esenciales (Barberá 1994). Y este esencialismo va unido irremediablemente a su fijismo, pues este eidos no es más que la posibilidad de eternidad que le es arrebatada a los individuos con la imposición de la vejez y la muerte (Papavero et al. 1995, 128). Como explica el estagirita, "la idea

\footnotetext{
${ }^{3}$ Abreviatras: $\mathrm{PA}=$ Partes de los animales; $\mathrm{DA}=\mathrm{Acerca}$ del Alma; IA=Investigación de los animales; Met= Metafísica.
}

Revista de Humanidades de Valparaíso, 2019, No 14, 395-426 
creadora preexiste a su producto y es igual que él" (Aristóteles 2000, PA I, 640a29-30), luego, a través de la reproducción, los progenitores generan individuos esencialmente iguales, de tal manera que aquellas características formales se mantienen de generación en generación. Entre especies hay, por tanto, un muro antitransformista: la esterilidad. La mezcla de especies no parecía posible, y de las pocas excepciones resultaban seres "inferiores" y estériles.

No resulta extraño que esta idea fijista se mantuviera con fuerza hasta el siglo XIX, pues encaja a la perfección con el dogma cristiano de la creación perfecta, acabada e inmutable de la obra divina (Papavero et al. 1995, 129). De este modo, autores como Andrea Cesalpino en el siglo XVI o William Harvey (1651) recurrían a la noción aristotélica de traspaso de la forma o esencia de padres a hijos en el proceso de reproducción. Esta idea de una esencia transgeneracional o "concepción generativa de la especie" postula que hay un "poder generativo compartido" que define a la especie y determina al individuo (Wilkins 2010). En la filosofía aristotélica, esta esencia puede identificarse con el alma, como aquello que es propio y germen de la vida. El alma es forma, acto, entelequia (Aristóteles 2010, DA II, I, 412a10). El alma es esencia y definición de los seres naturales, es su telos. Es fácil apreciar, dicho esto, que el fijismo es inherente a tal doctrina, pues si el alma define a un ser vivo y es traspasada por el padre a través del semen, no cabe más que las especies sean inmutables.

Aún así, Aristóteles llega a una preconcepción de la adaptación, que se muestra en la relación que establece entre la funcionalidad de un órgano y la estructura y existencia de este. Así, en Acerca del alma infiere que, puesto que "la Naturaleza no hace nada en vano" (Aristóteles 2010, DA III, 12, 434a31), los animales, además del sentido del tacto necesario para sobrevivir, tienen los diferentes sentidos y órganos en dependencia de su función y utilidad en un entorno indicado (Aristóteles 2010, DA, 12, 434b). He aquí la belleza de la naturaleza, el acoplamiento de cada ser y parte a su finalidad, pues "en las obras de la naturaleza, en efecto, no existe el azar, sino el para qué de algo" (Aristóteles 2000, PA I, 654a24-25). Mas esta belleza no parece sensible, sino inteligible, admirable a través del poder de la contemplación racional. La influencia platónica queda patente, como bien explica Geoffrey Lloyd (1974), pues la ordenación de los seres y la pluralidad de estos están orientadas a un fin que es dado por naturaleza y que, por tanto, confluye con la Belleza y el Bien presentes en los procesos naturales. Es, por ello, que no se puede entender el concepto de especie sin percatarse de que ese eidos definitorio estipula un orden y atribuye un sentido natural.

En suma, hay dos características principales en el concepto de especie aristotélico: el fijismo y la sumisión de la causa eficiente sobre la final. Sirva de ejemplo el siguiente párrafo en cuanto a su conjugación:

Por eso Empédocles no tenía razón al decir que muchas características se dan en los animales por haberse producido durante el proceso de formación, [...]. Desconoce, en 
primer lugar, que el germen constituyente debe existir ya con tal potencialidad; luego, que lo que produce existe con anterioridad no sólo lógicamente, sino también temporalmente: así el hombre engendra un hombre, de modo que, al tener tales características aquél, el proceso de formación de este otro se produce de tal manera. (Aristóteles 2000, PA I, 640a20-27)

Este párrafo expresa con fuerza cómo cualquier proceso animal tiene su razón de ser en la esencia que define a la especie. Los procesos biológicos se dan para realizar la esencia prefijada e innata. Fin, logos, alma, esencia y causa final parecen identificarse aquí. Esto quiere decir que, si la esencia pasa de padre a hijo, también el propio telos y, por lo tanto, cualquier proceso natural ha de ser el mismo en cada generación. Se puede apreciar, por ende, que finalismo y fijismo son interdependientes en la biofilosofía aristotélica.

Por último, la oscuridad escenificada en la obra aristotélica respecto al uso en su teoría biológica de los términos 'genos' y 'eidos' converge con una cierta ambigüedad acerca del conocido problema de los universales. En ocasiones resulta difícil conjugar su esencialismo con su crítica al realismo radical de Platón acerca de los universales. El universal no puede ser sustancia o entidad, dice Aristóteles (cf. Aristóteles 2010, Met Z, 13). El universal es "común", es decir, pertenece a una pluralidad de cosas (cf. Aristóteles 2010, Met Z, 13, $1038 \mathrm{~b} 8$ y ss.), pero se encuentra in re y depende, por tanto, de los individuos particulares. No hay dos individuos iguales por más que existan las esencias.

Muchos son los que consideran la postura de Aristóteles como un realismo moderado. En verdad, el filósofo griego quiere huir de la teoría de las Ideas platónica, donde se da un salto injustificable de lo epistemológico a lo ontológico al considerar lo universales como preexistentes a los objetos particulares porque se accede a los primeros a través de la ciencia y de la razón, mientras que los segundos quedan relegados a la percepción sensible. A pesar de que para Aristóteles el conocimiento humano es siempre de lo universal, no da un salto afirmando un estatus ontológico supremo para los universales al modo que lo hace Platón. Los universales existen en la medida que son "expresión sustancial" de los individuos (Boecio 2010, Segundo Comentario a la Isagoge 1.11.14), pero sin individuos particulares no podrían existir.

A modo de resumen, se puede concluir lo siguiente: 1) el uso no actual y estricto de los términos 'genos' y 'eidos' por parte de Aristóteles; 2) el fuerte finalismo de su biofilosofía es indesligable de su fijismo y 3 ) detrás de esta teoría finalista hay un realismo moderado esencialista respecto a las especies.

\section{La era de la taxonomía: Linneo y Buffon}

Tras una Edad Media en la que el pensamiento biofilosófico quedó relegado a un segundo plano, la Edad Moderna y la Ilustración abrieron paso a un creciente interés naturalista y trabajo clasificatorio, a lo que contribuyó la riqueza natural del nuevo 
continente descubierto. Sí hubo, sin embargo, en el ámbito filosófico, un fuerte debate medieval acerca de la naturaleza de los universales que resulta, cuanto menos, de interés adyacente a la noción de especie. La definición de universal propuesta por Aristóteles como lo común a una multiplicidad fue tomada de forma indirecta por Severino Boecio a través de Porfirio (cf. Boecio 2010, Segundo comentario a la 'Isagoge' de Porfirio, 1.10.13). Las apreciaciones de Boecio tuvieron gran influencia a lo largo de la Edad Media. Para este, los universales no existen realmente en el mundo, pero tampoco son meras abstracciones mentales (Espinal 2011, 381).

Es interesante señalar para después analizar las posturas de Linneo y Buffon en torno a la realidad ontológica de las especies que, frente a los diferentes realismos, surgió una posición nueva: el nominalismo. Fue Roscelino quien inauguró esta corriente que toma los universales por flatus vocis, por convenciones lingüísticas que reúnen lo común de entes individuales pero que carecen de existencia ontológica. Sin embargo, la perspectiva nominalista vio su consolidación en el antirrealismo de Pedro Abelardo, que en esta discusión medieval moderó la postura radical de Roscelino. Los universales dejan de ser meras voces para adquirir un sentido lingüístico-semántico con Abelardo: los universales tienen sentido en un leguaje compartido (García-Encinas 2005, 181).

Ahora bien, ¿existe algún reflejo de estas reflexiones en los naturalistas del siglo XVIII? El análisis de los universales sirve para conectar con el pensamiento de Linneo y Buffon acerca de la realidad y naturaleza de las especies, lo cual quedará reflejado en los siguientes párrafos.

Linneo dominó el panorama de la biología durante su siglo por ser un "trabajador incansable" que tenía muy en cuenta las necesidades de la ciencia de su época (Blunt 1982, 11). Como un segundo Adán ${ }^{4}$ (Harrison 2009), se otorgó la tarea de nombrar a los seres vivos. La analogía resulta oportuna por el gran sentido religioso patente en la obra del autor sueco, donde ciencia y teología natural diluyen sus fronteras. Esto es algo observable ya en la primera tabla de su Systema Naturae. Allí, en Observaciones sobre los tres reinos de la naturaleza parece afirmar que el Creador ha dotado al hombre de sensibilidad e intelecto para admirar la majestuosa obra natural:

Thus I wonder why the Creator put man, who is thus provided with senses and intellect, on the earth globe, where nothing met his senses but natural objects, constructed by means of such an admirable and amazing mechanism. Surely for no other reason than that the observer of the wonderful work might admire and praise its Maker. (Linneo 1964, 18)

Sin embargo, esta admiración intelectual requiere de tiempo y necesita del clasificador y descriptor para poder darse de forma efectiva. Al identificar la naturaleza con la obra de Dios le da una finalidad — ser admirada - y un sentido al ser humano: adorarla y

\footnotetext{
${ }^{4}$ Acusación de Johann Stöver en una carta de 1746.
} 
desentrañar los mecanismos de esta (Gilson 1980, 87). Pero, más allá de esto, parte de la asunción de que todos los seres naturales son "obra de Dios" y que todos provienen de un huevo de donde surge una cría semejante al padre. Esto concluía en su postura fijista con claro eco aristotélico:

As there are no new species (1); as like always gives birth to like (2); as one in each species was at the beginning of the progeny (3), it is necessary to attribute this progenitorial unity to some Omnipotent and Omniscient Being, namely God, whose work is called Creation. This is confirmed by the mechanism, the laws, principles, constitutions and sensations in every living individual. (Linneo 1964, 18)

En el párrafo anterior no solo se afirma que las especies se mantienen debido a que cada ser produce uno similar, sino que también se alude a la especie como unidad que gobierna el orden. Esto último le adhiere al realismo y a la concepción generativa de la especie. Las especies son inamovibles, clases naturales —al menos para el primer Linneo ${ }^{5}$ y "la generación supone la continuidad de las formas" y, por tanto, la discontinuidad entre especies (Álvarez López 1948, 15). Las clases naturales tienen como principal característica la perpetuidad de sus propiedades (Ruse 1987, 229). Por ello, la especie será también la unidad taxonómica de Linneo, y su inmutabilidad es un axioma necesario para cualquier clasificación. Y la clasificación era imprescindible, a su vez, porque todo verdadero conocimiento natural dependía de conocer las especies (Larson 1971).

El fijismo de Linneo ya es evidente en su obra temprana: en Genera Plantarum (1737) ya se refleja algo muy parecido a su famosa sentencia "Species tot sunt, quot diversas formas ab initio produxit Infinitium Ens" (Linneo 1780). La suposición de un creador intencional daba irremediablemente un carácter (pre)determinado a la teleología de Linneo. Las especies, generadas por obra divina, tienen como fin el que Dios les haya impuesto.

El éxito de la clasificación linneana tiene, también, motivos circunstanciales. Su oportunismo es innegable, "pues desde el Renacimiento se habían reunido tantas plantas europeas y extraeuropeas que ya se hacía indispensable alguna guía que permitiera ordenarlas" (Papp y Babini 1958, 77). Como bien señala Ernst Mayr, "las clasificaciones son necesarias dondequiera que uno tenga que lidiar con la diversidad" (Mayr 2000, 147, traducción propia), y esa diversidad se hizo demasiado grande con la recolección natural en los nuevos mundos. Pero este afán taxonómico no era compartido por todos sus coetáneos. Linneo, fiel expresión del realismo y un sistemático obsesivo, tiene su antagonista en Buffon, un antirrealista convencionalista y asistemático (Diéguez 2012,

\footnotetext{
${ }^{5}$ El esencialismo de Linneo se va diluyendo con el paso de los años. Ya en 1755, en su Metamorphosis plantarum, duda acerca de la inmovilidad de las especies. Se abre, así, un período de conflicto entre su fe creacionista y sus observaciones, que descartaban el fijismo.

6 "Hay tantas especies como formas distintas creó inicialmente el Ser Infinito” (traducción propia).
} 
210). Buffon, cansado de ver cómo el lenguaje de la ciencia se hacía más difícil que la propia ciencia, afirmaba que no existen más que los individuos y que las clasificaciones no son más que categorizaciones humanas que introducen a la fuerza el mundo vivo en cajones demasiado estrechos. En un arrebato nominalista declaraba: “¡Sólo un montón de nombres, nada más!" (Papp y Babbini 1958, 118). Tal enemistad era manifiesta: "Buffon detestaba las clasificaciones, los clasificadores y, más que a ningún otro a Linneo" (Gilson 1980, 90).

De forma contraria a Linneo, Buffon se vio incapaz de afirmar la discontinuidad entre especies, pues estas no están delimitadas de forma precisa, existen cantidad de eslabones intermedios que no permiten dividir concisa y tajantemente a las diferentes especies:

Pero la naturaleza opera por gradaciones desconocidas, y, por consiguiente, no puede prestarse totalmente a estas divisiones, ya que pasa de una especie a otra especie, y con frecuencia de un género a otro, por matices imperceptibles; de modo que existe un gran número de especies medias y de objetos semipartidos que no se sabe dónde colocar, y que, necesariamente, perturban el proyecto de un sistema general. (Buffon 1884, 370, traducción propia)

Es algo palmario, para Buffon, que los órdenes y los géneros son instrumentos artificiales y propios de la imaginación humana, rara vez útiles. Linneo no conocía la verdadera naturaleza de las especies y, por tanto, acudía a definiciones dogmáticas para realizar su sistema, consideraba el autor francés (Perrier 2009, 47). Sin embargo, también es cierto que había cierta oscilación respecto a su postura acerca del concepto de especie. El problema de los universales no fue algo cerrado en la mente de Buffon. Era incapaz de afirmar la realidad ontológica de las especies, pero tampoco podía prescindir de ellas. Buffon tuvo que quedarse a medio camino y, a la vez que afirmaba que las especies no existen, tenía que asumir que "ningún individuo existe fuera de una especie" (Gilson 1980, 94).

Por otro lado, sin llegar a dar jamás el paso transformista que daría Lamarck, Buffon asumió la variabilidad provocada generalmente por las circunstancias climáticas y alimenticias. Abre, así, el camino a la teleología adaptativa quedándose al inicio de este. Sin embargo, este cambio cualitativo no interrumpía el prototipo permanente de la especie. En otras palabras, afirma el transformismo, pero interno a las propias especies.

Buffon caminaba entre lo clásico y lo innovador. Por un lado, la idea de la scala naturae ronda toda su obra, y aunque ha sido un común denominador desde Aristóteles, en el francés adquiere una importancia muy notable. En el escalafón más alto estarían los hombres, que son cualitativamente diferentes de los animales: "el hombre no es un simple animal, como su naturaleza es superior a la de los animales, tenemos que trabajar para demostrar la causa de esta superioridad" (Buffon 1749-1788, tomo IV, 5) (traducción propia). Ahora bien, lo original de su escala natural es que presupone la continuidad: "no 
hay delimitación clara entre animales y plantas", solo entre seres vivos y no vivos (Alsina 2013, 78). Buffon tiene ya en mente el transformismo, pero reniega de ello obnubilado por la semejanza estructural y vital del mundo animal. Así, el asno no sería más que la degeneración del caballo.

Además de esto, Buffon, en su volumen V de la Historia Natural pone en cuestión que la naturaleza opere a través de causas finales, pues ofrece órganos sin ninguna utilidad (sirva de ejemplo los dedos de los cerdos o las tetillas de los machos), lo cual refuta aquel gran principio aristotélico que afirma la utilidad de todos los órganos. Otra de las razones para no confiar en el finalismo es que la naturaleza no parece hacer siempre lo más conveniente y funcional (Caponi 2012, 45). Caponi recoge un pasaje maravilloso donde Buffon muestra su antirrealismo, esta vez, hacia la causa final:

Todo aquello que no se daña a sí mismo al punto de destruirse, todo aquello que puede subsistir conjuntamente, subsiste; y puede ser que, en la mayoría de los seres, haya menos partes relativas, útiles o necesarias, que partes indiferentes, inútiles o superabundantes. Pero como siempre queremos reportar todo a un fin, cuando las partes no tienen usos aparentes, les atribuimos usos escondidos, imaginamos relaciones que no tienen ningún fundamento, que no existen en la naturaleza de las cosas, y que sólo sirven para oscurecerla: no percibimos que alteramos la filosofía, que desnaturalizamos su objeto, que es conocer el cómo de las cosas, la manera de actuar de la naturaleza; y substituimos ese objeto real por una idea vana procurando adivinar el porqué de los hechos, el fin que ella se propone al actuar. (como se cita en Caponi 2012, 46)

Esto no solo arremetía contra el funcionalismo de las partes, sino que también atacaba otro principio aristotélico ya mencionado supra, a saber, el de la naturaleza no hace nada en vano. En concreto, está refutando aquella noción de ser organizado, que Kant (2011, $\S 66)$ afirma en su Crítica del Juicio y Georges Cuvier consolida con su Principio de la correlación de las partes en los seres organizados: "todas sus partes [de todo cuerpo organizado] tienen una acción recíproca que las une por encima de todas las demás y contribuye a un fin común, que es el mantenimiento de la vida" (Cuvier 1798, 5) (traducción propia). Como se puede apreciar, es difícil separar tal principio de una cierta concepción finalista, pues muestra una imagen del individuo como absolutamente dependiente de una estructura esencial de la especie en la que ya están impresas las funciones y fines de cada parte del organismo, el cual actúa como un todo gracias a tal equilibrio sistémico.

Esta lucha entre antirrealismo y realismo continuaría durante las siguientes décadas. El finalismo, por su parte, seguirá acompañando al concepto de especie. Lejos de morir con el mecanicismo, la teleología va adquiriendo nuevas formas, se adapta a las diferentes teorías, se sofistica con las diferentes observaciones. Al incluir el factor externo o ambiental como una de las causas del estado actual de las especies, el finalismo adquirirá un carácter más circunstancial. En la biología aristotélica los fines son fijos, un órgano cumple una función y es así siempre por naturaleza. Por esta razón, las especies han de ser inmutables. 
Sin embargo, el transformismo y la aceptación del influjo del entorno necesariamente socavan la invariabilidad de los fines. La relación del medio ambiente con la modificación del individuo será esencial, por tanto, para el origen del transformismo, pero también para un finalismo no predeterminado desde el comienzo, para un finalismo no fijo.

\section{Un evolucionismo finalista: las ideas de Lamarck}

Durante la primera mitad del siglo XX, fijismo y transformismo tuvieron en Cuvier, Saint-Hilaire y Lamarck una de sus mayores disputas. El transformismo evolucionista de este último resultaba algo rompedor, tanto que fue condenado a la desatención de sus coetáneos. A pesar de que Lamarck contaba con un cierto número de predecesores evolucionistas, él fue el primero en conformar esas ideas en una teoría estructurada. Ya Anaximandro estaba convencido del origen marino de toda la fauna y de cómo a partir de estos animales acuáticos evolucionaron el resto, incluido el hombre (Mayr 2000, 301302). Sin embargo, como nota curiosa, las ideas más parecidas a las de Lamarck aparecen en Zoonomia or Laws of Organic Life de Erasmus Darwin ${ }^{7}$ (1794), abuelo de Charles, aunque no se tiene constancia de que el francés conociera tal obra.

Aunque hay una serie obvia de antecesores, las ideas de Lamarck probablemente provengan de sus observaciones y trabajos como clasificador (Lamarck fue fijista hasta 1794). Precisamente, fue este ámbito el que más reconocimiento le otorgó, pero no mostró dubitaciones a la hora de afirmar su postura antirrealista respecto a las especies y demás categorías, cuya función pragmática, eso sí, es indudable:

Nada ha hecho la Naturaleza semejante, y para no engañarnos confundiendo nuestras obras con las suyas, debemos reconocer que las clases, los órdenes, las familias, los géneros, las nomenclaturas respecto de ella constituyen medios de nuestra invención, de los cuales no podríamos prescindir, pero que es forzoso emplear con discreción. [...] Pero tales clasificaciones [...] son medios artificiales en absoluto. [...] la Naturaleza no ha formado realmente ni clases, ni órdenes, ni especies constantes, sino solo individuos que se suceden los unos a los otros y que se asemejan a los que los han producido. (Lamarck 1986, 27-28)

Lamarck asevera que existe un mismo orden, indivisible, continuo, sin saltos. Esto se puede apreciar, según él, a través de uno de sus métodos principales: la analogía entre los diferentes individuos, que muestra cuán borrosas son las líneas divisorias de las clasificaciones (Lamarck 1986, 29). Esta noción continuista encaja a la perfección con un transformismo radical; aquel que Buffon no se atrevió a aceptar. El principio de la

\footnotetext{
${ }^{7}$ Para un mayor acercamiento a la obra de Erasmus Darwin y a sus tesis más importantes se recomienda la sección XXXIX de su Zoonomia disponible en https://archive.org/details/zoonomiaorlawsof1794darw. Para una aproximación al pensamiento de Erasmus Darwin sin pasar por su extensa obra, se recomienda la obra de Samuel Butler (1948), donde además se muestran las ideas de Erasmus en comparación con las de Buffon, Lamarck y su nieto Charles Darwin.
}

Revista de Humanidades de Valparaíso, 2019, No 14, 395-426 
continuidad progresiva, ya presente en la escala natural de Aristóteles, y la teoría de la evolución lamarckiana son algo inseparable, pero esta vez la escala dejó de tener forma lineal para adquirir forma de árbol con numerosas ramificaciones que culminan con el hombre (Lamarck 1986, 54). Esta continuidad tiene como núcleo central un principio que es común denominador en muchos transformistas - sobre todo en Spencer- ya presente en Aristóteles: lo simple es el origen de lo complejo. Sobre la génesis de lo simple, Lamarck acude a la generación espontánea como respuesta.

Ahora bien, más allá de la importancia que tiene no dar una respuesta teológica al origen de la vida, el punto central es discernir cómo es posible ese progreso de lo simple a lo complejo. Sin duda alguna, la respuesta del naturalista francés a esta cuestión revela un finalismo sin precedentes desde el estagirita. Existe una tendencia en lo vivo a la complejidad, una propensión de la naturaleza al perfeccionamiento. Pocas conclusiones pueden desvelar una teleología tal. Toda tendencia supone no solo un fin al que tender, sino un fin activo o causal que impele su búsqueda. Las fuerzas naturales y los impulsos de la materia viva son los principales promotores del cambio, pero, si estos fueran los únicos motores, la escala natural sería lineal. La razón por la que esta es ramificada se debe a las causas externas, es decir, circunstanciales, medioambientales. De esta forma, la modificación del entorno supone, en muchas ocasiones, un cambio en las necesidades de los seres vivos que viven en él. Esta modificación de las necesidades lleva irremediablemente a que los animales varíen sus hábitos. Si los nuevos hábitos implican, de forma prolongada, la utilización de un órgano o, por el contrario, una disminución del uso de otro, estos se verán alterados por tal situación. El uso de un órgano lo fortifica, lo impulsa para su desarrollo; el desuso todo lo contrario. Incluso, afirma que a través de estos "esfuerzos de la sensibilidad interior", pueden surgir órganos nuevos que antes no estaban, al igual que el desuso prolongado puede llevar a su desaparición. Estos cambios son heredables, tal que, tras muchas generaciones, los organismos están cada vez mejor adaptados a las nuevas circunstancias.

Lo verdaderamente importante de lo anterior es que en lugar de ser los órganos los que determinan las costumbres o hábitos de los seres vivos, son estos últimos, esto es, su forma de vida, la que, en relación con las circunstancias ambientales, ha determinado en un período extenso de tiempo la existencia o no de determinados órganos y, por tanto, las diferentes formas corporales. Nada de esencias fijas, nada de inmovilismo; el concepto de especie propio del fijismo no tiene sentido ante tales afirmaciones y, con ello, menos sentido tenía aún una postura realista acerca de la existencia de las categorías taxonómicas. La constancia de las especies parece tal ante la mirada limitada del ser humano, cuya historia no abarca lo suficiente para ser consciente de los cambios de la naturaleza. Pero incluso tomando a las especies de forma estática en su estado actual, la delimitación de estas es imperfecta e imposible a nivel completo. De esta forma, el concepto de especie que propone Lamarck —el cual solo tiene valor práctico, pero no 
ontológico - ha de añadir la cláusula circunstancial, es decir, los individuos se mantienen semejantes siempre y cuando las condiciones de vida no cambien tanto como para variar los hábitos de los individuos.

Se puede observar con claridad el carácter capital de las costumbres, que componen algo así como una segunda naturaleza (Gilson 1980, 106). En la teoría de Lamarck, tanto las necesidades como los hábitos tienen un carácter mediador entre la naturaleza y los individuos, entre el medio ambiente y los órganos que se relacionan con él. El cambio en el medio no provoca directamente el cambio de los organismos, sino nuevas necesidades a las que van asociados nuevos hábitos para satisfacerlas. Son estos nuevos hábitos los que implican un uso o desuso de determinados órganos o un esfuerzo para usarlos.

Ahora bien, más allá del principio teleológico que supone la dinámica natural hacia lo complejo, en esta interacción entre medio ambiente e individuos hay un finalismo que Gilson $(1980,107)$ se encargó de evidenciar: "como consecuencia inevitable, y sin embargo inesperada, el transformismo de Lamarck acaba en un derroche de finalismo. [...] los órganos nacen, crecen y se forman ellos mismos a fin de satisfacer las necesidades del organismo". Los órganos tienen su razón de ser en su finalidad, en su objetivo de solventar una necesidad. "Los pájaros no vuelan porque tengan alas, sino que tienen alas a fin de volar" (Gilson 1980, 112).

Llegados a este punto, es oportuno subrayar que, como se puede apreciar, para Lamarck existen dos fuerzas principales del cambio que se nutren de conceptos diferentes (cf. Gould 2002, 175-186). La primera de ellas tiene como base los conceptos de adaptación y entorno que se sustentan sobre un firme funcionalismo. La conformación de los organismos a los cambios del entorno supone una verdadera apertura al adaptacionismo. Sin embargo, en vista de que la historia ambiental no tiene dirección para el francés, necesitaba acudir a otra explicación para su arraigada tesis de la escala progresiva de seres. Si los entornos cambian sin fin alguno, la adaptación a estos no puede reflejar ningún tipo de cambio progresivo. De ahí la gran necesidad e incluso preminencia de la segunda fuerza, la tendencia a la ordenación compleja, sustentada sobre los conceptos de progreso, escala y jerarquía. Este es un caso paradigmático de teleología predeterminada e intraorgánica.

Ahora bien, aunque haya cierta prevalencia de la teleología predeterminada y la adaptación quede relegada a un segundo plano, no hay que restar importancia a la gran apertura hacia al adaptacionismo que Lamarck llevó a cabo. De hecho, el concepto de adaptación en el entramado teórico de Lamarck tuvo tanto peso en su creatividad teórica, como convincentemente argumentan Corsi (1988) y Gould (2000), que llegó a la noción de su mecanismo progresivo a partir de las ideas formuladas previamente sobre la adaptación. Y toda adaptación, en su caso, es difícilmente emancipada de una teleología.

Cabe preguntarse si la adaptación basada en este mecanismo del uso y desuso es de verdad semejante al concepto que se establece a partir del darwinismo. No cabe duda, que 
si se lee detalladamente la argumentación de Lamarck se encuentran claras diferencias con lo que Darwin entendía por adaptación. La explicación a las trasformaciones que propone Lamarck se produce como una respuesta a las circunstancias, aunque mediada por los hábitos. El hecho de que a través del uso o desuso se desarrolle o atrofie un órgano señala solamente que se ha utilizado o no o que se ha hecho o no el esfuerzo por hacerlo. Lamarck ofrece una explicación basada en un mecanismo de respuesta de los individuos ante la situación. En este aspecto parece, más bien, un "buffoniano radical" (Caponi 2006): el entorno simplemente cambia, "degenera", desvía a los seres al cambiar sus hábitos. Esto desvela, en definitiva, que, para Lamarck, el solo mecanismo a través del cual los seres se ven influidos por el medio no hubiera sido suficiente para llegar a la complejidad, verdadera meta de lo vivo.

En definitiva, en la obra de Lamarck hay una mezcla clara y contundente entre dos finalismos: uno necesario o determinado, dirigido a un fin, proveniente de una naturaleza que tiende a lo complejo desde sus orígenes; pero también uno más de corte adaptativo e indeterminado, que proviene de la interacción entre individuo y entorno y su preservación por la transmisión hereditaria. Este último sería no dirigido y es inherente a una postura transformista compleja. Sin embargo, la existencia del humano como cumbre de la escala natural y la gran diversidad de complejidad que encontramos en el mundo de lo vivo parece indicar que hay una cierta subordinación del segundo respecto al primero. De ahí que, aunque no sea linealmente, sino de forma ramificada, el plan de la naturaleza hacia lo complejo termina por cumplirse, sin que los cambios circunstanciales supongan un obstáculo definitivo para tal propósito. Por ende, ciertamente, la teleología adaptativa en Lamarck está subordinada a un fin predeterminado. No obstante, el naturalista francés realizó un paso crucial, a saber, vincular la adaptación con la transformación al poner la función como causa de la estructura. Así, la teleología adaptativa mostraba sus primeros brotes.

\section{Darwin, la teleología adaptativa y la caída del esencialismo}

En el presente apartado se intentará mostrar que es Darwin el que consigue dar el paso definitivo hacia una teleología adaptativa gracias al mecanismo de la selección natural. De esta forma, el concepto de especie tomó el desvío final hacia el transformismo y, también, hacia un cierto antirrealismo, al no haber clases naturales fijas que poder discernir. Sin embargo, en el apartado 6 se argumentará que, pese a este movimiento de Darwin, existen ciertos elementos de su teoría que todavía guardan un poso de finalismo predeterminado y que, además, provocarán inclinaciones realistas que entrarán en tensión con el antirrealismo en ocasiones promulgado.

A lo largo de la historia natural, las tesis adaptacionistas pre-darwinianas son verdaderamente escasas. Hasta el asentamiento de la doctrina darwinista, "cada ser vivo tenía una función a cumplir y no un lugar a conquistar y a defender" (Caponi 2006, 10).

Revista de Humanidades de Valparaíso, 2019, No 14, 395-426

(ㄷ)(1)(8) CC BY-NC-ND 
Realmente, antes de la irrupción del Origen de las especies (1859) y, sobre todo, hasta los años 40 del pasado siglo, el tema de la relación entre los rasgos morfológicos de los seres vivos y su medio no ocupaba un espacio privilegiado en la disciplina naturalista. Lejos de ser un tema digno de controversia, la relación entre las estructuras orgánicas y su entorno se tomó en sus inicios como prueba o evidencia empírica del plan divino. Así lo fue para John Ray, Linneo o William Paley. El mirífico orden de la naturaleza, la asombrosa economía animal y natural y la intricada conjugación de todos los elementos de los sistemas ecológicos era más fácilmente atribuible a un origen suprasensible y director que a uno inmanente y no intencional. Por otro lado, la verdadera meta de Lamarck, pese a la importante apertura que realizó, tampoco era el adaptacionismo, sino justificar su escala natural basada en la tendencia a lo complejo.

Escapar de esto fue la verdadera revolución de Darwin: desvincular la adaptación de cualquier designio, orientación o plan dirigido intencionalmente y dar un verdadero carácter útil a las adaptaciones. No hay una preordenación de la evolución, tampoco hay un sentido o dirección en ella, no va de lo simple a lo complejo, no cambia lo imperfecto por algo más perfecto. ¿Esto significa que Darwin dio con la fórmula para acabar con la teleología en biología? Cierto es que algunos vieron en Darwin al Newton de la brizna de hierba, un nuevo mesías mecanicista. Pero esto está lejos de cualquier pretensión que él tuviera. Prueba de ello es su asentimiento ${ }^{8}$ a aquella afirmación de Asa Gray (1874, 81): "let us recognise Darwin's great service to Natural Science in bringing back to it Teleology: so that instead of Morphology versus Teleology, we shall have Morphology wedded to Teleology". El trabajo de James Lennox (1993) demuestra a la perfección que Darwin no rehuyó de la finalidad, a pesar de que su teleología era particular, seguramente muy diferente de lo que entendía por ello el propio Asa Gray. La explicación darwiniana está lejos de cualquier teleología trivial. En consecuencia, es necesario hacer un análisis de algunos aspectos de su teoría para poder entender correctamente la teleología darwinista.

Hasta el darwinismo, la relación entre el ambiente y los seres no iba mucho más allá de la propuesta buffoniana de los efectos del clima y la alimentación (Caponi 2006). Más que adaptación, esto parecía revelar una aclimatación. El gran valor de Darwin fue su capacidad para explicar el transformismo a través de un mecanismo terrenal y coherente con sus observaciones. Uno de los rasgos principales y continuos en su teoría es su gradualismo: las diferentes características de los individuos obedecen a un proceso gradual. Este curso paulatino y continuo necesita de tres principios fundamentales (Lewotin 1982): variación, herencia y selección natural.

En su The Variations of Animals and Plants under Domestication, Darwin expresa de forma maravillosa que no existe relación alguna entre las variaciones generadas por las leyes de la naturaleza en los seres vivos (las cuales admite son fijas e inmutables) y

\footnotetext{
${ }^{8}$ La respuesta de Darwin a Asa Gray se puede consultar en el siguiente enlace: https://www.darwinproject. ac.uk/letter/DCP-LETT-9483.xml.
} 
la utilidad que estos pueden obtener de ellas en un entorno determinado. Es igual que si un constructor utiliza solamente piedras caídas por un precipicio sin ser estas cortadas y modificadas por el ser humano, es decir, su forma accidental depende únicamente de leyes naturales, como la ley de la gravedad o la erosión del viento. La utilidad que encuentra el constructor en dichas piedras nada tiene que ver con las leyes naturales que las han deformado (Darwin 1868, 263). Si se sigue con la analogía, el arquitecto encontrará algunas de esas piedras útiles para su construcción y otras las desechará por no tener las condiciones necesarias para la edificación que quiere realizar. Esto es lo que sucede con la selección natural, pero sin constructor que elija y compare. Por tanto, aunque las variaciones son requisito necesario para la adaptación, no son suficiente, puesto que no surgen con un objetivo. Por ello, es necesario un mecanismo que haga la criba, que permita a lo útil mantenerse. Este mecanismo es la selección natural.

Es de esta manera que aquellas variantes más aptas y, por lo tanto, con rasgos adaptativos, pasan de generación en generación y se extienden. La selección natural es el principal motor del cambio (aunque no el único) dentro de las especies —al ser el mecanismo gradual a través del cual unos rasgos triunfan sobre otros al triunfar los individuos que los portan - y la herencia es la forma en la que se mantienen. Es fácil apreciar, después de esto, que mientras Lamarck explicaba a través de la interacción entre el individuo y su entorno el surgimiento de los rasgos adaptativos, Darwin, a través de esa interacción, explica el triunfo y extensión de dichos rasgos, pero no el origen de las variedades como tal. Darwin afirmaba que las variaciones eran aleatorias, con lo cual quiere decir dos cosas: que su causa es desconocida y que no hay un finalismo detrás del surgimiento de las diferentes variedades, es decir, que no hay relación entre la génesis de las variaciones y las posibles utilidades que pueden tener en el entorno, a diferencia de la postura lamarckiana (Sober 2003; 2011). En definitiva, no media la necesidad entre el ambiente y el rasgo adaptativo. Las variaciones se dan sin responder a fin alguno. Darwin no pudo dar con la causa de tales variaciones, pero era algo totalmente observable que efectivamente se daban en las diferentes poblaciones. Y no solo eso, sino que, a través de la comparación, afirma, parece que son las mismas leyes las que obran en las variaciones más pequeñas y en las mayores diferencias (Darwin 1988, 213).

Aunque Darwin no podía explicar el motivo de dichas variaciones, sí podía justificar su heredabilidad (la selección artificial lo demostraba) y podía argumentar su implicación en la reproducción diferencial a través del principio de la selección natural:

[...] si las variaciones útiles a un ser orgánico ocurren alguna vez, los individuos caracterizados de este modo tendrán seguramente las mayores probabilidades de conservarse en la lucha por la vida, $y$, por el poderoso principio de la herencia, tenderán a producir descendientes con caracteres semejantes. A este principio de conservación o supervivencia de los más adecuados lo he llamado selección natural. (Darwin 1988, 179)

Revista de Humanidades de Valparaíso, 2019, No 14, 395-426 
La reproducción diferencial se da porque los rasgos adaptativos cumplen una función que permite a los individuos que los poseen tener una mejor posición en su interacción con el medio. La selección se produce sin seleccionador, las variaciones no responden a un fin. ¿Dónde está entonces la teleología? Algunos han respondido que su lenguaje (metafórico o no) implica tratar a la selección natural no tanto como el resultado del proceso anteriormente indicado, sino como una especie de causa o fuerza activa. Sin embargo, no es en este lenguaje metafórico - al menos en el sentido más importantedonde reside el componente teleológico de la explicación darwinista ${ }^{9}$. Darwin elimina la teleología predeterminada del principio de selección natural — no existe un fin que origine las variaciones, tampoco hay una causalidad retroactiva-, pero el hecho de que se mantengan unas y otras queden relegadas a la extinción solo puede ser explicado, como explicita Caponi (2003), bajo una estructura explicativa de problema-solución irreductible a una explicación "causal humeana". Por tanto, esta estrategia de explicación supone una cierta perspectiva teleológica, solo que indeterminada y adaptativa. Sin apelar a un designio ni a una causalidad retroactiva, la pregunta a responder y la respuesta explicativa que se da sigue estando bajo el yugo de las razones. Es decir, se intenta "explicar por qué algo pudo resultar un medio más adecuado que otro para la consecución de un determinado resultado y eso, aunque no lo queramos, no nos lleva al orden de las causas mecánicas sino que nos pone ante una provincia muy particular del orden de las razones" (Caponi 2003).

Como el propio Darwin admite, los rasgos de un individuo deben ser tomados como útiles en los especímenes, directa o indirectamente, o como útiles para alguno de sus ancestros. Esto parece ofrecernos una visión de la selección natural como un mecanismo resolutorio de problemas. Ante un entorno hostil, donde hay escasez de alimentos, depredadores, enfermedades, etc., se mantienen las mejores soluciones para los diferentes problemas. Es la escasez y la resolución para solventar sus consecuencias la que marca el destino de los individuos y no ningún determinismo físico. No se explica la causa de las variaciones, pero sí el porqué de su mantenimiento y extensión; y resulta que ese porqué es un para qué (Brandon 1990, 1996). La forma que tiene el biólogo de averiguar el porqué de un determinado rasgo es indagar en el para qué de este, qué función cumplía, para qué era útil. En toda adaptación no solo hay un qué o quién se adapta, sino también un respecto $a$ qué, y es esa unión entre lo adaptado y el entorno lo que requiere de una explicación teleológica. En definitiva, el hecho de que la estructura explicativa de las adaptaciones sea la de problema-solución (Caponi 2003) dota a tal explicación de un irremediable nexo teleológico entre las presiones selectivas y las estructuras más eficientes que se mantienen (nexo que, en cambio, no se podrá encontrar nunca con el origen de dichas estructuras).

\footnotetext{
${ }^{9}$ Para una defensa de que la teleología darwinista se expresa a través de la acudida metáfora del diseño véase Ruse (2000).
} 
Dicho esto, es oportuno recalcar que la explicación de las adaptaciones es una cuestión de elección entre las alternativas existentes:

[...] no se trata, entonces, de explicar cómo algo ocurre o actúa sino de mostrar por qué eso pudo ser mejor que otra cosa que se presentaba como alternativa. Es decir, no se trata simplemente de saber lo que algo hace, sino de saber en qué sentido lo hace mejor que alguna alternativa efectiva. La pregunta deja de ser simplemente ¿qué es lo que $\mathrm{X}$ hace? o, incluso, ¿para qué sirve X?; y, en lugar de ello, nos encontramos con una interrogación doble: ¿qué es lo que x hace mejor que z? y ¿en qué sentido lo hace mejor? (Caponi 2003, 1004)

Ahora bien, una alternativa sólo es más eficiente en relación con las demás. Por lo tanto, la selección natural solo puede llevar hacia la perfección local o relativa a las especies, es decir, en relación con el resto de las alternativas. Y con perfección Darwin se refiere a adaptación, a utilidad, siempre delimitada por el dominio de su entorno:

La selección natural tiende solo a hacer a cada ser orgánico tan perfecto como los otros habitantes de la misma comarca con los que entra en competencia, o un poco más perfecto que ellos. [...] La selección natural no producirá perfección absoluta [...] (Darwin 1988, 253)

Con esta relativización de la perfección, Darwin da el estoque definitivo a las leyes progresivas. Las especies más aptas solo lo son en la relación a su entorno y al resto de habitantes que lo ocupan. La adaptación no es prueba de la complejidad de los organismos. Se deshace del predeterminismo y también de la teleología intra-orgánica. No hay, en principio, un impulso finalista dentro del individuo. Esto suponía dejar, de una vez por todas, cualquier postura esencialista. No hay un eidos unitario e inmutable para cada especie ni un telos específico. Una vez se abre el paso definitivo al adaptacionismo, el esencialismo y el fijismo caen.

Las especies, incluso advirtiendo que son un artificio, difícilmente pueden ser delimitadas como ya decía Buffon. Darwin asumió la imposibilidad de diferenciar lo que son las variedades de lo que son las especies. "No es posible determinar la cantidad de diferencia necesaria para conceder a dos formas la categoría de especies" (Darwin 1988, 109-110). Este párrafo es fundamental para mostrar su antirrealismo:

Por estas observaciones se verá que considero la palabra especie como dada arbitrariamente, por razón de conveniencia, a un grupo de individuos muy semejantes y que no difiere esencialmente de la palabra variedad, que se da a formas menos precisas y más fluctuantes. A su vez, la palabra variedad, en comparación con meras diferencias individuales, se aplica también arbitrariamente por razón de conveniencia. (Darwin 1988, 104)

Revista de Humanidades de Valparaíso, 2019, No 14, 395-426 
Darwin creía oportuno abrazar ese convencionalismo, dar por combinaciones artificiales a las especies por poco atrayente que parezca. Asumir esto ayudará a quedar "libres de las infructuosas indagaciones tras la esencia indescubierta e indescubrible del término especie" (Darwin 1988, 569). Sin embargo, el que no haya una barrera nítida entre especie y variedad no implica que no existan las especies individuales (Sloan 2009). Tampoco existe una barrera nítida entre políticas de izquierdas y de derechas o entre ricos y pobres, pero eso no impide admitir que hay, efectivamente, ricos y pobres y políticas de izquierdas y de derechas (Sober 2011). Darwin, no podía definir o delimitar lo que era una especie, pero tampoco podía prescindir de ellas, su teorizar dependía de tal concepto, como se verá en el siguiente apartado.

Hasta ahora se ha señalado de manera general cómo la teoría de la selección natural implica un cierto punto de inflexión en lo que a la teleología en biología se refiere. También se ha subrayado brevemente qué consecuencias tiene esto para el concepto de especie. El debate acerca de si hay vestigios teleológicos y de qué tipo en la teoría darwinista ha sido rico y amplio, pero dónde enlazan la teleología y la noción de especie en dicha teoría no ha sido tratado en profundidad. Se viene argumentando desde el comienzo que las nociones de especie y finalidad no se pueden desligar fácilmente en la historia del pensamiento biofilosófico (al menos hasta Darwin). Y esa conexión en la teoría del naturalista inglés no obtiene su lado más fecundo del mecanismo de selección natural en sí mismo, sino en la conjunción de dos principios fundamentales para este: la lucha por la existencia y la superfecundidad. Por otro lado, hay otro punto fundamental donde se da dicho enlace, a saber, el principio de divergencia. Es más, Darwin necesitó acudir a una teleología determinada para desarrollar este último e intercambia el vocabulario típico del pensamiento poblacional — en el sentido que explica Mayr (1991) — por uno de corte tipológico. Por eso, el giro darwiniano, aun siendo radical, no es completo, no destruye de forma definitiva a la teleología, ni siquiera aquella que parecía enterrar. Esto es lo que se analizará en el siguiente apartado.

\section{Superfecundidad y divergencia: elementos teleológicos que necesitan un concepto realista de especie}

Como se ha venido indicando, Darwin hirió de muerte a la teleología predeterminada e intra-orgánica. Fue el causante principal del resurgimiento de aquel problema al que ya se enfrentó Kant en la segunda parte de la Crítica del Juicio: conciliar el mecanicismo triunfante en la física newtoniana con la ciencia natural de los organismos. Los organismos vivos, al ser entidades materiales, deberían poder ser explicados mediante leyes mecánicas, pero es inevitable acudir a explicaciones teleológicas, como si los organismos fueran "propósitos naturales" (Walsh 2006; Rosas 2008). Ambas soluciones no son compatibles, 
suponen una antinomia, pero es una tensión de difícil solución, a la que Kant no da una respuesta del todo satisfactoria y que, como se argumentará, Darwin tampoco terminó de cerrar.

En este apartado, se tratarán por separado dos cuestiones fundamentales: por un lado, se examinará cómo la premisa de superfecundidad es clave en la noción de lucha por la existencia y cómo esta implica un cierto posicionamiento teleológico al cumplir una labor semejante a una disposición natural. Por otro lado, se analizará cómo el principio de divergencia, que el propio Darwin consideraba como su aportación más importante junto a la selección natural, requiere de una teleología de corte determinista. Además de esto, se mostrará que nuestro naturalista acude a una noción de especie como fenómeno real y natural.

\subsection{Superfecundidad como premisa fundamental}

El uso de la idea de "selección natural" era relativamente común antes del empleo que se le dio en el Origen (cf. Zirkle 1941). Incluso el propio Darwin sabía de ella antes de lo que algunos han llamado el "descubrimiento malthusiano" de 1838. Hasta la teoría darwinista, la selección natural era un principio conservador, el mecanismo natural que se encargaba de eliminar las desviaciones, era la "policía de la naturaleza", el conjunto de procesos que permitía mantener el equilibrio en la economía de la naturaleza que ya promulgaba Linneo. El gran salto de Darwin fue hacer de este principio un proceso creativo. La selección natural dejaba de ser un procedimiento natural de extirpación de cualquier perturbación para convertirse en el motor principal del cambio evolutivo (cf. Gruber 1984).

Como ya se ha argumentado, para Darwin la selección natural no es la causa de las variaciones, sino que es un proceso de criba que permite a las variedades más aptas sobrevivir. Esto suponía desvincular de una vez por todas el origen de las variaciones de las adaptaciones. En su prematura teoría de las mónadas, Darwin seguía manteniendo el nexo entre la génesis de las variaciones y las adaptaciones, es decir, como en la teoría lamarckiana, creía que las variaciones son respuestas adaptativas. Si las variaciones fueran consecuencia de las presiones del entorno, entonces no sería necesaria ningún tipo de selección. En cambio, en la teoría de la selección natural ante la ausencia de un enlace causal entre el origen de la variación y la adaptación, lo que necesitaba era suponer un número alto de variaciones en la descendencia que le dieran a la selección natural el material necesario para trabajar. Volviendo a la metáfora del constructor, Darwin necesitaba suponer no solo un gran número de piedras con las que el constructor pueda trabajar, sino que estas tuvieran una gran diversidad de formas. Con otras palabras, necesitaba asumir un alto grado reproductivo de los seres vivos que implique importantes cifras de descendencia con gran diversidad de variaciones:

Revista de Humanidades de Valparaíso, 2019, No 14, 395-426

(ㄷ)(1)(8) CC BY-NC-ND 
La evolución de la biología y la biología evolucionista: especie y finalidad

Daniel Labrador Montero

Mientras la variación fue concebida como directamente adaptativa, únicamente podía existir una sola modificación apropiada para cada cambio en el medio. Solo después de haber descartado la idea de que las variaciones son necesariamente adaptativas se hacía necesario disponer de diferentes variaciones entre las que la selección debiera escoger. Pero cuando el número de variaciones requeridas por la teoría se hizo muy grande, el principio de la superfecundidad pasó a primer plano de atención. Deben existir muchos individuos que sirvan de «portadores» de las diferentes variaciones. Puede que la variación y la selección sean principios separados, pero ambos son aspectos de la misma realidad, un gran número de individuos que varían. (Gruber 1984, 218)

Estas dos premisas, a saber, la superfecundidad y la variabilidad, son fundamentales para la noción central de la selección natural: la lucha por la existencia. Mientras que Malthus había visto en la superfecundidad un peligro para la supervivencia de la especie humana, Darwin le dio un carácter positivo. Solo hay competencia si hay un número de individuos cuyo consumo de recursos excede la cantidad disponible de estos, y es precisamente la competencia la que provoca que solo los más aptos sobrevivan y se reproduzcan (selección), dándose así seres cada vez más adaptados a su medio. No se puede obviar que para el naturalista británico es la competencia intraespecífica la más severa y el principal impulsor selectivo, lo que le da todavía más importancia a la superfecundidad.

Hay quienes han visto en la lucha por la existencia un principio de corte claramente metafísico (Hernández-Pacheco 2014): lo vivo lucha por vivir. Hay que plantearse si es lícita la deducción de que "como se producen más individuos que los que pueden sobrevivir, tiene que haber en cada caso una lucha por la existencia", sobre todo, si tenemos en cuenta que "las causas que contienen la tendencia natural de cada especie al aumento son oscurísimas" (Darwin 1988, 115 y 117). La variación y la selección serían inocuas sin este afán de supervivencia, sin ese intento de imposición de lo individual. Esto querría decir que la vida no es resultado de la evolución, sino que es la causa (HernándezPacheco 2014, 75), es decir, no es la evolución la causa que permite la vida a través de la adaptación, sino que es la propia vida, esto es, el propio afán por vivir lo que pone en marcha a la evolución.

Sin embargo, entender la lucha por la existencia como imposición individual es desatender el carácter metafórico y amplio de tal noción especificado por el propio Darwin en el apartado 2 del tercer capítulo del Origin. Lejos de las guerras y hambrunas de Malthus, Darwin entiende la lucha por la existencia más bien como codependencia entre los diferentes organismos dentro de un "lugar en la economía de la naturaleza", y el resultado de dicha "pugna" es fundamentalmente la supervivencia reproductiva. Es decir, la lucha por la supervivencia "incluye no solo la vida del individuo, sino también el éxito al dejar descendencia", pues, al fin y al cabo, "todos y cada uno de los seres orgánicos puede decirse que están esforzándose hasta el extremo por aumentar en número" (Darwin 1988,113 y 117).

Revista de Humanidades de Valparaíso, 2019, No 14, 395-426

(ㄷ)(1)(8) CC BY-NC-ND 
He aquí, por tanto, el rol fundamental de la superfecundidad en la teoría darwinista: es una premisa indispensable y, además, una disposición natural de corte finalista. Esta premisa, en primer lugar, es de suma importancia porque la necesita para poder explicar los mecanismos selectivos basados en la competencia y, en segundo término, es una noción teleológica porque Darwin la toma como una orientación ineludible de todo ser vivo. Continuamente Darwin trata este principio como algo parecido a un fin impreso en todo organismo: "All that we can do is to keep steadily in mind that each organic being is striving to increase in a geometrical ratio" (Darwin 1859, 61). Su obra cumbre está plagada de pasajes en los que señala que los organismos se esfuerzan (strive), tienden (tend) o incluso luchan (struggle) por conseguir el mayor número de descendientes posibles. La misma forma de expresarlo utiliza en The Variation of Animals and Plants under Domestication (cf. Darwin 1868, 1-14) Dicho de otro modo, parece que Darwin considera que todos los individuos están determinados a reproducirse todo lo que puedan, y la forma en la que lo expresa y el papel que ocupa tal cuestión en su teoría va más allá de la tendencia a la replicación a la que acude el modelo genocéntrico dawkinsiano y la biología actual.

Darwin se había encontrado con la idea de "sobreproducción de descendencia" mucho antes de leer a Malthus, pero no fue consciente de su importancia teórica hasta que enlazó toda esta serie de conceptos. Por ejemplo, había leído sobre ella en los trabajos de C. G. Ehrenberg y la idea de la gran fertilidad de la naturaleza ya había sido expuesta por sus principales influencias: Erasmus Darwin, Paley, Lyell y Humboldt (cf. Gruber 1984, 216218). Por superfecundidad hay que entender "[...] el grado en que un organismo tiende a reproducir un número de individuos de su propio tipo mayor que el número vivo en cualquier generación parental dada" (Gruber 1984, 216).

Teniendo en cuenta todo lo dicho, en la lucha por la existencia darwiniana se tienen en cuenta tanto las adaptaciones individuales al entorno, por un lado, como la eficacia reproductiva, por el otro. Ahora bien, como se ha señalado, es el proclamado "esfuerzo" por reproducirse todo lo posible un elemento teórico indispensable para la tesis de la selección natural. Por esta razón, Darwin necesita asumir que la supervivencia y la existencia (y, por tanto, la lucha por ella) incluyen el éxito reproductivo (como él mismo señala en Darwin 1988, 113). ¿Cómo seguir afirmando solo a los individuos cuando parece que el mecanismo selectivo depende del afán de supervivencia a través de la reproducción? ¿Cómo explicar de forma mecanicista el impulso de lo vivo a la competencia para mantener la vida? Es necesario recordar en este punto que para Darwin la selección solo obra sobre los individuos, para el "beneficio" de los organismos. Pero, siendo estrictos, no hay razones para considerar como beneficioso para el individuo (y solía considerarlo así) el hecho de mantener sus características (hoy diríamos la promoción de sus genes) en su descendencia, a no ser que se suponga dicha finalidad como un impulso o una "tendencia" generadora de "esfuerzos" individuales. De no hacer tal suposición, se estaría dando el paso a considerar los beneficios del grupo como directos a la selección, cosa que Darwin 
no estaba dispuesto a hacer, aunque sí Wallace. Es decir, si Darwin no hubiera asumido la tesis de la superfecundidad como algo semejante a una disposición natural individual, habría algo más que una tensión entre el individualismo darwinista y dicha premisa. Sin embargo, sigue rezumando por detrás una noción realista de especie con consecuencias reales sobre el mundo, pues resulta difícil explicar dicha disposición sin entender, de alguna manera, que la especies existen.

Esta teleología basada en disposiciones naturales parece suponer una noción de especie difícilmente asumible por un antirrealista radical. Si lo de Aristóteles era un realismo moderado, se podría decir que lo de Darwin se asemeja a un antirrealismo con el mismo calificativo. Por otro lado, la teleología intra-orgánica no decae del todo con Darwin, pero esta vez aparece ocupando un papel central en la metafísica de la selección natural. Un principio metafísico que en definitiva depende del concepto de especie o, al menos, de variedad como subespecie, porque ese impulso hacia sobrevivirse a sí mismo a través de la progenie tiene como condición de posibilidad a la subespecie o a la especie. Hay que recordar que es el propio Darwin el que confirma que la lucha por la existencia incluye el dejar la mayor progenitura posible. Entonces, ¿cuál es la existencia que se pone en juego? Parece que no solamente la individual. La frase 'los más aptos dejan más descendencia' incluye el supuesto de que ser más apto implica reproducirse más, y dicho supuesto es alimentado por un concepto de supervivencia en el que se incluye la perduración de la variedad o, incluso, de la especie.

\subsection{El principio de divergencia y la maximización de la cantidad de vida}

En la teoría de Darwin hay otro principio fundamental además de la selección natural: el principio de divergencia, calificado como una piedra angular (keystone) de la teoría por el propio Darwin. Aunque tanto en El Origen como en el Species Book este principio se incluye dentro del capítulo que aborda la selección natural — pues, depende de este último - lo cierto es que la importancia que le confiere su autor es casi equiparable a la del otro gran principio, y así lo expresa en una carta a Joseph Hooker: "the "principle of Divergence,' which with 'Natural Selection' is the keystone of my Book \& I have very great confidence it is sound" (Burkhardt y Smith 1991, VII 102).

Dicho principio estaba destinado a explicar tanto la progresiva divergencia entre las variedades y especies como, también, la extinción de las especies emparentadas no exitosas. Respecto a lo primero, Darwin tenía que demostrar cómo se producen los procesos de especiación, de tal manera que las variedades poco diferenciadas (consideradas como especies incipientes) acaben dando lugar a especies bien diferenciadas. En otras palabras, tenía que explicar cómo variedades muy cercanas respecto a su tronco parental terminarían por dar lugar a especies situadas en ramas distantes en el árbol de la vida. Respecto a la extinción, debía dar con el mecanismo que explicara cómo el triunfo de dichas variedades implicaba la desaparición de las variedades y especies intermedias,

Revista de Humanidades de Valparaíso, 2019, No 14, 395-426

(). (18) CC BY-NC-ND 
así como de los antecesores. Esto conllevaba dar razón de por qué aquellos seres más divergentes, esto es, que más se alejaban de sus predecesores y del resto de variedades emparentadas tienen ventaja y más posibilidades de ser seleccionados.

Uno de los grandes escollos teóricos de Darwin fue dar con dicha razón, pues tenía que hallar el fundamento de la afirmación de que las variedades extremas tienen ventaja respecto a sus competidoras para ser seleccionadas. La respuesta que Darwin defendió es que las variedades extremas, esto es, las más diversificadas, son capaces de "apoderarse" de más cantidad y más diversos lugares en la economía de la naturaleza. O sea, que aquellos organismos más divergentes tendrían una mayor capacidad de hacerse con nuevos y diferentes nichos ecológicos (en el vocabulario actual). Sin embargo, esto abre otro abanico de preguntas de difícil respuesta: ¿por qué las variedades extremas tienen ventaja sobre aquellas con cambios más moderados a la hora de ocupar otros nichos? ¿Por qué si ocupan nuevos nichos se extinguen las variedades intermedias y los antecesores? Ninguna de las dos preguntas obtuvo una solución clara. En lo relativo a la primera, no se ofrece ningún motivo por el que ser mas divergente otorgue una mayor capacidad para ocupar otros nichos. Es más, como bien señala Richards $(2012,262)$, las características extremas suelen ser más bien perjudiciales en la lucha por la existencia. Hay que tener en cuenta que el hecho de ser divergente no tiene por qué conferir una mayor flexibilidad o plasticidad adaptativa. De hecho, esto sería más común en descendientes con modificaciones moderadas. En cuanto a la segunda cuestión, Darwin ofrece la resolución de que dichas variedades extremas mantienen los rasgos adaptativos de sus antecesores. Con esto vendría a decir que son igualmente competitivos que sus predecesores con el añadido de alguna característica valiosa nueva y que, por ello, son capaces de trasladarse de nicho, pero también de ocupar el lugar de sus predecesores provocando la extinción de estos. Sin embargo, resulta difícil explicar por qué si se ven favorecidos en los nichos nuevos iban a quedarse habitando y compitiendo en los ocupados por sus antecesores.

Por debajo de esta debilidad argumentativa se manifiesta cierta carga teleológica, principalmente respecto a la primera incógnita. Así, David Kohn (2009) intenta responder a la cuestión argumentando que Darwin propone una "selección divergente", es decir, una ampliación de la selección natural que implica que, bajo ciertas condiciones, se seleccionan las variantes más extremas. Ahora bien, ¿cómo puede afirmarse tal cosa? ¿Cómo la naturaleza iba a saber cuál es la variante más extrema? Hay que dar la razón a Richards (2012) cuando explica que esto es ir muy lejos y que la interpretación de Kohn de un principio selectivo especial solo tendría cabida bajo una naturaleza intencional y clarividente. En realidad, el verdadero núcleo del problema surge porque no se da una razón fundamentada de por qué la divergencia, cuanto más radical, es más ventajosa para ocupar nichos. Y esto se debe, como de nuevo Richards (2012) observa, a que Darwin en ocasiones abusa de la analogía con la selección artificial. No se puede obviar que, después 
de todo, la selección del criador está basada en actos intencionales y con finalidades marcadas. De esta manera, Darwin, convencido de la analogía, transporta la estructura argumentativa al principio de divergencia:

The breeder thus selects the most extreme traits and ultimately winds up with a morphologically very extreme individual. Darwin believed nature acted analogously: she chooses extreme traits at every iteration and finally produces a quite distinct species. The advantage realized would be a more secure hold on resources and greater numbers [...]. What seems to have escaped his reflective notice, however, was the salient difference between nature and the breeder: the pigeon fancier can detect extreme traits and carefully select out of his flock just those birds that display such traits and mate the individuals together. Nature, it would seem, cannot accomplish a comparable feat. (Richards 2012, 262-263)

Darwin había comprobado la idoneidad y eficacia de esta analogía respecto a otros aspectos. No obstante, en este caso se excedió. Mientras que a través de dicha analogía aún podía explicar cómo no era necesario un seleccionador ni un telos para que prevalezcan los individuos más aptos, no lo pudo conseguir para explicar cómo son seleccionadas las variedades más extremas. Ciertamente, una vez Darwin necesitó abrirse a la especiación simpátrica, el problema del swamping argument — posteriormente explicitado por Fleeming Jenkin, pero del que Darwin ya tenía cierta conciencia - tenía difícil remedio, es decir, resultaba muy complicado que una variación beneficiosa se extendiera y mantuviera en una población sin que se viera inundada con rasgos ordinarios e intermedios en pocas generaciones ${ }^{10}$. El hecho de que las variaciones de las especies incipientes pudieran verse invadidas por las modificaciones moderadas de variedades intermedias, o incluso desfavorables, iría en contra de la fuerte dinámica divergente que Darwin proponía y solo podría ser solventado tal inconveniente si la naturaleza es capaz de seleccionar las variantes extremas.

Llegados a este punto, Darwin no tuvo solo que acudir a cierto finalismo para solventar las dificultades teóricas del principio de divergencia, sino que también tuvo que dar irremediablemente a la especie la categoría de unidad descriptiva. Como explicitan Schweber (1980) y Gould (2002, 224-246), Darwin intercala con evidente incomodidad entre el individuo como unidad y la dupla variedad-especie. Esto es algo palmario cuando uno se enfrenta a las páginas que abordan el principio de divergencia. Efectivamente, Darwin no pudo mantener el nivel organísmico y explicar el principio de divergencia como una consecuencia directa de la selección natural entre individuos.

[...] his full argument demands a major contribution from species level selection (or, at the very least, strong attention to explicit sorting at the species level). I don't know that Darwin

\footnotetext{
${ }^{10}$ No hay que olvidar que no contaba con una teoría genética y, por tanto, quedaba lejos la genética de poblaciones que resolvería tal problema.
} 
La evolución de la biología y la biología evolucionista: especie y finalidad

Daniel Labrador Montero

ever grasped this need in a fully explicit way, committed as he was to the exclusivity of selection on organisms. But he recognized the crucial difficulty at several places in his exposition; and, with his usual honesty, he made his distress palpable again and again. (Gould 2002, 237)

Schweber $(1980,240)$, desde un punto de vista semejante, señala que hay una clara e inconsistente intercalación entre niveles de descripción. En la argumentación de este principio hay un continuo cambio sin enlace del pensamiento poblacional al tipológico al no haber una clara diferenciación entre lo que son las variedades intrapopupales y las subespecies geográficas. Darwin utiliza el mismo concepto de variedad en ambos sentidos de forma indiferenciada (Mayr 1992, 345). El nivel individualista se mantiene para los problemas relacionados con la lucha por la existencia y la adaptación (excepto por las observaciones anteriormente hechas), pero, al no contar con una teoría de la herencia, los problemas que englobaban cuestiones hereditarias y de variación, como son la divergencia y la especiación, necesitan del nivel descriptivo variedad-especie (Schweber 1980, 239240). Esto se puede apreciar claramente en las conclusiones que Darwin obtiene acerca de la variabilidad de los grandes géneros. Acudió incluso a las demostraciones matemáticas (cf. Browne 1980) para llegar a conclusiones tales como que los grandes géneros tienen un mayor número de variedades o que las especies actuales fueron variedades (en el sentido de subespecie) de especies anteriores. Y todo esto desvela un pensamiento en el que las categorías taxonómicas son una parte nuclear.

Una de sus grandes incoherencias — señalada por Gould $(2002,239)$ y derivada de este doble uso indiferenciado de variedad y del nexo entre los fenómenos adaptativos y de variabilidad - radica en intentar armonizar el argumento de la ventaja que obtienen los individuos con variaciones extremas con la idea de que el cálculo de dicha ventaja se obtiene de la cantidad de taxones descendientes. En otros términos, Darwin cayó en la incongruencia de defender que el cálculo del éxito individual era revelado a través del número de taxones descendientes que generaba. Es decir, el éxito de las variantes extremas implica para Darwin una capacidad para ocupar más nichos ecológicos y esto quedaría demostrado por su propagación en muchos y diferentes taxones. Sin embargo, resulta inconsistente tratar el éxito en la lucha individual haciendo referencia a categorías taxonómicas.

Todo este esfuerzo realizado por Darwin implica, como subraya Mayr $(1992,348)$, que, en cierta manera, considera a las especies un "fenómeno real de la naturaleza". No obstante, Darwin se mantiene invariable hacia la arbitrariedad entre las categorías de variedad y especie, sin que esto parezca ir en menoscabo de ciertas consecuencias realistas respecto a la existencia de las especies a lo largo de estas fundamentales páginas.

Ciertamente, y para ir cerrando esta cuestión, hay un principio rector que parece vincular de manera determinante la selección de las variantes extremas con el inevitable uso de las categorías taxonómicas: la maximización de la cantidad de vida en una región 
dada. Su compromiso acerca de las bondades de dicho principio revela, de nuevo, cierta teleología e incluso un orden moral. Gould $(2002,229)$ llega a calificarlo de "objetivo natural", como un principio metafísico que subraya la tendencia y la virtud de alcanzar la mayor cantidad de vida en un área determinado. Y esto solo es posible a través de la divergencia, a saber, ocupando los máximos nichos posibles disponibles en una región.

El origen de dicho compromiso con las bondades de la maximización radica, como explica Schweber (1980), en el cálculo de optimización de Bentham, muy extendido en aquella época. A fin de cuentas, los ecosistemas pueden funcionar con menos especies y sin tender al mayor rendimiento. La idea de la conveniencia de una mayor diversificación para que más habitantes sean soportados en una región geográfica al ocupar más y diferentes nichos ecológicos y al ser más eficientes en el consumo de recursos es del todo injustificada. Sin embargo, solo esta idea de optimización une realmente la adaptación con la especiación en la teoría darwinista. Es solo mediante este objetivo natural que se puede entender tomar como éxito individual el dar lugar al máximo número de taxones, pues esto implicaría la ocupación de más lugares en la economía de la naturaleza, acercándose así al objetivo de la maximización. He aquí cómo esta nueva forma de teleología tiene implicaciones sobre la noción de especie, a saber, sobre las virtudes de una mayor diversificación de las especies. A más diversidad y divergencia mejor optimización de los recursos, más nichos ocupados y maximización de la cantidad de vida. En otras palabras, la diversificación de las especies o la apertura a lo ancho del árbol de la vida ayuda a cumplir este "objetivo natural" de maximización de la vida. Por tanto, el finalismo en la argumentación de Darwin no radica solo en la tendencia a dejar el mayor número de descendientes (superfecundidad), sino en que estos sean muy diversificados y den lugar a taxones diferenciados que ocupen diferentes puestos en la economía de la naturaleza. La consecuencia implícita es que dicho finalismo requiere de una noción de especie con consecuencias reales (como fenómeno natural) sobre el mundo. Teleología y especie, aunque de forma mucho más sutil y compleja, siguieron siendo elementos teóricos codependientes en la teoría de Darwin.

\section{Conclusiones}

El propósito de este artículo era ver la progresión del concepto de especie ligado a las pautas teleológicas de las diferentes teorías de los máximos exponentes en el pensamiento biológico hasta Darwin, siendo este último el núcleo central de este artículo por suponer un punto de inflexión. La encrucijada final que se presenta en la teoría darwiniana se hace pensando solo en las tesis y lenguaje del propio Darwin y no en las teorías neodarwinistas. Huelga decir que en la biología actual tales dilemas no son los mismos.

En resumidas cuentas, se ha intentado mostrar que: 1) existe una codependencia histórica entre el concepto de especie y las diferentes perspectivas teleológicas. 2) El finalismo esencialista, determinado e intra-orgánico propio de la reflexión biológica hasta

Revista de Humanidades de Valparaíso, 2019, No 14, 395-426

()ㅇㅇㅛ CC BY-NC-ND 
el siglo XVIII requería de un concepto de especie fuertemente realista y fundado en el fijismo, mientras que el paso al transformismo científico y a una postura continuista entre las especies va de la mano de una apertura a la teleología adaptativa e indeterminada. 3) Darwin se deshace del esencialismo y la teleología determinada tal y como aparecía en sus antecesores naturalistas y en las teorías imperantes, pero no suprime la teleología del lenguaje, la estructura explicativa y la metafísica que sustenta su teoría. A tenor de lo anterior, además de cierta estructura explicativa teleológica (problema-solución), se pueden encontrar aspectos de la teoría con una carga teleológica que se escapa de este terreno. Así, la premisa de la superfecundidad adquiere el carácter de disposición natural y en el principio de divergencia se encuentran dos cuestiones que revelan un alto componente teleológico: la selección de las variantes más extremas y el principio de maximización de la cantidad de vida. 4) Existen ciertas tendencias antirrealistas respecto a las especies en la obra de Darwin al no afirmarse clases naturales, pero en determinados elementos de su teoría necesita acudir al nivel de variedad-especie como unidad descriptiva y a un concepto de especie con consecuencias reales en el mundo, es decir, como un verdadero fenómeno natural. Además, se da el caso de que los dos aspectos fundamentales de la teoría darwinista en los que se desvela una teleología de corte determinista — superfecundidad y principio de divergencia - son precisamente en los que la noción de especie adquiere sus tintes más realistas.

\section{Agradecimientos}

Este trabajo ha sido posible gracias a las ayudas de carácter público para la contratación predoctoral cofinanciadas por la Junta de Castilla y León y el Fondo Social Europeo.

\section{Referencias bibliográficas}

Alsina, J. (2013). Conceptos anteriores a la propuesta del término biología: Historia de los Animales de Buffon. Filosofia e História da Biologia, 8(1): 75-90.

Álvarez López, E. (1948). De la «Philosophia Botanica» de Linneo a algunos temas fundamentales de la biología. Anales del Jardín Botánico de Madrid, 8(1): 5-87.

Aristóteles (2000). Investigación sobre los animales. Madrid: Gredos.

Aristóteles (2000). Partes de los animales. Madrid: Gredos.

Aristóteles (2010). Acerca del alma. Madrid: Gredos.

Aristóteles (2010). Metafisica. Madrid: Gredos.

Bacon, F. (1984). Novum Organum. Aforismos sobre la interpretación de la naturaleza y el reino del hombre. Barcelona: Orbis. 
Balme, D. M. (1962). ГENO $\Sigma$ and EI $\triangle \mathrm{O} \Sigma$ in Aristotle's Biology. The Classical Quarterly, 12(1): 81-98.

Barberá, Ó. (1994). Historia del concepto de especie en biología. Enseñanza de Las Ciencias, 12(3): 417-430.

Blunt, W. (1982). El naturalista: vida, obra y viajes de Carl von Linné (1707-1778). Barcelona: Ediciones Serbla.

Boecio, S. (2010). Segundo comentario a la "Isagoge" de Porfirio. En A. Tursi (selec.), La cuestión de los universales en la Edad Media. Selección de textos de Porfirio, Boecio y Pedro Abelardo. Buenos Aires: Ediciones Winograd.

Brandon, R. (1990). Adaptation and environment. Princeton: Princeton University Press.

Brandon, R. (1996). Concepts and methods in evolutionary biology. Cambridge: Cambridge University Press.

Browne, J, (1980). Darwin's botanical arithmetic and the principle of divergence, 1854-1858. Journal of the History of Biology, 13(1): 53-89.

Buffon (1749-1788). L'Histoire Naturelle, générale et particulière, avec la description du Cabinet $d u$ Roi. Edición digital en francés a cargo de Thierry Hoquet y Pietro Corsi. Disponible en http://www.buffon.cnrs.fr/

Buffon (1884). Ouvres complétes de Buffon. Nouvelle édition. París: Librairie Abel Pilon, A. le Vasseur, Succ. Disponible en http://gallica.bnf.fr/ark:/12148/bpt6k62187908/

Burkhardt, F. y Smith, S. (eds.) (1991). The Correspondence of Charles Darwin. Cambridge: Cambridge University Press.

Butler, S. (1948). Evolution, Old \& New or the Theories of Buffon, Dr. Erasmus Darwin and Lamarck, as compared with that of Charles Darwin. New York: Cornell Universy Library.

Caponi, G. (2002). Explicación seleccional y explicación funcional: la teleología en la Biología contemporánea. Episteme: Filosofia E Historia Das Ciencias Em Revista, 14: 57-88.

Caponi, G. (2003). Darwin: entre Paley y Demócrito. História, Ciências, Saúde - Manguinhos, 10(3): 993-1023.

Caponi, G. (2006). El viviente y su medio: antes y después de Darwin. Scientia Agricola, 4(1): 9-43.

Caponi, G. (2012). Kant entre Buffon y Cuvier. Filosofia e História da Biologia, 7(1): 43-53.

Corsi, P. (1988). The Age of Lamarck: Evolutionary Theories in France, 1790-1830. Berkeley: University of California Press.

Cuvier, G. (1798). Tableau élémentaire de l'histoire naturelle des animaux. Disponible en http:// gallica.bnf.fr/ark:/12148/bpt6k64769551

Darwin, C. (1859). On the Origin of Species by Means of Natural Selection, or, The Preservation of Favoured Races in the Struggle for Life. London: John Murray. 
Darwin, C. (1868). The Variation of Animals and Plants under Domestication. $2^{\circ}$ Vol. New York: D. Appleton.

Darwin, C. (1988). El origen de las especies. Madrid: Espasa-Calpe.

Darwin, E. (1794). Zoonomia or Laws of organic Life. London: J. Johnson. Disponible en https:// archive.org/details/zoonomiaorlawsof1794darw

Diéguez, A. (2012). La vida bajo escrutinio. Una introducción a la filosofía de la biología. Barcelona: Intervención Cultural.

Espinal, J. (2011). Universales, individuos e individuación en la edad media. Escritos, 19(43): 371-400.

García-Encinas, M. J. (2005). La crítica de Abelardo a otros nominalismos. Revista Española de Filosofia Medieval, 12: 179-190.

Gilson, E. (1980). De Aristóteles a Darwin (y vuelta). Ensayo sobre algunas constantes de la biofilosofia. Pamplona: Eunsa.

Gould, S. J. (2000). A Tree Grows in Paris: Lamarck's division of Worms and Revision of Nature. En S. J. Gould, The Lying Stones of Marrakech: Penultimate Reflections in natural History, pp. 115-143. New York: Harmony Books.

Gould, S. J. (2002). The Structure of Evolutionary Theory. Cambridge, Massachussets y Londres: The Belknap Press of Harvard University Press.

Gray, A (1874). Charles Robert Darwin. Nature, 10(240): 79-81. Disponible en: https://www. nature.com/nature/journal/v10/n240/index.html

Grene, M. (1974). Is genus to species as matter to form? Aristotle and taxonomy. Synthese 28: 51-69.

Gruber, H. (1984). Darwin sobre el hombre. Un estudio psicológico de la creatividad cientifica. Madrid: Alianza.

Harrison, P. (2009). Linnaeus as a second Adam? Taxonomy and the religious vocation. Zygon, 44(4): 879-893.

Harvey, W. (1651). Exercitationes de generatione animalium. Disponible en: https://babel. hathitrust.org/cgi/pt?id=ucm.5325107039; view=1up;seq=13

Hernández-Pacheco, J. (2014). Evolución, erotismo y origen de las especies. De vuelta desde Darwin a Platón y Aristóteles. Naturaleza y Libertad. Revista de estudios interdisciplinarios, (4): 63-95.

Jahn, I., Löther, R., Senglaub, K. (1990). Historia de la biología: teorías, métodos, instituciones y biografias breves. Barcelona: Labor.

Jiménez Sánchez-Escariche, E. (2000). Introducción. En Aristóteles, Partes de los Animales. Madrid: Gredos.

Kant, I. (2011). Crítica del Juicio. Madrid: Tecnos.

Revista de Humanidades de Valparaíso, 2019, No 14, 395-426

()ㅇㅇㅛ CC BY-NC-ND 
Kohn, D. (2009). Darwin's Keystone: The Principle of Divergence. En The Cambridge Companion to the Origin of Species, pp. 87-108. Cambridge: Cambridge University Press.

Lamarck, J. B. (1986). Filosofía zoológica. Barcelona: Editorial Alta Fulla.

Larson, L. (1971). Reason and Experience: The Representation of Natural Order in the Work of Carl yon Linné. Berkeley: University of California Press.

Lennox, J. G. (1993). Darwin was a teleologist. Biology and Philosophy, 8: 409-421.

Lewotin, R. C. (1982). Organism and Environments. En H. C. Plotkin(ed.), Learning, Development, and Culture, pp. 151-170. Chichester: John Wiley \& Sons.

Linneo, von C. (1737). Genera Plantarum. Disponible en: http://visualiseur.bnf.fr/ Visualiseur?Destination $=$ Gallica\&O=NUMM-096793

Linneo, von C. (1780). Philosophia Botanica. Ed. 4, no 157, p. 99. Disponible en https://www. biodiversitylibrary.org/bibliography/37651\#/summary

Linneo, von C. (1964). Systema Naturae. Facsimile of the first edition. Nieuwkoop: B de Graaf.

Lloyd, G. E. R. (1974). Early Greek Science: Thales to Aristotle. New York: W. W. Norton \& Company.

Mayr, E. (1988). Toward a New Philosophy of Biology. Cambridge: Harvard University Press.

Mayr, E. (1991). Una larga controversia: Darwin y el darwinismo. Barcelona: Crítica.

Mayr, E. (1992). Darwin's Principle of Divergence. Journal of the History of Biology, 25(3): 343-359.

Mayr, E. (2000). The Growth of Biological Thought Diversity, Evolution, and Inheritance. Massachussets: The Belknap Press of Harvard University.

Papavero, N., Pujol, J. R., Llorente, J. (1995). Historia de la biología comparada. De Descartes a Leibniz (1628-1716). México D. F.: Las Prensas de Ciencias.

Papp, D., Babini, J. (1958). Panorama general de historia de la ciencia IX. Biología y medicina en los siglos XVII y XVIII. Buenos Aires: Espasa-Calpe.

Pellegrin, P. (1987). Aristotle's classifications of animals: Biology and conceptual unity of Aristotelian corpus. Berkeley y Los Angeles: University of California Press.

Perrier, E. (2009). The Philosophy of Biology before Darwin. New York: Springer.

Richards, R. J. (2012). Darwin's principles of divergence and natural selection: Why Fodor was almost right. Studies in History and Philosophy of Biological and Biomedical Sciences, 43(1): 256-268.

Rosas, A. (2008). Kant y la ciencia natural de los organismos. Ideas Y Valores, 137: 5-23.

Ruse, M. (1973). La filosofia de la biología. Madrid: Alianza.

Ruse, M. (1987). Biological Species: Natural Kinds, Individuals, or What? The British Journal for the Philosophy of Science, 38(2): 225-242.

Revista de Humanidades de Valparaíso, 2019, No 14, 395-426

(c) (1) $\mathrm{O}$ (ㄱ BY-NC-ND 
Ruse, M. (2000). Teleology: Yesterdey, Today and Tomorrow. Studies in History and Philosophy of Biological and Biomedical Sciences, 31(1): 213-232.

Schweber, S. (1980). Darwin and the Political Economist: Divergence of Character. Journal of the History of Biology, 13(2): 195-289.

Sloan, P. R. (2009). Originating Species: Darwin on the Species Problem. En M. Ruse, R. Richards (eds.), The Cambridge Companion to the "Origin of Species", pp. 67-86. Cambridge: Cambridge University Press.

Sober, E. (2003). Metaphysical and epistemological issues in modern Darwinian theory. En J. Hodge, G. Radick (eds.), The Cambridge Companion to Darwin, pp. 267-287. Cambridge: Cambridge University Press.

Sober, E. (2011). Did Darwin Write the "Origin” Backwards. New York: Prometheus Book.

Von Uexkull, J. (1945). Ideas para una concepción biológica del mundo. Buenos Aires: Espasa Calpe.

Walsh, D. M. (2006). Organisms as Natural Purposes: The Contemporary Evolutionary Perspective. Studies in History and Philosophy of Science Part C: Studies in History and Philosophy of Biological and Biomedical Sciences, 37(4): 771-791.

Wilkins, J. S. (2010). What is a species? Essences and generation. Theory in Biosciences, 129(23): $141-148$.

Zirkle, C. (1941). Natural Selection before the "Origin of Species". Proceedings of the American Philosophical Society, 84(1): 71-123 

